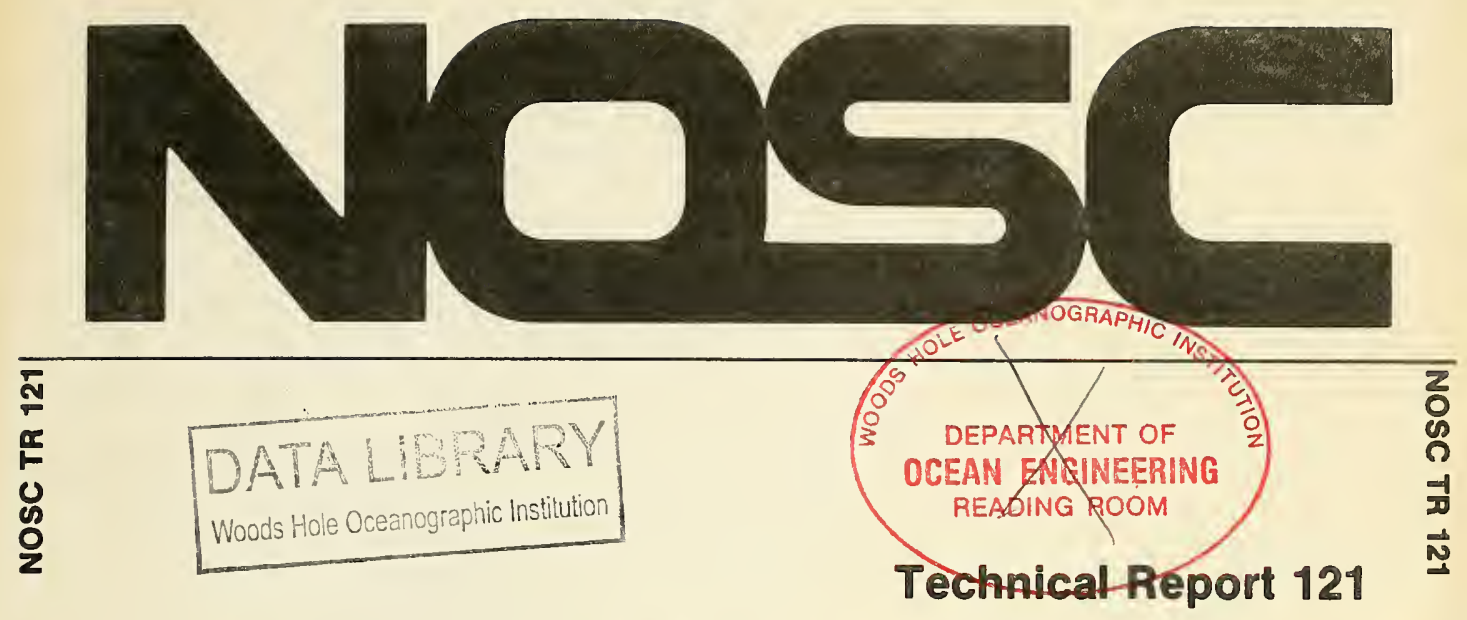

\title{
SURVEY OF OCEANOGRAPHIC AND METEOROLOGICAL PARAMETERS OF IMPORTANCE TO THE SITE SELECTION OF AN OCEAN FOOD AND ENERGY FARM (OFEF) IN THE EASTERN PACIFIC
}

PF Seligman 15 August 1977

Final Report: July 1975-September 1976 Prepared For U.S. Energy Research \& Development Administration

Approved for public release; distribution unlimited.

$T C$

1501

NAVAL OCEAN SYSTEMS CENTER

14 SAN DIEGO, CALIFORNIA 92152

no. 121 


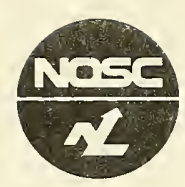

NAVAL OCEAN SYSTEMS CENTER, SAN DIEGO, CA. 92152

AN ACTIVITY OF THE NAVAL MATERIAL COMMAND
RR GAVAZZI, CAPT, USN
$\begin{gathered}\text { Commander } \\ \text { HOWARDL BLOOD, PhD }\end{gathered}$
Technical Director

\section{ADMINISTRATIVE INFORMATION}

The Ocean Food and Energy Farm (OFEF) Project was managed by the Naval Ocean Systems Center. The project is funded jointly by the U.S. Energy Research and Development Administration (ERDA) and the American Gas Association (AGA). This is the final report of Subtask 5 of the ERDA sponsored work for the year ending June 30,1976 and is funded under an Interagency Agreement No. E(49-26)-1027 from ERDA, Division of Solar Energy to the U.S. Naval Ocean Systems Center.

Released by

S. YAMAMOTO, Head

Chemistry and Environmental

Sciences Group
Under authority of

B. A. POWELL, Head

Undersea Sciences Department

\section{ACKNOWLEDGEMENTS}

The assistance from and continuing critical review of this report by Dr. Howard Wilcox, OFEF Program Manager, is gratefully acknowledged. Many valuable suggestions were given to me by Dr. Wheeler North of the California lnstitute of Technology, and Dr. Alberto Zirino and Mr. Doug Murphy of the Naval Ocean Systems Center. The continuing support of Dr. Sachio Yamamoto is appreciated. Assistance in the NODC computer survey was given by Mr. Joseph Colborn. 
UNCLASSIFIED

SECURITY CLASSIFICATION OF THIS PAGE (When Dete Entered)

\begin{tabular}{|c|c|}
\hline REPORT DOCUMENTATION PAGE & $\begin{array}{l}\text { READ INSTRUCTIONS } \\
\text { BEFORE COMPLETING FORM }\end{array}$ \\
\hline $\begin{array}{l}\text { 1. REPORT NUMBER } \\
\text { TR- } 121\end{array}$ & 3. RECIPIENT'S CATALOG NUMBER \\
\hline \multirow{2}{*}{$\begin{array}{l}\text { 4. TITLE (and Subtitle) } \\
\text { SURVEY OF OCEANOGRAPHIC AND METEOROLOGI- } \\
\text { CAL PARAMETERS OF IMPORTANCE TO THE SITE } \\
\text { SELECTION OF AN OCEAN FOOD AND ENERGY } \\
\text { FARM (OFEF) IN THE EASTERN PACIFIC }\end{array}$} & $\begin{array}{l}\text { S. TYPE OF REPORT \& PERIOO COVEREO } \\
\text { Final Report: ERDA } \\
\text { Subtask } 5 \text { - OFEF Project }\end{array}$ \\
\hline & 6 PERFORMING ORG. REPORT NI MBER \\
\hline Peter F. Seligman & 8. CONTRACT OR GRANT NUMBER(S) \\
\hline $\begin{array}{l}\text { 9. PERFORMING ORGANIZATION NAME ANO AODRESS } \\
\text { Naval Ocean Systems Center } \\
\text { San Diego, CA } 92152\end{array}$ & $\begin{array}{l}10 \text { PROGAAM ELEMENT, PROJECT, TASK } \\
\text { AREA A WORK UNIT NUMBERS } \\
\text { ERDA lnteragency Agreement } \\
\text { No. E(49-26)-1027 to NUC }\end{array}$ \\
\hline $\begin{array}{l}\text { 11. CONTROLLING OFFICE NAME ANO AOORESS } \\
\text { Energy Research and Develop. Admin. }\end{array}$ & $\begin{array}{l}\text { 12. REPORT DATE } \\
\text { August } 1977\end{array}$ \\
\hline Solar Energy Division & $\begin{array}{c}13 \text { NUMBER OF PAGES } \\
267\end{array}$ \\
\hline 14 MONITORING AGENCY NAME A ADORESS(If different Iram Contriffing Office) & $\begin{array}{l}\text { 15. SECURITY CLASS. (of thes report) } \\
\text { Unclassified }\end{array}$ \\
\hline & $\begin{array}{l}\text { ISa OECLLASSIFICATION'OOWNGRAOING } \\
\text { SCHEOULE }\end{array}$ \\
\hline
\end{tabular}

Approved for public release; distribution unlimited.

17. OISTRIBUTION STATEMENT (of the abstract entered in Block 20, if different from Report)

18 SUPPLEMENTARY NOTES

Oceanography

Ocean Farms

Meteorology

Kelp

Eastern Pacific

Macrocystis pyrifera

19. KEY WOROS (Confinue on reverse side it necessary end identity by block number)

20. ABSTRACT (Continue on reverse side "I necessary and identily by block number)

Oceanographic and meteorological parameters necessary for selection of productive Ocean Food and Energy Farm (OFEF) sites are presented and compared for the eastern Pacific Ocean. Optimum values for biological, chemical, physical, and engineering requirements are estimated for both farm structures and the giant kelp Macrocystis pyrifera, the proposed OFEF crop plant. From these data, requirements, and limitations, preliminary site selection criteria are established.

(over) 
20. (Continued)

Selection candidate Phase $1 \mathrm{OFEF}$ and future farm sites are given after a thorough review of pertinent data and literature. It is determined that within the area studied, the southern California offshore region from approximately $32^{\circ} 30^{\prime} \mathrm{N}$ to $34^{\circ} 30^{\prime} \mathrm{N}$ is best suited for siting preliminary Ocean Farms. Detailed maps and tables of currents, ocean temperatures, winds, nutrient concentrations and other parameters are presented. 


\section{SUMMARY}

\section{OBJECTIVES}

The principal objectives of this site selection project are to:

- establish preliminary site selection for an ocean food and energy farm (OFEF) based on the requirements and limitations of OFEF as delineated by the principal investigators;

- compile a digest of oceanographic and meteorological data useful to the selection of the Phase 1 and future farm sites; and

- select candidate Phase 1 sites after a thorough review of pertinent data and literature, and report these sites in order of increasing importance.

\section{RESULTS}

Site selection criteria and requirements are developed and are listed. Pertinent oceanographic and meteorological data are given in tables, figures and appendices. By comparing these criteria to the available environmental data, the southern California of fshore region from $32^{\circ} 30^{\prime} \mathrm{N}$ to $34^{\circ} 30^{\prime} \mathrm{N}$ was chosen as the most suitable preliminary site for OFEF. This area has been selected as the optimal location for Phase 1, and probably for Phase 2 and early 3 as well, for the following reasons.

1. The sites chosen are within the U.S. economic zone (increased to 200 miles in March 1977), thereby avoiding possible in ternational conflict.

2. The region has the most mild and least severe extreme weather conditions of any off shore area within the economic zone of the continental United States or Hawaii. 1t has a very low occurrence of high velocity winds and high waves. This is because the region is north of the tropical cyclone zone and is located on the southern extreme of the extra-tropical cyclone region.

3. In this nearshore area, nutrients of adequate concentrations are relatively near the surface (15-25 $\mu \mathrm{g}$-at/liter $\mathrm{NO}_{3}$ at 100 meters).

4. Research and support facilities are available close to the proposed sites.

5. The region is with in the natural habitat zone of Macrocystis pyrifera. Temperature and light regions are excellent for Macrocystis growth.

6. Current speeds are mostly within the ranges specified for optimal OFEF operations and kelp growth characteristics.

\section{RECOMMENDATIONS}

It is recommended that: (i) siting of Phase 1 and probably future ocean farms be within the southern California off shore region; (ii) further research on $\underline{M}$. Pyrifera be performed to define nutrient and temperature requirements and possible synergistic effects for better definition of potential growing sites; (iii) other worldwide geographic locales be investigated for possible future siting of OFEF's; and (iv) that thorough current surveys be conducted at final sites prior to placement of farm. This is necessary for final engineering requirements and farm configuration planning. 


\section{CONTENTS}

Page

INTRODUCTION

OFEF SITE SELECTION CRITERIA

Biological Requirements/Limitations

Nutrients

Temperature

Currents

Engineering Limitations/Requirements

Economic Requirements

Geopolitical Considerations

OCEANOGRAPHIC AND METEOROLOGICAL SURVEY

Oceanography

Currents

Temperature

Nutrients

16

Meteorology

20

Tropical and Extratropical Cyclones

Winds

Wind-Generated Ocean Waves

Summary of Meteorological Data

24

Extreme Meteorological Data

PRELIMINARY OFEF SITE SELECTION

Biological Criteria

Temperature

Nutrients

Currents

Engineering Criteria

Currents

Storms/Wind

Waves

86

Economic and Geopolitical Considerations 


\section{CONTENTS (Continued)}

PHASE 1 SITE SELECTION

Southern California OFEF Site Selection

Southern California Offshore Characteristics 88

Prioritized Phase I OFEF Site Selection

APPENDIX A. SEASONAL NITRATE PROFILES

APPENDIX B. SEASONAL TEMPERATURE PROFILES

APPENDIX C. STATISTICAL SUMMARY OF PHYSICAL OCEANOGRAPHIC DATA

APPENDIX D. METEOROLOGICAL DATA

APPENDIX E. DISCUSSION OF STORM-GENERATED CURRENTS 



\section{INTRODUCTION}

The Ocean Food and Energy Farm (OFEF) concept envisions large areas of open ocean under cultivation utilizing solar energy input and the photosynthetic process to produce high yields of marine algae. The proposed crop plant, the giant brown kelp Macrocystis pyrifera, is expected to yield in excess of 270 wet metric tons ( 36 dry metric tons) of harvested organic material per acre per year (Refs. 1 and 2). This material would be harvested and processed to produce methane gas, food and feed products, fertilizer, ethanol, and other organic products, many of which are currently produced from nonrenewable petroleum sources (Ref. 3 ). In addition, a mariculture subsystem would produce highvalue finfish and shellfish products for human consumption.

The economic success of any aquaculture system is dependent on the selection of an appropriate site. Factors which must be considered in selecting potential sites include various physical, chemical, biological, economic, and geopolitical parameters.

Proper selection of a farm site requires that the needs and limitations of the total farm system be considered. Particularly important are the biological requirements of the kelp Macrocystis pyrifera and the practical engineering and economic factors which affect design of the farm substrate and artificial upwelling systems.

Biological and chemical parameters of importance to site selection include the availability and concentration of nutrients in both the near-surface mixed layer (directly available to crop) and at intermediate depths ( 100 to 300 meters of depth and available to the crop after artificial upwelling). Nutrient concentration and availability in combination with light intensity and temperature are among the principal factors which will determine the rate of OFEF primary productivity and therefore, economic return. Nutrient concentrations are highly variable in both location and season with the principal determining factors being the amount of wind-caused mixing, natural upwelling, and biological utilization.

The cost of the substrate system will constitute a large part of the total cost of the OFEF. The substrate therefore "represents a major investment in an ocean structure which may be vulnerable to damage during periods of storm and adverse weather conditions" (Ref. 2). Selection of a farm site which minimizes the chance for environmental damage is consequently of great importance.

The location and intensity of prevailing currents are also important; areas of highspeed currents may have to be avoided whereas weaker currents can act to remove waste materials and replenish nutrient supplies.

Other aspects important to the farm location include the amount of incident solar radiation and degree of light penetration (both vary geographically), the ocean temperature in relation to $\mathrm{M}$. pyrifera tolerance, and the location and concentration of potential sources of pollution. 
Economic and geopolitical considerations are briefly addressed. The location of future support and processing facilities in relation to the farm site are important economic factors. Previously claimed or disputed territorial waters will be areas of high risk until international agreements are made. Location of traditional sea lanes must be considered.

The general region of the eastern Pacific was chosen for study because of the proximity of support facilities, the positive geopolitical environment, and the need to limit the area of preliminary consideration to a manageable size.

This report discusses the site selection for one or more Phase 1 prototype farms. The summary of available environmental data presented, however, are also applicable to the selection of future Phase 2 and 3 locations. Site selection is based on criteria as developed by the principal investigators for the OFEF Project and include Dr. W. North of the California Institute of Technology and Dr. H. Wilcox and Mr. D. Murphy of the Naval Ocean Systems Center. 


\section{OFEF SITE SELECTION CRITERIA}

\section{BIOLOGICAL REQUIREMENTS/LIMITATIONS}

Site selection criteria dealing with the biological requirements and limitations are summarized in Table 1.

\section{Nutrients}

Surface waters of the open ocean in temperate and tropical areas beyond coastal and upwelling influences are generally nutrient-limited to the degree that the naturally available nutrients will sustain only low levels of productivity. It has been demonstrated that nitrogen is the principal controlling nutrient in the eastern tropical Pacific (Refs. 4 and 5 ) and is the primary nutrient limiting growth of phytoplankton off southern California (Ref. 6).

Studies of marine macroalgae productivity as a function of nutrient concentration are few. Waite and Mitchell (Ref. 7) have demonstrated that increases in the concentration of ammonia and phosphate significantly increase the rate of carbon fixation (photosynthesis) in Ulva lactuca, a green macroalgae. In the red alga Eucheuma, periods of maximum growth coincide with maximum nutrient concentrations during periods of lowered temperatures and reduced light along the Florida coast (Ref. 8).

Jackson states in his PhD thesis that for natural kelp beds (M. pyrifera) off San Diego "the condition most limiting Macrocystis production was the low concentration of dissolved nutrients, especially nitrogenous substances, near the surface" (Ref. 9). Nitrate concentrations in the San Diego Point Loma kelp bed were generally low, less than $1 \mu \mathrm{g}$-at/liter $\mathrm{NO}_{3}-\mathrm{N}^{*}$ (Ref. 9), however, during upwelling periods can go as high as $5.8 \mu \mathrm{g}$-at in the nearsurface (Ref. 10). There is evidence that M. pyrifera compensates for this nitrogen limitation by translocating it from depths where concentrations are significantly higher (Ref. 9). This characteristic is very significant and should be considered when designing the upwelling and distribution systems for the Ocean Farm.

Natural populations of M. pyrifera off southern California experience nitrate concentrations on the surface from near $0 \mu \mathrm{g}$-at/liter to as high as $9 \mu \mathrm{g}$-at/liter $\mathrm{NO}_{3}-\mathrm{N}$, but generally less than $4 \mu \mathrm{g}$-at/liter. At 8-10 meters depth the concentrations are usually higher, varying from about $1 \mu \mathrm{g}$-at to as high as 16 with a mean range of 2-6 $\mu$ g-at $\mathrm{NO}_{3}-\mathrm{N}$ (Refs. 9 through

12). Nutrient concentrations are usually highest in the January to June period and lowest in late summer. Growth rates have been observed to be decidedly low when dissolved nitrogen falls below $1.0 \mu \mathrm{g}$-at/liter (Ref. 13). Preliminary studies by W. North ind icate that $\mathrm{K}_{\mathrm{m}}$ for $\mathrm{NO}_{3}$ (the concentration of nitrate at which the uptake velocity of nitrate is $1 / 2$ maximum) is near $9.4 \mu \mathrm{g}$-at/liter (Ref. 13). Optimally, the concentration of nutrients should be above the $\mathrm{K}_{\mathrm{m}}$ for maximal productivity. An area having a 10-15 $\mu \mathrm{g}$-at/liter $\mathrm{NO}_{3}-\mathrm{N}$ should yield a very high growth rate. Above this concentration the uptake rate curve levels off, therefore,

${ }^{*} 1$ gg-at/liter $\mathrm{NO}_{3} \mathrm{~N}=14$ micrograms nitrate nitrogen/liter or 14 parts per billion (ppb). 
Table 1. Ocean Energy Farm: summary of site selection criteria.

\section{BIOLOGICAL REQUIREMENTS/LIMITATIONS}

1. $20^{\circ}$ maximum mean surface temperature

2. a. $3-5 \mu \mathrm{g}$-at/liter nitrate (minimum)

b. 10-15 $\mu \mathrm{g}$-at/liter nitrate (optimal)

3. a. $25 \mathrm{~cm} / \mathrm{sec}(0.5 \mathrm{kn})$ current maximum OFEF $(\geqslant 25 \mathrm{~cm} / \mathrm{sec}$ sustained current causes plants to approach horizontal at substrate depth)

b. Optimal: $10 \mathrm{~cm} / \mathrm{sec}(0.2 \mathrm{kn})$

c. Minimal: $4 \mathrm{~cm} / \mathrm{sec}(0.08 \mathrm{kn})$

\section{ENGINEERING LIMITATIONS/REQUIREMENTS}

1. a. $0.5-\mathrm{m} / \mathrm{sec}(1-\mathrm{kn})$ current at substrate depth (Phase 1 operational current)

b. Maximum 1.5-m/sec sustained current design limitation

2. a. Avoid storm-force winds (greater than $25 \mathrm{~m} / \mathrm{sec}$ ) (locate in area of least storm probability)

b. Minimize gale-foree winds (greater than 17-m/sec, 5.5-meter waves)

3. a. Maximum significant wave height 11 meters (35 feet) (design for Phase 1 test module)

b. Extreme wave hejght 19 meters (63 feet) (extreme design wave)

c. Minimum mean wave height 1 meter (required for upwelling system)

Optimal wave height 2-3 meters (for upwelling system)

\section{ECONOMIC}

1. Moored substrate - maximum depth 600 meters (Phase 3)

2. Proximity to research and support facilities

Phase 1: 32-kilometers maximum (2-hour transit time)

GEOPOLITICAL

1. Avoid traditional sea lanes and submarine transit zones

2. Locate outside claimed economic and territorial zones

(probably 320-kilometer zones will be adopted - needs international clarification) 
providing the plants with greater than $15 \mu \mathrm{g}$-at- $\mathrm{NO}_{3}-\mathrm{N}$ would probably not be economical (e.g., an increase from 16 to $23 \mu$ g-at/liter only causes an increase in uptake rate of 12 percent, Ref. 13). Minimum levels of $\mathrm{NO}_{3}$ required for the marine farm are estimated to be between 3 and $5 \mu \mathrm{g}$-at/liter (an increase in uptake rate of 400 percent is computed when $\mathrm{NO}_{3}$ levels are increased from 1 to $5 \mu \mathrm{g}$-at/liter from W. North data, Ref. 13), since average levels of $\mathrm{NO}_{3}$ off the southern California coast at depths between 100 and 300 meters vary from 15 to $30 \mu \mathrm{g}$-at/liter. If the nitrate required by $\mathrm{M}$. pyrifera is between 3 and $15 \mu \mathrm{g}$-at/ liter, then the estimated amount of upwelled water to provide this level of nutrient to the plants is between 10 and 50 percent assuming thorough mixing of upwelled with surface waters. A very important parameter discussed by North (Ref. 13), is the percentage of surface area of kelp that is exposed to given levels of $\mathrm{NO}_{3}$. This factor should be considered in the design of the distribution system. If exposure area on the M. pyrifera can be maximized, then the concentration of $\mathrm{NO}_{3}$ might be reduced significantly while maintaining adequate growth rates.

\section{Temperature}

In most biochemical systems, increases in temperature cause increases in chemical reaction rates to some maximal temperature level beyond which inhibition occurs. Temperature is found to be very important in modifying kelp growth rate. Comparison of elongation growth rates measured at different temperatures yield a $Q_{10}$ of approximately 1.7 for M. pyrifera (Ref. 14). This indicates that the expected increase in frond elongation for a $10^{\circ} \mathrm{C}$ rise in temperature is by the factor 1.7. However, M. pyrifera off southern California does poorly at temperatures above $20^{\circ} \mathrm{C}$, and when above $25^{\circ} \mathrm{C}$ the symptoms of "temperature damage" (pigment loss, brittleness, sloughing) appear in a week or less (personal communication, W. North).

Clendenning studied the effect of short-term exposures to high temperatures and found that light-saturated photosynthesis was always highest between $20^{\circ}$ and $25^{\circ} \mathrm{C}$ (Ref. 15). At $30^{\circ} \mathrm{C}$ photosynthesis was completely inactivated within the first hour of exposure in kelp collected from depths of 15 to 20 meters, and it was partially inactivated in one hour in kelp collected from the surface canopy. In longer term experiments at $23.9^{\circ} \mathrm{C}\left(75^{\circ} \mathrm{F}\right), \mathrm{M}$. pyrifera showed a decrease in photosynthetic capacity after one day and severe degradation of the plant after two days (Ref. 15). M. pyrifera from Bahia Tortugas, Baja California, flourishes in water that reaches approximately $26^{\circ} \mathrm{C}$ for several weeks during late summer (W. North, personal communication). Clendenning demonstrated that the photosynthetic temperature optimum for the Turtle Bay kelp was between $25^{\circ}$ and $30^{\circ} \mathrm{C}$. These plants also exhibited a 50-percent-higher photosynthetic capacity per unit area than has been observed in local southern California kelp (Ref. 15).

Studies on the effect of temperature on M. pyrifera growth have not generally included nutrient measurements. In the reported cases where there has been a summer die-off of kelp, allegedly caused by higher than normal temperatures, nutrient data are

\footnotetext{
*Temperature coefficient. The increase in rate of a process (expressed as a multiple of initial rate) produced by raising the temperature $10^{\circ} \mathrm{C}$.
} 
sparse or unavailable. Warmer surface water from the south is very low in nutrients, and when there is an intrusion of this water along the southern California coast, it is possible, if not probable that the plants suffer from nutrient deficiency rather than high temperature degradation, or perhaps there is a synergistic effect. An experiment to investigate the combined nutrient and temperature effects on the growth rate of $\mathrm{M}$. pyrifera must be completed to better define temperature and nutrient limitations and thus more accurately characterize potential ocean farm geographic ranges.

The initial sustained temperature limitation is therefore tentatively put at $20^{\circ} \mathrm{C}$. Temperatures above this value appear to have a degrading effect on the kelp off southern California and this area will probably be the first source of plants for early experimental farms. The $20^{\circ} \mathrm{C}$ assumed limiting temperature may eventually be increased if southern (Bahia Tortugas) plants are used or if genetic manipulation in the future creates strains of greater temperature tolerance. (Note: Figure 11 shows the approximate ranges of Macrocystis if limited to $20^{\circ} \mathrm{C}$ and with varying amounts of surface cooling from artificial upwelling.)

\section{Currents}

The magnitude of the current field to which the proposed marine farm is exposed is of great importance to its overall success. Currents of high velocities relative to the substrate will entail high cost structures and will tend either to cause the kelp to trail horizontally at or near the depth of the substrate, thus reducing light level and productivity. In extreme conditions such currents might cause the plants to break away. In combination with high waves they could cause damage to the substrate structure itself. Conversely, a low velocity water movement is required to replenish nutrients in the vicinity of the plants and carry off waste products.

Besides major current systems, other forms of water movement are important. These include local wind-derived currents, swell and chop, internal waves, and natural and artificial upwelling. Artificial upwelling may become very important as a water movement factor in a large marine farm where the other forms may be severely diminished by the frictional characteristics of the plants (Ref. 16).

Preliminary experiments at the University of California, Santa Barbara, indicate that for tissue excised from adult Macrocystis, a maximum photosynthetic rate ( $\mathrm{ml} \mathrm{O}_{2}$ evolved/

$\mathrm{cm}^{2}$ blade/hr) is observed with a water velocity of $10 \mathrm{~cm} / \mathrm{sec}$ or approximately $0.2 \mathrm{knot}$ (W. Wheeler, personal communication). In several as yet unpublished experiments, W. Wheeler utilized a variable flow-through system to measure the $\mathrm{O}_{2}$ evolution rom Macrocystis tissue while keeping nutrients and light levels constant. The rate of photosynthesis with no water movement was measured to be approximately $1 / 5$ that at $10 \mathrm{~cm} / \mathrm{sec}$. At a velocity of 4 $\mathrm{cm} / \mathrm{sec}(0.08 \mathrm{knot})$ the photosynthetic rate was $1 / 2$ maximum. It is apparent from these experiments that some degree of water movement is required to increase nutrient availability, and thus the rate of photosynthesis, above that supported by purely diffusive processes. 
The optimum current velocity recommended for the Ocean Farm is $10 \mathrm{~cm} / \mathrm{sec}$ $(0.2 \mathrm{knot})$. An absolute minimum sustained velocity of $4 \mathrm{~cm} / \mathrm{sec}(0.08 \mathrm{knot})$ is recommended. These recommendations are for mean water speed past the kelp plants and are tentative until more thorough experiments can be accomplished. The important parameter is relative water speed which can be the combined result of current, swell, internal waves, and upwelling. If factors other than primary current create an adequate water flow, the site could successfully be located in an area where current velocity is reduced below the levels listed above as minimum. Some degree of water movement is necessary, however, to ensure an interchange of nutrient-depleted, high-waste-concentration water with fresh water.

At the other extreme, sustained currents of relatively high velocity can be destructive to the plants or cause them to trail horizontally, thus reducing their photosynthetic capacity by reducing available light. Currents above $25 \mathrm{~cm} / \mathrm{sec}(0.5 \mathrm{knot})$ tend to cause mature $\underline{\mathrm{M}}$. pyrifera to trail towards the horizontal, approaching the depth of their substrate (W. North, personal communication). For this reason, the maximum, mean sustained relative current that can be tolerated within the marine farm is taken as $25 \mathrm{~cm} / \mathrm{sec}$.

\section{ENGINEERING LIMITATIONS/REQUIREMENTS}

The preliminary design criteria for a moored ocean farm grid system for Phase 1 and 2 farms have been delineated (Ref. 17). The wind is the principal driving force behind most environmental parameters of importance to structural integrity. Although the wind itself has a negligible effect on submerged substrates and kelp plants and is not considered in the engineering criteria, it is the driving force for both wave height and localized currents. Because wind is more frequently measured than other parameters it is discussed here and in more detail in the meteorology section. For design purposes, the maximum significant wave height (significant height defined as average height of the $1 / 3$ highest waves) is set at 11 meters (35 feet) (the extreme wave height is set at 19 meters) and the significant period set at 12.6 seconds. The design operational current is an omnidirectional $0.5 \mathrm{~m} / \mathrm{sec}$, with a maximal total design current of $1.5 \mathrm{~m} / \mathrm{sec}$. Above $1.5 \mathrm{~m} / \mathrm{sec}$ relative current the kelp plants begin to come apart (W. North, personal communication). These engineering criteria were defined after using a single cable dynamic load model with the worst case defined as the substrate at a 15-meter depth experiencing 11-meter waves with the peak load approximately $2.8 \mathrm{~m} / \mathrm{sec}$ (effect of $0.5-\mathrm{m} / \mathrm{sec}$ current plus action of waves) (Ref. 17). In order to avoid maximum wave heights and currents as delineated above and in Table 1, areas considered for locating the marine farm should be as free as possible of gale-force winds (greater than 17 $\mathrm{m} / \mathrm{sec}$ ) and should be positioned to avoid (minimize probability of occurrence) storm-force winds $(25 \mathrm{~m} / \mathrm{sec}$ or greater $)$.

At present, wave-powered pumps appear to be the most promising means of delivering high-nutrient water to the farms (Ref. 18). First estimates indicated that a minimum mean wave height of 1 meter is required to pump sufficient water to maintain desired nutrient levels. A wave height of 2 to 2.5 meters is preferred to supply enough energy to upwell the deep water needed to fertilize one acre (4000 square meters) of ocean farm with one pump utilizing a 3-meter-diameter float (Ref. 18). 


\section{ECONOMIC REQUIREMENTS}

It is presently planned to have Phase 1 and 2 farms in the form of moored grids while the feasibility of dynamically positioned farms is being studied. One of the most important economic parameters when considering anchored substrates is the cost of mooring and mooring materials. It is currently not feasible to place multipoint mooring anchors and lines for large OFEF substrates below about 600 meters in depth because of the extreme rise in costs beyond that depth ( $\mathrm{H}$. Wilcox, personal communication). This cost factor will limit moored farms to approximately the 700-meter contour. Early experimental farms will require much smaller mooring systems and are governed by different economic pressures, allowing them to be moored at deeper depths.

A second cost factor related to site selection is the proximity of logistic and support facilities. For Phase 1 sites, a distance of approximately 32 kilometers (2-hour transit time) to support facilities is considered maximum due to the significant amount of experimental effort and support required for these early prototype farms. For future Plase 2 farms, the distance to support facilities might be increased to approximately 80 kilometers; however, there is potentially a bottom depth constraint. Phase 3 and future farms may have support facilities incorporated into the farm itself and so it may be economically feasible for the site to be three to several hundred kilometers from the final processing centers on land.

\section{GEOPOLITICAL CONSIDERATIONS}

The selection of an appropriate site must take certain geographical and political factors into account. Traditional sea lanes and submarine transit zones should be avoided to prevent navigational hazards. Until international agreements are made, the site will have to remain outside the claimed economic and territorial zones of other nations. It is probable that in the near future most of the countries of the world will claim 322-kilometer (200mile) economic zones. Many of the countries of South and Central America have already claimed 322-kilometer economic zones; some, including Brazil and Ecuador, have claimed 322-kilometer territorial limits. Mexico has recently (effective July 1976) claimed a 322kilometer economic zone, restricting significantly the southern areas where marine farms might be placed, at least until agreements can be made with Mexico. Dr. Arvid Pardo of USC, a convener of the Law of the Sea Conference, has strongly recommended that marine systems (such as the Food and Energy Farm) be maintained within the U.S. economic zone, which is currently 19 kilometers (12 miles), but likely will soon (March 1977) be extended to 320 kilometers, unless prior international agreements are made concerning the utilization of open ocean (unclaimed) areas (Dr. B. Anderson, personal communication). 


\section{OCEANOGRAPHIC AND METEOROLOGICAL SURVEY}

The world oceans, including adjacent seas, encompass over 361 million square kilometers (139 million square miles) of surface area with a tremendous diversity of environmental conditions (Ref. 19). Because of the need in this preliminary study to limit the site survey area to a manageable size, the eastern Pacific Ocean from $50^{\circ} \mathrm{N}$ to $10^{\circ} \mathrm{S}$ latitude and from the west coast of the Americas to Hawaii $\left(160^{\circ} \mathrm{W}\right.$ longitude) was chosen (Fig. 1). This area encompasses approximately 36 million square kilometers $\left(14 \times 10^{6} \mathrm{mi}^{2}\right)$ or 10 percent of the world ocean (20 percent of the Pacific Ocean). This area, particularly the northeastern Pacific, is highly appropriate to study for potential ocean farm sites for several reasons, some of which are listed below.

1. Much of the area is within operating range of scientific and support facilities of personnel who have been involved in Macrocystis research and other aspects of the Ocean Farm Project.

2. The northern distribution of the genus Macrocystis, the proposed ocean farm organism, falls within this area (Fig. 2). Therefore, at least in the nearshore environment, the ecological requirements for the growth of Macrocystis are met.

3. The general oceanographic/meteorological climate in much of the survey area appears to be moderate enough to allow large open ocean farms.

The survey area was initially divided into eleven natural oceanic regions, (Ref. 20, Fig. 1, A-K) which are based on the properties of surface waters, their biology, currents, and current boundaries, rather than classical oceanic water masses which are based primarily on deep water characteristics (Ref. 19). Within these natural oceanic regions, 20 geographic areas were picked as representative portions of the whole region. These areas were then analyzed using National Oceanographic Data Center data tapes on the Naval Ocean Systems Center (NOSC) Univac 1110 computer. Temperature, salinity, density, and nutrient profiles for the representative areas were produced.

In addition, these areas were surveyed for meteorological data by the Naval Weather Service Detachment at the Environmental Data Service, National Climatic Center, Asheville, North Carolina. Other environmental parameters and informational sources were utilized to characterize the regions, to eliminate areas which were significantly beyond the defined criteria, and finally to select optimal sites.

\section{OCEANOGRAPHY}

\section{Currents}

The general current regimes (direction and mean velocities) are given for summer and winter for the north Pacific Ocean in Figs. 3 and 4, respectively. The principal current in the area of the survey is the California Current. This current has a rather poorly defined and variable southerly flow which is easily influenced by prevailing winds. The California Current starts its southerly movement at $45^{\circ}$ to $48^{\circ} \mathrm{N}$ at a position where the North Pacific and Aleutian (Subarctic) Currents impact the coast. The current varies in wid th from about 
400 kilometers ( $250 \mathrm{mi}$ ) off Washington to 720 kilometers $(450 \mathrm{mi}$ ) off southern California (Fig. 5). The California Current turns westerly between $20^{\circ}$ and $25^{\circ} \mathrm{N}$ and becomes the North Equatorial Current with mean speeds between 15 and $30 \mathrm{~cm} / \mathrm{sec}$ to the longitude of Hawaii.

Overall, the California Current averages about 15 to $30 \mathrm{~cm} / \mathrm{sec}$ (Figs. 3 and 4). The southward flow, particularly near the coasts (areas C and D in Fig. 5), predominates from March through September. During the months October to February the weak northward moving Davidson Current predominates near the coast. Even during the summer months, when the current is most stable, it tends to be variable. In region A the current sets directly south 23 percent of the time; all other directions average about 10 percent (Ref. 28). In region $\mathrm{B}$ the current becomes more consistent, setting between the southwest and southeast 48 percent of the time with little or no secondary flow. The speeds in sections $A$ and $B$, as listed in Fig. 5, vary from 0.15 to $1.1 \mathrm{~m} / \mathrm{sec}$. The maximum speeds (above $0.6 \mathrm{~m} / \mathrm{sec}$ ) are probably somewhat high because they are mostly based on ship drift measurements on which prevailing winds can have a highly significant effect. In region $C$ the nearshore currents are higher in velocity and more consistent than in region $\mathrm{D}$.

During the winter months (November to February) the prevailing current direction in regions $\mathrm{C}$ and $\mathrm{D}$ in the California Current region (Fig. 5) shifts northward and is called the Davidson Current (Fig. 6), which can be termed more accurately the Winter Coastal Countercurrent (Ref. 28). It has a rather poorly defined variable flow dependent mainly on the influence of the wind. Figure 6 shows the boundary within which the prevailing northward flow generally occurs.

The table with Fig. 6 indicates the variability of flow by showing monthly percent frequency of observations of speed and direction. The Davidson Current is interrupted by the prevailing southerly flow of the California Current from March through the first half of October. The southern portion of the current (Fig. 6, region B) is more variable than the northern part, with sets occurring in the opposite direction (south) frequently in January and February. There is evidence that there is a permanent northward flow below 200 meters of depth running about 64 kilometers wide at speeds of about $25 \mathrm{~cm} / \mathrm{sec}$. It is probable that when northerly winds become weak or negligible in late autumn and winter, a nortlsetting countercurrent forms at the surface inshore of the main California Current. During this period coastal upwelling lessens (upwelling is strongest in the spring and early summer months), and numerous irregular eddies occur along the coast (Refs. 28 and 29). Nearshore currents may be influenced by coastal tidal currents (which are rotary and thus will set in all directions) and by the local winds, hence will tend to have a highly variable nature. In summary, the Davidson Current begins at about $32^{\circ} \mathrm{N}$, is variable and weak in the southern section ( 10 to $25 \mathrm{~cm} / \mathrm{sec}$ ), but becomes more constant as it moves northward. In the nortlern section it averages slightly higher speeds $(20$ to $35 \mathrm{~cm} / \mathrm{sec})$ and meets the more swiftly northern-moving Alaska Current (25 to $50 \mathrm{~cm} / \mathrm{sec}$ ) at about $48^{\circ} \mathrm{N}$.

Current profile (velocity with depth) measurements are relatively sparse. However, this type of information is extremely important to the planning and development of the ocean farm because of the need to design substrate and mooring systems to withstand current and current shear. Figure 7 gives several current profiles for the nor theast Pacific 
region. As can be seen in the figure, current measurements are highly diverse and vary from rather high surface speeds, 25 to $120 \mathrm{~cm} / \mathrm{sec}$, in the northern portion near the coast (profile 8-11) to the very low speed currents, less than $10 \mathrm{~cm} / \mathrm{sec}$, at $35^{\circ} \mathrm{N}$ (profile 14). The northern area $\left(48^{\circ}\right.$ to $\left.52^{\circ} \mathrm{N}\right)$ is the terminus of the Aleutian Current and the southeastern portion of the northward-moving Alaska Current. In locations 8 and 9 the current remains near the same velocity or increases with depth; there may be some tidal influence from the inlet north of Vancouver Island. Slightly further south the strong surface currents (greater than $1 \mathrm{~m} / \mathrm{sec}$ in locations 10 and 11 ) are reduced to nearly $25 \mathrm{~cm} / \mathrm{sec}$ by 25 -meter depths. It is probable that these rather high maximum surface current speeds were wind-induced (wind velocities are not given). The measurement locations off the continental slope (locations 12 , 13 , and 14) are relatively low (10 to $20 \mathrm{~cm} / \mathrm{sec}$ ) in current speed and nearly constant with depth. In the southern portion of the California Current region the profiles show slow (5 to $15 \mathrm{~cm} / \mathrm{sec}$ ) surface currents that decrease in speed slowly with depth or remain roughly constant.

The need for further current time histories and depth profiles is apparent. Prior to placement of the prototype marine farm, current velocity profile measurements should be made to estimate better the probable stresses on the substrate and upwelling systems.

In the central portion of the survey area, northeast of Hawaii, a large gyre is formed during the summer from the forces of the weak easterly-moving North Pacific Current, the southerly California Current, and the relatively strong westerly-setting North Equatorial Current $\left(25\right.$ to $50 \mathrm{~cm} / \mathrm{sec}, 13^{\circ}$ to $\left.18^{\circ} \mathrm{N}\right)$. The current flow in the central gyre area is relatively slow, ( 5 to $15 \mathrm{~cm} / \mathrm{sec}$ ). The gyre tends to disappear in the winter (Fig. 4). Further to the south, the North Equatorial Countercurrent runs steadily towards the east at 25 to 50 $\mathrm{cm} / \mathrm{sec}$ from about $5^{\circ}$ to $7^{\circ} \mathrm{N}$. At the point of the northward deflection of the countercurrent as it impinges on the coast of Central America, there is a redistribution of mass that is effected by divergence and crosscurrent flow thus causing an upwelling zone about 400 kilometers across (Refs. 24 and 25). This zone is termed the Costa Rica Dome and is characterized by lower near-surface temperatures and elevated nutrient concentrations (see Fig. 1).

From approximately $4^{\circ} \mathrm{N}$ to $1^{\circ} \mathrm{S}$ the high-velocity South Equatorial Current sets in a westerly direction with speeds up to $1 \mathrm{~m} / \mathrm{sec}$ near the equator. The South Equatorial Current originates principally from the Peru Current, which moves up the coast of South America with a mean velocity of approximately $30 \mathrm{~cm} / \mathrm{sec}$ in the region of $10^{\circ} \mathrm{S}$ increasing to about $45 \mathrm{~cm} / \mathrm{sec}$ in the northern portion where it turns west (regions 9 and 10, Fig. 8) at about $3^{\circ} \mathrm{S}$. The surface current velocity is roughly constant both seasonally and over most of its length. Slight seasonal changes are shown in Fig. 8. The current close inshore is under the nearly continuous influence of small-scale upwelling (Ref. 28). The upwelling takes place from about 130 meters from $35^{\circ} \mathrm{S}$ to $2^{\circ} \mathrm{S}$ (Ref. 29) and causes lower temperatures and increased nutrient concentrations near the coast.

\section{Temperature}

Temperature is important biologically for two principal reasons: (1) it has a stimulatory effect on the growth rate of Macrocystis as the temperature increases from low values, 
and (2) it may have an inlibitory effect when the temperature rises above $20^{\circ} \mathrm{C}$ for northern strains of M. pyrifera (somewhat higher than $20^{\circ} \mathrm{C}$ for the southern, Baja California, plants). A most important parameter, in terms of selecting an Ocean Food and Energy Farm site, is the maximum temperature reached during the summer months. Figure 9 gives the mean temperature of the north Pacific for September; generally, the warmest water temperatures are observed during this month. The mean $20^{\circ} \mathrm{C}$ isotherm $\left(68^{\circ} \mathrm{F}\right)$ runs eastward from the western Pacific very close to $40^{\circ} \mathrm{N}$ latitude to approximately $150^{\circ} \mathrm{W}$ where it bends southward meeting the west coast at about $32^{\circ} \mathrm{N}$, just south of San Diego (Fig. 9). This southern bending of the isotherms along the west coast is caused by significantly cooler temperatures resulting from the southerly movement of the cold California Current; during some months, the effect of coastal upwelling intensifies the cooling trend. Figure 10 gives the surface thermal structure for maximum September temperatures. The thermal configuration is basically the same (as Fig. 9) except the warmer isotherms are extended further to the north. The $20^{\circ} \mathrm{C}$ maximum isotherm rums across the Pacific at $43^{\circ} \mathrm{N}$, bends southward at $130^{\circ} \mathrm{W}$, and meets the coast at about $39^{\circ} \mathrm{N}$.

The selection of the Ocean Farm site, again, is dependent on the surface thermal structure, to the extent that (1) Macrocystis is temperature-limited (needs further research), (2) the degree of optimization of growth rate desired, and (3) the surface water can be cooled with artificial upwelling. Considering point (3) above, Fig. 11 shows the incremented temperature reduction of surface waters, by artificial upwelling, required to lower the mean ambient September temperature to $20^{\circ} \mathrm{C}$, the estimated sustained upper temperature limit for M. pyrifera.

Figures 12 and 13 give the mean and minimum temperatures, respectively, for the north Pacific for February.

Nutrients

Most open ocean areas under consideration for the OFEF are nutrient-limited (Refs. 4,5 , and 6), given the selection criteria delineated in Table 1 (3-5 $\mu$ g-at/liter nitrate minimum, 10-15 $\mu \mathrm{g}$-at/liter optimum). Even in the nearshore environment where Macrocystis grows, the nitrogen concentration is frequently limiting (Ref. 9). 1t seems apparent that artificial fertilization (probably by upwelling pumps) will be necessary at most sites (Refs. 3 and 18). The geographic distribution of nutrients (both horizontally and vertically) is a very important parameter that must be considered in the OFEF site selection process. Because there is strong evidence that nitrogen is the principal macro-nutrient that is limiting to Macrocystis and because other nutrients generally occur in constant ratios to nitrogen, $\mathrm{NO}_{3}$ is the only nutrient surveyed below.

In general, nitrate concentrations at the surface are less than $1 \mu \mathrm{g}$-at/liter except for certain near-coastal areas where natural upwelling occurs and two major upwelling areas, the Costa Rica Dome and equatorial upwelling zone shown in Fig. 1.

National Oceanographic Data Center data tapes were surveyed for nitrate profiles; these data are presented in Appendix A. In areas I through 9 and 15 (Fig. 1), NODC nutrient data were unavailable. Because nutrient data are strongly correlated with thermal structure, a 
review of temperature profiles is given in Appendix B. For those areas where nutrient data are lacking, a qualitative estimate of the depth from which artificial pumping will be necessary can be made by determining the depth of the bottom of the thermocline.

The nutrient profiles in Appendix A are divided into four seasons, winter (Jan-Mar), spring (Apr-Jun), summer (Jul-Sep), and fall (Oct-Dec). Table 2 gives the depth range at which a concentration of $30 \mu \mathrm{g}$-at/liter $\mathrm{NO}_{3}$ can be expected for the survey area given. In the northern sector of the study area (area 12, Fig. 1), surface nutrients are relatively high (1-6 $\mu$ g-at/liter) in the winter, probably caused by heavy wind mixing and low biological utilization. At 100 meters of depth, nitrate concentration varies from about 12 to $25 \mu \mathrm{g}$-at/ liter, and this increases gradually to $20-35 \mu$ g-at/liter at 300 meters of depth (Fig. A. $3^{*}$ ). During the other seasons, particularly summer, the near-surface nitrate concentrations (upper 50 meters) are consistently low, being generally below $1 \mu \mathrm{g}$-at/liter. This fact is probably caused by the increased biological productivity found in the mixed surface layer

*In Figures A.3 to A. 6 the reduced nitrate values (all from a single research cruise) which form an astatistical profile to the left of the main profile appear to be incorrect data and should be ignored.

Table 2. Depth range at which a concentration of $30 \mu \mathrm{g}-\mathrm{at} / \mathrm{liter}$ nitrate can be expected for seasons in the areas surveyed.

\begin{tabular}{c|c|c|c|c}
\hline \multirow{2}{*}{ AREA $^{+}$} & \multicolumn{3}{|c}{ Depth in meters of $30 \mu \mathrm{g}$-at/liter } \\
\cline { 2 - 5 } $1-9$ & WINTER & SPRING & SUMMER & FALL \\
\hline 10 & $200-300$ & $200-300$ & $200-300$ & $200-300$ \\
11 & $\mathrm{~N}$ & $250-350$ & $\mathrm{~N}$ & $\mathrm{~N}$ \\
12 & $\mathrm{~N}$ & $150-250$ & $\mathrm{~N}$ & $\mathrm{~N}$ \\
13 & $100-200$ & $100-250$ & $150-300$ & $\mathrm{~N}$ \\
14 & $* 450$ & $\mathrm{~N}$ & $\mathrm{~N}$ & $\mathrm{~N}$ \\
15 & $* 325$ & $* 500$ & $* 475$ & $\mathrm{~N}$ \\
16 & $* 325-450$ & $* 500$ & $\mathrm{~N}$ & $\mathrm{~N}$ \\
17 & 100 & $\mathrm{~N}$ & $* 475$ & $\mathrm{~N}$ \\
18 & $\mathrm{~N}$ & $* 250-300$ & $\mathrm{~N}$ & $\mathrm{~N}$ \\
19 & $100-500$ & $120->500$ & $100->500$ & $\mathrm{~N}$ \\
20 & $225-350$ & $200->500$ & $100->500$ & $250-350$ \\
\hline
\end{tabular}

* Data sparse

$N$ Data not available

+ A reas defined in Fig. $I$. 
(Ref. 31). As the mixed layer increases in depth, the maximum concentration of phytoplankton (microalgae) gradually deepens, leaving a zone of nitrate-deficient water between it and the upper pycnocline.* North of $45^{\circ} \mathrm{N}$, nitrate remains at relatively high concentrations throughout the year. South of $45^{\circ} \mathrm{N}$, nitrate is present at the surface during winter and late fall but becomes depleted in spring and summer. The maintenance of relatively high concentrations of nitrate north of $45^{\circ} \mathrm{N}$ is attributed to relatively intensive entrainment of deep water into the upper zone coupled with a slow rate of removal of nutrients by primary producers (Ref. 31 ).

For areas south of $40^{\circ} \mathrm{N}$ in the eastern Pacific Ocean there have been two major surveys of nutrient and other oceanographic parameters. The California Cooperative Oceanic Fisheries Investigation Program (CALCOFI) has been studying oceanic properties on the California Current region from approximately $40^{\circ} \mathrm{N}$ to $20^{\circ} \mathrm{N}$ since 1950 and the Eastern Tropical Pacific (EASTROPAC) cruises were fielded during 1967 and 1968 to survey the tropical and subtropical eastern Pacific from about $25^{\circ} \mathrm{N}$ to $20^{\circ} \mathrm{S}$ and from the coast west to $130^{\circ} \mathrm{W}$.

Near-surface nutrient concentrations from $40^{\circ} \mathrm{N}$ to about $35^{\circ} \mathrm{N}$ tend to be low during spring and summer but with slightly higher concentrations in the winter. Concentiations of $30 \mu \mathrm{g}$-at $\mathrm{NO}_{3}-\mathrm{N} /$ liter are generally located between 150 and 300 meters of depth.

Figure A. 2 shows nitrate levels increasing rapidly from near $0 \mu \mathrm{g}$-at/liter at about 50 meters of depth to 20-25 $\mu \mathrm{g}$-at $\mathrm{NO}_{3} /$ liter at 200 meters in area 11 .

South of $35^{\circ} \mathrm{N}$, near-surface $\mathrm{NO}_{3}$ concentrations tend to be very low, $0.1 \mu \mathrm{g}$-at/liter or less. Figures 14-17 (from CALOFI Atlas, Ref. 32) show the nitrate concentrations at 10 meters for the four seasons. Near-shore concentrations can be very high in certain areas along the Baja California and California coasts during the spring and summer upwelling periods. Concentrations as high as $16 \mu \mathrm{g}$-at/liter $\mathrm{NO}_{3}-\mathrm{N}$ are observed at Pt. Eugenia, $27^{\circ}$ $30^{\prime} \mathrm{N}$ and Pt. Antonia, $30^{\circ} \mathrm{N}$, both in Baja California; and at California's Pt. Conception, $34^{\circ} 30^{\prime} \mathrm{N}$ (Fig. 15, Ref. 32). Relatively high concentrations are observed off San Francisco in the fall (Fig. 17). South of $35^{\circ} \mathrm{N}$, nitrate concentrations at distances greater than 8 kilometers off the coast are consistently low. Figures 18 through 21 show the seasonal concentration of $\mathrm{NO}_{3}$ at 100 meters of depth.

Seasonal variations are not as apparent as areal trends. Nitrate concentrations at 100 meters of depth decrease from approximately $25 \mu \mathrm{g}$-at/liter at $35^{\circ} \mathrm{N}$ near the coast to about $5 \mu \mathrm{g}$-at/liter at $35^{\circ} \mathrm{N}$ but 240 to 300 kilometers farther west. To the south there is also a trend of generally decreasing nitrate concentrations but with higher values at greater depths. Figure A.1 shows three profiles for spring in area 10 (Fig. 1) taken in the vicinity of $27^{\circ} \mathrm{N}, 117^{\circ} \mathrm{W}$. The nitrate concentration is at undetectable concentrations down to about 50 meters of depth, but then the concentration rapidly increases to between 7 and $22 \mu \mathrm{g}-a \mathrm{t} /$ hiter at 100 meters of depth and $30 \mu \mathrm{g}$-at/hiter between 250 and 350 meters (Table 2).

\footnotetext{
*Vertical zone of maximum density gradient; usually corresponds with the thermocline.
} 
Areas further to the west (region 13, in the north Pacific gyral water, Fig. 1) show low surface concentrations which increase to $30 \mu \mathrm{g}$-at/liter $\mathrm{NO}_{3}-\mathrm{N}$ at near 450 meters of depth. From limited data, there appears to be a seasonal near-surface increase of concentration from winter to summer (Figs. A.7 to A.9) to a value of approximately $1 \mu \mathrm{g}$-at in the spring and summer.

In Hawaiian offshore waters (area 14, Pacific north equatorial region, Fig. 1), nearsurface nitrate concentrations are again low (less than $0.5 \mu \mathrm{g}$-at/liter) and do not reach 30 $\mu \mathrm{g}$-at/liter levels until a depth of between 325 and 500 meters is reached (Figs. A.10 to A.12). Average nitrate levels for Hawaiian offshore waters are given in Table 3. There is little upwelling in the Hawaiian area except in some very localized near-shore sites; overall the area can be considered nutrient-limited.

In area 18, the western extreme of California water (Fig. 1), nutrient values are low in the upper 100 meters (less than $0.2 \mu \mathrm{g}$-at/liter) (Figs. B.54 through B.61). Nitrate levels of $30 \mu \mathrm{g}$-at/liter are reached at approximately 300 meters of depth. Further to the south $\left(3^{\circ} \mathrm{N}\right.$ to $\left.15^{\circ} \mathrm{N}\right)$ in the North Equatorial Countercurrent region (region 17, Fig. 1), nutrient concentrations are again low in the upper 50 meters, but rise rapidly to between 15 and 25 $\mu \mathrm{g}$-at $\mathrm{NO}_{3}$ /liter at 100 meters of depth. Below 100 meters, the concentration remains relatively constant, approaching $30 \mu \mathrm{g}$-at/liter at 250-300 meters of depth but in some measurements not going above 20 to $25 \mu$ g-at/liter at depths of 350 meters (Fig. A.13). In this area, therefore, little would be apparently accomplished by upwelling water artificially from deeper than 150 meters.

Further to the east, (area 19 in the southern portion of the west Mexican water), surface concentrations are low to about 30 meters of depth (Figs. A.16 to A.19). There are a few high surface values (between 2 and $7 \mu \mathrm{g}$-at $\mathrm{NO}_{3} /$ liter) during the winter (Fig. A.16), a phenomenon which might be caused by local wind-induced upwelling. Below 30 to 50 meters there is a very rapid increase in concentration which reaches $20-25 \mu \mathrm{g}$-at/liter at a depth of 100 meters. A nitrate concentration of $30 \mu \mathrm{g}$-at/liter is reached between 100 and 500 meters. Nitrate concentrations are generally directly related to the temperature profile (thermocline). Nutrient concentration increases rapidly near the base of the thermocline.

Table 3. Average nitrate concentration for Hawaiian offshore waters (Ref. 33).

\begin{tabular}{c|c}
\hline DEPTH $(\mathrm{m})$ & $\mathrm{NO}_{3}-\mathrm{N}(\mu \mathrm{g}-\mathrm{at} /$ liter $)$ \\
\hline 0 & 0.05 \\
100 & 0.08 \\
200 & 2.18 \\
300 & 11.90 \\
400 & 23.92 \\
500 & 33.03 \\
600 & 34.77
\end{tabular}


For example, during the fall in area 19, the thermocline is between 30 and 90 meters of depth (Fig. B.77) and the nitrate concentration rapidly increases over this range (Fig. A.18).

Area 20 in the Peru-Galapagos water (Fig. 1) is in the equatorial region $\left(2^{\circ} \mathrm{S}\right.$ to $3^{\circ} \mathrm{N}$ ) west of the Galapagos Islands. This is an area of intense natural upwelling caused by a strong divergence at the equator which acts to bring water of low temperature and high nutrient concentration to the surface (Ref. 29). Figures 22 through 25 show nitratenitrogen levels for winter and summer at a depth of 10 and 100 meters for a major portion of the eastern tropical Pacific (Ref. 22). Ten-meter nitrate concentrations are highly elevated, averaging between $8 \mu \mathrm{g}$-at $\mathrm{NO}_{3} /$ liter (winter, Fig. 22) and $10 \mu \mathrm{g}$-at/liter (summer, Fig. 23). The equatorial upwelling region extends from the Peruvian and Ecuadorian coasts (from about $12^{\circ} \mathrm{S}$ to the equator) and in the westerly direction to at least $150^{\circ} \mathrm{W}$ (Figs. 1, 22 , and 23). In region 20, 100 -meter nitrate levels average from 15 to $25 \mu \mathrm{g}$-at/liter for winter (Fig. 24) and summer (Fig. 25). Concentrations as high as $40 \mu \mathrm{g}$-at/liter are observed southeast of the Galapagos $\left(8^{\circ} \mathrm{N} 86^{\circ} \mathrm{W}\right)$ during the winter months (Fig. 24). Figures A.20 through A.24 give nitrate concentration profiles for area 20 for the four seasons. Surface concentrations are variable but high (maximum of $14 \mu \mathrm{g}$-at/liter in summer, Fig. A.21). Because of the upwelling, surface temperatures are significantly depressed (Figs. 9 and 10); during the summer and fall mean temperatures are $6^{\circ}$ to $7^{\circ} \mathrm{C}$ lower in region 20 than in region 19 (Appendices B and C). Reduced temperatures and increased nutrients in the natural upwelling zones would, of course, allow for much reduced artificial upwelling rates and possibly eliminate the need for upwelling completely.

In summary, nutrient concentrations in the surface waters of the eastern Pacific Ocean are highly variable. Concentrations of nitrate-nitrogen are usually higher over the continental shelf because of localized upwelling and increased nutrient input from terrestrial runoff. Generally, nitrate concentration decreases in a westerly direction and the isonutrient depths increase. For example, in regions 1 through 9 the $30 \mu \mathrm{g}$-at/liter $\mathrm{NO}_{3}$ depth is between 200 and 300 meters, in region 18 it is 250-300 meters, and near Hawaii (region 14) it is 325-500 meters. The trend is similar from north to south; there are higher surface concentrations seasonally north of $35^{\circ} \mathrm{N}$. In more temperate waters ( south of $35^{\circ} \mathrm{N}$ to about $3^{\circ} \mathrm{N}$ ) surface concentrations of nitrate are generally below $1 \mu \mathrm{g}$-at/liter and frequently below the level of detection. In the Costa Rica Dome and equatorial upwelling regions, surface nitrate levels run as high as 8 to $10 \mu \mathrm{g}$-at/liter and reach levels of 20 to $25 \mu \mathrm{g}$-at/liter in the upper 100 meters.

\section{METEOROLOGY}

The meteorological parameters of greatest significance to OFEF, probably are wind velocity and duration. Severe storms with high velocity winds cause high waves and increased current speeds, which in turn can create increased stresses on substrate structures and kelp plants. Because wave heights and periods are related to wind speed, wind and storm characteristics are considered in this section. The ocean, as a liquid medium, is greatly influenced by severe storms, and siting of an OFEF in an area of minimal storm activity is more than likely important for its economic success and survival. It is probable that future technology will allow placement of the farm in areas of high-storm frequency but the resulting higher costs may dictate selection of areas of low-storm frequency and severity. 


\section{Tropical and Extratropical Cyclones}

Tropical cyclones develop in the vicinity of $15^{\circ}$ to $20^{\circ} \mathrm{N}$ and near $20^{\circ} \mathrm{S}$ latitude. In the northern hemisphere, tropical storms and hurricanes evolve from tropical cyclones which have grown from low level disturbances originating in the intertropical convergence zone (ICZ), an area where northeast and southwest trade winds meet $\left(5^{\circ}\right.$ to $\left.10^{\circ} \mathrm{N}\right)$. Figure 26 gives the average number of cyclones per 5-degree square per year, and the principal season for storm activity is also given for each region. Large areas off the east coast of the United States and the east coast of Asia, Australia, India, and Madagascar are characterized by relatively frequent tropical cyclones. Off the east coast of the U.S. there is at least one tropical cyclone per year per 5-degree square as far north as $42^{\circ}$ (Fig. 26), due in part to the influence of the warm, northerly moving Gulf Stream. In the area of study (eastern Pacific), the region of cyclone frequency greater than or equal to one per year per 5-degree square only extends to $27^{\circ} \mathrm{N}$ because of the cooler California Current water moving south. The greatest frequency of cyclones, however, is in the eastern tropical Pacific, where it reaches a mean of six per year per 5-degree square in the vicinity of $16^{\circ} \mathrm{N}, 110^{\circ} \mathrm{W}$ (Fig. 26, Ref. 34). In the eastern Pacific, tropical cyclones generally occur in the period June through October, with the greatest frequency occurring during September.

The various stages of tropical cyclones, as well as other meteorological data, are given in Appendix D. Figure D.1 shows the areal distribution plus frequency and speed statistics for cyclonic winds of $18 \mathrm{~m} / \mathrm{sec}$ ( $34 \mathrm{knot}$ ) or greater (gale-force winds) for 5-degree squares in the northeastern Pacific. During the 22-year period of record, there was only a single tropical cyclone in the vicinity of San Diego (4 percent probability of occurrence) whereas in the square $15^{\circ}$ to $20^{\circ} \mathrm{N}$ and $105^{\circ}$ to $110^{\circ} \mathrm{W}$ there were 106 such cyclones. The frequency and distribution of tropical storms (with winds of $25-32 \mathrm{~m} / \mathrm{sec}$ or $48-63 \mathrm{knots}$ ) and hurricanes (winds $\geqslant 33 \mathrm{~m} / \mathrm{sec}$ ) are given in Figs. D.2 and D.3, respectively.

Figure 27 shows the maximum extent and mean tracks of both tropical and extratropical cyclones for the northeastern Pacific. Most tropical cyclones originating southwest of the area of maximal cyclone frequency (indicated by crosshatched line) move westnorthwestward and reach as far as $180^{\circ}$. The maximum northerly extent of tropical storms with winds of $18 \mathrm{~m} / \mathrm{sec}$ or greater is approximately $35^{\circ} \mathrm{N}$. Hurricane-force storms (winds $\geqslant 33 \mathrm{~m} / \mathrm{sec}$, in the period of record) have not extended beyond $30^{\circ} \mathrm{N}$ (322 kilometers south of San Diego) and have reached the southern portion of the Hawaiian Islands (Fig. 27).

During autumn and early winter the cooling of the Asiatic continent and adjacent seas strengthens the surface temperature gradients and the polar front. This cooling trend and an intensification of the jet stream aloft leads to more frequent formation and greater development of extratropical cyclones.

The usual extratropical cyclone track is east to southeast (Fig. 27). The Gulf of Alaska is frequented by more extratropical cyclones than any other region of the north Pacific. Their maximum frequency and intensity is attained during early and middle winter. Off the west coast there are fewer than one extratropical cyclone per 5-degree square (during February) south of approximately $44^{\circ} \mathrm{N}$. The intensity of extratropical cyclones 
decreases in a southerly direction. The maximum southerly range of extratropical cyclones (with winds of $\geqslant 18 \mathrm{~m} / \mathrm{sec}$ ) is about $31^{\circ} \mathrm{N}$.

\section{Winds}

Tropical and extratropical cyclone intensities are reflected in surface-wind velocities. In the northern portion of the survey area maximal surface winds occur in November and December and generally blow from the southwest. Figures D. 4 through D.7 give wind data for the northern portion of the survey area and show percent frequency of wind speed and direction for 5-degree squares for four months representative of seasonal wind characteristics; January, April, July, and November, respectively. During November and December in the area between $40^{\circ}$ and $50^{\circ} \mathrm{N}$ the frequency of gale-force winds $(\geqslant 14 \mathrm{~m} / \mathrm{sec}$ ) can be as high as 30 to 35 percent. Figure 28 shows the percent of surface winds of Beaufort force $\leqslant 3(5 \mathrm{~m} / \mathrm{sec})$ and $\geqslant 8(17 \mathrm{~m} / \mathrm{sec})$ in the northern portion of the survey area.

For November there is a broad region of maximum frequency of strong winds where greater than 5 percent of the time winds of $\geqslant 18 \mathrm{~m} / \mathrm{sec}$ were observed north of approximately $40^{\circ} \mathrm{N}$. These frequencies decrease to the south. Conversely, light winds $(\leqslant 5 \mathrm{~m} / \mathrm{sec})$ are most frequent nearshore with decreasing percentage frequencies to the north and west. The area of maximum frequency of light winds and minimum frequency of gale-force winds is off southern Califomia and northern Baja California $\left(30^{\circ}-35^{\circ} \mathrm{N}\right)$, where light winds prevaif 50-60 percent of the time (Fig. 28). Light winds also prevail along the coast of Canada throughout most of the year.

Mid- and late-winter bring a gradual reduction in mean surface wind speed and cyclone frequency. By February, average wind speeds are generally lower $(9-10 \mathrm{~m} / \mathrm{sec})$ in the northern and central portion of Fig. 28. There is a general decline in average speeds toward the annual minimum in July or August. Minimum average speeds in most of the quadrangles vary between 4.9 and $6 \mathrm{~m} / \mathrm{sec}$ during the summer months, with some increase occurring in the southeast section, south of $40^{\circ} \mathrm{N}$. The reversal of climatic trends initiated over the northern part of the area during the latter part of August spreads rapidly and causes a marked increase of wind speeds and frequency of gales to nearly all of the area except the southeast corner.

In the southern portion of the survey area, wind speeds are generally less than those in the northern portion. The trade winds derived from the north and south Pacific subtropical high-pressure centers are the predominant factor in the area $30^{\circ} \mathrm{N}$ to the equator. Figures D. 8 to D.1 I give the percent frequency of wind speed and direction for the southern portion of the survey area. The trades are exceptionally steady winds, come from the northeast in all seasons, and overlie the region extending from $30^{\circ} \mathrm{N}$ to the intertropical convergence zone ( $\mathrm{ICZ}$ ) at approximately $10^{\circ} \mathrm{N}$. Mean trade wind speed is nearly $8 \mathrm{~m} / \mathrm{sec}$. South of this region, the southeast trade winds predominate, intersecting with the northeast trades at the ICZ. Figure 29 gives the percent frequency of winds Beaufort force $\leqslant 3$ ( 5 $\mathrm{m} / \mathrm{sec})$ and $\geqslant 8(18 \mathrm{~m} / \mathrm{sec})$ for February and August.

In the coastal areas north of $10^{\circ} \mathrm{N}$, intrusions of air from the Caribbean and the Gulf of Mexico are common. The more than 1 percent frequency of gales (Beaufort force 8) off 
southern Mexico and Guatemala in February are caused by northerly winds from the Caribbean. There are large regions in the southeastern portion of the area where there is greater than 80 percent frequency of winds equal to or less than $5 \mathrm{~m} / \mathrm{sec}$. This and other areas where there are a high percentage of light winds are generally out of the major influence of the trade winds. In the areas where trade winds are strong, light winds usually represent only 10 to 30 percent of the total. Although high velocity winds are not common to most of the area, hurricane-force winds $\geqslant 33 \mathrm{~m} / \mathrm{sec}$ ) caused by strong tropical cyclones have been reported as far north as $30^{\circ} \mathrm{N}$ (once in 6 years) and more frequently south of Baja California in the vicinity of $20^{\circ} \mathrm{N}, 115^{\circ} \mathrm{W}$ ( 12 times in six years) and to the west towards Hawaii (Figures C.5 through C.8). Wind velocities in these areas in excess of $50 \mathrm{~m} / \mathrm{sec}$ have been reported $(62 \mathrm{~m} / \mathrm{sec}$ winds were measured in Hurricane Maggie, 480 kilometers south of Baja California in 1974, Ref. 44). Strong local winds are frequent during the winter in the Gulf of Tehuantepec and along the Central American coast $\left(17^{\circ} \mathrm{N}\right.$ to $\left.8^{\circ} \mathrm{N}\right)$. These winds reach gale strength during periods of high pressure over the Caribbean and Gulf of Mexico. Local nearshore gale-force winds associated with violent thunderstorms are relatively common along the west coast of Mexico and Central America during the summer months.

Figure 30 gives a summary of environmental data for the central northeast Pacific, including percent frequency of wind velocity $\geqslant 17 \mathrm{~m} / \mathrm{sec}$ for two Ocean Weather Stations (OWS N, $30^{\circ} \mathrm{N}, 140^{\circ} \mathrm{W}$, and OWS $\mathrm{P}, 50^{\circ} \mathrm{N}, 145^{\circ} \mathrm{W}$ ) and four quadrangles in between. The value of the OWS data is that the weather observation ships were continuously manned by professional observers for over twenty years (including periods of severe weather). Other data sources are usually from ships of opportunity and have a fair weather bias because most ships tend to avoid bad weather (Ref. 27). It is apparent from Fig. 30 that there is a marked reduction in frequency of gale-force winds from OWS P south to OWS N. At OWS P galeforce winds occur more than 10 percent of the time during January through March and October through December. The peak months are November and December where galeforce winds blow over 20 percent of the time. At OWS N, winds of greater than $17 \mathrm{~m} / \mathrm{sec}$ occur near 1 percent of the time in January, February, and December and occur rarely, if ever, between June and September. Areas 1 through 4 show intermediate frequency structures. Figures 31 and 32 are monthly persistence graphs of gale-force winds for OWS N and P. These graphs depict the cumulative percent frequency of hours of duration of the event (winds $\geqslant 17 \mathrm{~m} / \mathrm{sec}$ ) equal to or less than the number of hours intersected by the solid curve; and also depict days interval between events equal to or less than the number of days intersected by the broken curve.

At OWS N winds of $17 \mathrm{~m} / \mathrm{sec}$ or greater are of short duration, and there is generally a long period of time between the events. There are very few winds of high velocity during May and October. At OWS P, winds of $17 \mathrm{~m} / \mathrm{sec}$ or greater are not uncommon during any month; the longest duration of event and shortest period between events occurs January through April and September through December (Fig. 32). Persistence graphs of lowvelocity winds $(\geqslant 2.5 \mathrm{~m} / \mathrm{sec}$ ) will give an estimate of total wind energy available if wind powered energy sources are considered for upwelling apparatus. Figures 33 and 34 present persistence graphs for winds $\geqslant 2.5 \mathrm{~m} / \mathrm{sec}$ for OWS N and $\mathrm{P}$, respectively.

In summary, the most severe persistent winds are in the northern portion of the survey area and frequently are associated with extratropical storms in the fall and winter. 
High-wind velocities are not uncommon north of $35^{\circ} \mathrm{N}$ but decrease significantly in frequency in southern California waters. The southern region of the area has steady, predominate trade winds averaging 5 to $10 \mathrm{~m} / \mathrm{sec}$, blowing from the northeast in latitudes $5^{\circ}$ to $25^{\circ} \mathrm{N}$ and from the southeast $10^{\circ} \mathrm{S}$ to $5^{\circ} \mathrm{N}$. Occasional high-velocity winds associated with local activity or tropical cyclones are observed along the coasts of Central America and Mexico. Other areas, particularly the northern Baja and southern California coast at latitudes $20^{\circ}$ to $35^{\circ} \mathrm{N}$, have very low-velocity winds (only rarely do they increase above $17 \mathrm{~m} / \mathrm{sec}$ ).

\section{Wind-Generated Ocean Waves}

Ocean waves are considered here as part of the meteorological data because nearly all near-surface waves are wind-generated and are directly related to wind velocity and duration. An exception would be the extremely rare tidal waves (tsunamis) generated by seismic disturbances or volcanic eruptions. Quantitative values for wave height (the vertical distance between a wave crest and the preceding trough) and period (length of time between successive crests) have been established as a function of wind speed, fetch (distance which the wind has blown over water), duration of the wind, and decay distance (distance the waves have progressed from the area of generation). Although ocean waves are generated as a direct result of wind action, other variables such as currents, bottom topography, and local winds affect their magnitude and direction.

Wave data are generally observed as either "sea" (waves generated by local winds) or "swell" (waves which travel beyond their source regions). The observed wave lieight is usually termed the "significant height" and is defined as the average value of the highest one third of all waves observed in a given wave train. "Extreme waves" are quite rare and occur when two or more very high waves come together in constructive phase. Extreme wave heights are discussed in the Extreme Meteorological Data Section and are defined by Thom (Ref. 37):

\section{Extreme Wave Height $=1.8 \times$ Significant Wave Height.}

Figure 35 gives an empirically-derived curve of sustained wind speed versus significant wave height for increasing and decreasing wind regimes. The figure indicates that for decreasing winds the significant wave height will generally be higher because of the longer period of time that the wind has blown. The right side of Fig. 35 thus demonstrates a "fully arisen" sea (the total energy possible from a wind has been translated to wave energy). This figure can be used to derive approximate values of significant wave heights from the wind data given in the previous section.

Wave period is highly important as an engineering consideration because it controls the depths reached by given fractions of the wave motion (amplitude and velocity). Figure 36 shows the attenuation of wave motion with depth given the period of the wave. For example, the motion of a wave with a 6 -second period is 50 percent attenuated at about 4.5 meters of depth and becomes insignificant ( 4 percent of surface wave energy remaining) at 26 meters, while a 12-second wave is 50 percent attenuated at 23 meters and becomes insignificant at 110 meters. (Note: Wave-induced drag forces scale with the square of the wave motion.) 
Figures 37 to 40 give percent frequency of wave height, period, and wave direction for winter (Jan-Mar), spring (Apr-Jun), summer (Jul-Sep), and fall (Oct-Dec), respectively, for the northern sector $\left(30^{\circ}\right.$ to $\left.45^{\circ} \mathrm{N}\right)$ of the survey area. During the winter months the frequency of high seas ( $\geqslant 3.7$ meters) increases from south to north and from east to west, showing a maximum of 15 percent in the northwest and a minimum of about 2 percent off southern California. The prevailing southwest to west winds, reflecting the steep pressure gradient between the Aleutian low and the north Pacific high, generate high frequencies $(>50$ percent) of seas 1.5 meters or higher in the west. These decrease substantially towards the east.

During May, seas of 1.5 meters or higher are at a maximum frequency (near 50 percent) at $30^{\circ}$ to $35^{\circ} \mathrm{N}$ and $120^{\circ}$ to $130^{\circ} \mathrm{W}$. The summer months represent the period of lowest sea state for the entire area. However, the winter trend is reversed; the wave heights tend to increase slightly toward the east with the area of maximum frequency of 1.5 meters or greater seas being located about $35^{\circ}$ to $40^{\circ} \mathrm{N}$ and $125^{\circ}$ to $130^{\circ} \mathrm{W}$. Waves of 3.7 meters or higher are observed with frequencies of 2 percent or less in all areas. During the fall, the sea state begins to increase toward winter values.

Wave heights of at least 1 meter will probably be necessary for wave-powered pumps of economical size. Figures 41 and 42 give persistence graphs for wave heights of 1 meter or greater at OWS N and P, respectively (see Fig. 30 for map). They give percent frequencies of the duration of events and days interval between events. At both weather stations there is a maximum of approximately 5 days between events $(100$ percent of the waves $\geqslant 1$ meter were followed by another such condition within 5 days).

The median duration of waves $\geqslant 1$ meter is about 50 hours in the summer and over 200 hours in the winter at OWS N, and 24 hours both summer and winter for OWS P. Figures 43 and 44 give persistence graphs for high seas ( $\geqslant 5$ meters) for OWS $N$ and $P$, respectively. At OWS $\mathrm{N}$ waves $\geqslant 5$ meters are rare or nonexistent during May through September. The rare occurrence in August is probably due to occasional tropical cyclones. During fall and winter the median duration of high seas is between 6 and 12 hours and the median interval is between 8 and 16 days. For OWS P, high seas are more frequent, with the median duration being similar (6-12 hours), but the median interval is reduced to 1 to 2 days in winter or fall and 40 to 48 days in summer (June, July).

In the southern portion of the survey area sea and swell are caused by the northeast trade winds. During winter and fall these winds blow from $5^{\circ}$ to $25^{\circ} \mathrm{N}$ and during spring and summer they blow from $10^{\circ}$ to $30^{\circ} \mathrm{N}$. Southeast trades are important in producing sea and swell in the southeast section during spring and summer.

The frequency of seas greater than or equal to 1.5 meters in height is generally greater in the western portion of the survey area because of the long northeast fetch. Figures 45 and 46 give the percent frequency of wave height, period, and direction characteristics for winter and summer for the southern portion of the survey area from $30^{\circ} \mathrm{N}$ to $0^{\circ}$. During the winter and spring, seas are normally from the northeast. South of $5^{\circ} \mathrm{N}$ the seas are generally from the southeast to east because of the southeast trades. The seas become calmer as the coast is approached, with the southeast being the calmest portion due to the short 
northeast fetch; about 10 percent of the waves are $\geqslant 1.5$ meters as compared to 60 percent in the northwest corner (Fig. 45). High seas, 3.7 meters or greater, occur less frequently in the southwest than throughout most of the northern section. They occur generally less than 2 percent of the time but approach 10 percent in two quadrats $\left(10^{\circ}\right.$ to $20^{\circ} \mathrm{N}, 120^{\circ}$ to $130^{\circ} \mathrm{W}$ and $20^{\circ}$ to $30^{\circ} \mathrm{N}, 130^{\circ}$ to $140^{\circ} \mathrm{W}$ ). Summer gives the most northerly advance of the southeast trades, to $10^{\circ} \mathrm{N}$. Frequency of 1.5 -meter or greater seas varies from a maximum of about 45 percent in the northwest to a minimum of 15 percent in the southeast. Seas of 3.7 meters are rare in the $20^{\circ}$ to $30^{\circ} \mathrm{N}$ region but are slightly more common in the $10^{\circ}$ to $20^{\circ} \mathrm{N}$ region due to the tropical cyclones (Fig. 46) which occasionally occur in that region.

In summary, sea states are generally higher at points further from the coast (west) and at the higher latitudes (north). Fall and winter show the highest seas, and summer is the calmest season except for occasional tropical cyclones through the southeastern section.

\section{Summary of Meteorological Data}

Wind and wave data for the survey area were requested from the Naval Weather Service Detachment, National Climatic Center, Asheville, North Carolina. Table 4 is a summary of these data and presents monthly mean and 99.5 percentile wind speeds and wave heights, the percentile of $18 \mathrm{~m} / \mathrm{sec}$ winds, and an annual wave period distribution. Events of 99.5 percentile indicate that 0.5 percent of the time ( 3.5 hours/month), during any given month, the event will occur at or greater than the level indicated. The areas of the meteorological survey are shown in Fig. 47. The areas delineated are equivalent to those oceanographic survey quadrats in Fig. 1 as indicated by the number in the lower right hand corner of each area. Areas 5 and 6 have the lowest mean wind velocities ( 3 to $5 \mathrm{~m} / \mathrm{sec}$ in winter and 4 to $6 \mathrm{~m} / \mathrm{sec}$ in summer) and have maximum wind velocities during summer of 19 and 14 $\mathrm{m} / \mathrm{sec}$, respectively. Area 5 is subject to tropical cyclones during late summer and early fall, which explains the elevated summer velocities. Area 4 has the highest mean $(6-8 \mathrm{~m} / \mathrm{sec})$ and 99.5 percentile $(19-26 \mathrm{~m} / \mathrm{sec})$ wind velocities. This represents the area north of Point Conception to $45^{\circ} \mathrm{N}$. The high winter maximums $(23-26 \mathrm{~m} / \mathrm{sec})$ represent the southerly extension of extratropical cyclones. Areas 1,2, and 3 are similar, averaging between 5 and 8 $\mathrm{m} / \mathrm{sec}$ winds with maximum winds $(99.5$ percent) varying between 13 and $18 \mathrm{~m} / \mathrm{sec}$. These winds are relatively constant because they are in the northeast trade wind zone.

Mean wave heights are rather constant in all the areas surveyed varying between 1 and 1.5 meters. Maximum waves vary significantly; the highest seas are in the north (area 4 , varying between 4.5 meters in the summer and 8 meters in January) and in the west ( 4 to 7.5 meters), due to the long fetch of the northeast trades. All the other areas have lower maximum sea states which vary between 3 and 5 meters at the 99.5-percent level. 
Table 4. Summary of mean and 99.5 percentile wind and wave data for the eastern Pacific.

$(1 \mathrm{knot} \approx 0.5 \mathrm{~m} / \mathrm{sec})$

(Data from the Naval Weather Service, Environmental Detachment, National Climatic Center, Asheville, NC)

\section{NOTES}

1. Values of the mean and 99.5 percentile of wind speed (knots) and wave height (meters) are presented for all months. Wave height is the greater of sea and swell when both are reported. Otherwise it is the reported value of sea or swell. A distribution of the annual percent frequency of wave period (seconds) by specified groups is also provided.

2. Observations in TDF-11 are primarily from ships-in-passage. These ships tend to avoid areas of known "heavy weather" (i.e., strong winds and high seas). Radio communications and optimum track ship routing have produced a "fair weather bias" (i.e., a decrease in the frequency of heavy weather observations) in this data file.

Area $1 ; 15-20^{\circ} \mathrm{N}, 145-155^{\circ} \mathrm{W}$.

JAN FEB MAR APR MAY JUN JUL AUG SEP OCT NOV DEC

$\begin{array}{lllllllllllll}\text { mean wind speed }(\mathrm{kts}) & 13 & 14 & 14 & 13 & 13 & 13 & 14 & 14 & 13 & 12 & 14 & 15 \\ 99.5 \text { percentile } & 35 & 35 & 31 & 31 & 28 & 27 & 27 & 28 & 26 & 29 & 35 & 35\end{array}$

Wind speeds of 34 knots

were in the 99.9 percentile.

$\begin{array}{lllllllllllll}\text { mean wave height }(\mathrm{m}) & 1.5 & 1.5 & 1.5 & 1.5 & 1.5 & 1 & 1 & 1 & 1 & 1 & 1.5 & 1.5\end{array}$

$\begin{array}{lllllllllllll}99.5 \text { percentile } & 7.5 & 6 & 5.5 & 4.5 & 4.5 & 4 & 4 & 3.5 & 3.5 & 4.5 & 5.5 & 6.5\end{array}$

Wave period distribution (annual):

$(<6 \mathrm{sec}) 42 \%,(6-7 \mathrm{sec}) 30 \%,(8-9 \mathrm{sec}) 15 \%,(10-11 \mathrm{sec}) 6 \%$

Area $2 ; 3-13^{\circ} \mathrm{N}, 120-140^{\circ} \mathrm{W}$.

JAN FEB MAR APR MAY JUN JUL AUG SEP OCT NOV DEC

$\begin{array}{lllllllllllll}\text { mean wind speed (kts) } & 12 & 12 & 11 & 12 & 10 & 10 & 10 & 11 & 11 & 10 & 11 & 12\end{array}$

99.5 percentile

$\begin{array}{llllllllllll}28 & 29 & 30 & 30 & 25 & 24 & 24 & 25 & 26 & 25 & 24 & 27\end{array}$

Wind speeds of 34 knots

were in the 99.9 percentile.

mean wave height $(\mathrm{m})$

99.5 percentile

$\begin{array}{llllllllllll}1.5 & 1.5 & 1.5 & 1.5 & 1 & 1 & 1 & 1.5 & 1.5 & 1.5 & 1 & 1.5\end{array}$

Wave period distribution (annual):

$(<6 \mathrm{sec}) 47 \%,(6-7 \mathrm{sec}) 25 \%,(8-9 \mathrm{sec}) 10 \%,(10-11 \mathrm{sec}) 5 \%$ 
Table 4. (Continued).

Area $3 ; 23-30^{\circ} \mathrm{N}, 120-130^{\circ} \mathrm{W}$.

JAN FEB MAR APR MAY JUN JUL AUG SEP OCT NOV DEC

mean wind speed (kts)

$\begin{array}{llllllllllll}12 & 12 & 12 & 13 & 13 & 12 & 12 & 11 & 11 & 11 & 10 & 12\end{array}$

99.5 percentile

$\begin{array}{llllllllllll}30 & 30 & 30 & 30 & 27 & 26 & 28 & 28 & 28 & 25 & 30 & 28\end{array}$

Wind speeds of 34 knots

were in the 99.9 percentile.

$\begin{array}{lllllllllllll}\text { mean wave height }(\mathrm{m}) & 1 & 1 & 1 & 1.5 & 1.5 & 1.5 & 1.5 & 1 & 1 & 1 & 1.5\end{array}$

99.5 percentile

$\begin{array}{lllllllllll}4 & 4.5 & 4.5 & 5 & 4.5 & 4.5 & 4.5 & 4.5 & 4 & 4 & 5\end{array}$

Wave period distribution (annual):

$(<6 \mathrm{sec}) 38 \%,(6-7 \mathrm{sec}) 29 \%,(8-9) 19 \%,(10-11 \mathrm{sec}) 8 \%$

Area $4 ; 35-45^{\circ} \mathrm{N}, 121-132^{\circ} \mathrm{W}$.

JAN FEB MAR APR MAY JUN JUL AUG SEP OCT NOV DEC

mean wind speed (kts)

$\begin{array}{llllllllllll}16 & 16 & 15 & 15 & 13 & 13 & 12 & 12 & 12 & 13 & 14 & 15 \\ 50 & 45 & 45 & 43 & 40 & 40 & 38 & 36 & 37 & 40 & 44 & 50\end{array}$

99.5 percentile

Wind speeds of 34 knots

were in the 97 percentile.

mean wave height $(\mathrm{m})$

$\begin{array}{llllllllllll}1.5 & 1.5 & 1.5 & 1.5 & 1.5 & 1.5 & 1 & 1 & 1 & 1 & 1.5 & 1.5\end{array}$

99.5 percentile

$\begin{array}{llllllllllll}8 & 7 & 6.5 & 6.5 & 6 & 5 & 5 & 4.5 & 5 & 6 & 6.5 & 8\end{array}$

Wave period distribution (annual):

$(<6 \mathrm{sec}) 33 \%,(6-7 \mathrm{sec}) 28 \%,(8-9 \mathrm{sec}) 20 \%,(10-11 \mathrm{sec}) 8 \%$

Area $5,10-15^{\circ} \mathrm{N}, 100-110^{\circ} \mathrm{W}$.

JAN FEB MAR APR MAY JUN JUL AUG SEP OCT NOV DEC

$\begin{array}{lllllllllllll}\text { mean wind speed }(\mathrm{kts}) & 8 & 8 & 7 & 7 & 7 & 9 & 8 & 8 & 9 & 8 & 7 & 7\end{array}$

99.5 percentile

$\begin{array}{llllllllllll}24 & 25 & 21 & 21 & 27 & 35 & 33 & 30 & 37 & 30 & 30 & 27\end{array}$

Wind speeds of 34 knots

were in the 99.7 percentile.

$\begin{array}{llllllllllllllll}\text { mean wave height }(\mathrm{m}) & 1 & 1 & 1 & 1 & 1 & 1 & 1 & 1 & 1.5 & 1 & 1 & \text { I }\end{array}$

99.5 percentile

$\begin{array}{llllllllllll}3 & 4 & 4 & 3.5 & 4 & 4.5 & 4 & 4 & 4.5 & 4 & 4 & 4.5\end{array}$

Wave period distribution (annual)

$(<6 \mathrm{sec}) 52 \%,(6-7 \mathrm{sec}) 18 \%,(8-9 \mathrm{sec}) 8 \%,(10-11 \mathrm{sec}) 4 \%$ 
Table 4. (Continued).

Area $6,2^{\circ} \mathrm{S}$ to $3^{\circ} \mathrm{N}, 95-110^{\circ} \mathrm{W}$.

JAN FEB MAR APR MAY JUN JUL AUG SEP OCT NOV DEC

\begin{tabular}{|c|c|c|c|c|c|c|c|c|c|c|c|c|}
\hline mean wind speed (kts) & 8 & 8 & 7 & 7 & 8 & 10 & 11 & 11 & 10 & 9 & 9 & 9 \\
\hline 99.5 percentile & 24 & 24 & 24 & 24 & 24 & 25 & 27 & 27 & 25 & 24 & 24 & 24 \\
\hline \multicolumn{13}{|c|}{$\begin{array}{l}\text { Wind speeds of } 34 \text { knots } \\
\text { were in the } 99.9 \text { percentile. }\end{array}$} \\
\hline mean wave height $(\mathrm{m})$ & 1 & 1 & 1 & 1 & 1 & 1.5 & 1.5 & 1.5 & 1.5 & 1.5 & 1.5 & 1 \\
\hline 99.5 percentile & 3.5 & 4 & 4 & 4 & 4 & 5 & 4.5 & 4.5 & 5 & 4 & 4 & 3.5 \\
\hline
\end{tabular}

\section{Extreme Meteorological Data}

Extreme wind and wave data are highly important to the design and siting of the OFEF. These data need to be assessed in relation to engineering and biological requirements and tolerances. Table 5 gives the extreme wind speed, significant wave heights, and extreme wave heights, for specified return periods for west coast, Hawaii, and east coast areas (the latter is included for informational comparison purposes). Figure 48 shows coastal areas where wind and wave recurrence statistics were computed. The table gives mean return period, which is defined as the average number of years between successive occurrence of values greater than, or equal to, the stated value. On the west coast from central California to Washington, areas 25 to 30 have the highest extreme winds; these areas have 25 -year wind returns value of 41 to $43 \mathrm{~m} / \mathrm{sec}$ (Ref. 38). The area off Hawaii has 37- to $40-\mathrm{m} / \mathrm{sec} 25$-year extreme winds. The coastal areas of lowest extreme velocities are southern California (area 22) and northern Baja California (Area 20), showing 31 and $35 \mathrm{~m} / \mathrm{sec}$, respectively for 25 year extremes. Off southern California, the five-year return extreme is by far the lowest at $26 \mathrm{~m} / \mathrm{sec}$.

Wave-height extremes show a similar trend to the wind values with the highest waves off northern California, Oregon, and Washington. The 25-year significant wave for this area varies between 15 and 16 meters (extreme waves of 27 to 29 meters), whereas off southern California the significant 25-year wave is between 11 and 12 meters (extremes of 19 to 21 meters).

Waves in the Hawaiian waters are estimated at 15 to 16 meters, significant height and 23 to 28 meters for extreme waves for 25 -year return periods.

Tables 6 and 7 give high-wind and wave-recurrence statistics foi the northwestern portion of the survey area. The highest winds occur in the northern portion at OWS P $\left(50^{\circ} \mathrm{N}\right)$ where the 5 -year wind is $43 \mathrm{~m} / \mathrm{sec}$ and the 25 -year wind is $51 \mathrm{~m} / \mathrm{sec}$. The minimum extreme winds are observed at OWS $\mathrm{N}\left(30^{\circ} \mathrm{N}\right)$ where the 5- and 25-year winds are 32 and 39 $\mathrm{m} / \mathrm{sec}$, respectively. Areas 1 to 4 have intermediate extreme winds. 
Table 5. Extreme wind speed, significant wave height and extreme wave heights for specified return periods for the West Coast, Hawaii and the east coast of the U.S. Survey areas are shown in Fig. 48. ( 1 foot $=0.3$ meter)

(Data from NOAA, Ref. 38)

\begin{tabular}{|c|c|c|c|c|c|}
\hline \multirow[b]{2}{*}{ Area } & \multirow[b]{2}{*}{$\underline{5 \mathrm{Yr}}$} & \multirow[b]{2}{*}{$10 \mathrm{Yr}$} & \multirow[b]{2}{*}{$\underline{25 \mathrm{Yr}}$} & \multicolumn{2}{|c|}{ Extreme wind speed } \\
\hline & & & & $50 \mathrm{Yr}$ & $100 \mathrm{Yr}$ \\
\hline 1 & 76 & 83 & 92 & 100 & 109 \\
\hline 2 & 68 & 78 & 93 & 108 & 125 \\
\hline 3 & 56 & 61 & 70 & 78 & 88 \\
\hline 4 & 71 & 77 & 86 & 94 & 103 \\
\hline 5 & 67 & 74 & 83 & 91 & 100 \\
\hline 6 & 63 & 70 & 78 & 86 & 96 \\
\hline 7 & 66 & 73 & 83 & 91 & 102 \\
\hline 8 & 68 & 76 & 90 & 104 & 120 \\
\hline 9 & 71 & 79 & 92 & 105 & 120 \\
\hline 10 & 72 & 81 & 96 & 110 & 128 \\
\hline 11 & 69 & 79 & 94 & 109 & 126 \\
\hline 12 & 63 & 73 & 88 & 102 & 118 \\
\hline 13 & 62 & 72 & 88 & 102 & 119 \\
\hline 14 & 62 & 73 & 89 & 103 & 120 \\
\hline 15 & 63 & 73 & 88 & 102 & 118 \\
\hline 16 & 63 & 72 & 86 & 100 & 116 \\
\hline 17 & 62 & 70 & 84 & 96 & 111 \\
\hline 18 & 60 & 68 & 79 & 97 & 104 \\
\hline 19 & 62 & 69 & 79 & 89 & 100 \\
\hline 20 & 56 & 61 & 69 & 75 & 81 \\
\hline 21 & 60 & 66 & 73 & 79 & 86 \\
\hline 22 & 50 & 55 & 61 & 66 & 72 \\
\hline 23 & 64 & 70 & 78 & 84 & 91 \\
\hline 24 & 56 & 60 & 67 & 73 & 79 \\
\hline 25 & 65 & 71 & 79 & 86 & 93 \\
\hline 26 & 68 & 74 & 83 & 90 & 97 \\
\hline
\end{tabular}

--Significant wave height estimates (feet) for specified retum periods.

\begin{tabular}{|c|c|c|c|c|c|}
\hline Area & $5 Y r$ & $10: r$ & $25 \mathrm{Yr}$ & $50 \mathrm{Yr}$ & $100 \mathrm{Yr}$ \\
\hline 1 & 44 & 50 & 59 & 66 & 74 \\
\hline 2 & 37 & 42 & 49 & 56 & 62 \\
\hline 3 & 31 & 36 & 42 & 47 & 53 \\
\hline 4 & 37 & 42 & 50 & 56 & 63 \\
\hline 5 & 35 & 40 & 47 & 53 & 59 \\
\hline 6 & 36 & 41 & 48 & 54 & $6 ?$ \\
\hline 7 & 38 & 43 & 50 & 56 & 63 \\
\hline 8 & 47 & 53 & 63 & 70 & 79 \\
\hline 9 & 50 & 57 & 67 & 75 & 84 \\
\hline 10 & 44 & 50 & 59 & 66 & 74 \\
\hline 11 & 41 & 47 & 55 & 6) & 69 \\
\hline 12 & 38 & 43 & 50 & 56 & 63 \\
\hline 13 & 36 & 41 & 48 & 54 & 61 \\
\hline 14 & 33 & 37 & 43 & 49 & 55 \\
\hline 15 & 34 & 38 & 45 & 51 & 57 \\
\hline 16 & 34 & 39 & 46 & 51 & 58 \\
\hline 17 & 34 & 39 & 45 & 51 & 57 \\
\hline 18 & 33 & 38 & 44 & 50 & 56 \\
\hline 19 & 32 & 36 & 43 & 48 & 54 \\
\hline 20 & 32 & 36 & 43 & 48 & 54 \\
\hline 21 & 30 & 34 & 39 & 44 & 50 \\
\hline 22 & 28 & 32 & 38 & 42 & 48 \\
\hline 23 & 26 & 30 & 35 & 39 & 44 \\
\hline 24 & 32 & 36 & 42 & 47 & 53 \\
\hline 25 & 38 & 43 & 50 & 56 & 63 \\
\hline 26 & 39 & 45 & 52 & 59 & 66 \\
\hline 27 & 38 & 43 & 50 & 57 & 64 \\
\hline 28 & 39 & 44 & 52 & 58 & 65 \\
\hline 29 & 39 & 44 & 52 & 58 & 65 \\
\hline 30 & 39 & 44 & 51 & 58 & 65 \\
\hline 31 & 34 & 39 & 45 & $5 !$ & 57 \\
\hline 32 & 39 & 44 & 51 & 58 & 65 \\
\hline 33 & 38 & 43 & 51 & 57 & 64 \\
\hline 34 & 38 & 43 & 50 & 56 & 63 \\
\hline 35 & 38 & 43 & 51 & 57 & 64 \\
\hline 36 & 38 & 43 & 51 & 57 & 64 \\
\hline 37 & 36 & 40 & 47 & 53 & 60 \\
\hline 38 & 41 & 46 & 54 & 61 & 68 \\
\hline 39 & 38 & 44 & 51 & 57 & 64 \\
\hline 40 & 38 & 43 & 51 & 57 & 64 \\
\hline 41 & 36 & 41 & 48 & 54 & 60 \\
\hline 42 & 33 & 37 & 43 & 49 & 55 \\
\hline 43 & 33 & 37 & 43 & 49 & 55 \\
\hline 44 & 31 & 35 & 41 & 46 & 52 \\
\hline 45 & 19 & 22 & 26 & 29 & 33 \\
\hline 46 & 22 & 25 & 29 & 33 & 37 \\
\hline 47 & - 18 & 20 & 24 & 27 & 30 \\
\hline 48 & 22 & 24 & 29 & 32 & 36 \\
\hline 49 & 18 & 21 & 24 & 27 & 31 \\
\hline 50 & 37 & 41 & 49 & 55 & 61 \\
\hline 51 & 31 & 35 & 41 & 46 & 52 \\
\hline 52 & 38 & 43 & 51 & 57 & 64 \\
\hline
\end{tabular}

\begin{tabular}{|c|c|c|c|c|c|}
\hline Area & $5 \mathrm{Yr}$ & $10 \mathrm{Yr}$ & $25 \mathrm{Yr}$ & $50 \mathrm{Yr}$ & $100 \mathrm{Yr}$ \\
\hline 27 & 66 & 72 & 80 & 87 & 94 \\
\hline 28 & 68 & 73 & 82 & 89 & 96 \\
\hline 29 & 67 & 73 & 82 & 88 & 96 \\
\hline 30 & 67 & 73 & 87 & 88 & 95 \\
\hline 31 & 59 & 65 & 72 & 78 & 85 \\
\hline 32 & 73 & 79 & 88 & 95 & 104 \\
\hline 33 & 71 & 77 & 86 & 93 & 101 \\
\hline 34 & 70 & 76 & 85 & 92 & 100 \\
\hline 35 & 71 & 77 & 86 & 93 & 101 \\
\hline 36 & 75 & 82 & 91 & 99 & 107 \\
\hline 37 & 69 & 75 & 84 & 91 & 98 \\
\hline 38 & 77 & 83 & 93 & 101 & 109 \\
\hline 39 & 73 & 80 & 89 & 96 & 104 \\
\hline 40 & 73 & 79 & 88 & 96 & 104 \\
\hline 41 & 74 & 80 & 89 & 97 & 105 \\
\hline 42 & 75 & 81 & 91 & 98 & 107 \\
\hline 43 & 76 & 83 & 92 & 100 & 108 \\
\hline 44 & 77 & 84 & 93 & 101 & 110 \\
\hline 45 & 76 & 83 & 92 & 100 & 108 \\
\hline 46 & 74 & 81 & 90 & 97 & 106 \\
\hline 47 & 67 & 73 & 81 & 88 & 95 \\
\hline 48 & 63 & 68 & 76 & 82 & 89 \\
\hline 49 & 54 & 59 & 65 & 71 & 77 \\
\hline 50 & 61 & 67 & 75 & 82 & 90 \\
\hline 51 & 59 & 65 & 72 & 79 & 87 \\
\hline 52 & 64 & 69 & 78 & 85 & 93 \\
\hline
\end{tabular}

--Extreme wave height estimates (feet) for specified return periods.

\begin{tabular}{|c|c|c|c|c|c|}
\hline Area & $5 \mathrm{Yr}_{\mathrm{r}}$ & $10 \mathrm{Yr}$ & $25 \mathrm{rr}$ & $50 \mathrm{Yr}$ & $100 \mathrm{Yr}$ \\
\hline 1 & 80 & 90 & 105 & 119 & 134 \\
\hline 2 & 67 & 76 & 89 & 100 & 112 \\
\hline 3 & 56 & 64 & 75 & 84 & 95 \\
\hline 4 & 67 & 76 & 90 & 101 & 113 \\
\hline 5 & 64 & 72 & 85 & 95 & 107 \\
\hline 6 & 65 & 74 & 87 & 97 & 109 \\
\hline 7 & 68 & 77 & 90 & 102 & 114 \\
\hline 8 & 85 & 96 & 113 & 127 & 142 \\
\hline 9 & 91 & 103 & 120 & 135 & 152 \\
\hline 10 & 80 & 90 & 106 & 119 & 134 \\
\hline 11 & 74 & 84 & 98 & 111 & 124 \\
\hline 12 & 68 & 77 & 90 & 101 & 114 \\
\hline 13 & 65 & 74 & 87 & 98 & 110 \\
\hline 14 & 59 & 66 & 78 & 87 & 98 \\
\hline 15 & 61 & 69 & 81 & 91 & 102 \\
\hline 16 & 62 & 70 & 82 & 92 & 104 \\
\hline 17 & 62 & 70 & 82 & 92 & 103 \\
\hline 18 & 60 & 68 & 80 & 90 & 101 \\
\hline 19 & 58 & 66 & 77 & 86 & 97 \\
\hline 20 & 58 & 66 & 77 & 86 & 97 \\
\hline 21 & 53 & 60 & 71 & 80 & 89 \\
\hline 22 & 51 & 58 & 68 & 76 & 86 \\
\hline 23 & 47 & 54 & 63 & 71 & 80 \\
\hline 24 & 57 & 65 & 76 & 85 & 96 \\
\hline 25 & 68 & 77 & 90 & 101 & 113 \\
\hline 26 & 71 & 80 & 94 & 106 & 119 \\
\hline 27 & 68 & 78 & 91 & 102 & 115 \\
\hline 28 & 70 & 80 & 93 & 105 & 118 \\
\hline 29 & 70 & 79 & 93 & 104 & 117 \\
\hline 30 & 70 & 79 & 93 & 104 & 117 \\
\hline 31 & 61 & 70 & 81 & 92 & 103 \\
\hline 32 & 70 & 79 & 92 & 104 & 117 \\
\hline 33 & 69 & 78 & 91 & 103 & 115 \\
\hline 34 & 68 & 77 & 90 & 101 & 114 \\
\hline 35 & 69 & 78 & 92 & 103 & 116 \\
\hline 36 & 69 & 78 & 91 & 103 & 115 \\
\hline 37 & 64 & 73 & 85 & 96 & - 108 \\
\hline 38 & 73 & 83 & 97 & 109 & 122 \\
\hline 39 & 69 & 78 & 92 & 103 & 116 \\
\hline 40 & 69 & 78 & 91 & 103 & 115 \\
\hline 41 & 65 & 74 & 86 & 97 & 109 \\
\hline 42 & 59 & 66 & 78 & 87 & 98 \\
\hline 43 & 59 & 66 & 78 & 87 & 98 \\
\hline 44 & 56 & 63 & 74 & 84 & 94 \\
\hline 45 & 35 & 40 & 46 & 52 & 59 \\
\hline 46 & 40 & 45 & 53 & 59 & 67 \\
\hline 47 & 32 & 36 & 43 & 48 & 54 \\
\hline 48 & 39 & 44 & 57 & 58 & 65 \\
\hline 49 & 33 & 38 & 44 & 49 & 56 \\
\hline 50 & 66 & 75 & 87 & 98 & 110 \\
\hline 51 & 56 & 63 & 74 & 83 & 93 \\
\hline 52 & 69 & 78 & 91 & 302 & 115 \\
\hline
\end{tabular}




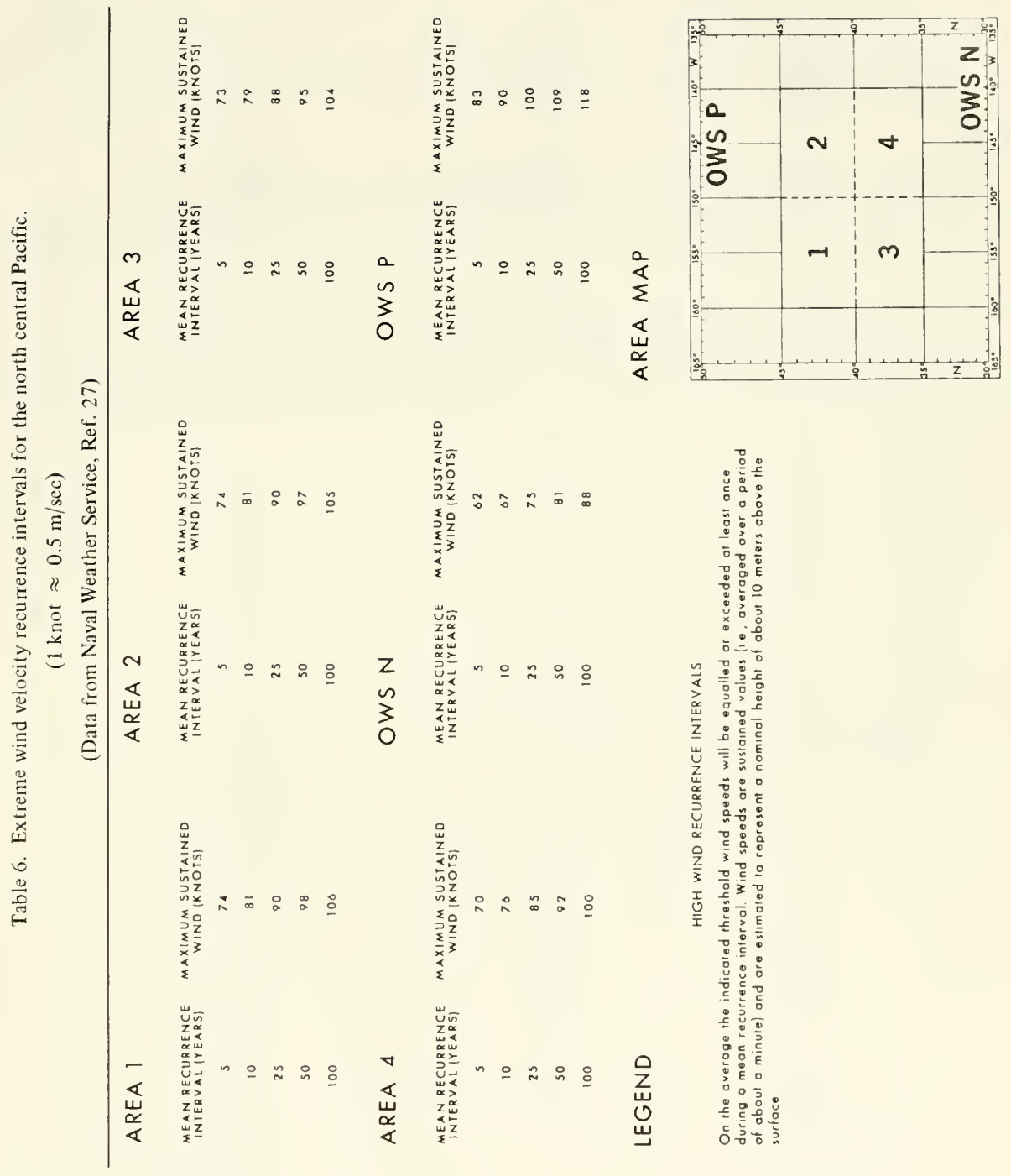




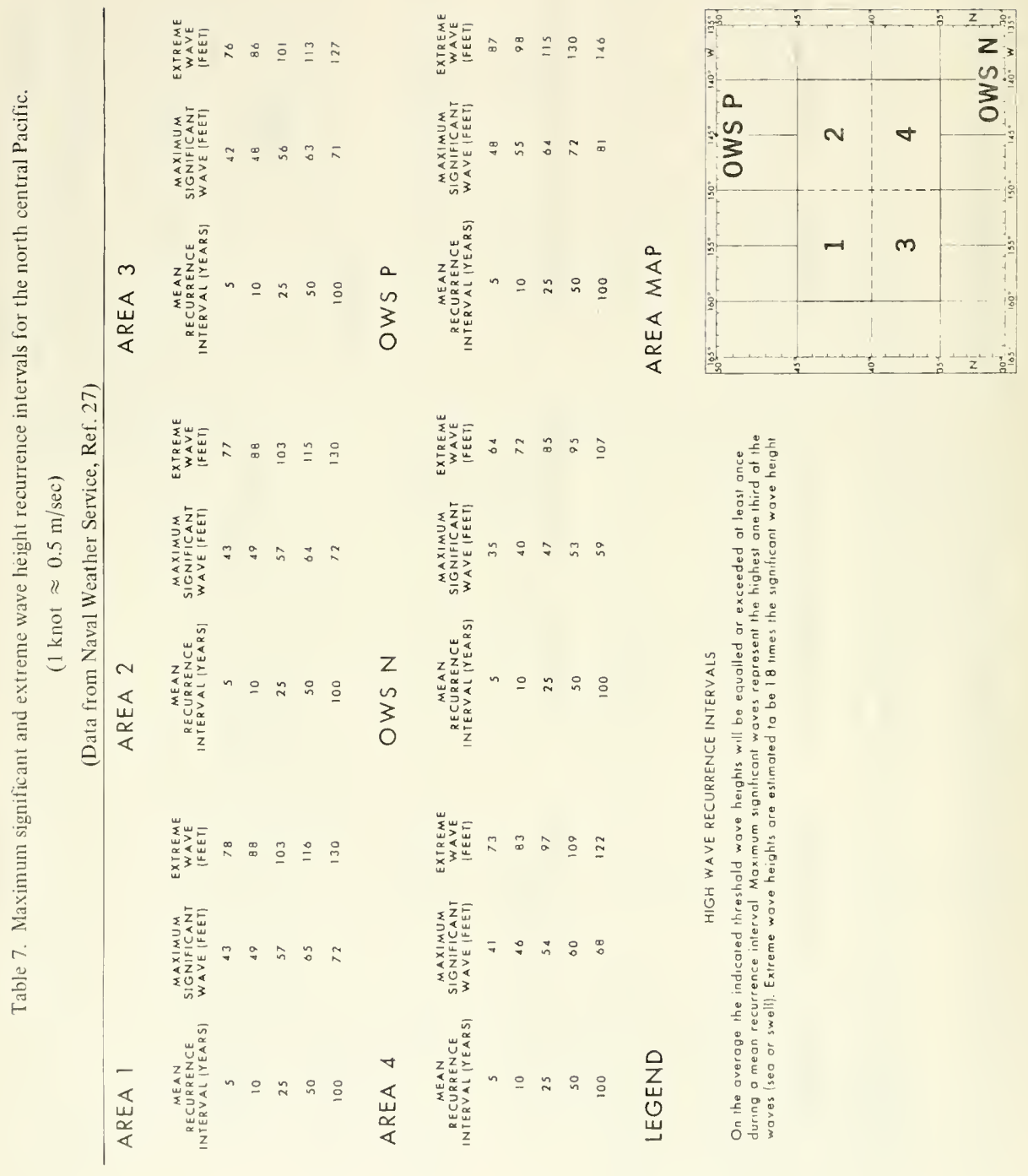


Maximum significant and extreme wave heights are given in Table 7 . The highest seas are at OWS P where the maximum significant wave heights for 5- and 25-year intervals are 15 and 20 meters and the extreme wave heights for the same periods are 27 and 35 meters. OWS $\mathrm{N}$ has the least severe seas in the northwest area with 11- to 14-meter maximum significant wave heights and 20- to 26-meter extreme wave heights for 5-and 25-year intervals. Again, because of the many years of data collected in bad as well as good weather, the Ocean Weather Station extreme data are probably the most accurate available for open ocean areas.

As a note of interest, probably the largest wave ever observed and accurately measured was in the general vicinity of the study area, at $34^{\circ} \mathrm{N}, 167^{\circ} \mathrm{W}$. The wave was approximately 34 meters high and was geometrically measured by personnel aboard the USS RAMAPO, 7 February 1933 (Ref. 39).

Extreme current data are also very important to the Ocean Farm. Current measurements in severe weather are extremely rare, and generally only theoretical data exists. A brief discussion of this topic is given in Appendix E. A further discussion of extreme meteorological data is given in Refs. 40 through 44. 

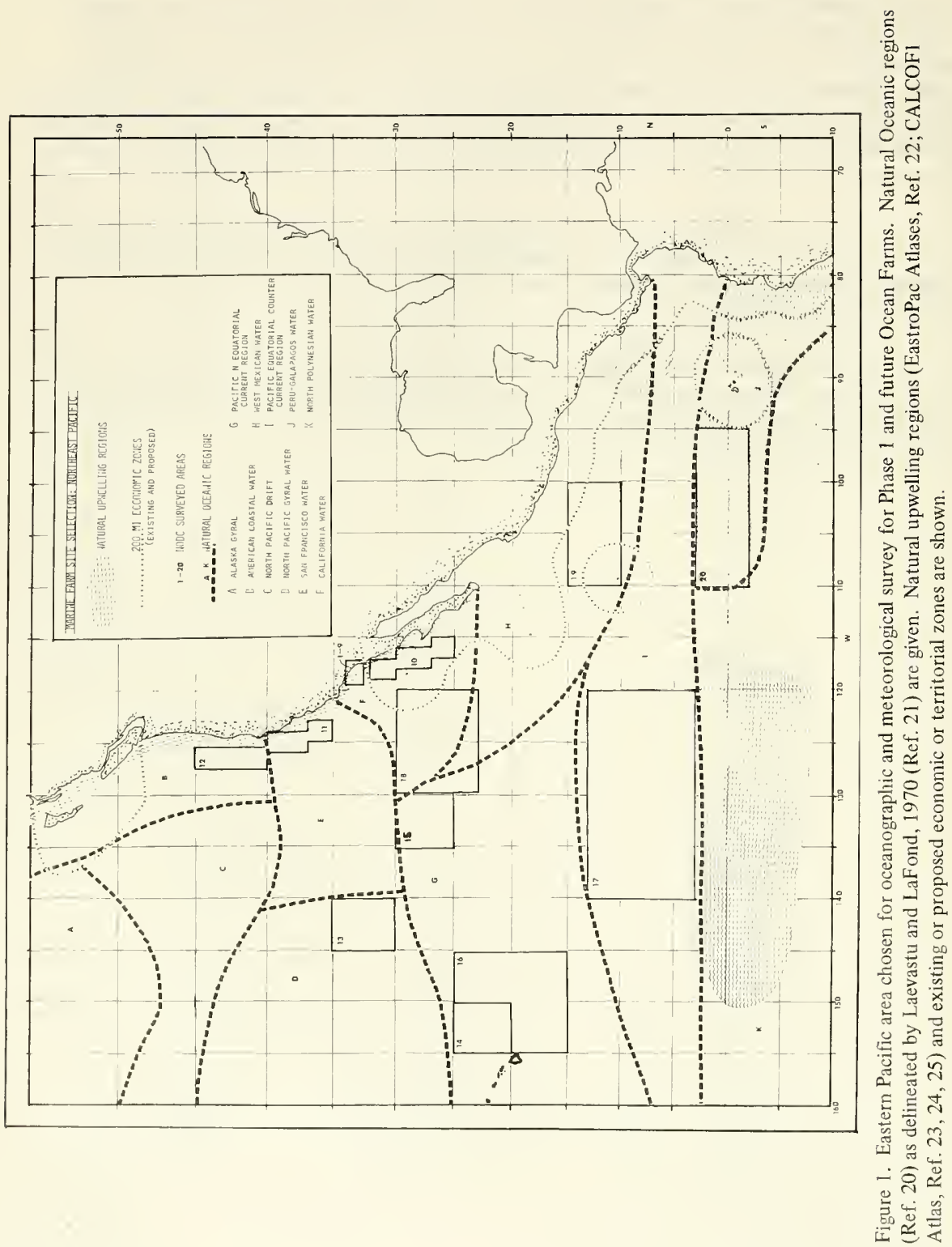


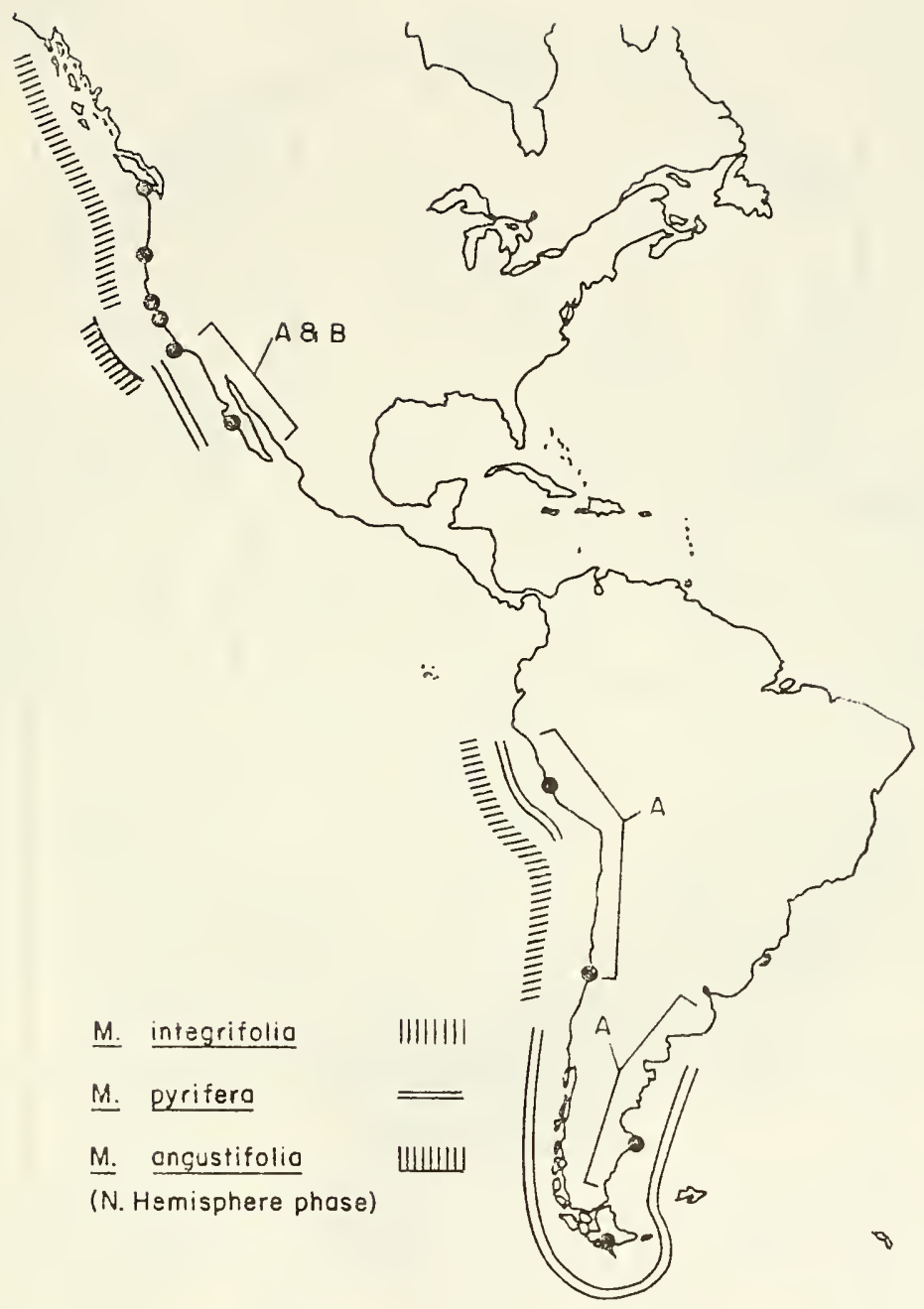

Figure 2. Distribution of Macrocystis in North and South America. A. Aerial observations of the coast. B. Detailed diving surveys; points where areas were examined intertidally or by diving are indicated. (From Neushul, 1971, Ref. 26) Note: M. pyrifera occurs as far north as the coast of Alaska but is not dominant north of about $35^{\circ} \mathrm{N}$. 


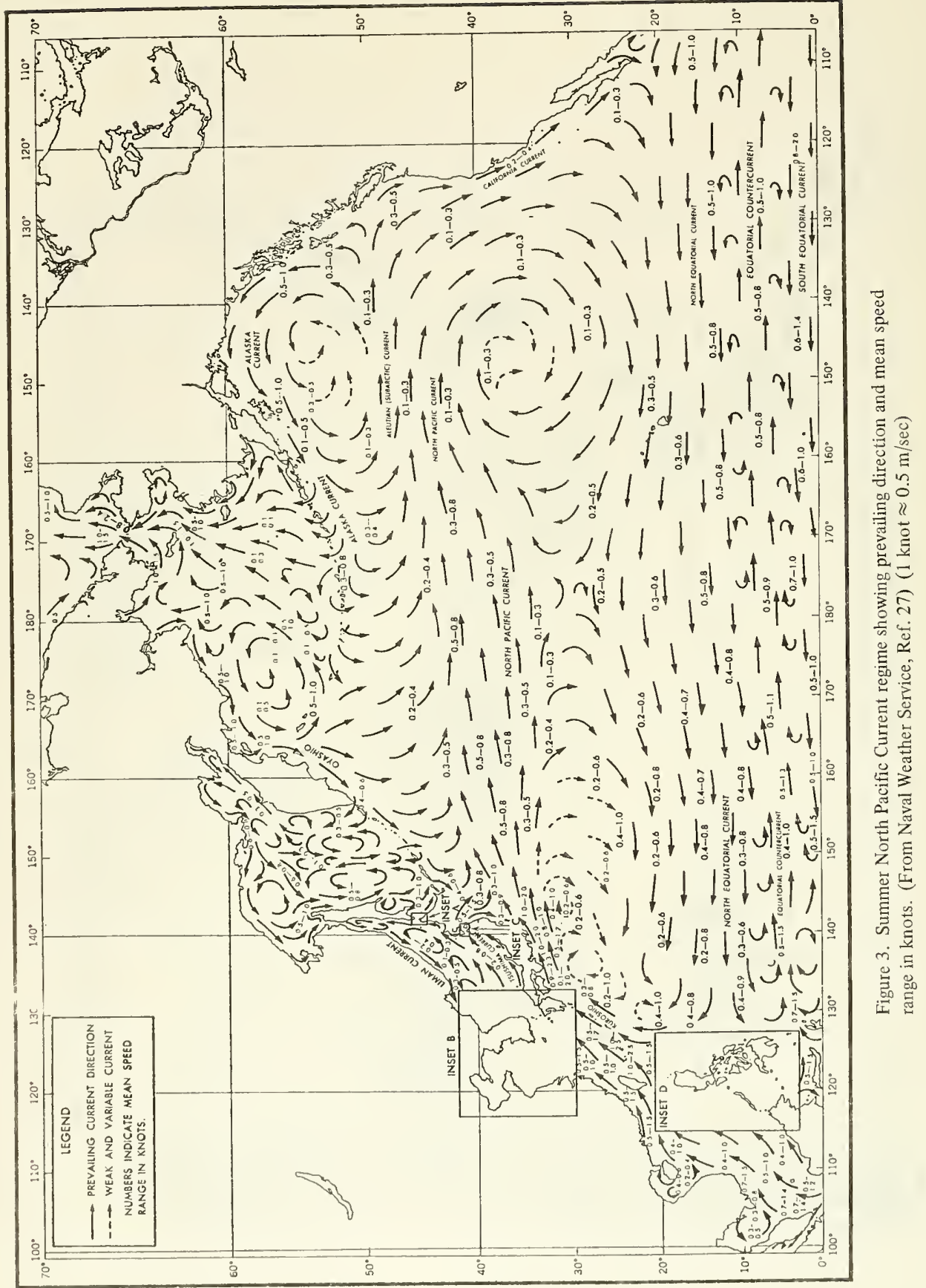




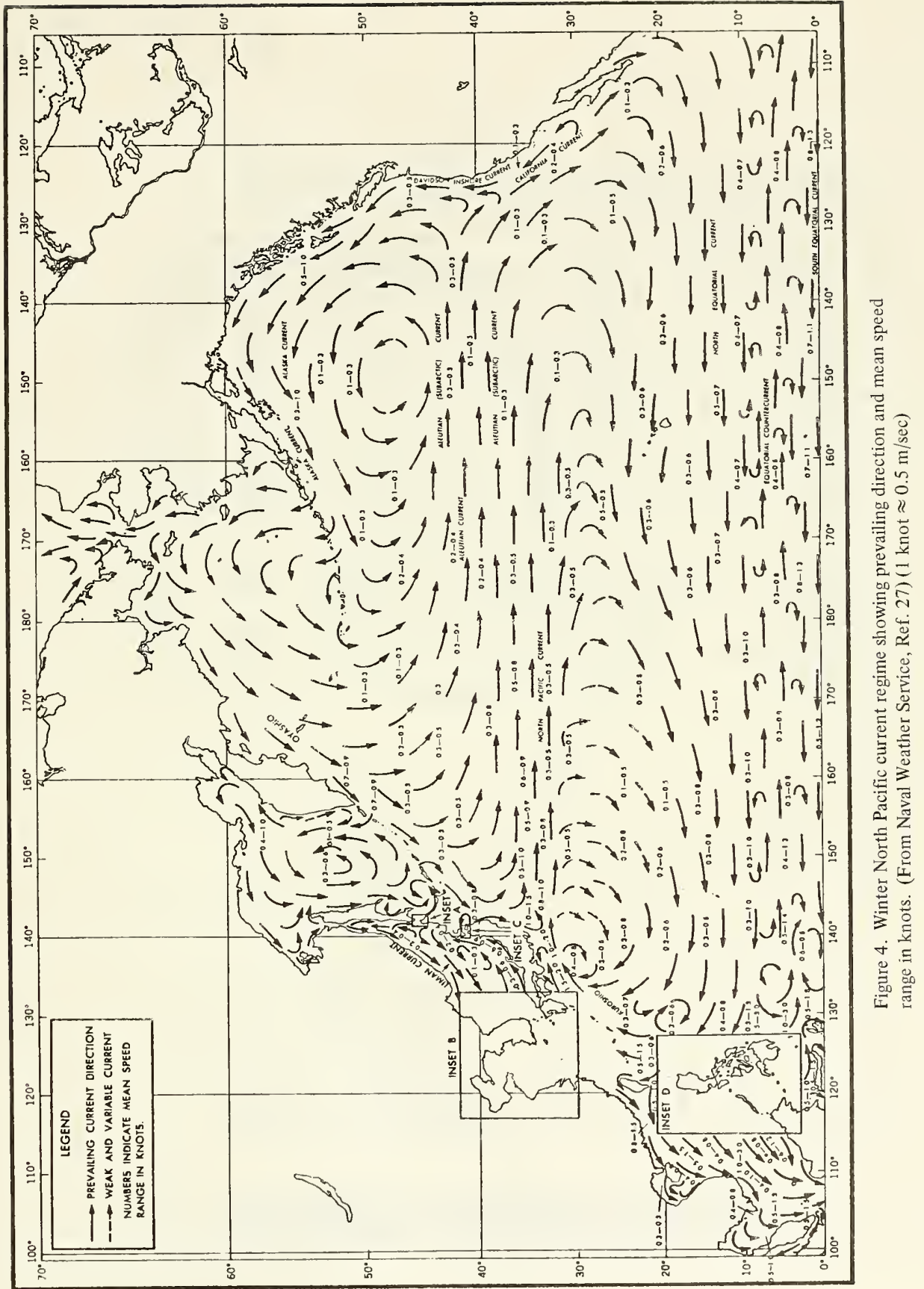




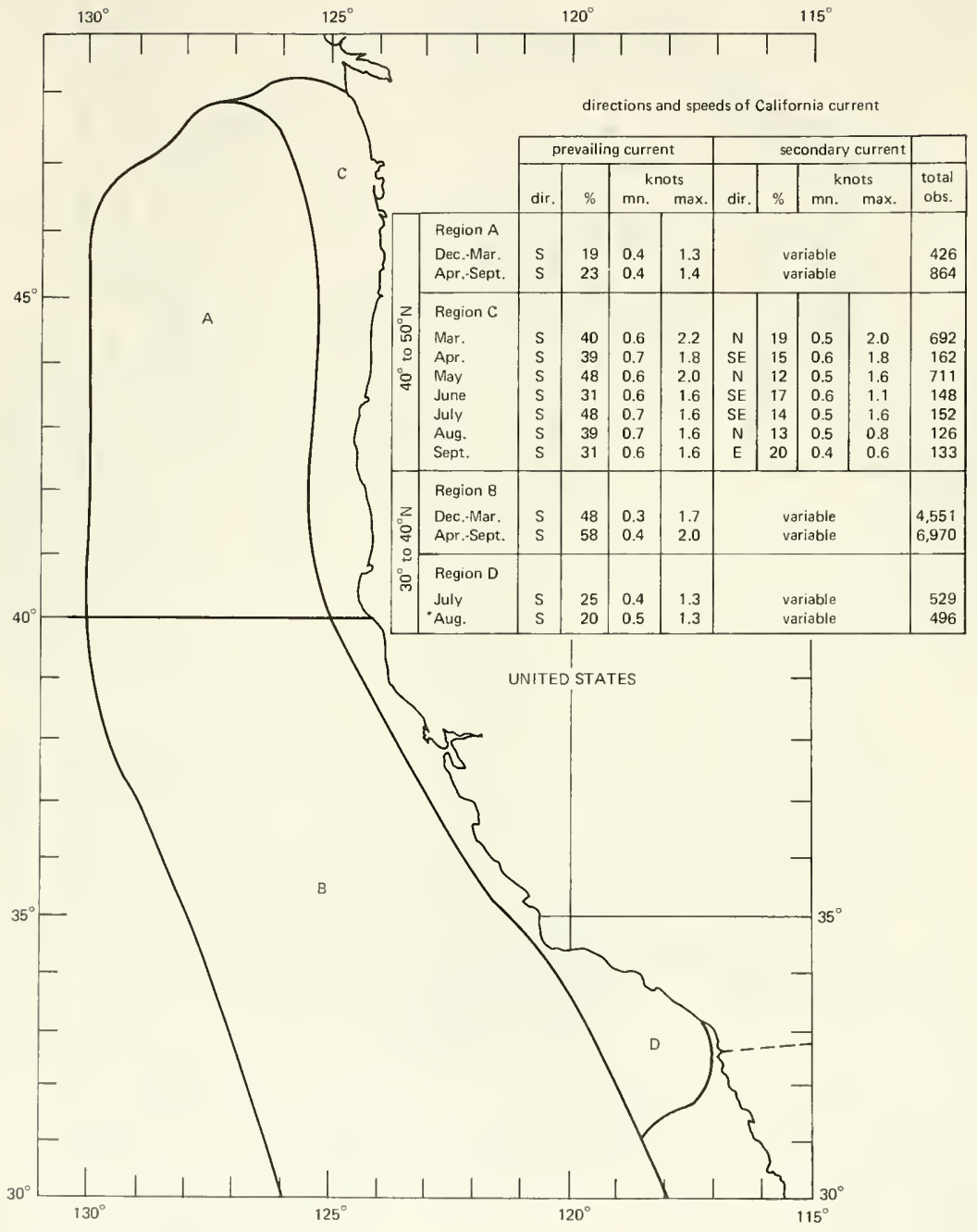

Figure 5. Boundaries, directions and speeds of the California Current. (From Naval Oceanographic Office, Ref. 28$)(1 \mathrm{knot} \approx 0.5 \mathrm{~m} / \mathrm{sec})$ 


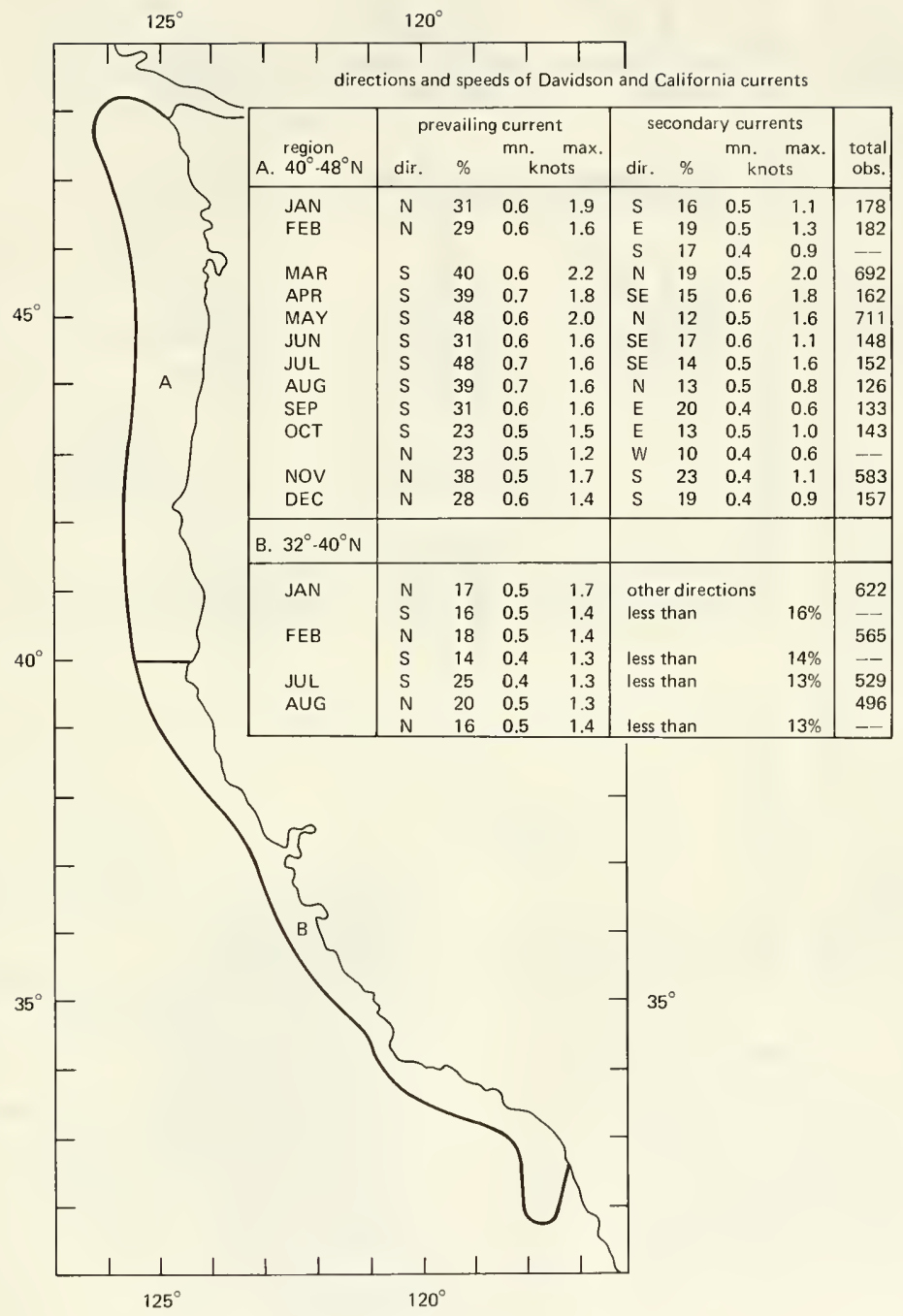

Figure 6. Boundaries, directions and speeds of the Davidson Current. (From Naval Oceanographic Office, Ref. 28$)(1 \mathrm{knot} \approx 0.5 \mathrm{~m} / \mathrm{sec}$ ) 

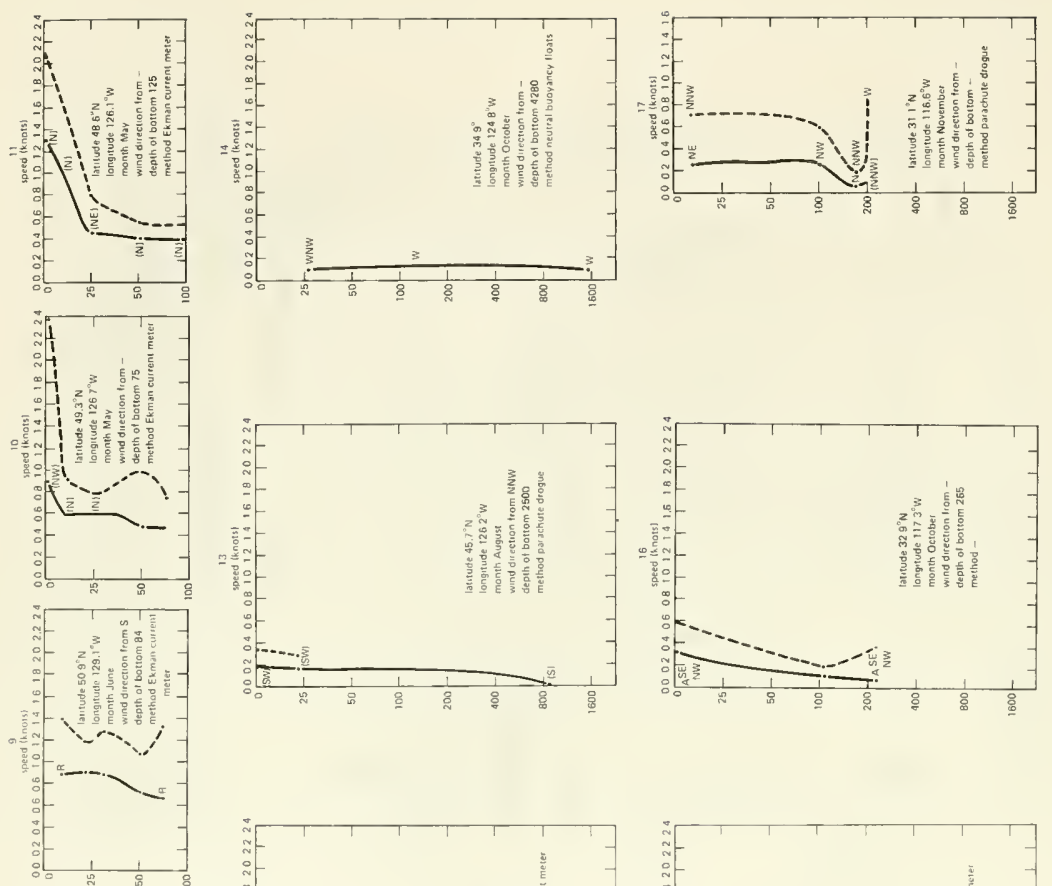

Oે
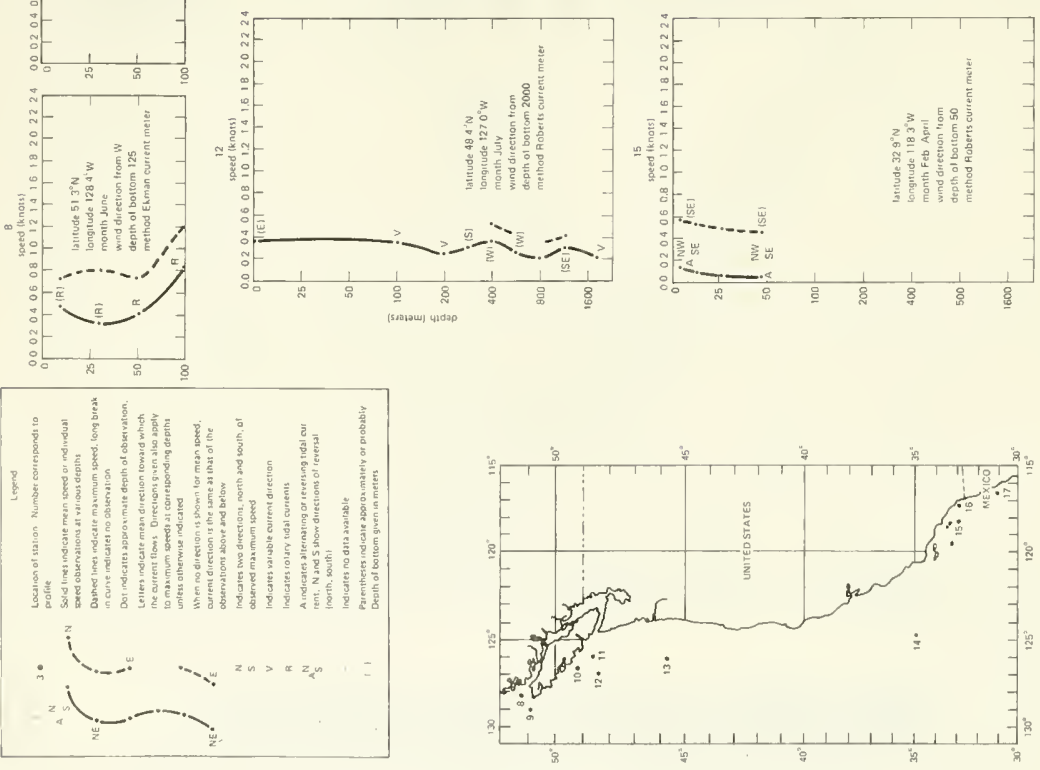

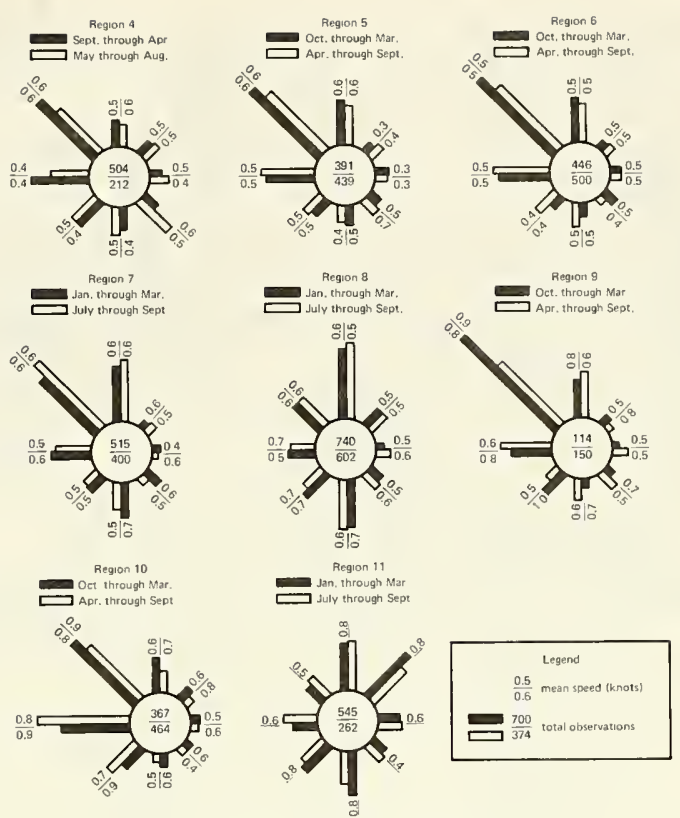

$\mid$

$\begin{array}{llllllllll}10 & 20 & 30 & 40 & 50 & 60 & 70 & 80 & 90 & 100\end{array}$

$$
\text { rose scale tpercent? }
$$
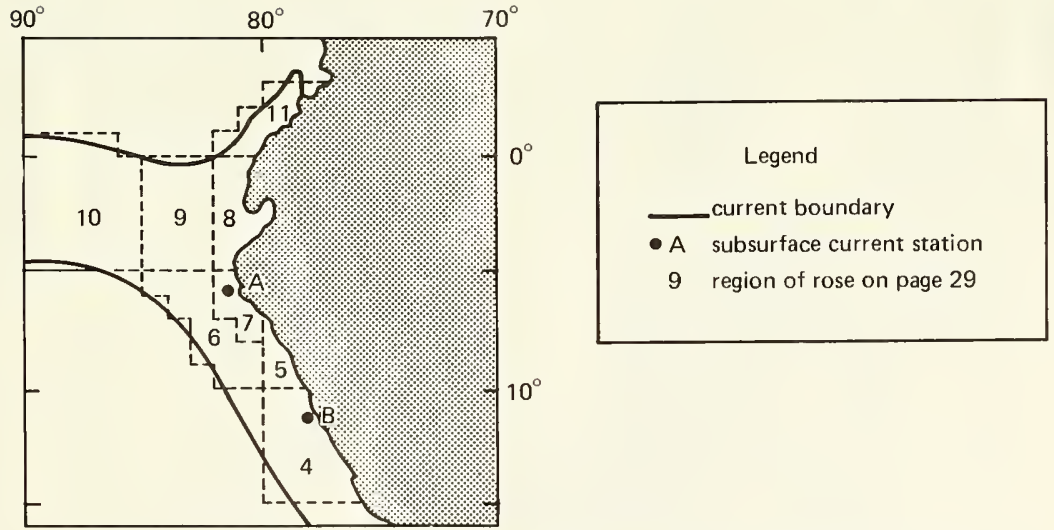

Figure 8. Boundary, direction and velocity of the northern portion of the Peru Current. (From Naval Oceanographic Office, Ref. 28 ) (1 knot $\approx 0.5 \mathrm{~m} / \mathrm{sec}$ ) 


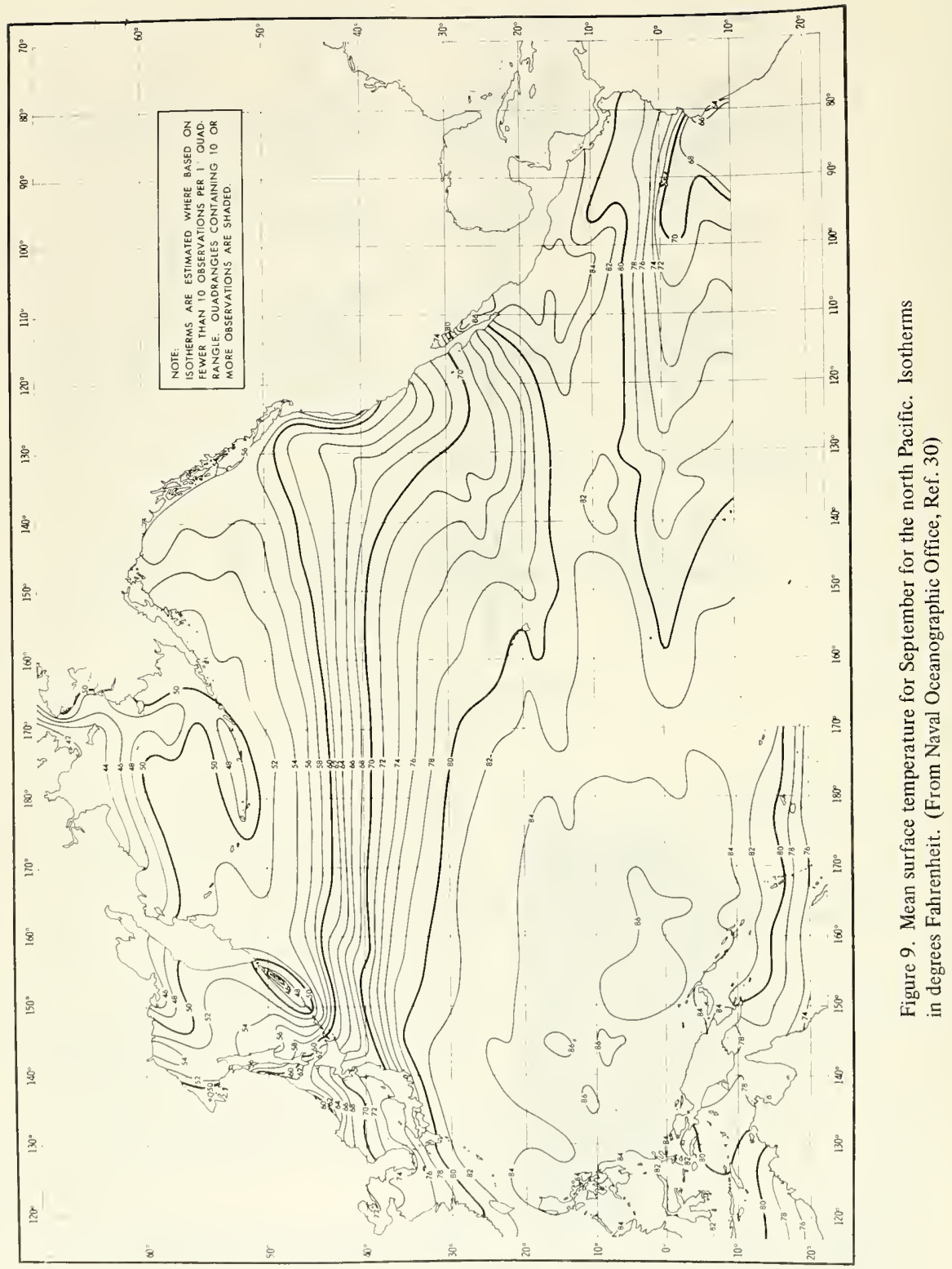




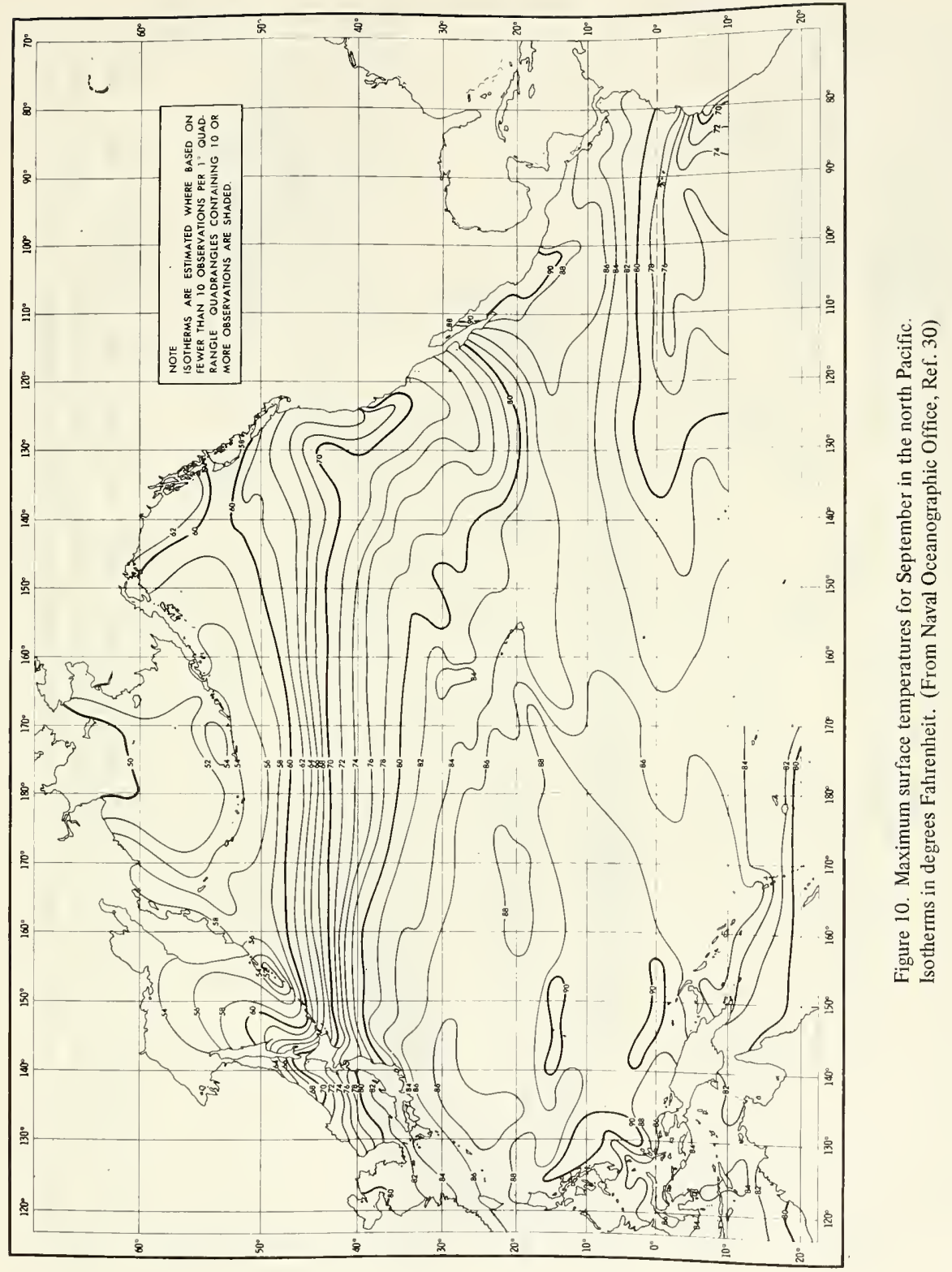




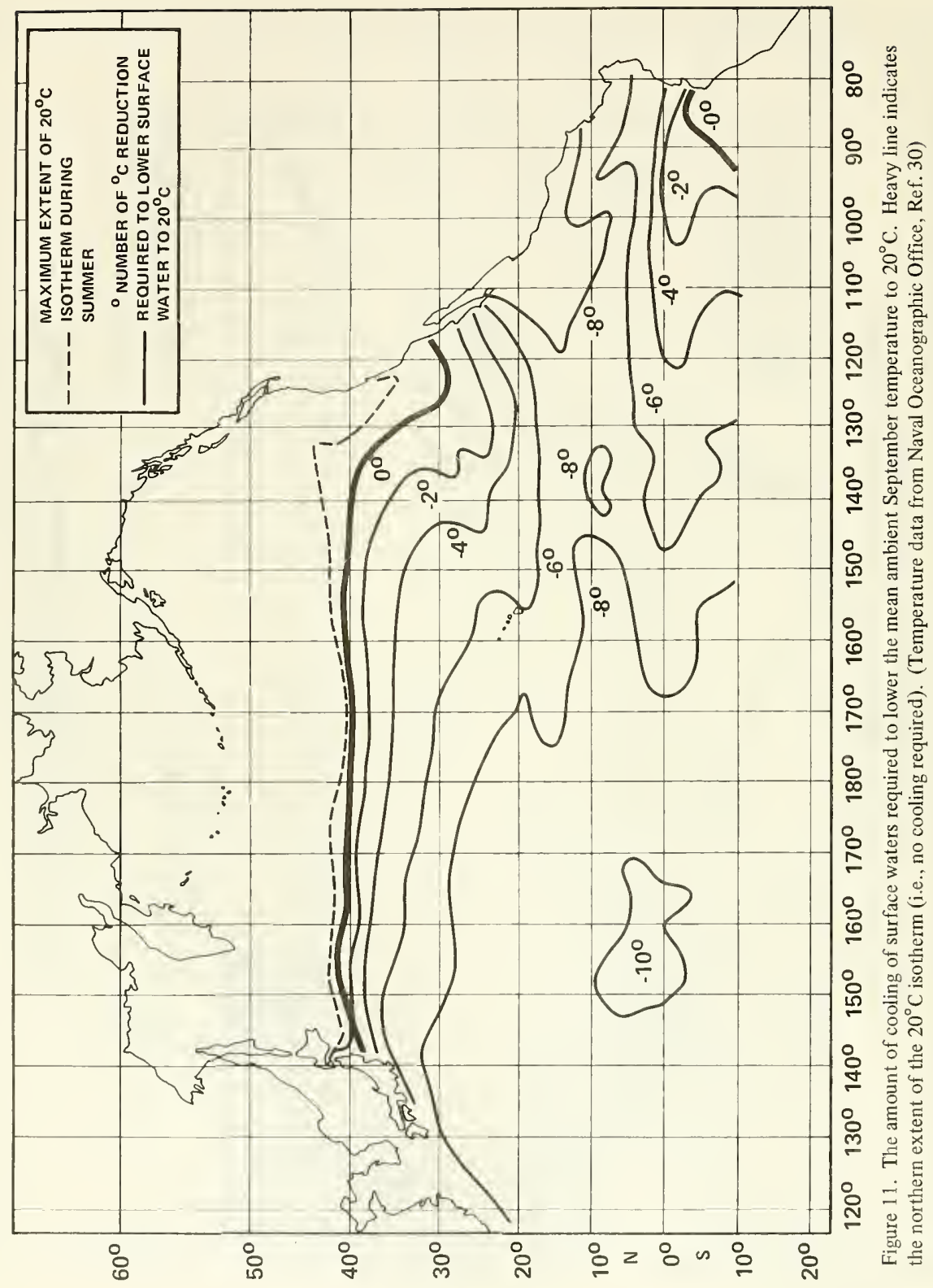




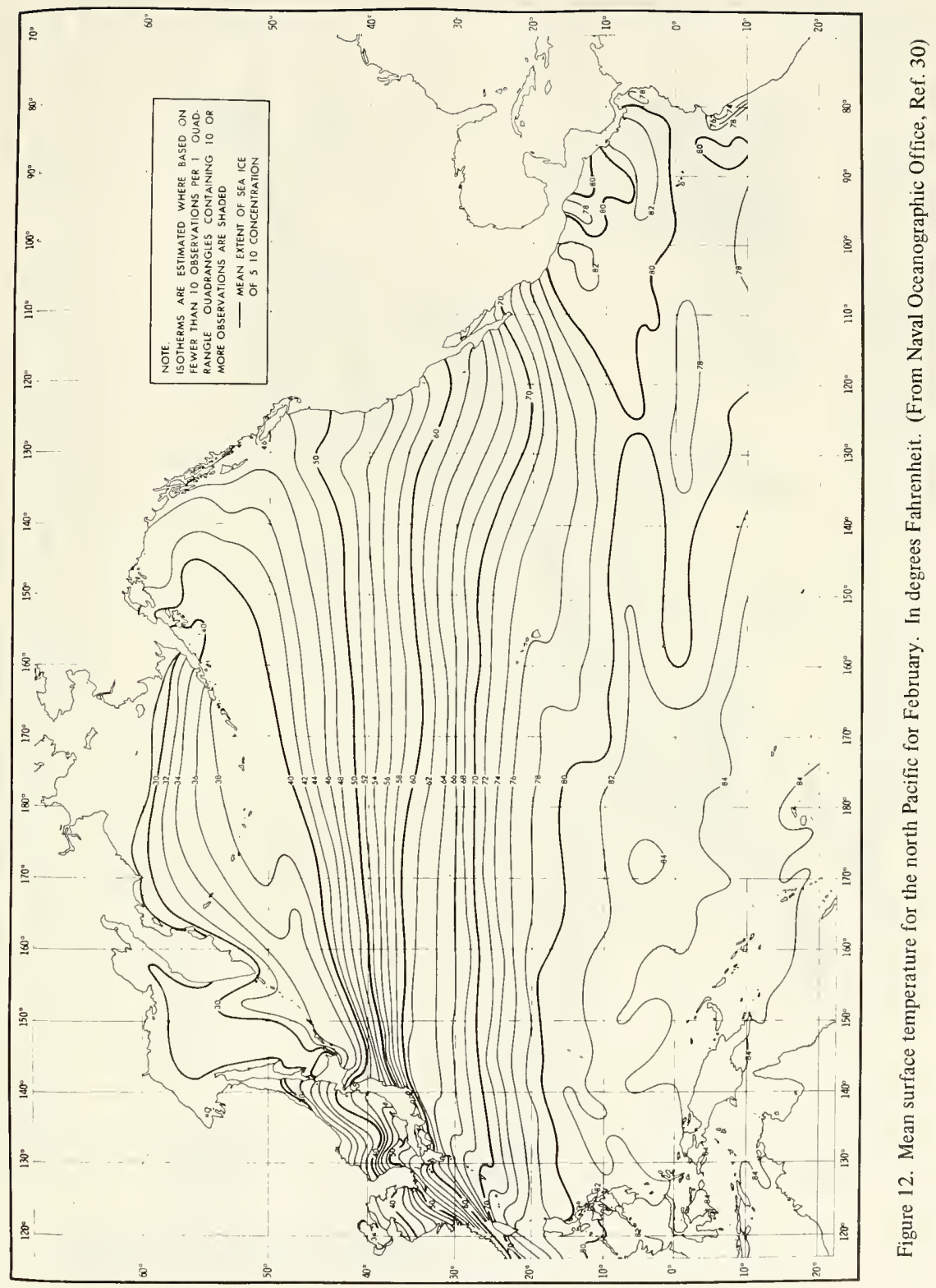




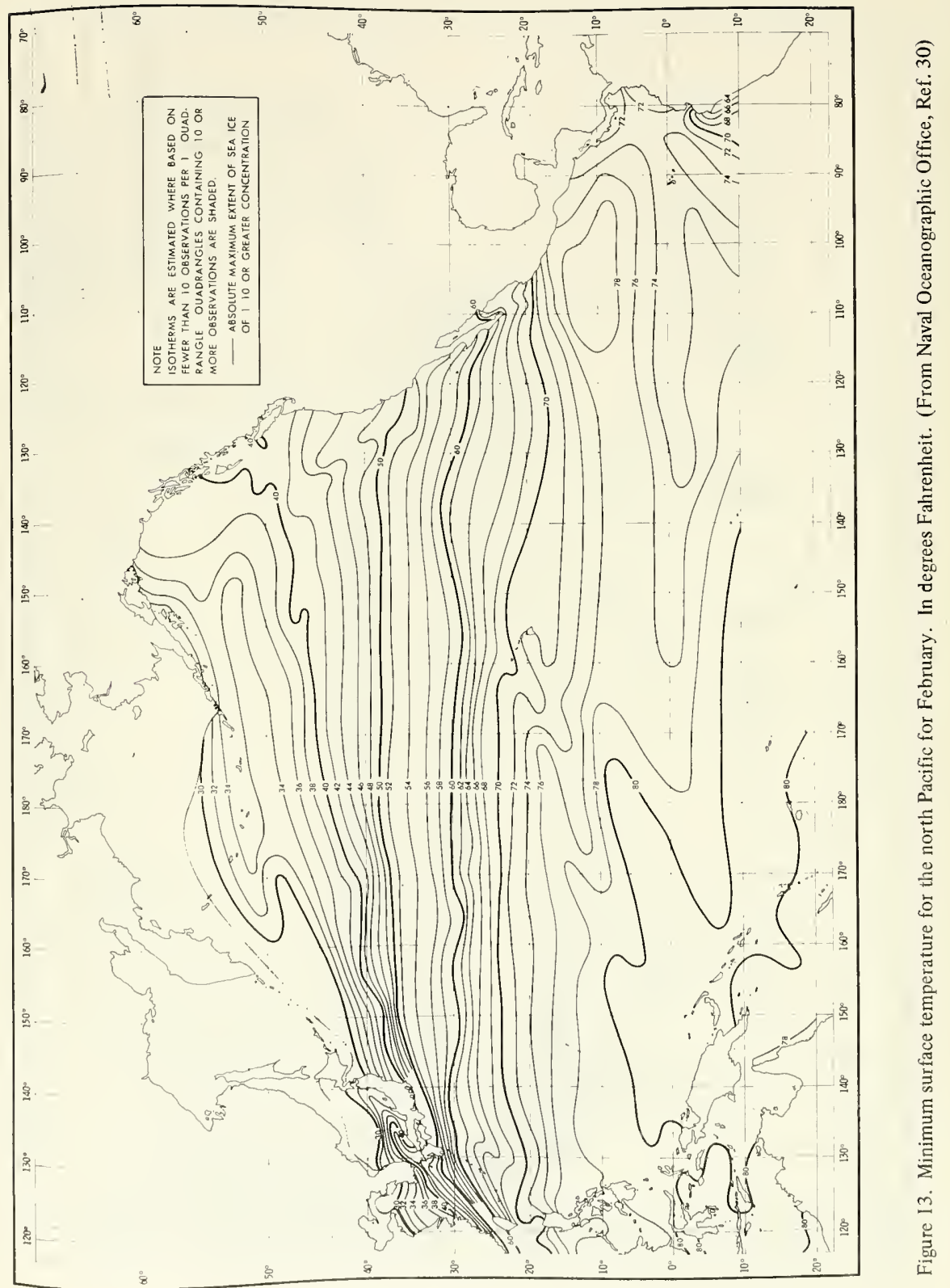




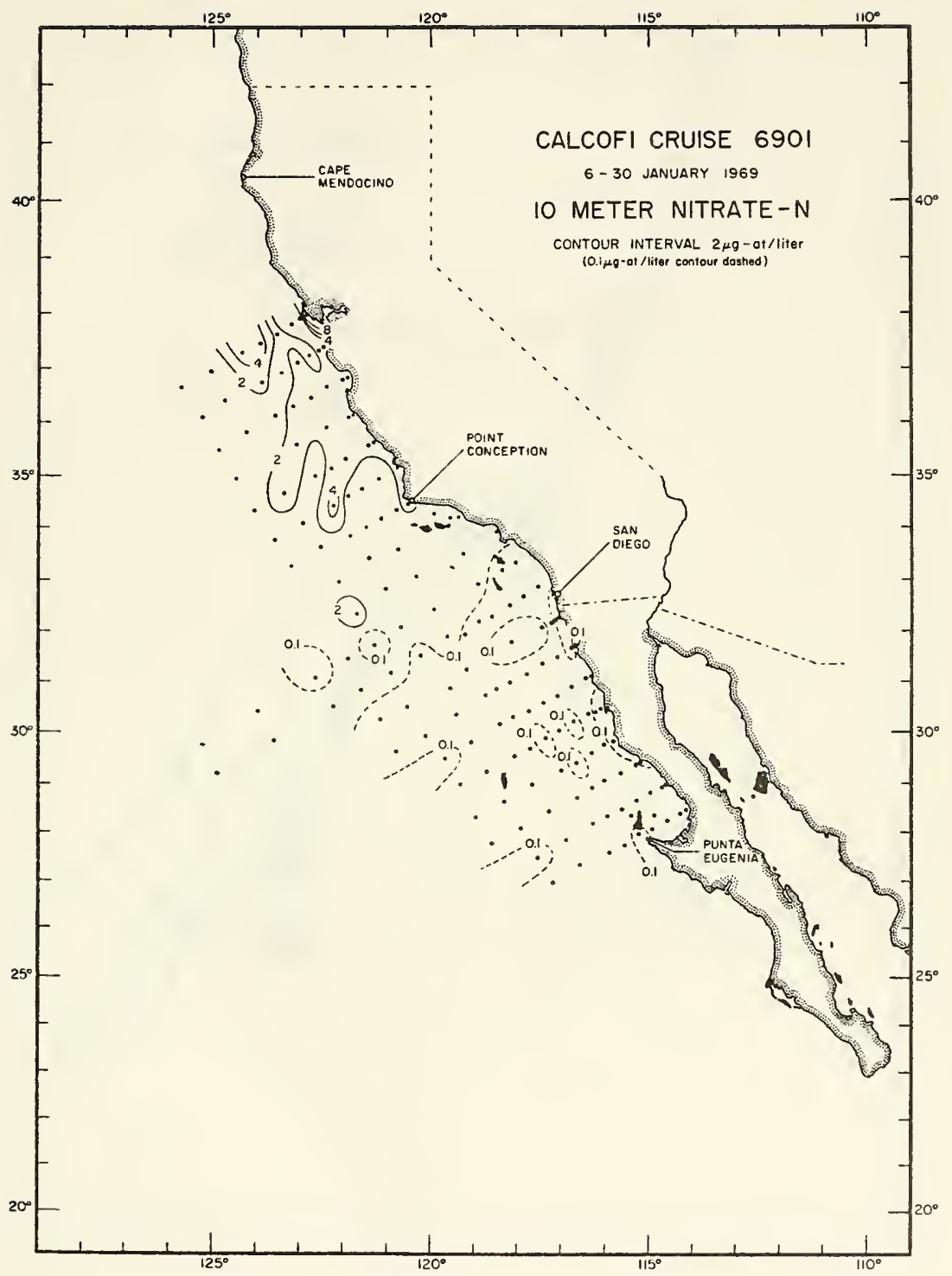

Figure 14. Nitrate nitrogen concentration, at 10 meters, for the southern California Current region - winter. (Duplicated from CALCOFI Atlas, Ref. 32) 


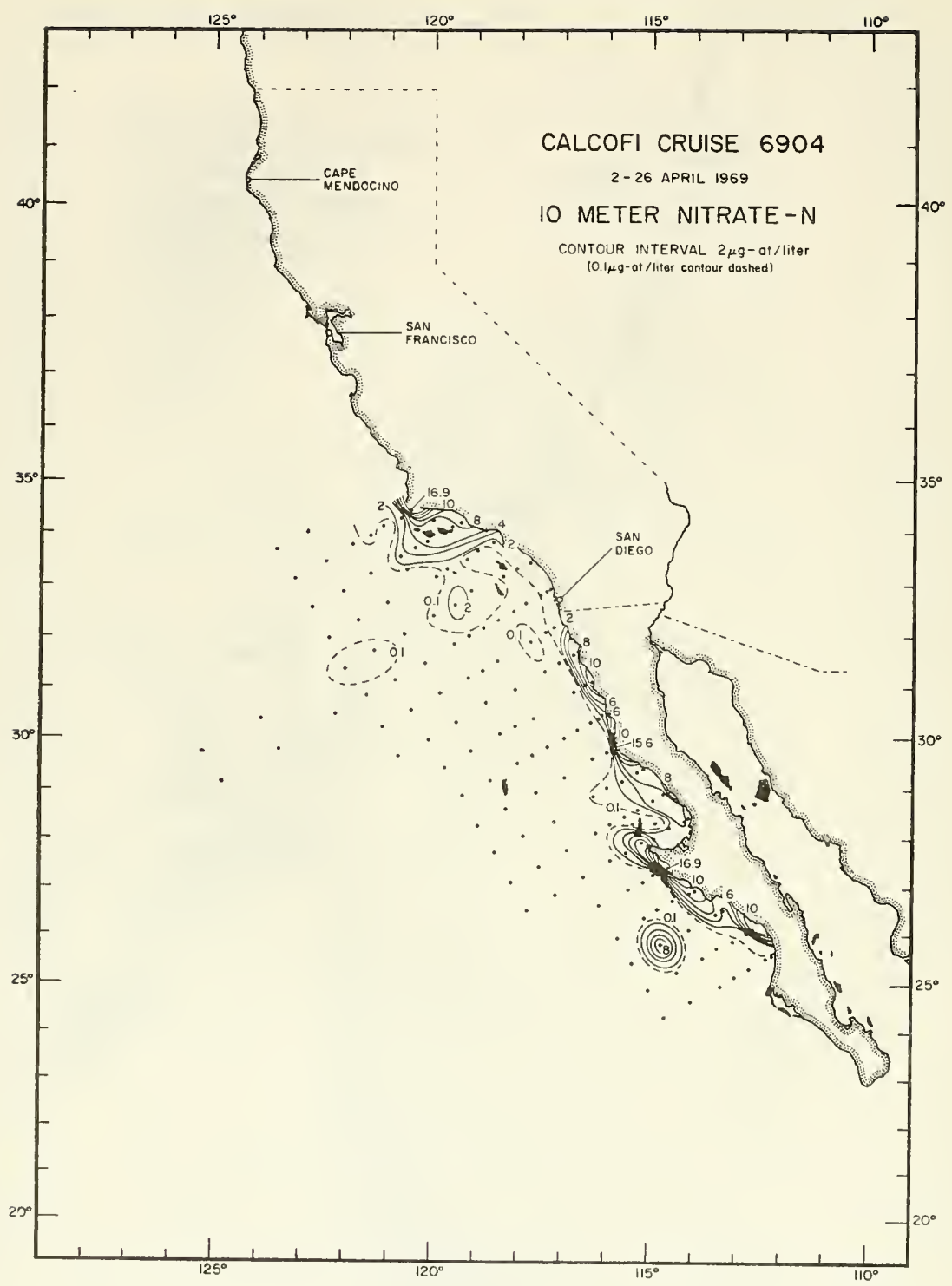

Figure 15. Nitrate nitrogen concentration at 10 meters for the southern California Current region - spring. (Duplicated from CALCOFı Atlas, Ref. 32) 


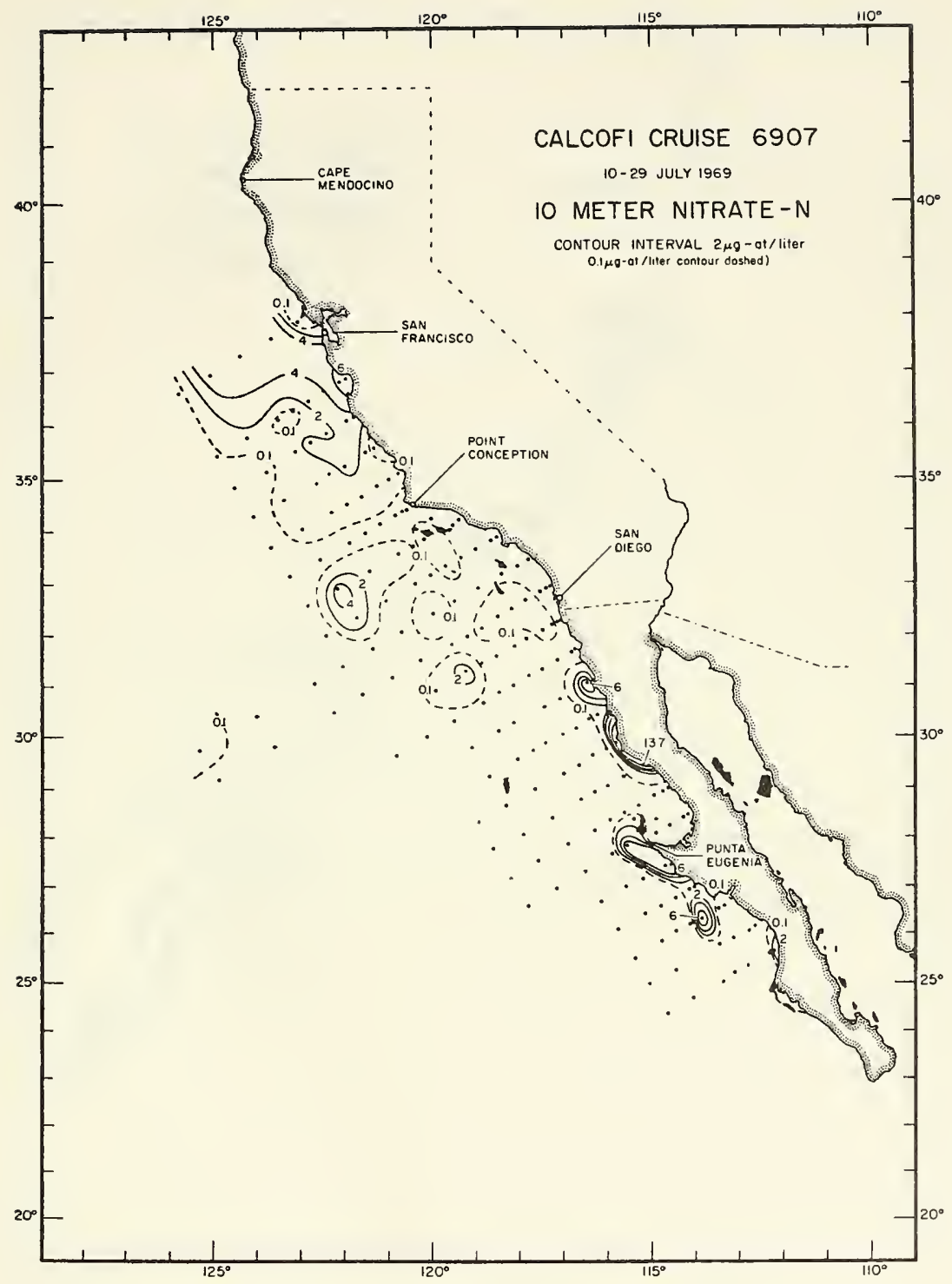

Figure 16. Nitrate nitrogen concentration at 10 meters for the southern California Current region - summer. (Duplicated from CALCOFI Atlas, Ref. 32) 


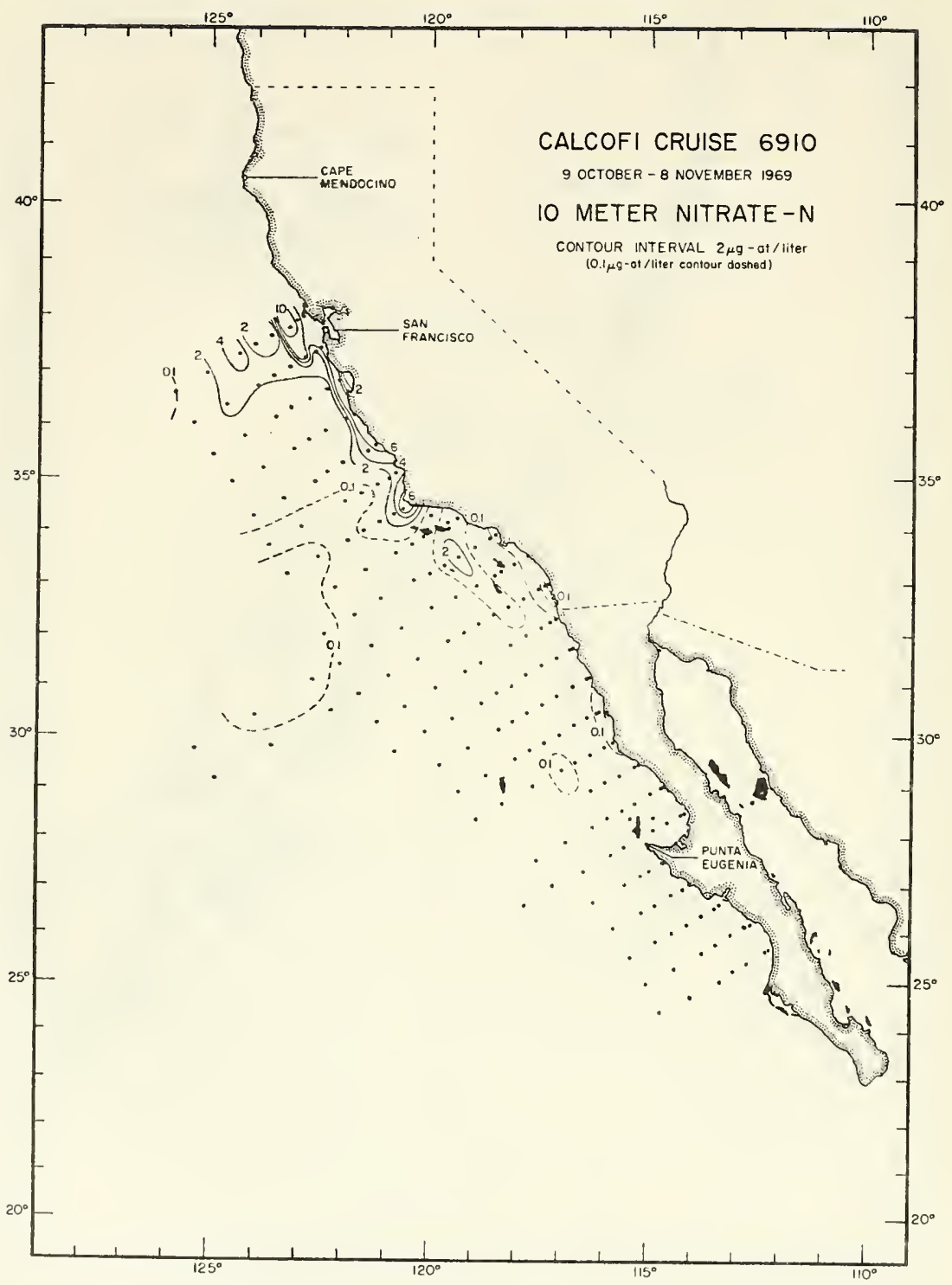

Figure 17. Nitrate nitrogen concentration at 10 meters for the southern California Current region - fall. (Duplicated from CALCOF1 Atlas, Ref. 32) 


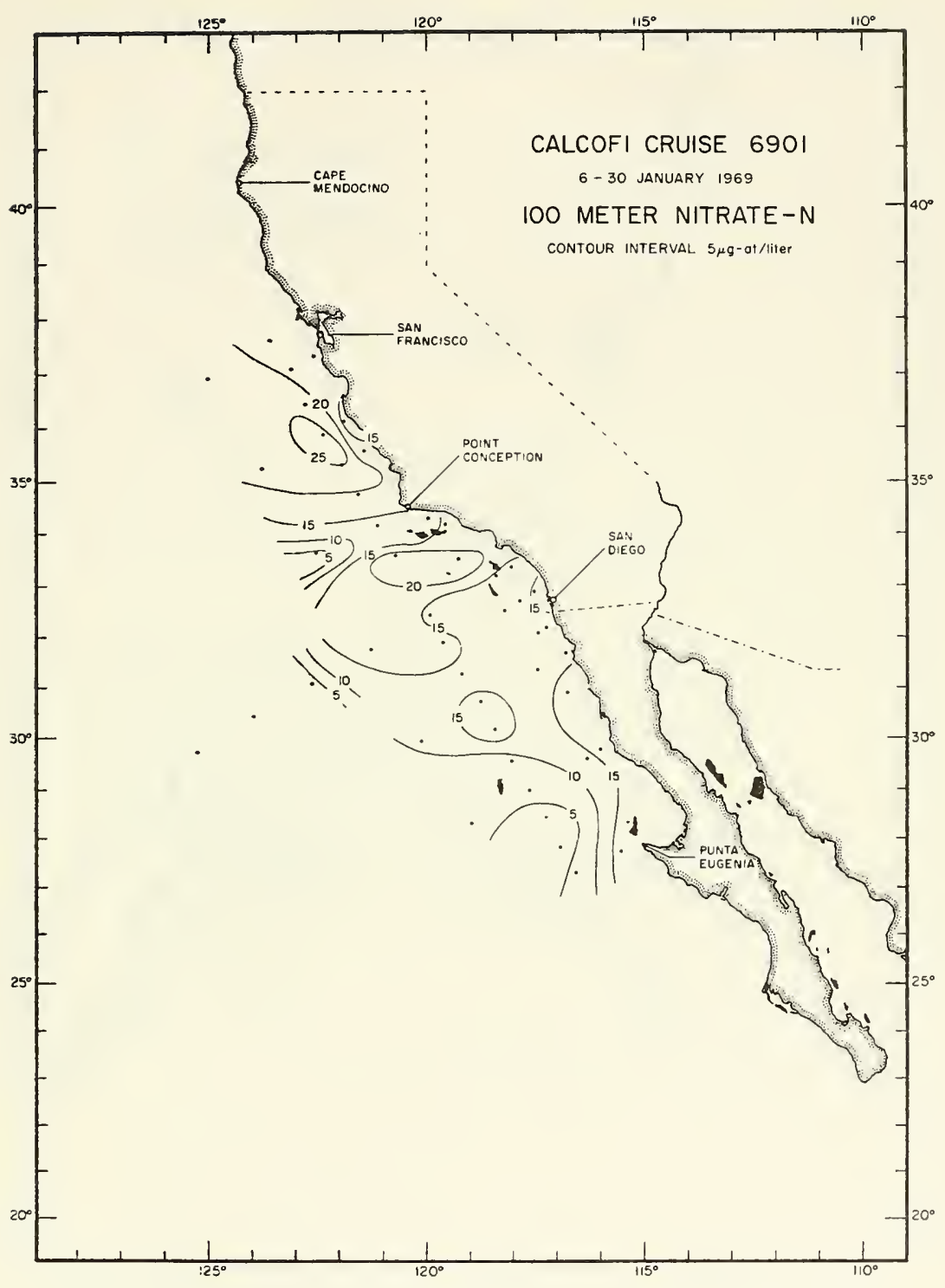

Figure 18. Nitrate nitrogen concentration at 100 meters for the southern California Current region - winter. (Duplicated from CALCOFI Atlas - Ref. 32) 


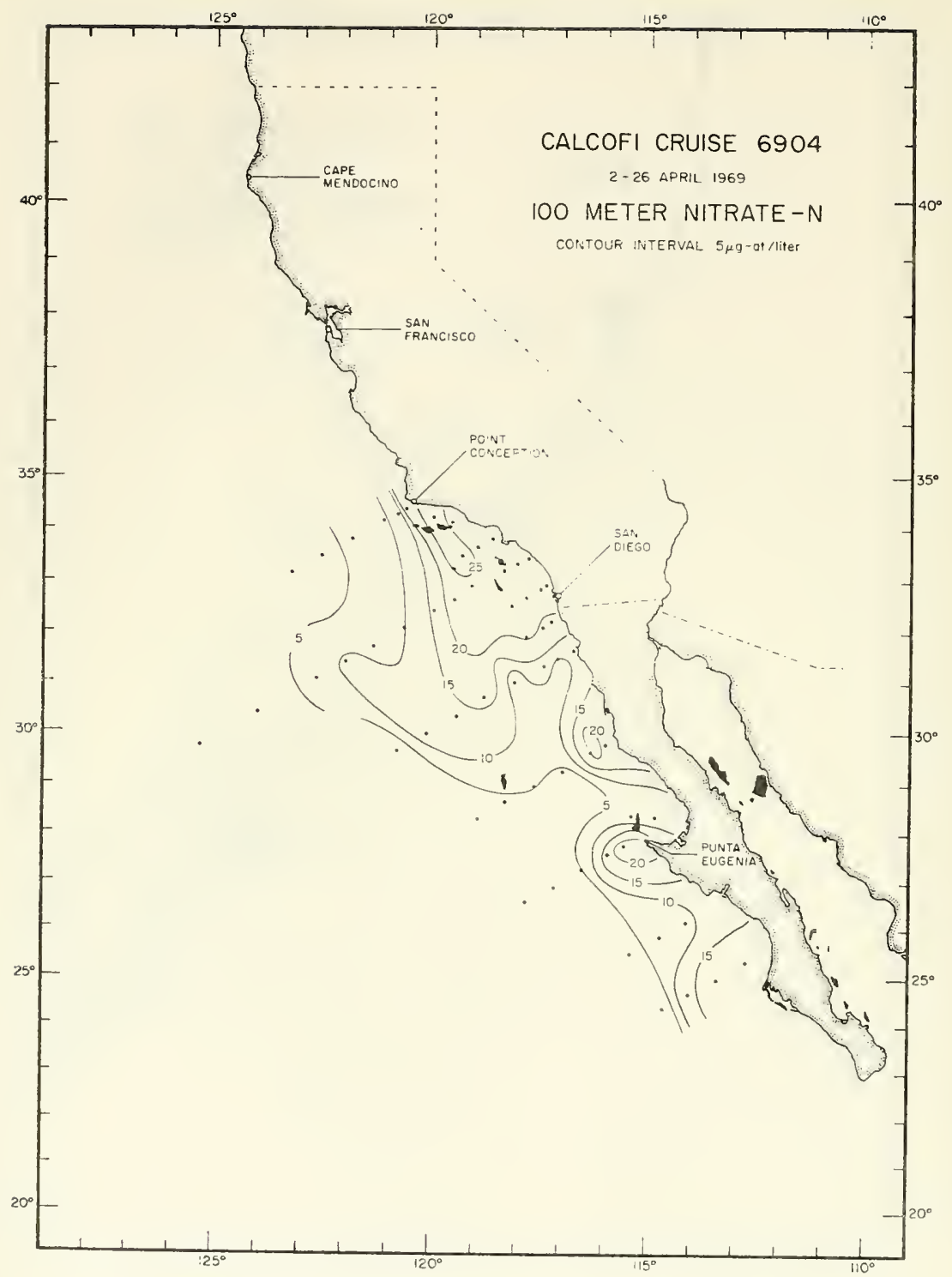

Figure 19. Nitrate nitrogen concentration at 100 meters for the southern California Current region - spring. (Duplicated from CALCOF1 Atlas, Ref. 32) 


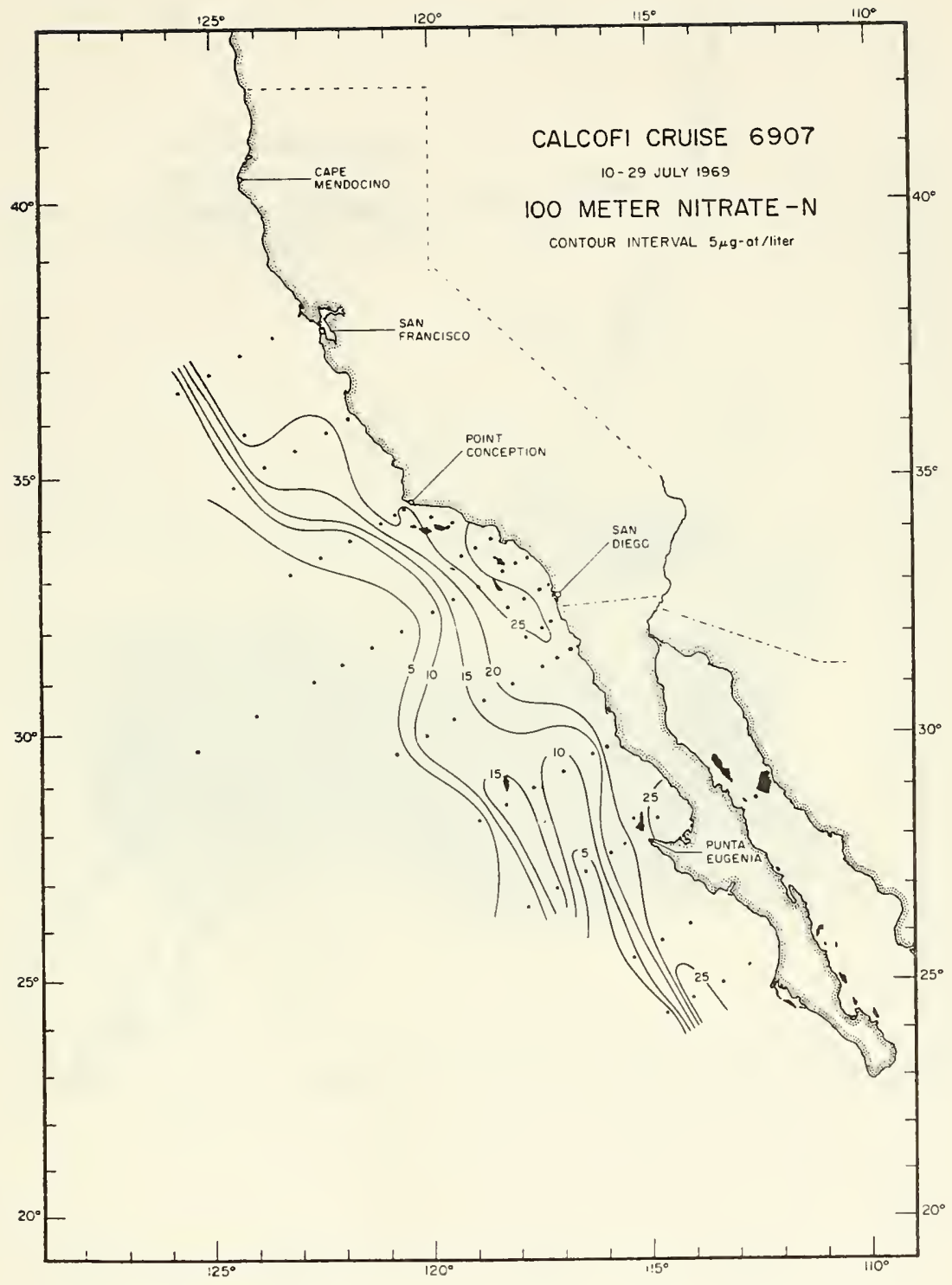

Figure 20. Nitrate nitrogen concentration at 100 meters for the southern California Current region - summer. (Duplicated from CALCOFI Atlas - Ref. 32) 


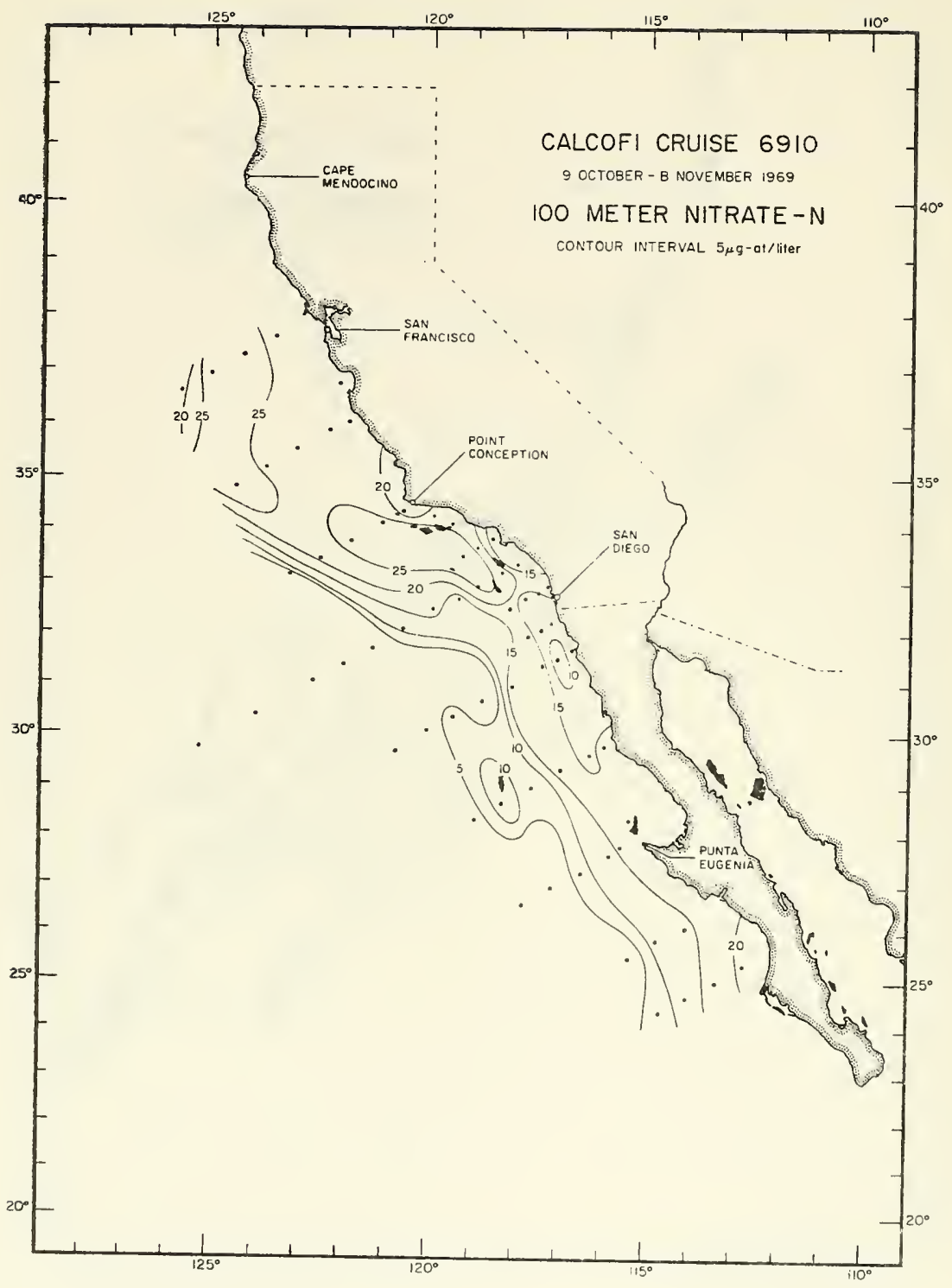

Figure 21. Nitrate nitrogen concentration at 100 meters for the southern California Current region - fall. (Duplicated from CALCOFI Atlas, Ref. 32) 


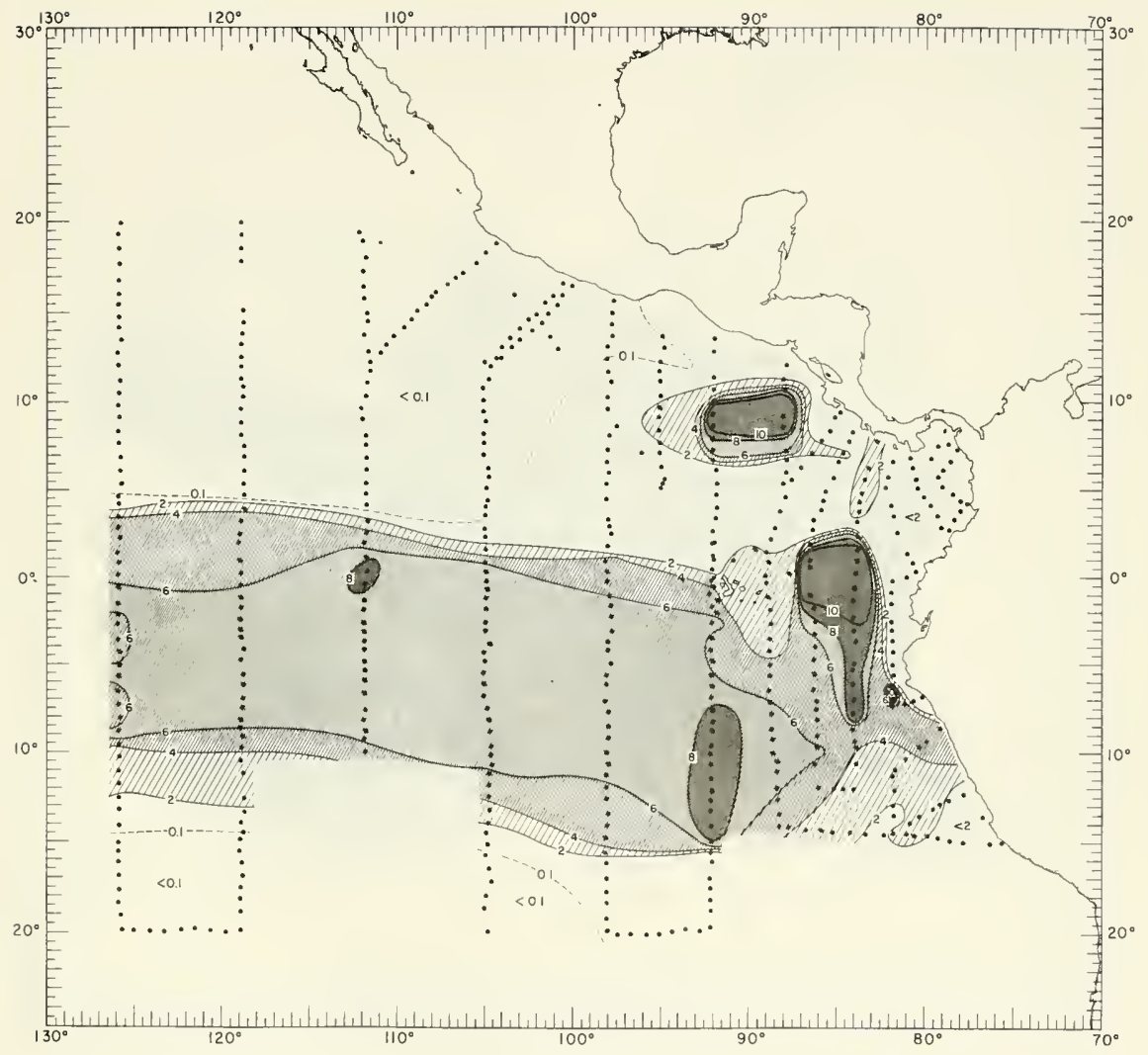

Figure 22. Nitrate-nitrogen ( $\mu \mathrm{g}$-at/liter) concentration at 10 meters; Feb-Mar 1967, for the eastern tropical Pacific. (Reproduced from EASTROPAC Atlas Vol. 2, Ref. 22). 


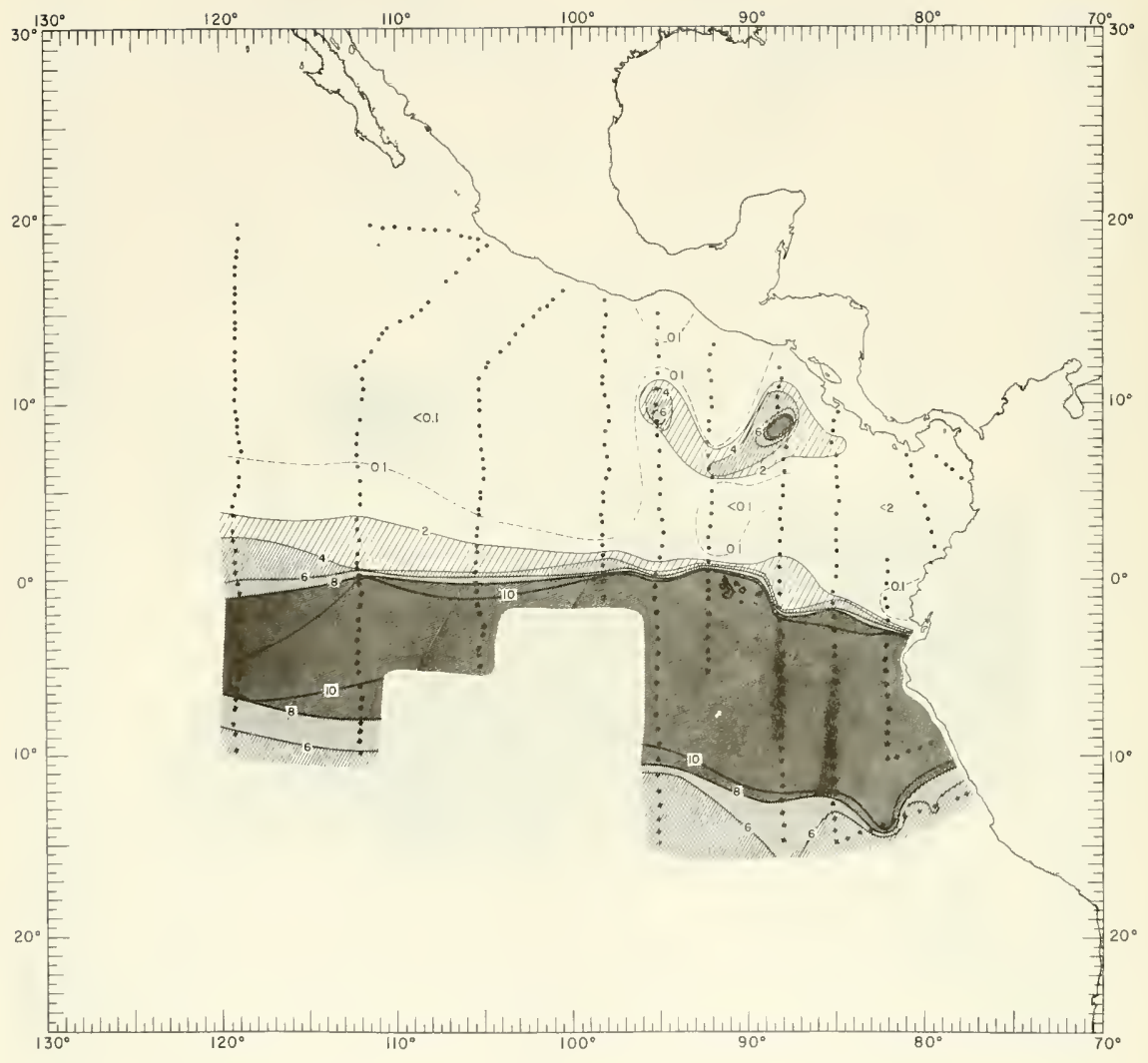

Figure 23. Nitrate-nitrogen ( $\mu$ g-at/liter) concentration at 10 meters; Aug-Sep 1967, for the eastern tropical Pacific. (Reproduced from EASTROPAC Atlas Vol. 6, Ref, 22). 


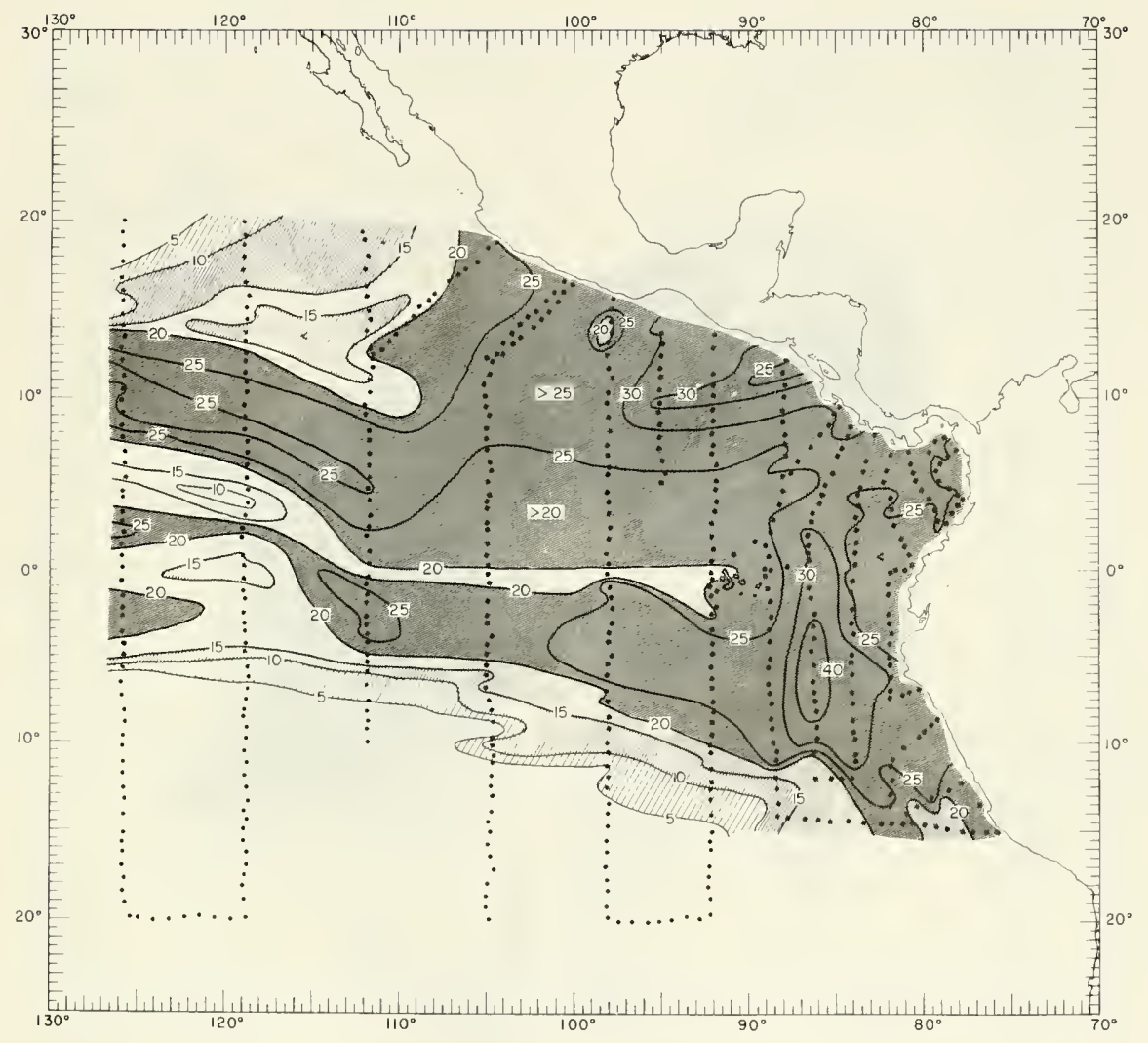

Figure 24. Nitrate-nitrogen ( $\mu$ g-at/liter) at 100 meters Feb-Mar 1967 for the eastern tropical Pacific. (Reproduced from EASTROPAC Atlas, Vol. 2, Ref. 22) 


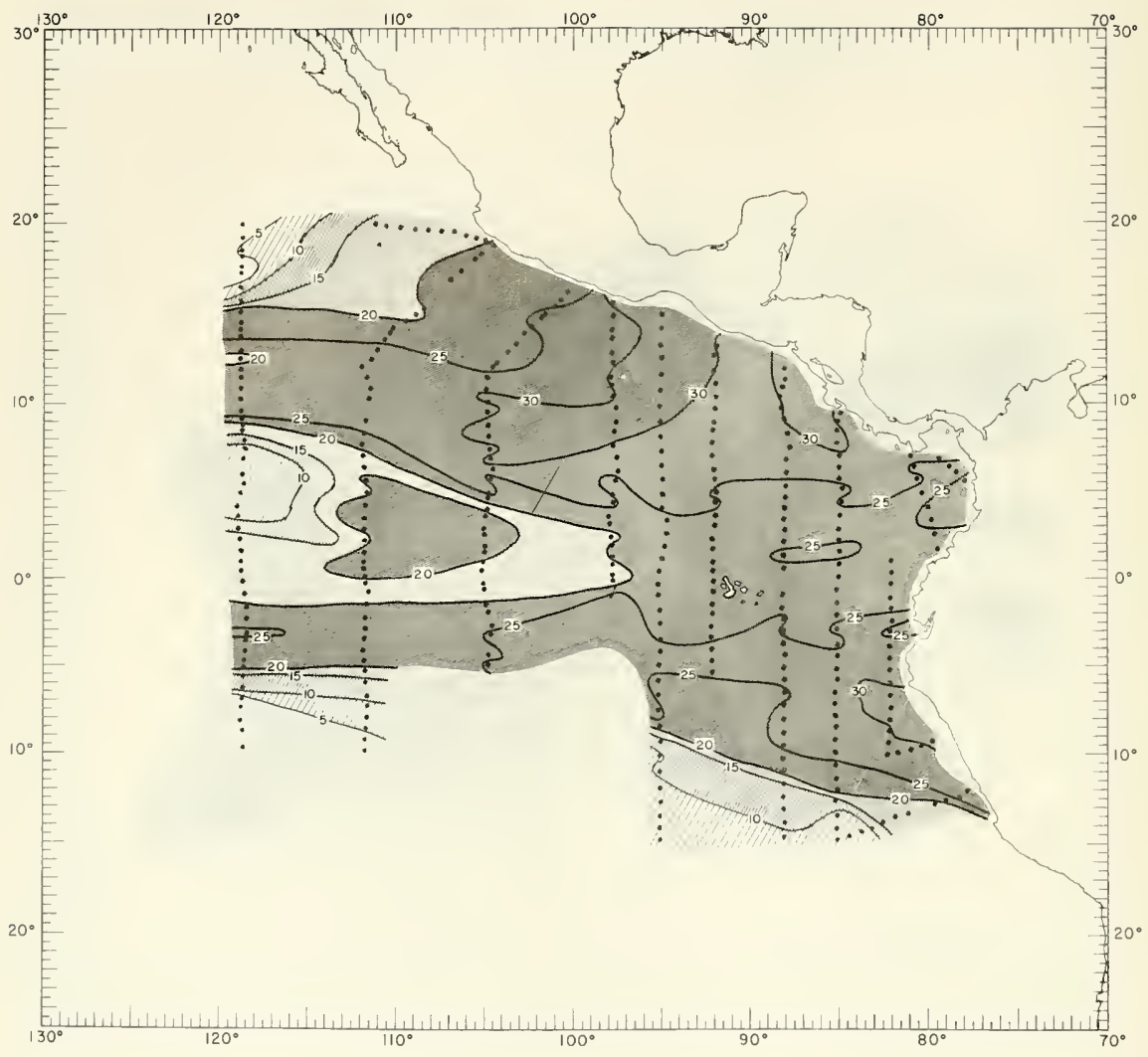

Figure 25. Nitrate-nitrogen ( $\mu$ g-at/liter) at 100 meters Aug-Sep 1967 for the eastern tropical Pacific. (Reproduced from EASTROPAC Atlas, Vol. 6, Ref. 22). 


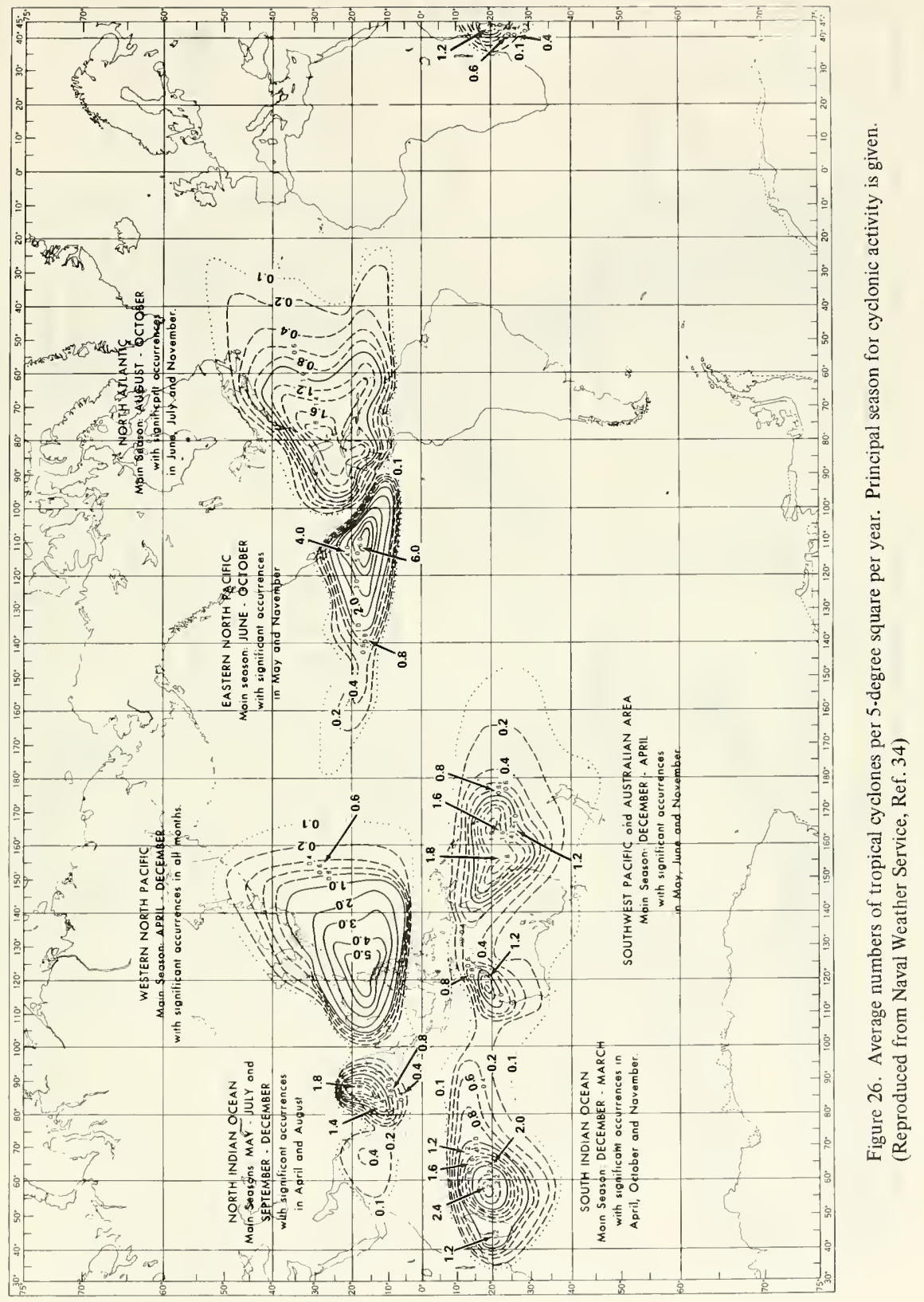




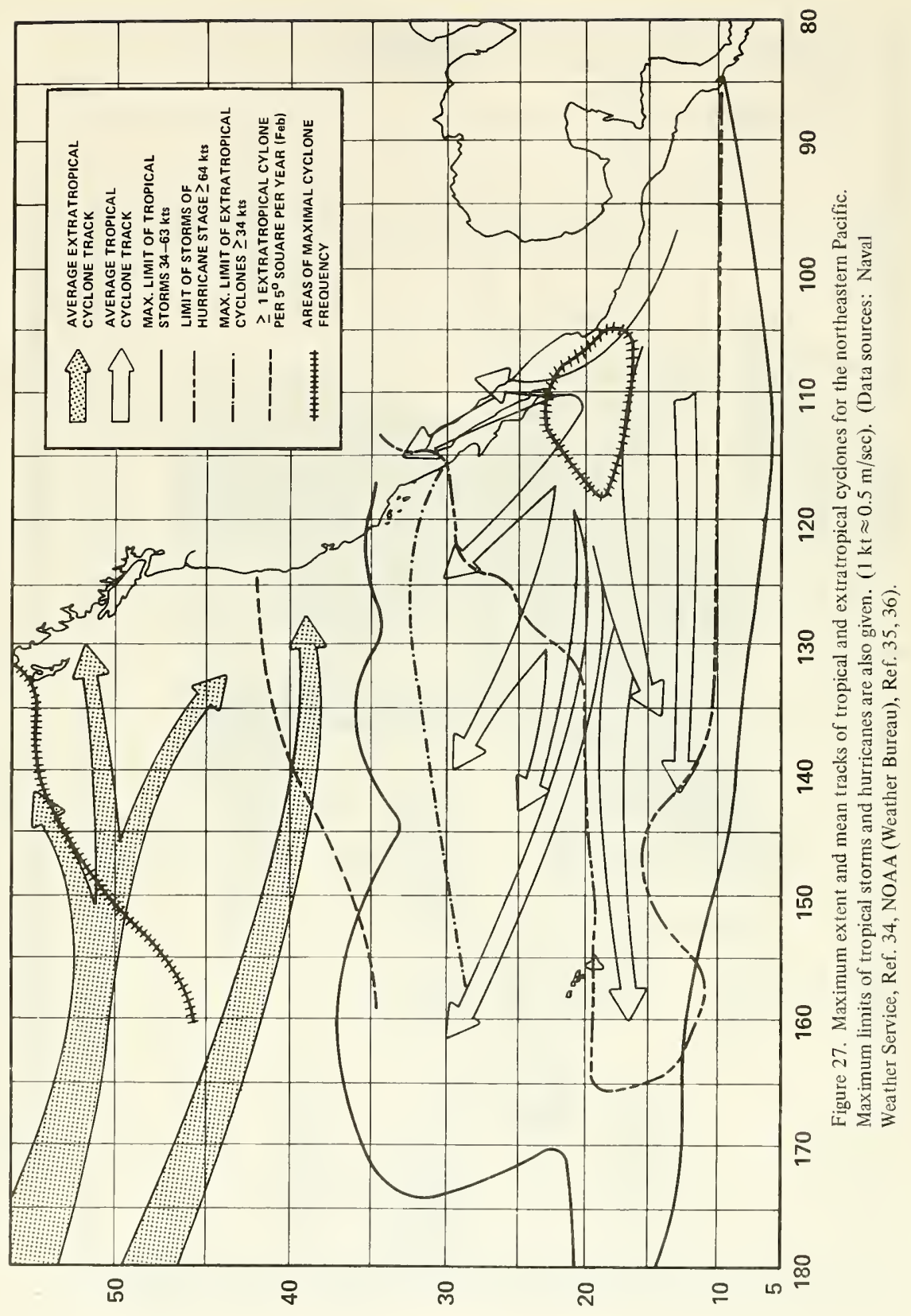



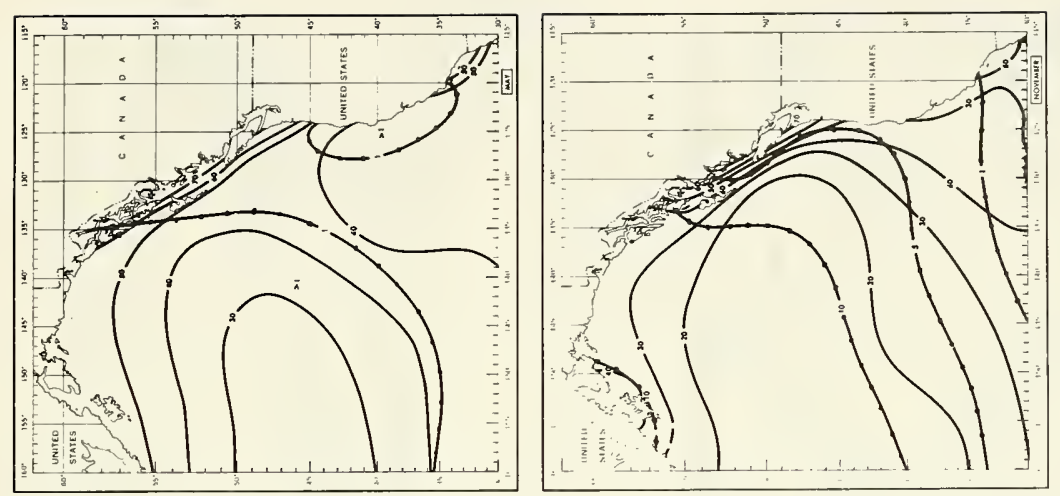

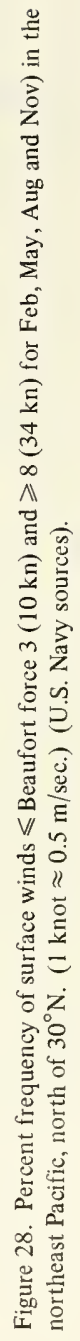
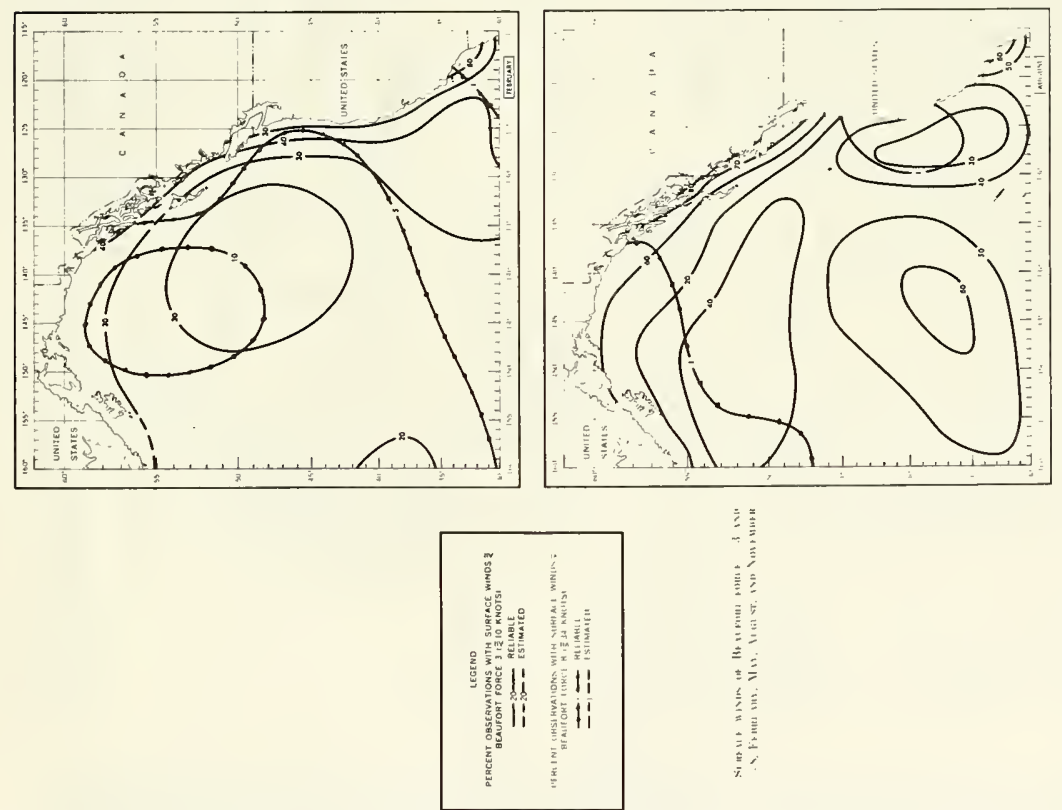

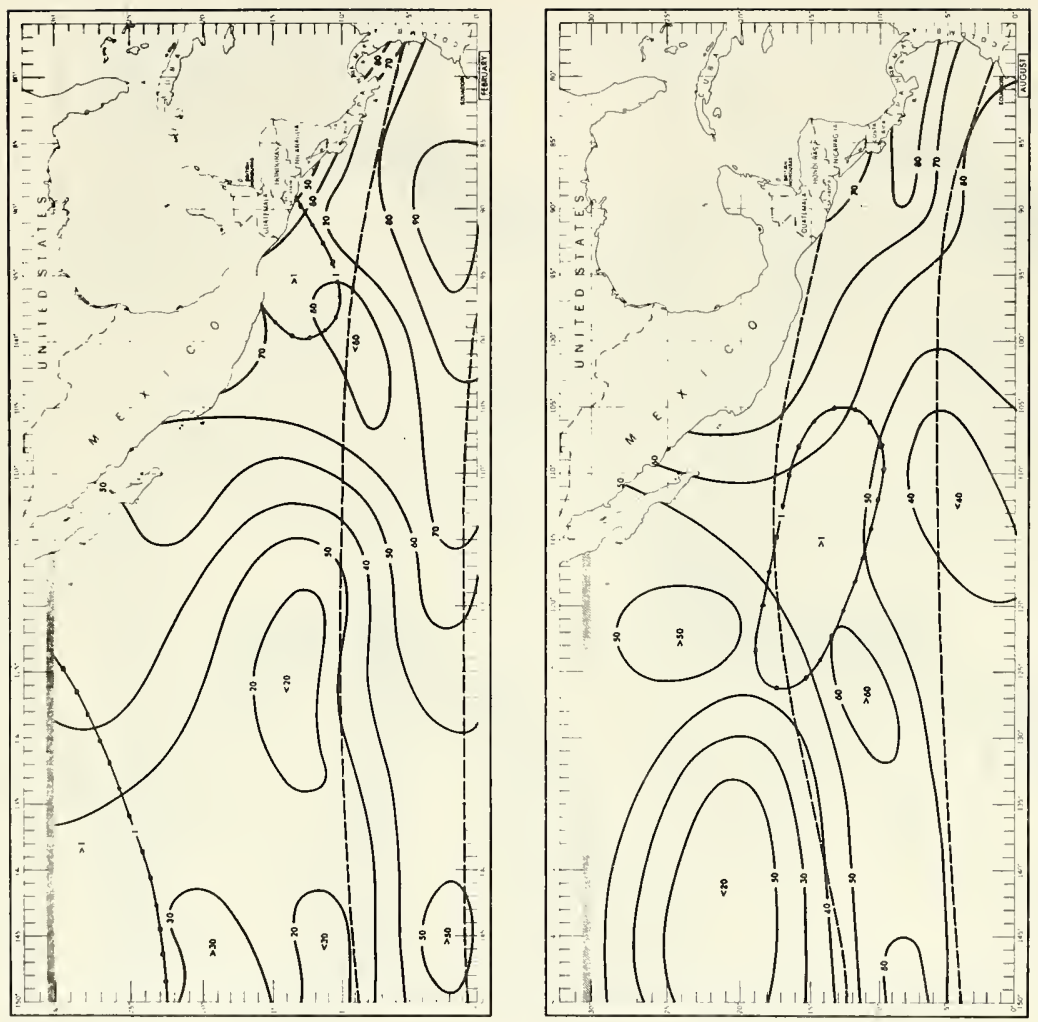

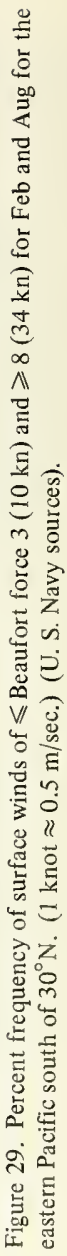
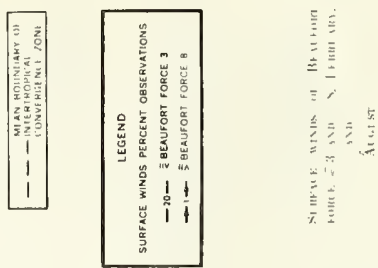


\section{CENTRAL NE PACIFIC ENVIRONMENT}

\section{Wave Height}
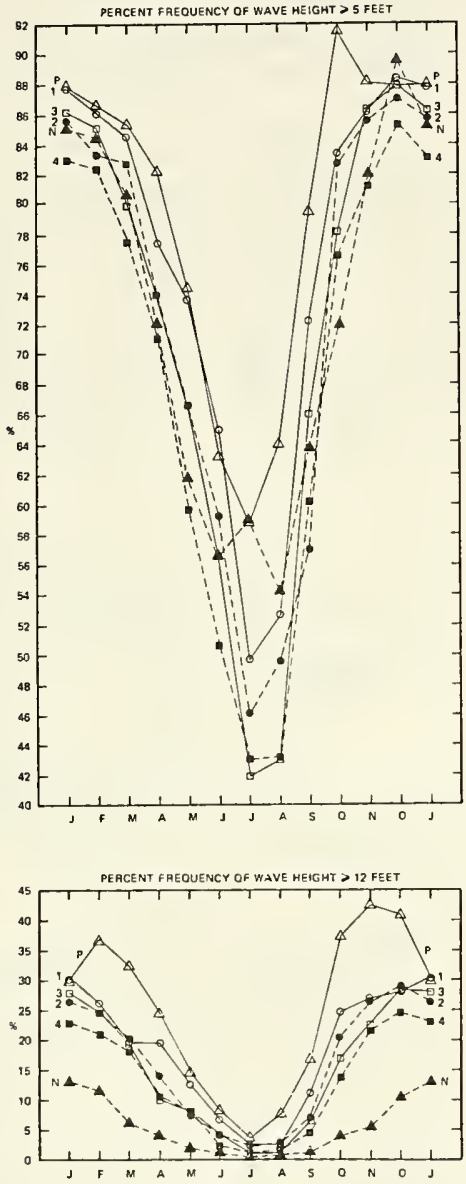

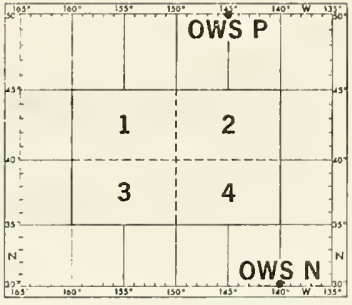

Area Map

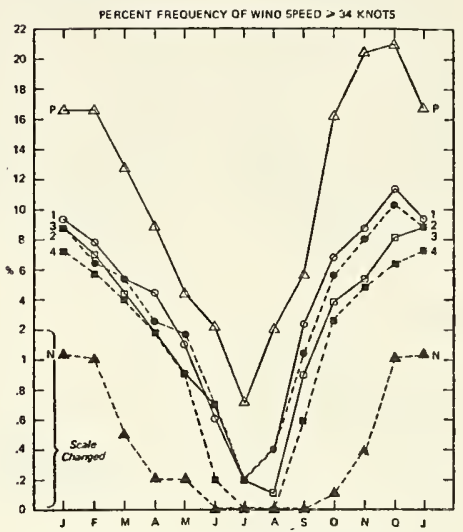

MEOIAN 5EA SUAFACE TEMPEPATUAE INEO F

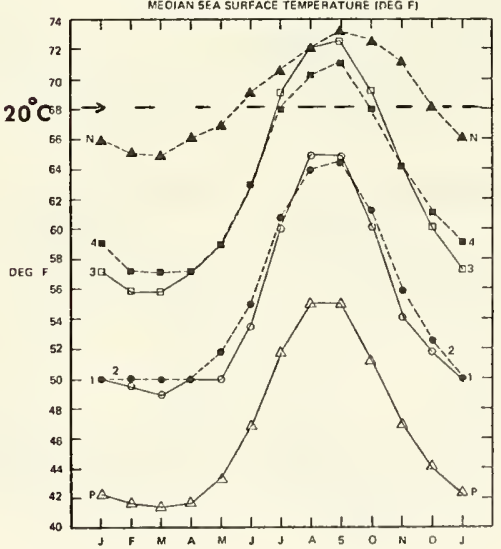

Figure 30. Environmental data for the central northeast Pacific showing monthly percent frequency of wave height $\geqslant 5$ and $\geqslant 12 \mathrm{ft}$, wind speed $\geqslant 34 \mathrm{kn}$ and median sea surface temperature. Area map gives location of Ocean Weather Station $N$ and $P$ and sample regions $t-4$. ( 1 knot $\approx 0.5 \mathrm{~m} / \mathrm{sec} ; 1 \mathrm{ft} \approx 0.3 \mathrm{me}$ ters) (Data from Naval Weather Service, Ref. 27). 
Durations of events meeting the above criterion are depicted by SOLID lines and refer to the TOP SCALE of each graph.

Intervals between events are depicted by DASHED lines and refer to the BOTTOM SCALE of each graph.

JANUARY

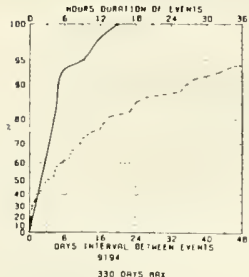

MAY

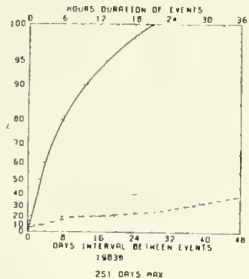

SEPTEMBER

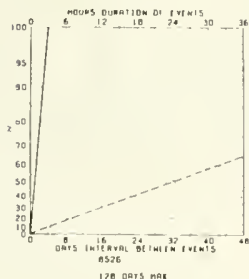

FEBRUARY

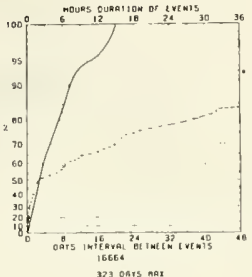

JUNE

INSUFFICIENT

DATA

OCTOBER

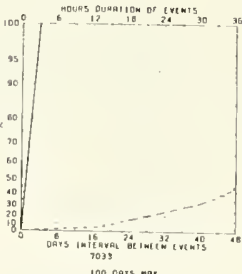

MARCH

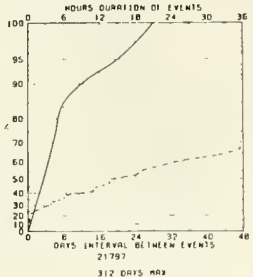

JULY

INSUFFICIENT

DATA

NOVEMBER

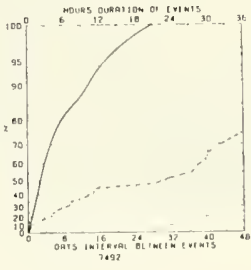

is oars nav
APRIL

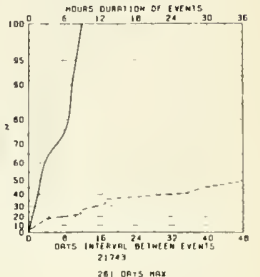

AUGUST

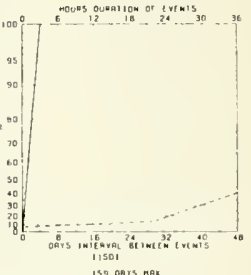

DECEMBER

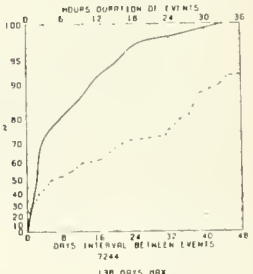

Figure 31. Wind speed persistence graph for the central northeast Pacific for Ocean Weather Station $\mathrm{N}$ giving percent frequency of duration and interval between $17 \mathrm{~m} / \mathrm{sec}$ or greater winds. ( $1 \mathrm{knot} \approx 0.5$ $\mathrm{m} / \mathrm{sec}$ ) (Reproduced from Naval Weather Service, Ref. 27). 
Durations of events meeting the above criterion are depicted by SOLID lines and refer to the TOP SCALE of each graph.

Intervals between events are depicted by DASHED lines and refer to the BOTTOM SCALE of each graph.

JANUARY

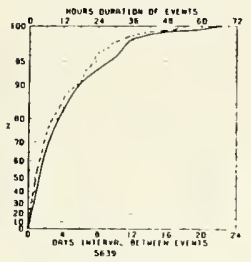

MAY

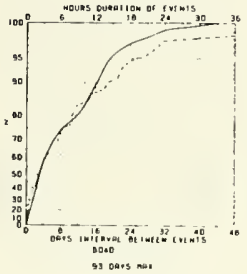

SEPTEMBER

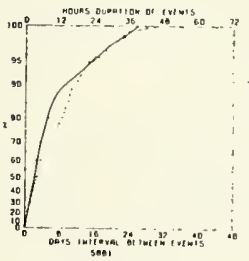

FEBRUARY

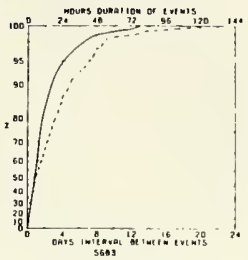

JUNE

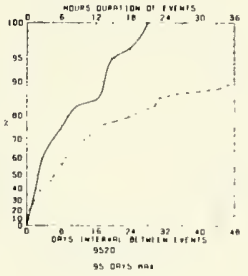

OCTOBER

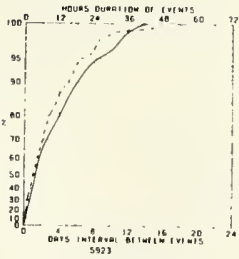

MARCH

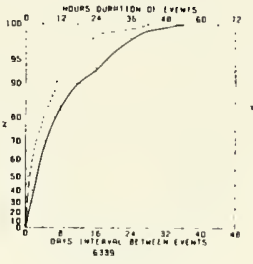

JULY

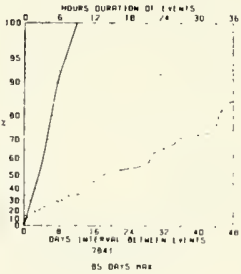

NOVEMBER

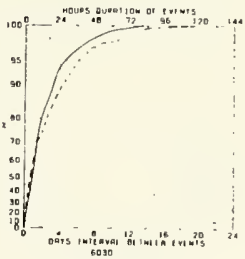

APRIL

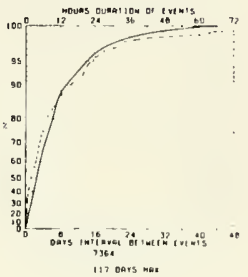

AUGUST

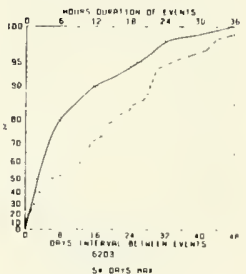

DECEMBER

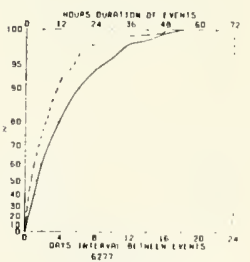

Figure 32. Wind speed persistence graph for the central northeast Pacific for Ocean Weather Station $P$ giving percent frequency of duration of and interval between $17 \mathrm{~m} / \mathrm{sec}$ or greater winds. (1 knot $\approx 0.5 \mathrm{~m} / \mathrm{sec}$ ) (Reproduced from Naval Weather Service, Ref. 27). 
Durations of events meeting the above criterion are depicted by SOLID lines and refer to the TOP SCALE of each graph.

Intervals between events are depicted by DASHED lines and refer to the BOTTOM SCALE of each graph.

JANUARY

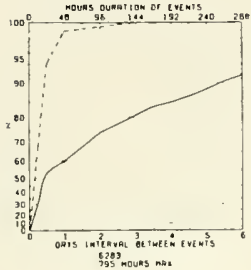

MAY

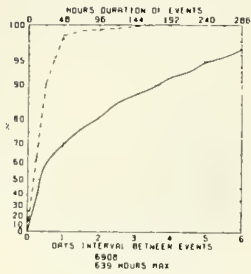

SEPTEMBER

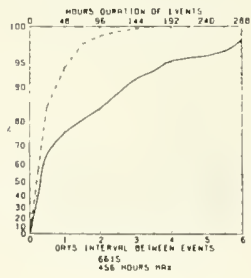

FEBRUARY

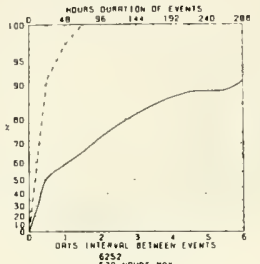

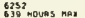

JUNE

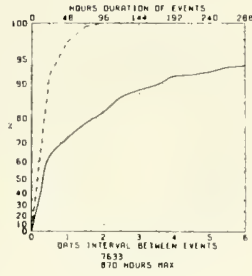

OCTOBER

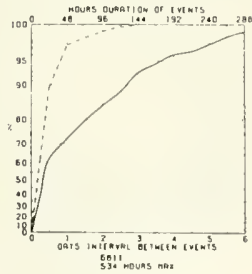

MARCH

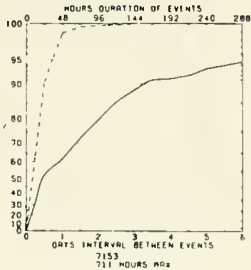

JULY

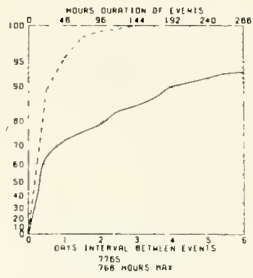

NOVEMBER

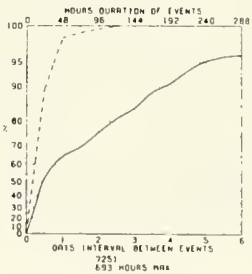

APRIL

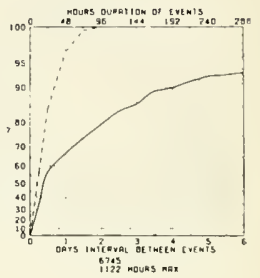

AUGUST

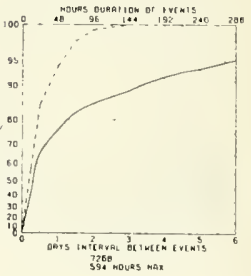

DECEMBER

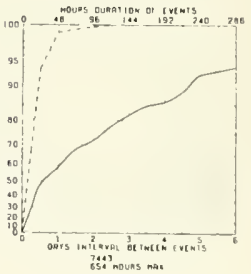

Figure 33. Wind speed persistence graph for the central northeast Pacific for Ocean Weather Station N giving percent frequency of duration of and interval between $2.5 \mathrm{~m} / \mathrm{sec}$ or greater winds. ( $1 \mathrm{knot}$ $\approx 0.5 \mathrm{~m} / \mathrm{sec}$ ) (Reproduced from Naval Weather Service, Ref. 27). 
Durations of events meeting the above criterion are depicted by SOLID lines and refer to the TOP SCALE of each graph.

Intervals between events are depicted by DASHED lines and refer to the BOTTOM SCALE of each graph.

\section{JANUARY}
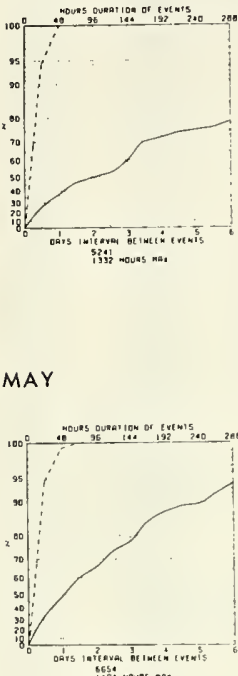

thes movers mat
FEBRUARY

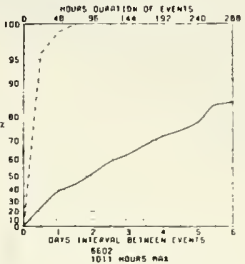

JUNE

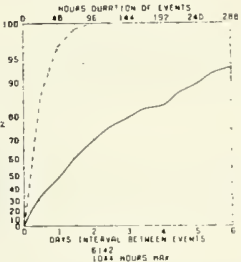

OCTOBER

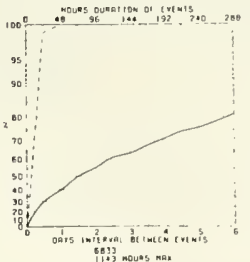

MARCH

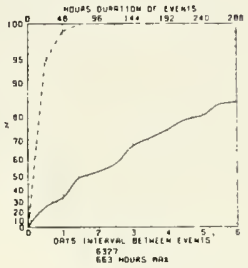

JULY

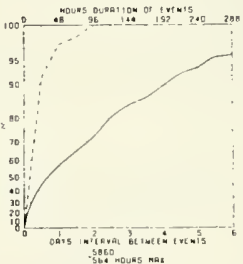

NOVEMBER

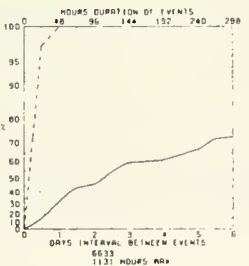

APRIL

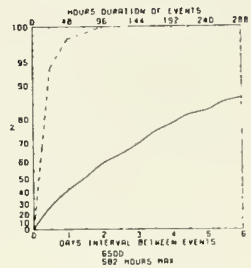

AUGUST

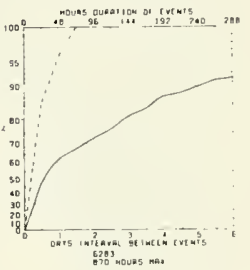

DECEMBER

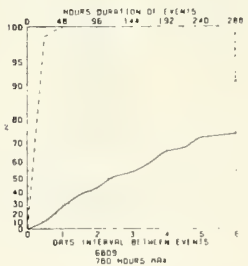

Figure 34. Wind speed persistence graph for the central northeast Pacific for Ocean Weather Station $P$ giving percent frequency of duration of and interval between $25 \mathrm{~m} / \mathrm{sec}$ or greater winds. (1 knot $\approx 0.5 \mathrm{~m} / \mathrm{sec}$ ) (Reproduced from Naval Weather Service, Ref. 27). 


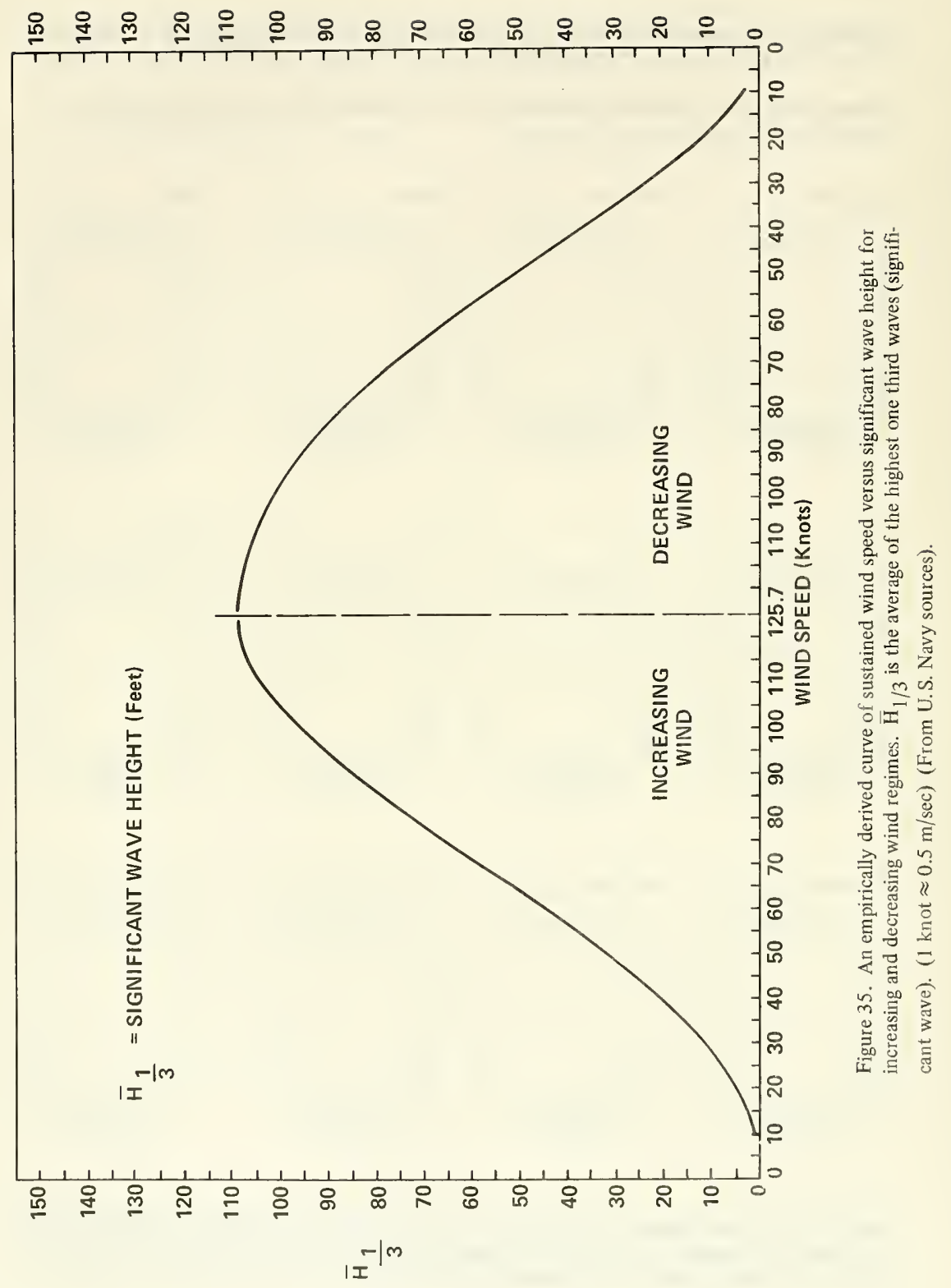




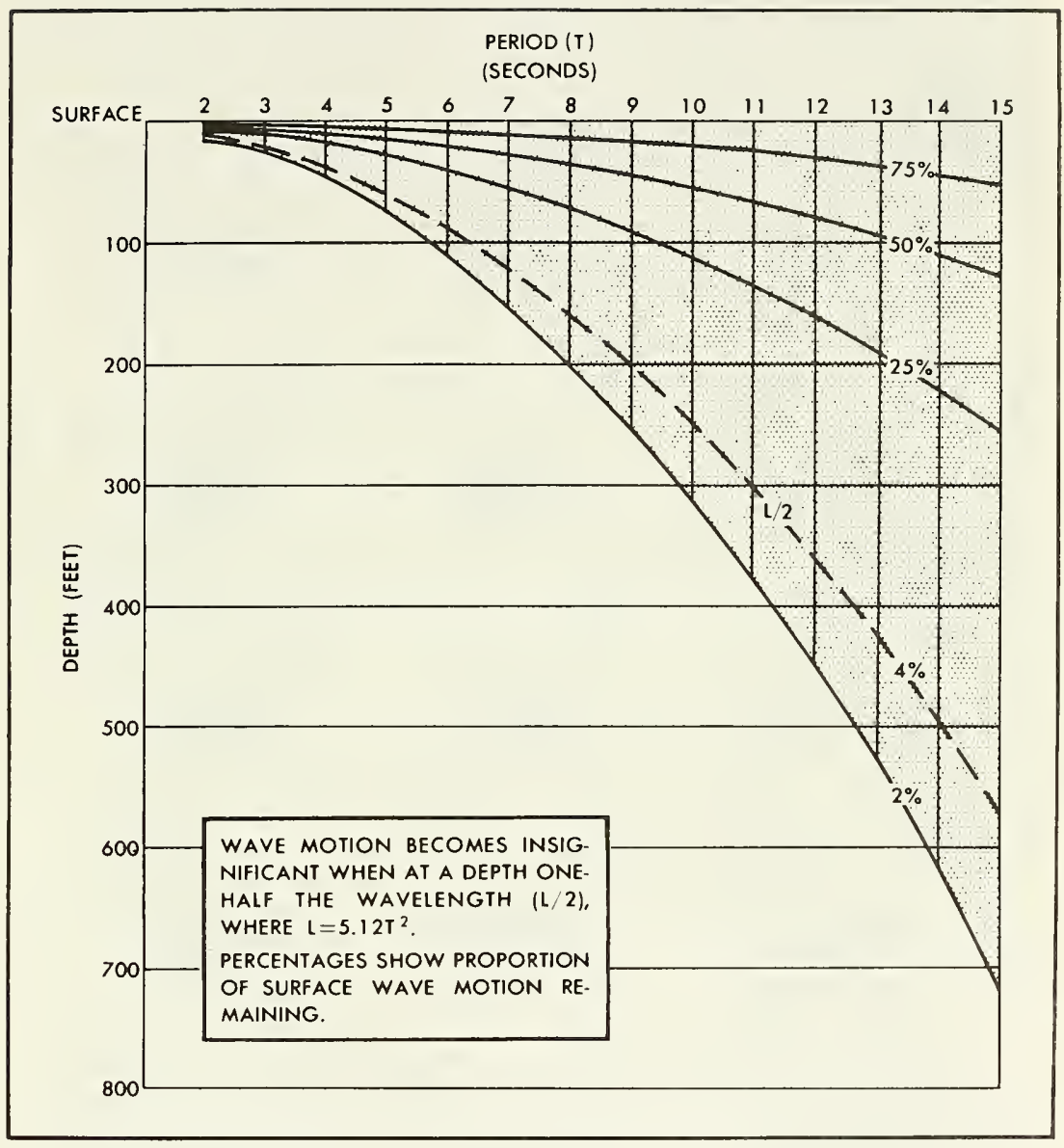

Figure 36. The percent attenuation of wave motion with depth given the period $(\mathrm{T})$ in seconds. ( 1 foot $\approx 0.3$ meter) (Data from U.S. Navy sources). 


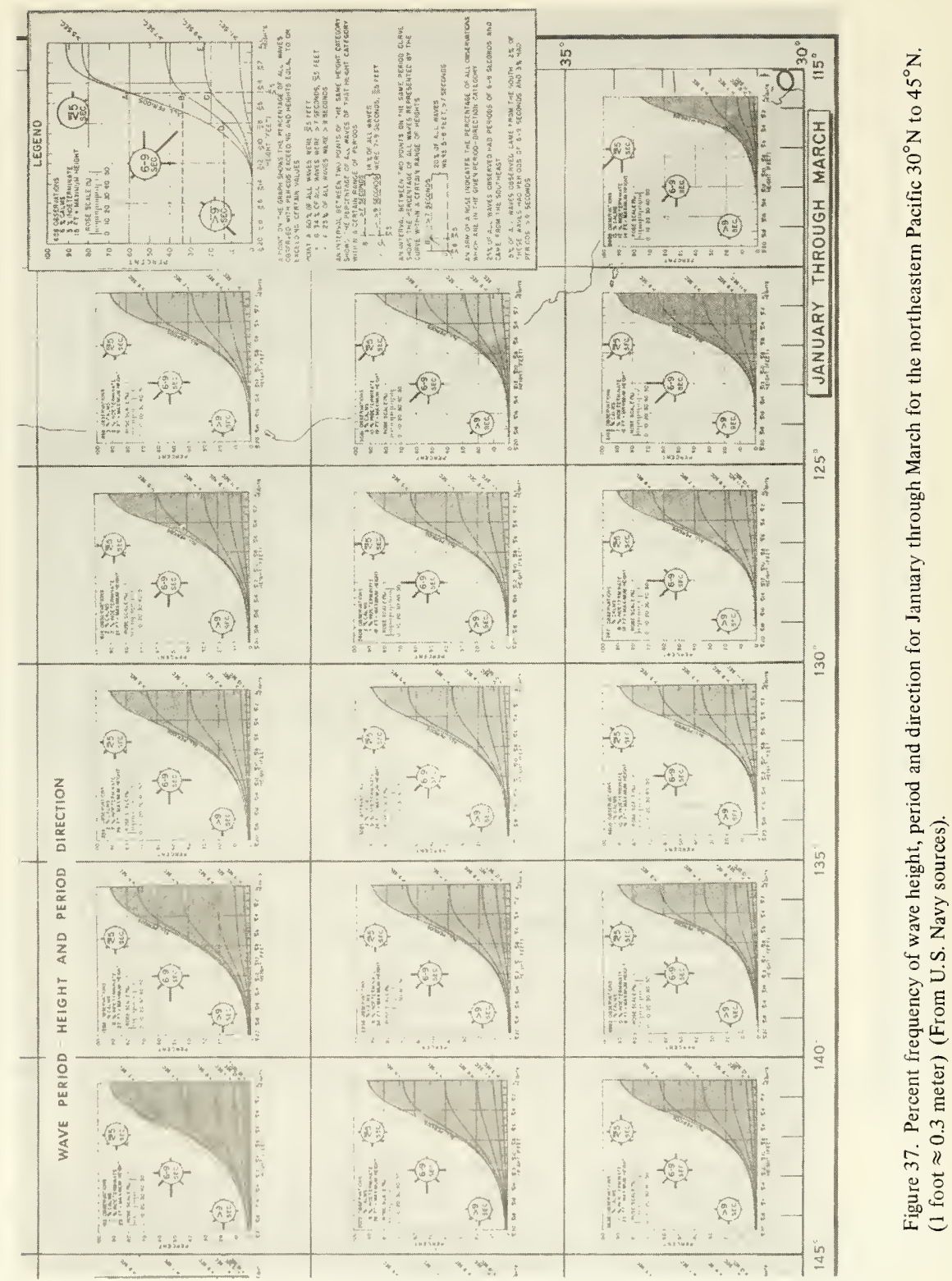




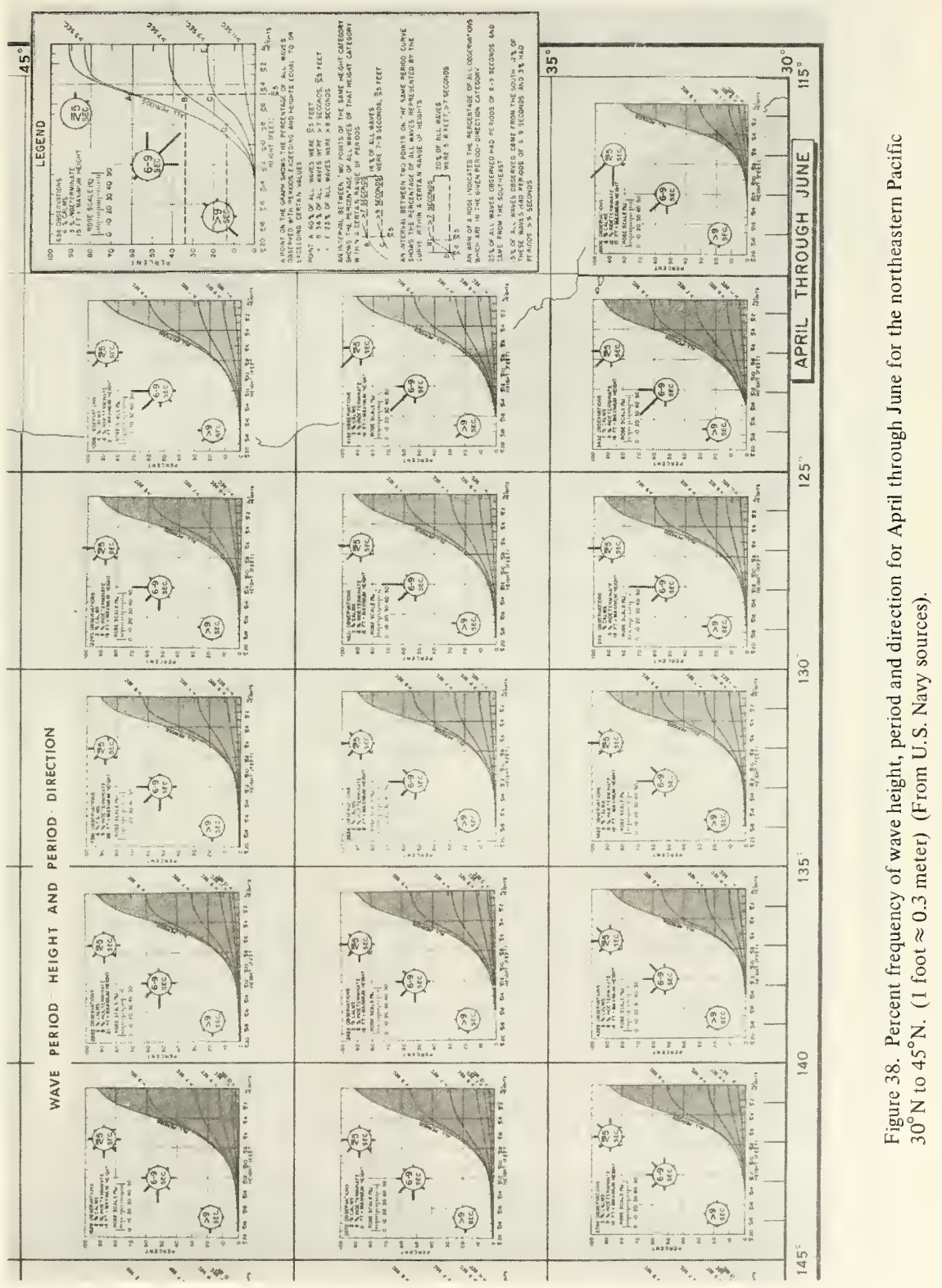




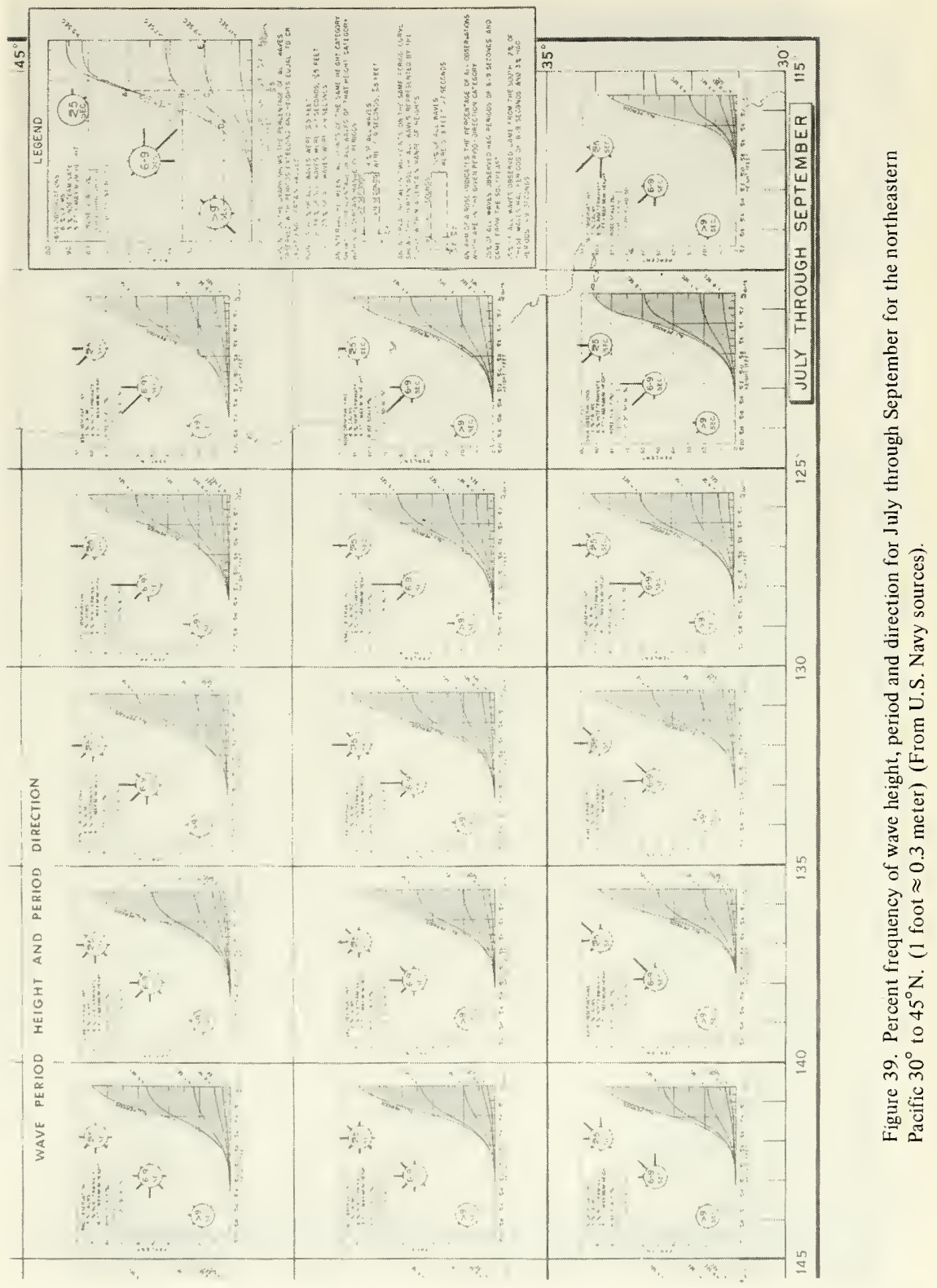




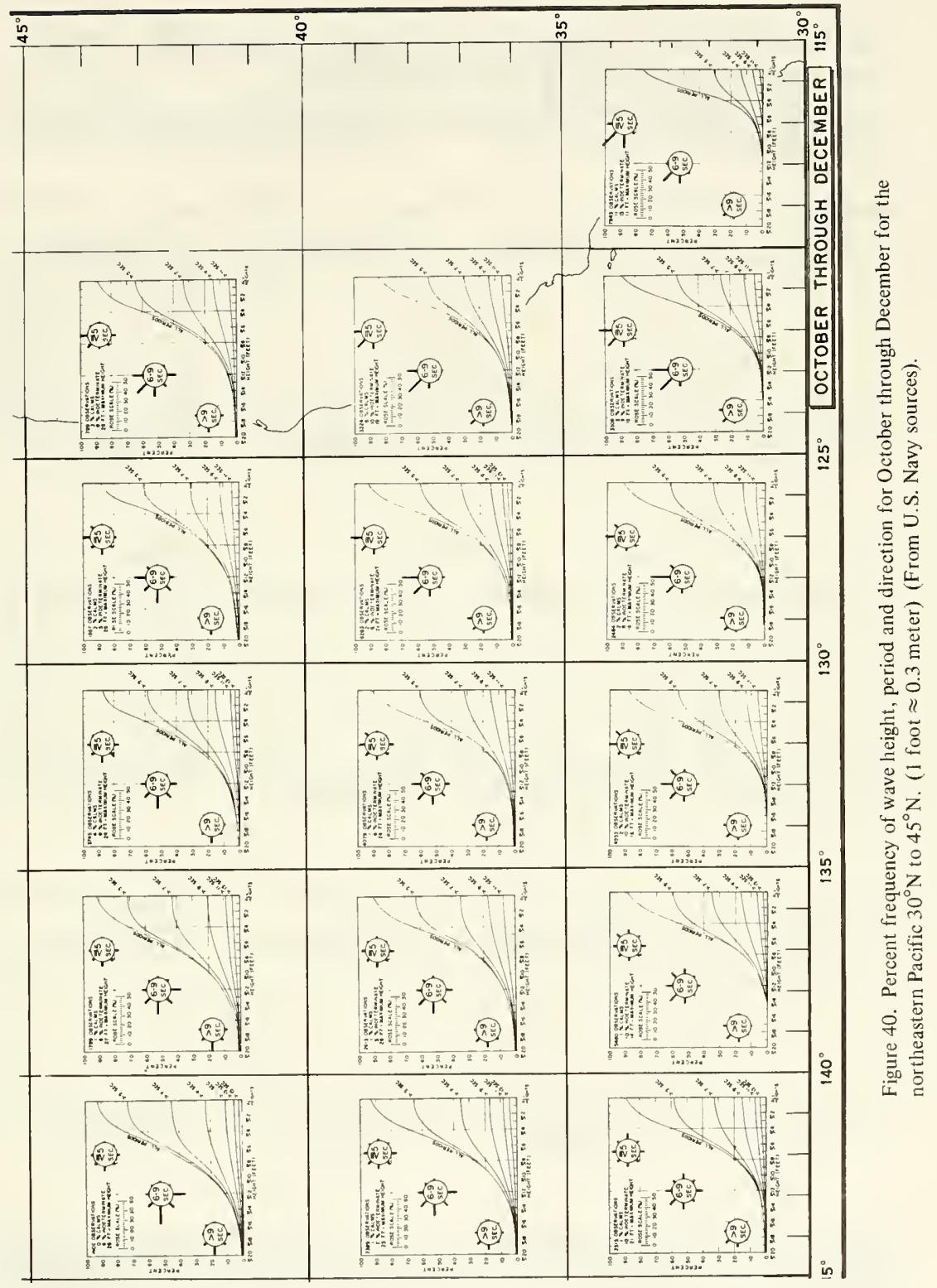


Durations of events meeting the above criterion are depicted by SOLID lines and refer to the TOP SCALE of each graph.

Intervals between events are depicted by DASHED lines and refer to the BOTTOM SCALE of each graph.

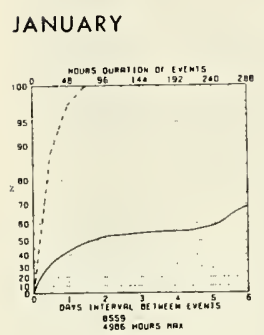

MAY

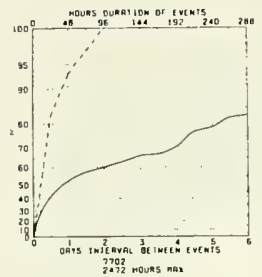

SEPTEMBER

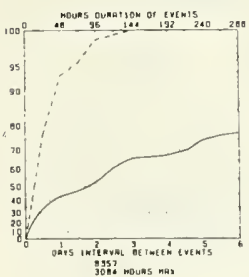

FEBRUARY

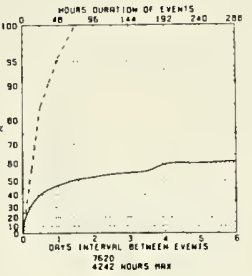

JUNE

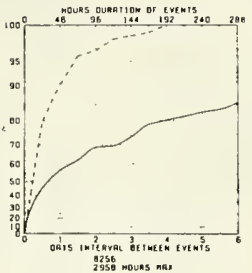

OCTOBER

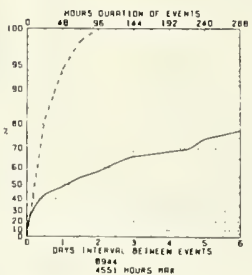

\section{MARCH}

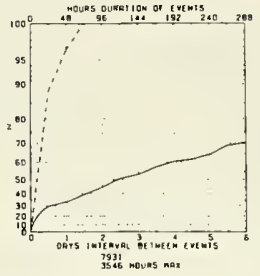

JULY

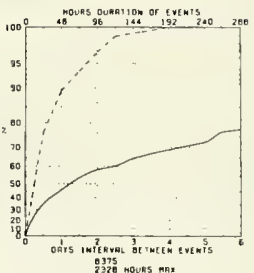

NOVEMBER

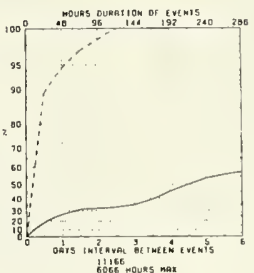

APRIL.

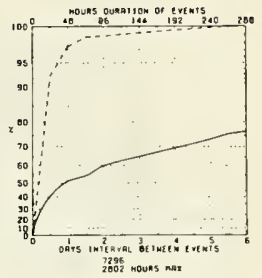

AUGUST

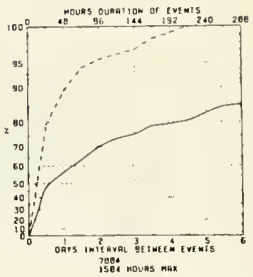

DECEMBER

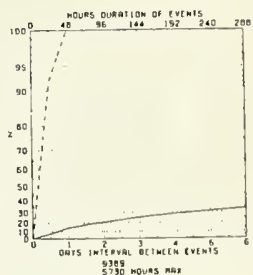

Figure 41. Monthly persistence graphs giving the cumulative percent frequency of hours of duration of a $\geqslant 1$-meter wave event and of days interval between events for OWS N. (Reproduced from Naval Weather Service, Ref. 27). 
Durations of events meeting the above criterion are depicted by SOLID lines and refer to the TOP SCALE of each graph.

Intervals between events are depicted by DASHED lines and refer to the BOTTOM SCALE of each graph.

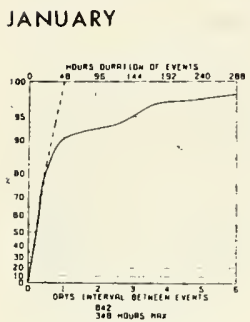

FEBRUARY

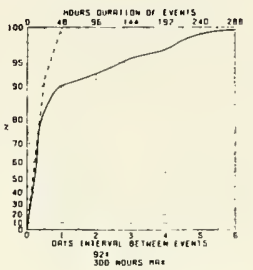

JUNE

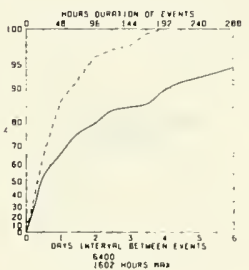

OCTOBER

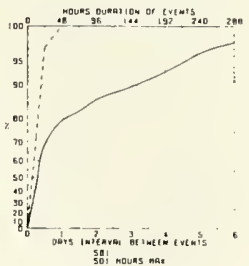

MARCH

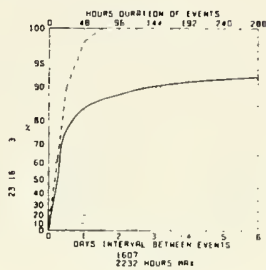

JULY

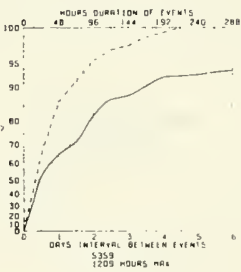

NOVEMBER

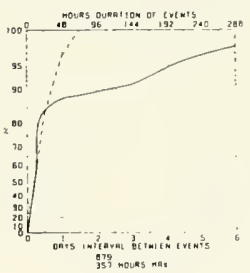

APRIL

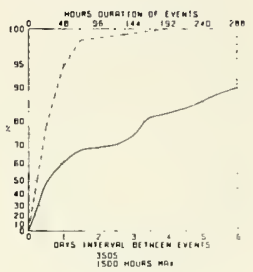

AUGUST

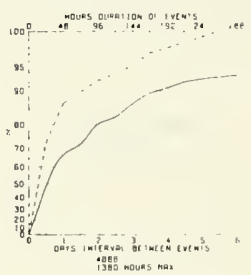

DECEMBER

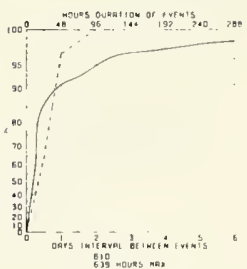

Figure 42. Monthly persistence graphs giving the cumulative percent frequency of hours of duration of a $\geqslant 1$-meter wave event and of days interval between events for OWS P. (Reproduced from Naval Weather Service, Ref. 27). 
Durations of events meeting the above criterion are depicted by SOLID lines and refer to the TOP SCALE of each graph.

Intervals between events are depicted by DASHED lines and refer to the BOTTOM SCALE of each graph.

JANUARY

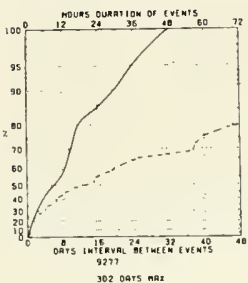

MAY

\section{FEBRUARY}

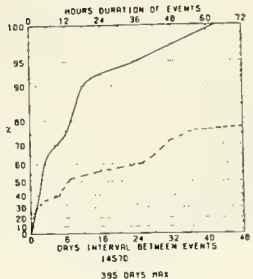

JUNE

INSUFFICIENT

DATA
MARCH

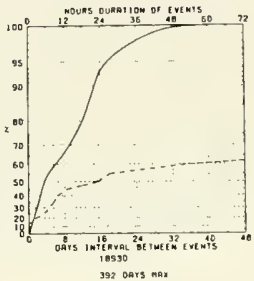

JULY

INSUFFICIENT

DATA
APRIL

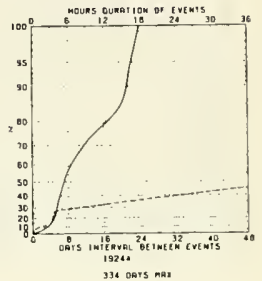

AUGUST

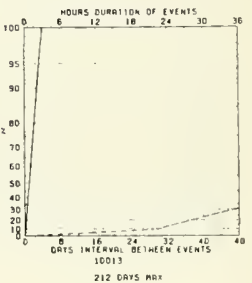

DECEMBER

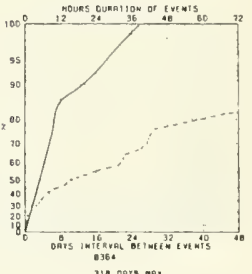

INSUFFICIENT

DATA

OCTOBER

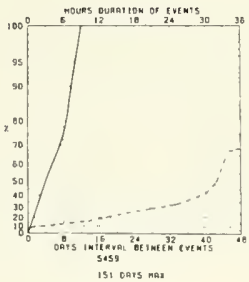

NOVEMBER

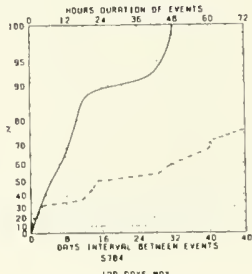

Figure 43. Monthly persistence graphs giving the cumulative percent frequency of hours of duration of a $\geqslant 5$-meter wave event and of days interval between events for OWS N. (Reproduced from Naval Weather Service, Ref. 27). 
Durations of events meeting the above criterion are depicted by SOLID lines and refer to the TOP SCALE of each graph.

Intervals between events are depicted by DASHED lines and refer to the BOTTOM SCALE of each graph.

JANUARY

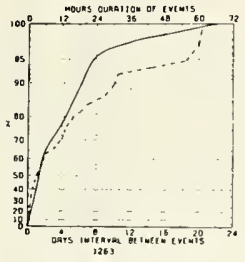

MAY

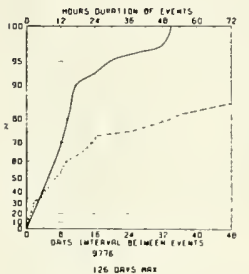

SEPTEMBER

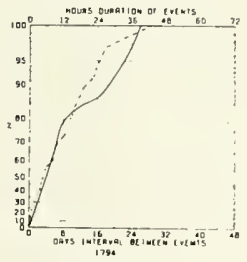

FEBRUARY

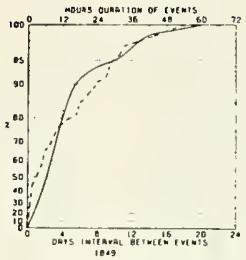

JUNE

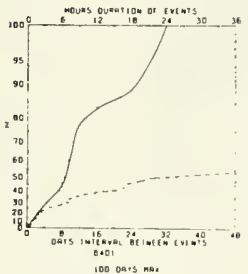

OCTOBER

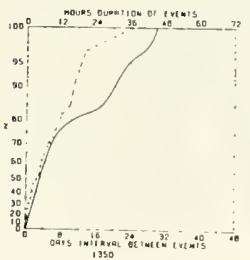

MARCH

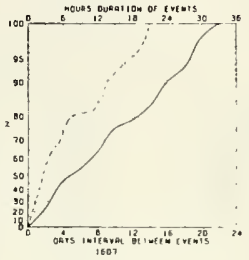

JULY

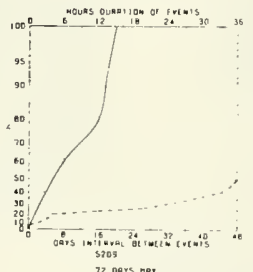

NOVEMBER

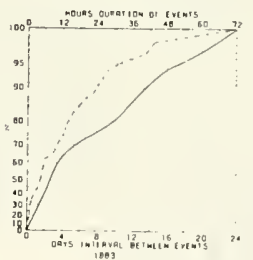

APRIL

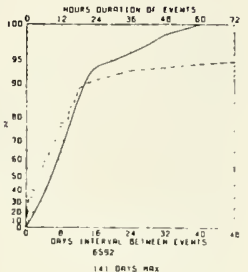

AUGUST

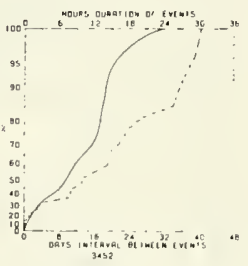

DECEMBER

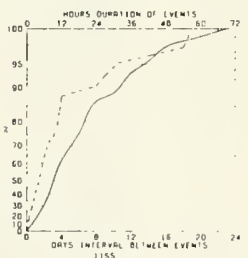

Figure 44. Monthly persistence graphs giving the cumulative percent frequency of hours of duration of a $\geqslant 5$-meter wave event and of days interval between events for OWS P. (Reproduced from Naval Weather Service, Ref. 27). 


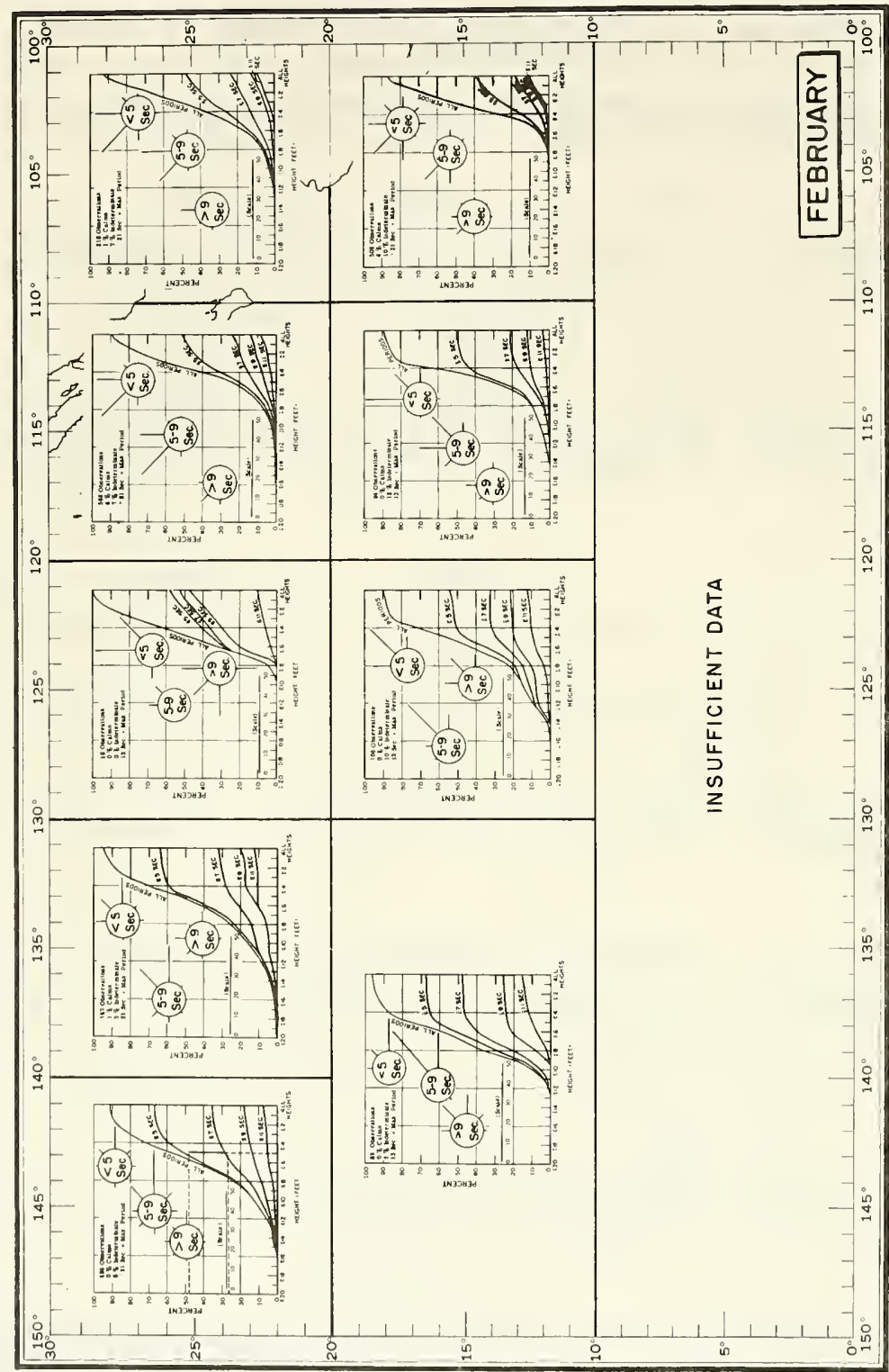

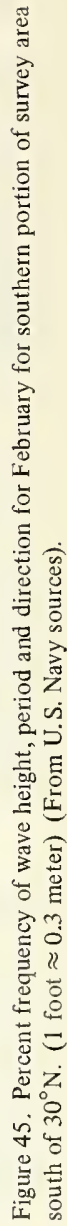




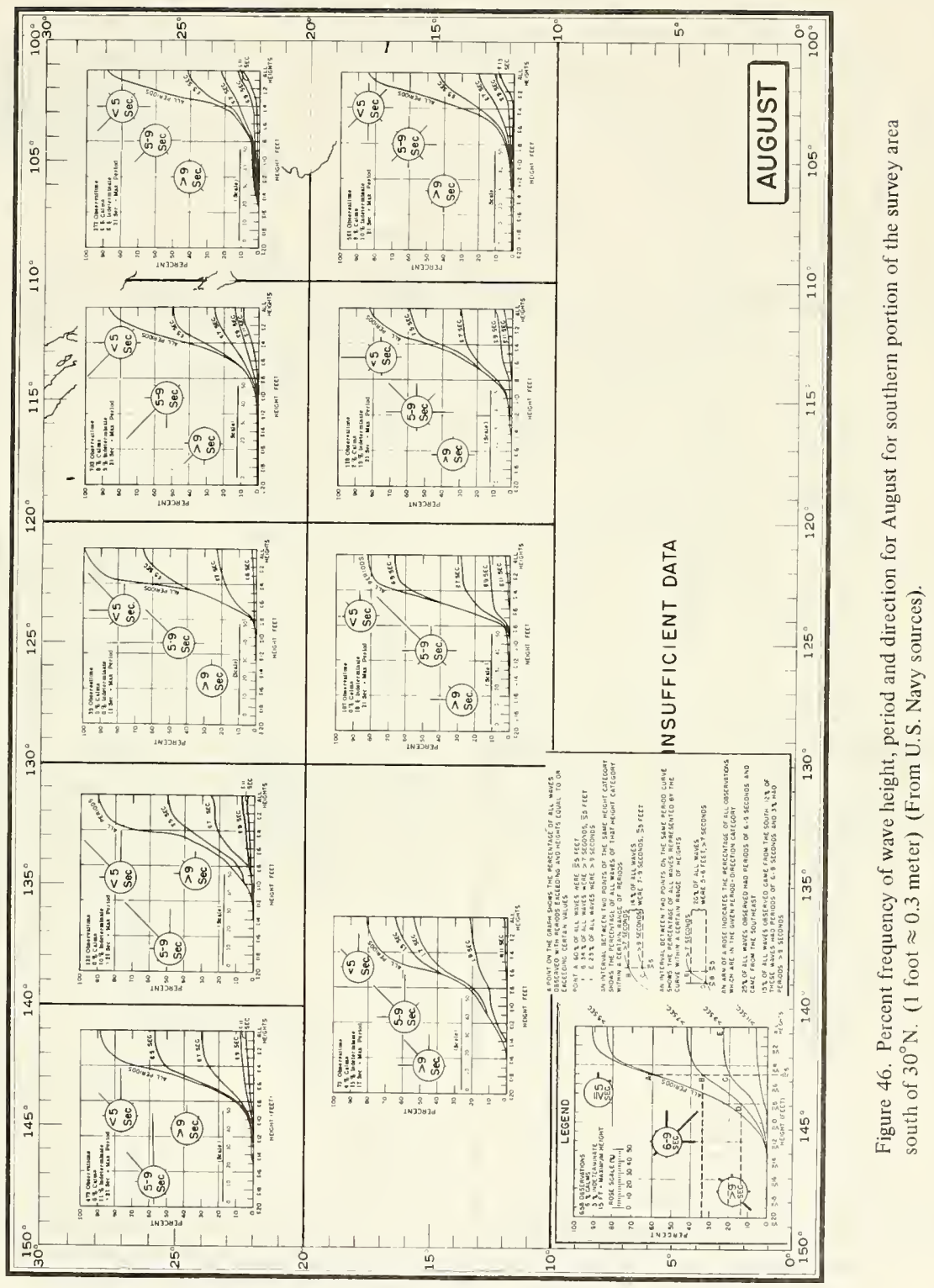




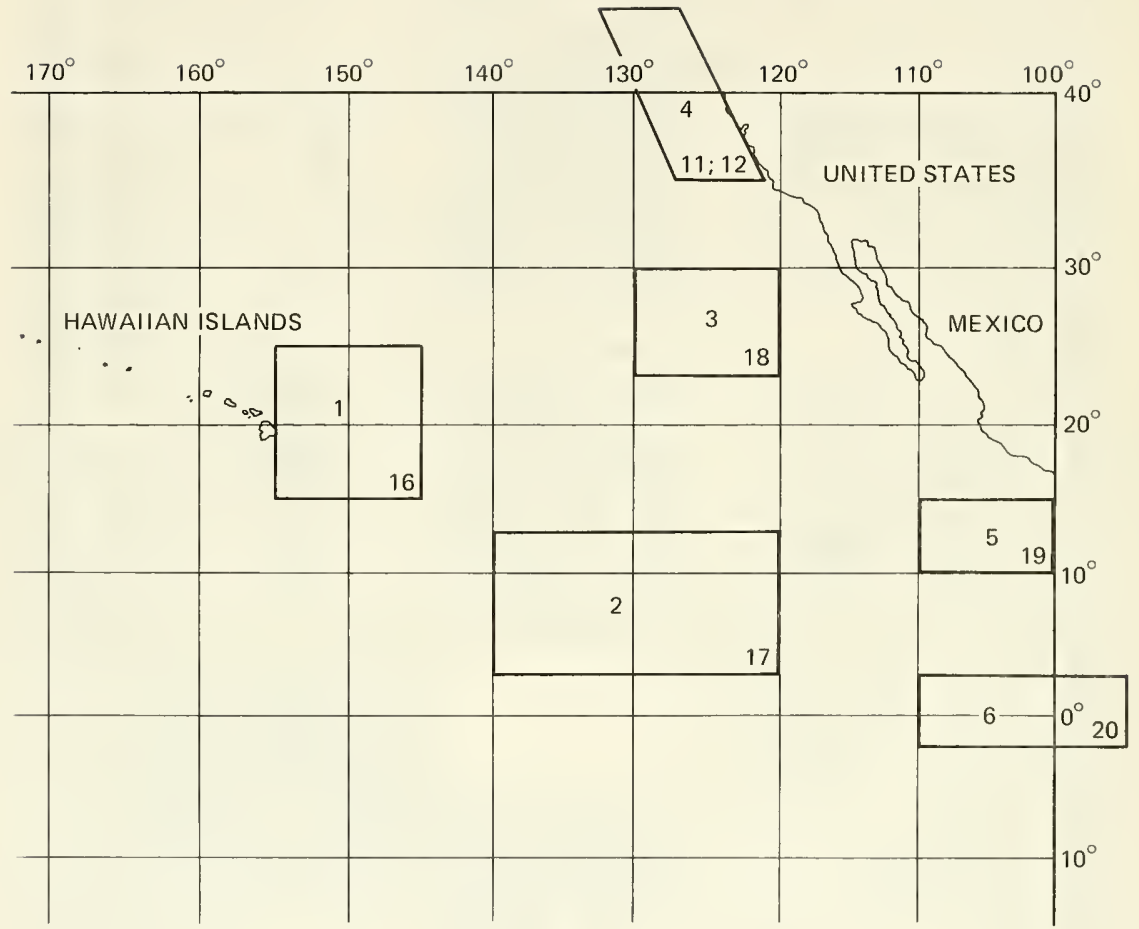

Figure 47. Geographic areas surveyed for the meteorological summary in Table 4. Numbers in the bottom right hand corner of each quadrant represent the survey areas in Fig. 1. (From Naval Weather Service Detachment, National Climatic Center, Asheville, NC). 

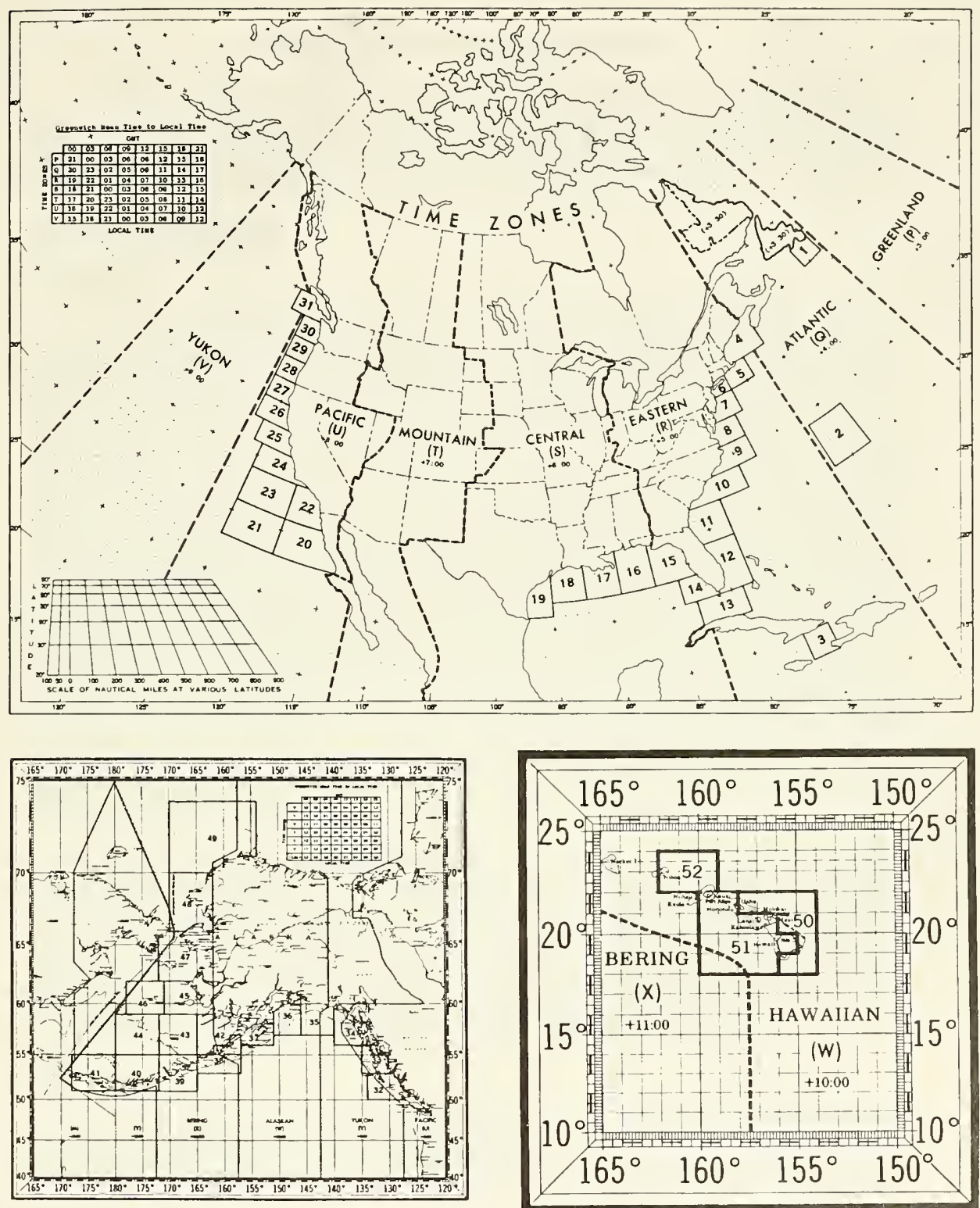

Figure 48. Maps showing coastal areas for which wind and wave recurrence statistics (Table 5) were computed. (Reproduced from NOAA, Ref. 38). 



\section{PRELIMINARY OFEF SITE SELECTION}

Before specific site selections are made, certain areas can be omitted because their environmental characteristics are completely outside the preliminary selection criteria. The following discussion will tentatively support or reject certain areas as potential farm sites for Phase 1; additionally, some discussion of site potentials for future phases will be given.

\section{BIOLOGICAL CRITERIA}

\section{Temperature}

Utilizing $20^{\circ} \mathrm{C}$ as the temperature maximum for Macrocystis tolerance and Fig. 11 as a guide, it is apparent that south of about $31^{\circ} \mathrm{N}$, cooling by upwelling will be required. The further south the site is located, the greater is the upwelling required to lower the ambient temperature to $20^{\circ} \mathrm{C}$, except for the equatorial upwelling region where ambient surface temperatures are lower, thus reducing the requirement for upwelled water. From Figs. 1 and 11 plus Appendices B and C, it is apparent that areas 11 and 12 require no cooling from upwelling (the need for nutrients in these areas may, of course, impose requirements for upwelling). Areas 1-9 are marginal and may require slight cooling during the late summer. Areas 10, 15, and 18 would require some cooling during the summer months. Area 13 would require 2 to 3 degrees cooling during summer and fall. Assuming that the upwelled water was from 200 meters $\left(13^{\circ} \mathrm{C}\right)$ and completely mixed, then approximately 33 percent upwelled water would be required in the surface layer to lower its ambient temperature to $20^{\circ} \mathrm{C}$. Off Hawaii (areas 14 and 16), approximately 50 percent of the surface water would have to be upwelied from 200 meters to meet the temperature requirement. Also, in areas 17 and 19 in the tropical eastern Pacific north of the equator, the surface waters would have to be mixed with approximately 50-percent upwelled water from 200 meters to lower ambient temperatures to $20^{\circ} \mathrm{C}$. In area 20 , the winter and spring seasons are the warmest $\left(25^{\circ} \mathrm{C}\right)$, thus requiring approximately 40-percent upwelled water mixed with ambient surface water to lower the temperature to $20^{\circ} \mathrm{C}$.

The $20^{\circ} \mathrm{C}$ temperature limitation has not been conclusively demonstrated, and the actual limiting temperature may be significantly higher, thus possibly requiring less upwelling for cooling purposes. If, however, $20^{\circ} \mathrm{C}$ is assumed to be limiting, then north of $30^{\circ} \mathrm{N}$ there appears to be little or no problem from upper temperature limitations whereas south to about $25^{\circ} \mathrm{N}$ some cooling will be required. Off Hawaii and between $25^{\circ} \mathrm{N}$ and the equator, surface temperatures may be limiting unless enough deep water (200-meter) can be brought to the surface to produce a 50 percent deep/50 percent surface water mixture.

\section{Nutrients}

Macrocystis nitrate requirements are tentatively placed at 3 to $5 \mu \mathrm{g}$-at/liter minimum, and $10-\overline{15 \mu \mathrm{g}-\mathrm{at} / \mathrm{lite}}$ optimal. The only areas where the required nitrate concentrations are observed at the surface are the near-coastal zones during the upwelling seasons and in the 
equatorial and Costa Rica Dome upwelling regions (Fig. 1). At all other offshore areas, artificial upwelling will be required. To provide adequate nutrients to the plants, using a reasonable upwelling volume, the upwelled water may need to contain some 20 to $30 \mu \mathrm{g}$-at $\mathrm{NO}_{3}$ /liter. In general, nutrient concentrations in the 20 to $30 \mu \mathrm{g}$-at/liter range are found at deeper depths as one moves west from the coast and from north to south. The depth of the $30 \mu \mathrm{g}$-at/liter $\mathrm{NO}_{3}$ level increases from 100-200 meters at $40-45^{\circ} \mathrm{N}$ to $250-350$ meters at $25-30^{\circ} \mathrm{N}$ along the west coast, and is at 350-500 meters off Hawaii. Other things being equal, the greater the depth from which water must be pumped, the greater the costs involved. The proposed pumping depth of 100 meters (Ref. 2) for a Phase 3 farm might necessitate locating the farm above $40^{\circ} \mathrm{N}$ or very close to west coast upwelling areas within a few kilometers from shore, or else pumping rates could possibly be increased somewhat beyond the proposed five acre feet (six cubic kilometers) per day (Ref. 2). Upwelling pipes might have to be 200-300 meters long off southern California in open ocean areas, and even longer to the south or west to provide adequate concentrations of nutrients to the surface. In the equatorial upwelling and Costa Rica Dome regions, it is possible that no artificial upwelling would be needed because of the continual high concentration of nutrients at the surface. Other factors, however, place these upwelling regions in doubt as potential farm locations for the near term because of the relatively high current speed, temperature regime, and remoteness from potential processing facilities. If, however, the OFEF concept of a dynamically-positioned farm capable of movement with propulsors (Refs. 2 and 3 ) is tenable, and at-sea processing and long-distance transportation become economically feasible, then large floating farms in the equatorial region become a strong possibility. The farms could float to the east with the Equatorial Countercurrent, move south a few hundred kilometers and move west with the South Equatorial Current, and then propulse north to the Equatorial Countercurrent again, thus remaining in a limited area of the central eastern Pacific and within high-nutrient waters.

The requirement for nutrients at a given concentration may be a significant economic factor because the costs increase with the depth of the required upwelling and the depth of derived nutrient levels varies with area. Therefore, location of the OFEF with regard to nutrients is more a question of economics than of Macrocystis requirements. Probably the most cost effective farm locations from the nutrient (near surface) availability stand point would be as follows:

1. Equatorial Upwelling Zone (area 20), Costa Rica Dome, and Peruvian upwelling regions;

2. Areas north of $40^{\circ} \mathrm{N}$ and coastal regions to $35^{\circ} \mathrm{N}$ (area 12);

3. Coastal regions south of $35^{\circ} \mathrm{N}$ to $25^{\circ} \mathrm{N}$ (areas 11 and $1-9$ );

4. Areas 10 and 18 ; and the

5. Central eastern Pacific areas 13, 14, 15, 16, 17 and 19.

Practically, for Phase 1 and 2 farms and early Pliase 3 farms, the areas included under 2 and 3 above are the most feasible from a nutrient viewpoint. 


\section{Currents}

Phase 1 and 2 farms will probably be moored and therefore the surface currents could be a major contributor to the water movement around the plants. Current speeds greater than the minimum $(4 \mathrm{~cm} / \mathrm{sec})$ requirements are observed almost continually throughout the eastern Pacific survey area. Current speeds less than the optimal $(10 \mathrm{~cm} / \mathrm{sec})$ can occur in the north Pacific gyral area, $25^{\circ}$ to $45^{\circ} \mathrm{N}$ and $130^{\circ}$ to $160^{\circ} \mathrm{W}$, and in the southern extreme of the California Current, $20^{\circ}$ to $25^{\circ} \mathrm{N}$. Because of the tendency of the plants to deflect toward the horizontal in currents of greater than $25 \mathrm{~cm} / \mathrm{sec}$, sustained currents of greater than this speed may have to be avoided, at least for the relatively small Phase 1 and 2 moored systems. * Areas where currents greater than $25 \mathrm{~cm} / \mathrm{sec}$ are observed for significant periods of time, include the northern Davidson Current during the winter and the Alaska Current to the north. Also, the North Equatorial Current, the Equatorial Countercurrent, and the South Equatorial Currents exhibit speeds greater than $25 \mathrm{~cm} / \mathrm{sec}$ much of the time between $5^{\circ} \mathrm{S}$ and $15^{\circ} \mathrm{N}$ from the coast to the western edge of the survey area.

Areas which meet the optimal current ranges $(10$ to $25 \mathrm{~cm} / \mathrm{sec})$ include the westwardmoving North Pacific and Subarctic Currents, $35^{\circ}$ to $42^{\circ} \mathrm{N}$; most of the California Current region south of $40^{\circ} \mathrm{N}$; the northern portion of the North Equatorial Current region from the coast westward between $15^{\circ}$ and $20^{\circ} \mathrm{N}$; and the South and Central American coastal areas from the equator to central Mexico $\left(20^{\circ} \mathrm{N}\right)$.

With the advent of floating OFEF's, current velocities above $25 \mathrm{~cm} / \mathrm{sec}$ may become less restrictive because the farms can float with the currents, thus reducing the relative water motion. In floating farms, the importance of wind mixing, internal waves, and upwelling velocity is increased while the importance of surface current velocity is decreased in relation to nutrient uptake rates. However, the energy requirements and engineering limitations for station-keeping must be considered as well.

\section{ENGINEERING CRITERIA}

\section{Currents}

Although current engineering limitations are not yet well defined, design requirements which meet certain minimal environmental forces will have to be met. A $50-\mathrm{cm} / \mathrm{sec}$ operational current is assumed for developmental design of the substrate structure (Ref. 17). A $1.5-\mathrm{m} / \mathrm{sec}$ sustained current is the initial engineering design limitation value. Both the operational and design currents are above the biological sustained current limitation of 25 $\mathrm{cm} / \mathrm{sec}$. In terms of engineering current limitations, the only areas which have sustained currents above $50 \mathrm{~cm} / \mathrm{sec}$ are the South Equatorial Current and the northeastern portion of the survey area near Vancouver Island (Fig. 7). Currents of $100 \mathrm{~cm} / \mathrm{sec}$ are observed in the California and Davidson Currents under extreme conditions (Figs. 5 and 6, these measurements are from ship drift and may be somewhat elevated). Storm-generated currents may, however, become highly important in terms of plant and structural survival (see Appendix E).

*Ambient currents will probably not penetrate far into large OFEF's, see Ref. 16. 


\section{Storms/Wind}

It will be best for the early OFEF's to avoid areas of strong storms because of the high waves and surface currents generated by them. If possible, areas of storm-force winds $(\geqslant 25 \mathrm{~m} / \mathrm{sec})$ and hurricane-force winds $(\geqslant 33 \mathrm{~m} / \mathrm{sec})$ should be avoided, and encounters with gale-force winds $(\geqslant 17 \mathrm{~m} / \mathrm{sec})$ should be minimized. In the north, extratropical cyclones are generated in the Gulf of Alaska, and these frequently move toward the south with diminishing intensity and frequency to a maximum southern limit of about $30^{\circ} \mathrm{N}$. Subtropical cyclones move from an area of generation near $15^{\circ} \mathrm{N}$ to the west and northwest with diminishing intensity to about $35^{\circ} \mathrm{N}$ (maximum northern limit of tropical storms). North of about $35^{\circ} \mathrm{N}$, and particularly to the northwest, storms and high-wind velocities are common. In the south, between $10^{\circ} \mathrm{N}$ and $30^{\circ} \mathrm{N}$, and to the west to $160^{\circ} \mathrm{W}$ the probability of strong subtropical storms and hurricanes is high, and these areas should initially be avoided. Areas of low-velocity winds with low probability of intense storms (the most desirable for OFEF location) are given below in order of preference.

1. Southern California and northern Baja California between $35^{\circ} \mathrm{N}$ and $30^{\circ} \mathrm{N}$ within 97 kilometers of the coast, (areas 1 through 9 and the northern portion of 10). This area has the lowest probability of extreme winds of any coastal area in the United States (approximately 1 storm $\geqslant 25 \mathrm{~m} / \mathrm{sec}$ in a 5 -year period).

2. $25^{\circ} \mathrm{N}$ to $32^{\circ} \mathrm{N}, 120^{\circ} \mathrm{W}$ to $140^{\circ} \mathrm{W}$ (areas 15 and 18 ).

3. Leeward side of Hawaiian Islands (area 51, Fig. 48).

4. Trade wind regions south of tropical cyclone areas, $10^{\circ} \mathrm{N}$ to $10^{\circ} \mathrm{S}$ from the coast, west to $160^{\circ} \mathrm{W}$. (Relatively constant winds of $5-10 \mathrm{~m} / \mathrm{sec}$.)

Waves

Wind-generated waves are relatively constant throughout the survey area. The mean wave height is between 1 and 1.5 meters in all areas (Table 4); however, 99.5 percentile and extreme waves are highly variable. North of $35^{\circ} \mathrm{N}$, both along the coast and to the west, 5year significant and extreme waves are higher than the proposed engineering limitations for preliminary farms (11 and 19 meters, respectively). Areas to the south, particularly the coastal regions from $34^{\circ} \mathrm{N}$ to $27^{\circ} \mathrm{N}$ and west to $125^{\circ} \mathrm{W}$ (areas 1 through 10 and the eastern half of 18, Fig. 1) and regions 20 to 23 (Table 5), show very low wave heights and 10-year extremes within the designated criteria. South of this area, to about $10^{\circ} \mathrm{N}$, tropical cyclones can cause very high waves which in conjunction with high currents might cause structural or plant damage to an OFEF located in this area. Wave heights increase in a westerly direction. OWS $\mathrm{N}\left(30^{\circ} \mathrm{N}, 140^{\circ} \mathrm{W}\right)$ is marginal, with an estimated 5 -year significant wave height of 11 meters (Table 6). North of OWS $N$ waves become significantly higher, making this region less desirable as an OFEF site. In Hawaiian waters, extreme wave heights on the windward side of the islands are estimated to be significantly higher than on the leeward side (area 51 , Table 5). The leeward side is within the engineering wave height limitations for 10-year waves, while the windward (north and east) side is not.

The southern California/northern Baja region is the area of least severe windgenerated waves. 


\section{ECONOMIC AND GEOPOLITICAL CONSIDERATIONS}

Economic considerations are discussed in detail in Ref. 2 and are certainly of major importance in OFEF site selection. For Phase 1 experimental farms, the factors of production and transport costs are not a consideration. However, because these early prototype farms will have limited budgets and will be designed essentially to prove the OFEF concept, it is important that they be located in reasonable proximity to scientific and logistic support. Approximately 30 kilometers maximum (2-hour transit) is considered an appropriate distance for adequate scientific support and study of Phase 1 farms. This distance will limit the site initially to a near-shore (coast or island) location in the vicinity of a marine laboratory or facility. For large moored OFEF systems, the depth of the bottom is an important factor. For depths greater than 610 meters the mooring costs become excessive. This depth limitation is not highly significant for Phase 1 and 2 farms because of their small size (610-meter water is available) and relaxed economic requirements. For Phase 3 and the future, however, it is not likely that large farms can economically be anchored; they will probably be dynamically positioned and so will not be geographically limited by bottom contour.

OFEF should presently remain outside claimed territorial and economic zones of other countries until mutual international agreements are made. Currently most South and Central American countries and Mexico have claimed 200-mile (322-kilometer) economic or territorial zones, and it now appears certain that the U.S. will do the same by March 1977. Figure 1 gives the approximate 322-kilometer economic zone boundaries. With economic zone exclusion of the 322 kilometers around Guadalupe Island, the islands south of Baja California, and the Galapagos Islands, much of the open ocean areas as well as all the coastal regions south of $32^{\circ} 30^{\prime} \mathrm{N}$ are removed from OFEF site availability at the present time. 


\section{PHASE 1 SITE SELECTION}

\section{SOUTHERN CALIFORNIA OFEF SITE SELECTION}

It is apparent that the first requirement for the Phase 1 OFEF prototype is that it should be located in the nearshore area to allow adequate access by scientific and support personnel. Secondly, it should be located in an area with mild oceanographic and meteoro-

logical characteristics and be within the criteria delineated in Table 1. The region best suited within the guidelines of the proposed and established criteria is the southern California offshore area from Pt. Conception, $34^{\circ} 30^{\prime} \mathrm{N}$, to the Mexican economic zone, $32^{\circ} 30^{\prime} \mathrm{N}$. This area is presented in Fig. 49, which also shows submarine transit lanes, shipping lanes, the 322-kilometer Mexican economic zone boundary and the proposed locations of selected OFEF Phase 1 sites listed in priority order.

The southern California offshore area has been selected as the optimal location for Phase 1, and will more than likely be selected for Phase 2 and early 3 as well, for the following reasons.

1. The sites chosen are within the U.S. economic zone which will be increased to 200 miles (322 kilometers) by March 1977, thereby avoiding possible international conflict.

2. The region has the most mild and least severe extreme weather conditions of any offshore area within the economic zone of the continental United States or Hawaii. 1t has a very low occurrence of high-velocity winds and high waves. This is because the region is north of the tropical cyclone zone and is located on the southern extreme of the extratropical cyclone region.

3. In this nearshore area, nutrients of adequate concentrations are relatively near the surface (15-25 $\mu \mathrm{g}$-at/liter $\mathrm{NO}_{3}$ at 100 meters).

4. Research and support facilities are available close to the proposed sites.

5. The region is within the natural habitat zone of Macrocystis pyrifera. Temperature and light regions are excellent for Macrocystis growth.

6. Current speeds are mostly within the ranges specified for optimal OFEF operations and kelp growth characteristics.

\section{SOUTHERN CALIFORNIA OFFSHORE CHARACTERISTICS}

Figures 50 through 71 (from the Naval Weather Service, Ref. 45) give detailed oceanographic and meteorologic data of the southern California offshore area. These data, along with the criteria below, were used to select specific sites. Table 8 gives nutrient concentrations for various depths off southern California and northern Baja California.

Winter (February) and summer (August) wave heights $>2$ and $>6$ feet $(>0.6$ and 1.8 meters) are given in Figs. 50 and 51 , and $>9$ and $>12$ feet $(>2.7$ and 3.7 meters) in Figs. 52 and 53. Percent frequency of the wave heights given increase to the west showing a 
minimal value of 20 percent for $>2$-foot (0.6-meter) waves in August nearshore (Fig. 51 ) to a maximum of 70 percent for $>2$-foot (0.6-meter) waves in the northern Channel Islands $\left(34^{\circ} \mathrm{N}\right)$. High waves $\left(>3.7\right.$ meters) occur rarely in August $\left(2.5\right.$ percent at about $121^{\circ} \mathrm{W}$, $32^{\circ} 30^{\prime} \mathrm{N}$ ) and are slightly more common in winter (Figs. 52 and 53 ).

Table 8. Nitrate concentration versus depth off southern California and northern Baja California.

\begin{tabular}{c|rrrrrrrrrrr}
\hline & \multicolumn{10}{c}{ Ocean Locations } \\
\cline { 2 - 10 } Depth $(\mathrm{m})$ & 1 & 2 & 3 & 4 & 5 & 6 & 7 & 8 & 9 & 10 & 11 \\
\hline & \multicolumn{10}{|c}{ Nitrate concentration $\left(\mu \mathrm{g}\right.$-at $\mathrm{NO}_{3}$-N/liter) } \\
0 & 1 & 1 & 2 & 0.5 & 0.5 & 0.5 & 0 & - & - & - & - \\
10 & 1 & 2 & 2 & 0.5 & 0.5 & 0.5 & 0 & - & - & - & - \\
50 & 2 & 7 & 2 & 18.0 & 7.0 & 16.0 & 12 & - & 16 & 13 & - \\
100 & 15 & - & 9 & 22.0 & 20.0 & 22.0 & 21 & - & - & - & - \\
200 & 24 & 20 & 19 & 30.0 & 28.0 & 26.0 & 28 & - & - & - & - \\
300 & 30 & 30 & - & 32.0 & 33.0 & 28.0 & 33 & 30 & - & - & $23-33$ \\
\hline
\end{tabular}

Ocean Locations

1. San Diego Trough - September 72

2. Off Baja California - July 72

3. Off Baja California - August 72

4. San Diego Trough - April 71

5. San Diego Trough - October 70

6. San Diego Trough - April 70

7. Santa Catalina Basin - May 65

8. San Diego Trough - April 75

9. Catalina 1sland - September 75

10. Catalina lsland - November 75

11. Range of values from 300 meters

\section{Data Sources}

unpublished data

unpublished $30^{\circ} \mathrm{N}, 120^{\circ} \mathrm{W}$

unpublished $30^{\circ} \mathrm{N}, 120^{\circ} \mathrm{W}$

unpublished $32^{\circ} 30^{\prime} \mathrm{N}, 117^{\circ} 30^{\prime} \mathrm{W}$

unpublished $32^{\circ} 30^{\prime} \mathrm{N}, 117^{\circ} 30^{\prime} \mathrm{W}$

unpublished $32^{\circ} 30^{\prime} \mathrm{N}, 117^{\circ} 30^{\prime} \mathrm{W}$

$33^{\circ} 18.5^{\prime} \mathrm{N}, 118^{\circ} 40^{\prime} \mathrm{W}$ (Ref. 46)

Supplied to W. North for upwelling experiments.

W. North, Personal Comm.

W. North, Personal Comm.

ICC experiment, from W. North (Ref. 12) 
Wind speeds are relatively low off southern California. Speeds of $6-11 \mathrm{~m} / \mathrm{sec}$ during the summer (Fig. 57) occur between 10 and 20 percent of the time in the nearshore area and up to 40 percent of the time west of San Clemente Island. In winter, the frequencies of nearshore winds of $6-10 \mathrm{~m} / \mathrm{sec}$ increase to 20 percent while those of offshore winds remain nearly the same. Winds of $\geqslant 18 \mathrm{~m} / \mathrm{sec}$ are increasingly frequent in winter, occurring about 1 to 3 percent of the time off the Channel Islands and less than 0.5 percent in the nearshore areas (Fig. 54). Winds of $\leqslant 3 \mathrm{~m} / \mathrm{sec}$ occur about 30 percent of the time in winter and summer in the Channel Island areas and about 50 to 60 percent of the time in the nearshore environment $\left(33^{\circ}-34^{\circ} \mathrm{N}\right)$.

The mixed layer* depth, given in Figs. 58 and 59, are relatively shallow in the nearshore areas and increase in a westerly direction. During summer the mixed depth is very shallow (about 6 meters) in the inshore areas; in winter this depth increases to 18 meters inshore, to about 24 meters off San Clemente Island, and to about 60 meters to the southwest $\left(30^{\circ} \mathrm{N}, 120^{\circ} \mathrm{W}\right)$.

Figures 60 through 71 give monthly prevailing current direction and mean current speed. Currents south of $32^{\circ} 30^{\prime} \mathrm{N}$ are generally south at 20 to $25 \mathrm{~cm} / \mathrm{sec}$. North of this, the currents are more variable in speed and direction. The prevailing nearshore currents are also 20 to $25 \mathrm{~cm} / \mathrm{sec}$. Currents in the Channel Island areas are more variable in direction including some westerly and northerly currents varying between 20 and $36 \mathrm{~cm} / \mathrm{sec}$ on average. During fall and early winter the prevailing currents change to predominately a north to northwest direction (Davidson Current) with speed averaging 20 to $25 \mathrm{~cm} / \mathrm{sec}$. A high northwesterly current approximating $50 \mathrm{~cm} / \mathrm{sec}$ off Santa Catalina is observed in December (Fig. 71). In January, near coastal currents are variable and in the spring the prevailing direction is south to southeast with speeds averaging from 20 to $30 \mathrm{~cm} / \mathrm{sec}$. Other current studies of the southern California area include CALCOFI, Ref. 47; Scripps Institute of Oceanography, Ref. 48; and the Oceanographic Survey of the Santa Barbara Channel Oil Spill, Ref. 49.

Specific Phase 1 site selections in the southern California area were made using the following criteria.

1. Locate within the 500-fathom (915-meter) contour to make mooring costs as economical as possible and still test the deep water OFEF concept.

2. Remain outside shipping and submarine transit lanes and common pleasureboating areas.

3. Be within 32 kilometers (2-hour transit) of scientific and logistic support due to the frequent observation and measurement requirements of the Phase 1 farms.

\footnotetext{
*The layer in which wind-mixing occurs and below which the thermocline begins. The mixed laver is usually at a very low nutrient concentration due to phytoplanktonic utilization in this zone.
} 


\section{PRIORITIZED PHASE 1 OFEF SITE SELECTION}

The selected sites as shown in Fig. 49 were prioritized as stated below.

1. Site 1 is located in the inshore area south of Corona del $\operatorname{Mar}\left(33^{\circ} 30^{\prime} \mathrm{N}, 117^{\circ}\right.$ $\left.55^{\prime} \mathrm{W}\right)$. It was chosen as the first priority site because it is within 8 to 16 kilometers of the $\mathrm{Cal}$ Tech marine laboratory, thus allowing easy access to the early prototype experiments. The depth range is approximately 100-200 fathoms (180-360 meters) and the site is between the pleasure and commercial routes from Los Angeles to San Diego and points south. In addition, the inshore area has somewhat milder conditions than the offshore sites. Wave heights and wind velocities are reduced below those of the offshore islands (see Figs. 50-59). Also, the thermocline (bottom of the mixed layer) is frequently shallower at site 1 than at 2 and 3, making high-nutrient concentrations nearer to the surface (Fig. 54).

2. Site 2 is located 8 to 24 kilometers northwest of San Clemente Island $\left(33^{\circ} 05^{\prime} \mathrm{N}\right.$, $118^{\circ} 45^{\prime} \mathrm{W}$ ). This site was chosen because it is close to the Naval Undersea Center facility on the northern portion of San Clemente lsland. An airstrip and small boats are available for farm support. This site would be an excellent location to test the deep water (away from coastal influence) concept of OFEF. In addition, this site would probably be less molested by private boats than the other two selections. A discussion of the near-surface nutrient regime is found in Ref. 10.

3. Site 3 is 5 to 15 kilometers northwest of Santa Catalina Island $\left(33^{\circ} 35^{\prime} \mathrm{N}, 118^{\circ}\right.$ $\left.35^{\prime} \mathrm{W}\right)$. It is within 8 to 19 kilometers of the University of Southern California marine laboratory, shown in Fig. 49, which could function as a support facility for the farm project. The currents in this region can be somewhat higher than in other parts of the southern California area in winter (Fig. 69). A few nutrient measurements are given in Table 8. Site 3 is located just south of the shipping lane from Los Angeles to Hawaii and west of the major pleasure-boat traffic to Avalon Bay in the southern portion of Santa Catalina. 


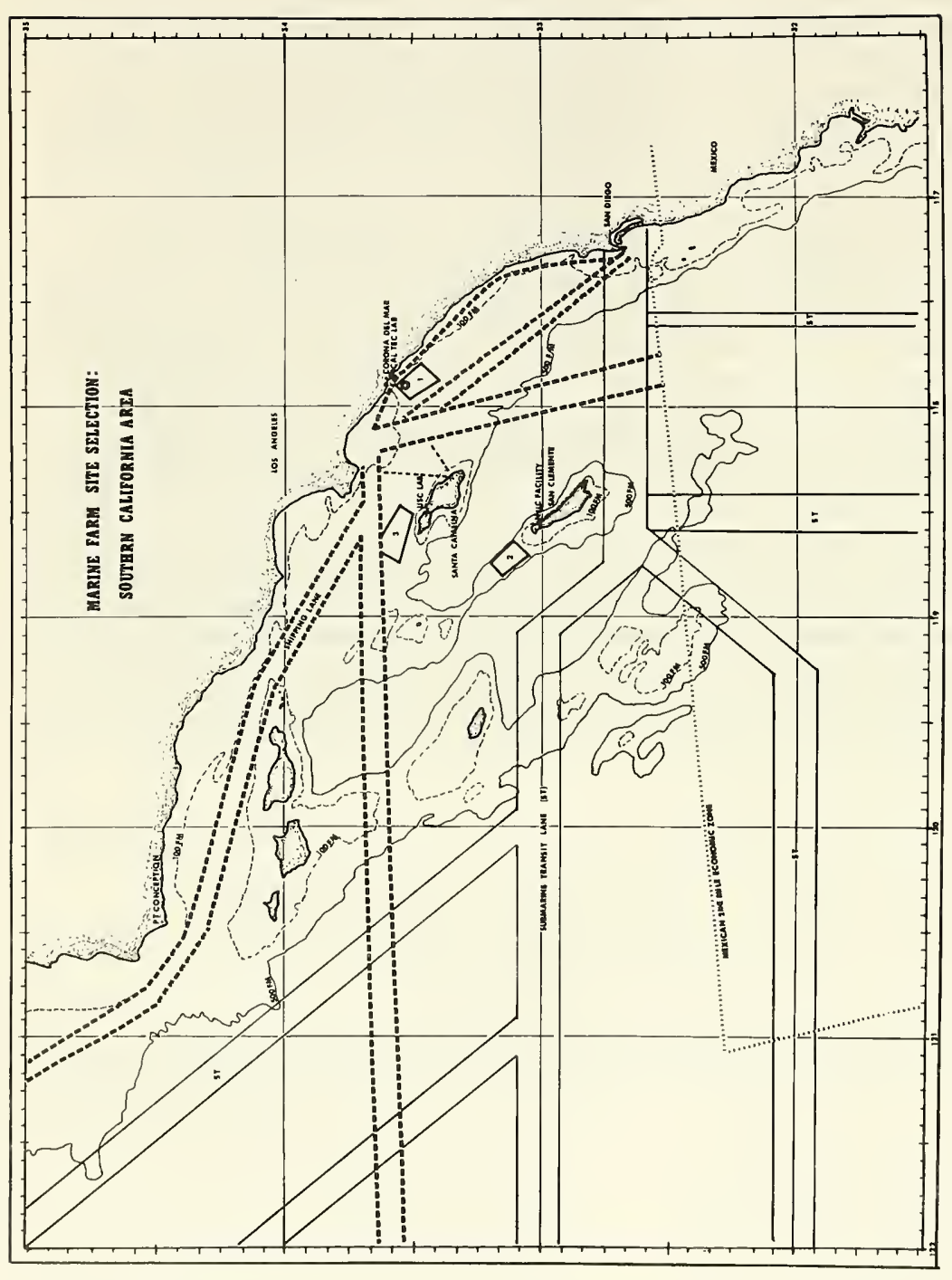

궁

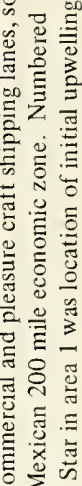

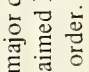

㐫苛

$\stackrel{\infty}{\Xi}$

प्ट $\frac{0}{2}$

ค 쿄

गี

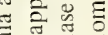

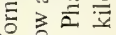

플 의

Uळ

E.

ङ 导

क $0-8$

Б료

䒕 $\frac{\pi}{2}$

巴)

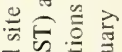

गू.

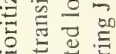

¿

- $\mathbb{0}$

过 己气

다 00

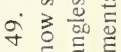

Q 䎡

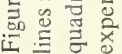




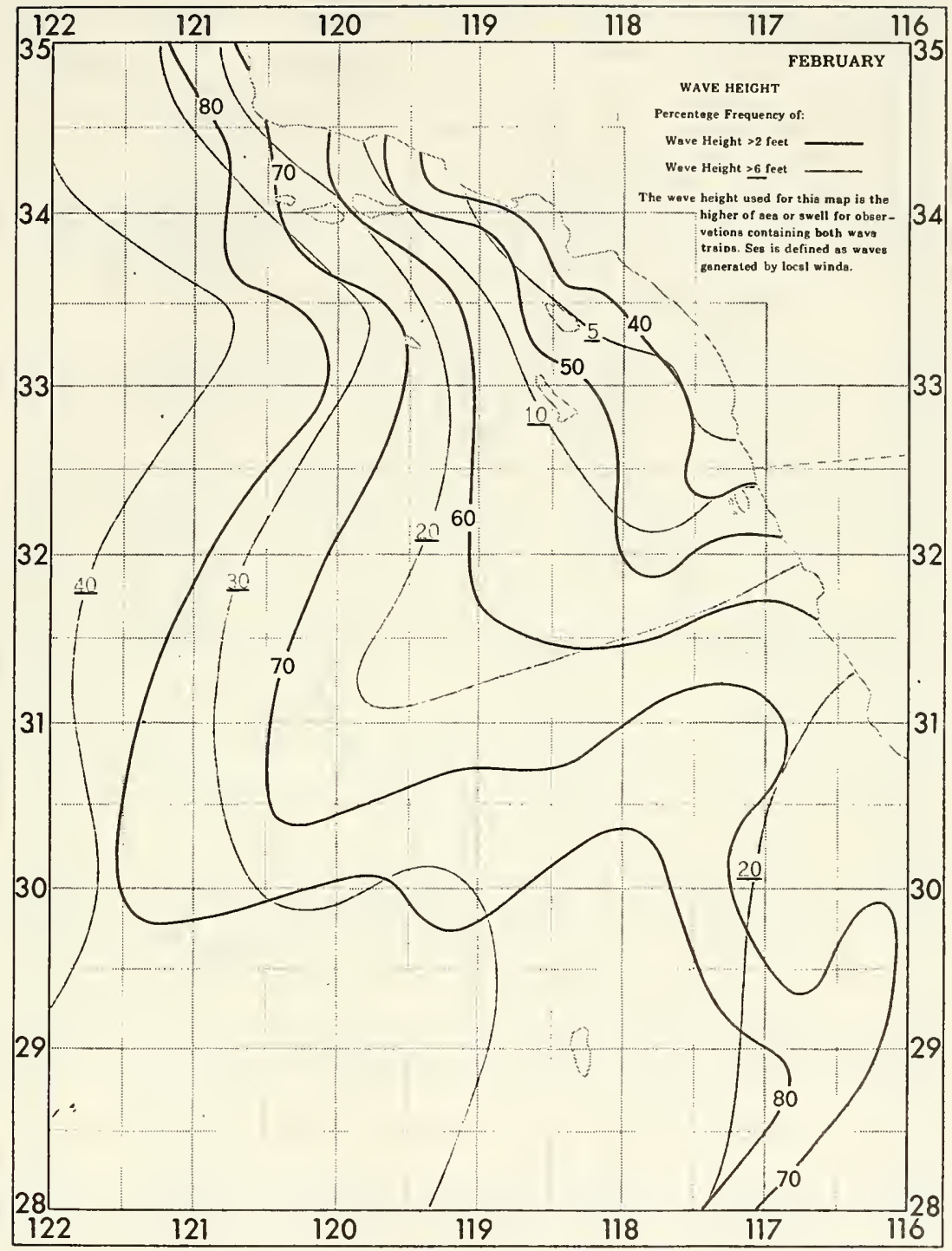

Figure 50. Percent frequency of wave height greater than 2 and 6 feet for the southem California area for February. ( 1 foot $\approx 0.3$ meter) (Reproduced from Naval Weather Service, Ref. 45) 


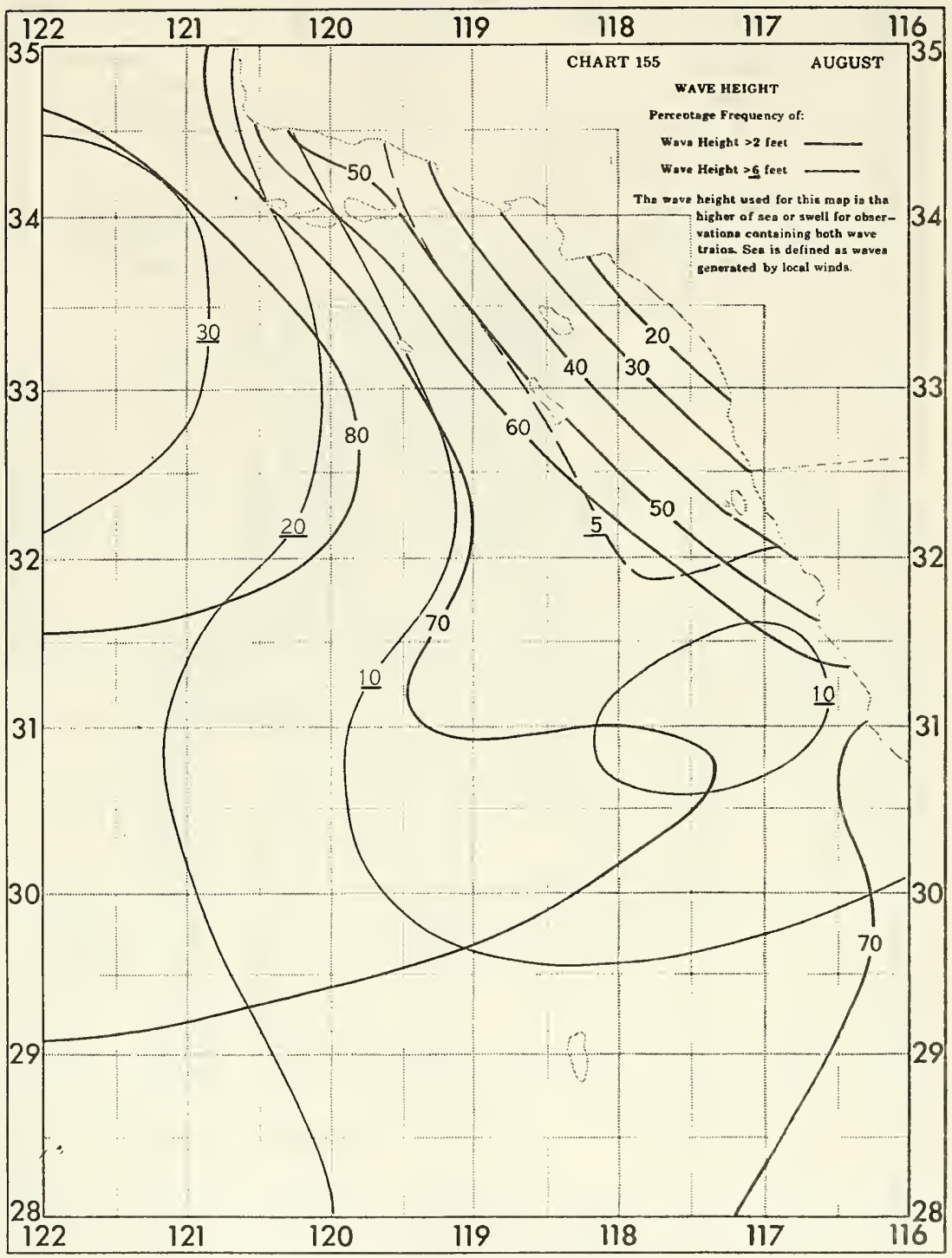

Figure 51. Percent frequency of wave height greater than 2 and 6 feet for the southem California area for August. ( 1 foot $\approx 0.3$ meter) (Reproduced from Naval Weather Service, Ref. 45) 


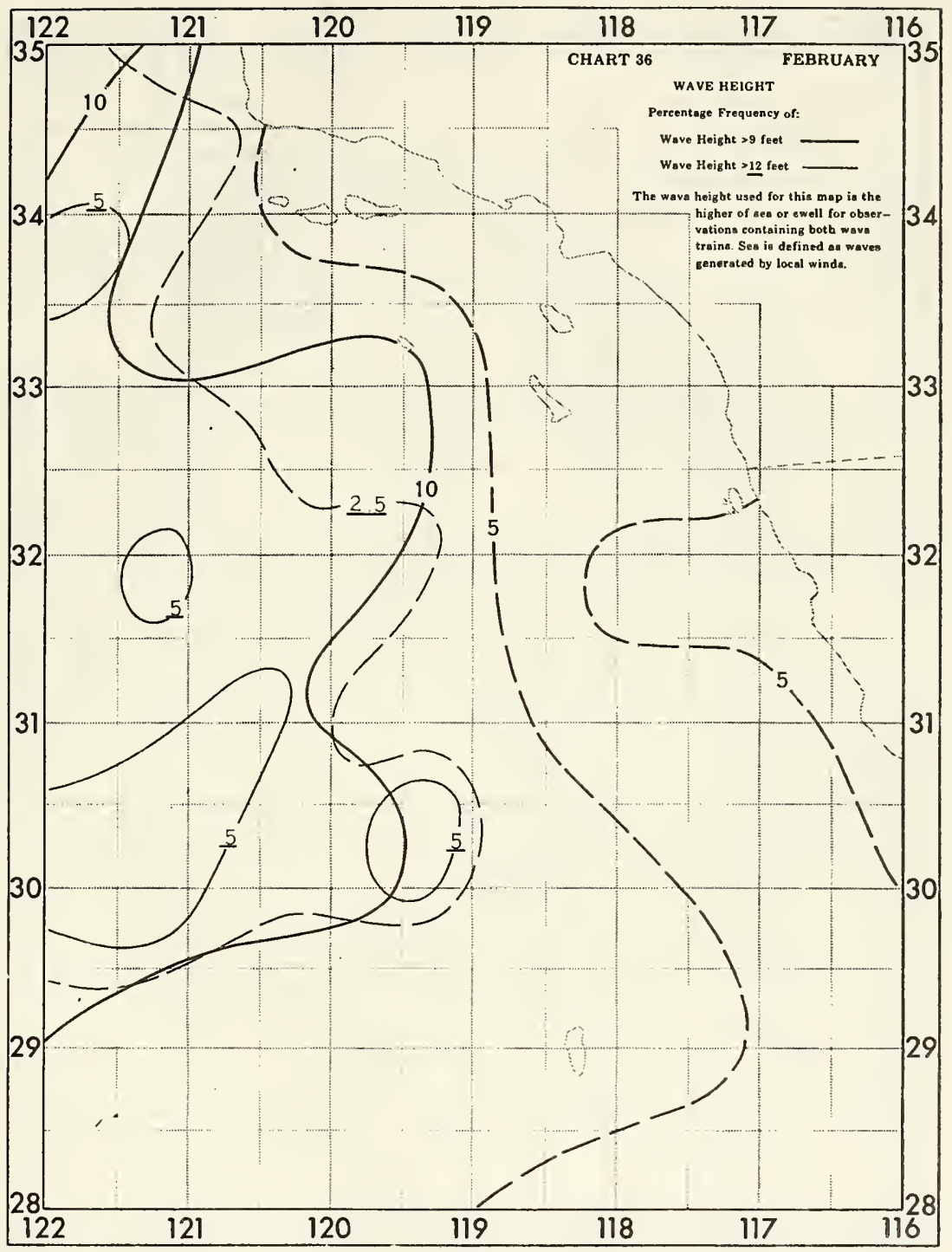

Figure 52. Percent frequency of wave height greater than 9 and 12 feet for the southern California area for February. ( 1 foot $\approx 0.3$ meter) (Reproduced from Naval Weather Service, Ref. 45) 


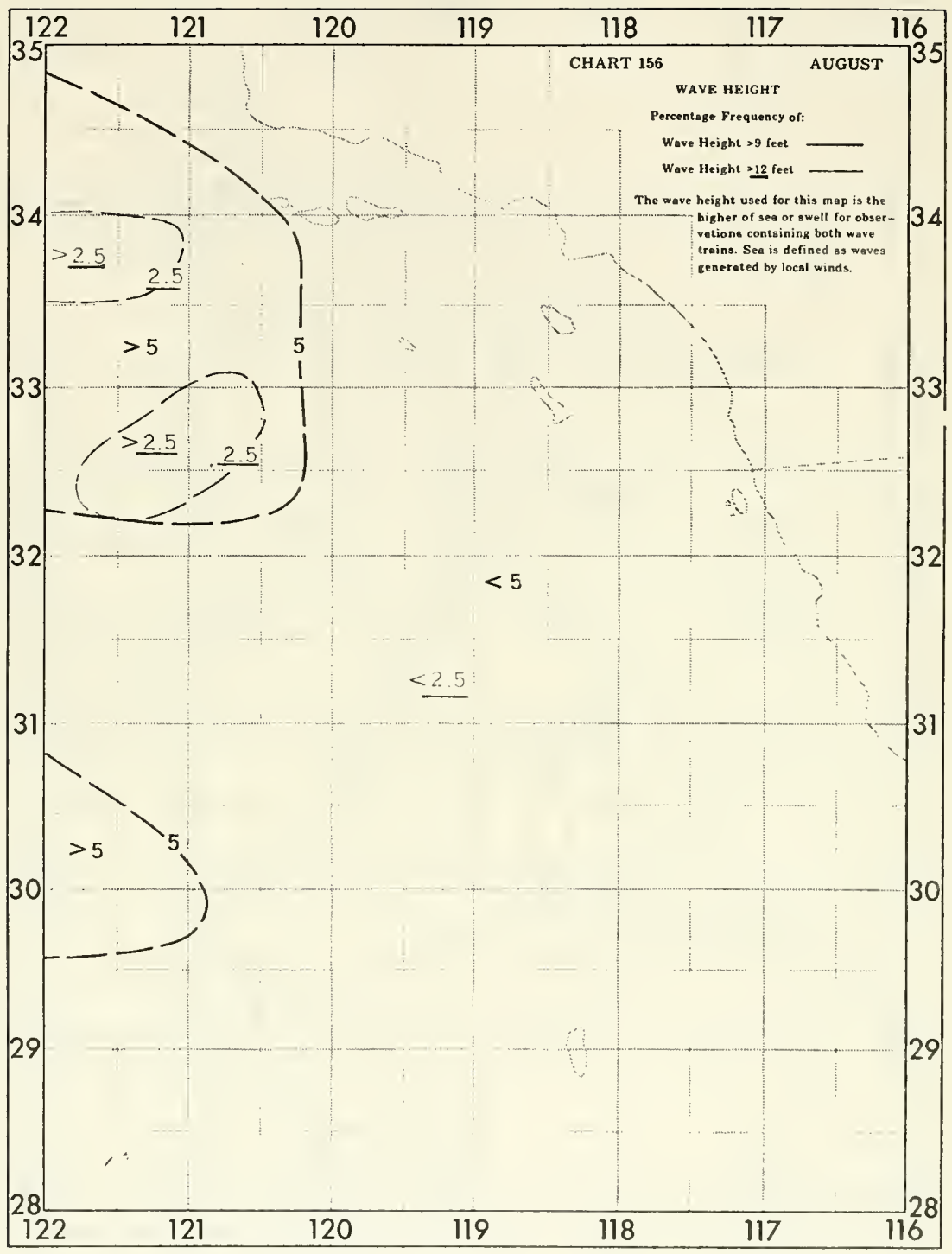

Figure 53. Percent frequency of wave height greater than 9 and 12 feet for the southern California area for August. ( 1 foot $\approx 0.3$ meter) (Reproduced from Naval Weather Service, Ref. 45) 


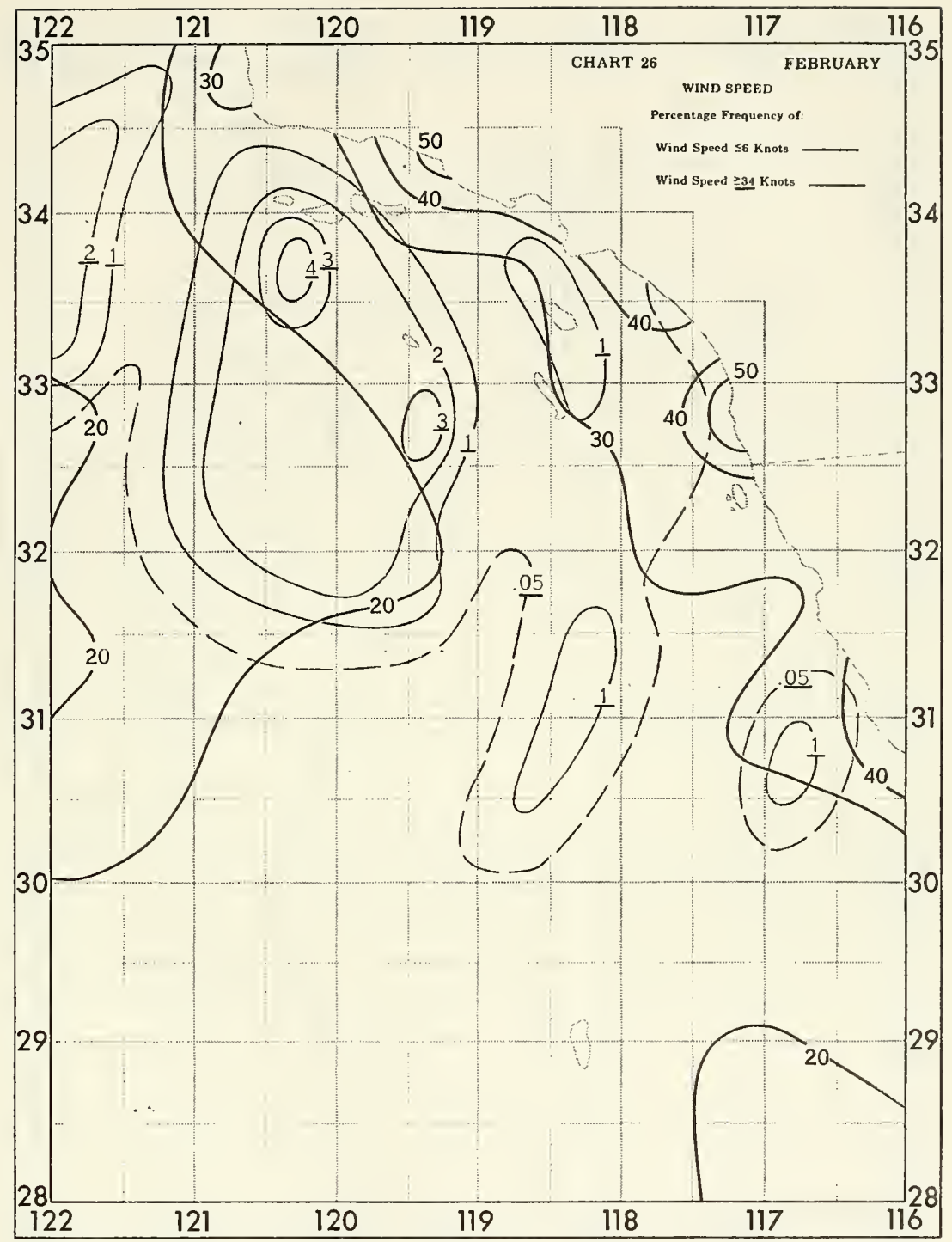

Figure 54. Percent frequency of wind speed less than or equal to 6 and greater than or equal to 34 knots for the southern California area for February. ( 1 knot $\approx 0.5 \mathrm{~m} / \mathrm{sec}$ ) (Reproduced from Naval Weather Service, Ref. 45) 


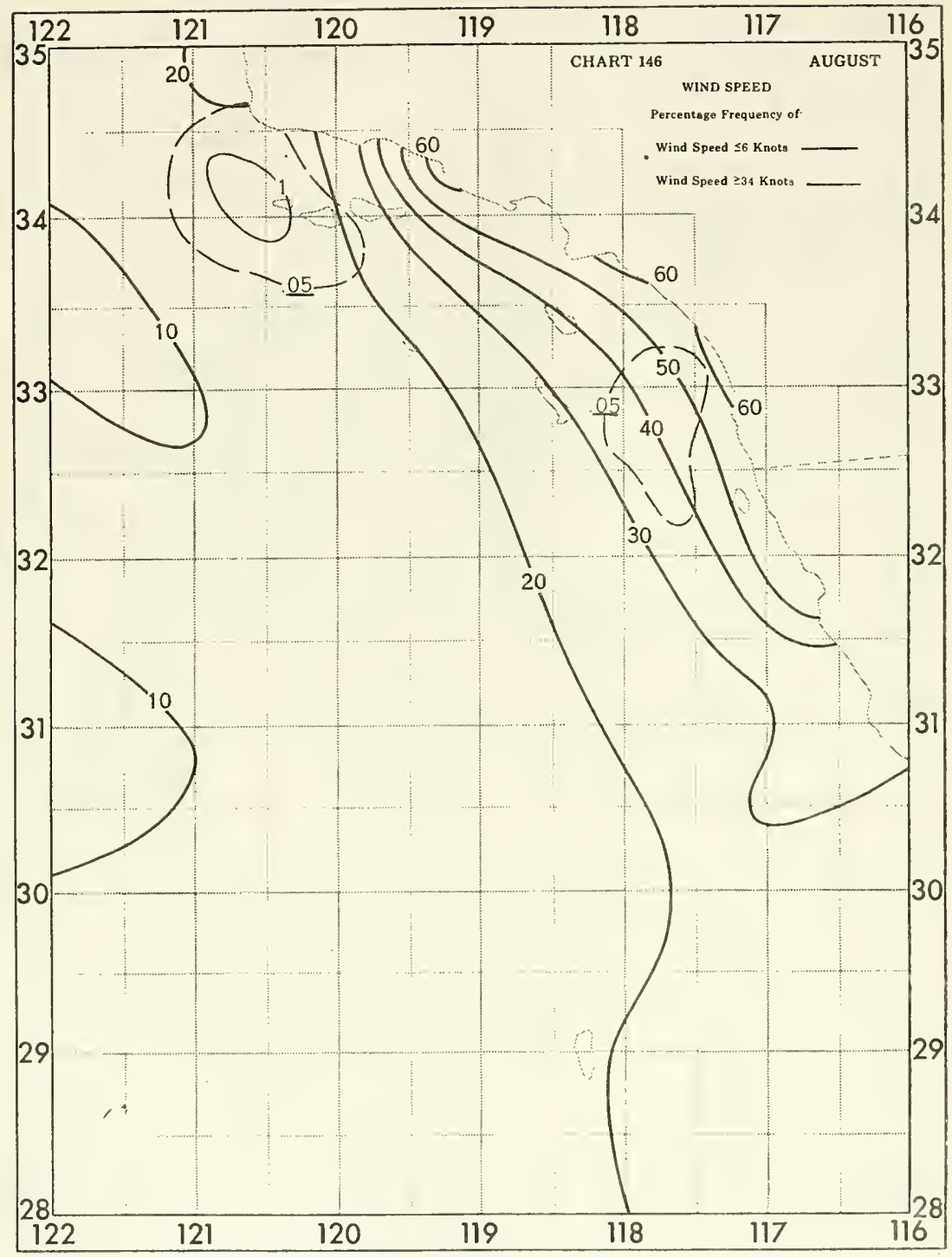

Figure 55. Percent frequency of wind speed less than or equal to 6 and greater than or equal to 34 knots for the southern California area for August. ( $1 \mathrm{knot} \approx 0.5 \mathrm{~m} / \mathrm{sec}$ ) (Reproduced from Naval Weather Service, Ref. 45) 


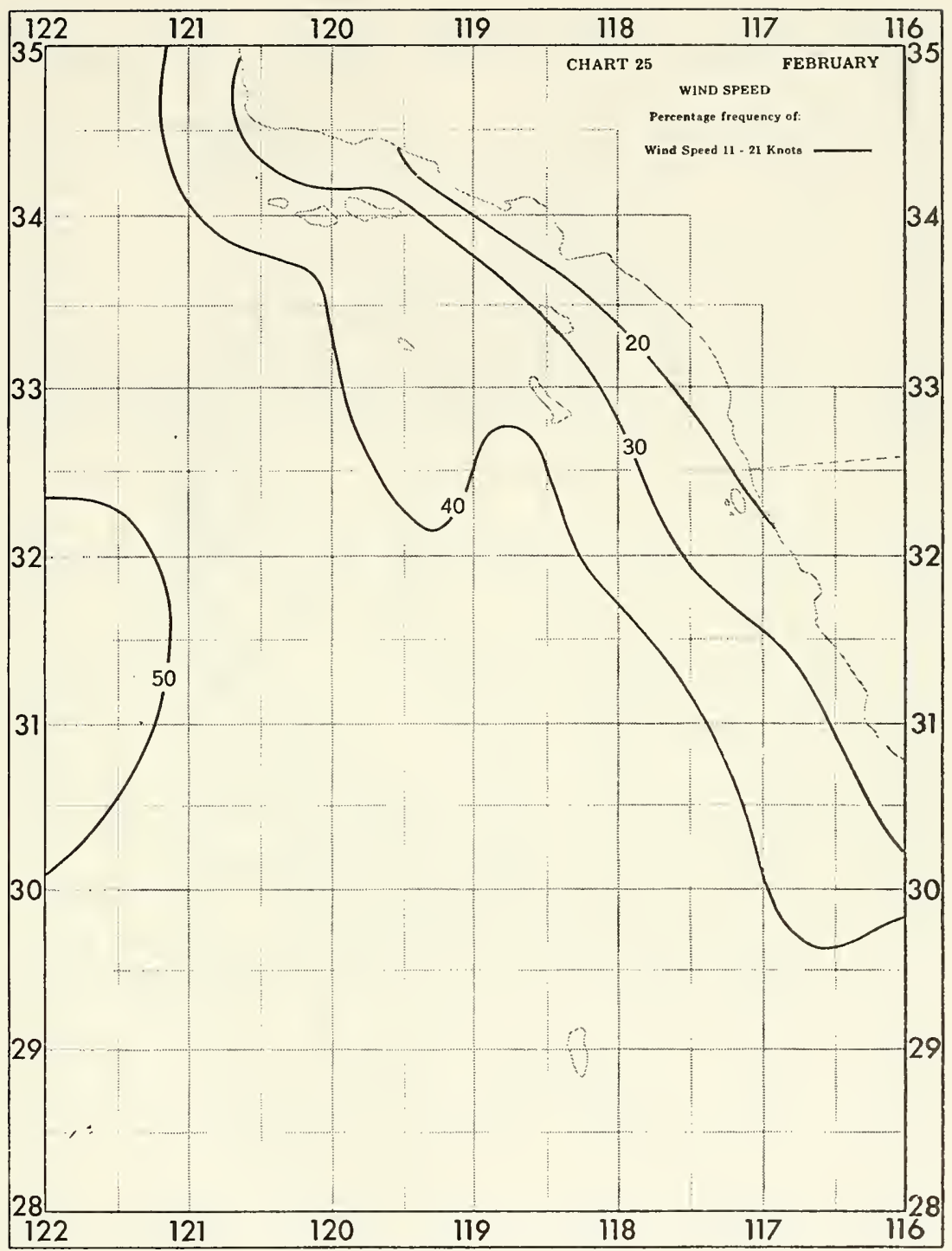

Figure 56. Percent frequency of wind speed 11-21 knots for the southern California area for February. ( $1 \mathrm{knot} \approx 0.5 \mathrm{~m} / \mathrm{sec}$ ) (Reproduced from Naval Weather Service, Ref. 45) 


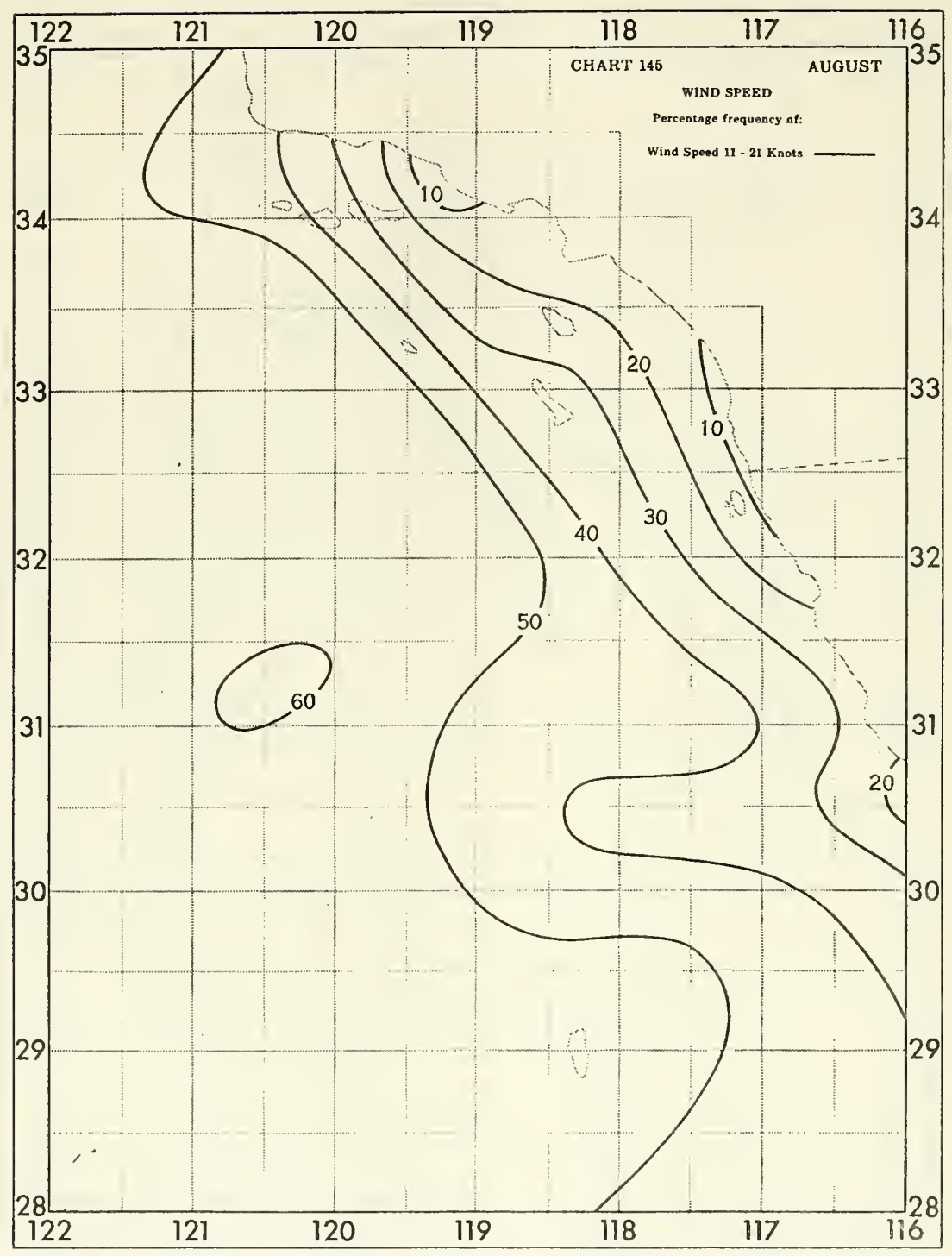

Figure 57. Percent trequency of wind speed 11-21 knots for the southern California area for August. ( $1 \mathrm{knot} \approx 0.5 \mathrm{~m} / \mathrm{sec}$ ) (Reproduced from Naval Weather Service, Ref. 45) 


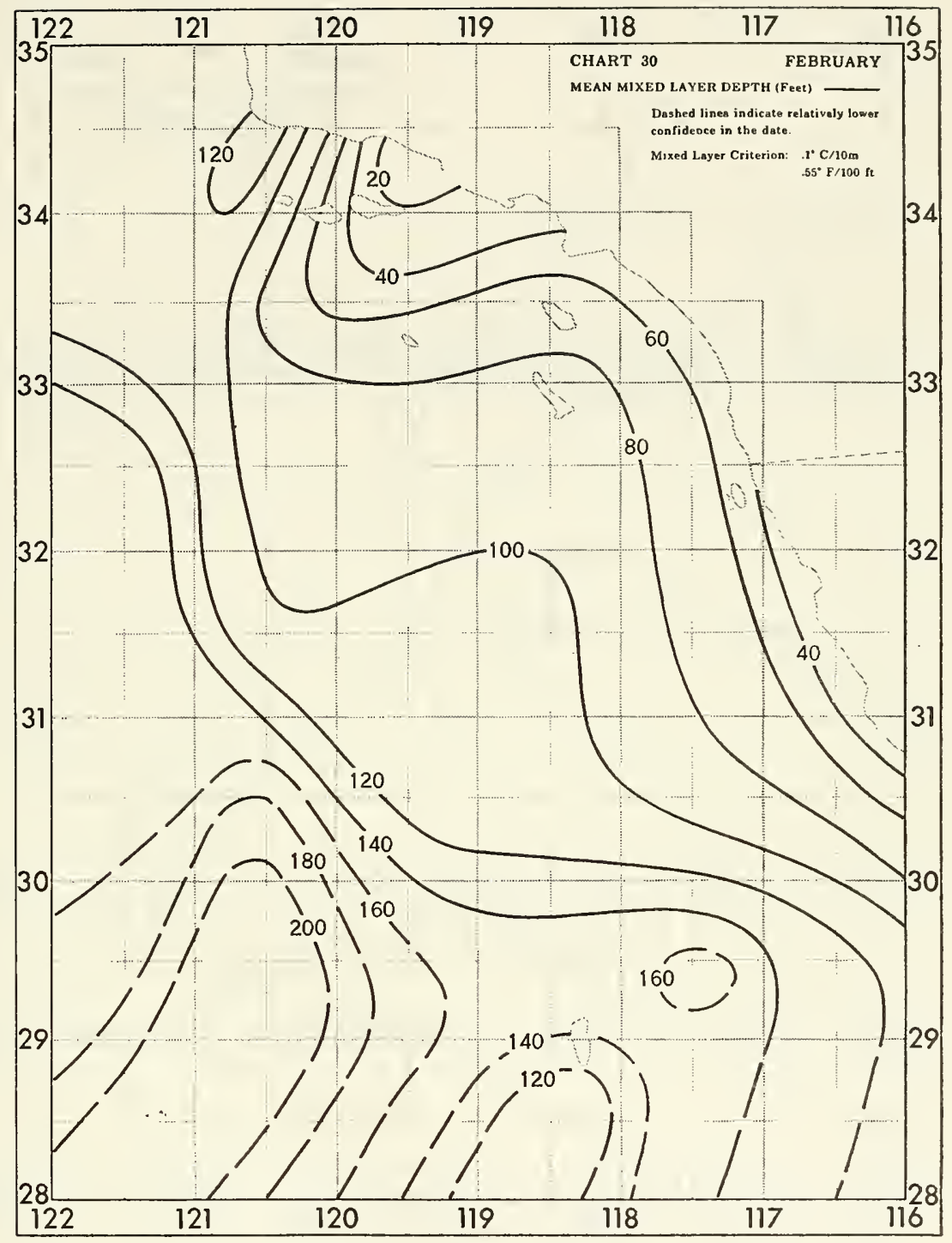

Figure 58. Depth of mean mixed layer off southern California for February. ( 1 foot $\approx 0.3$ meter) (Reproduced from Naval Weather Service, Ref. 45 ) 


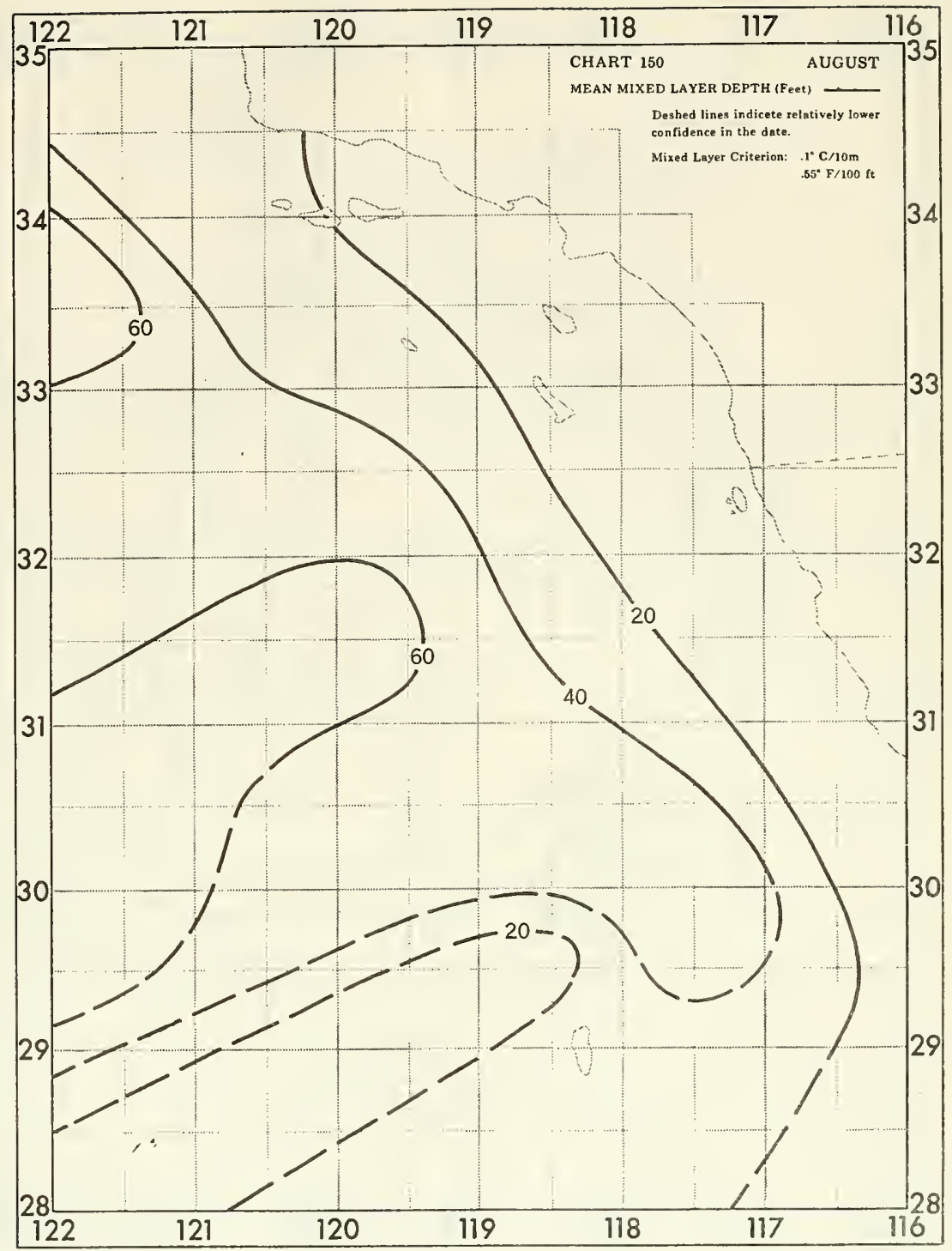

Figure 59. Depth of mean mixed layer off southern California for August. ( 1 foot $\approx 0.3$ meter) (Reproduced from Naval Weather Service, Ref. 45) 
Figures 60-71. Prevailing current direction and mean current speed for the southern California area. Secondary currents are indicated with dashed lines and variable currents with a V. Monthly data, January through December are given. ( $1 \mathrm{knot} \approx 0.5 \mathrm{~m} / \mathrm{sec}$ ) (Data reproduced from Naval Weather Service, Ref. 45) 


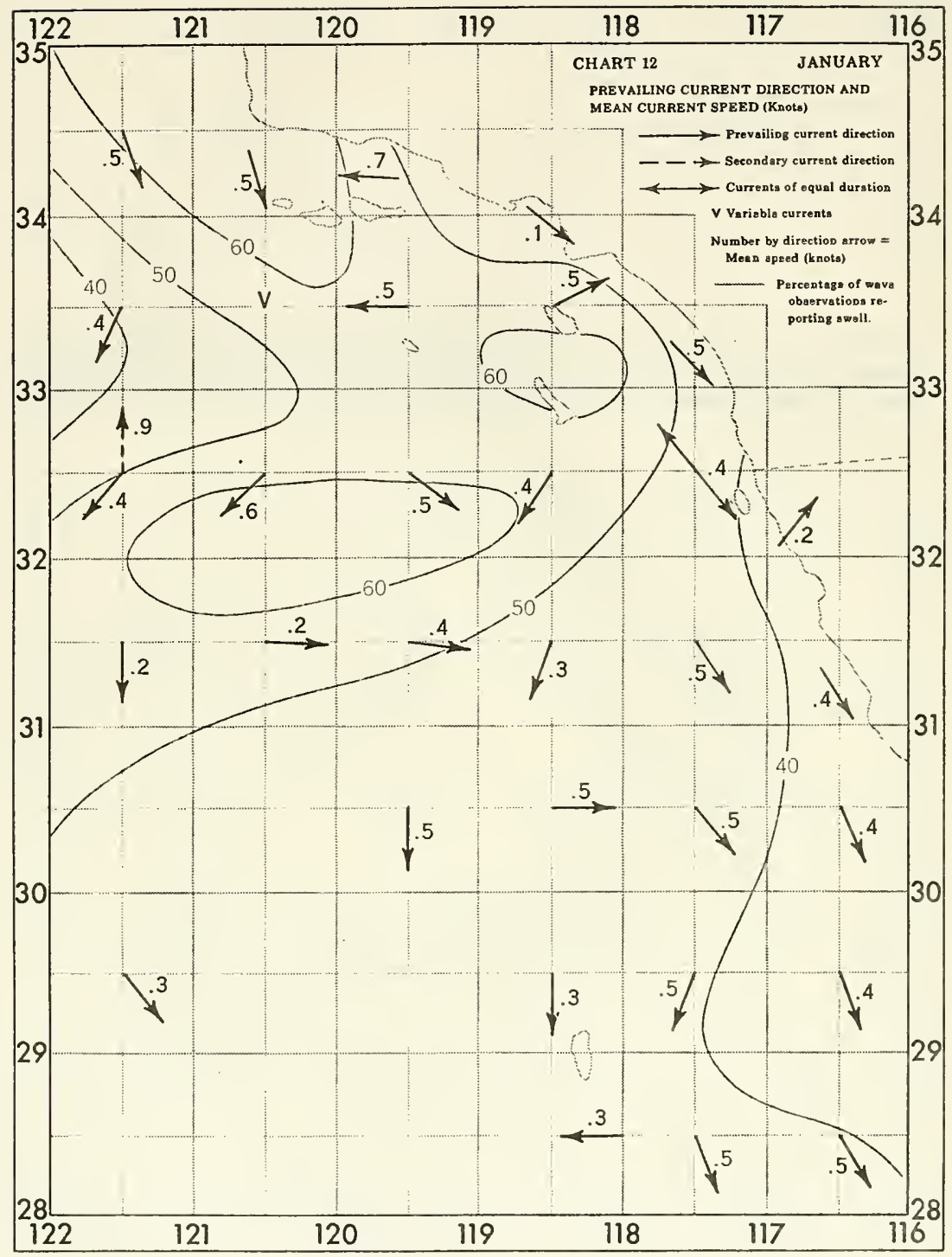

Figure 60. January 


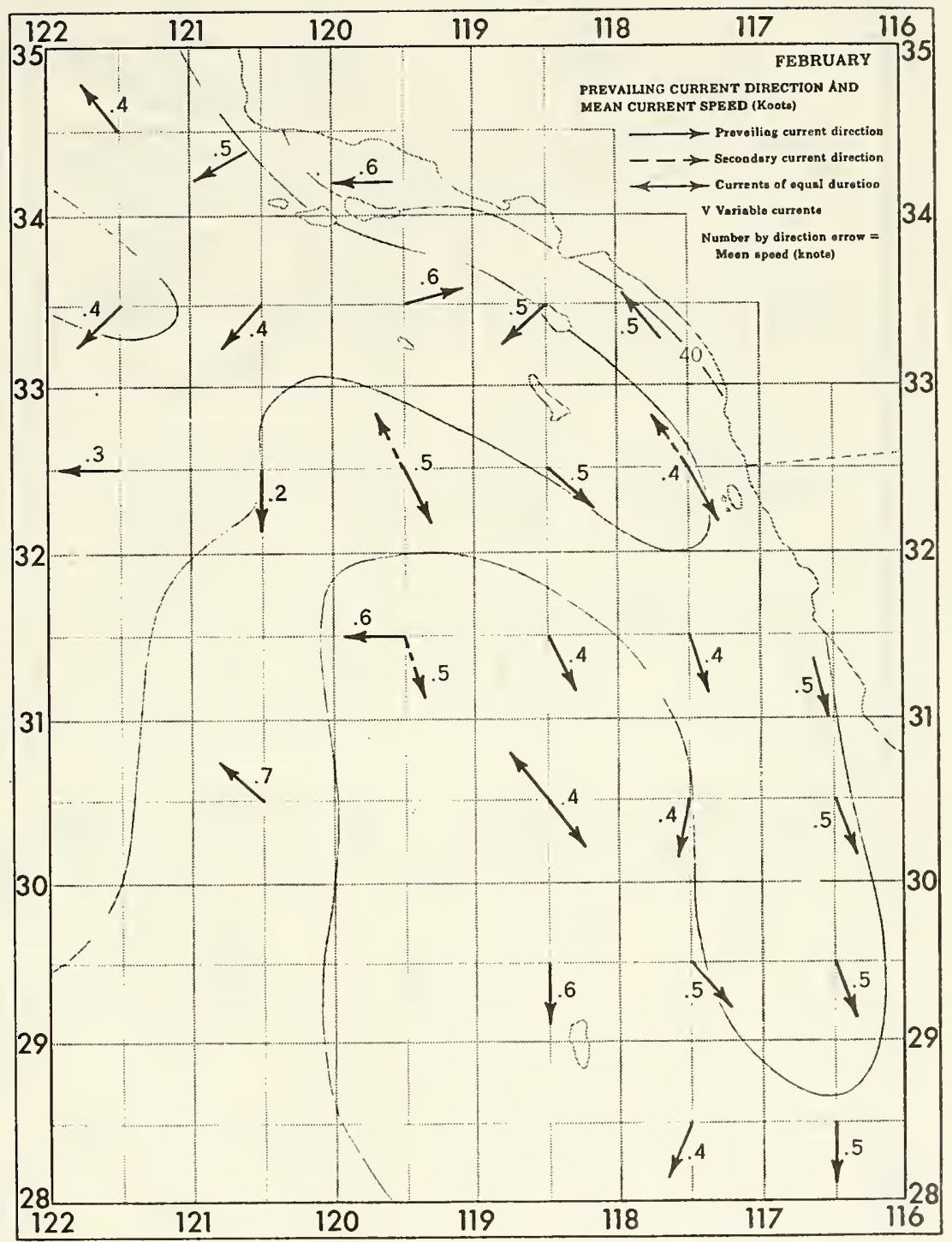

Figure 61. February 


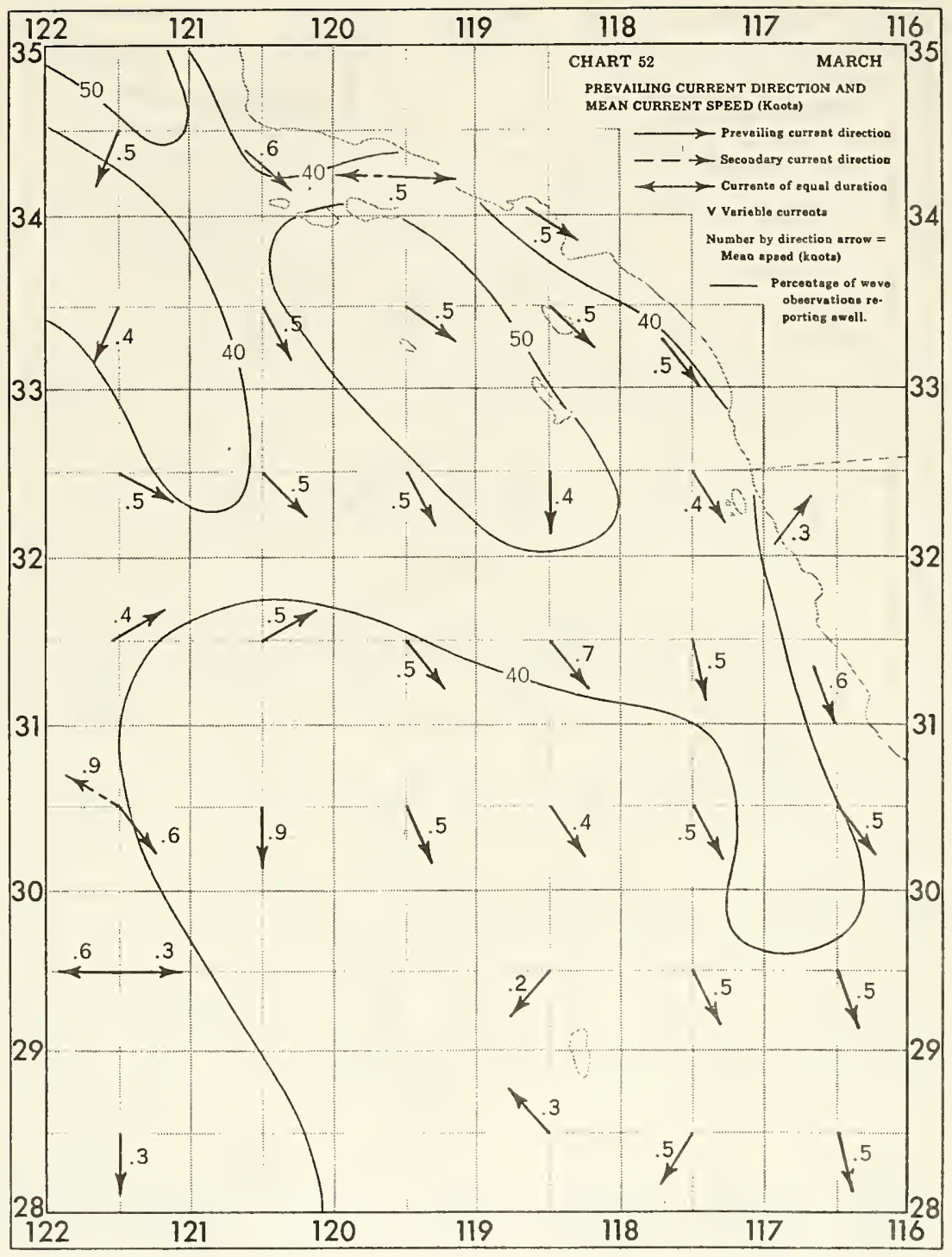

Figure 62. March 


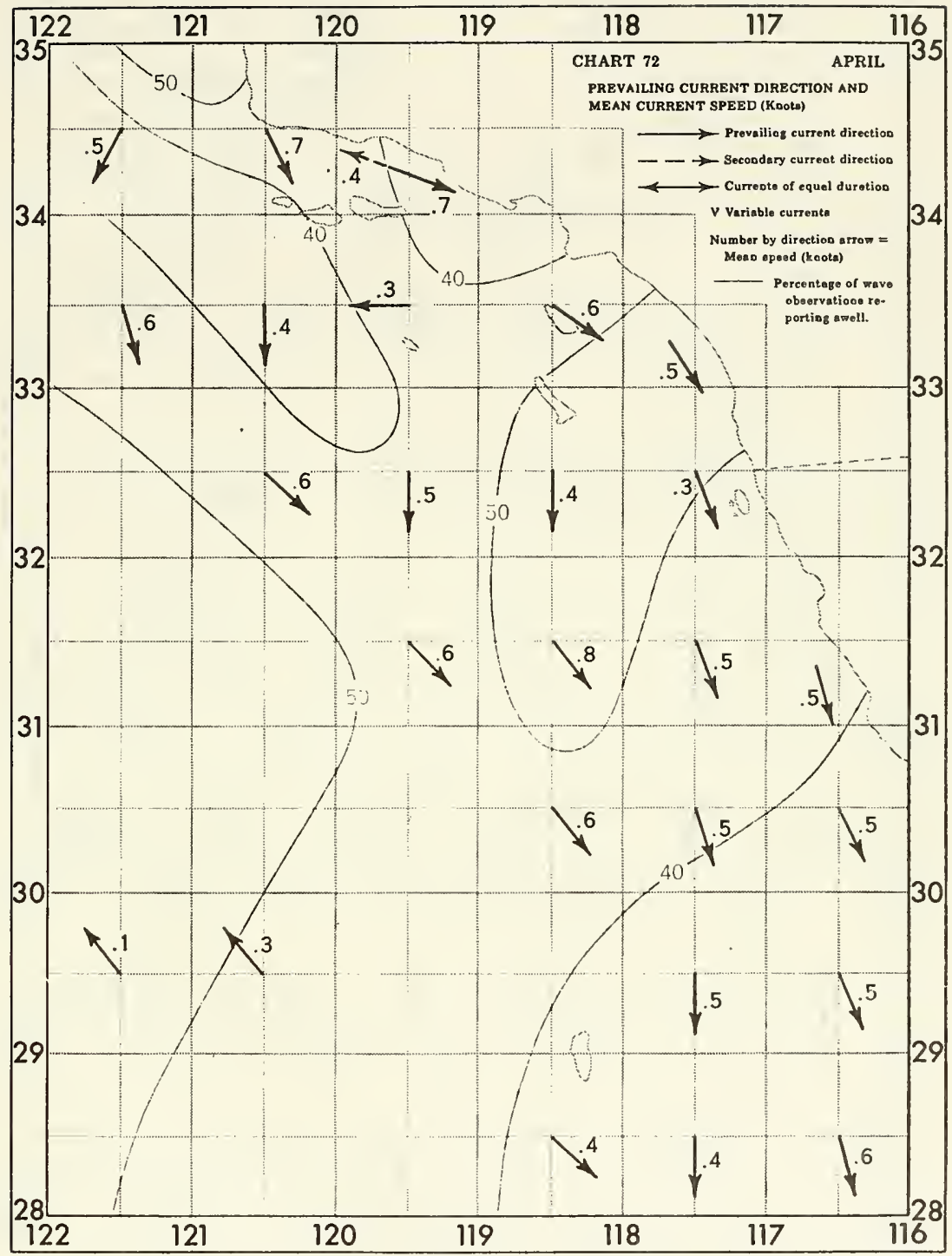

Figure 63. April 


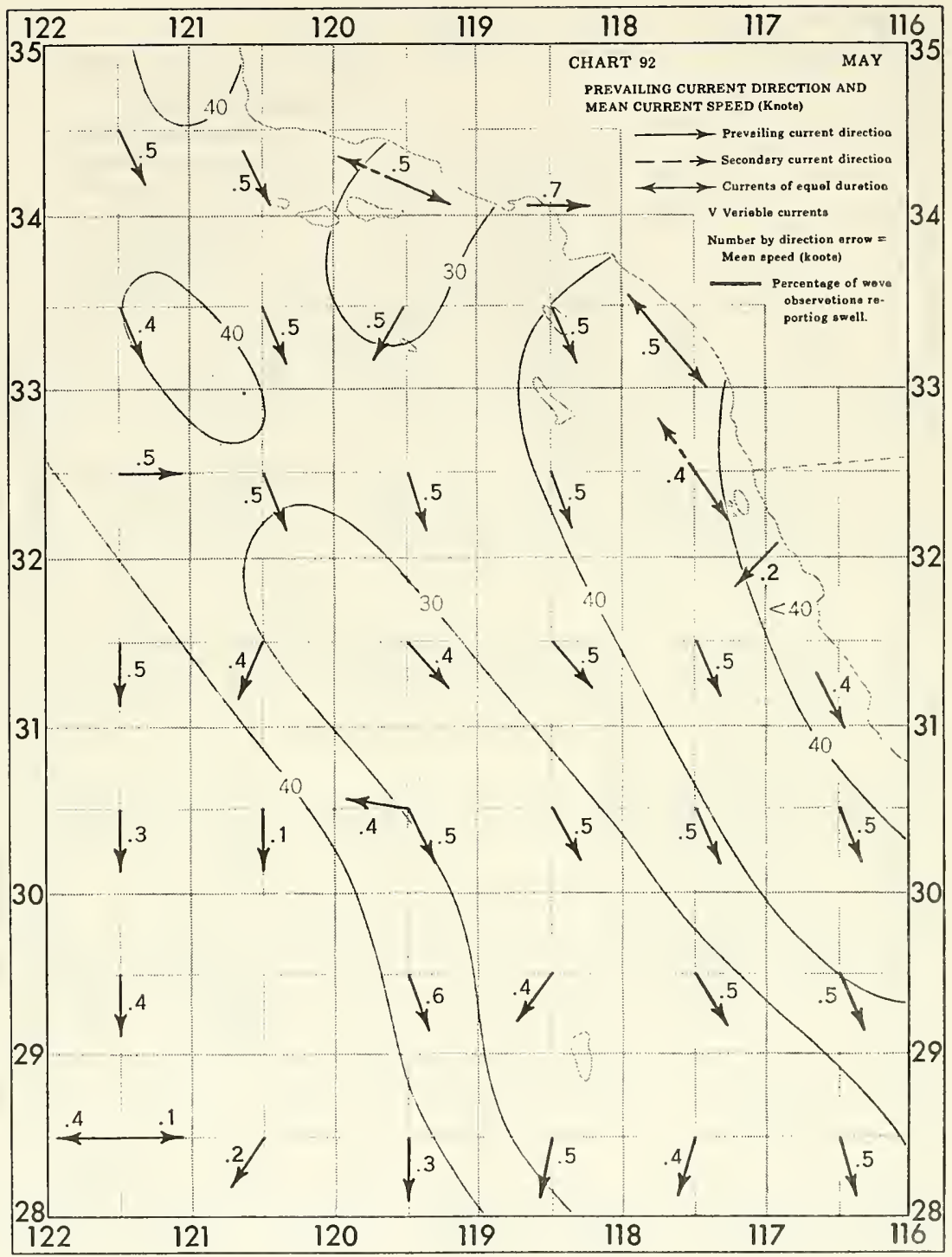

Figure 64. May 


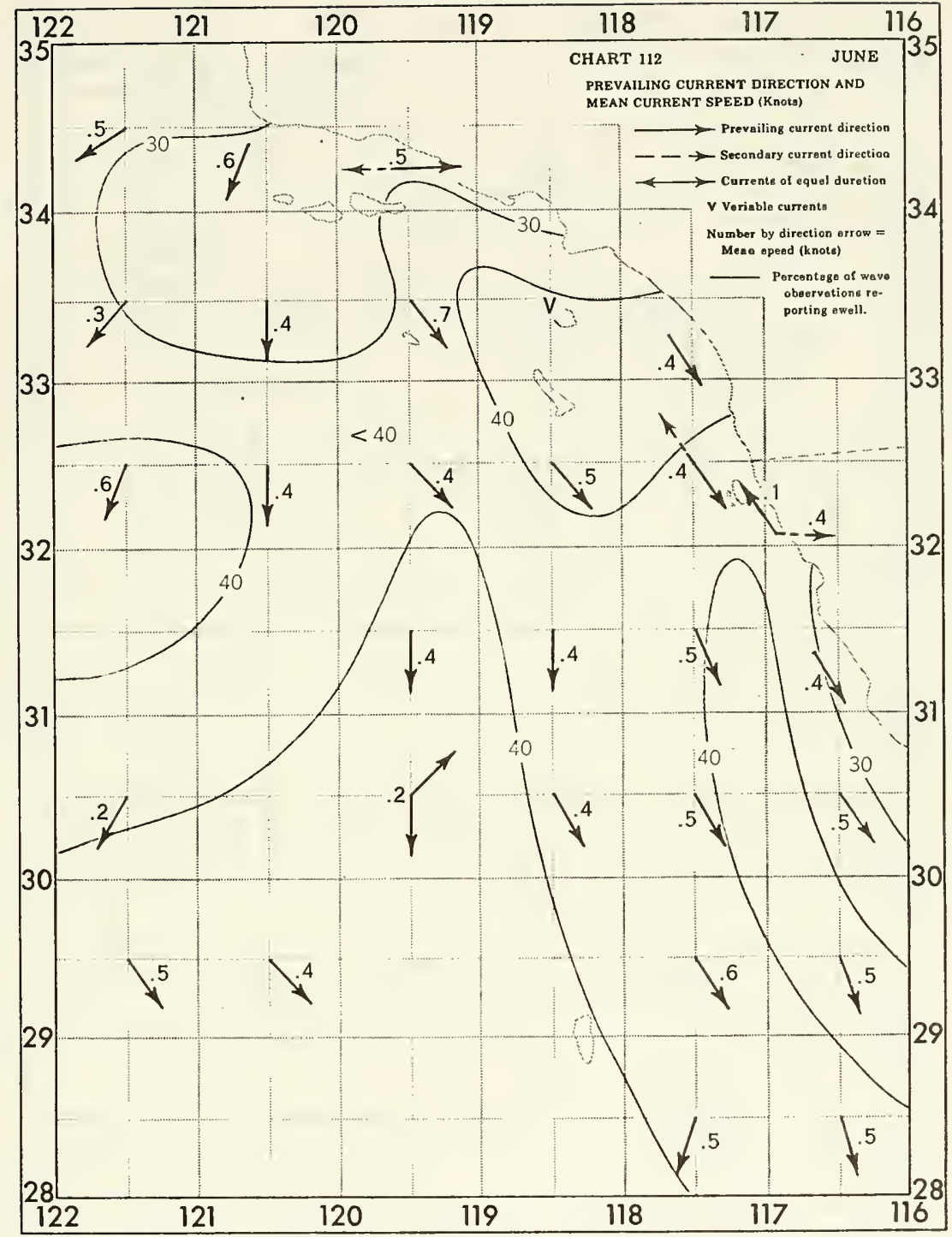

Figure 65. June 


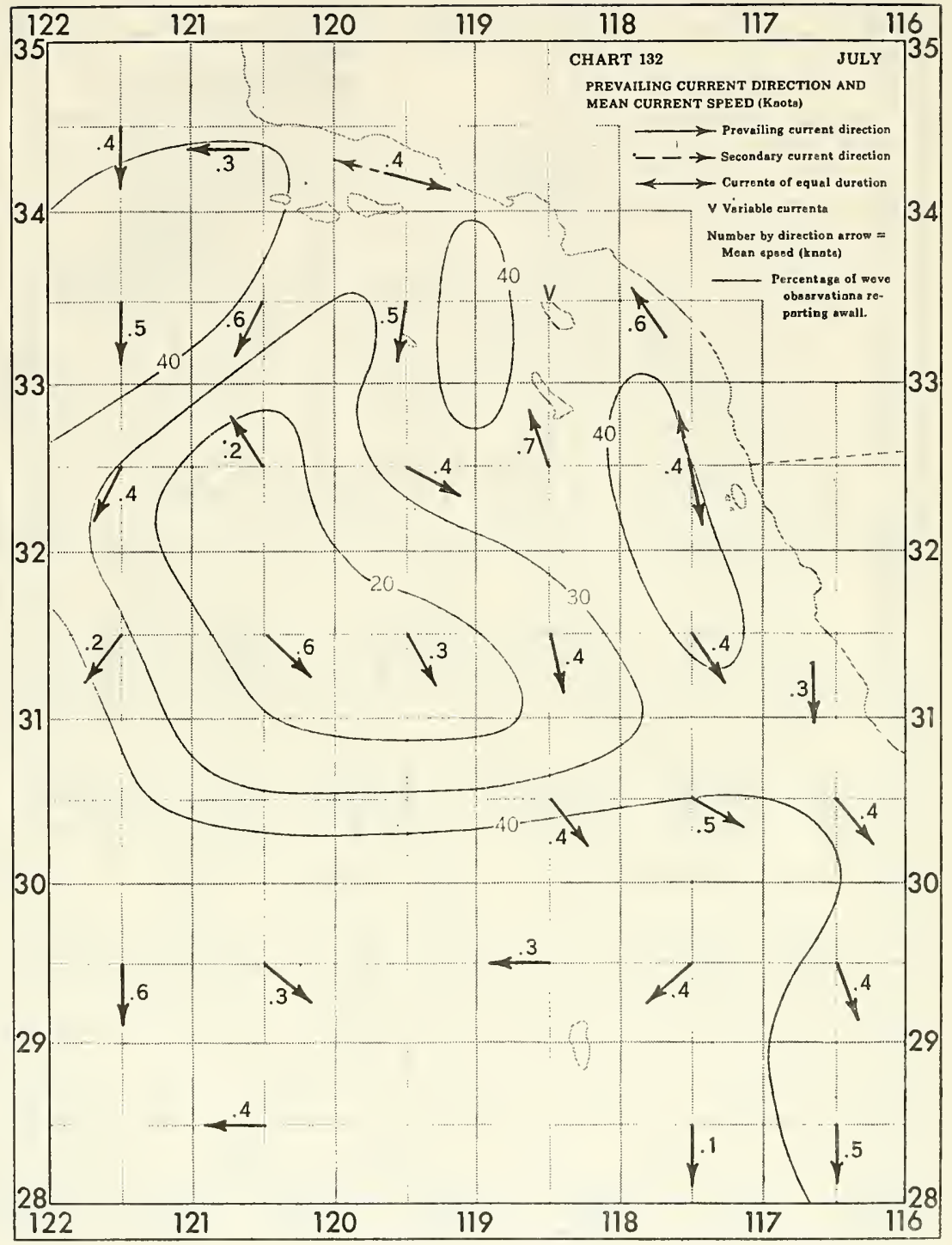

Figure 66. July 


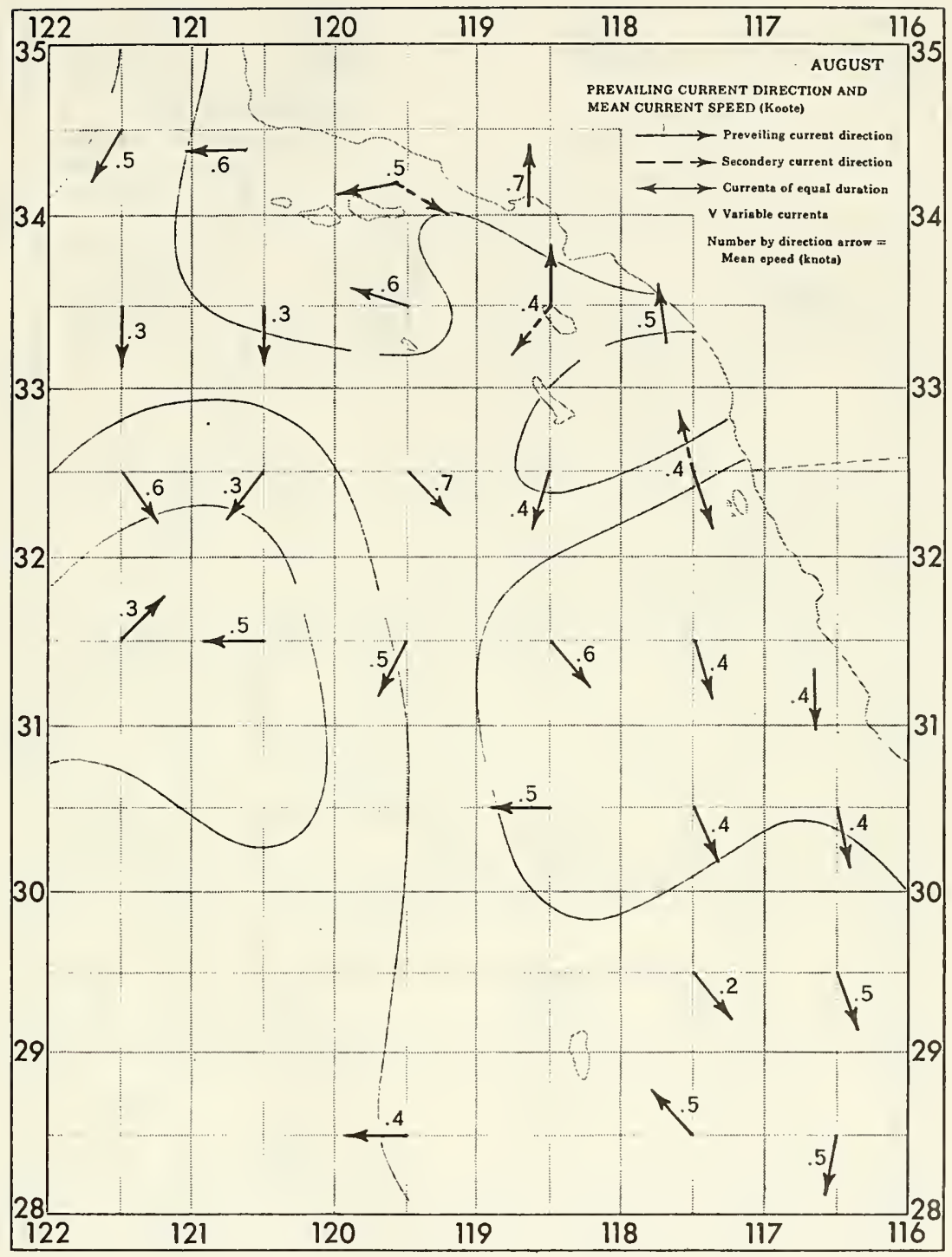

Figure 67. August 


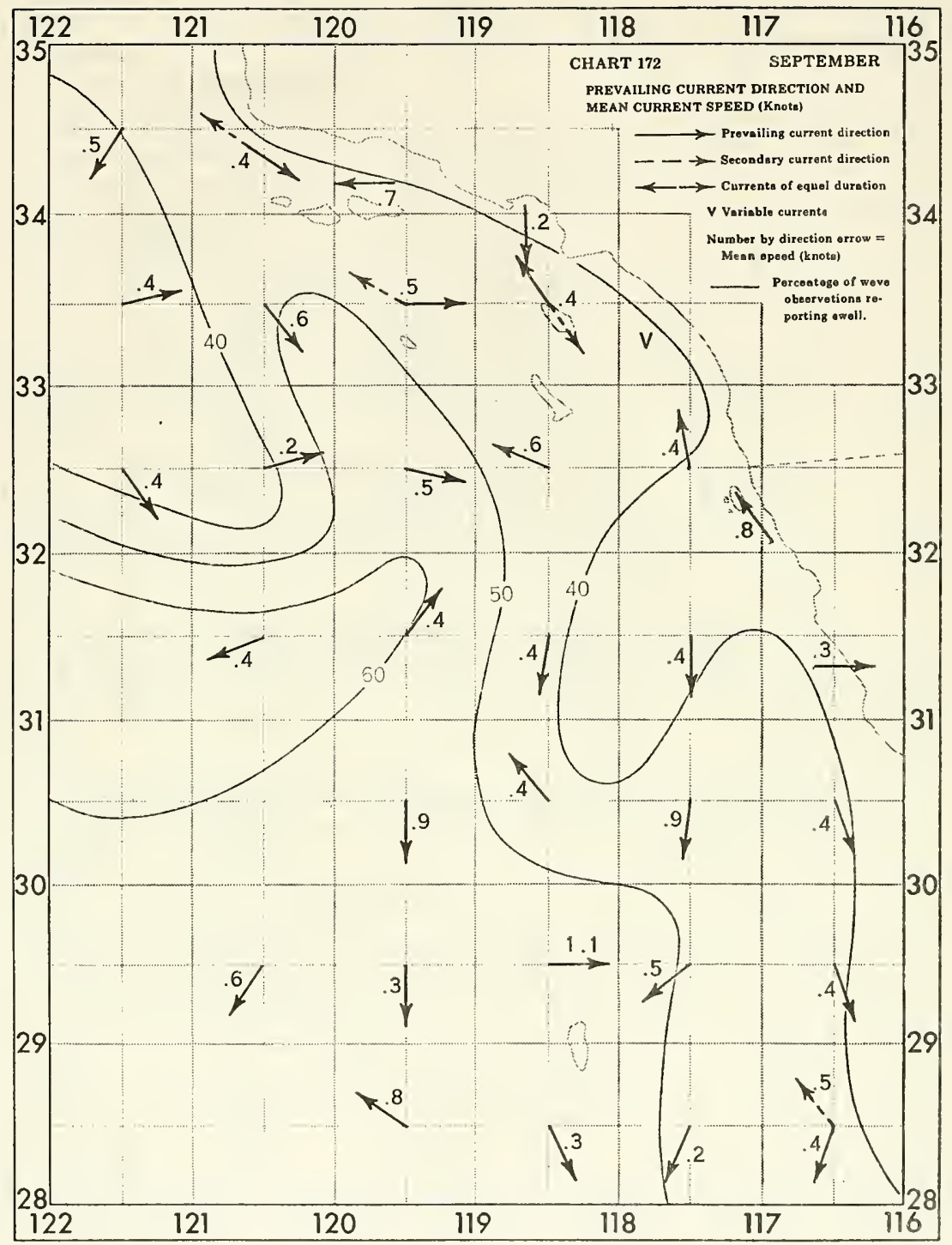

Figure 68. September 


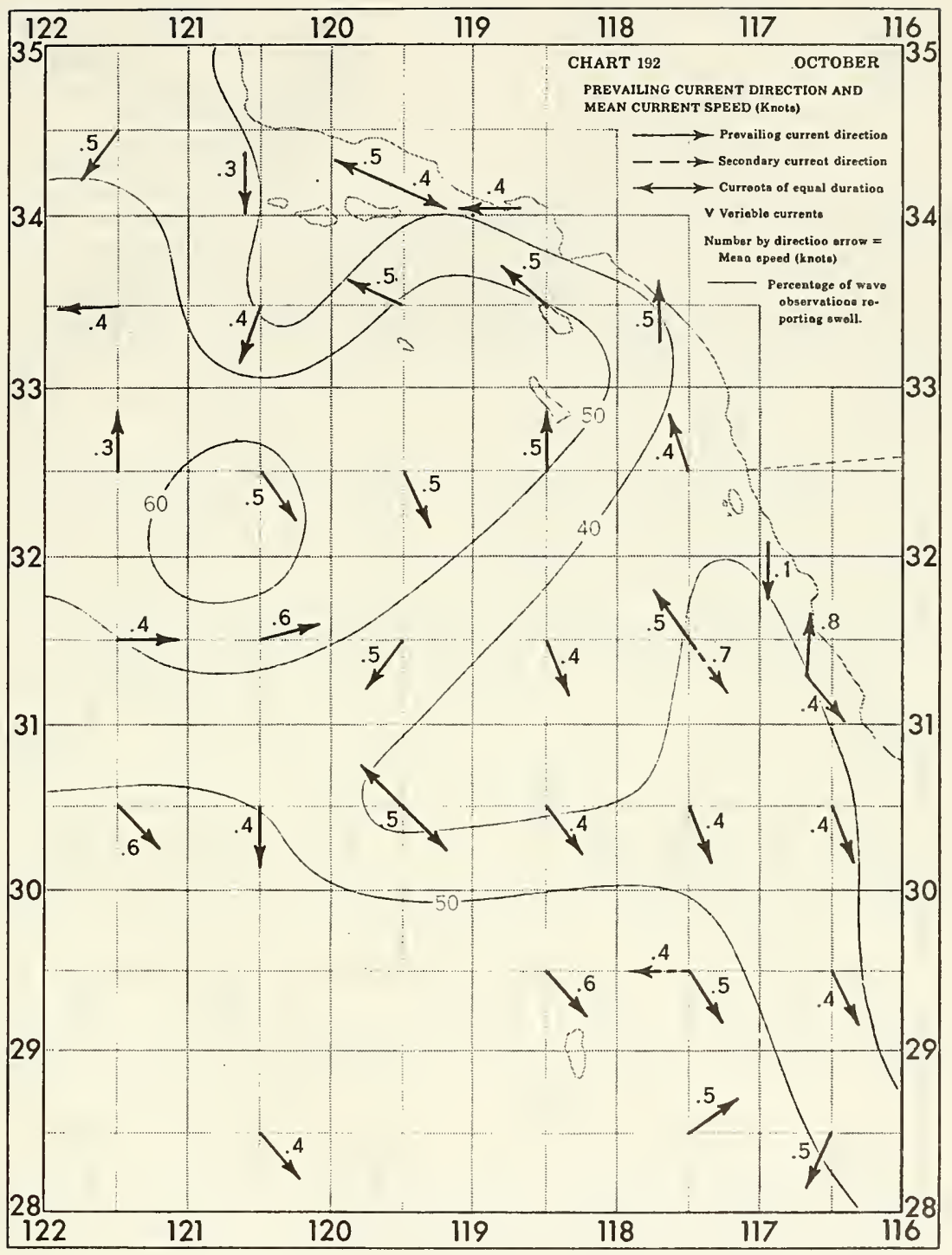

Figure 69. October 


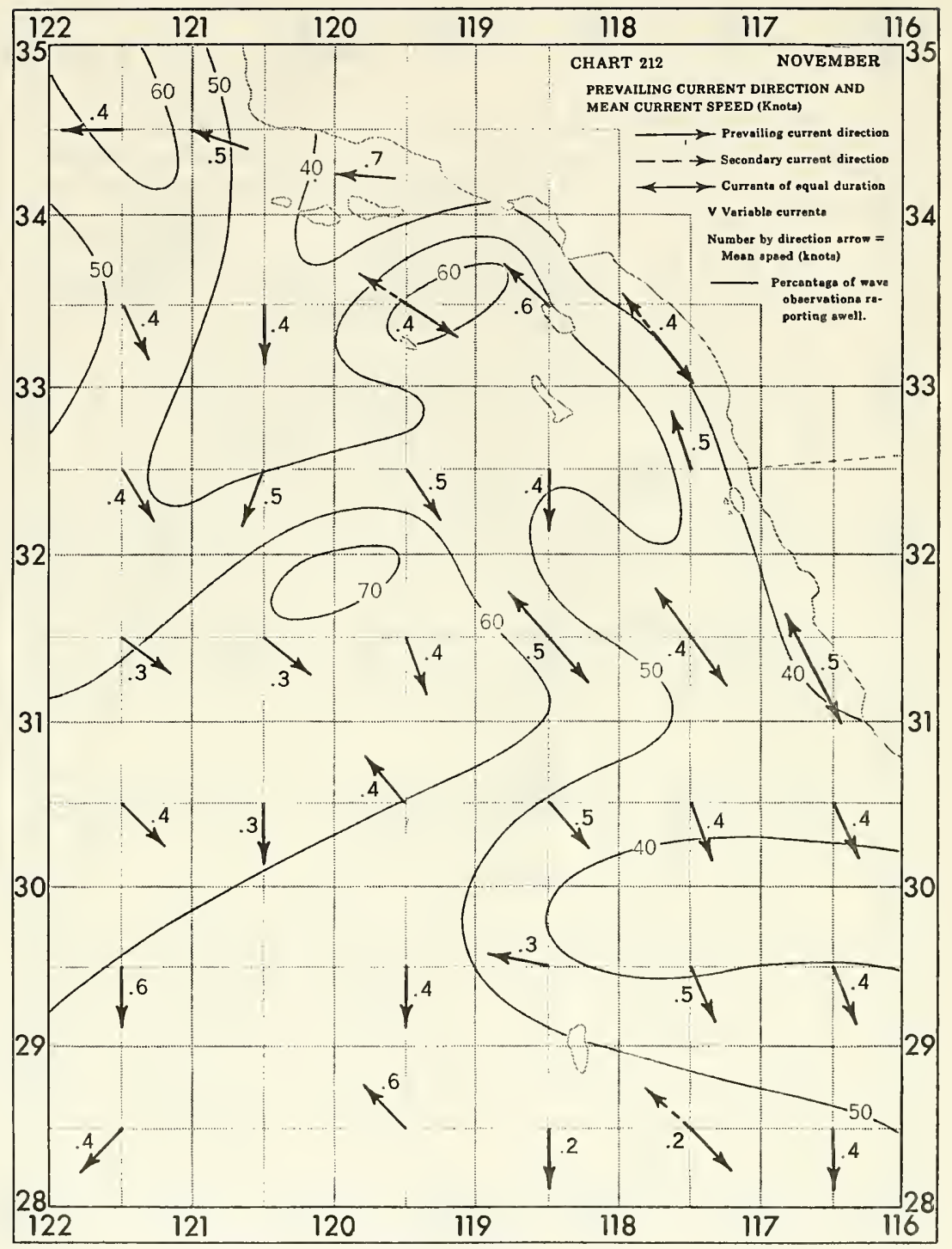

Figure 70 . November 


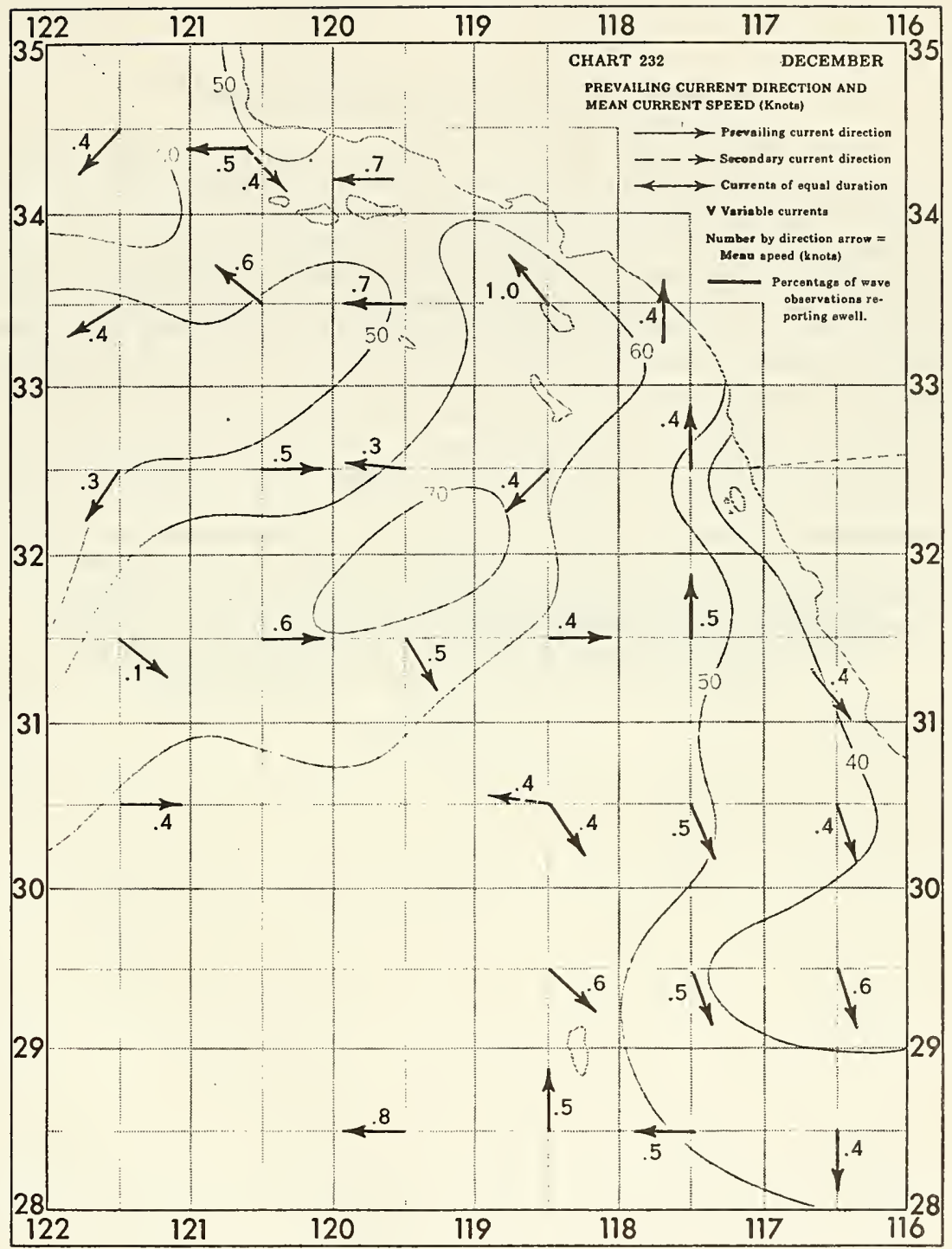

Figure 71. December 


\section{RECOMMENDATIONS FOR FUTURE OFEF SITING}

It is recommended that one or more of the Phase 2 and Phase 3 farms be located in the southern California offshore region from $32^{\circ} 30^{\prime} \mathrm{N}$ to $34^{\circ} \mathrm{N}$ and from $117^{\circ} 30^{\prime} \mathrm{W}$ to $120^{\circ} \mathrm{W}$. If dynamically-positioned farms have not been completely engineered by the time large-scale OFEF's are ready to be tested, a number of possible locations exist in water sliallow enough to allow for mooring. One possible offshore region is the zone from Cortes Bank at $32^{\circ} 30^{\prime} \mathrm{N}, 119^{\circ} \mathrm{W}$ northwest past San Nicolas Island to Santa Rosa Island at $34^{\circ} \mathrm{N}, 120^{\circ} \mathrm{W}$ (Fig. 49). This region is called the Santa Rosa-Cortes Ridge and is a relatively shallow region, 100 to 500 fathoms ( 180 to 900 meters), 24 to 40 kilometers across and covering approximately 5000 square kilometers (1,280,000 acres). Other possible regions include the area south of site 1 between commercial and pleasure traffic zones covering about 1300 square kilometers of nearshore sites and the area northwest of San Clemente and Catalina Islands, $33^{\circ} 15^{\prime} \mathrm{N}$ to $34^{\circ} \mathrm{N}$ and $118^{\circ} 20^{\prime} \mathrm{W}$ to $119^{\circ} 20^{\prime} \mathrm{W}$, encompassing about 2600 square kilometers (not including shipping lanes). These areas could conceivably support some 22 Phase-1 (405 square kilometer) farms, all within 120 kilometers of potential support and processing centers. As dynamically-positioned farms are engineered and built, and as international agreements are made, the farms could spread further west and south, thus opening up millions of square kilometers to potential OFEF farming. 
SURVEY OF OCEANOGRAPHIC AND METEOROLOGICAL PARAMETERS OF IMPORTANCE TO THE SITE SELECTION OF AN OCEAN FOOD AND ENERGY FARM (OFEF) IN THE EASTERN PACIFIC.

APPENDICES A-E 


\section{APPENDIX A \\ SEASONAL NITRATE PROFILES FOR THE EASTERN PACIFIC OCEAN AREAS AS DEFINED IN FIGURE I}

Data for nitrate profiles were obtained from the National Oceanographic Data Center and summarized using the Naval Undersea Center UNIVAC 1110 computer and developed software.

Nitrate is given in micrograms-atoms/liter on a log scale and are shown to a maximum depth of 500 meters. 


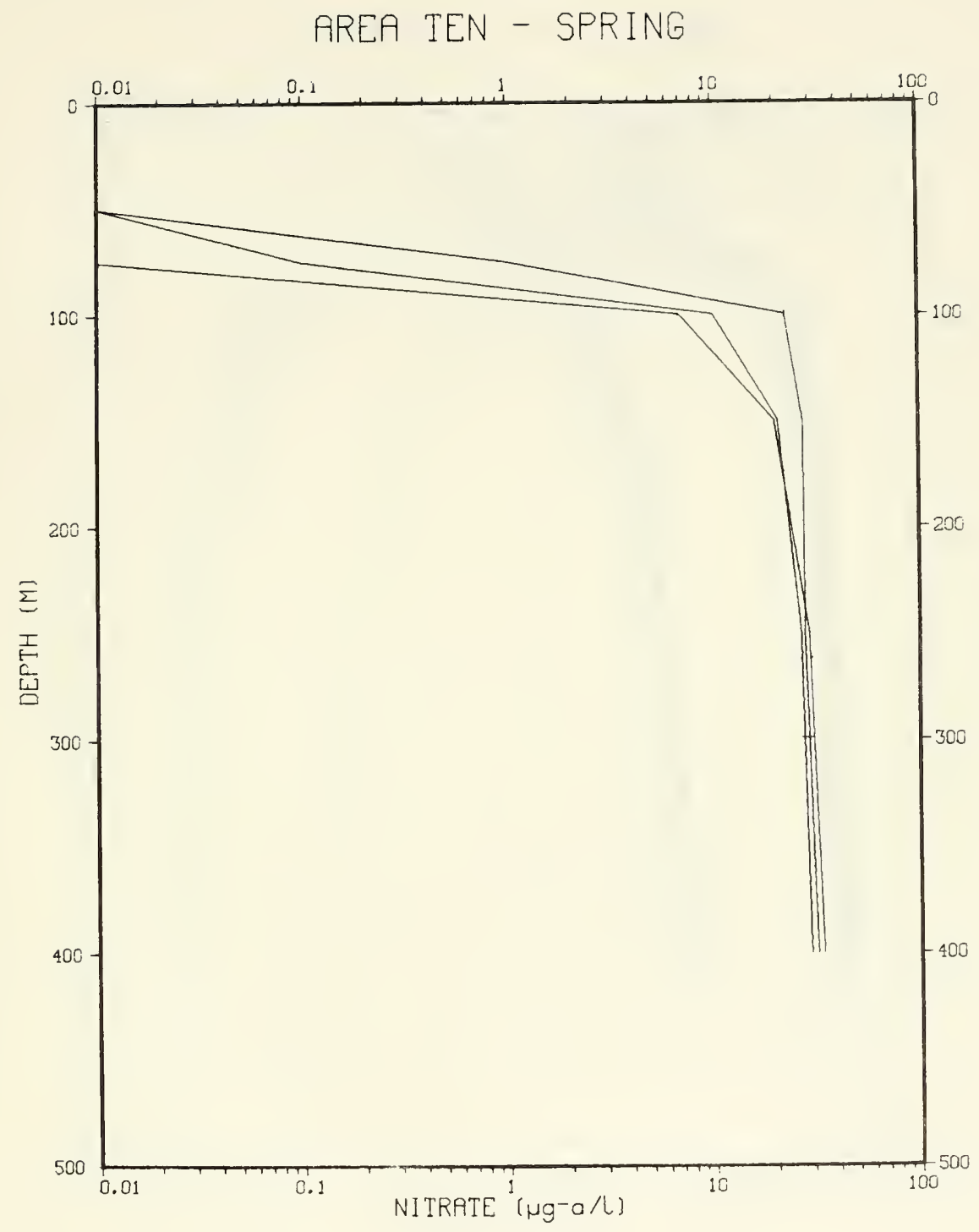

Figure A.1. 


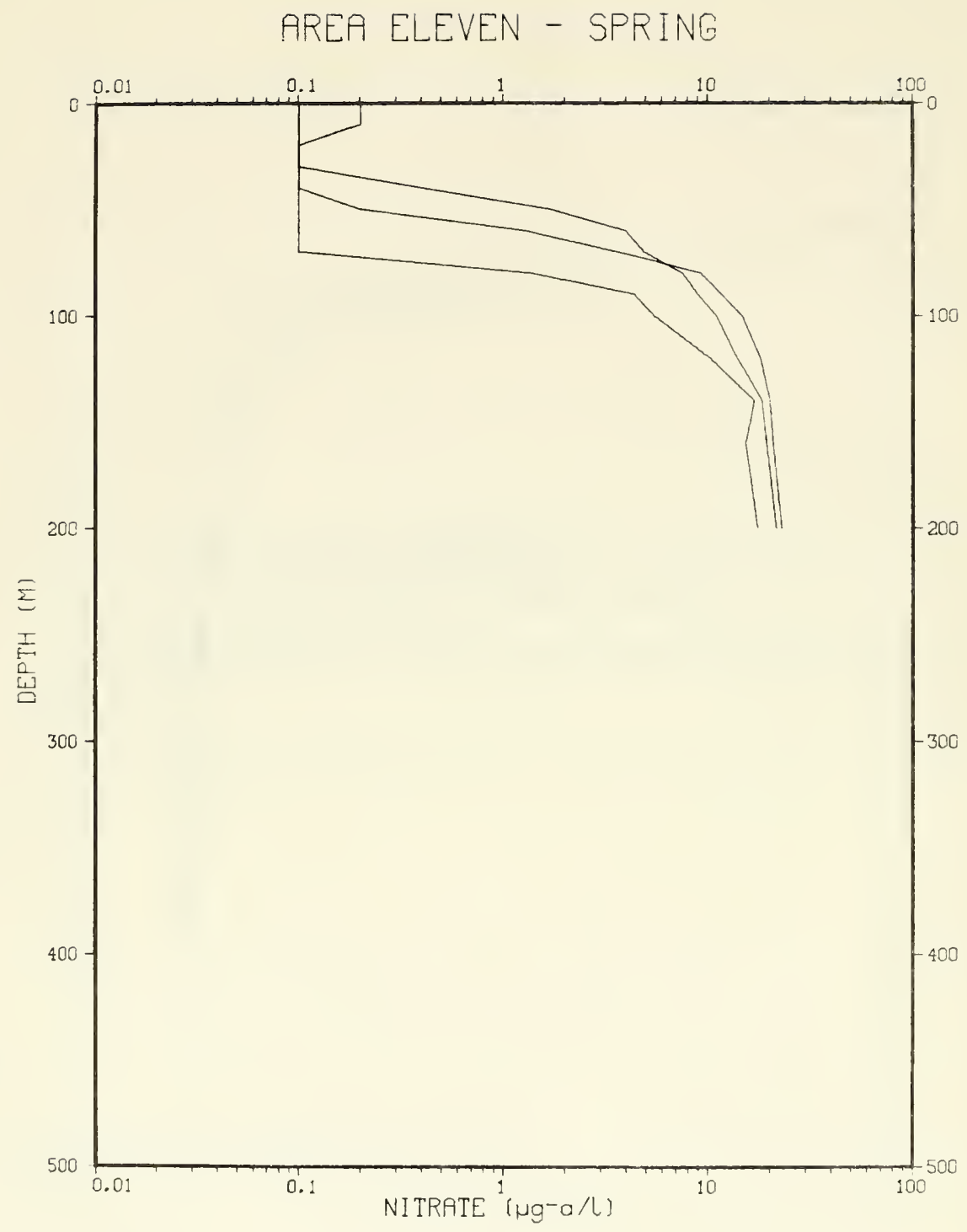

Figure A.2. 


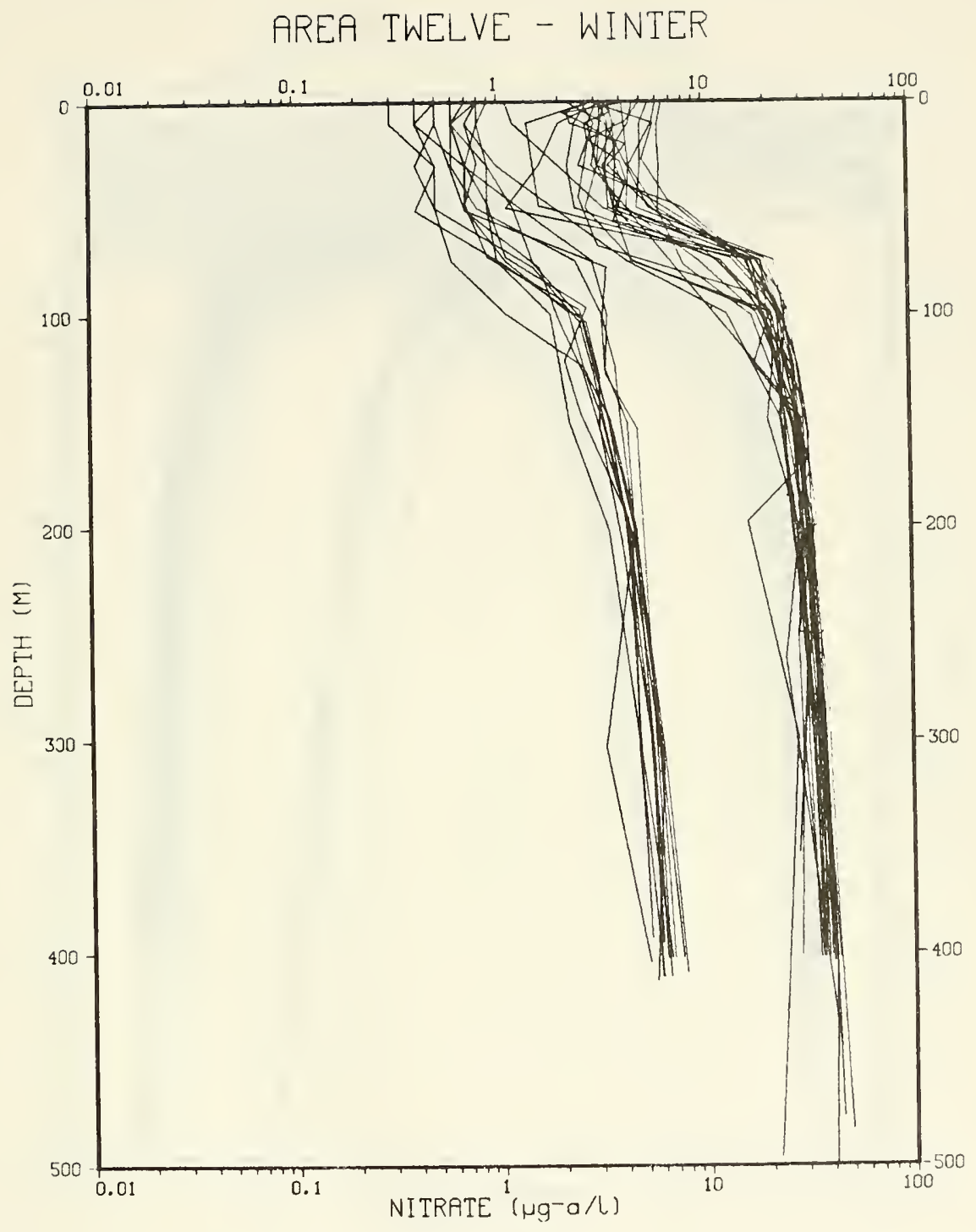

Figure A.3. 


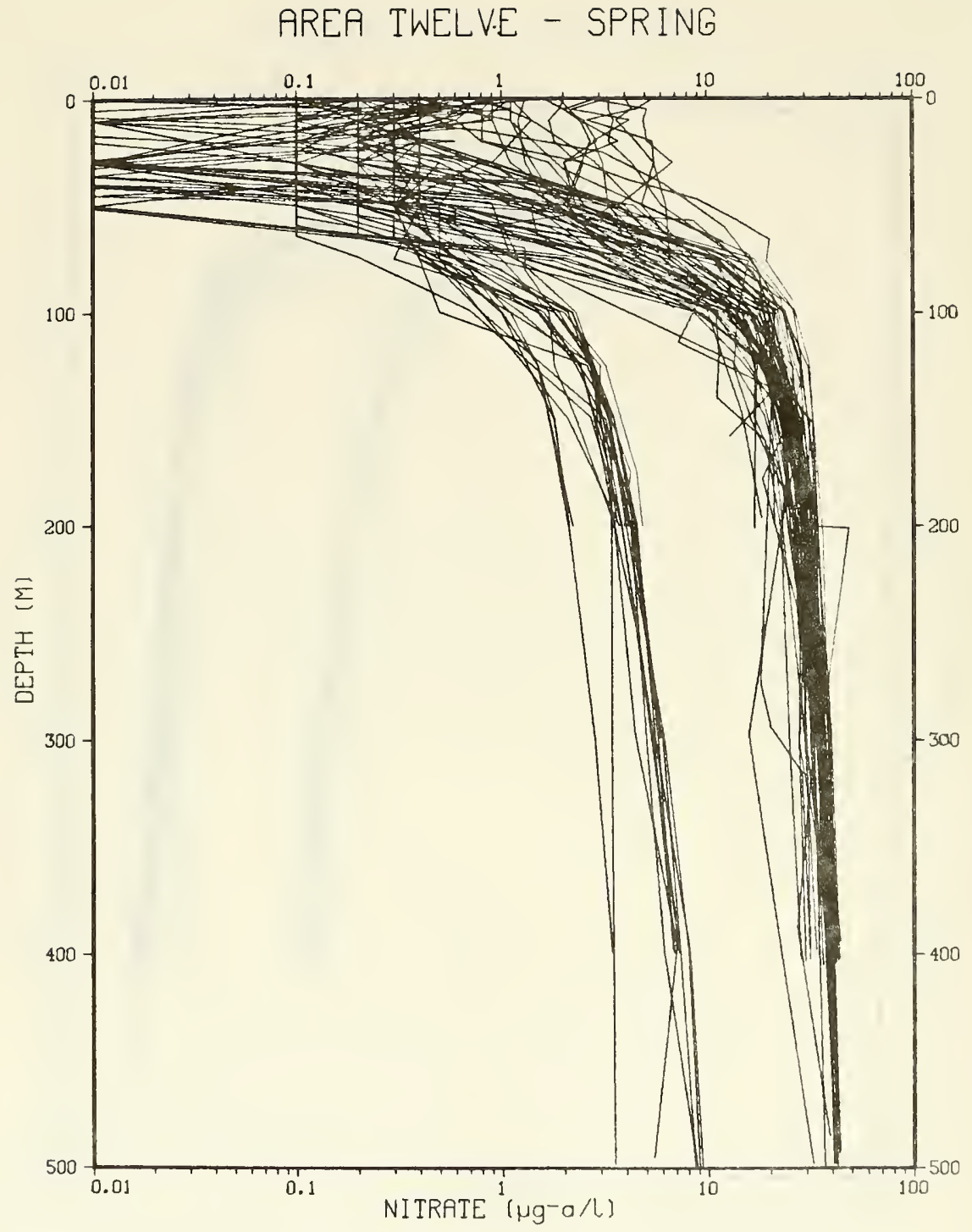

Figure A.4. 


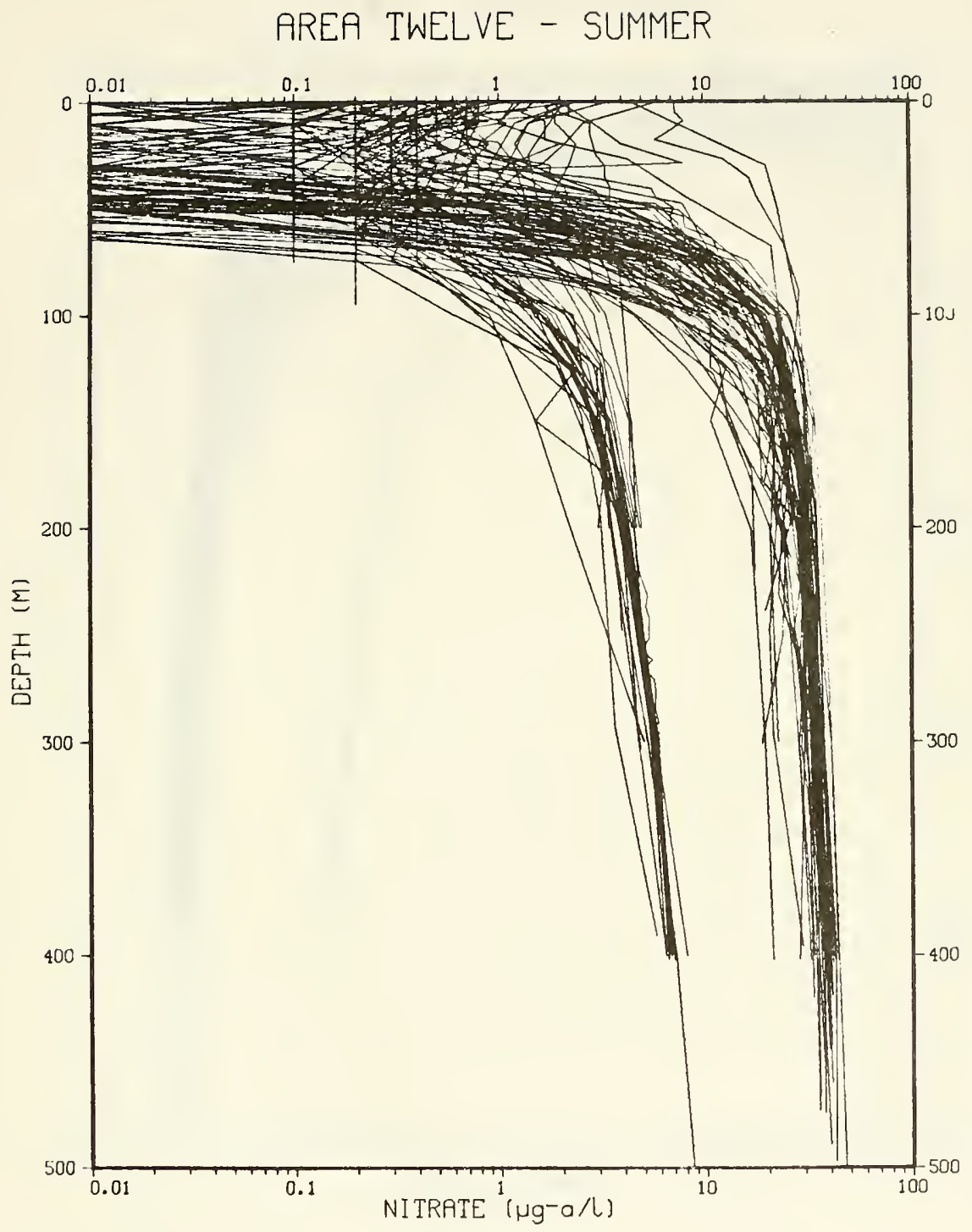

Figure A.5. 


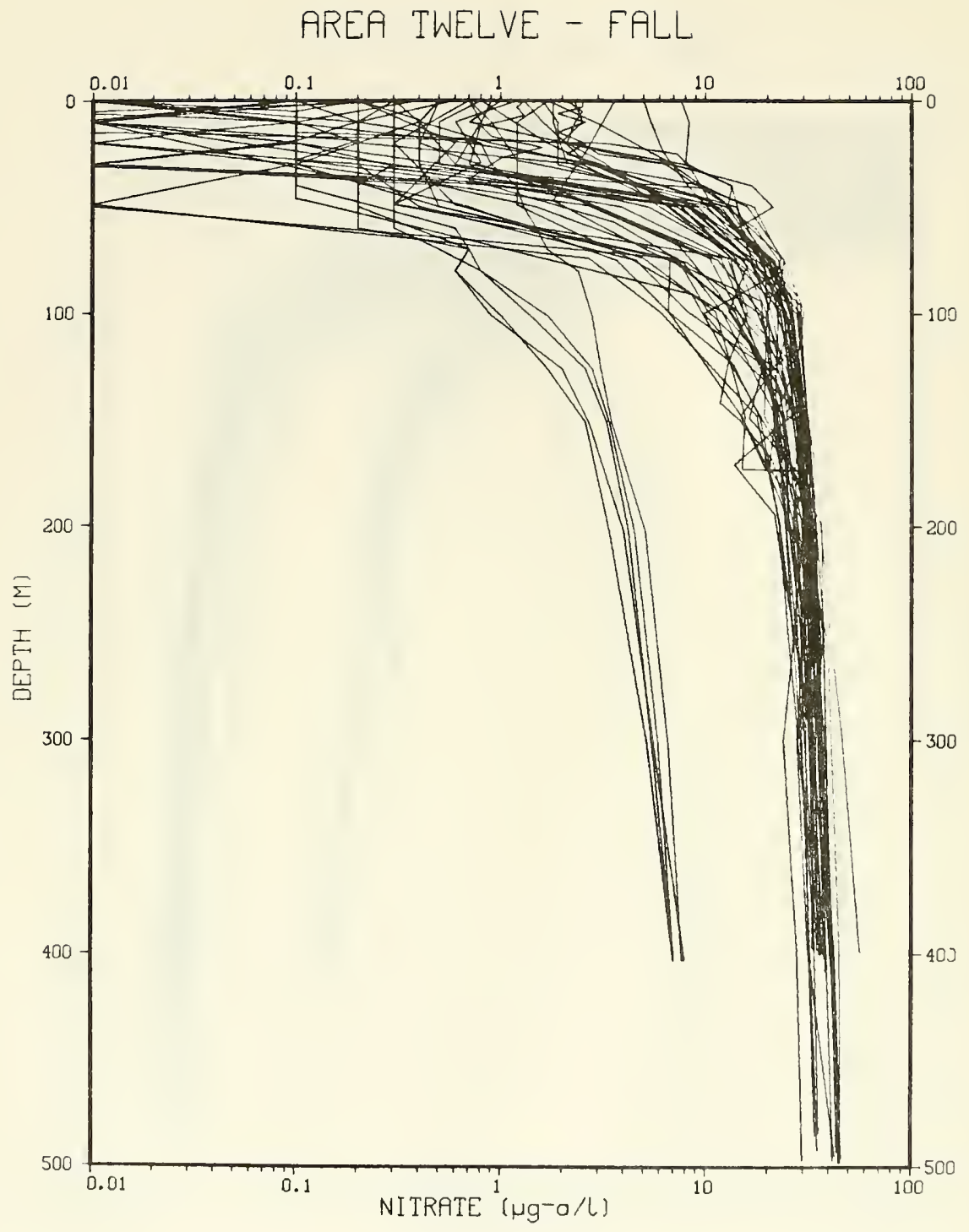

Figure A.6. 
AREA THIRTEEN - WINTEP

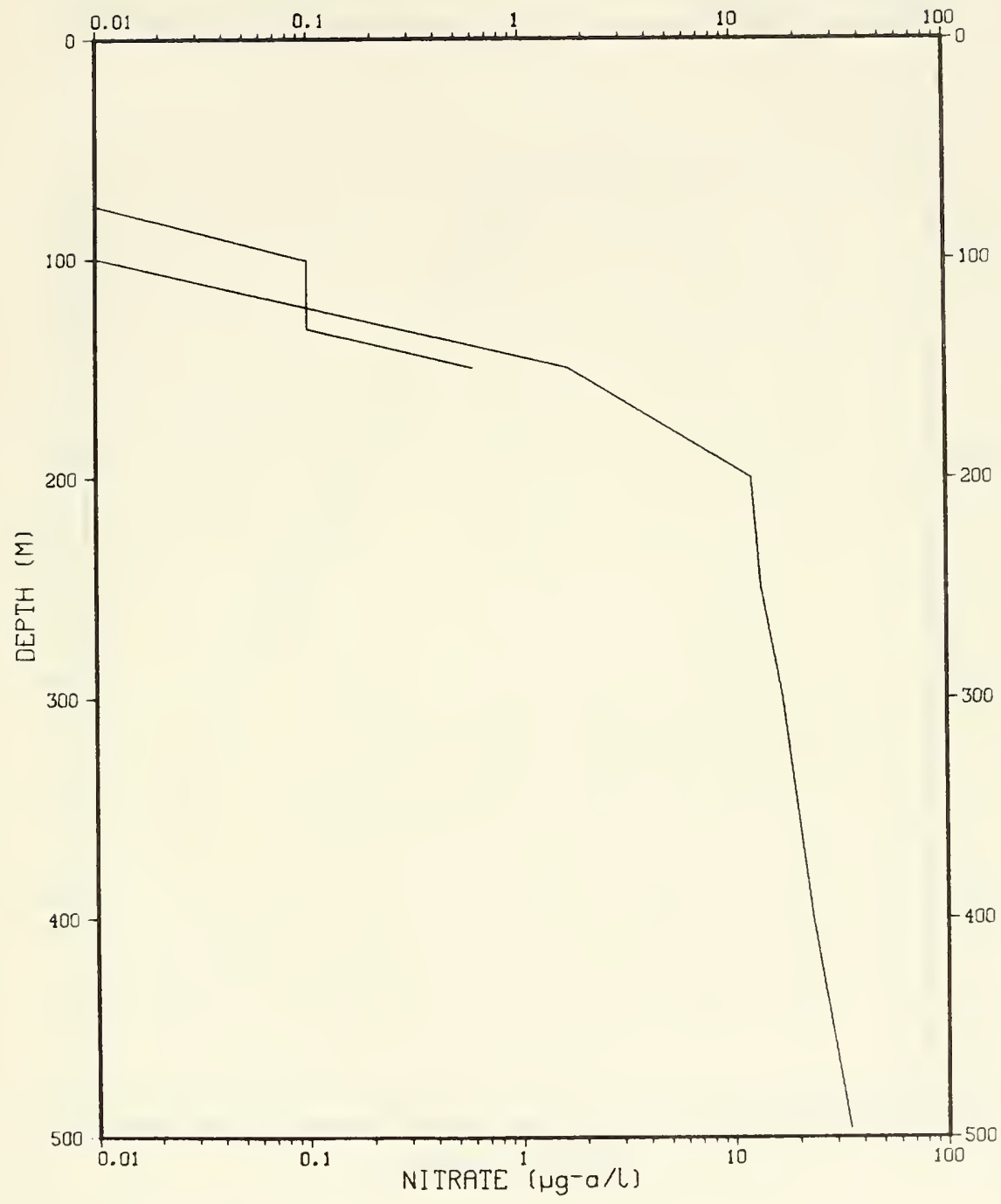

Figure A.7. 


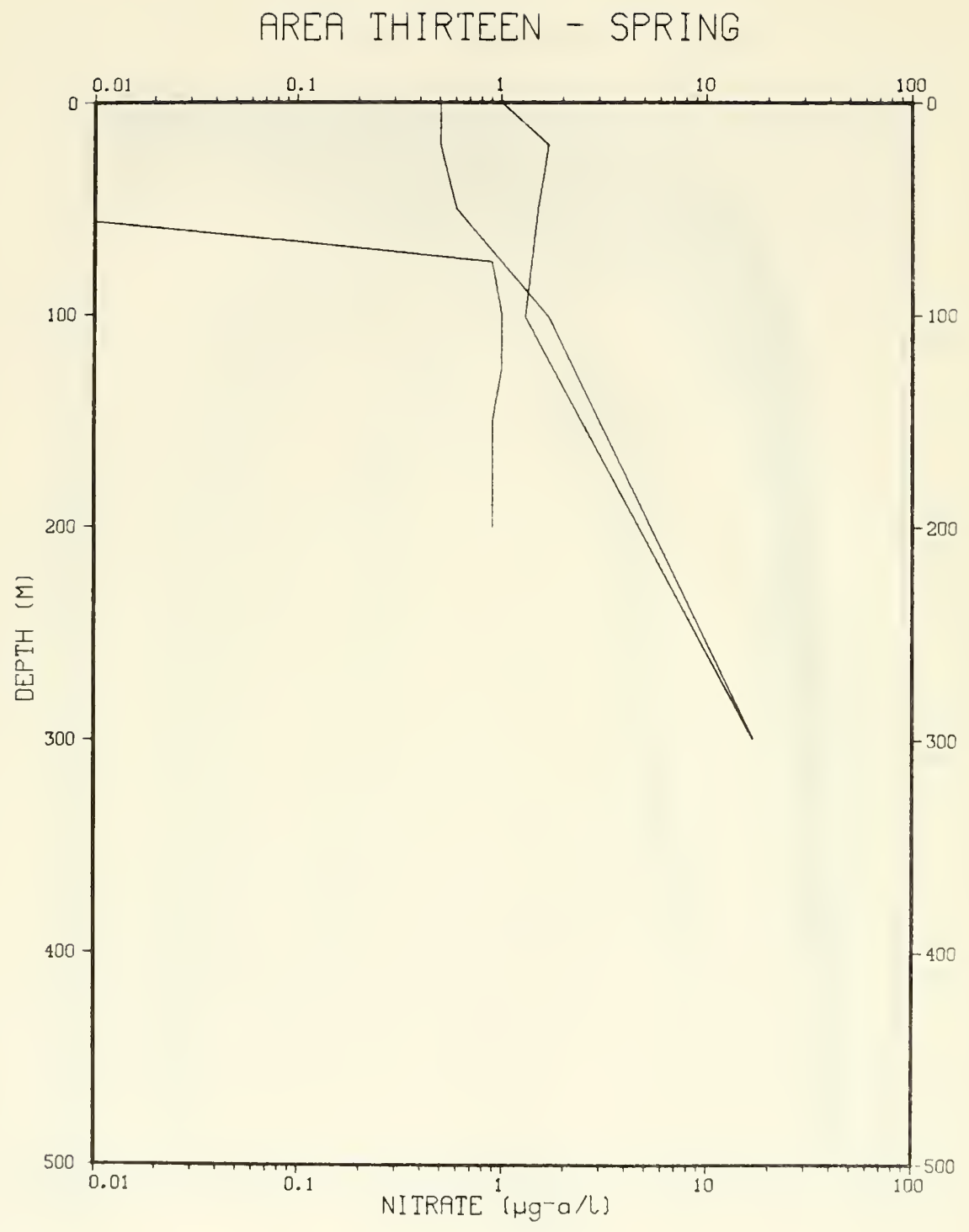

Figure A.8. 
AREA THIRTEEN - SUMMER

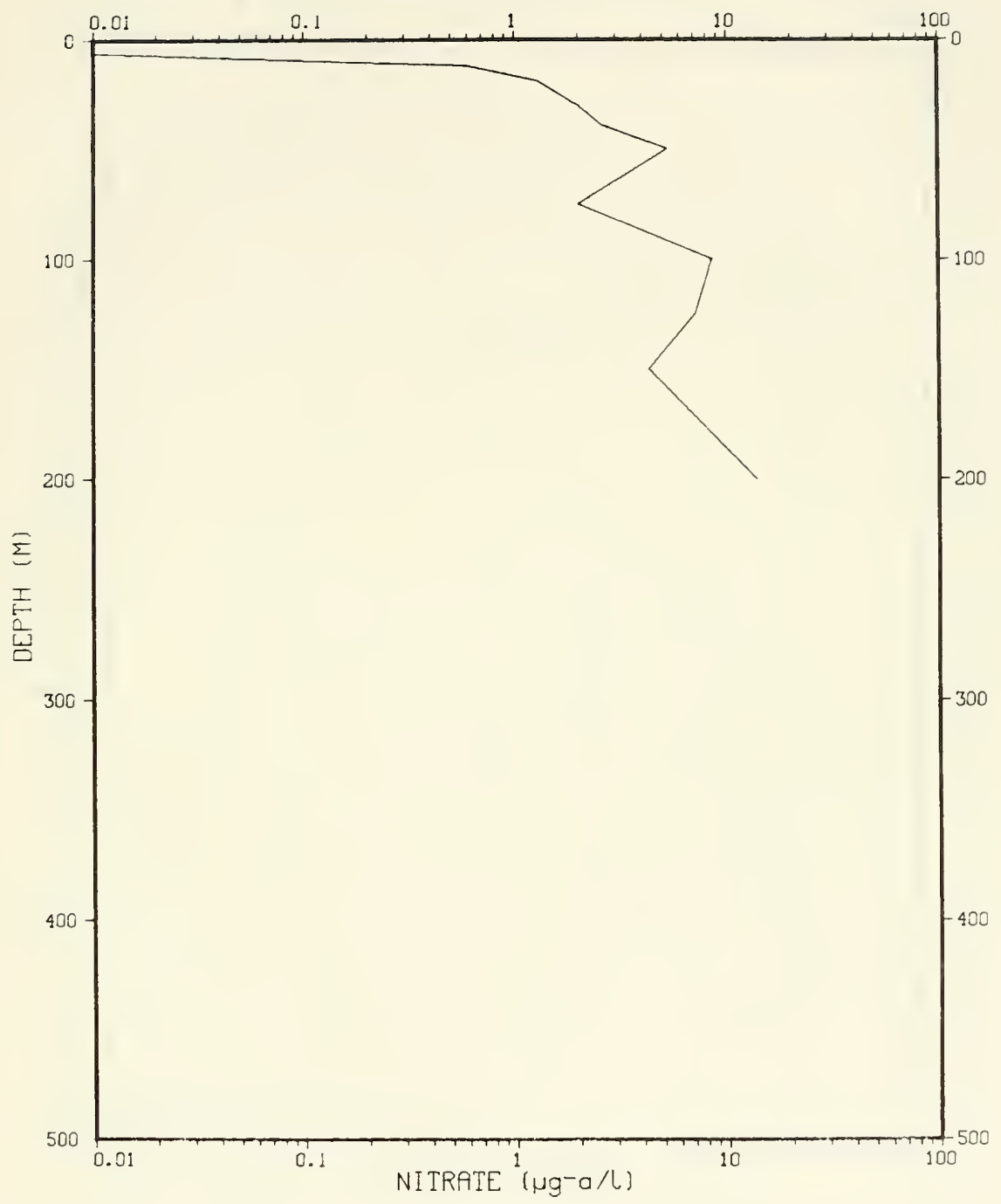

Figure A.9. 


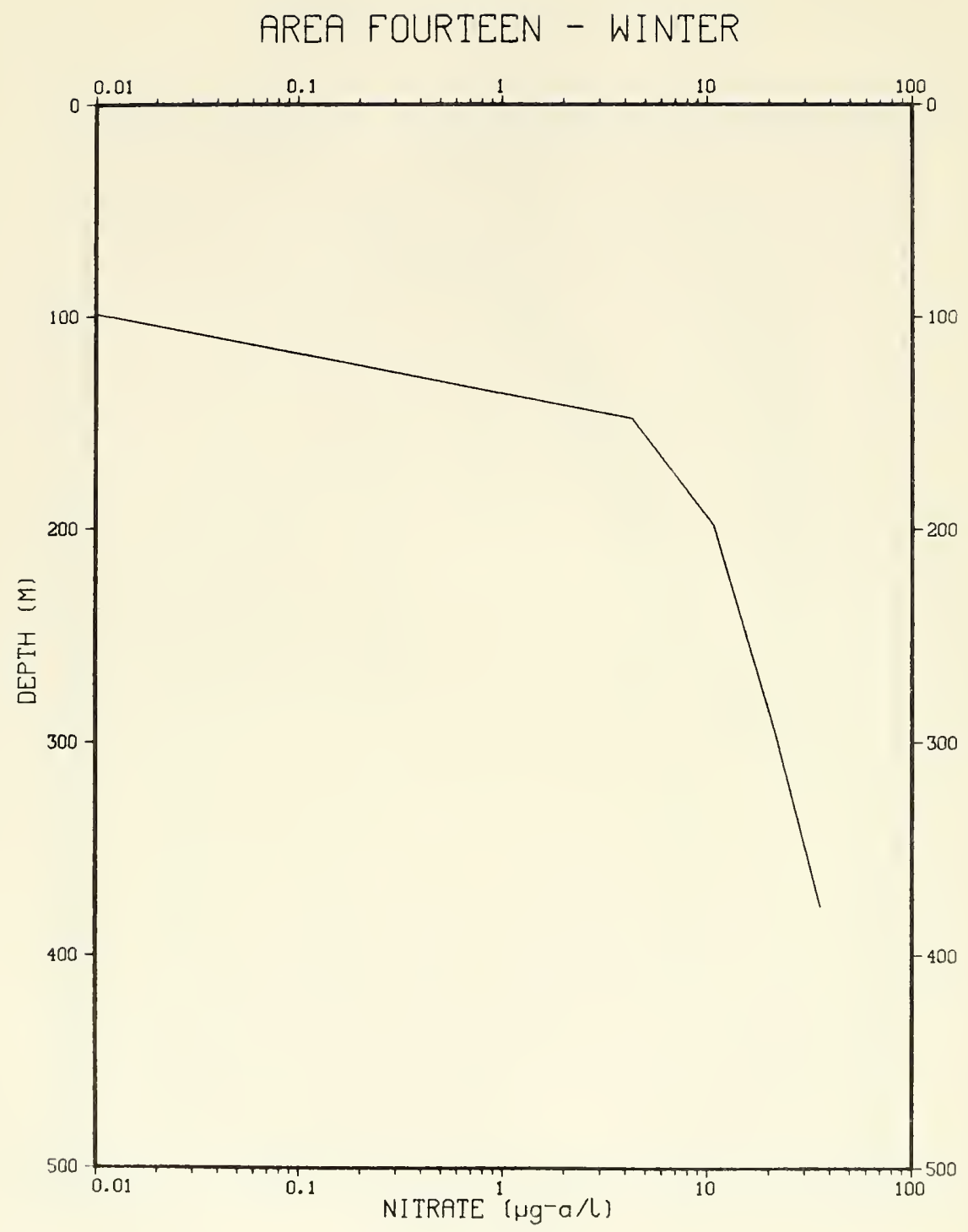

Figure A.10. 
AREA FOURTEEN - SPRING

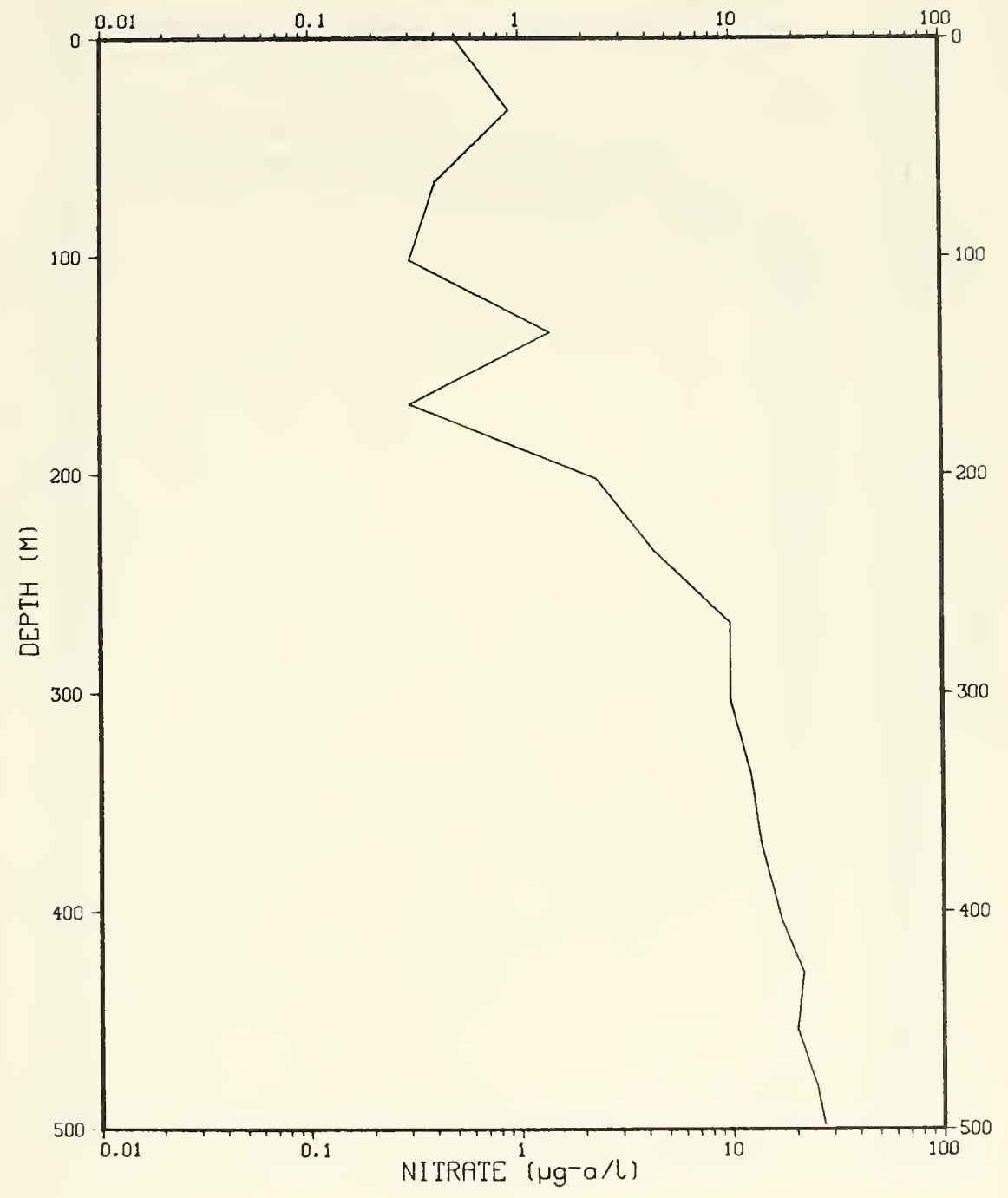

Figure A.11. 


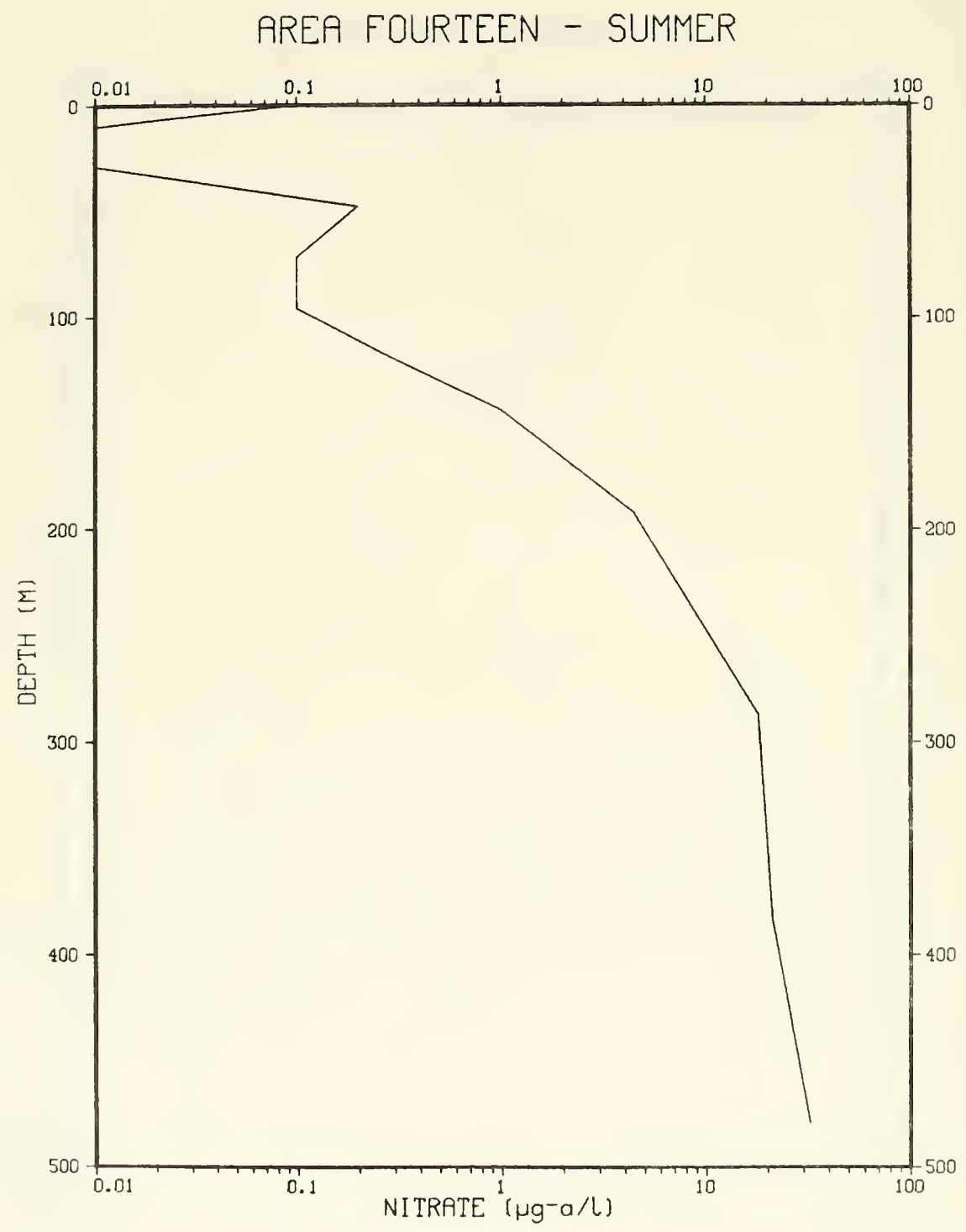

Figure A.12. 


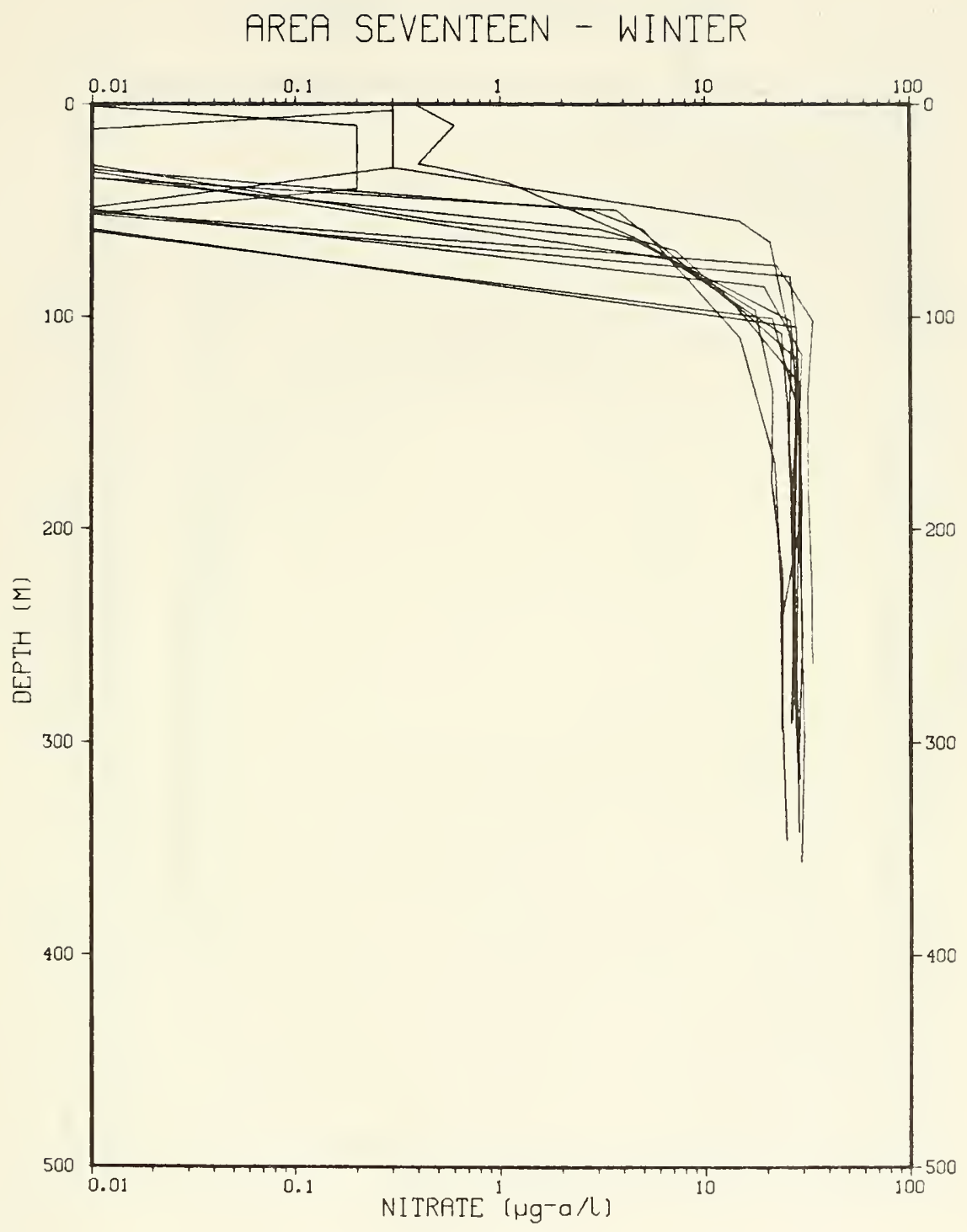

Figure A.13. 


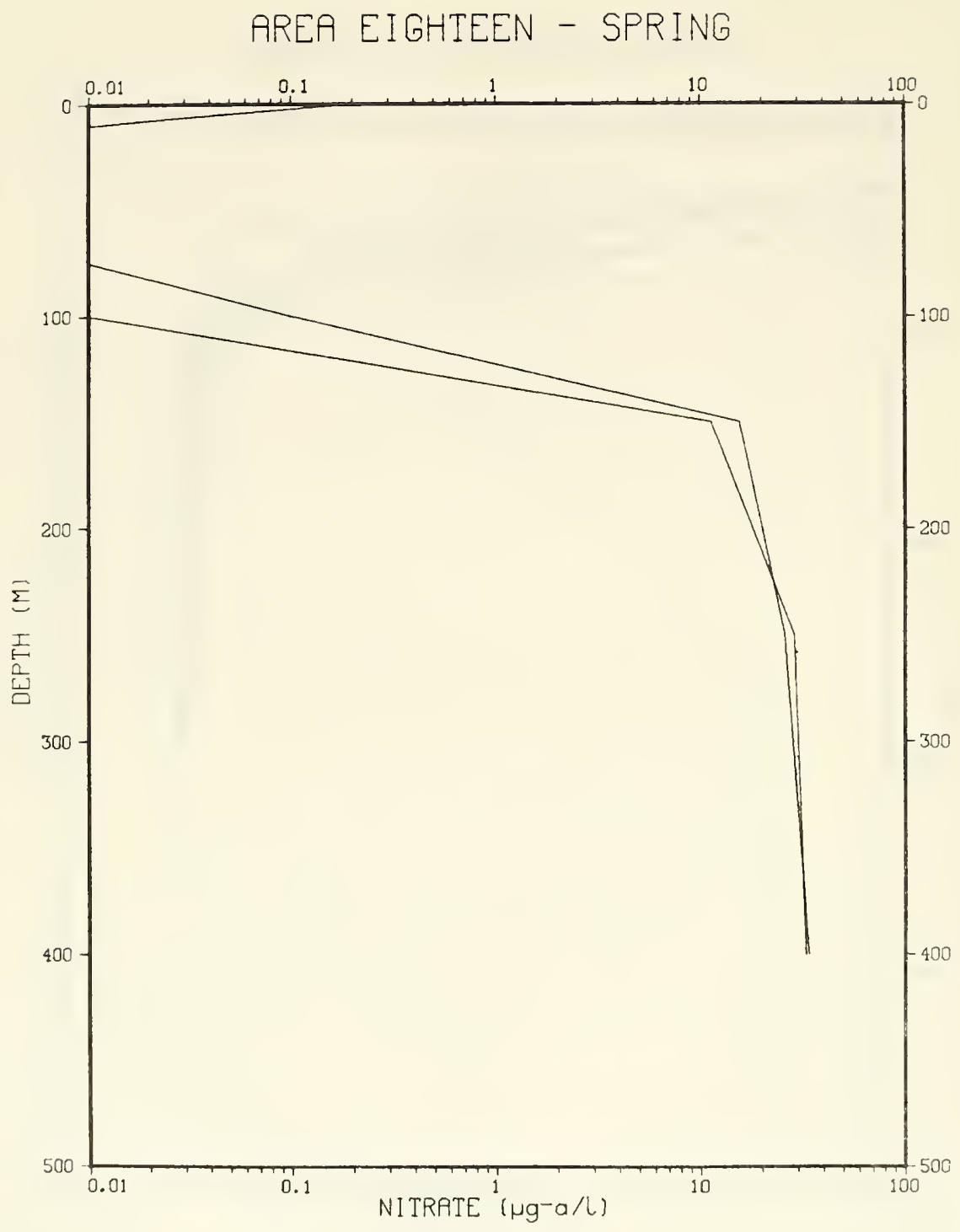

Figure A.14. 


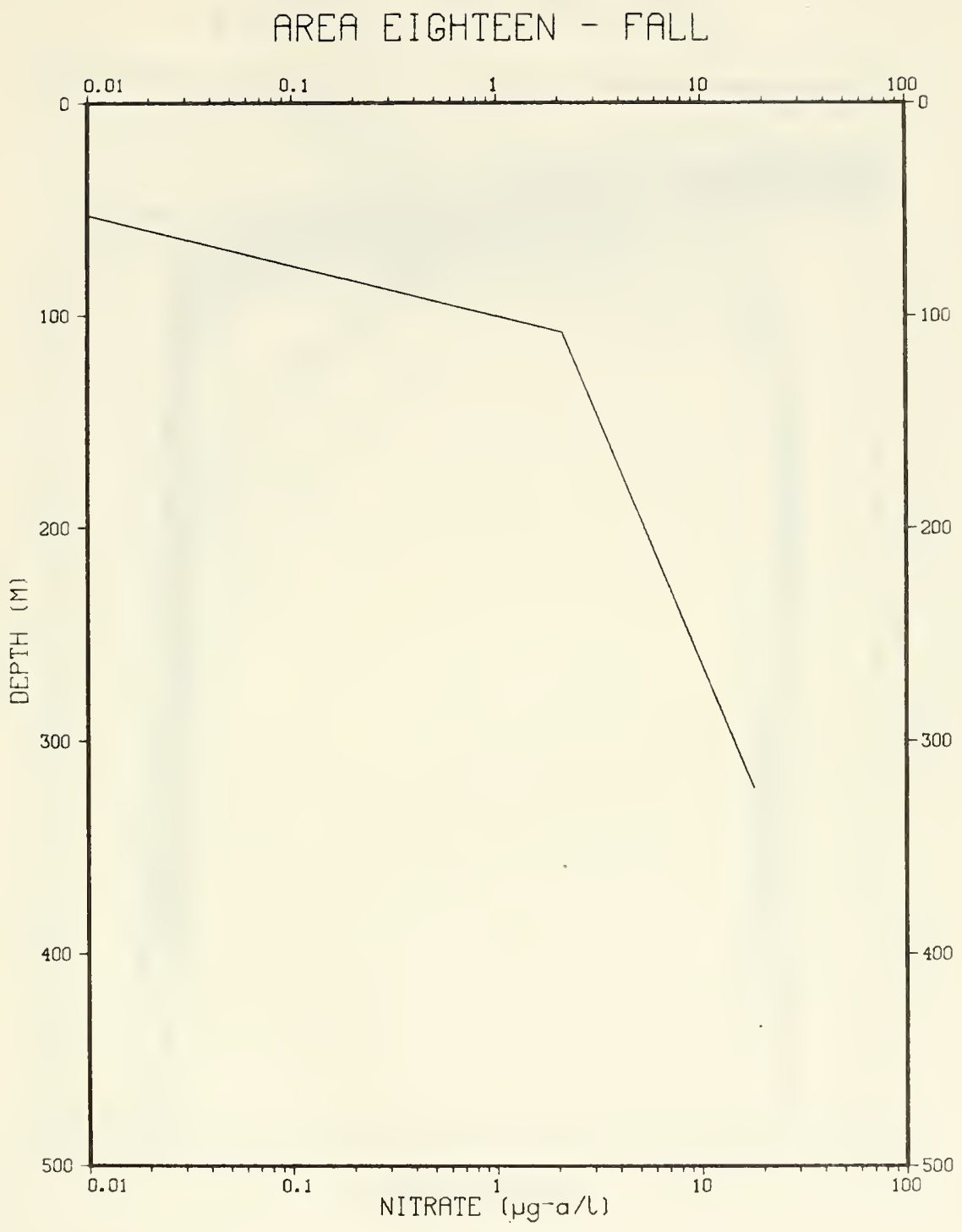

Figure A.15. 


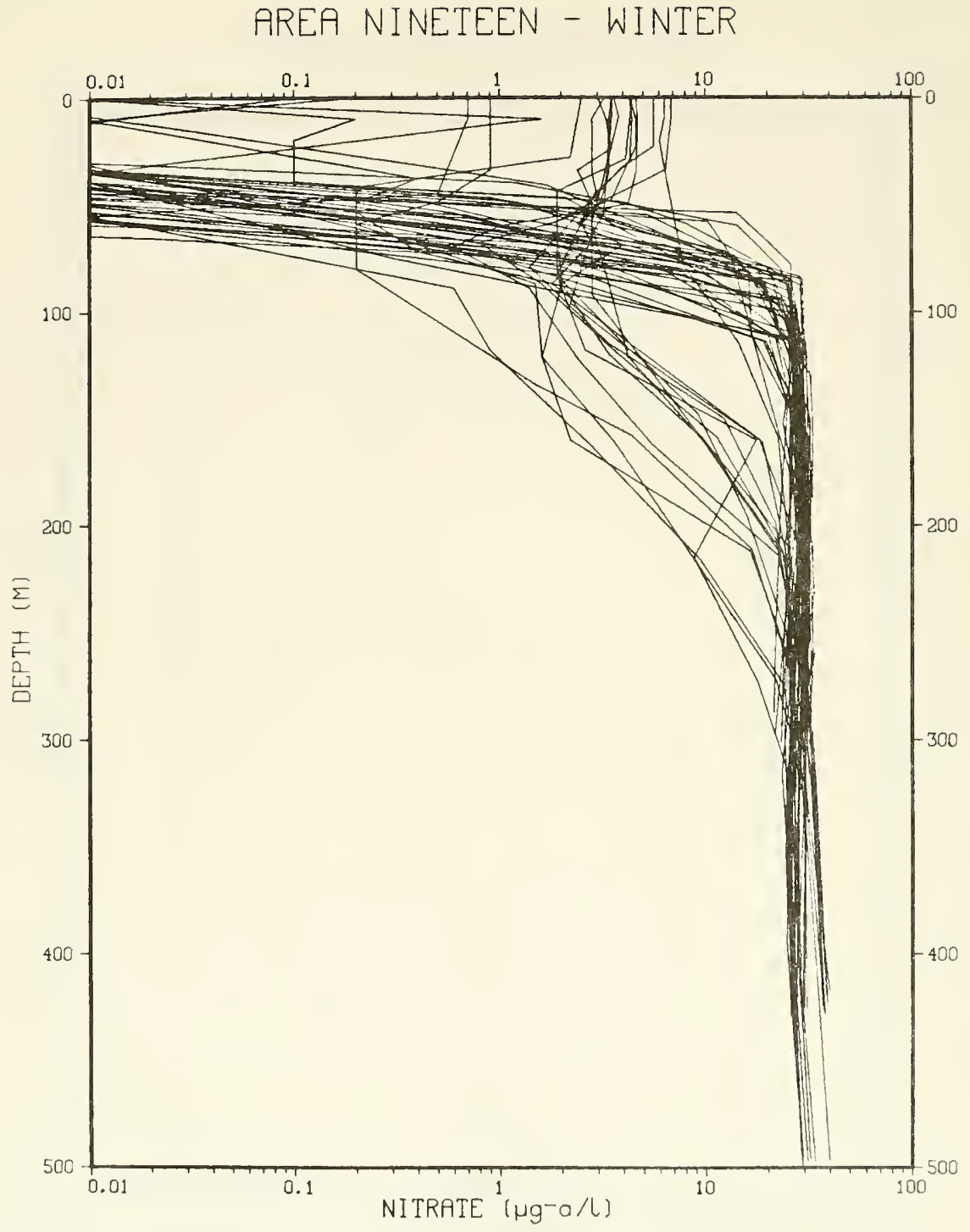

Figure A.16. 


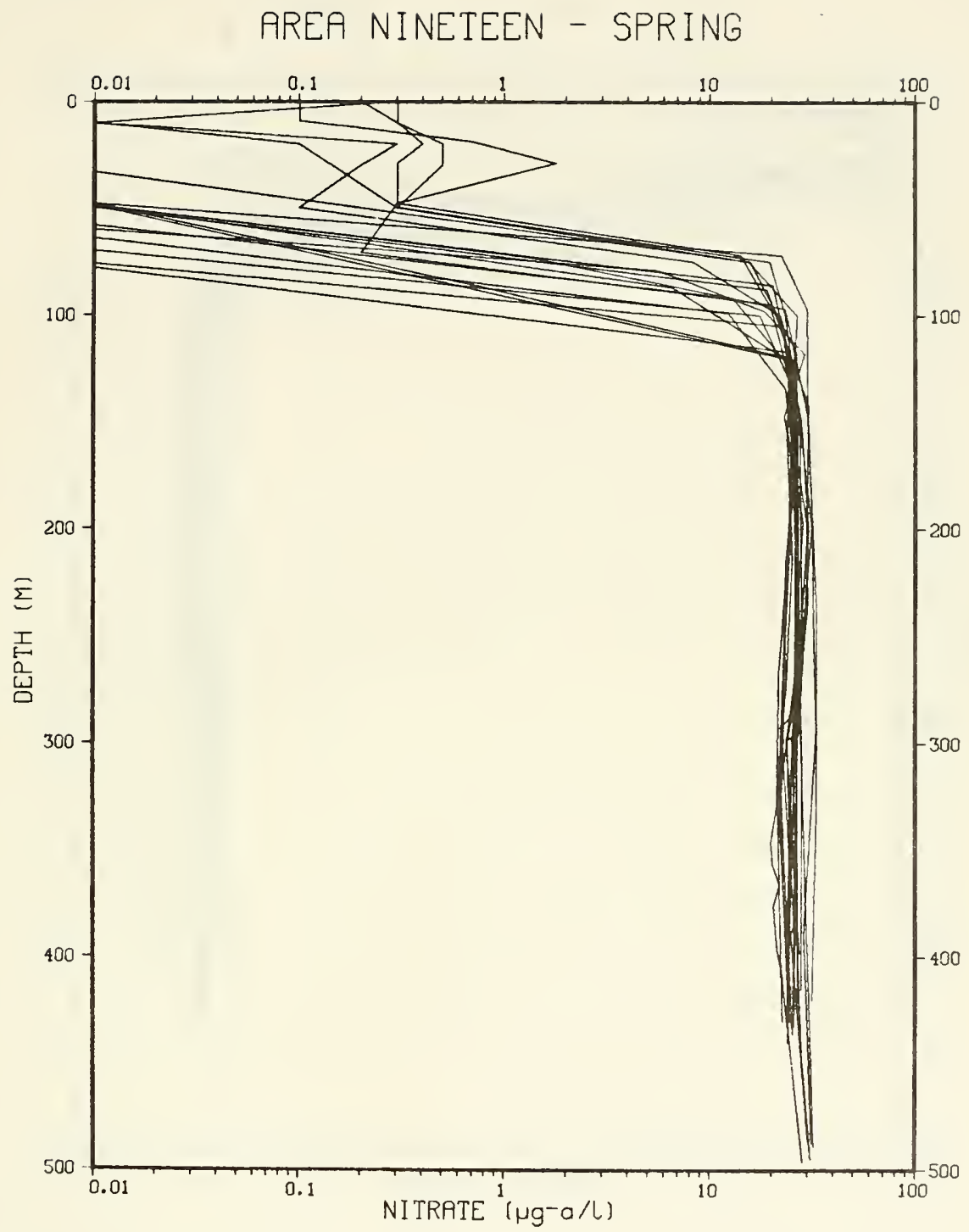

Figure A.17. 


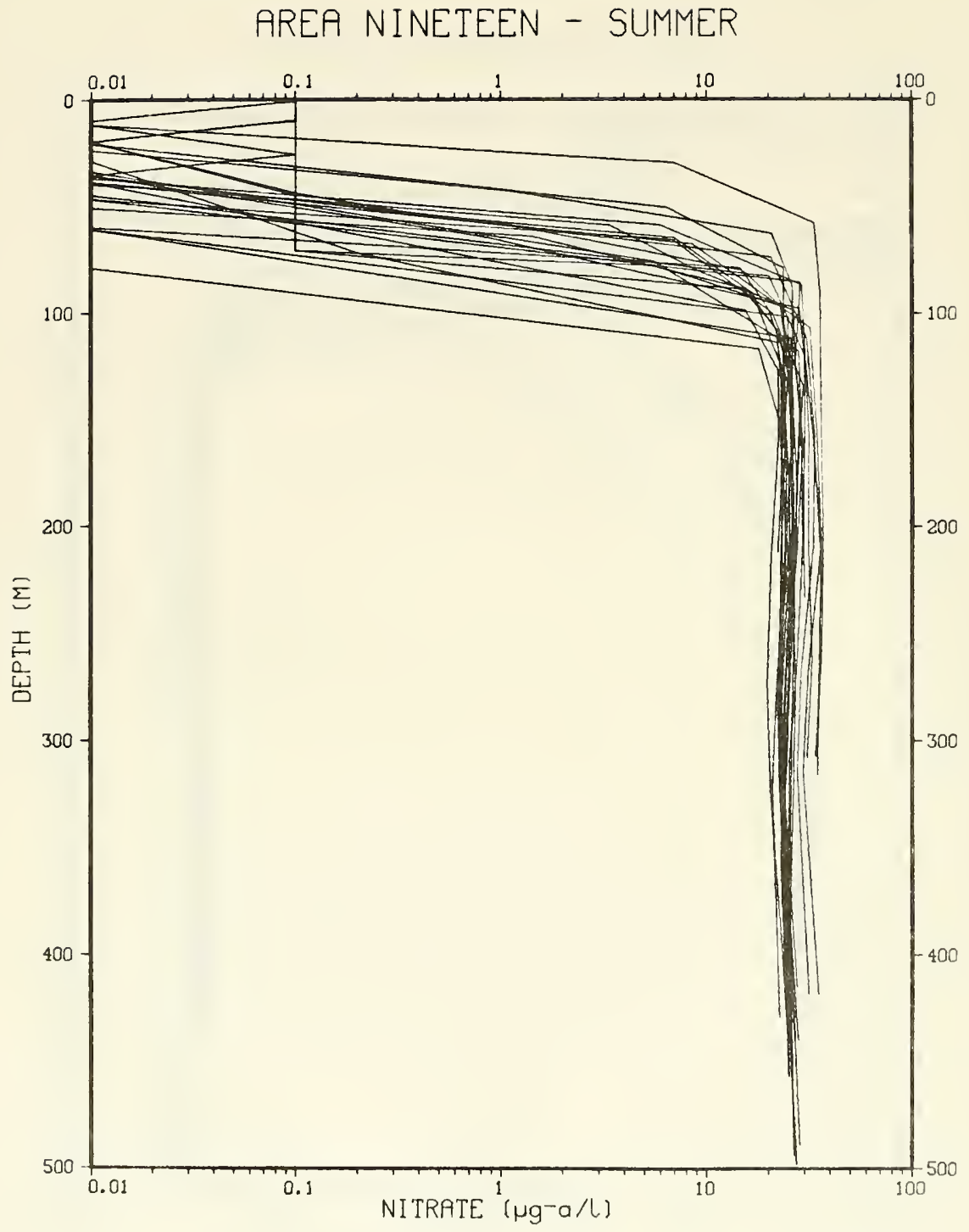

Figure A.18. 


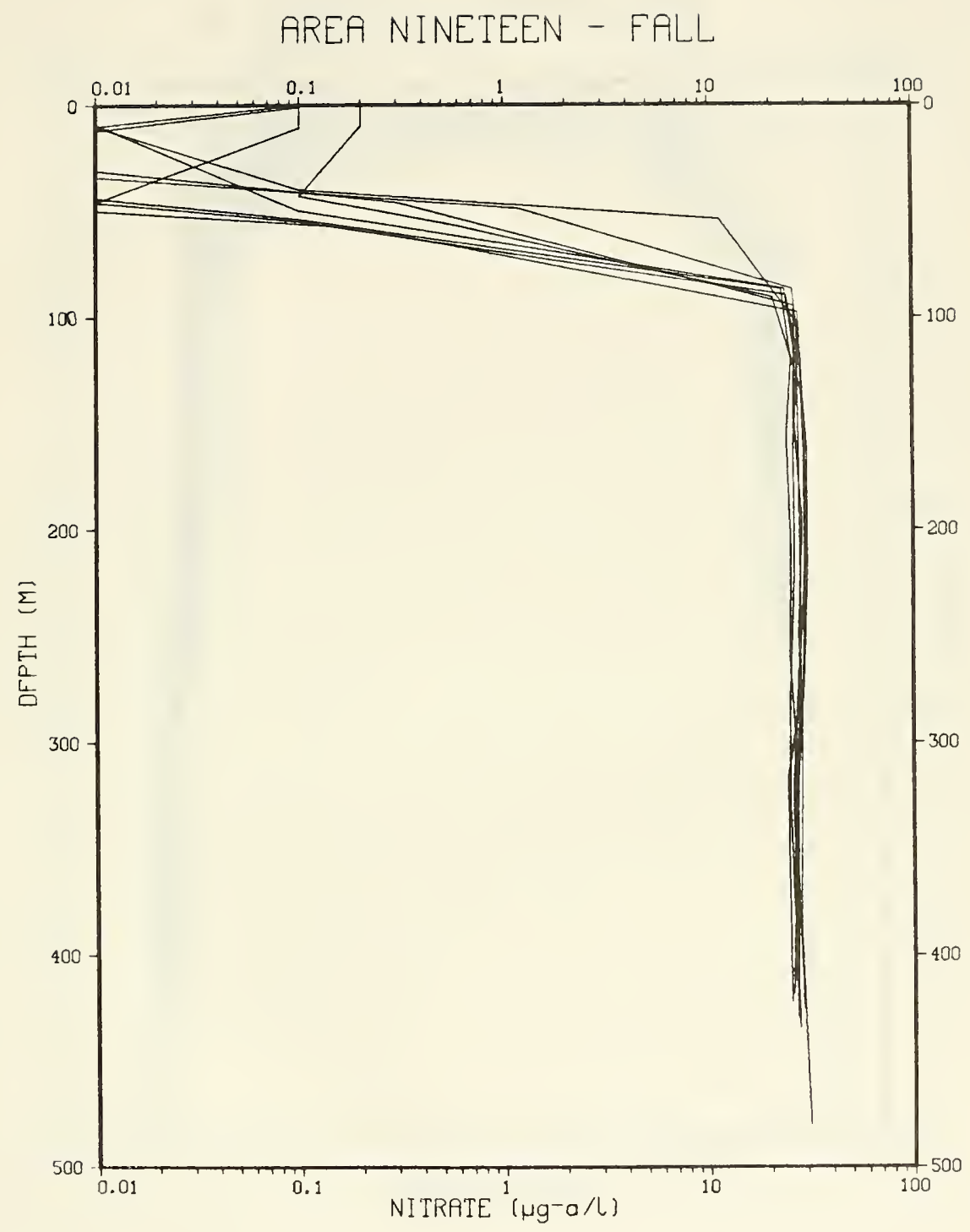

Figure A.19. 


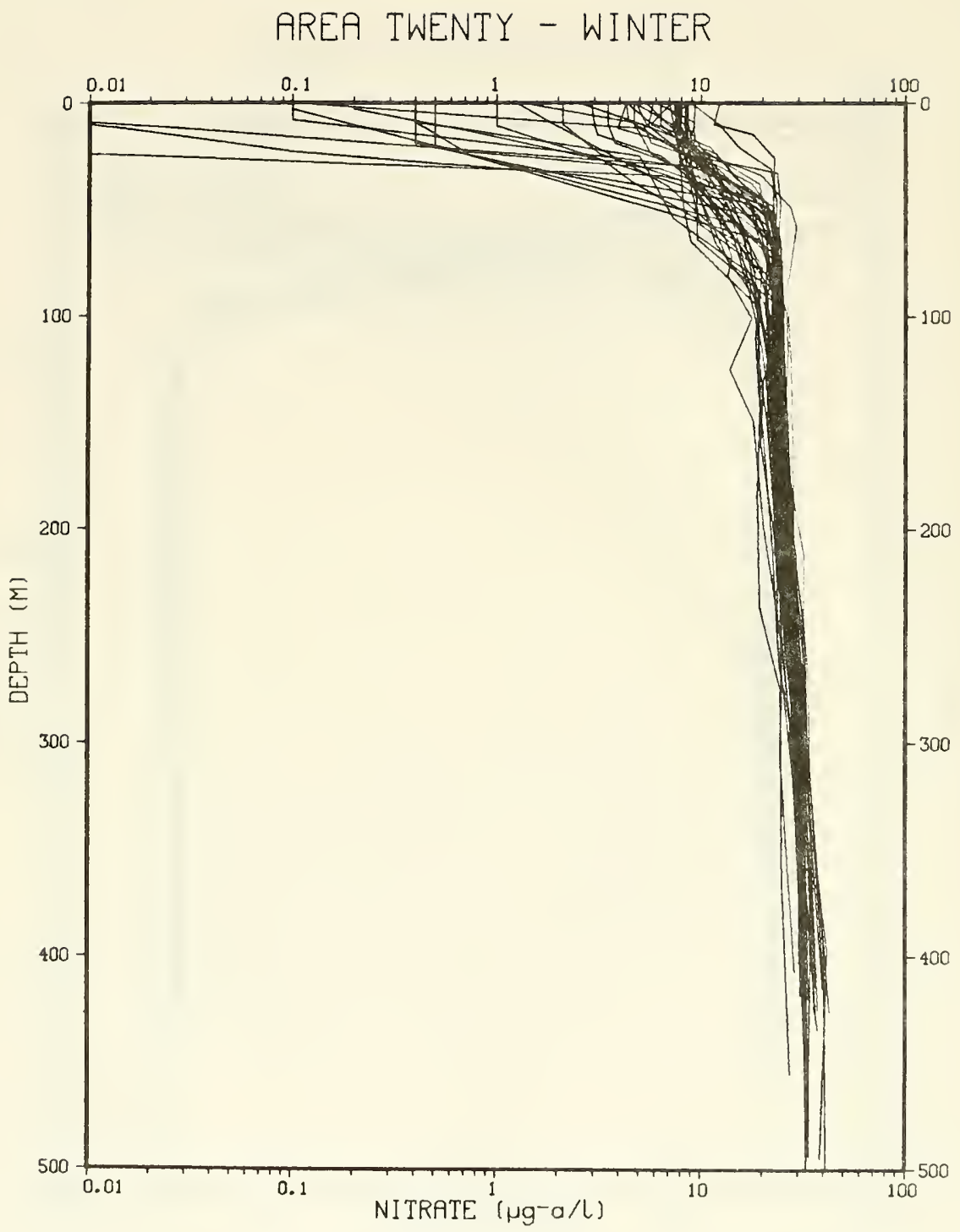

Figure A.20. 


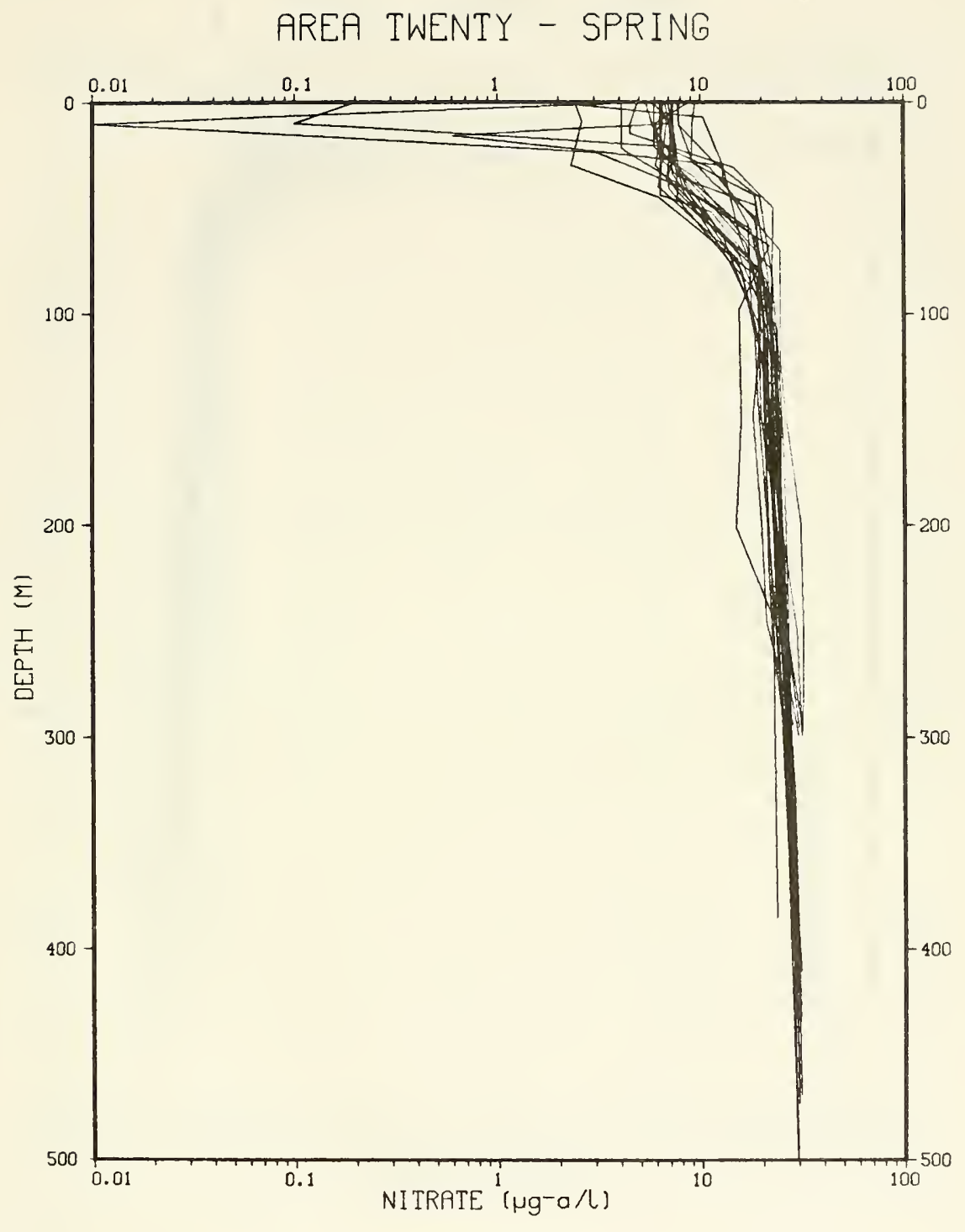

Figure A.21. 


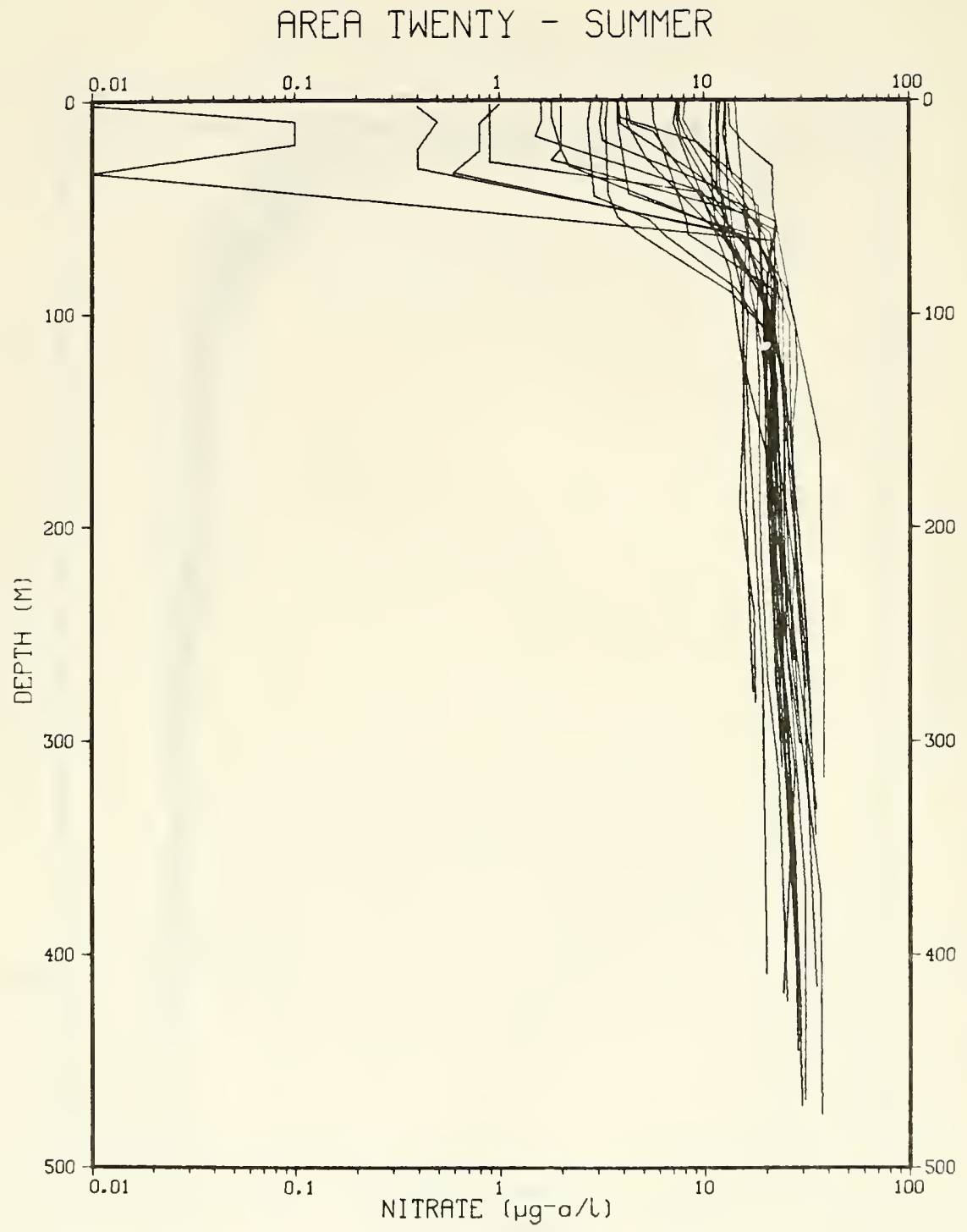

Figure A.22. 


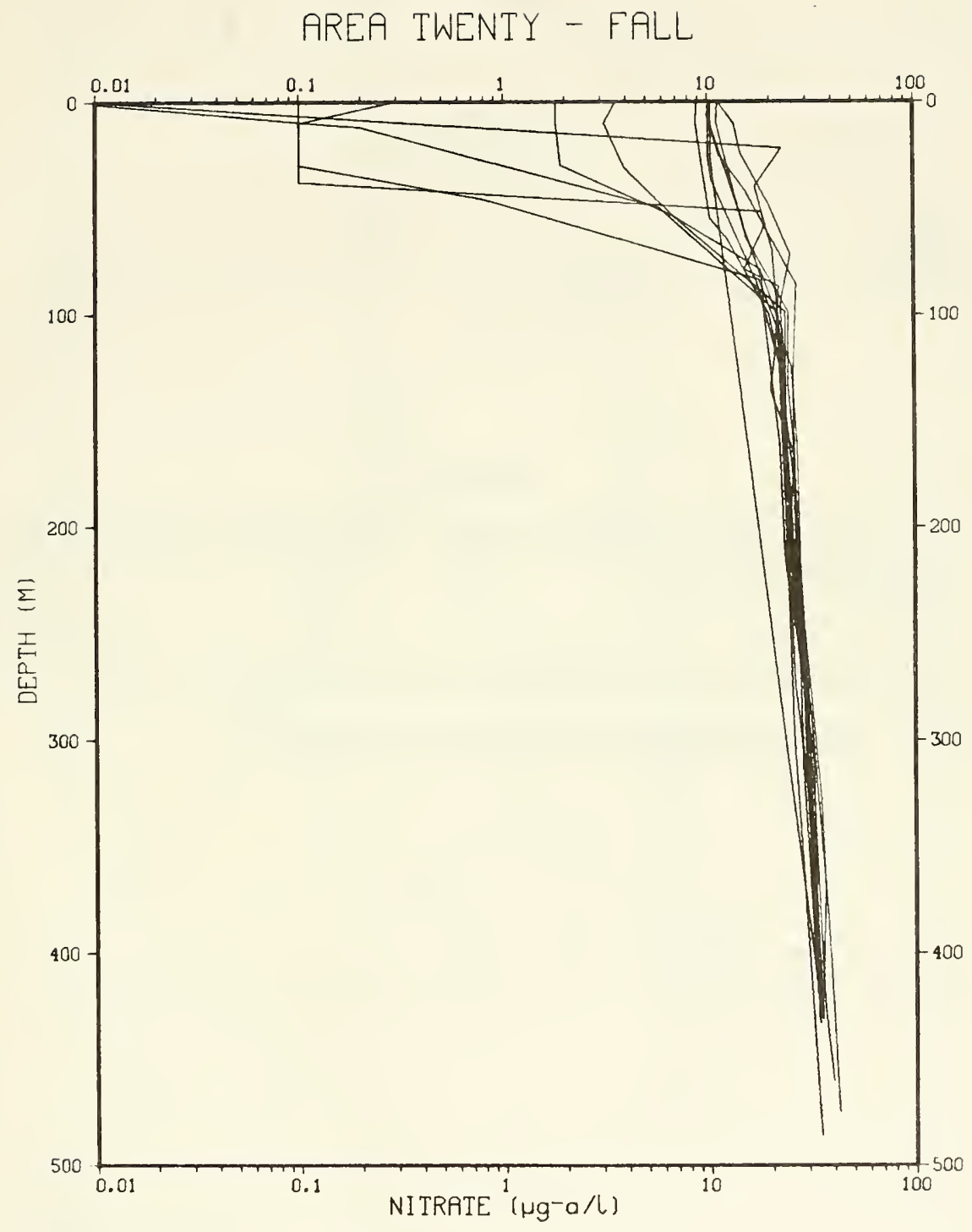

Figure A.23. 


\section{APPENDIX B}

Seasonal temperature profiles for survey areas shown in Figure 1. Temperature data is from the National Oceanographic Data Center and represents all hydrocasts of record for the season and area depicted.

Temperature envelopes give an approximation of minimum and maximum temperatures at various depths and the range of depths at which the thermocline is located.

Figure B.1 shows the geographic location of survey areas 1-9. 


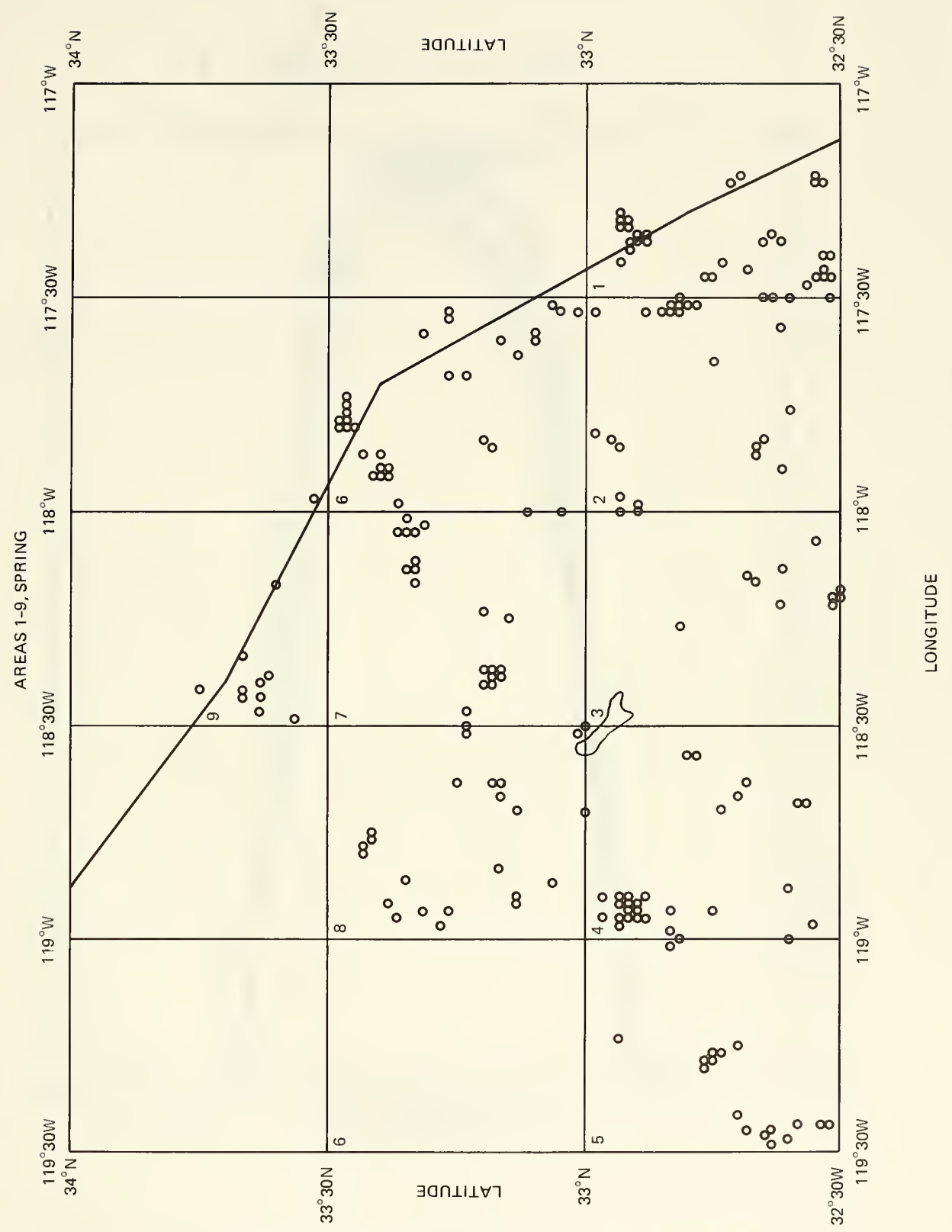

Figure B.1. Geographic location of survey areas 1-9, southern California area. 


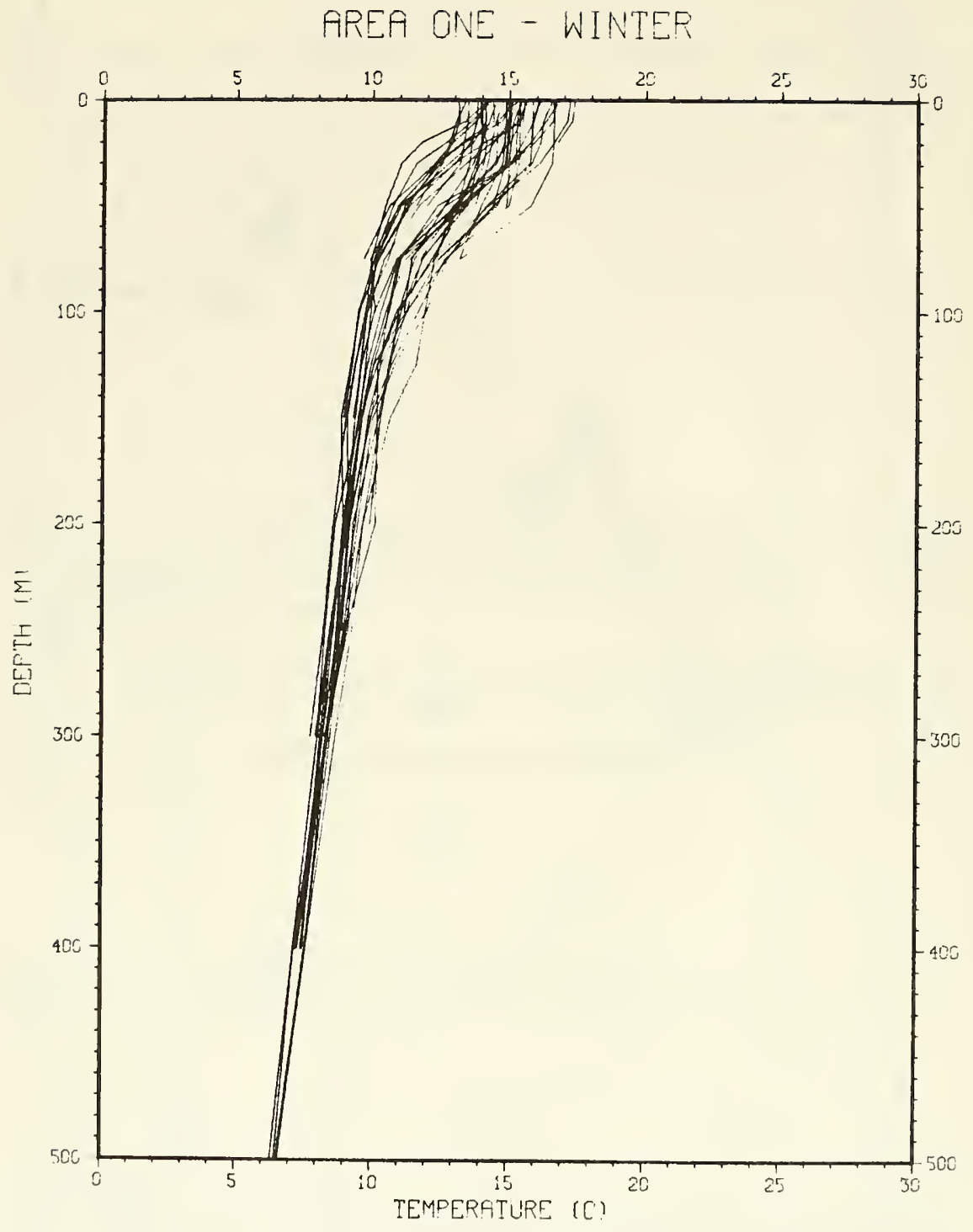

Figure B.2. 


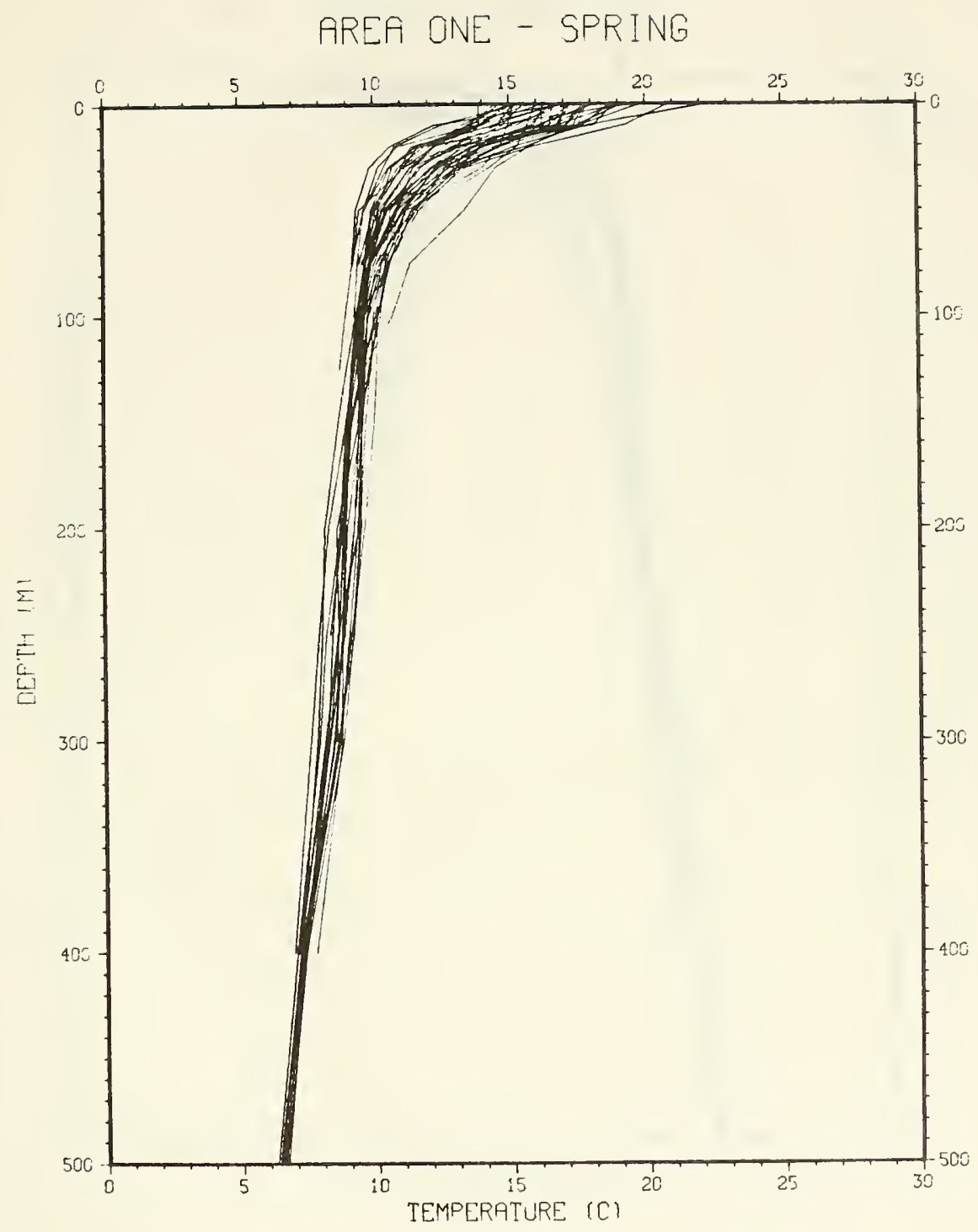

Figure B.3. 


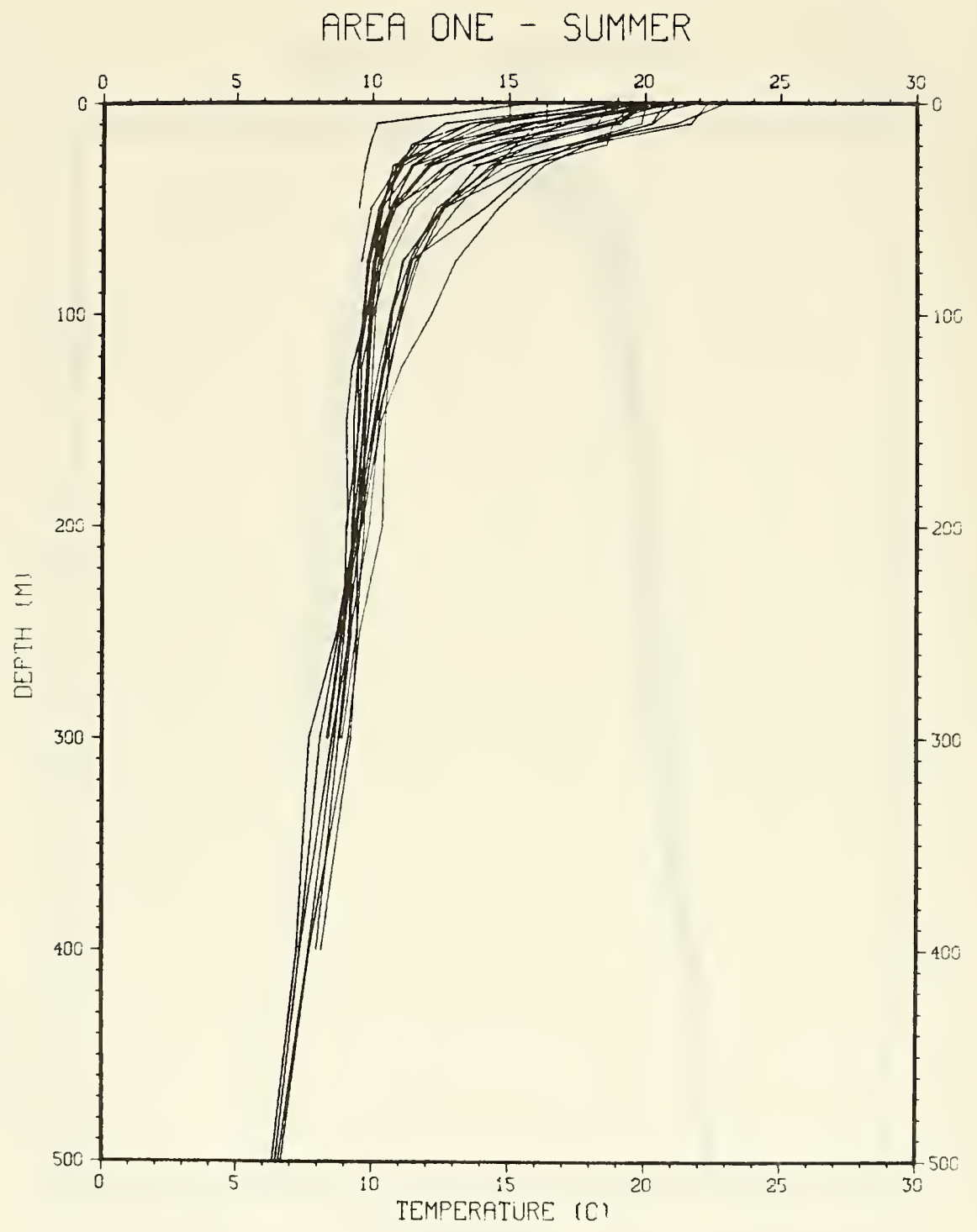

Figure B.4. 


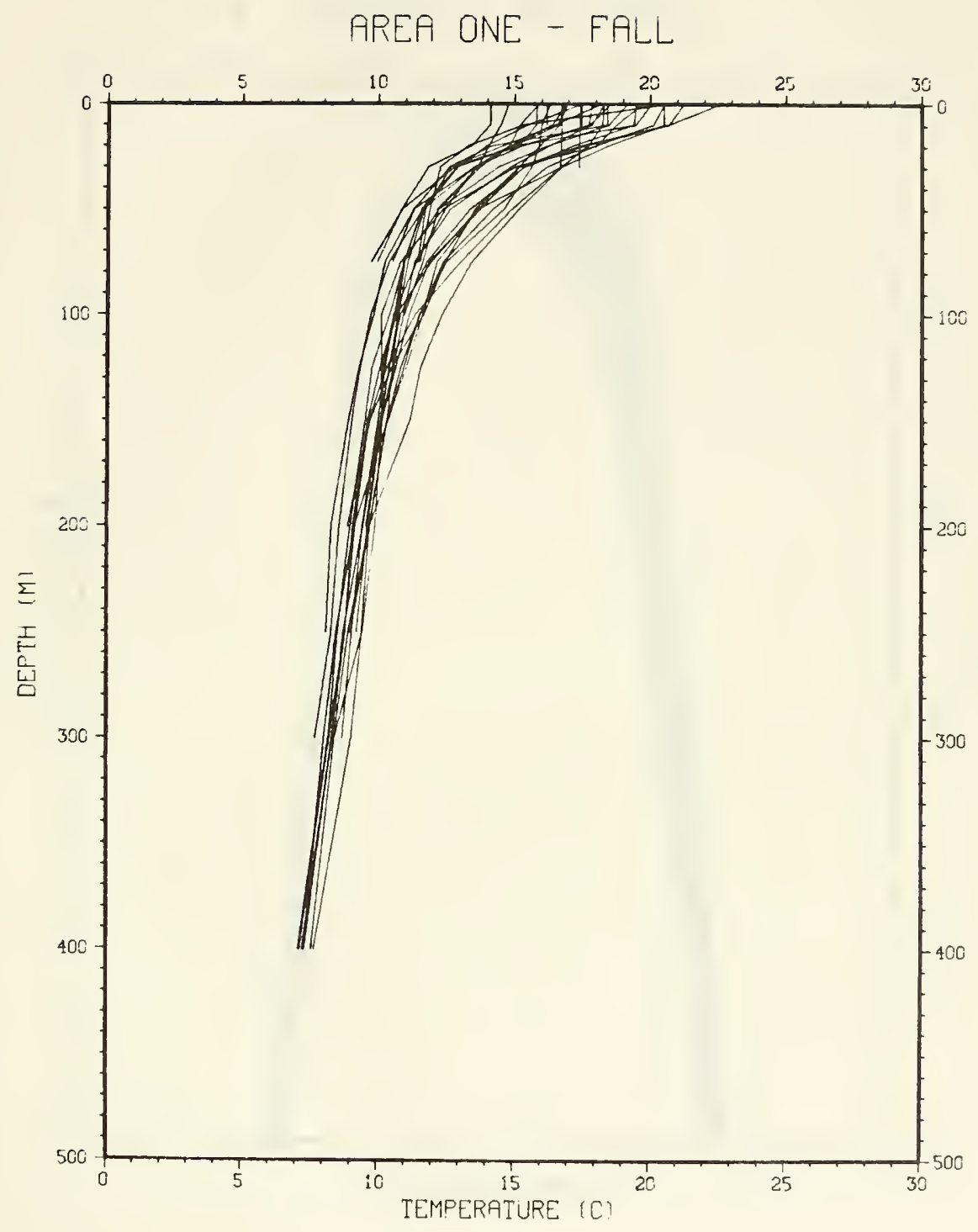

Figure B.5. 


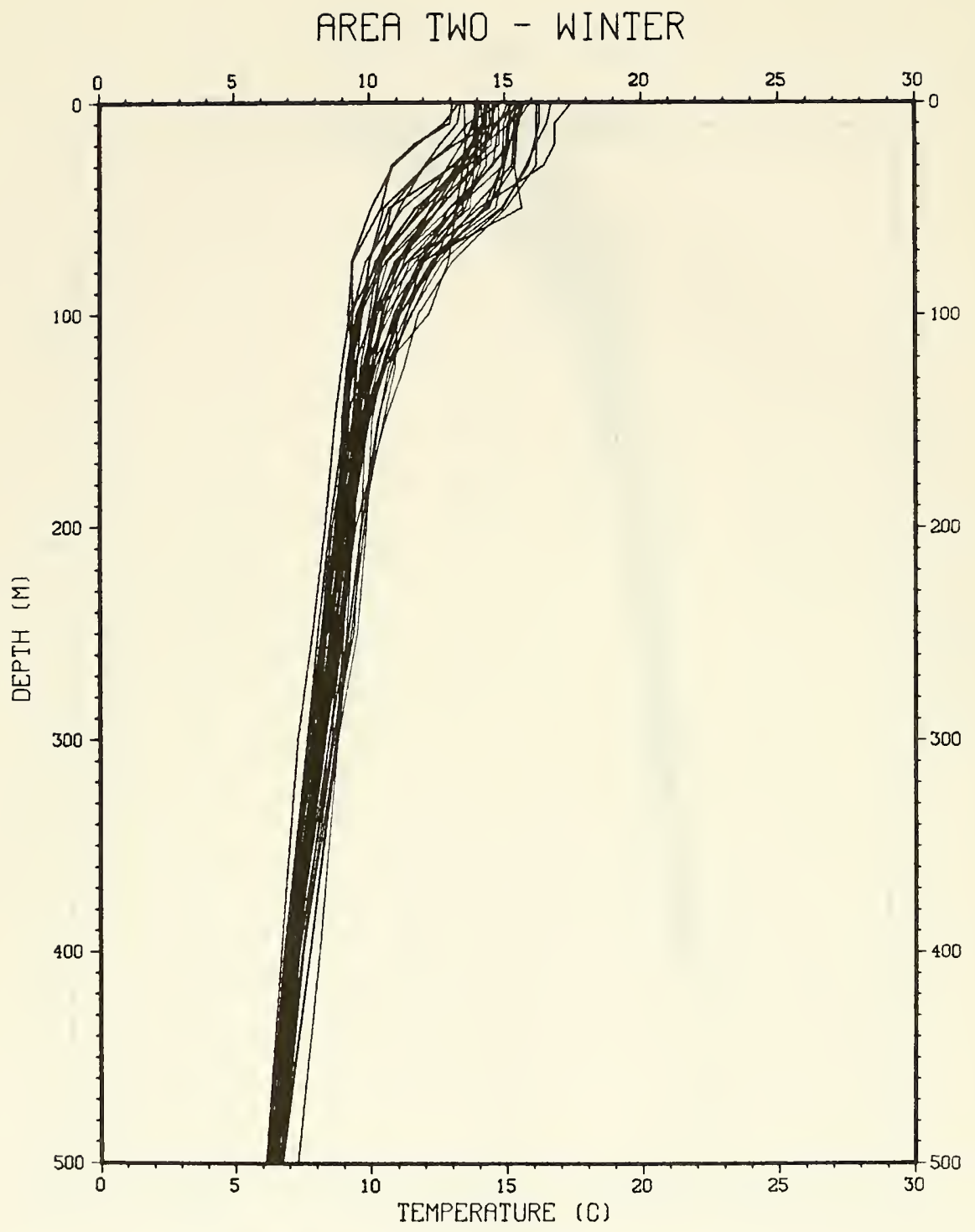

Figure B.6. 


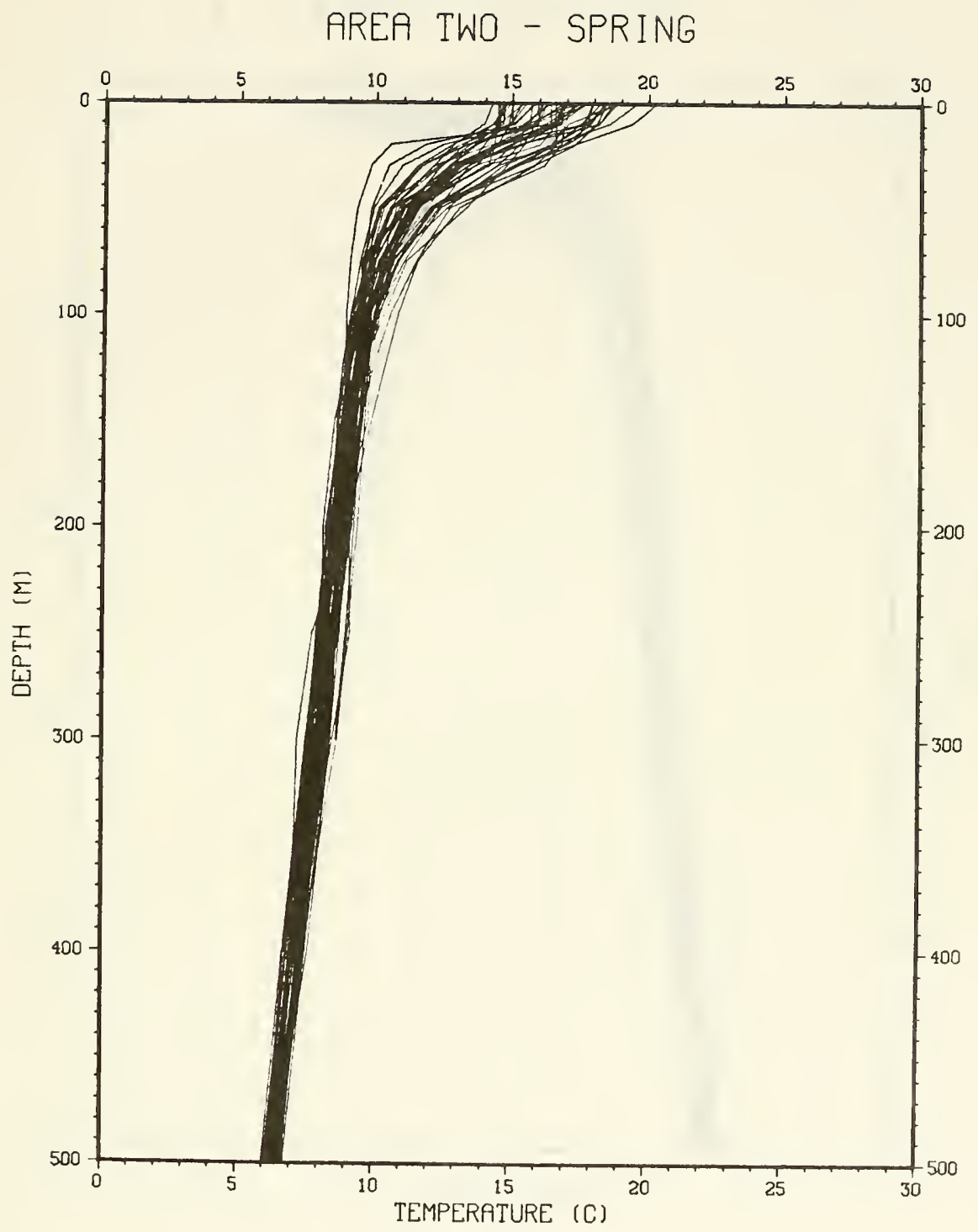

Figure B.7. 


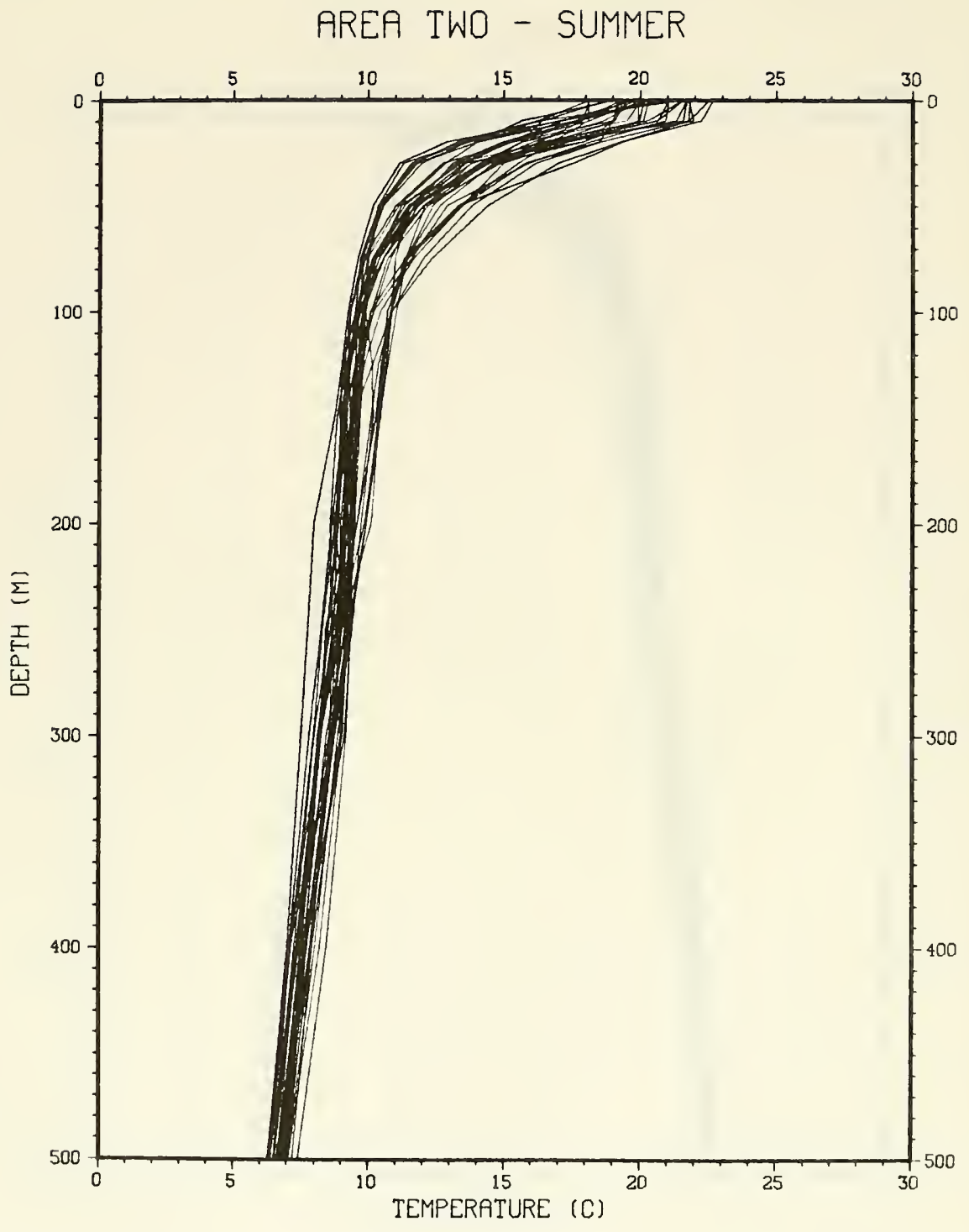

Figure B.8. 


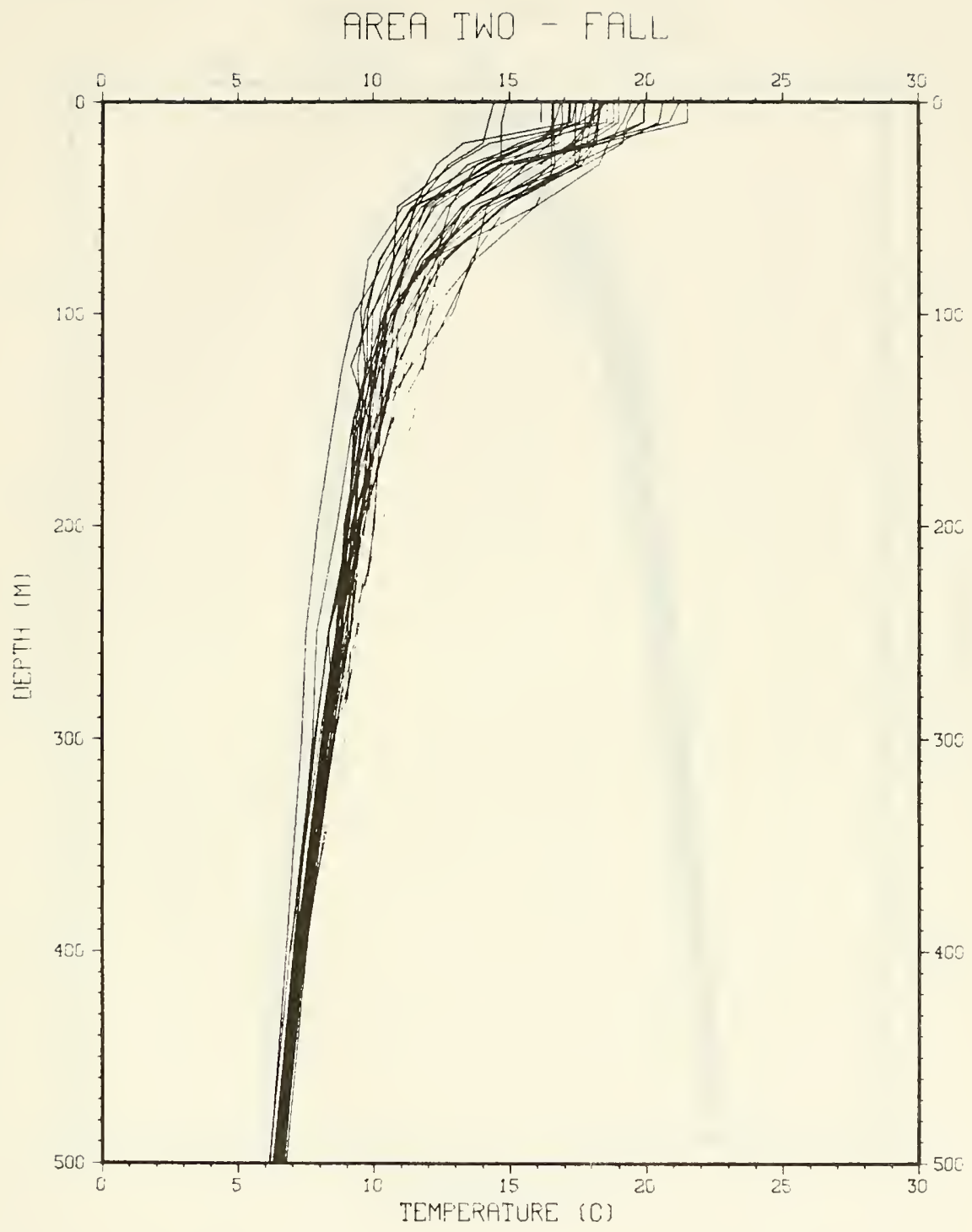

Figure B.9. 


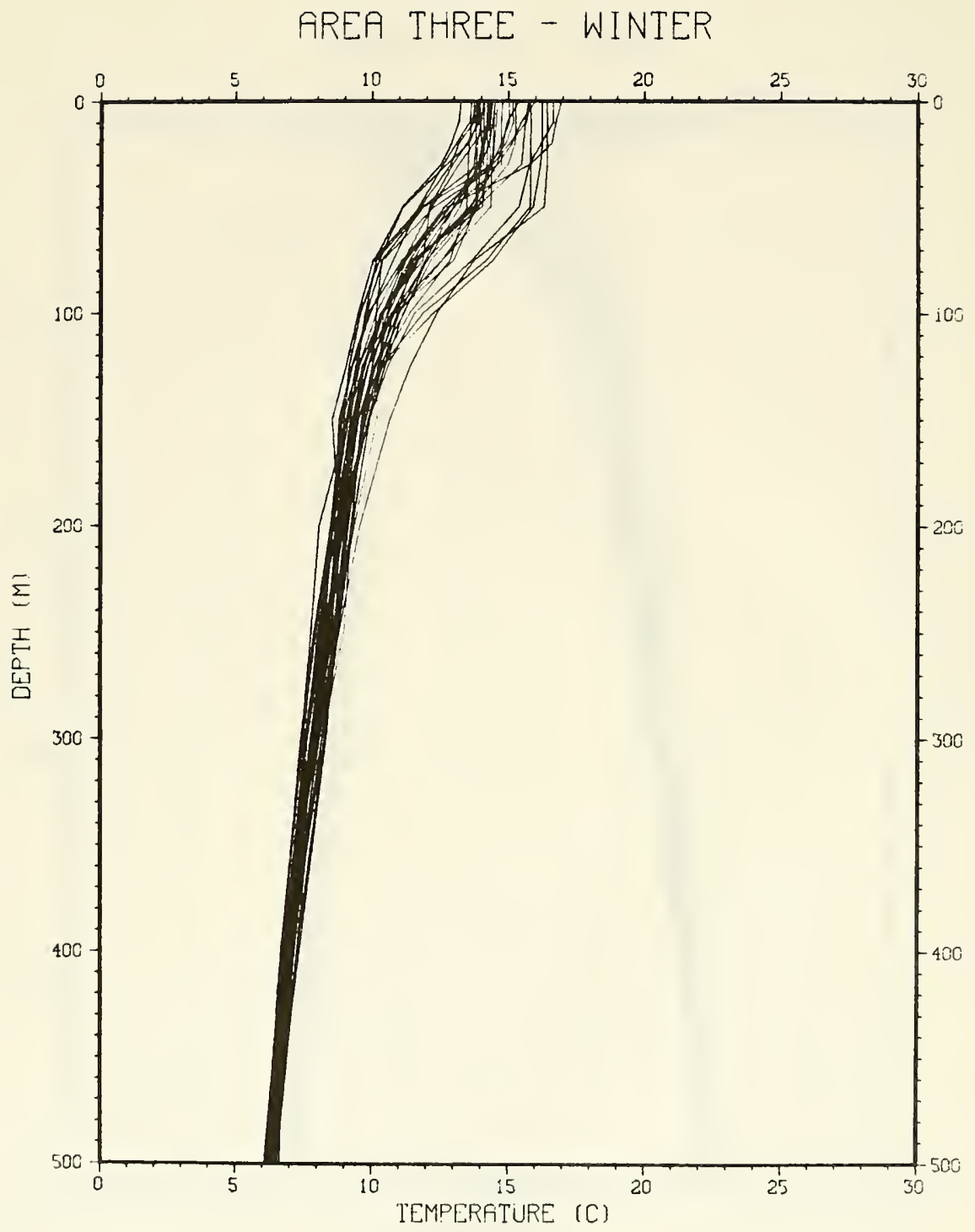

Figure B.10. 


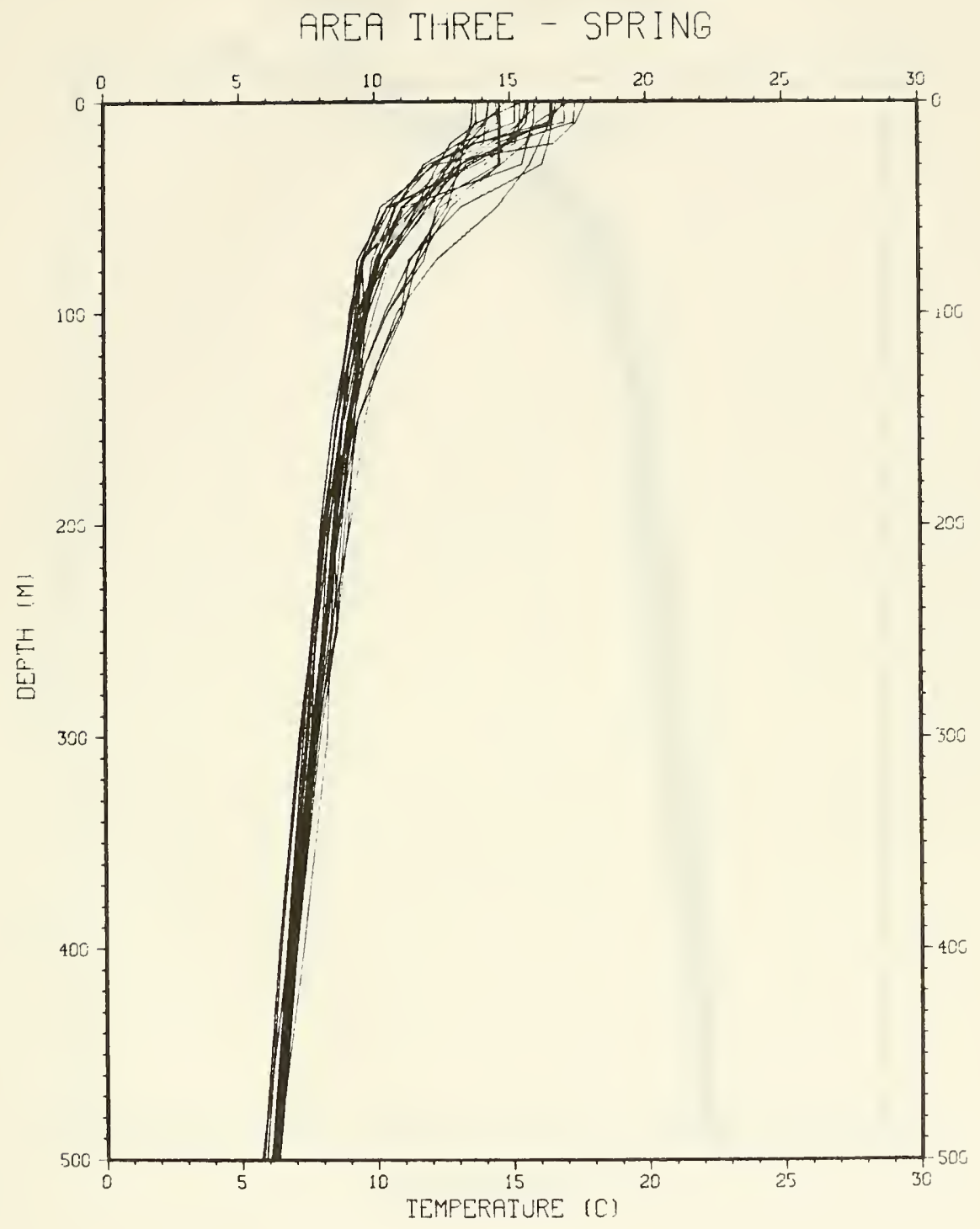

Figure B.11. 


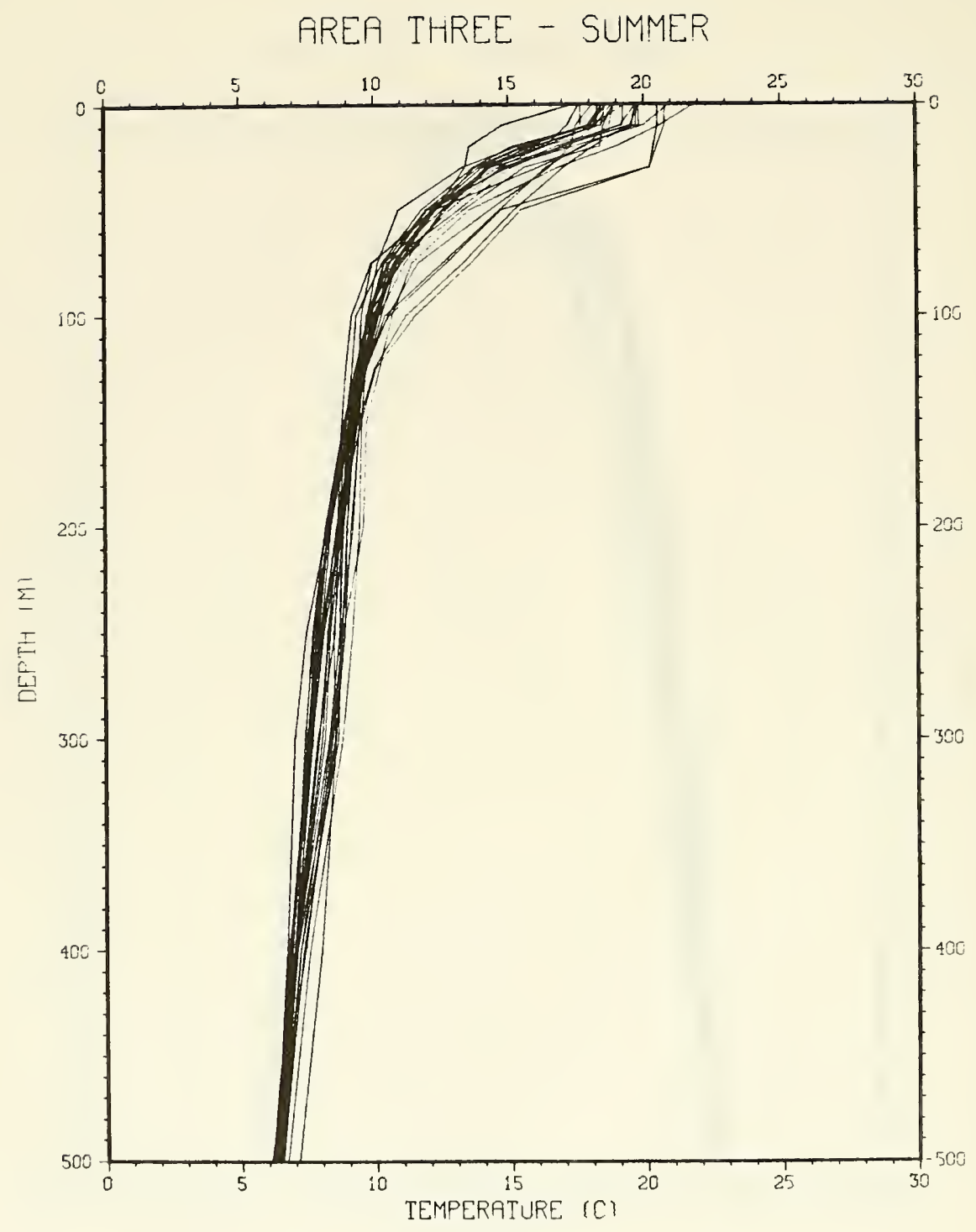

Figure B.12. 


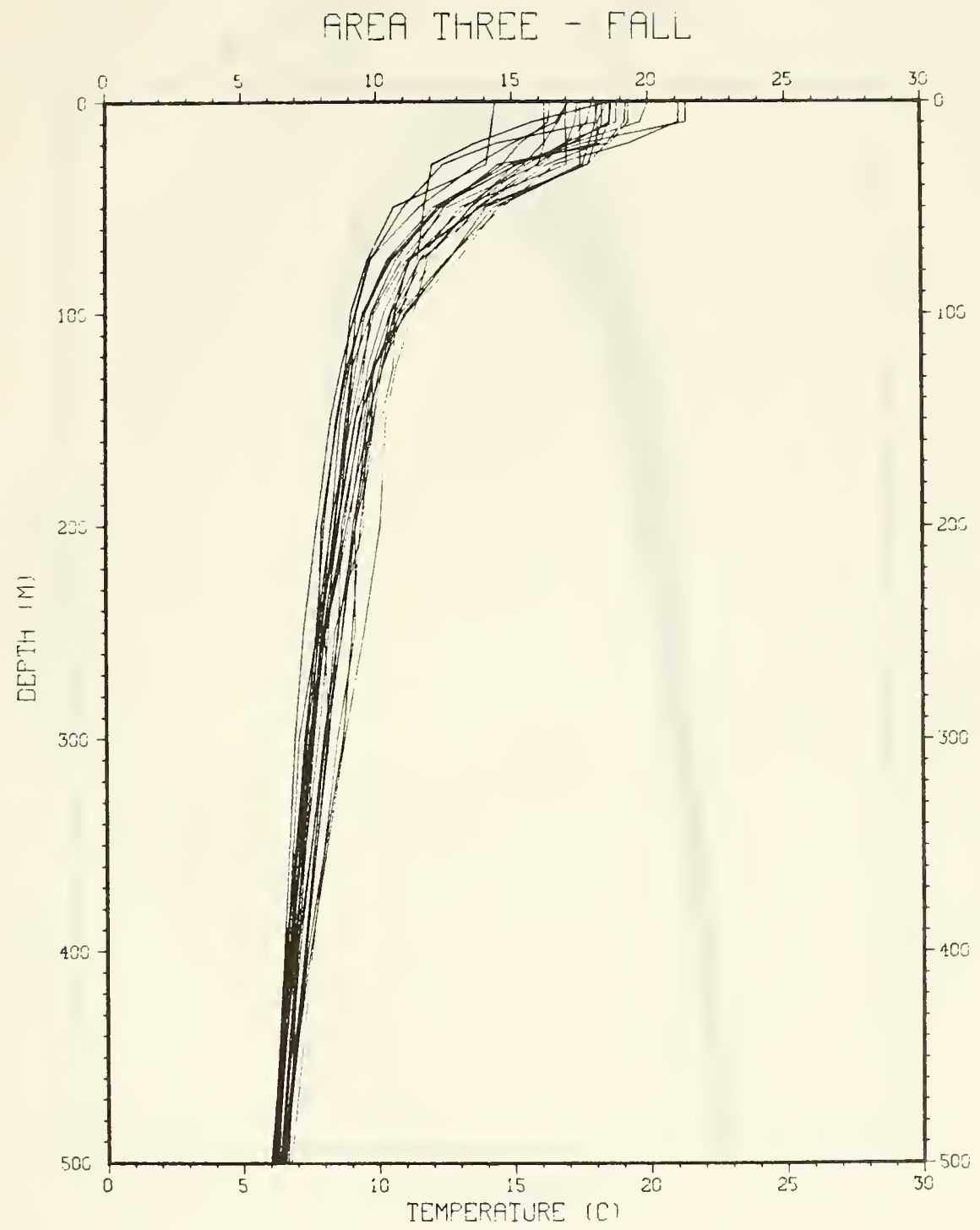

Figure B.13. 


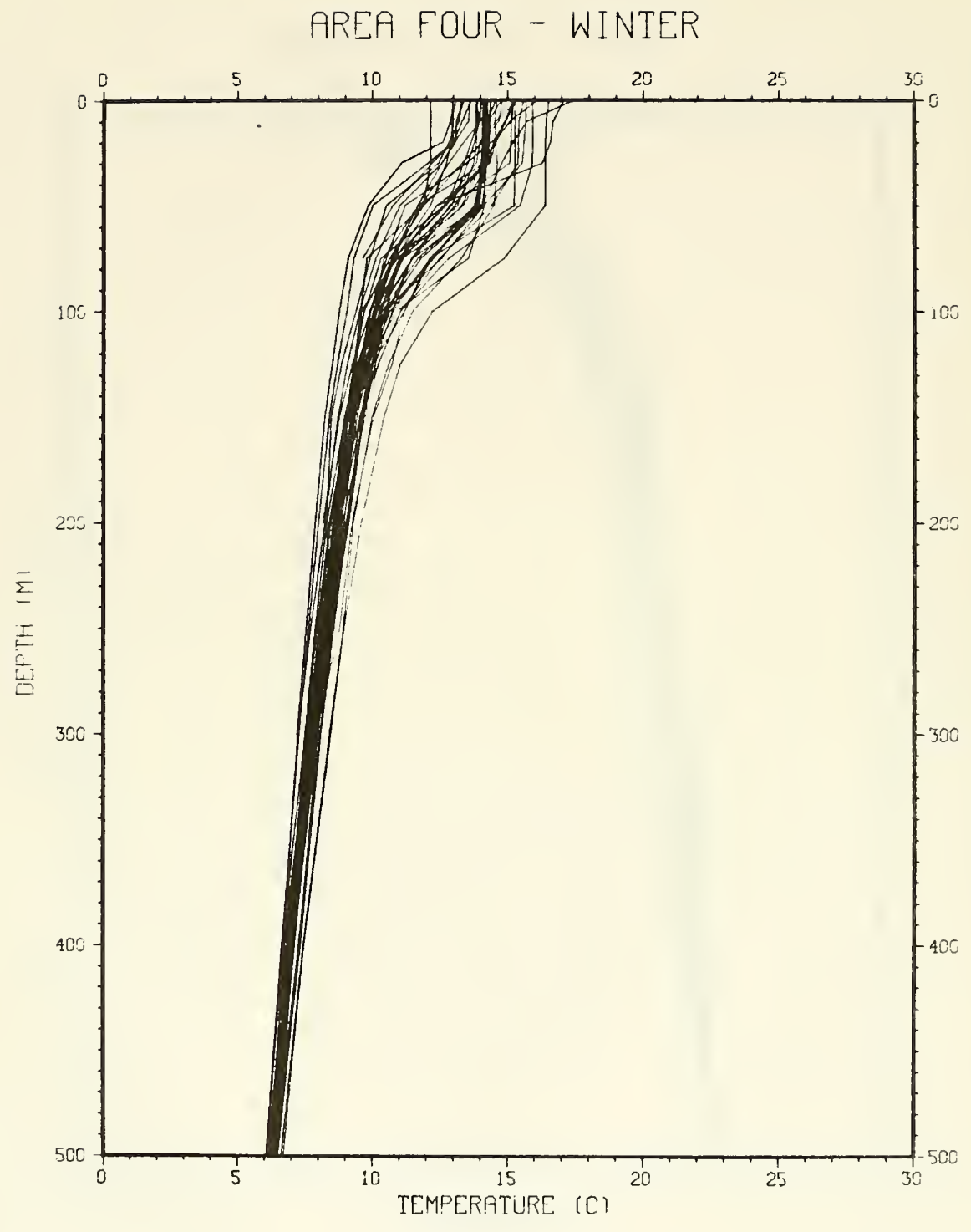

Figure B.14. 


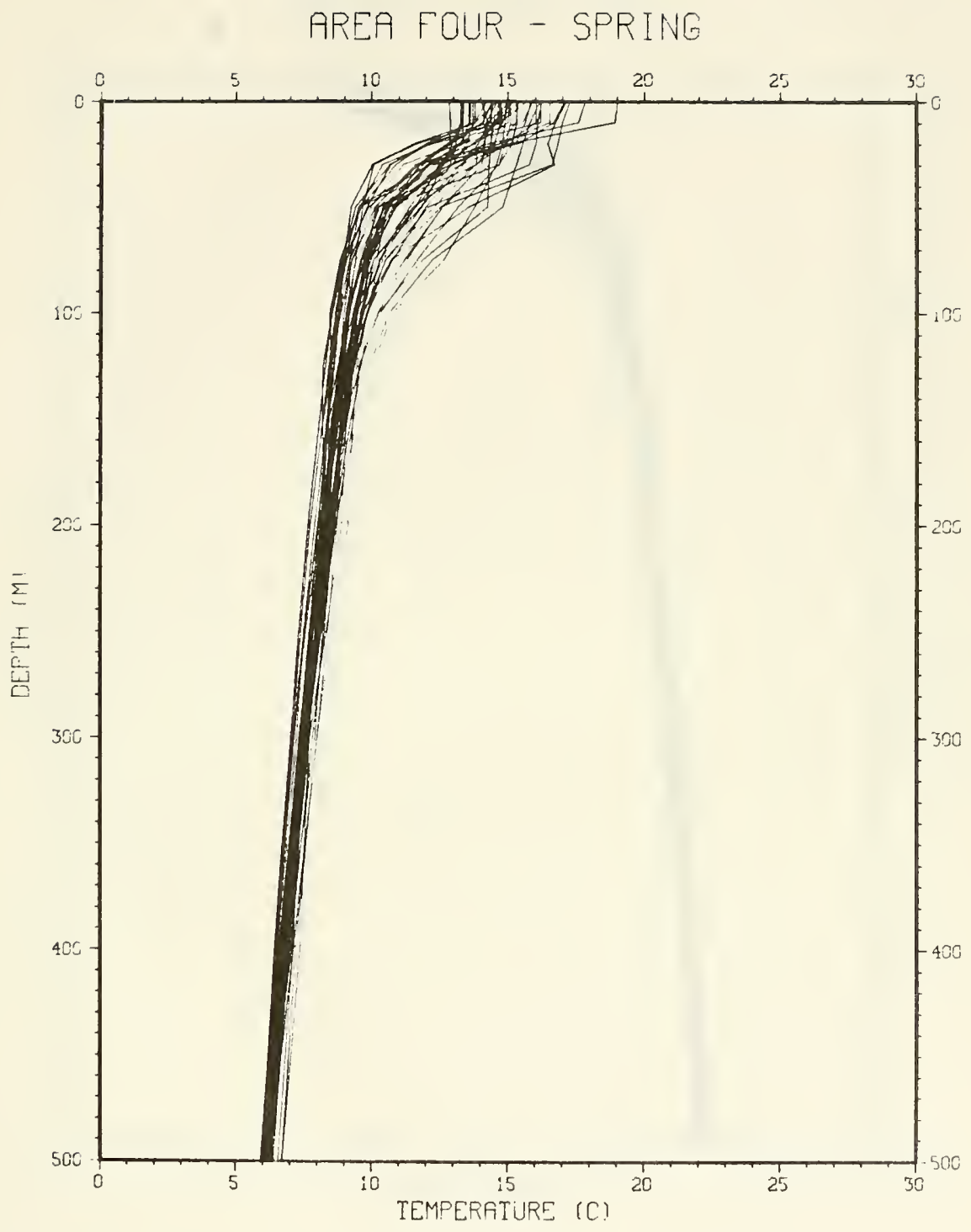

Figure B.15. 


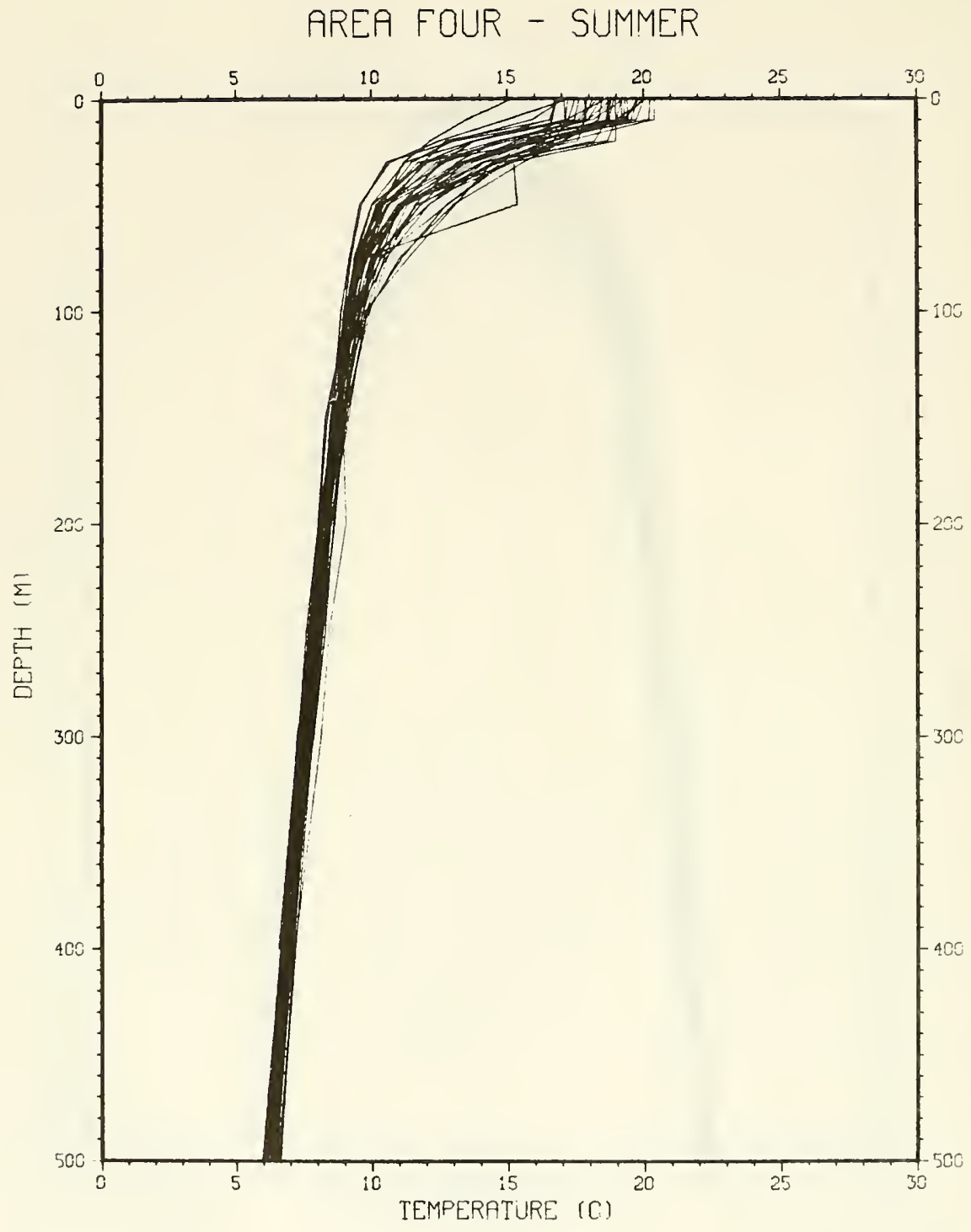

Figure B.16. 


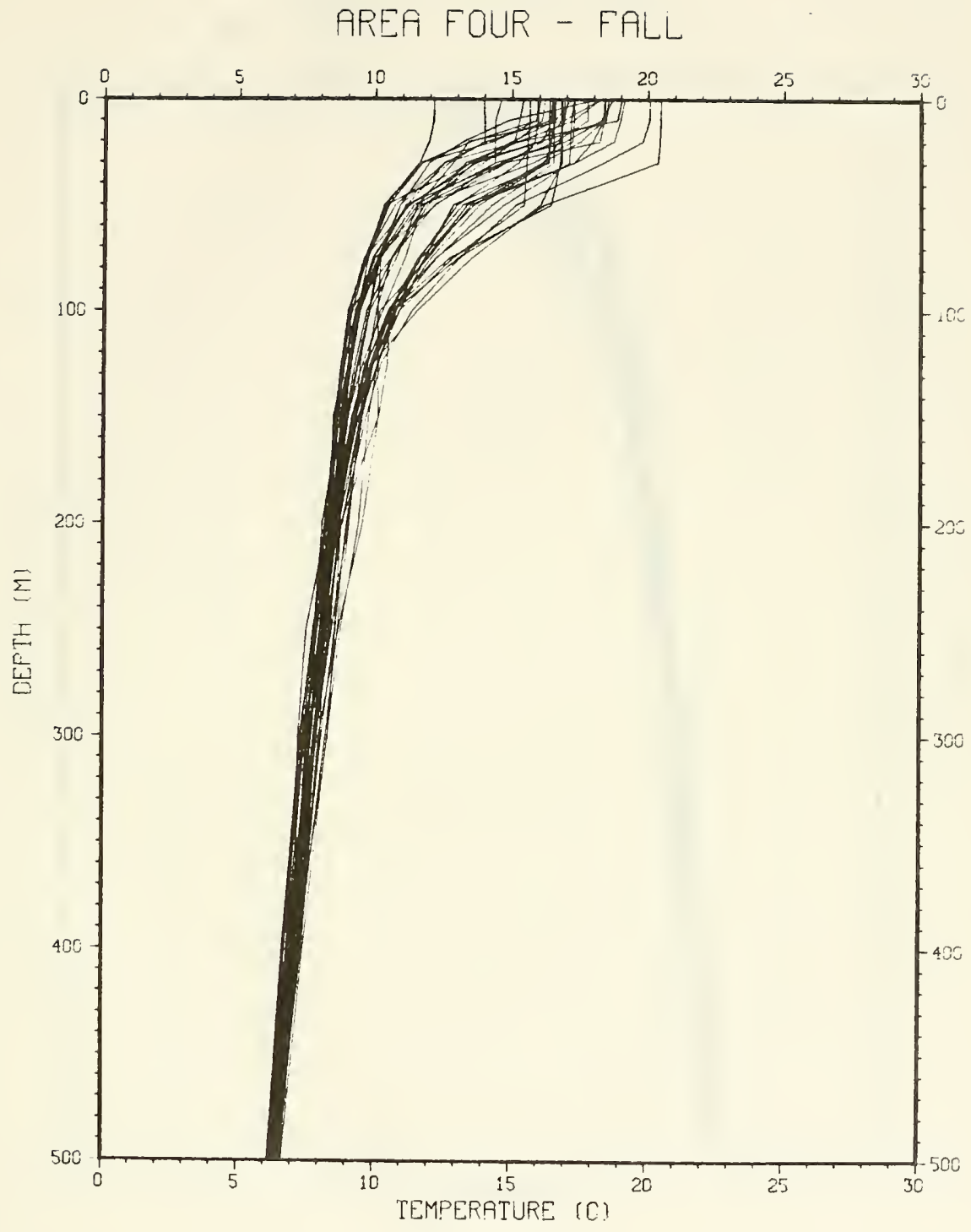

Figure B.17. 


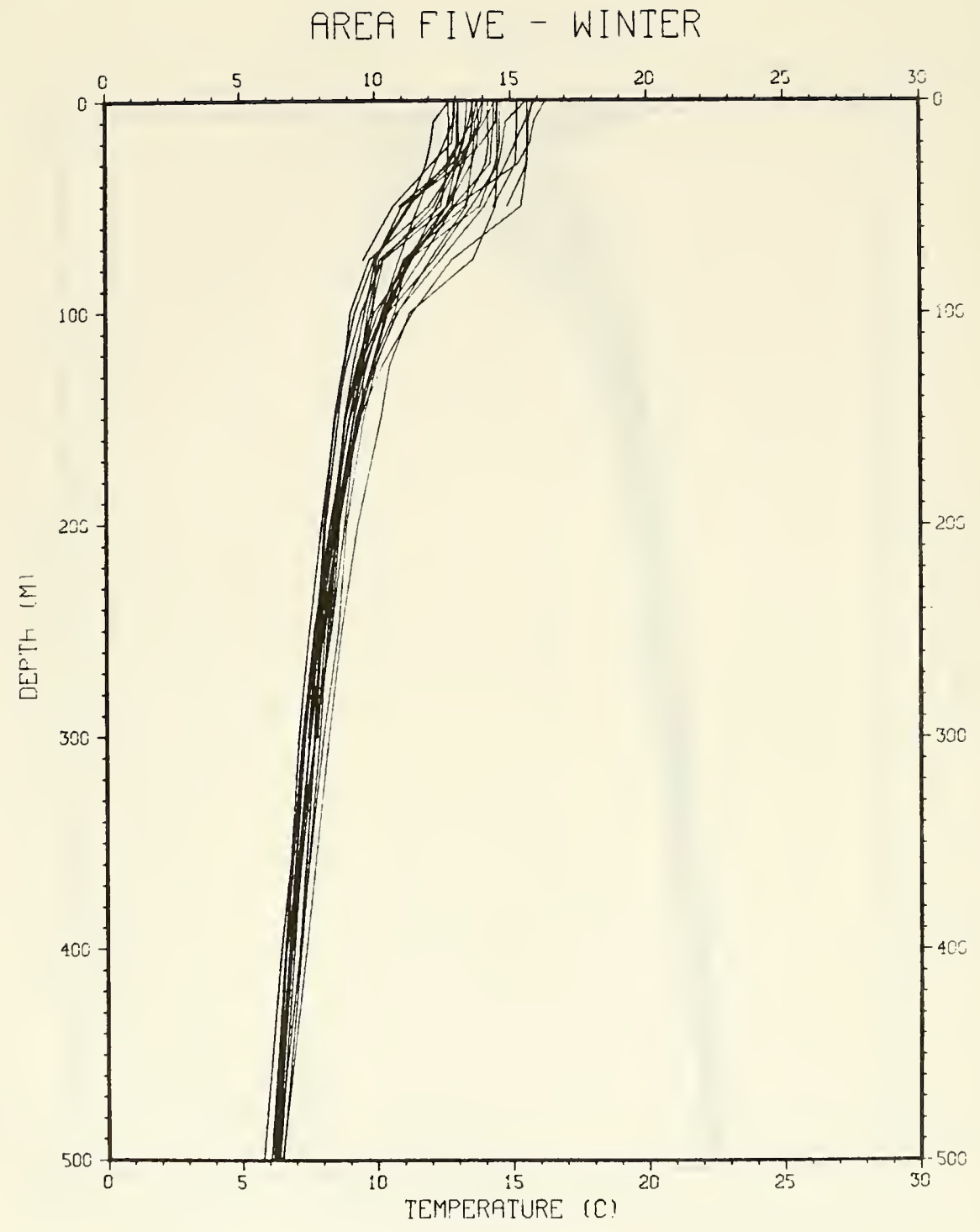

Figure B.18. 


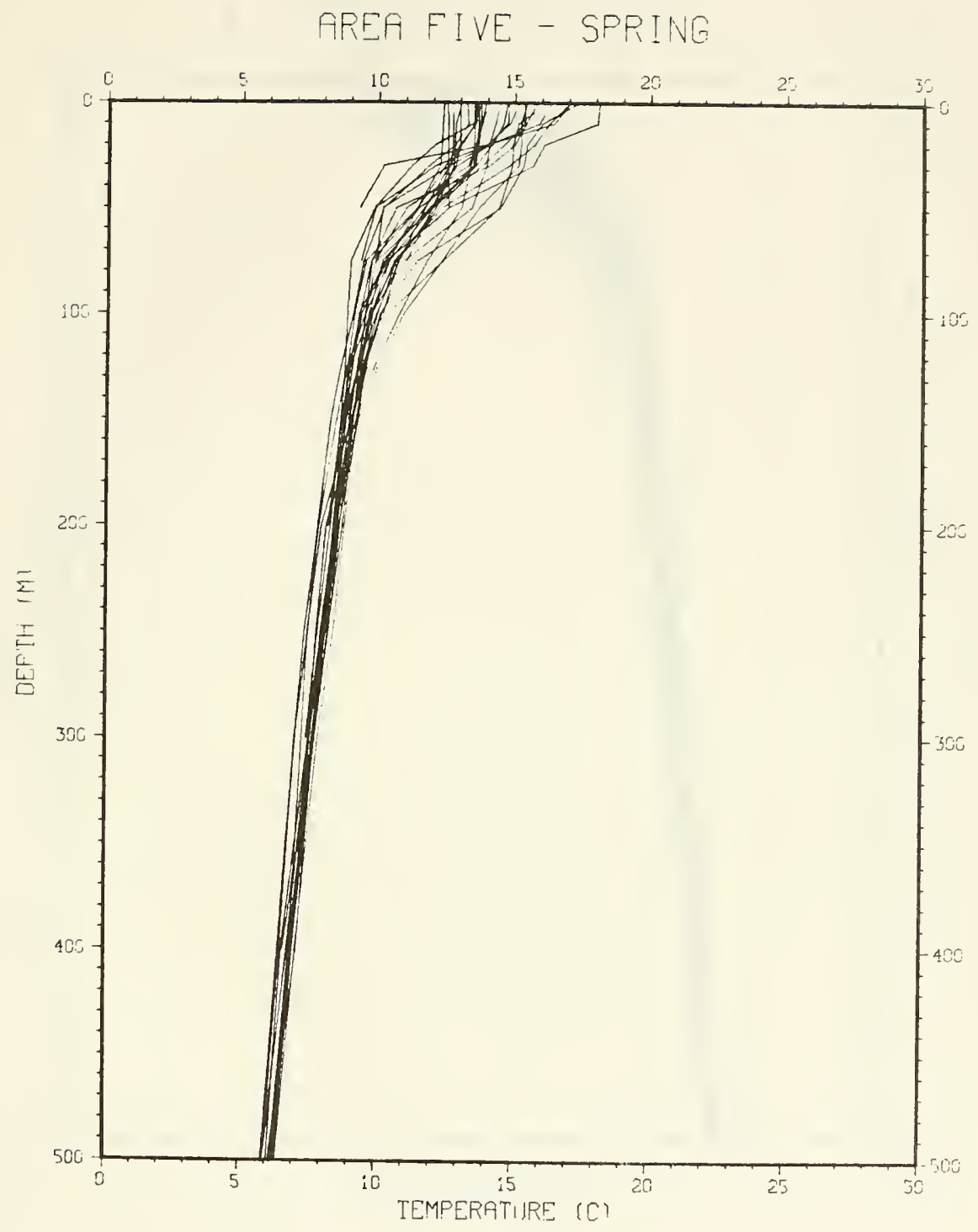

Figure B.19. 


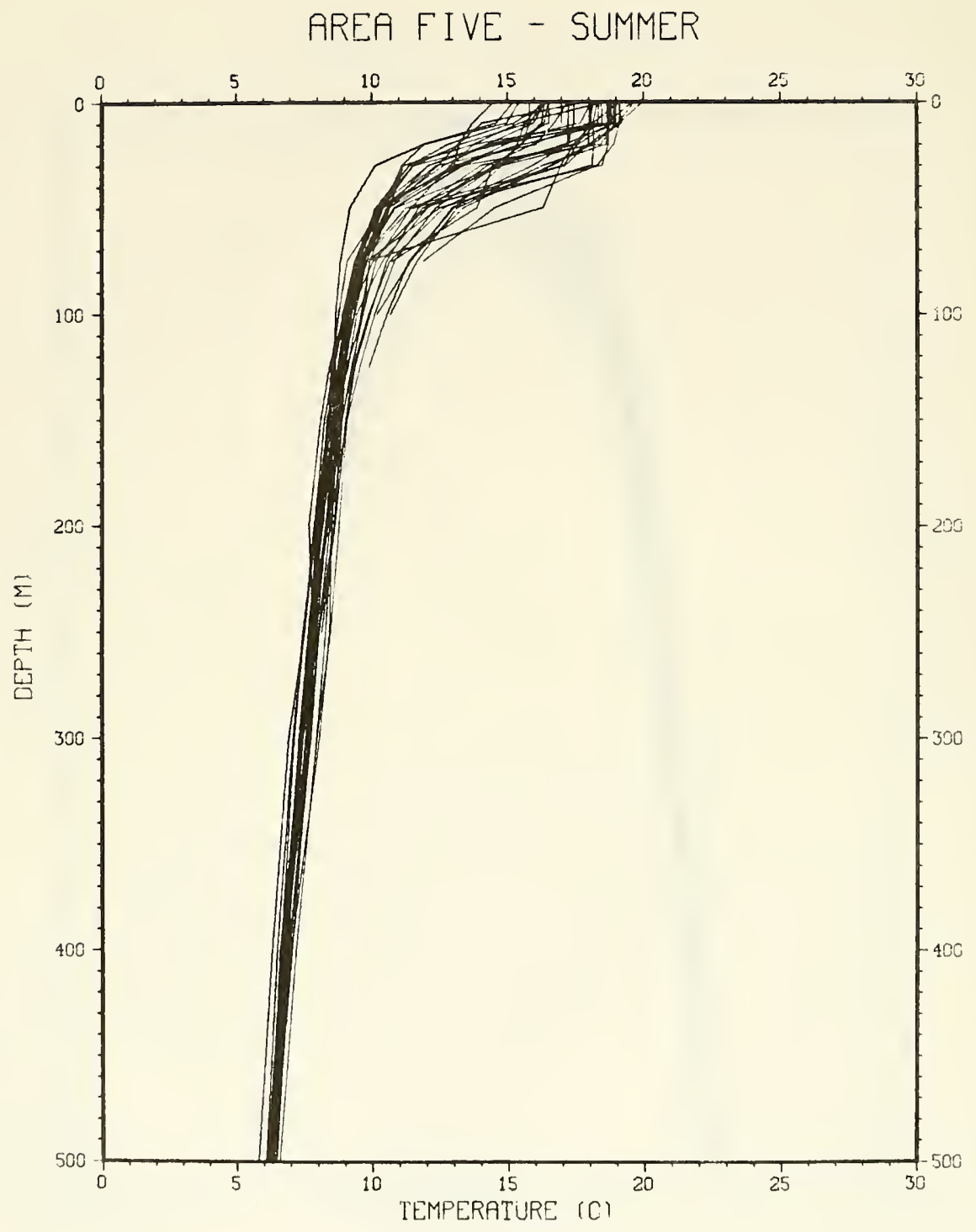

Figure B.20. 


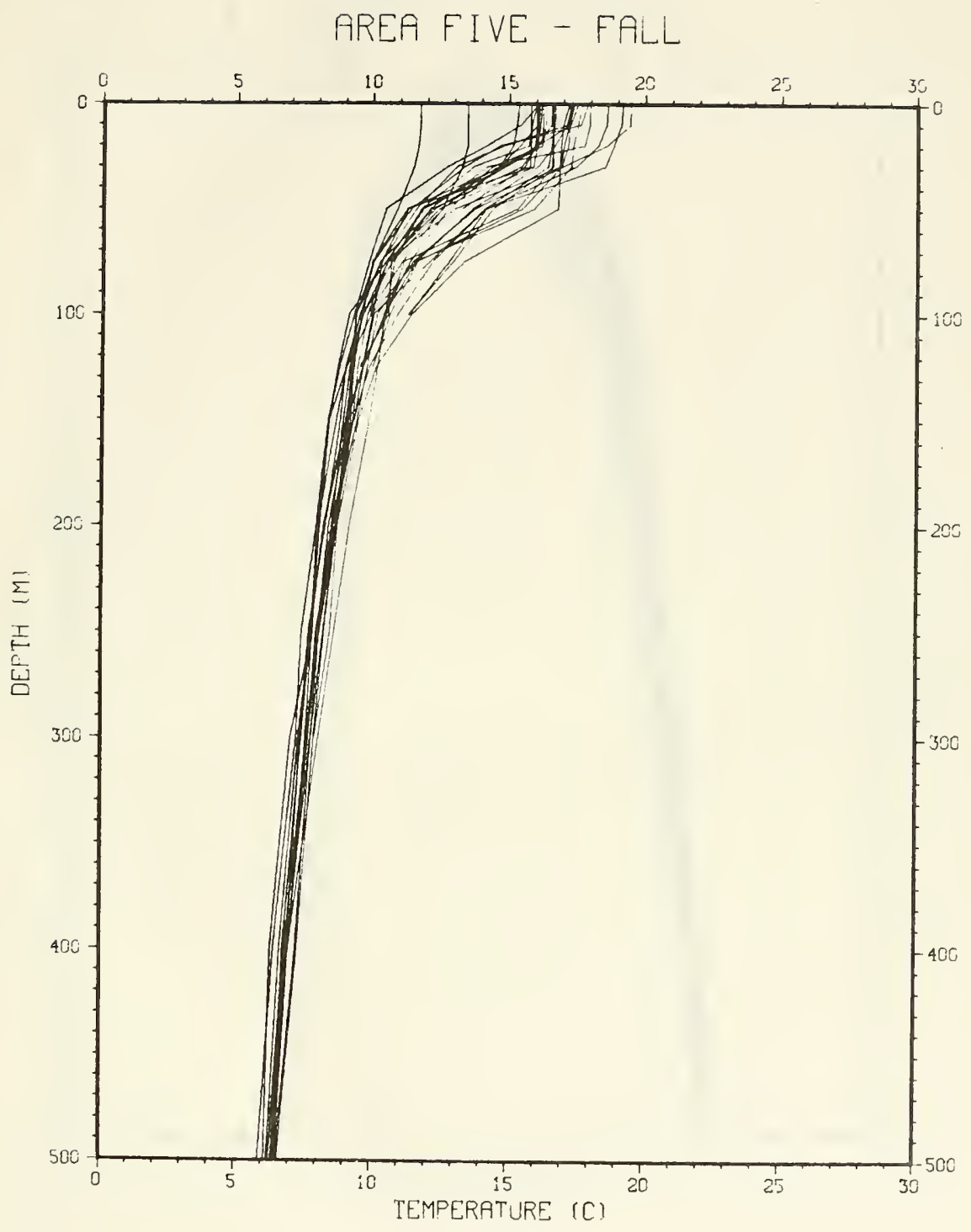

Figure B.21. 


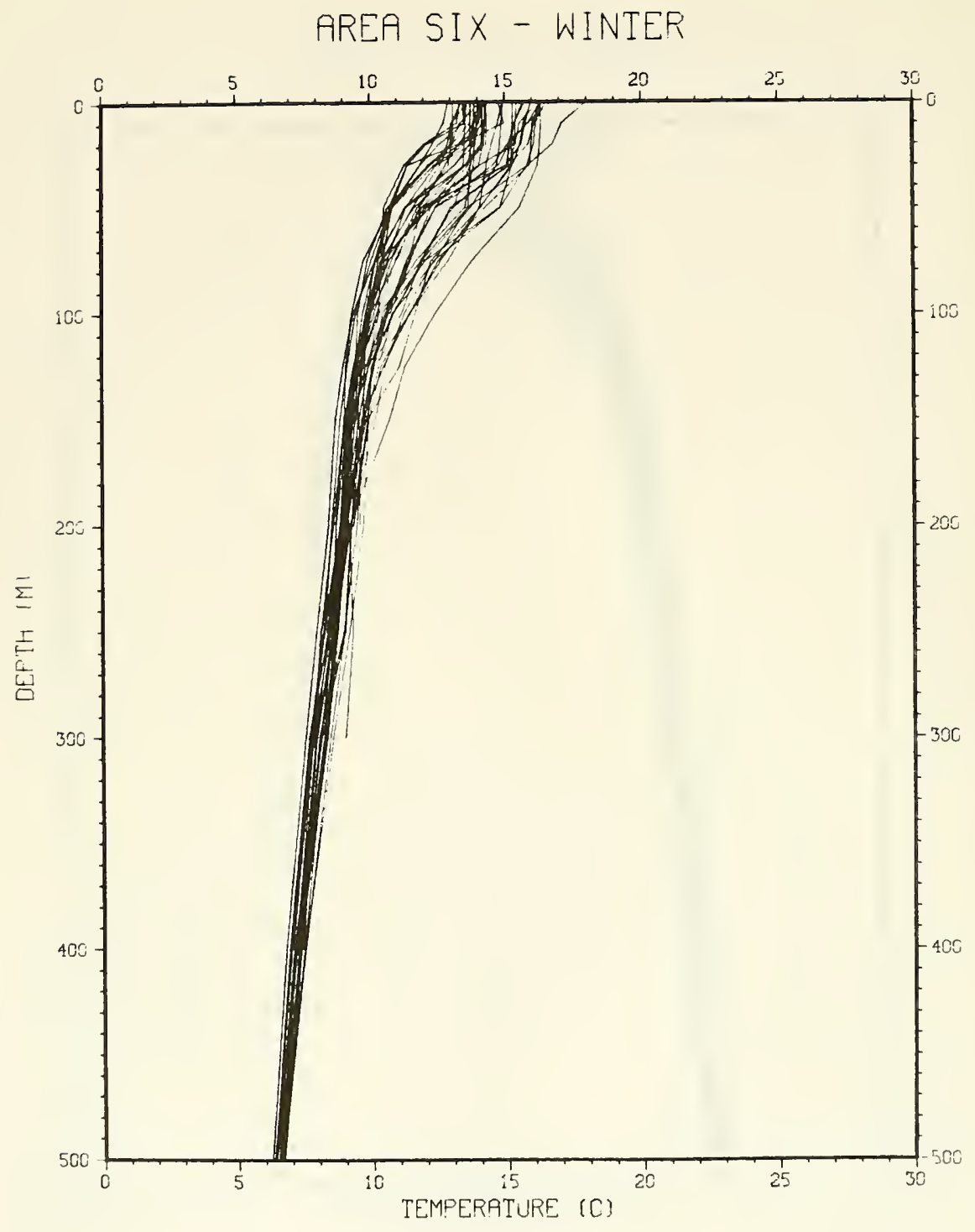

Figure B.22. 


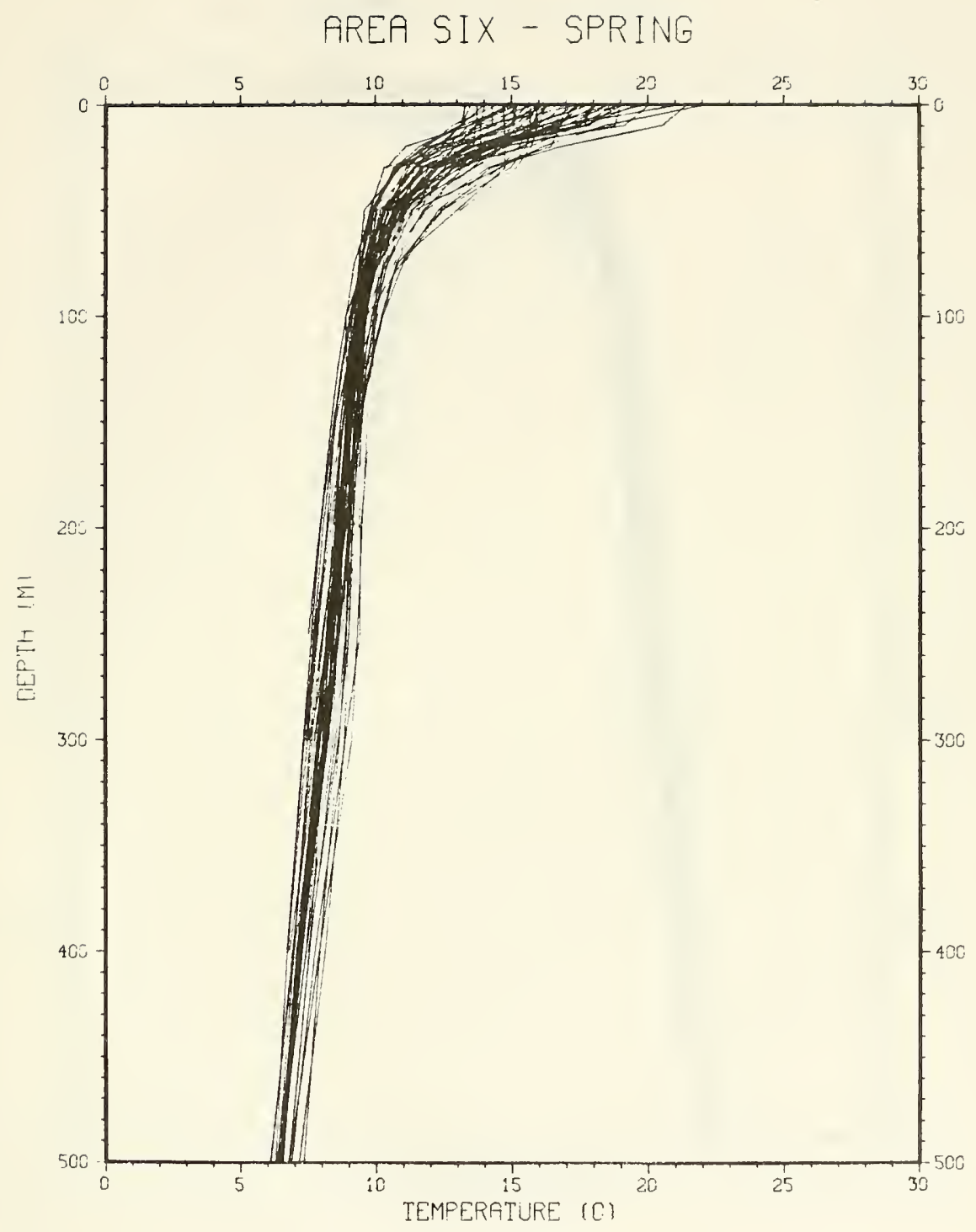

Figure B.23. 


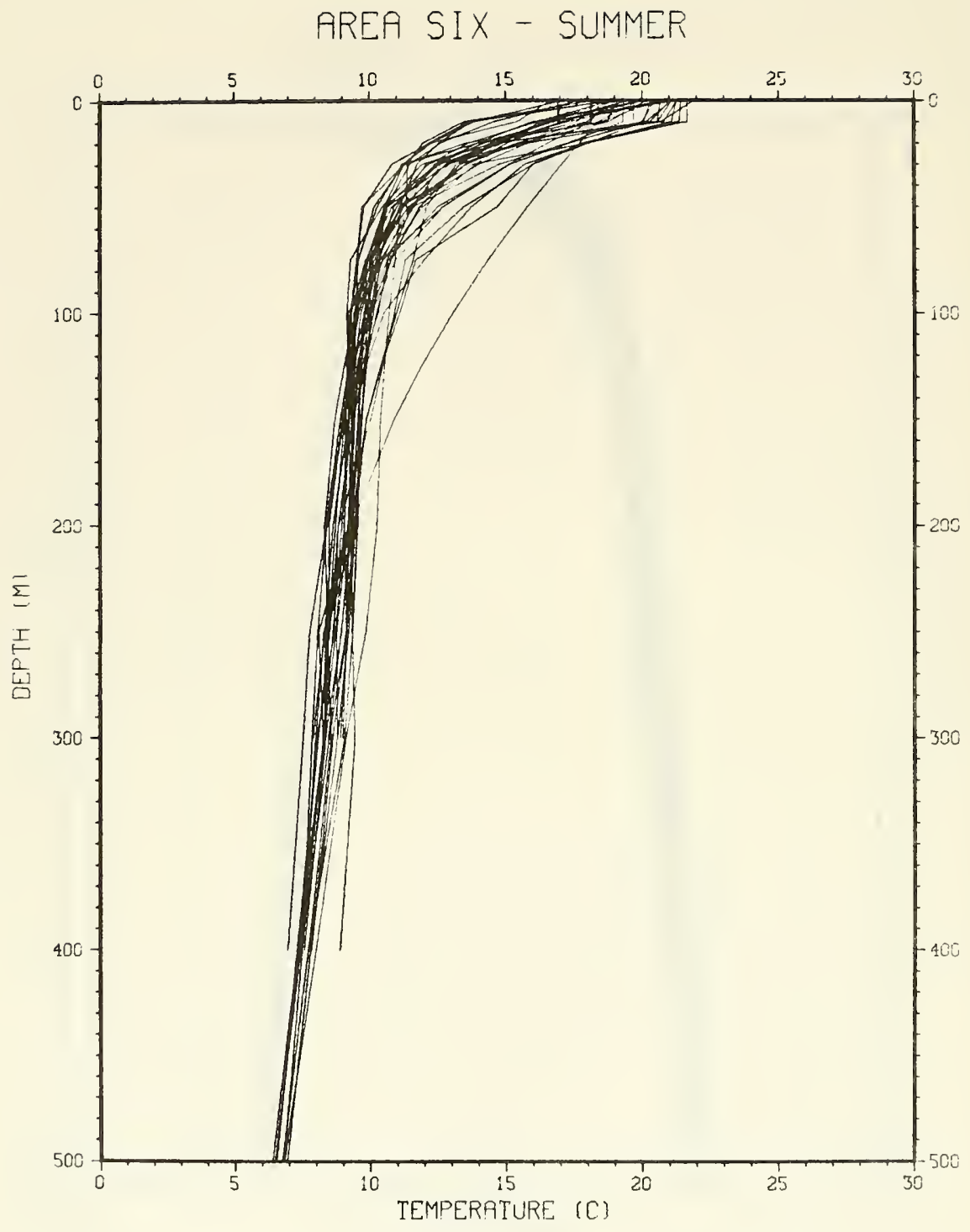

Figure B.24. 


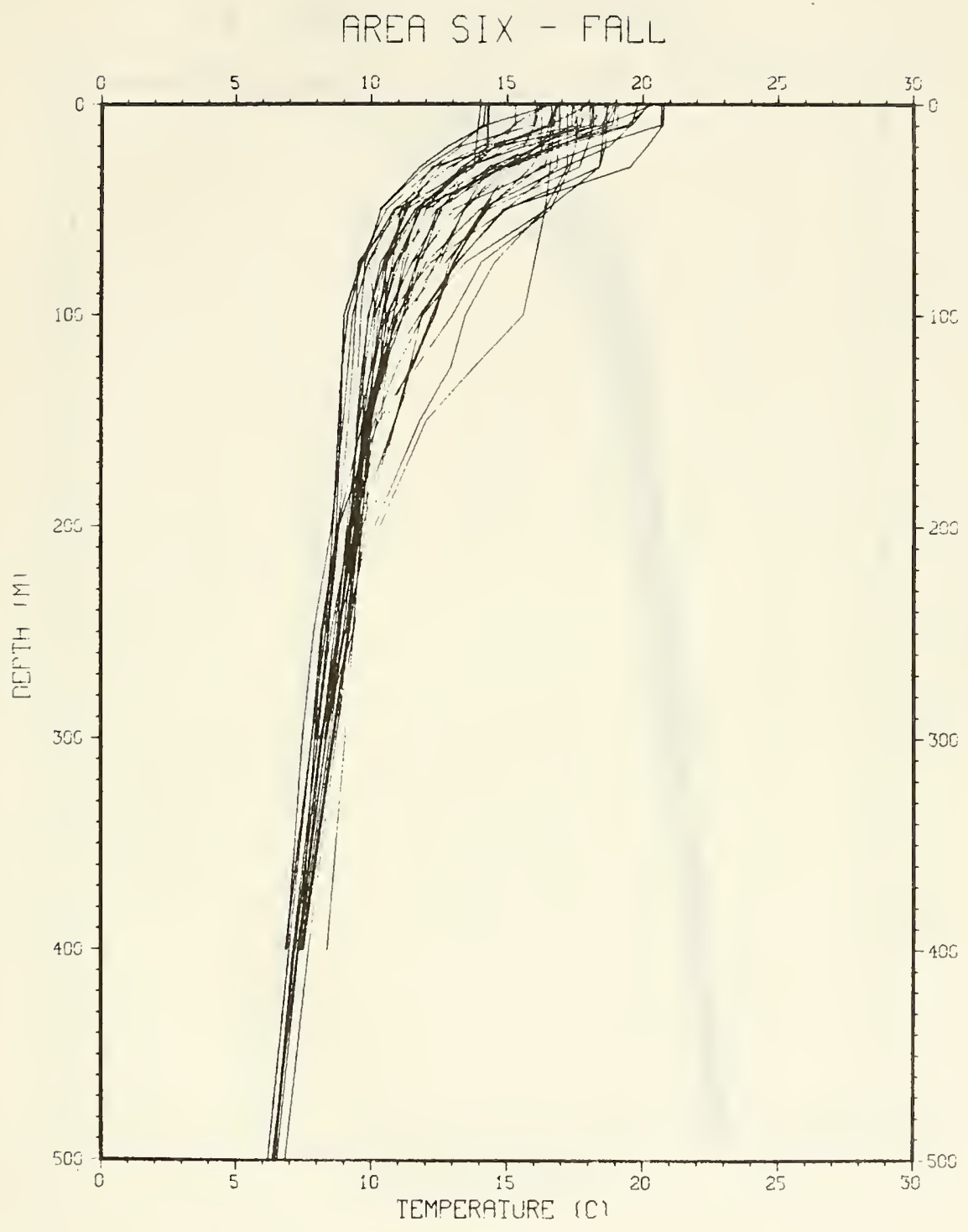

Figure B.25. 


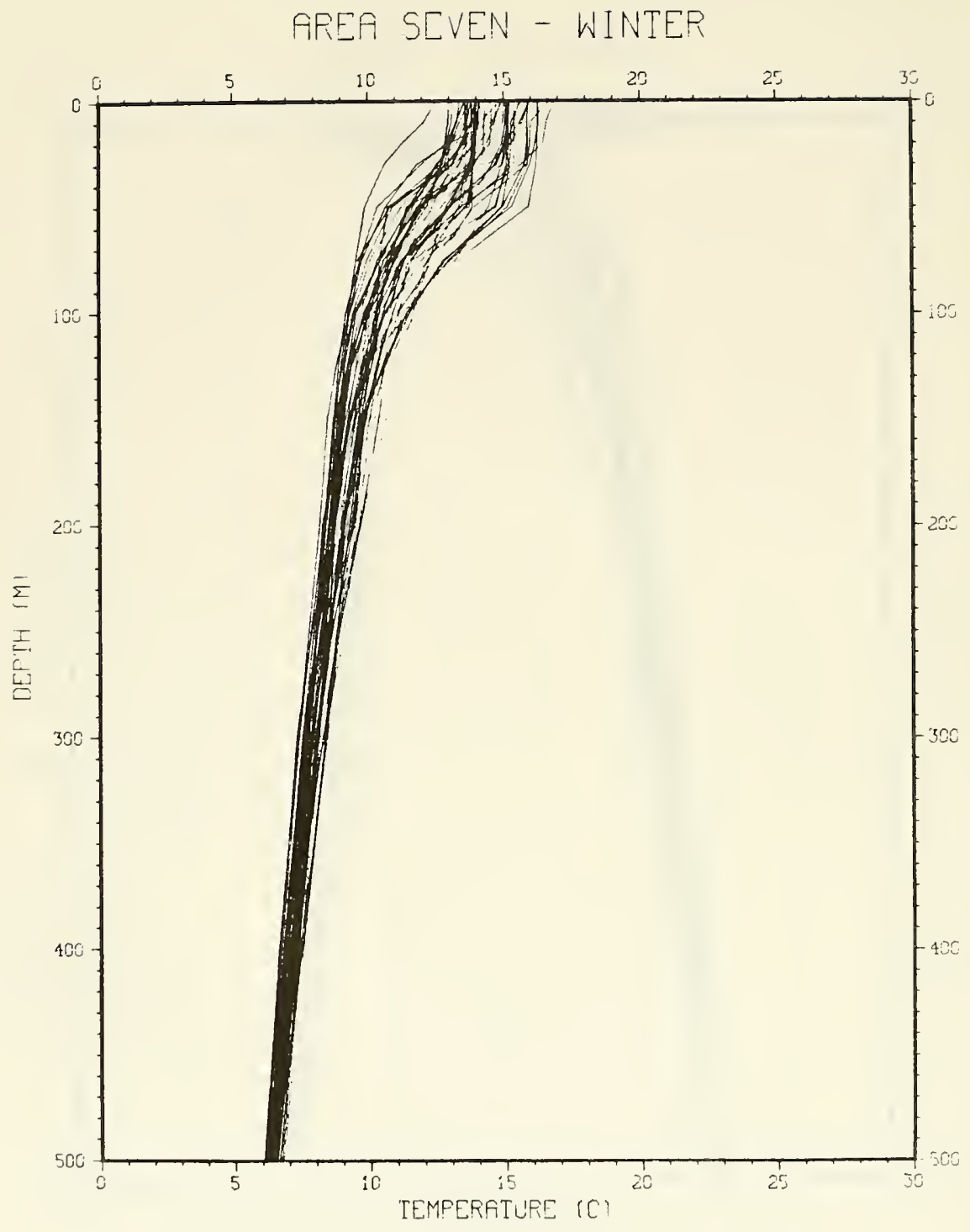

Figure B.26. 


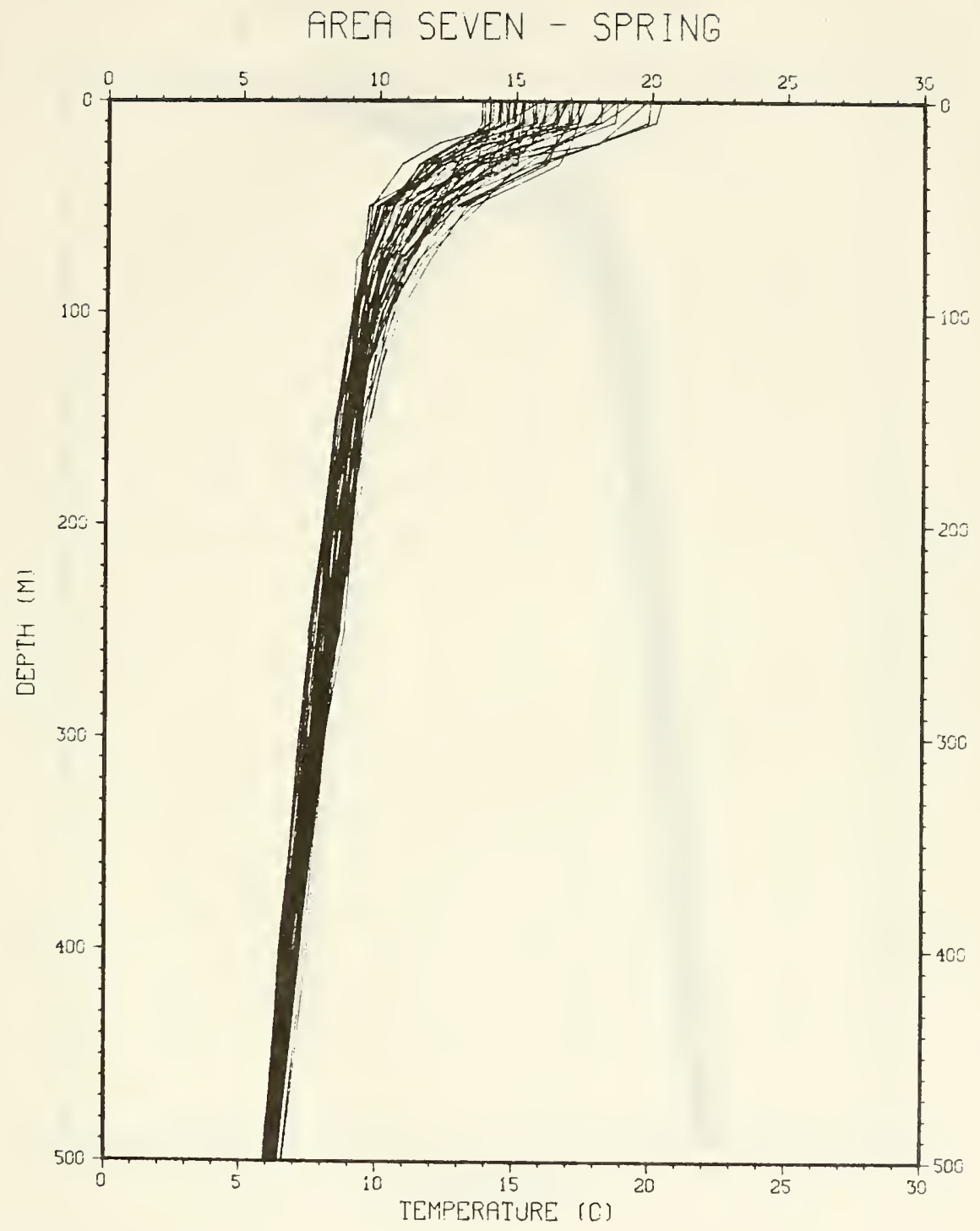

Figure B.27. 


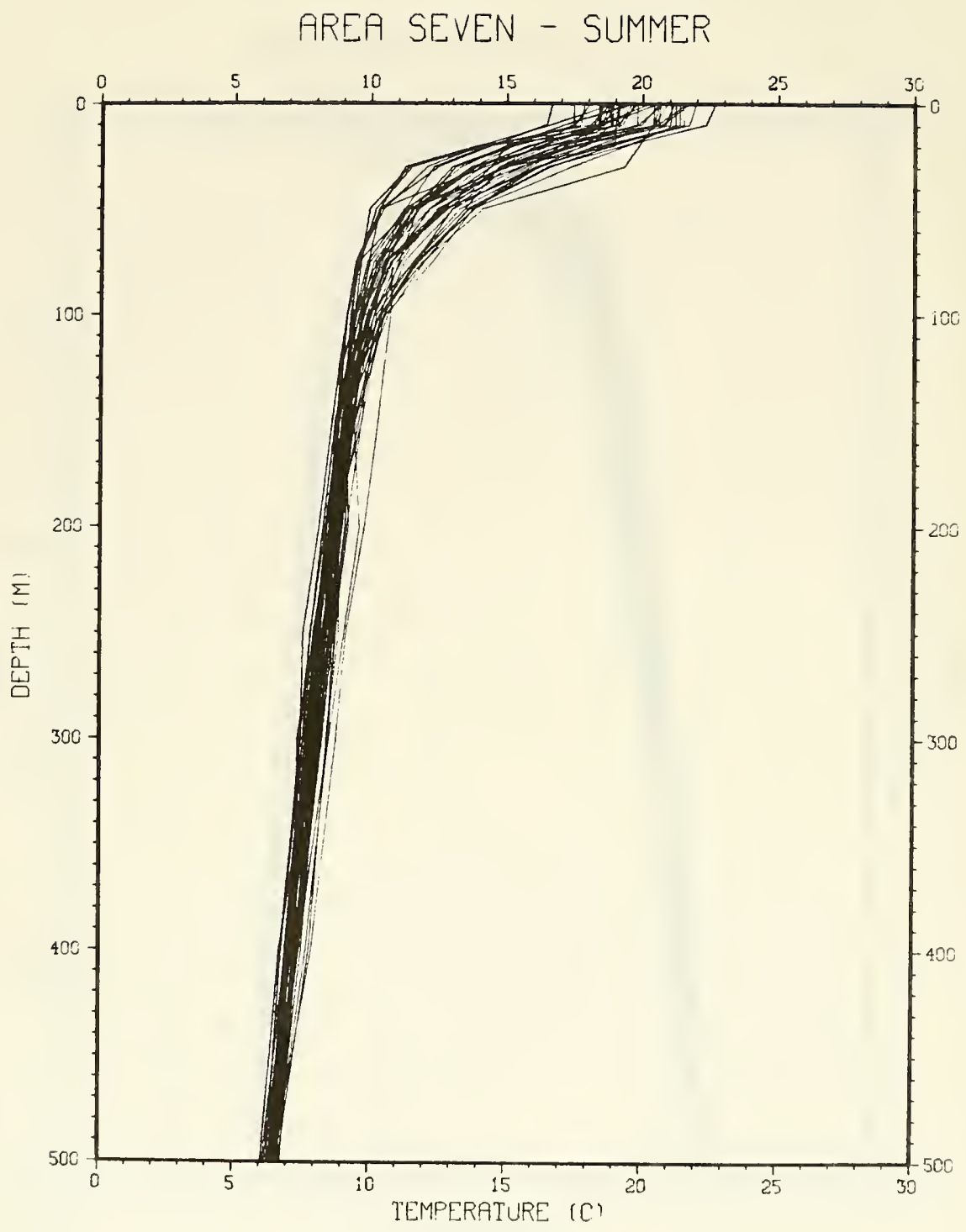

Figure B.28. 


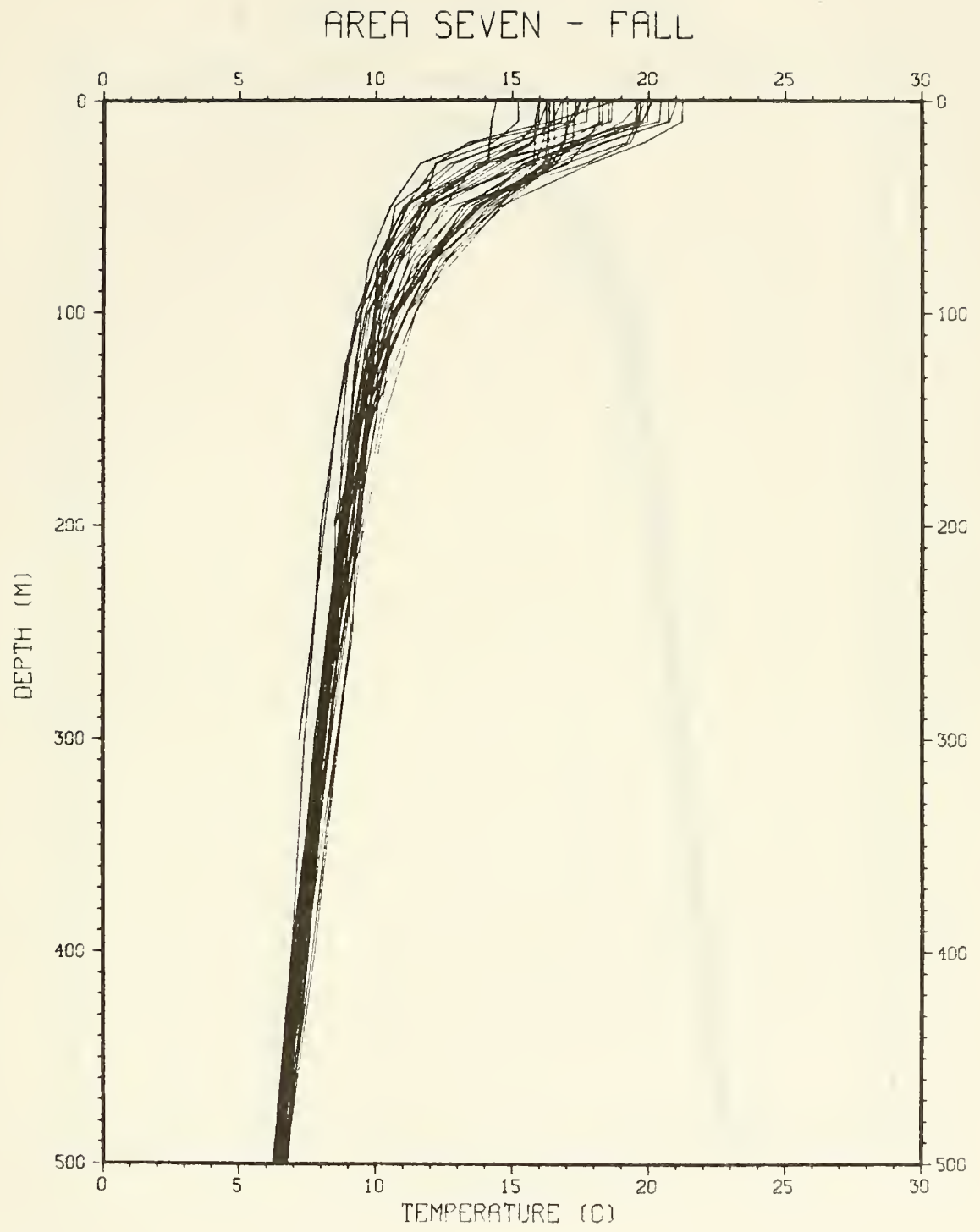

Figure B.29. 


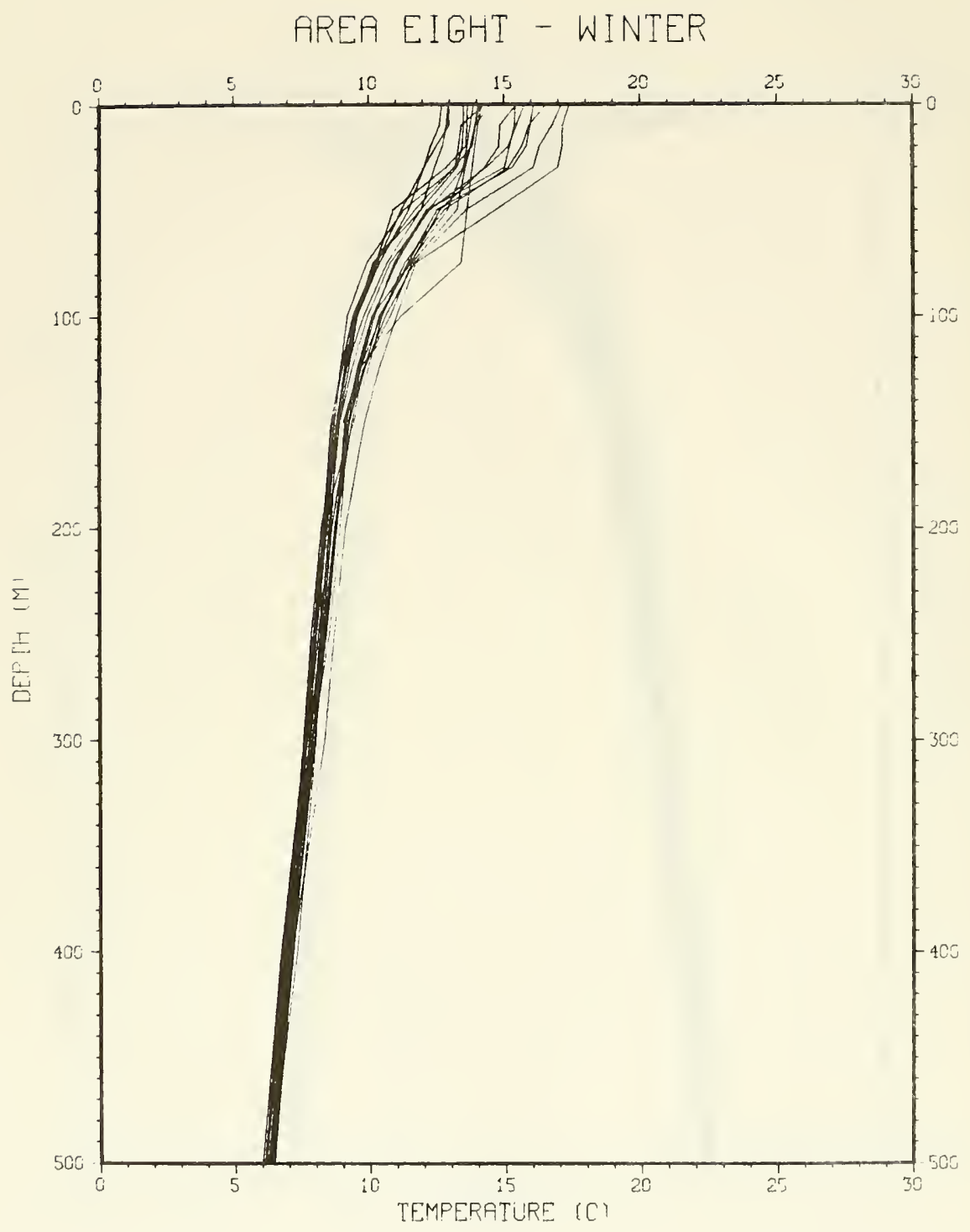

Figure B.30. 


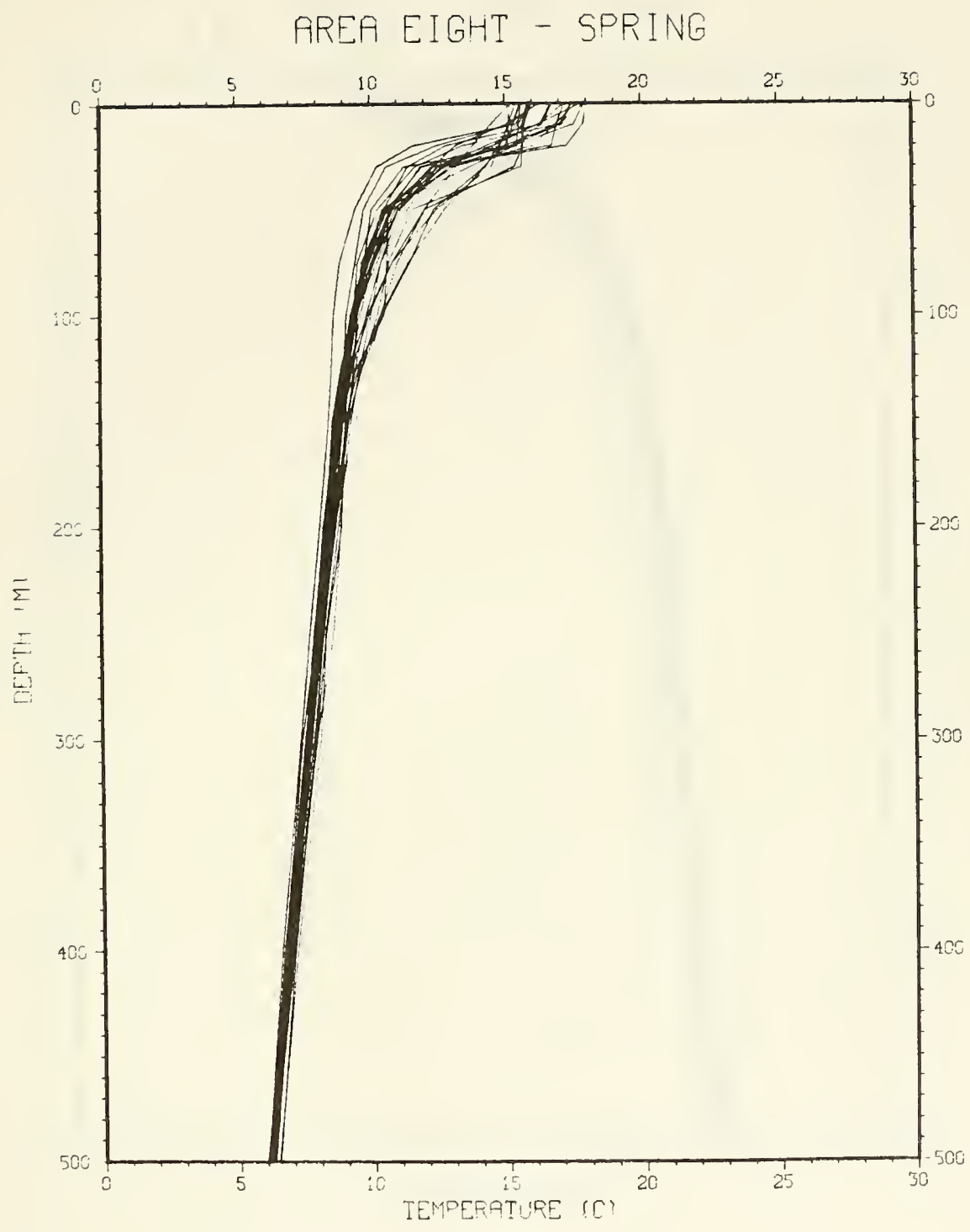

Figure B.31. 


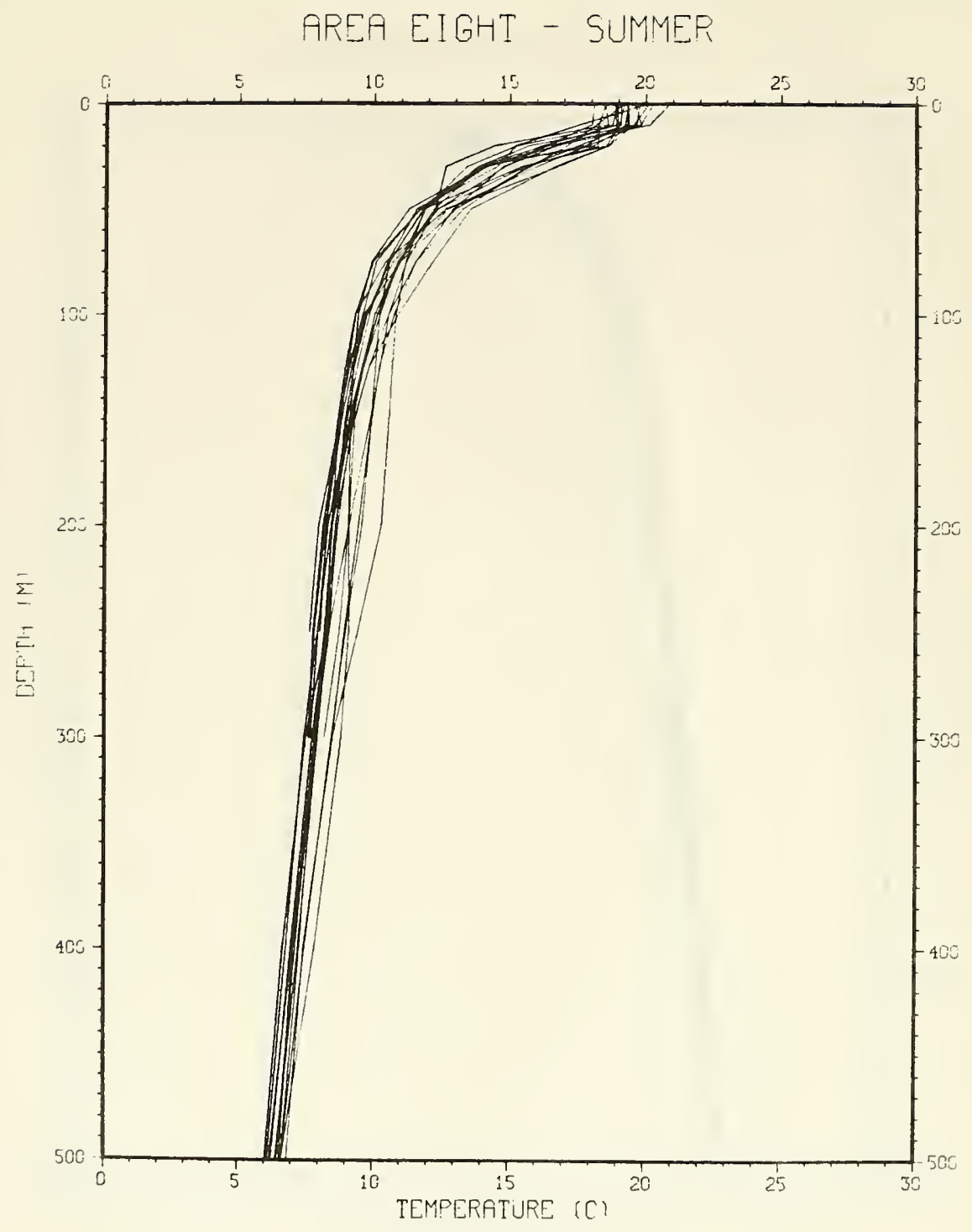

Figure B.32. 


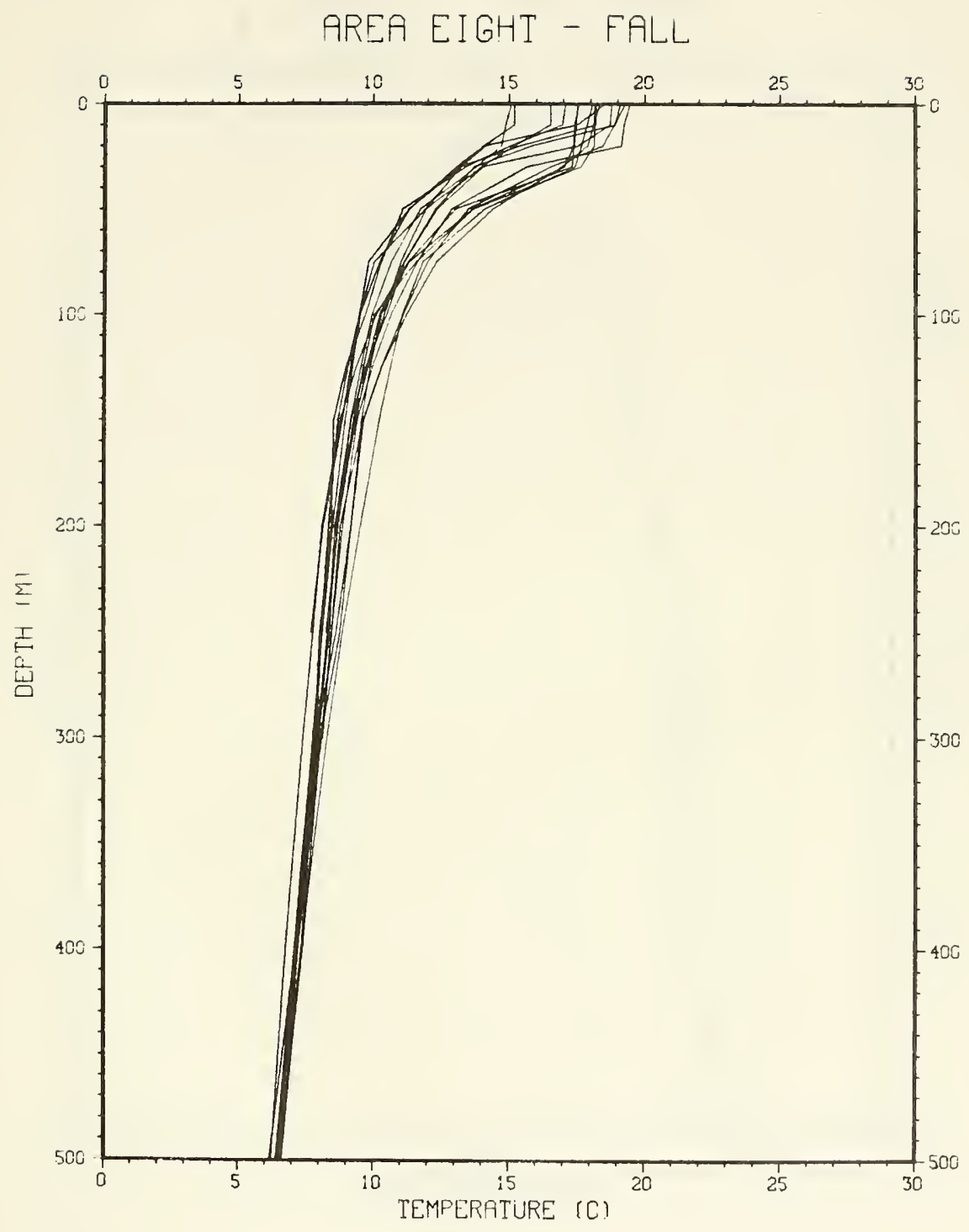

Figure B.33. 


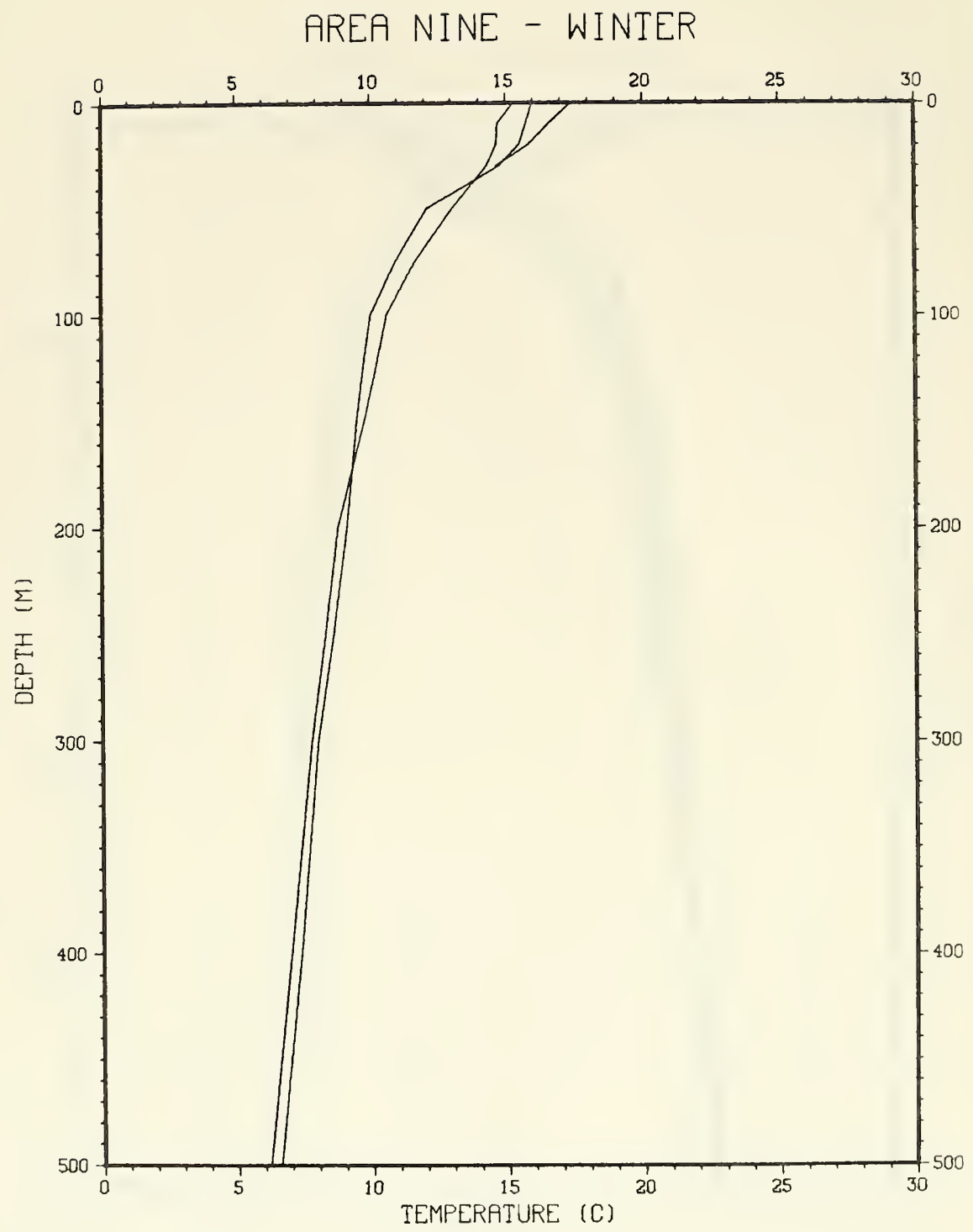

Figure B.34. 


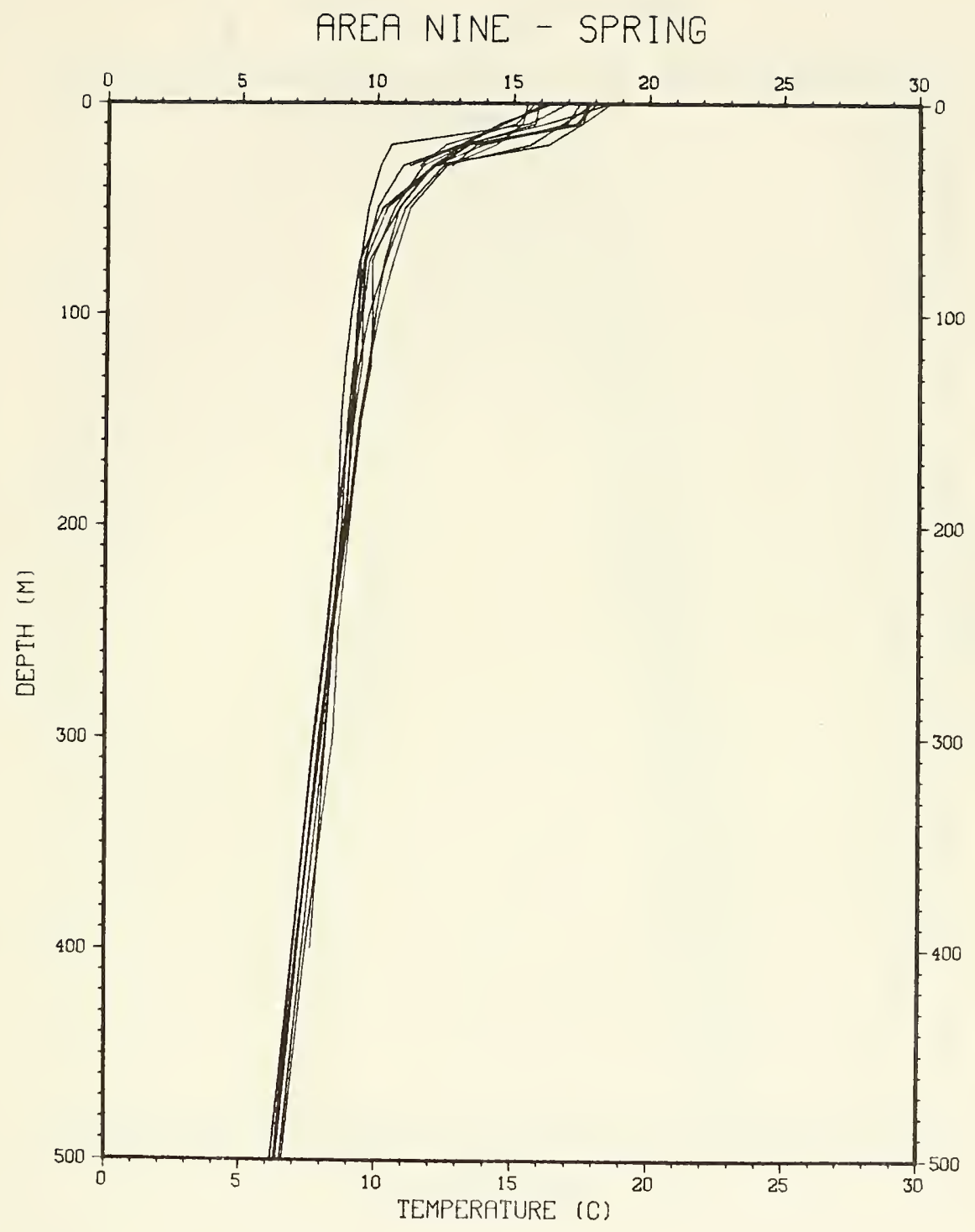

Figure B.35. 


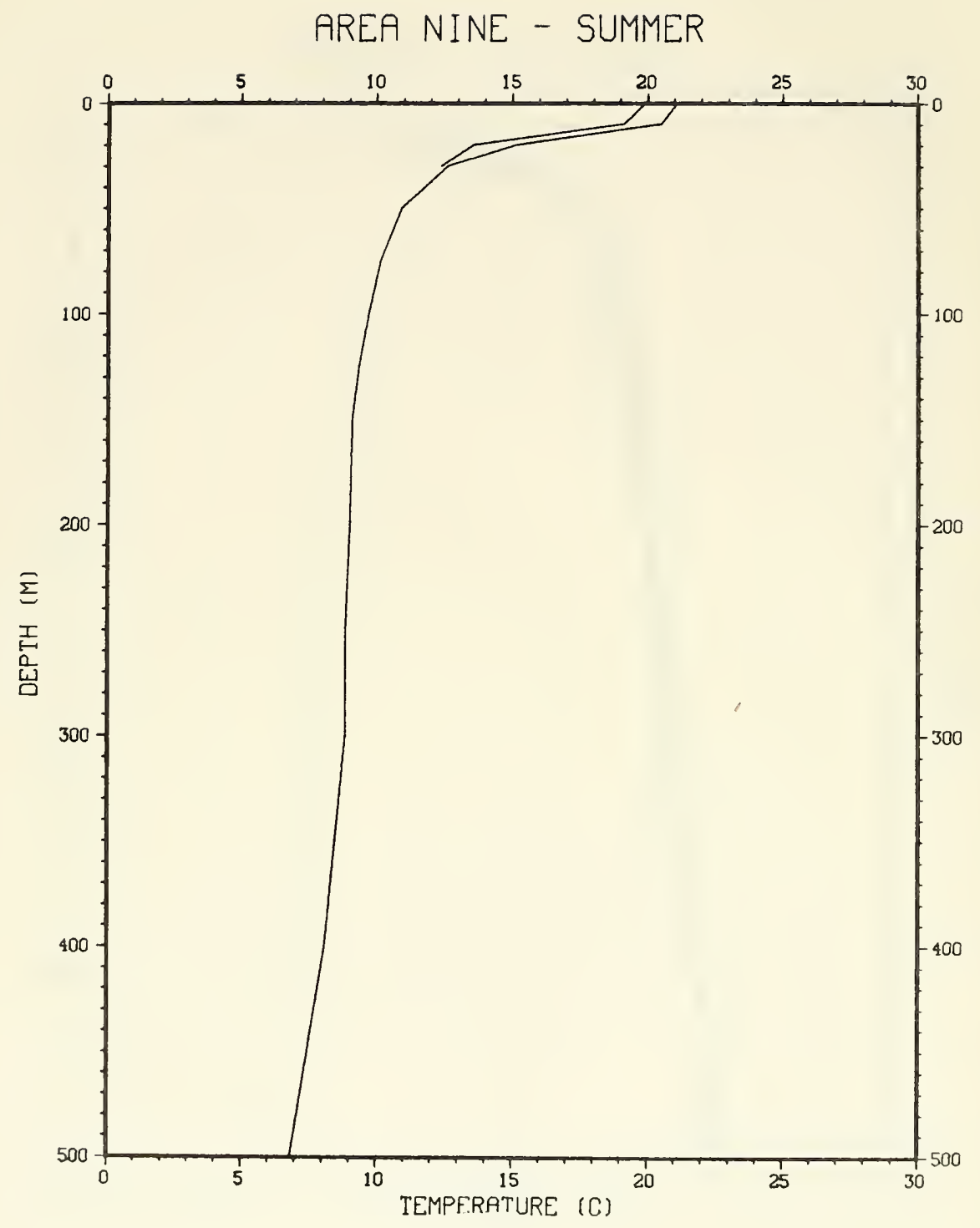

Figure B.36. 


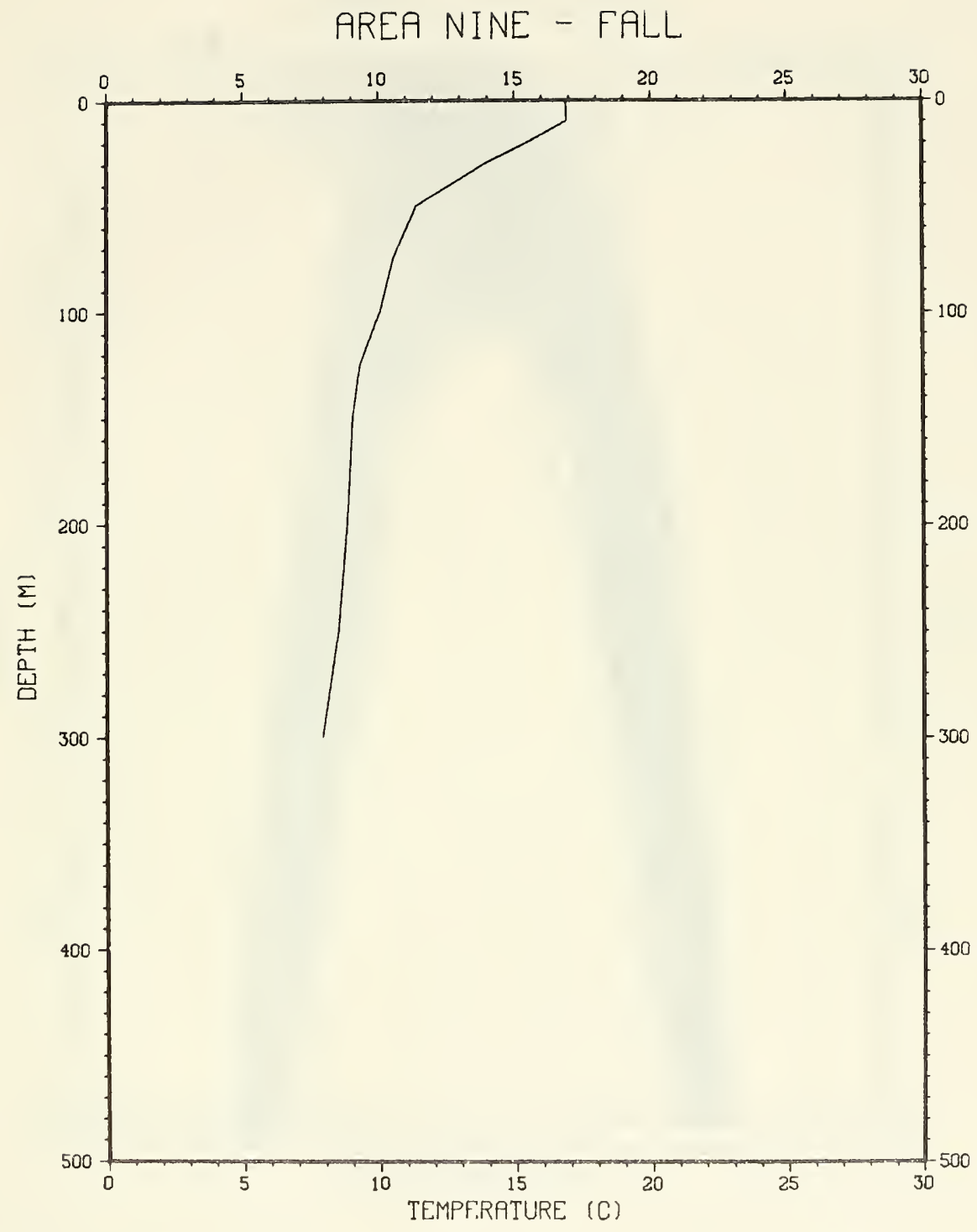

Figure B.37. 


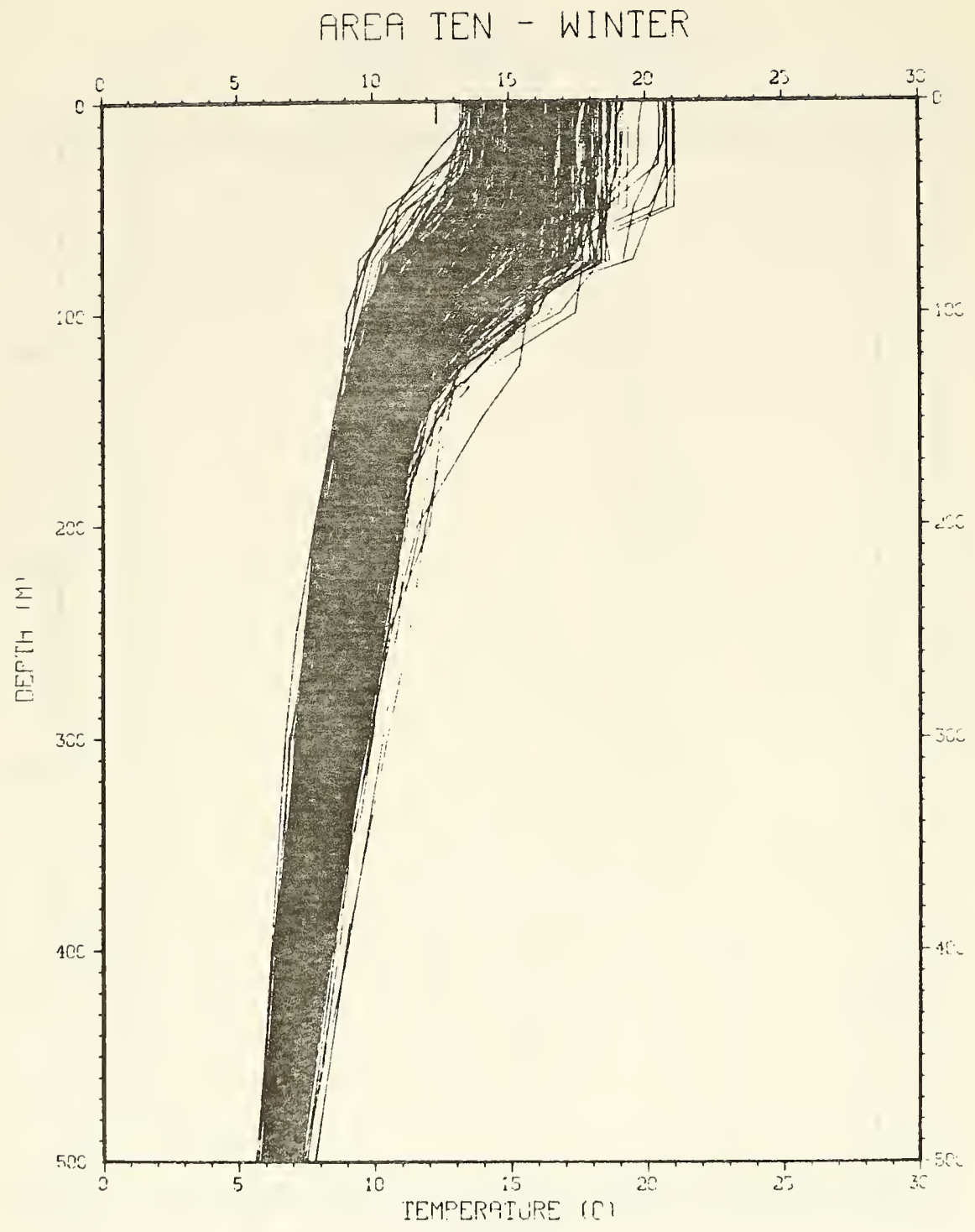

Figure B.38. 


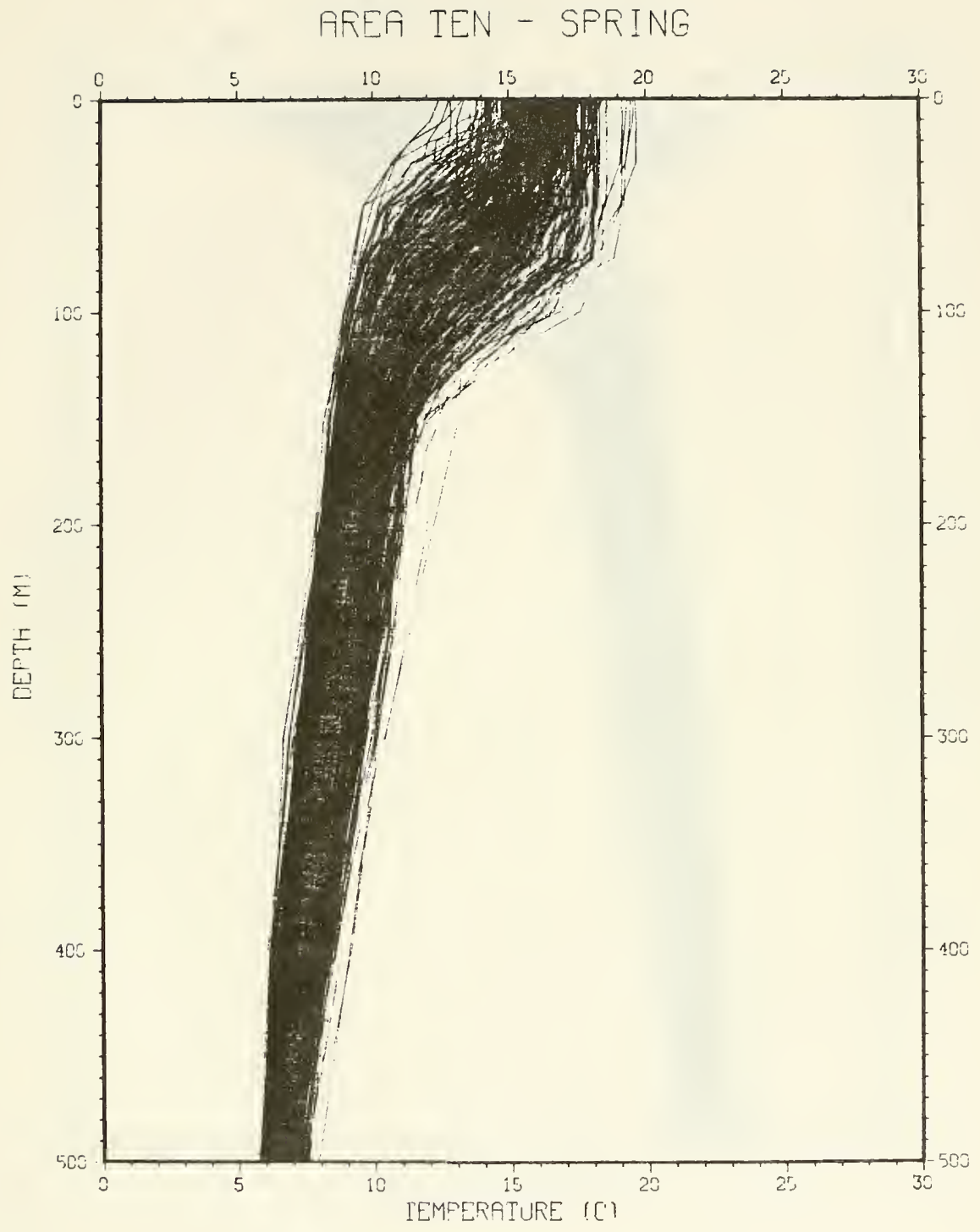

Figure B.39. 


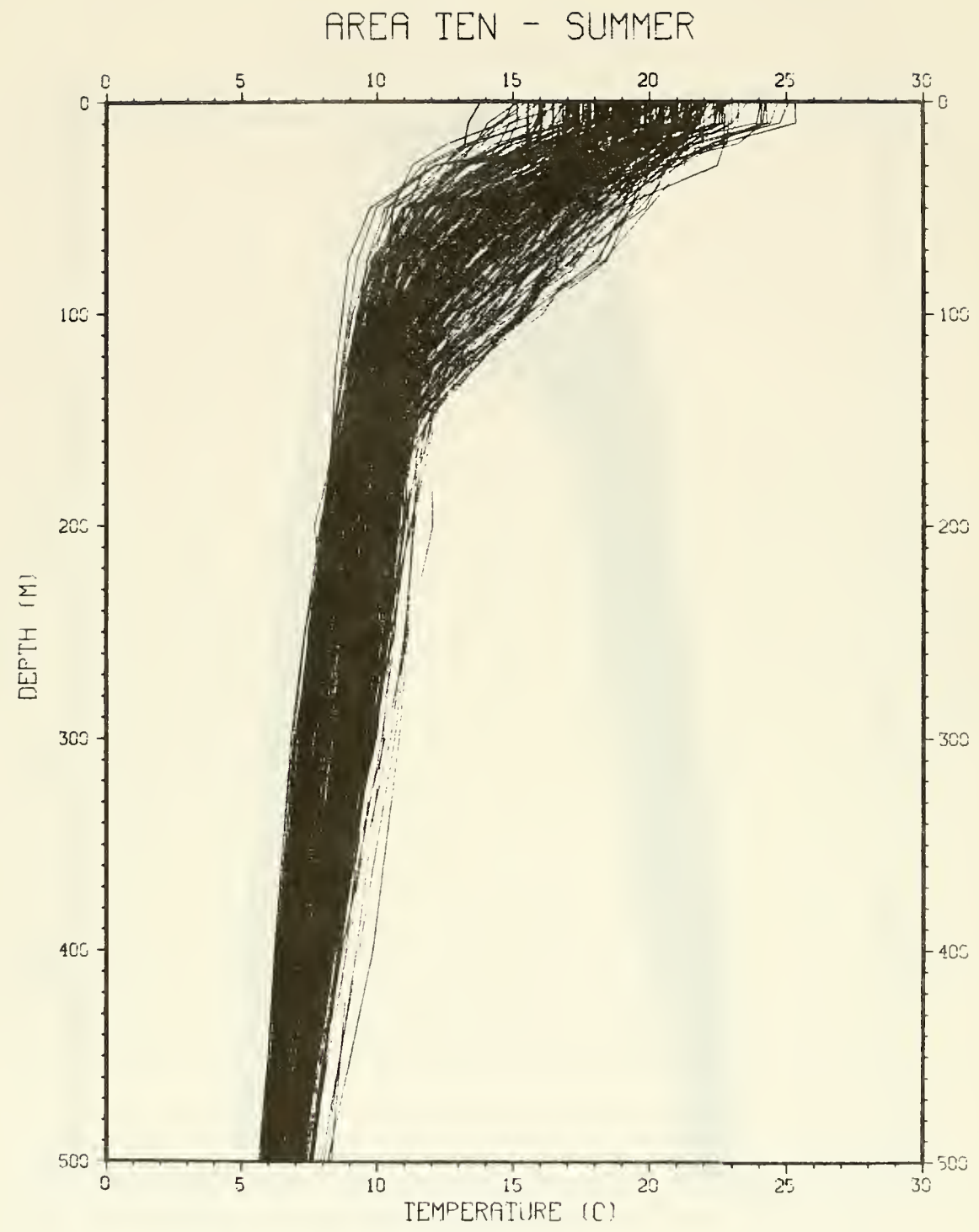

Figure B.40. 


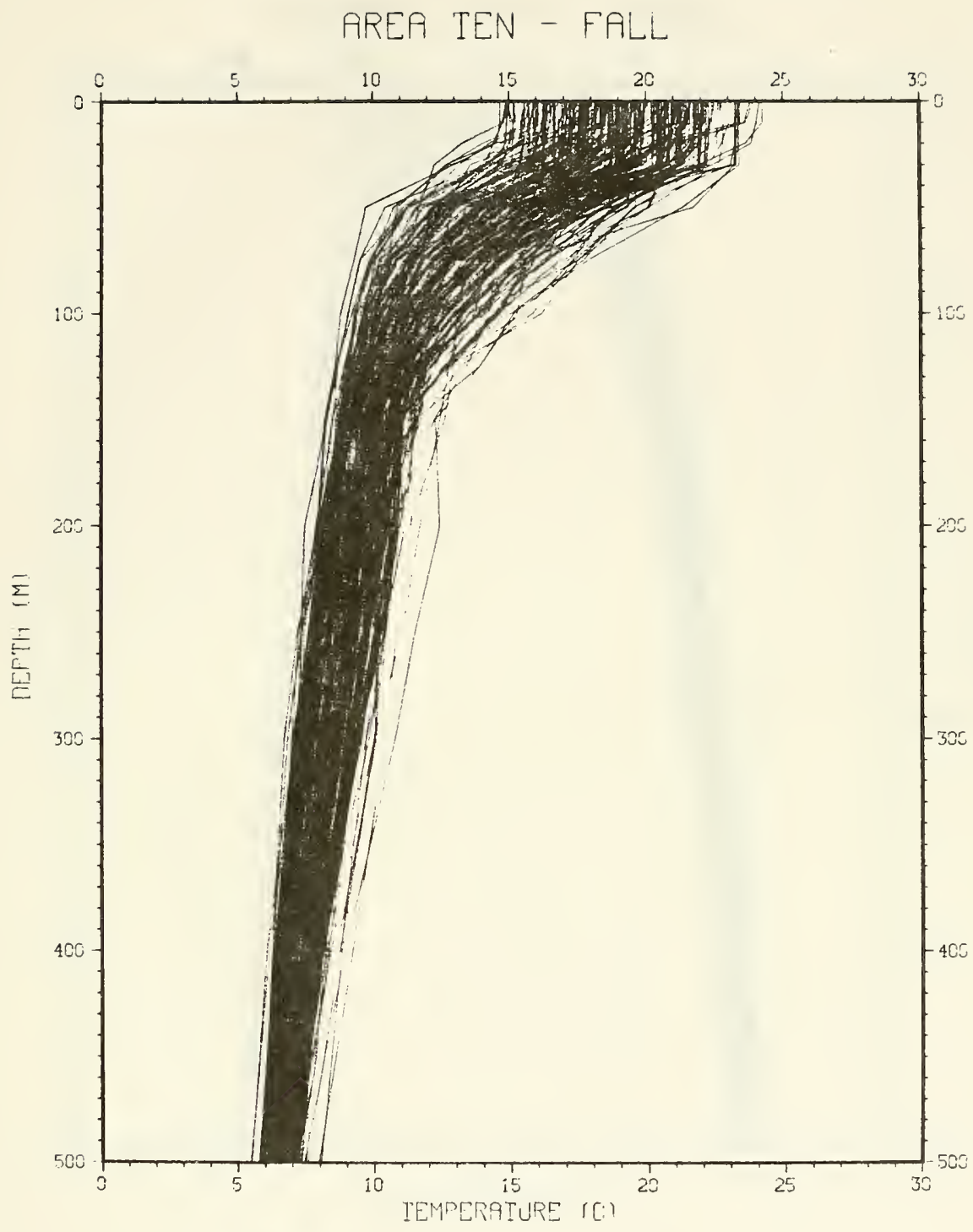

Figure B.41. 


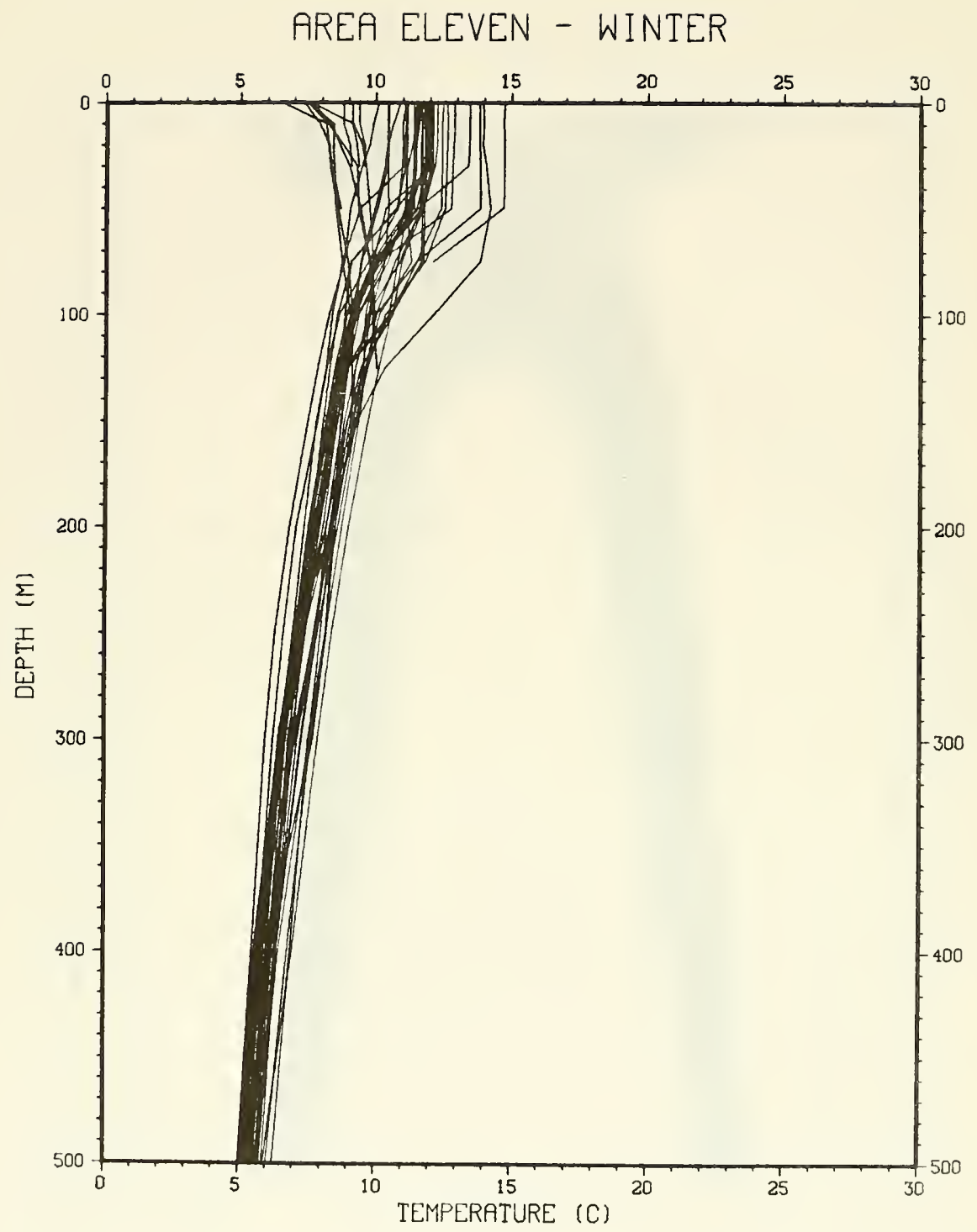

Figure B.42. 


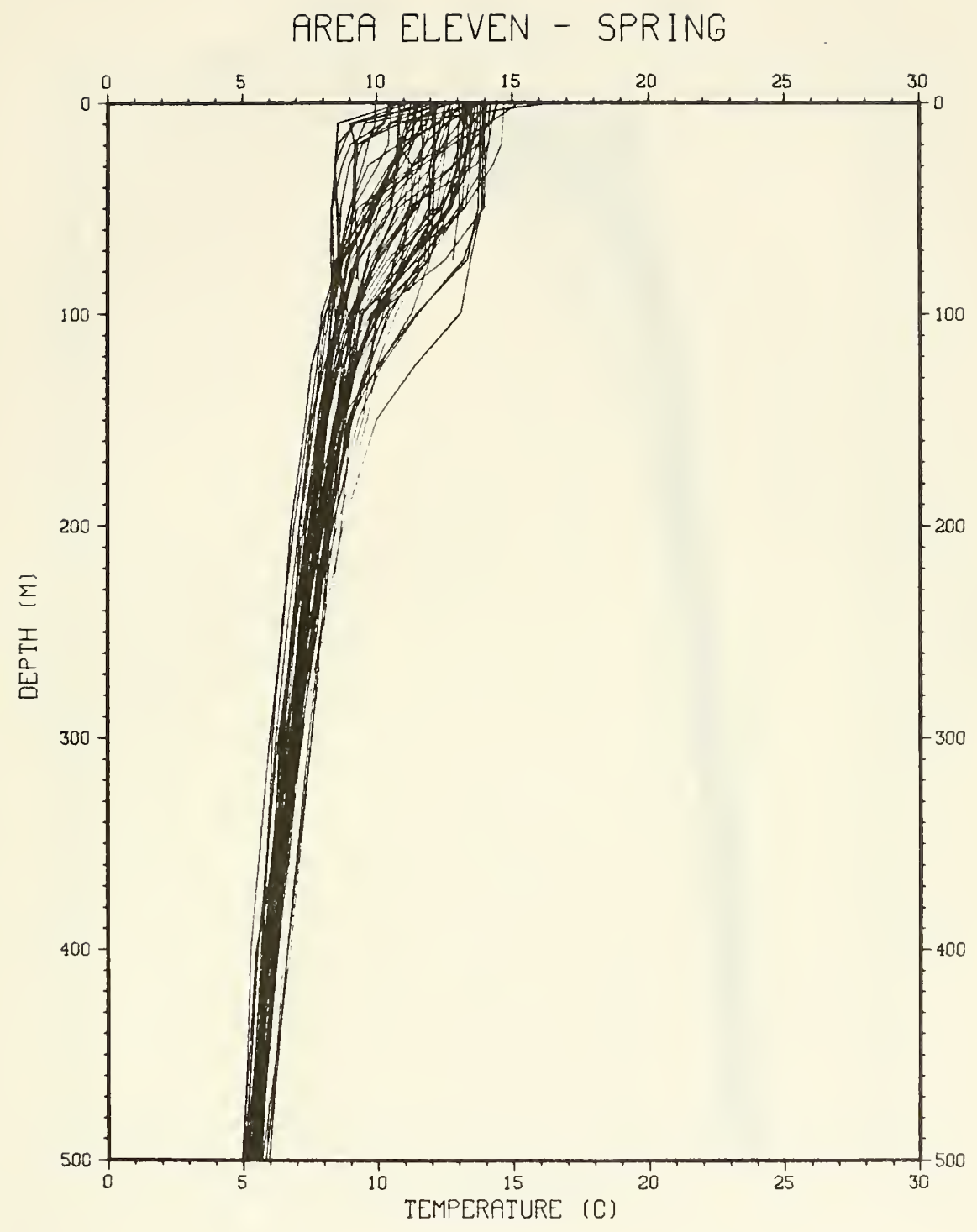

Figure B.43. 


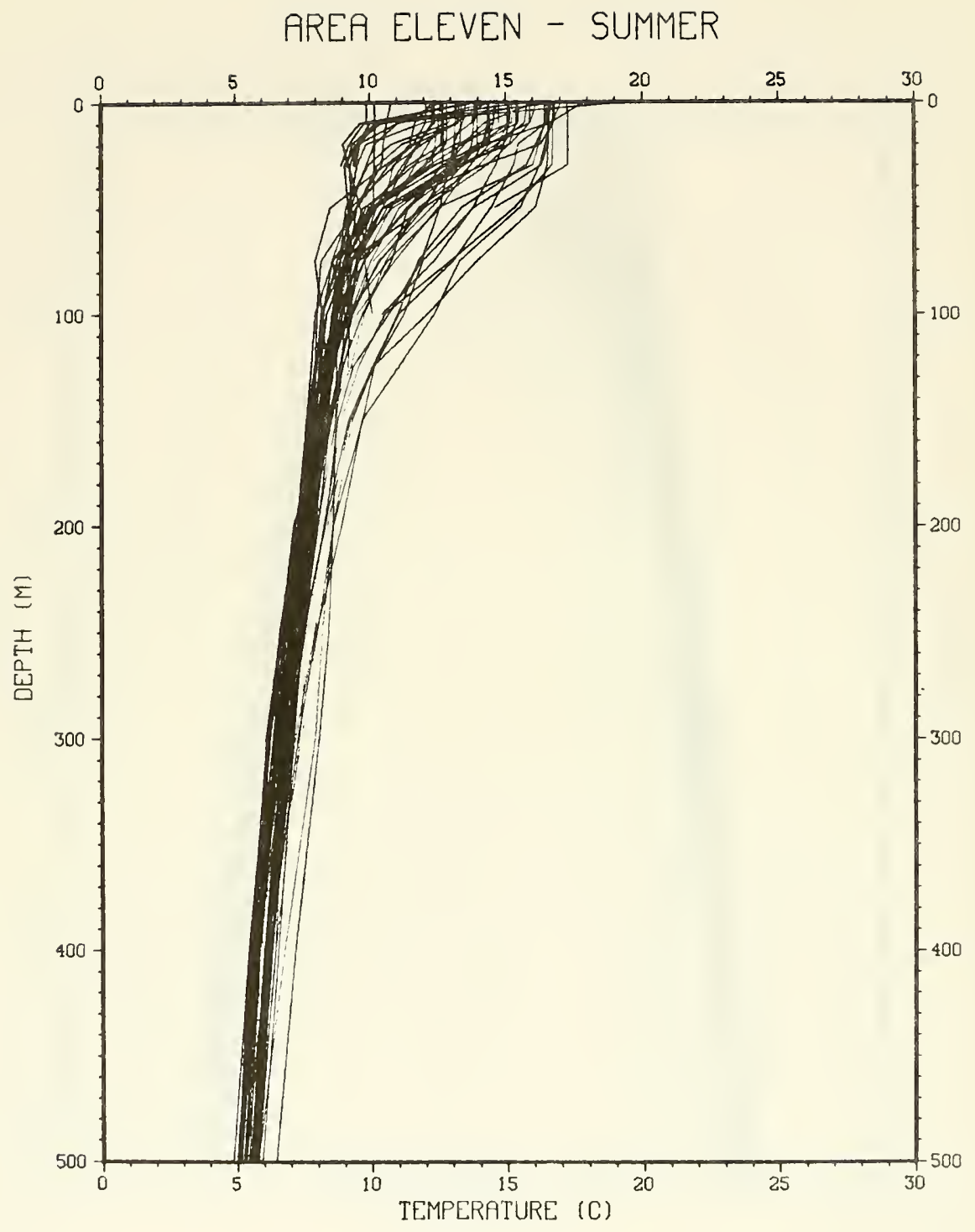

Figure B.44. 


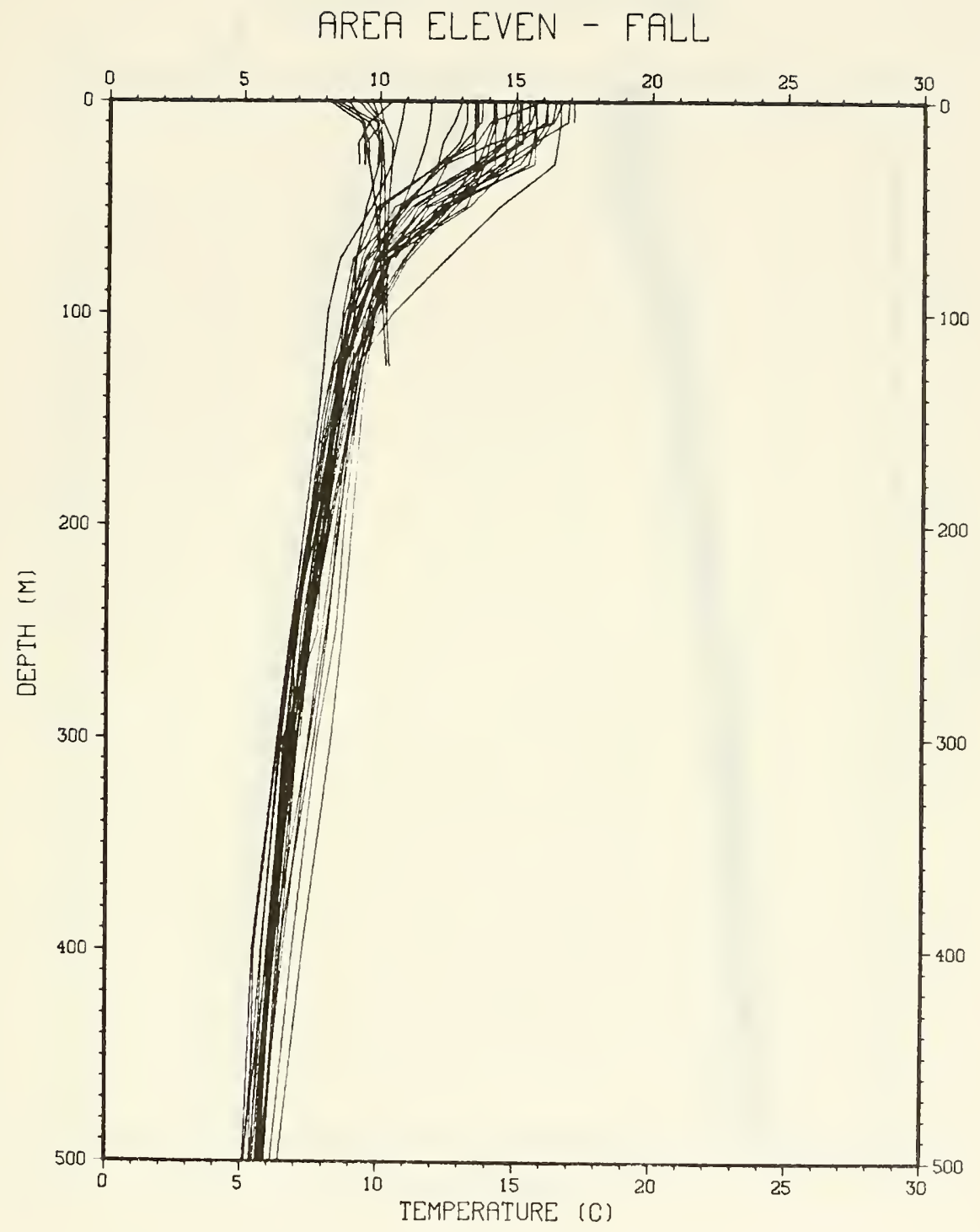

Figure B.45. 


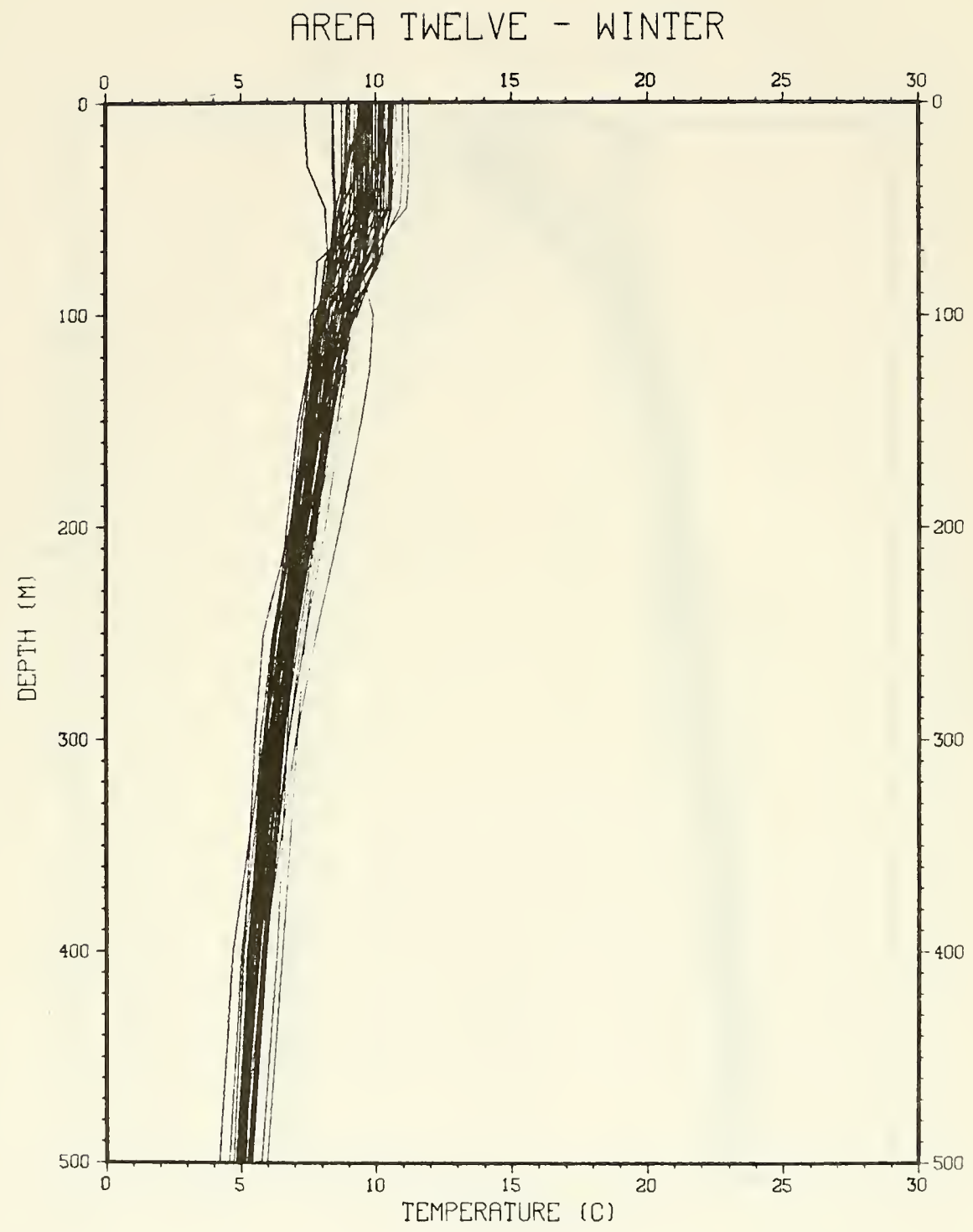

Figure B.46. 


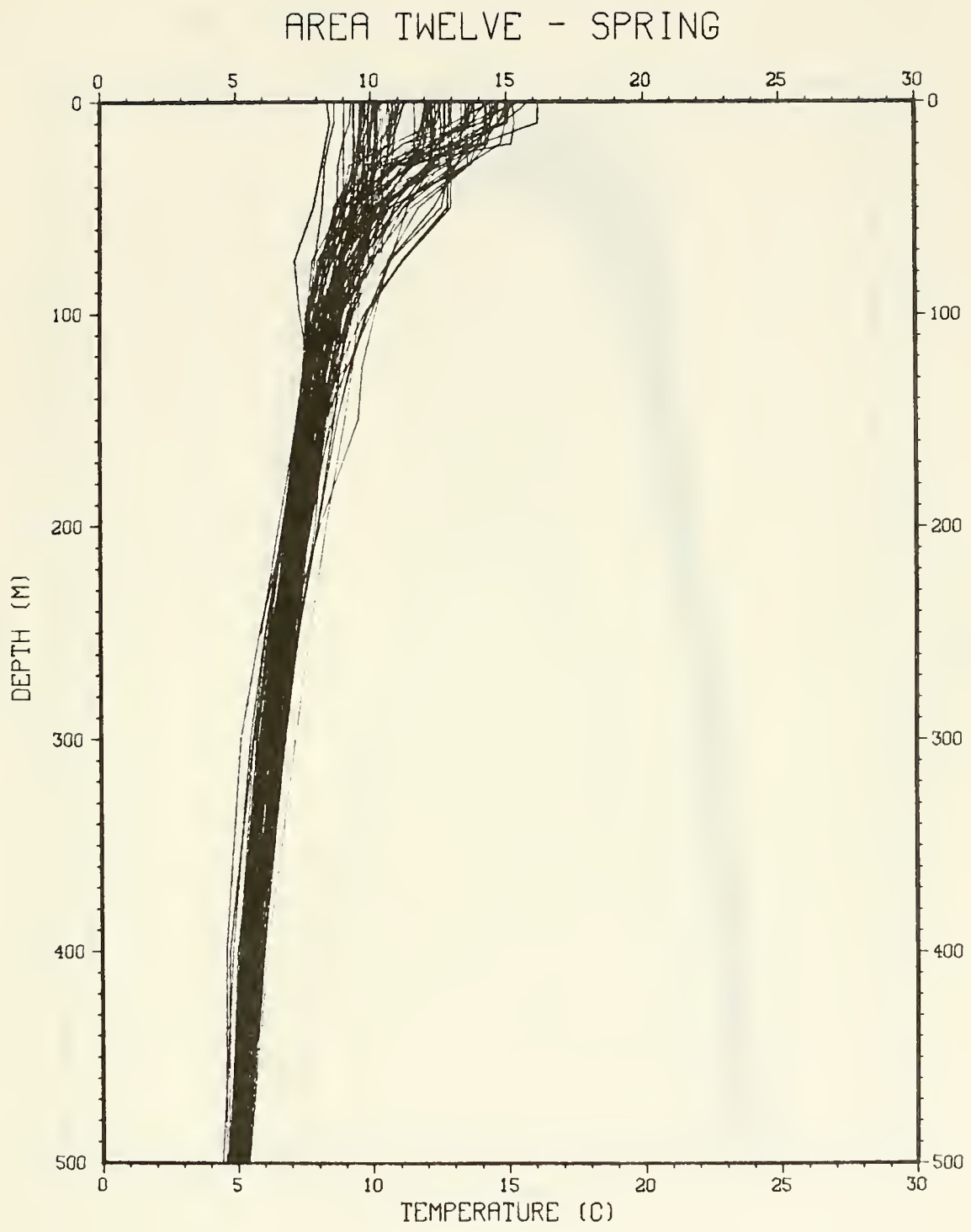

Figure B.47. 


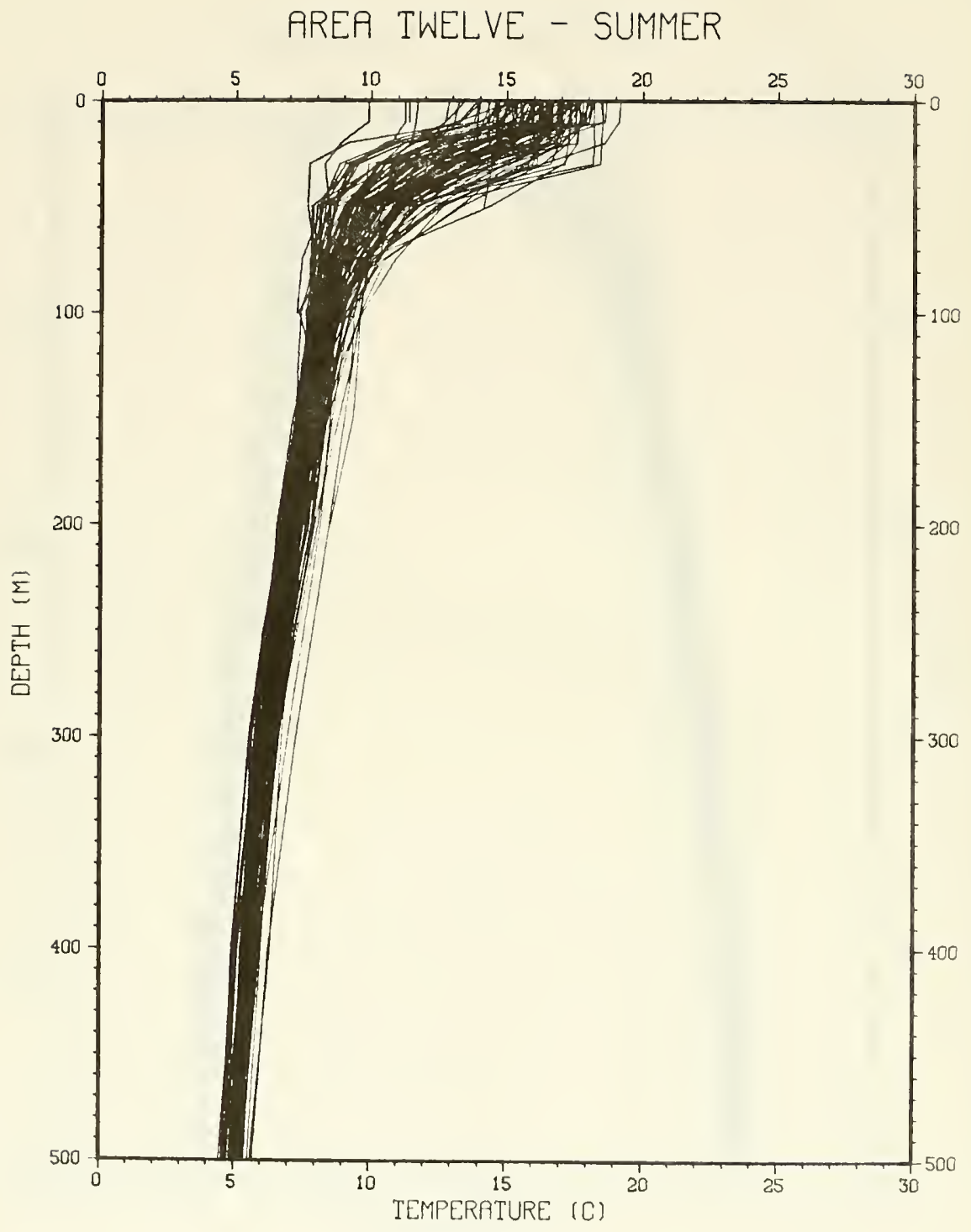

Figure B.48. 


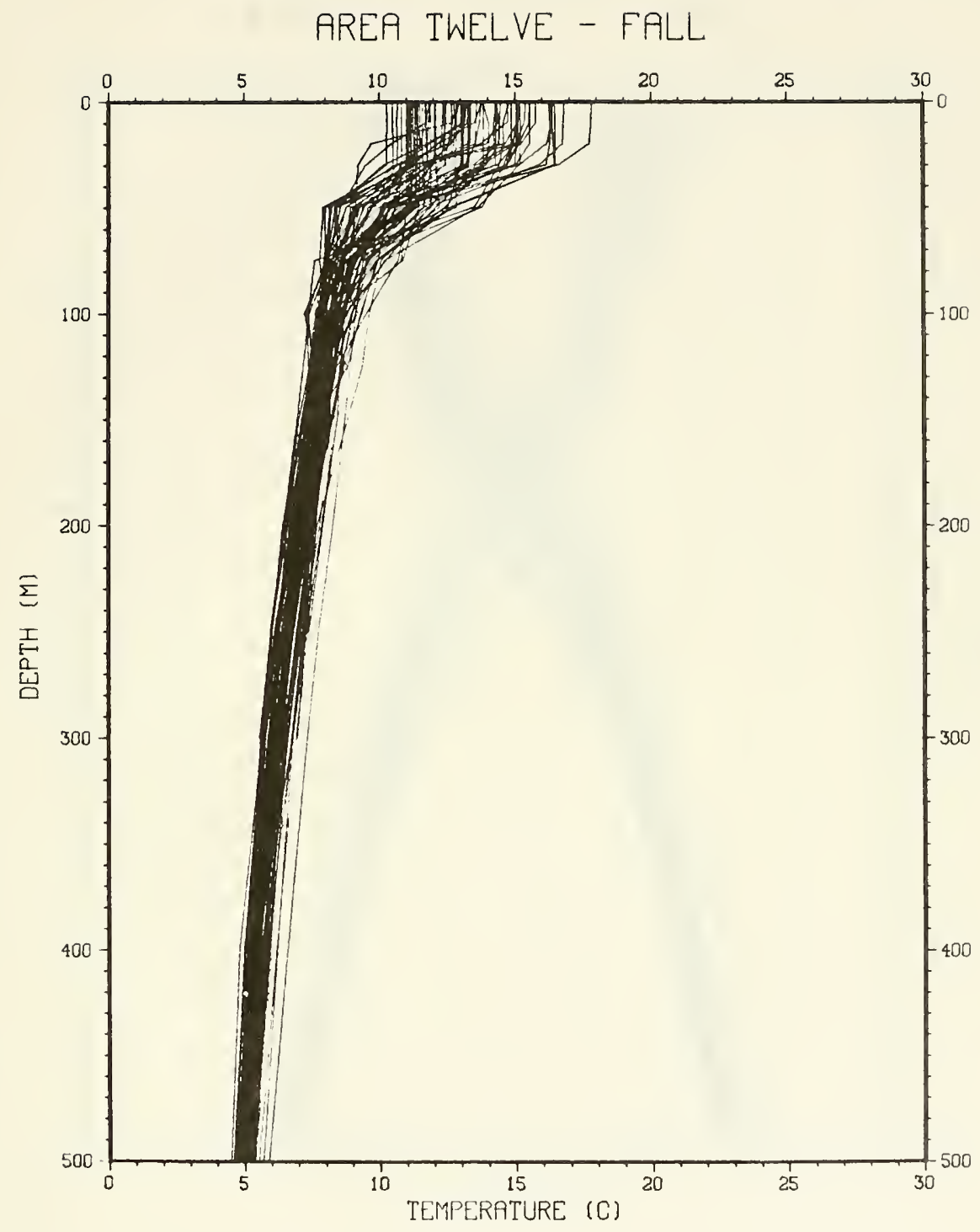

Figure B.49. 


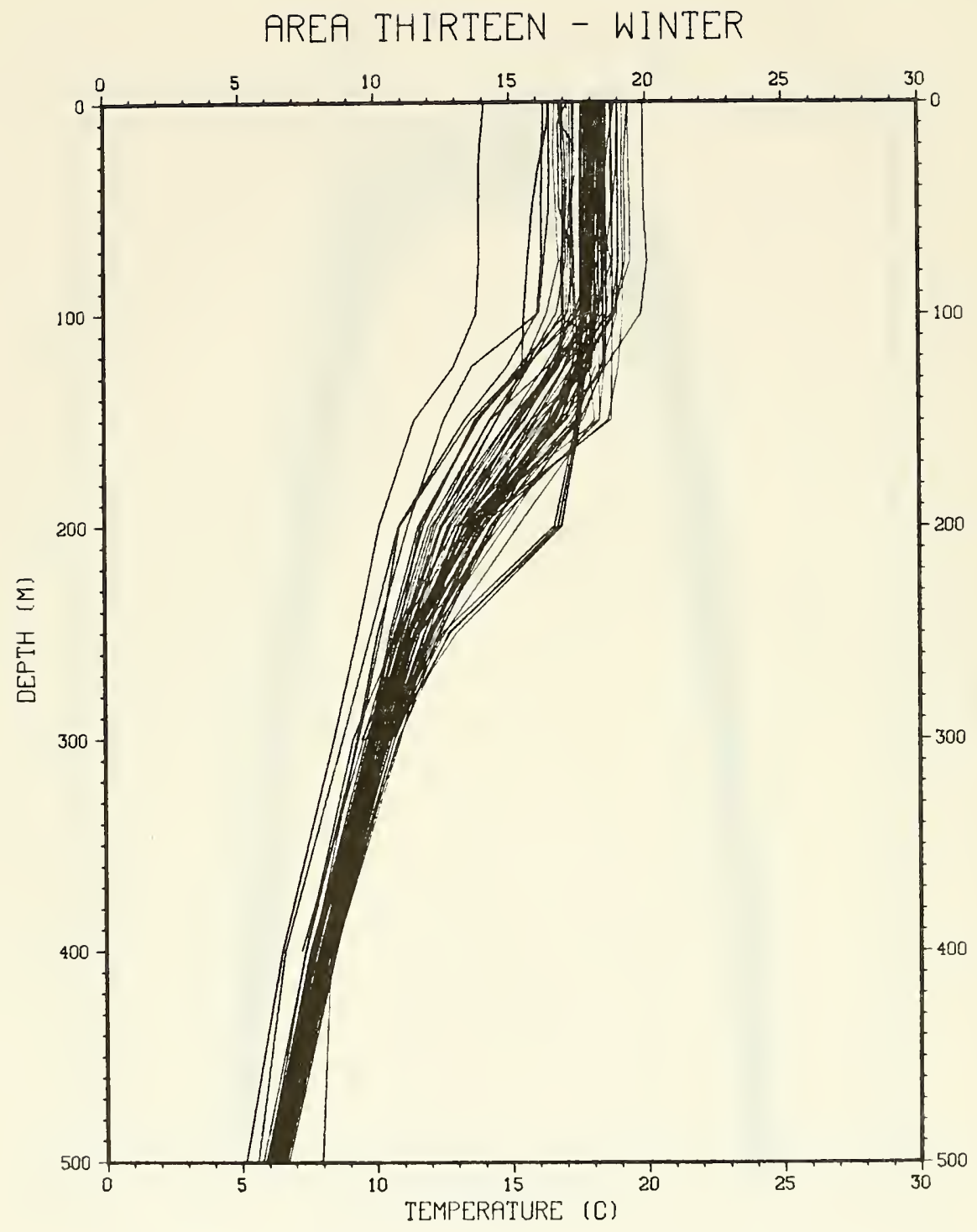

Figure B.50. 


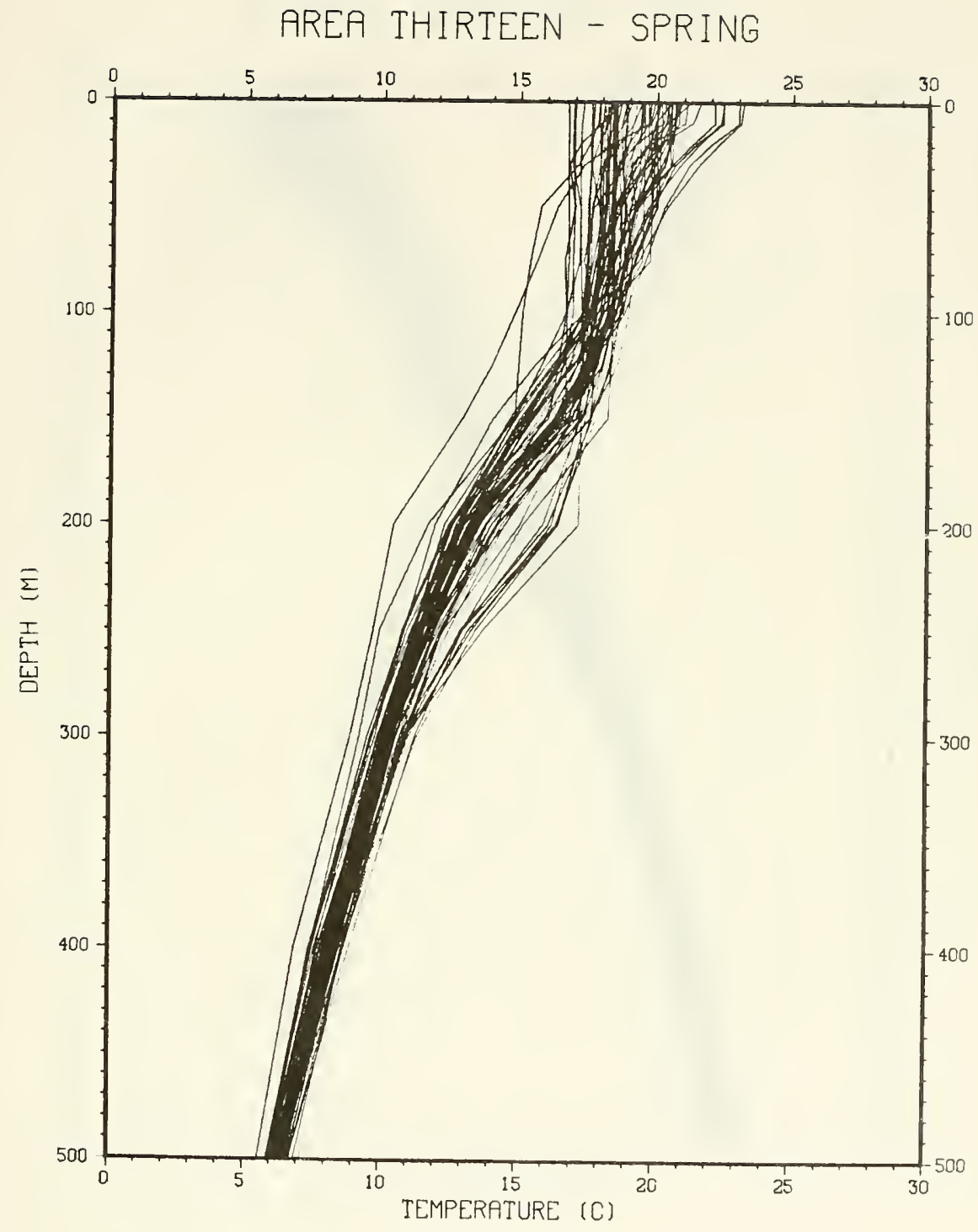

Figure B.51. 


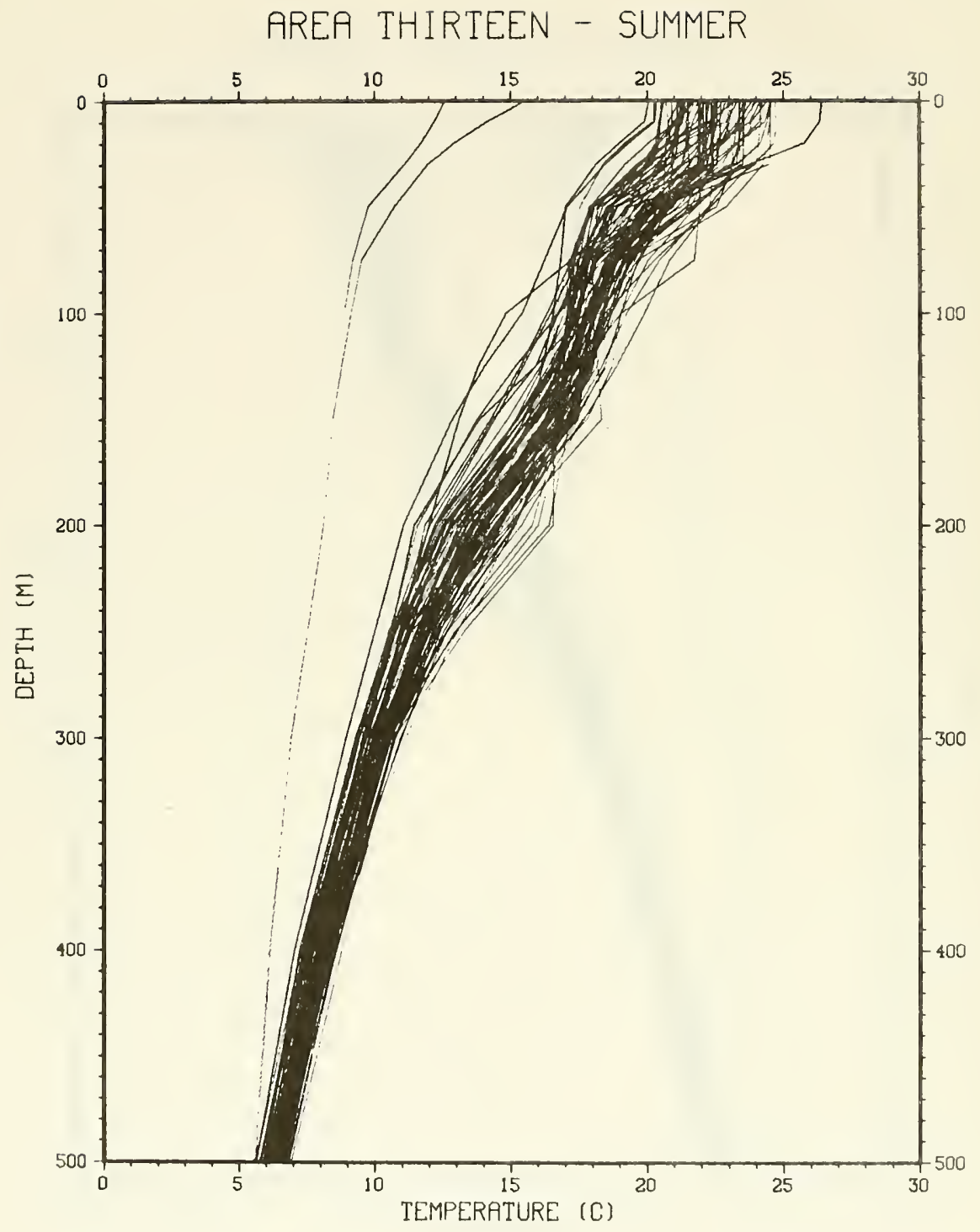

Figure B.52. 


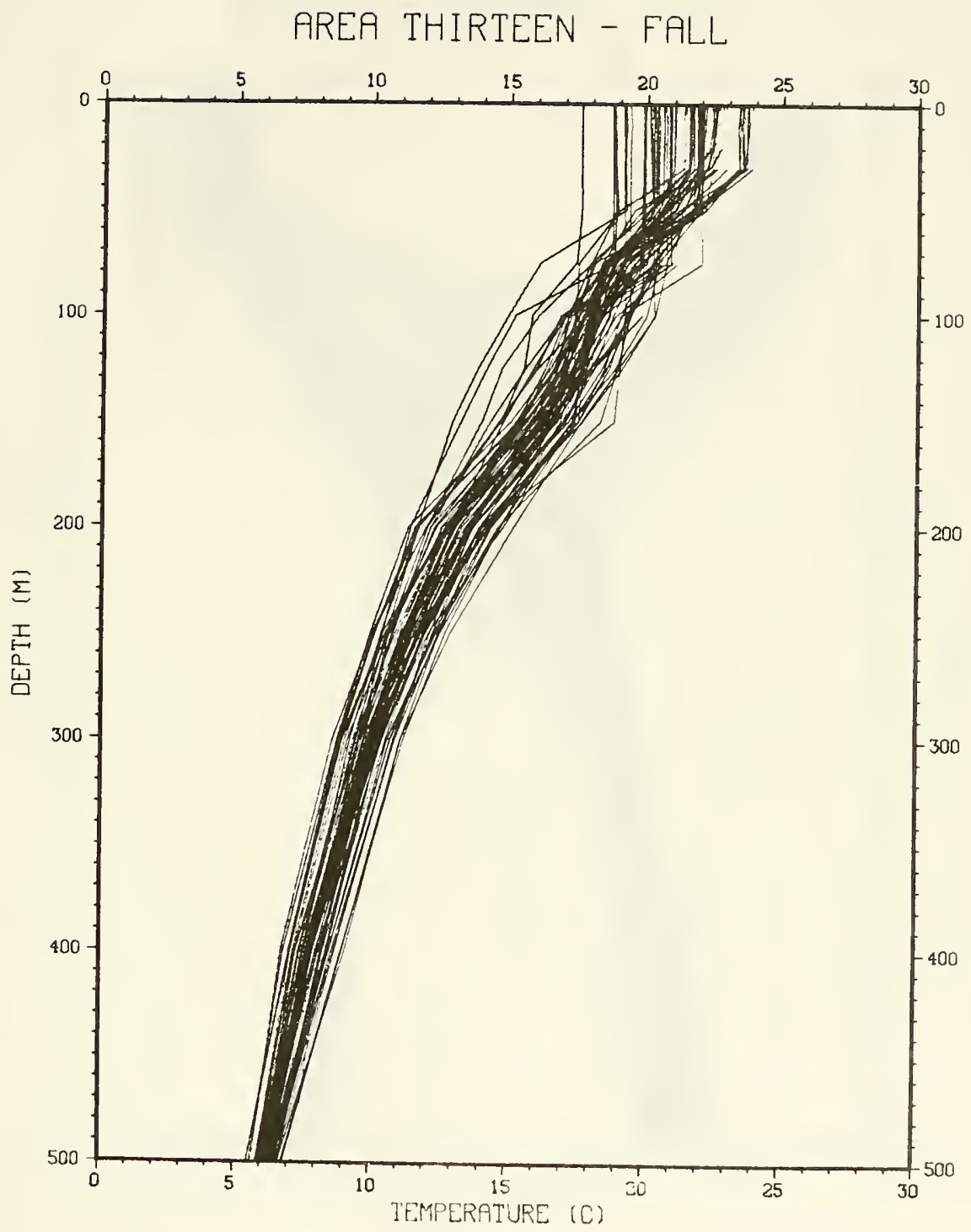

Figure B.53. 


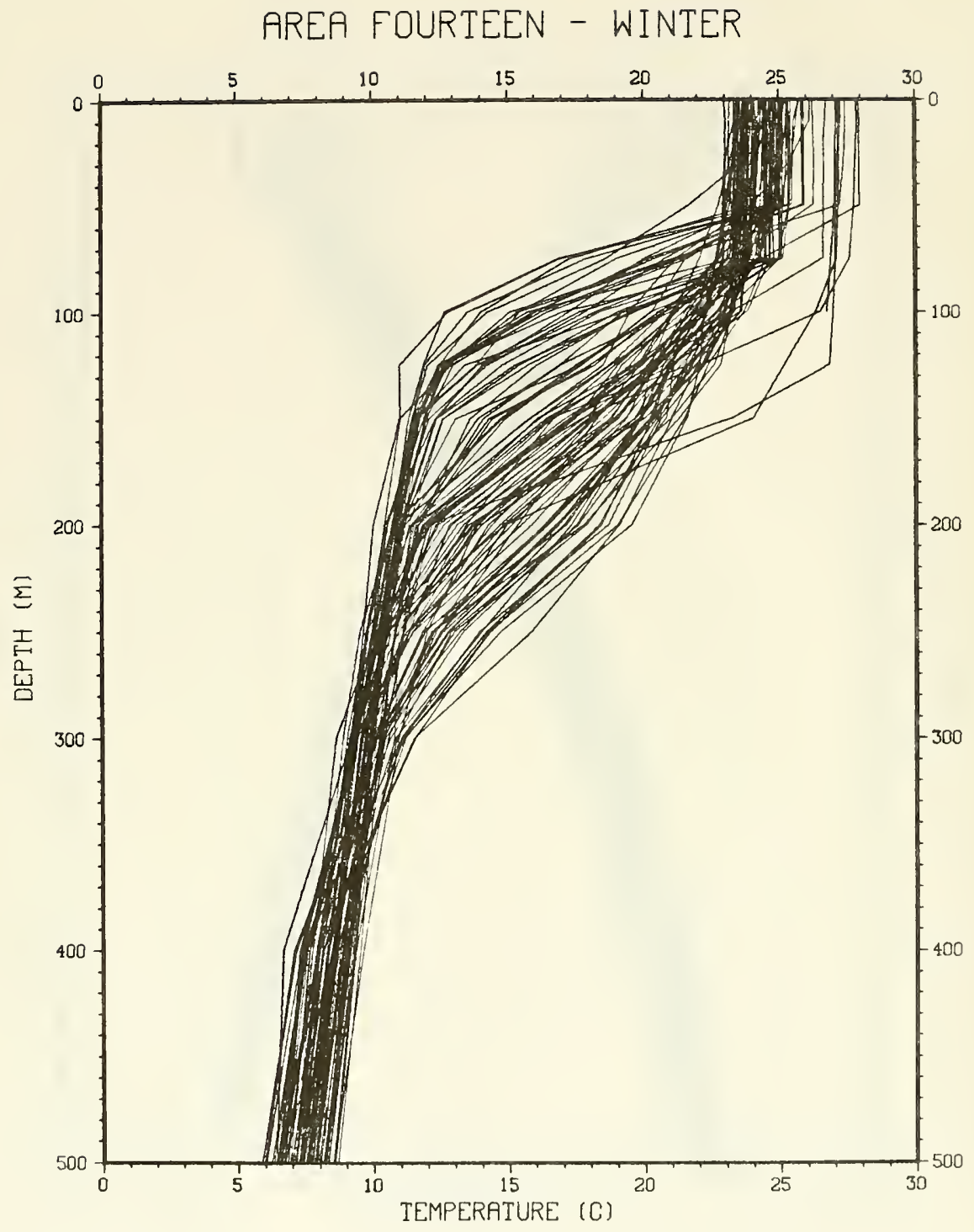

Figure B.54. 


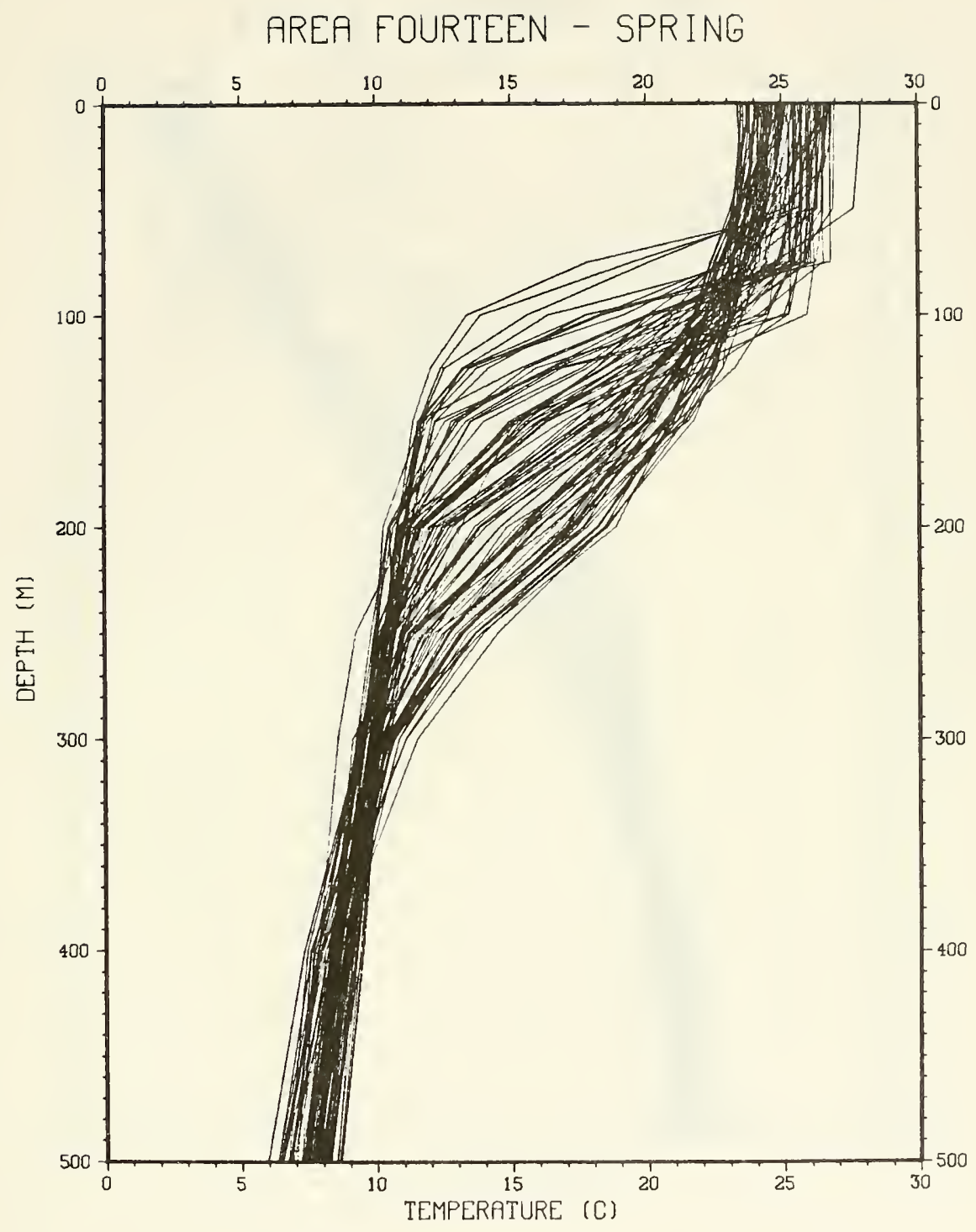

Figure B.55. 


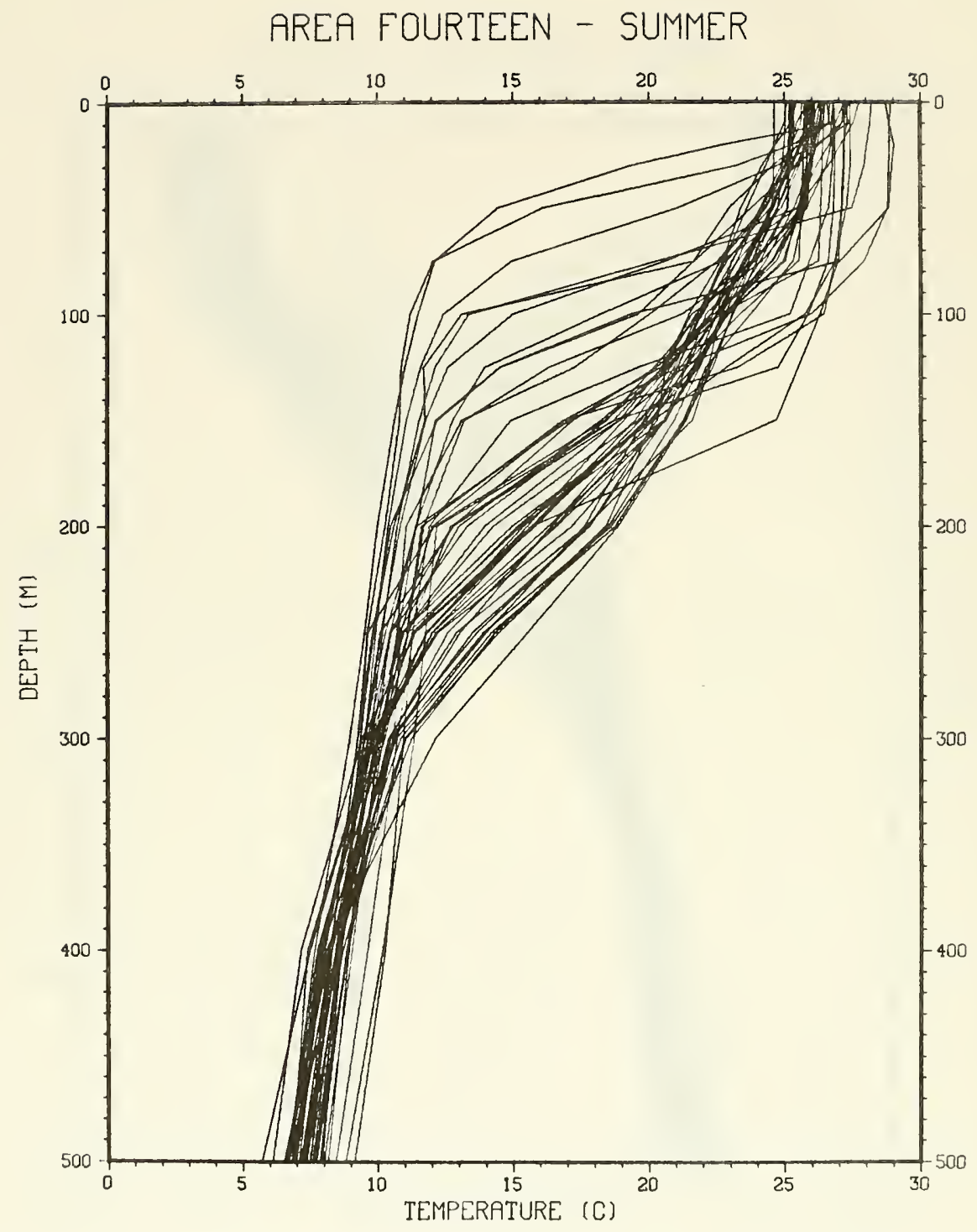

Figure B.56. 


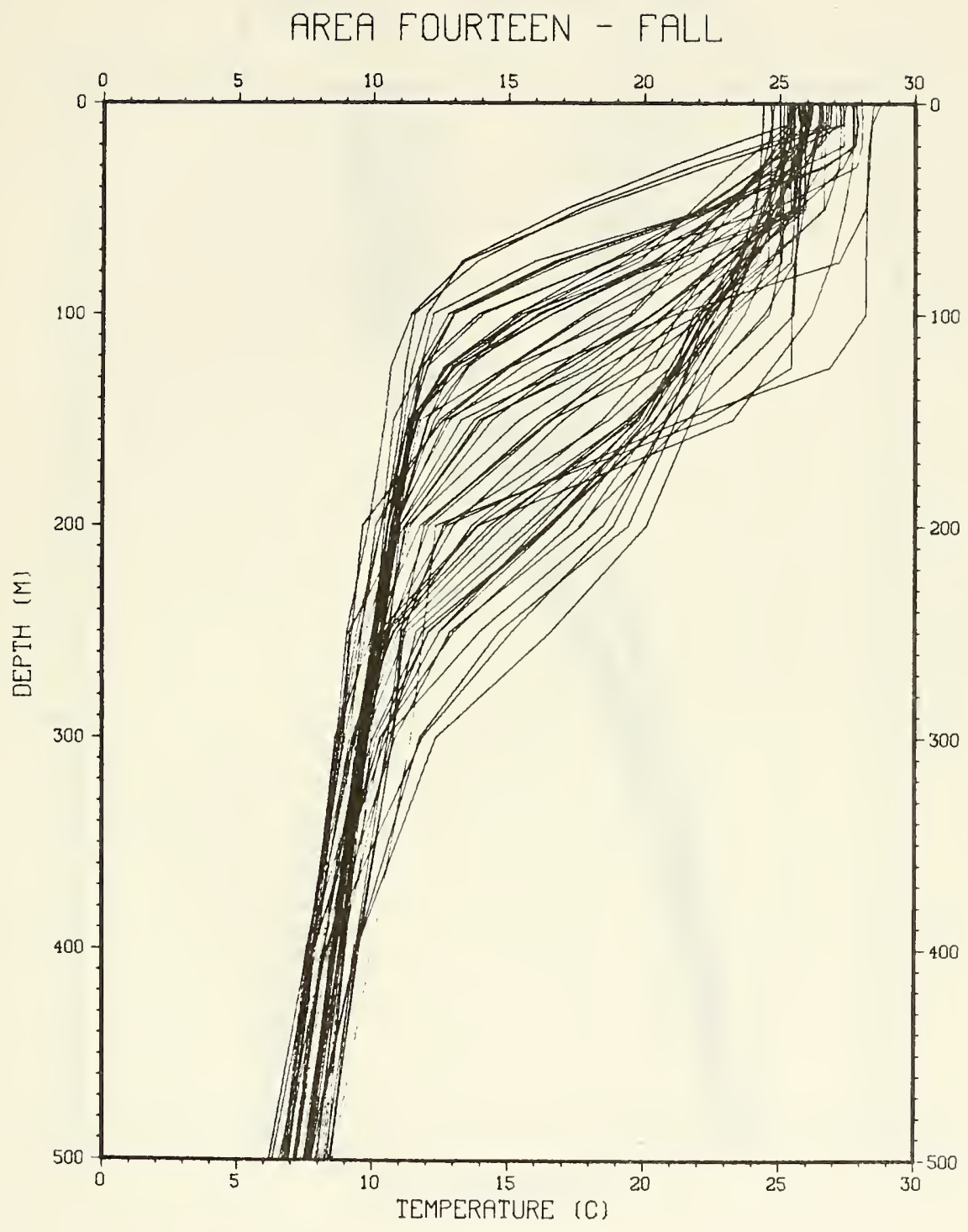

Figure B.57. 


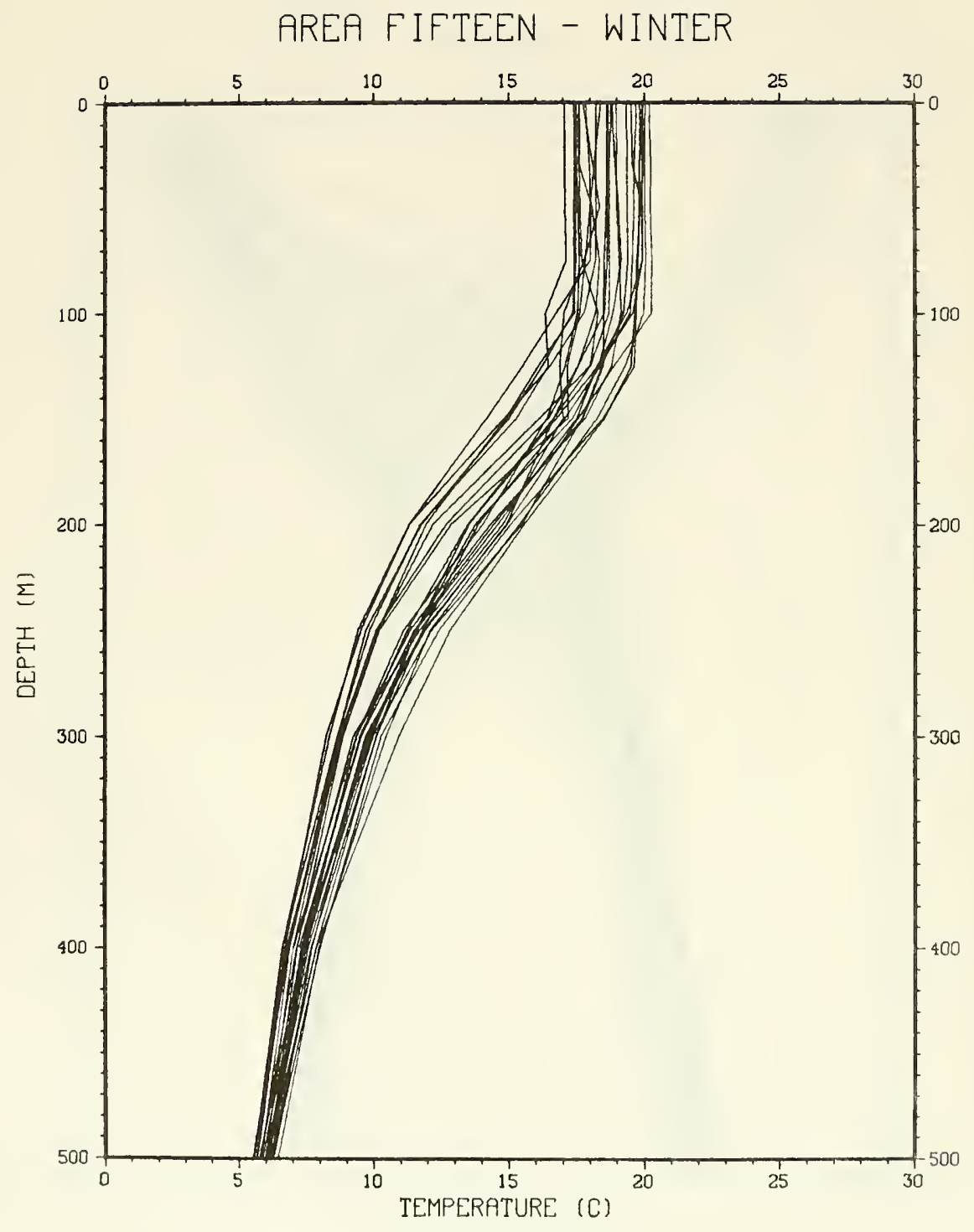

Figure B.58. 


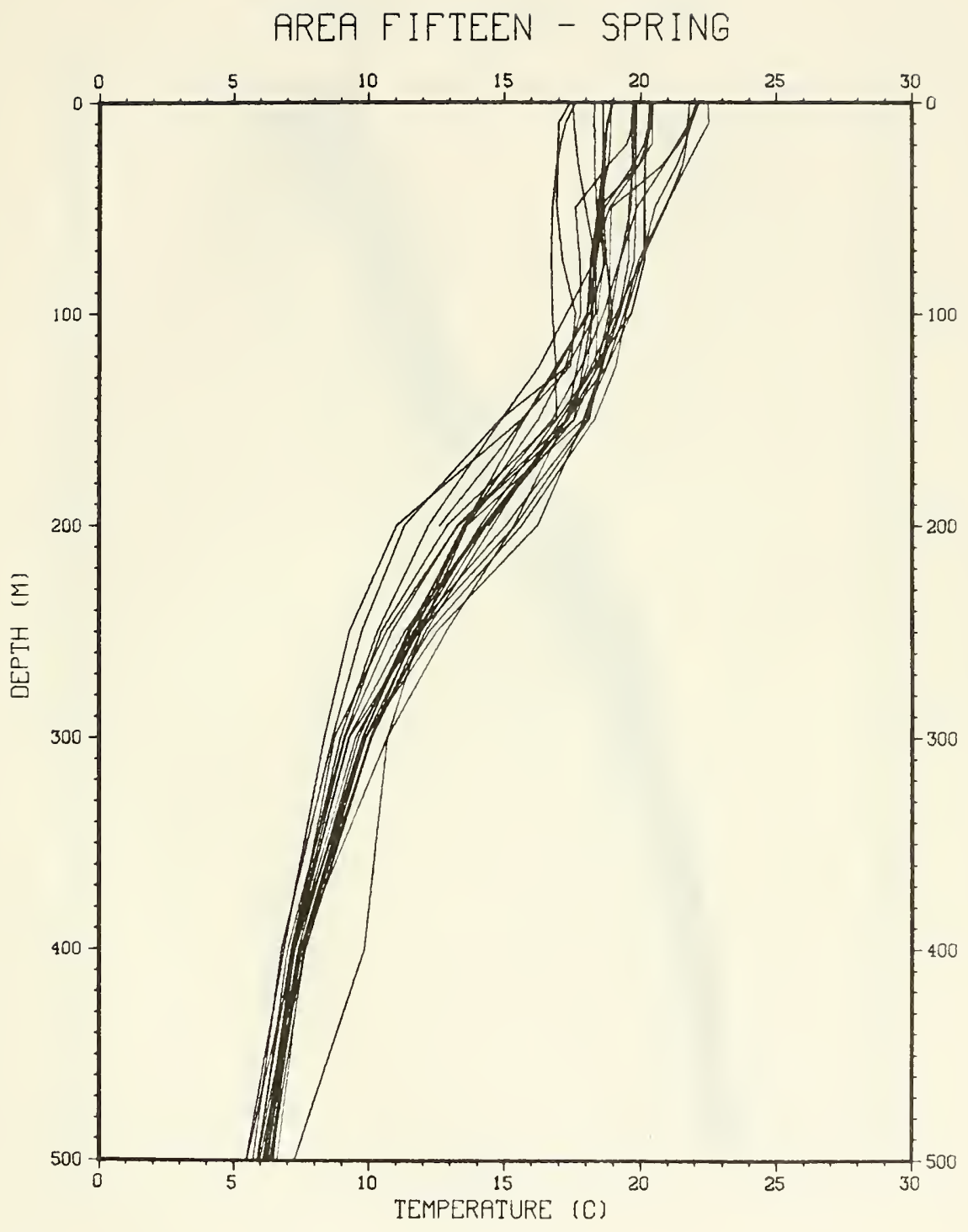

Figure B.59. 


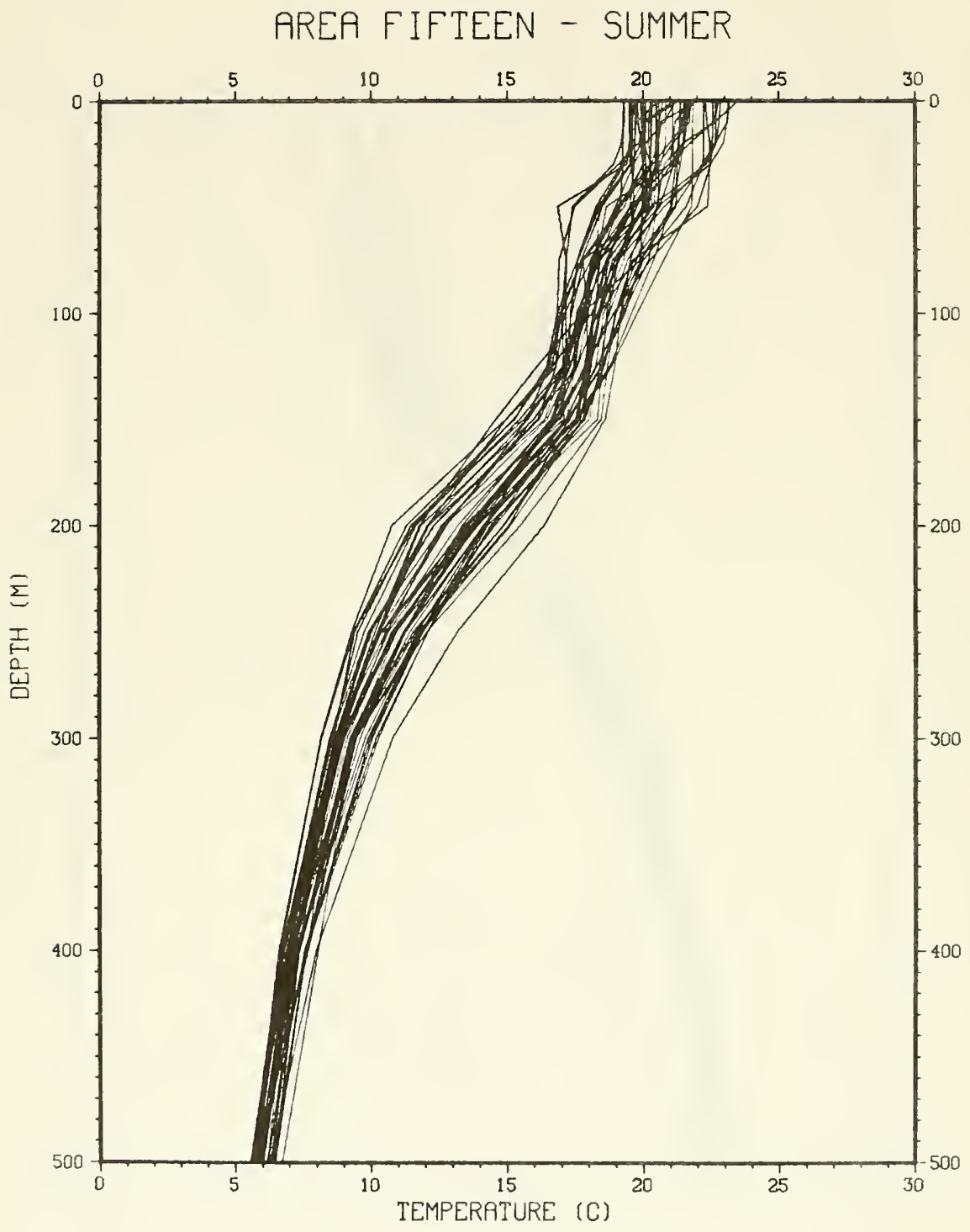

Figure B.60. 


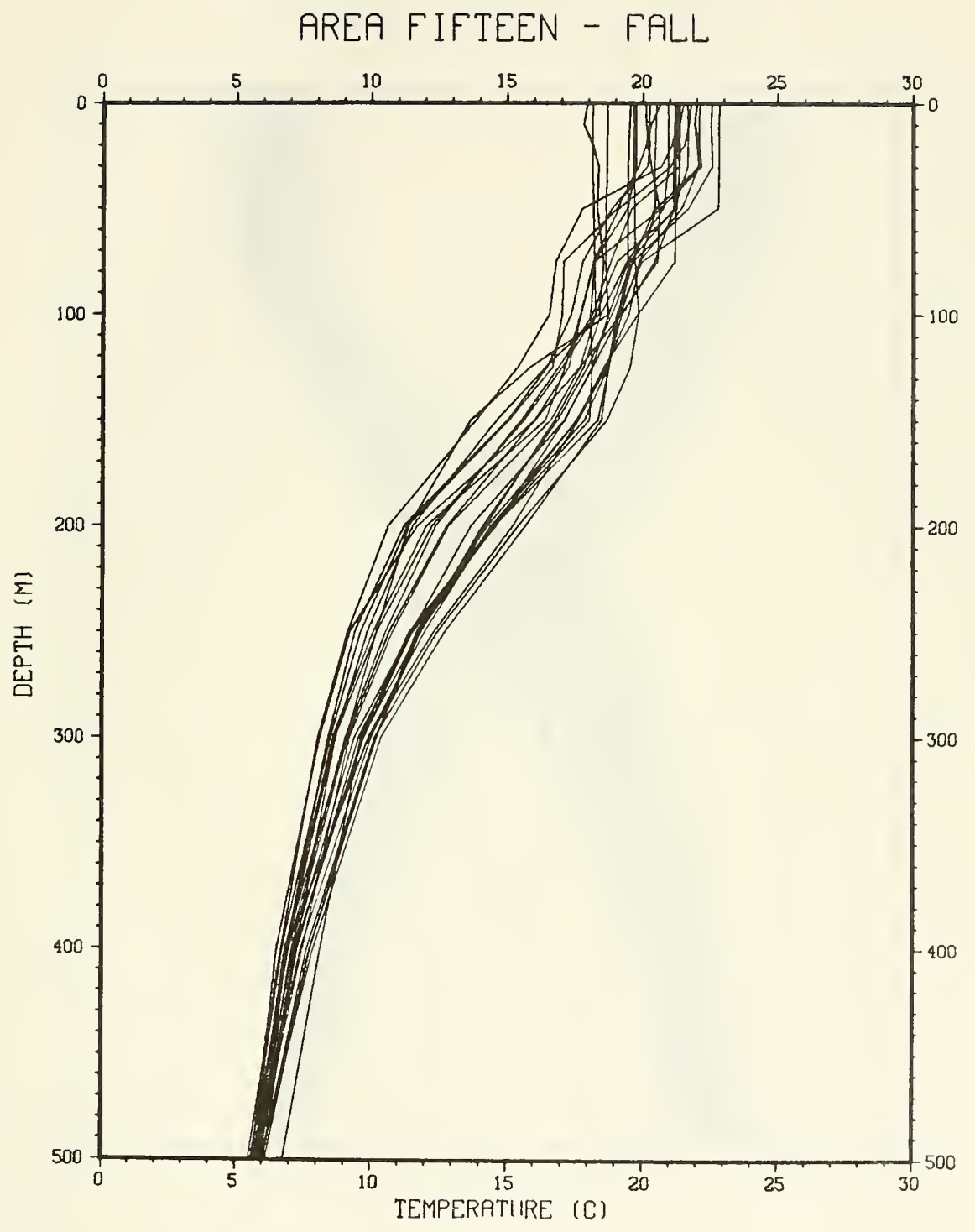

Figure B.61. 


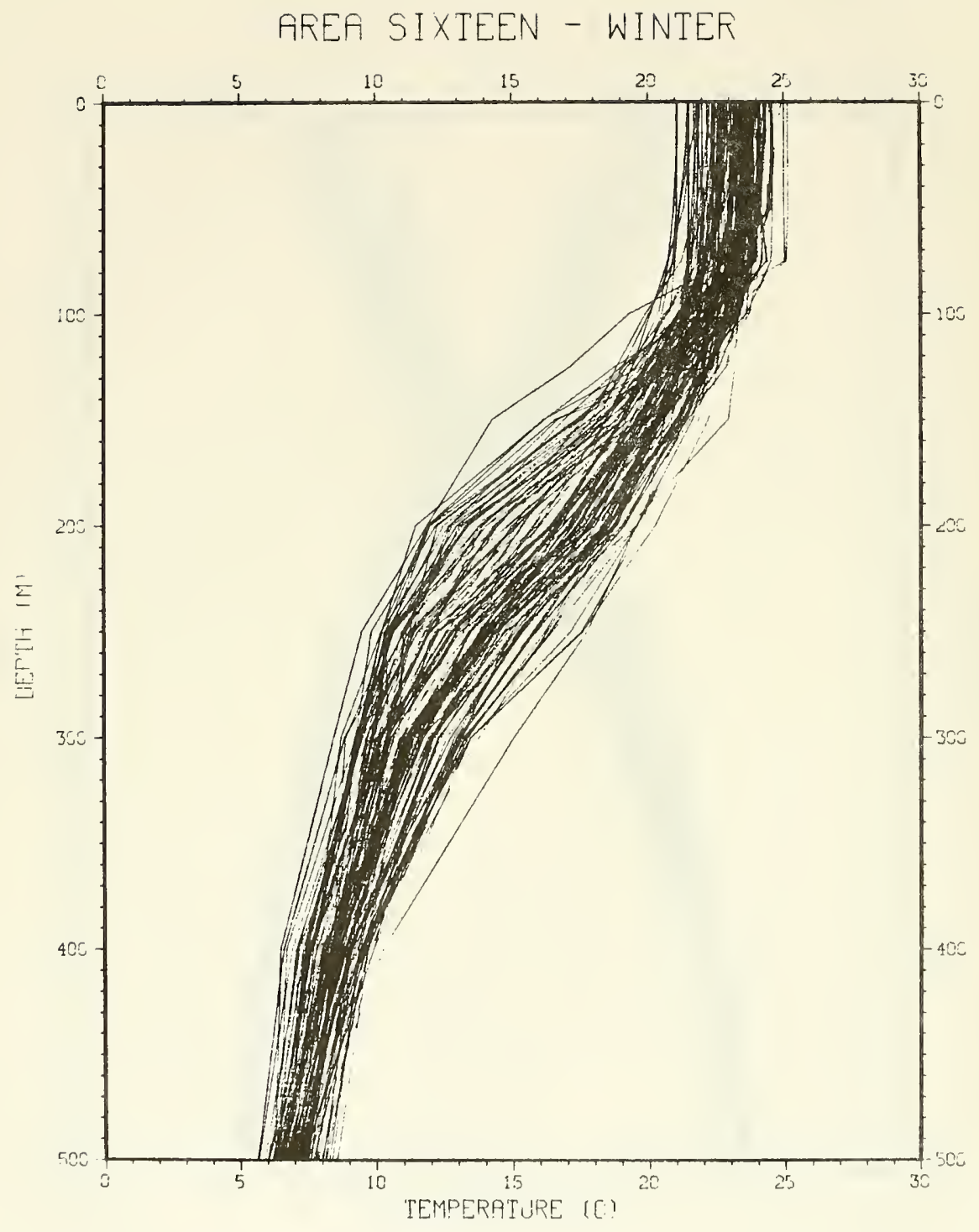

Figure B.62. 


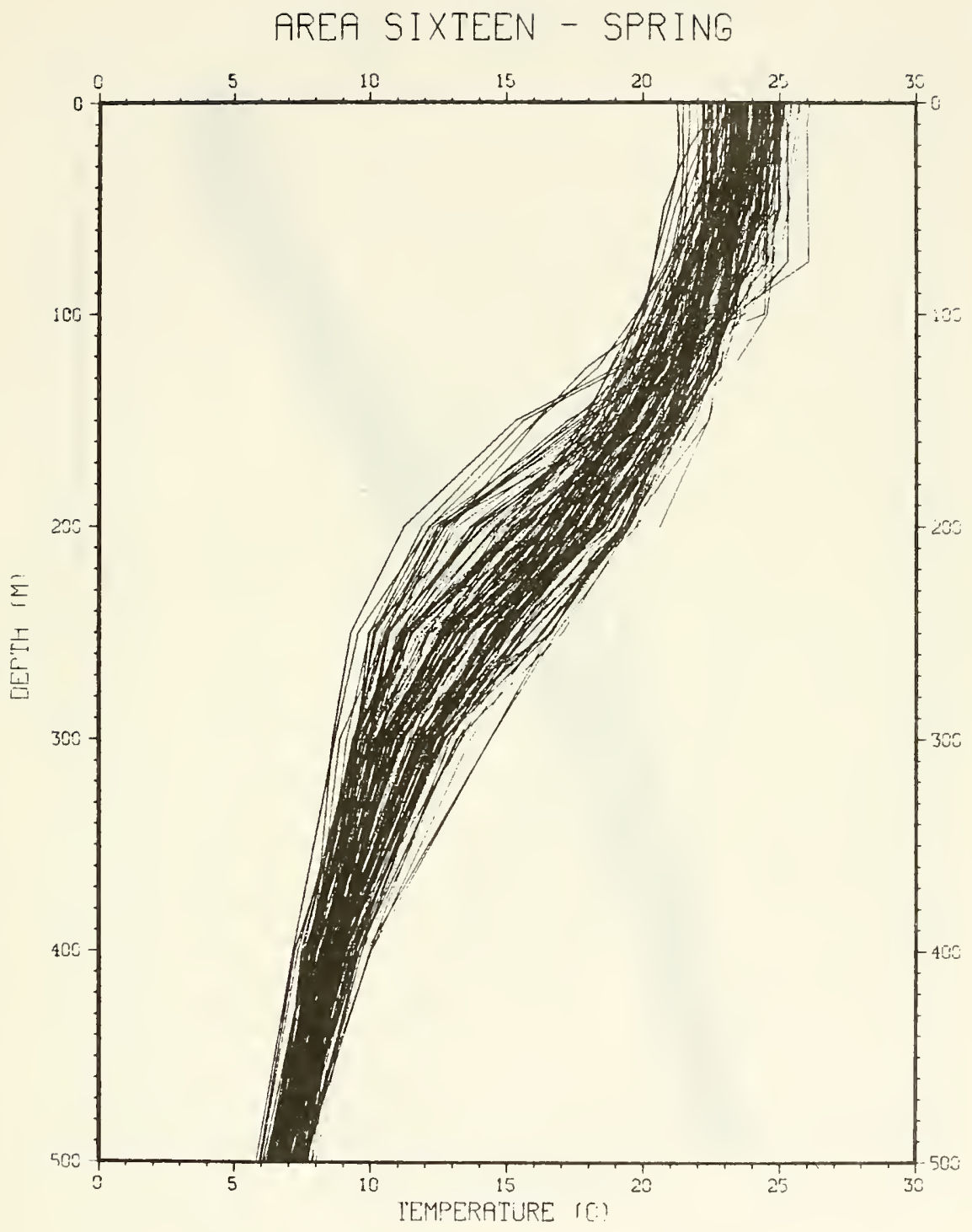

Figure B.63. 


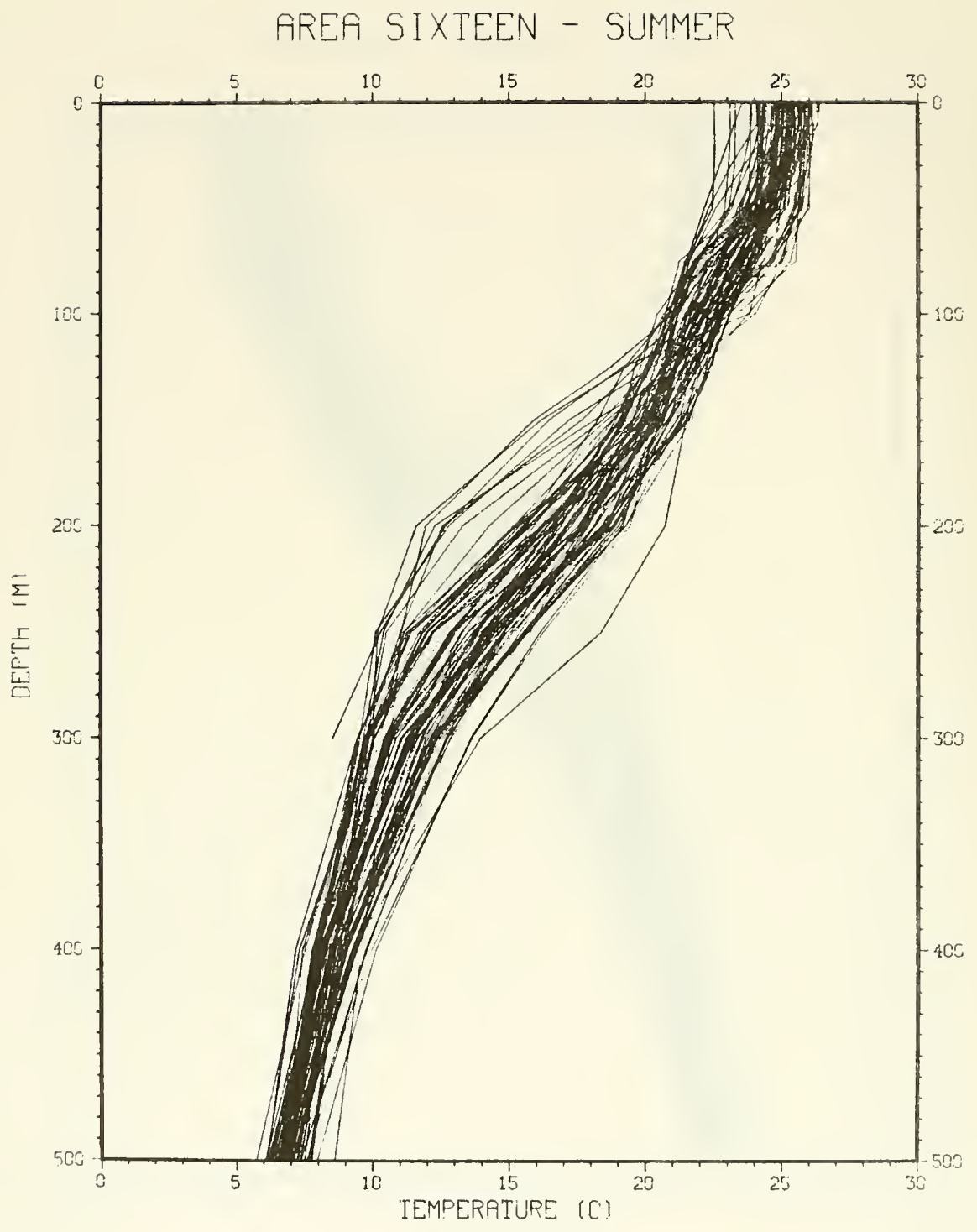

Figure B.64. 


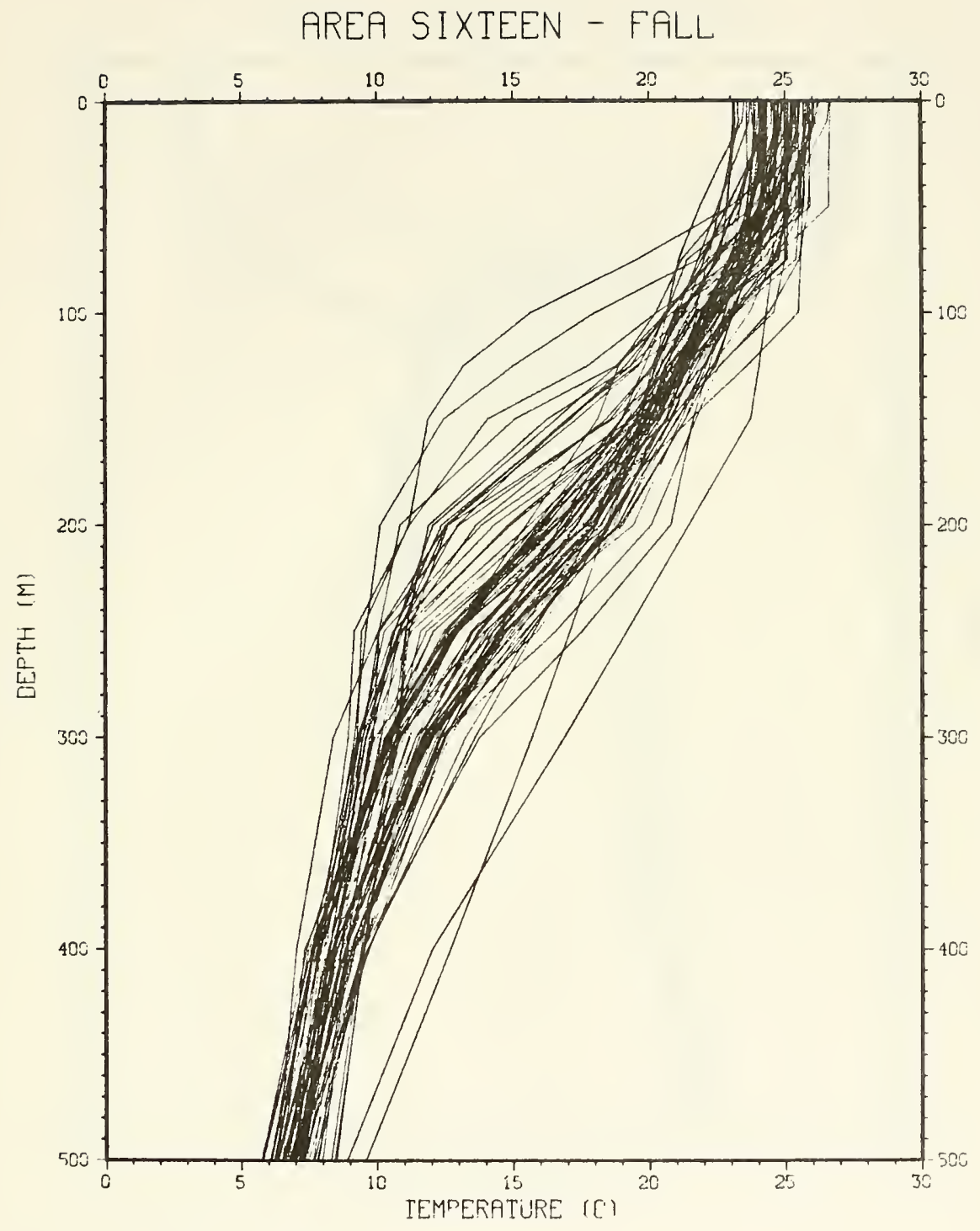

Figure B.65. 


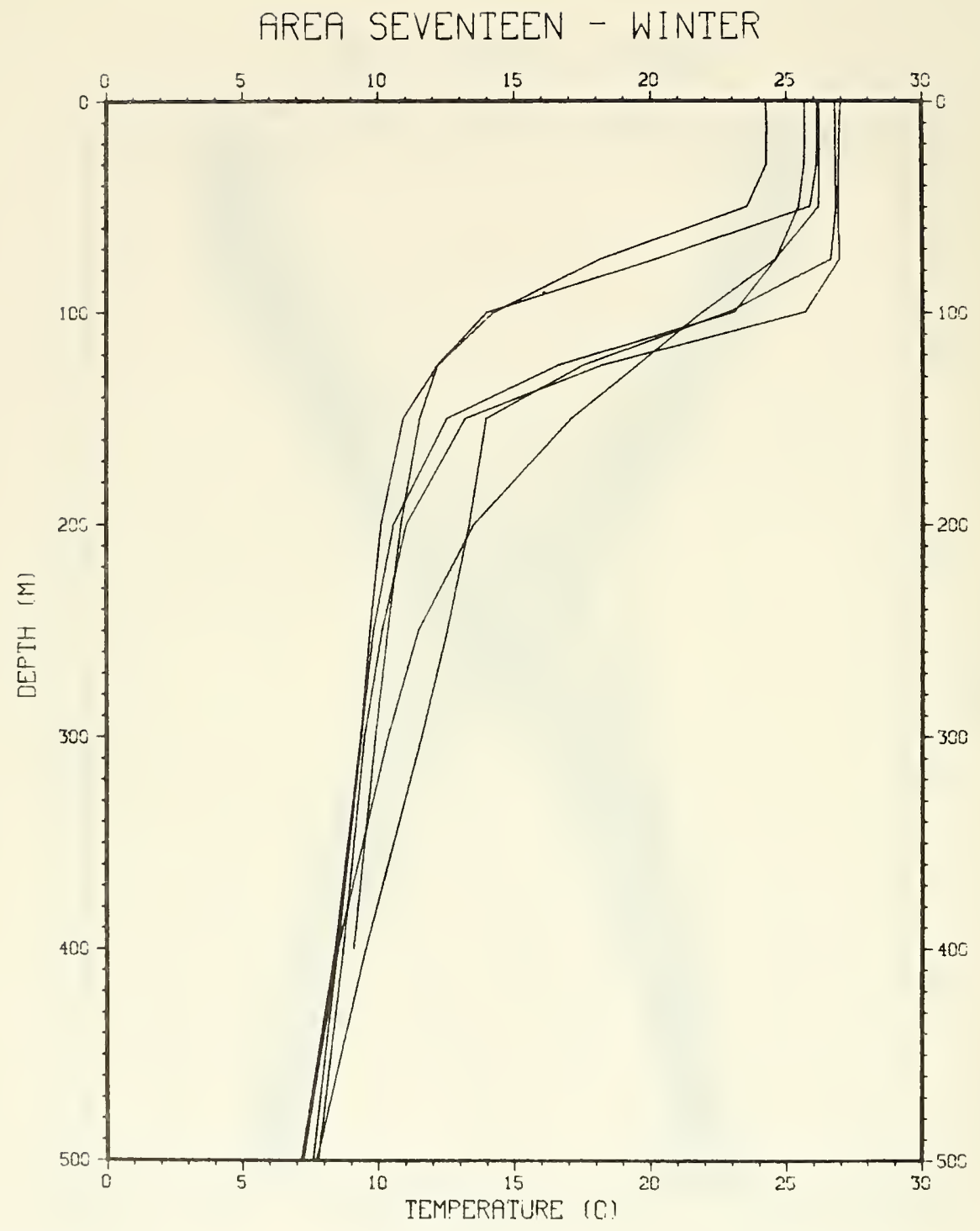

Figure B.66. 


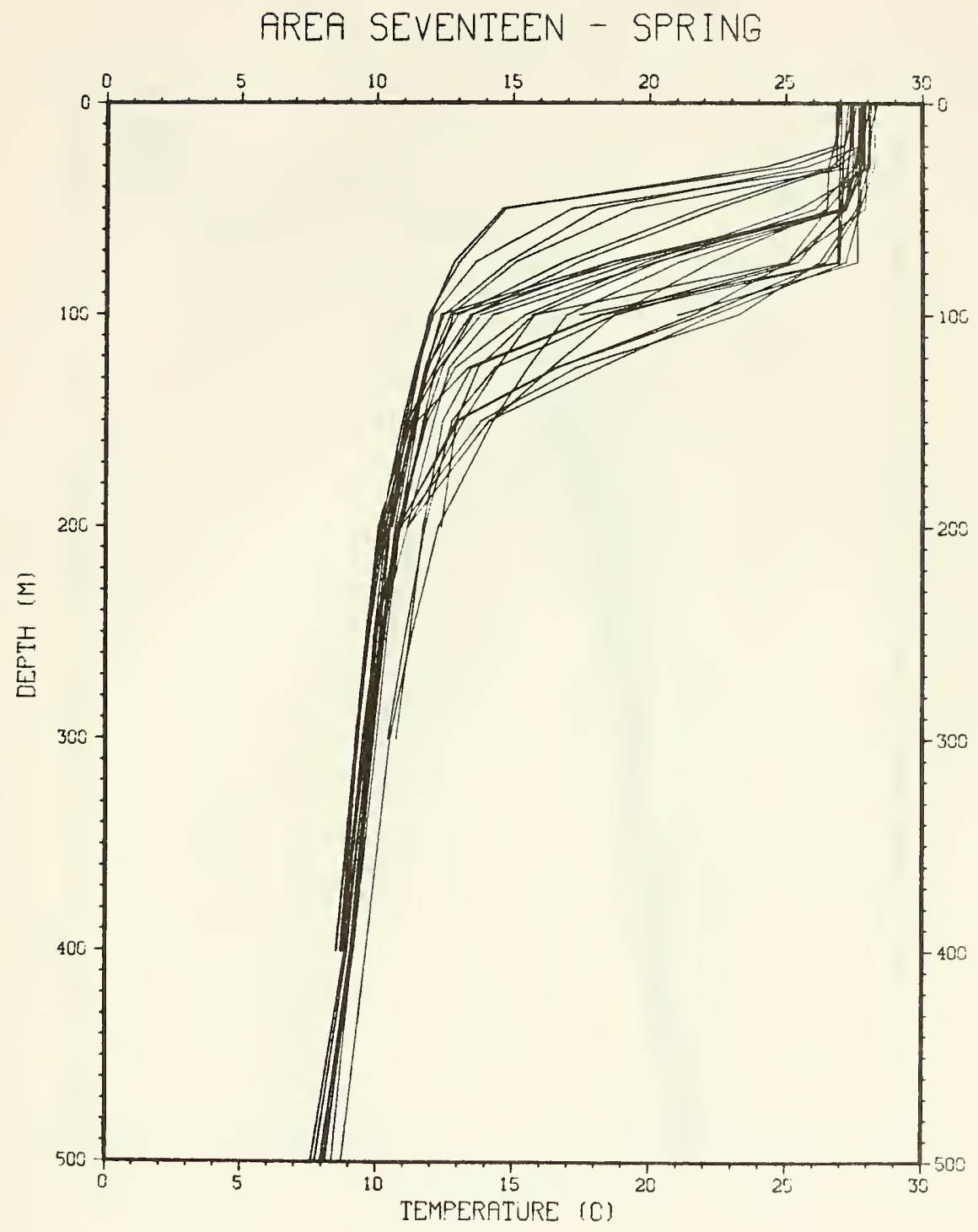

Figure B.67. 


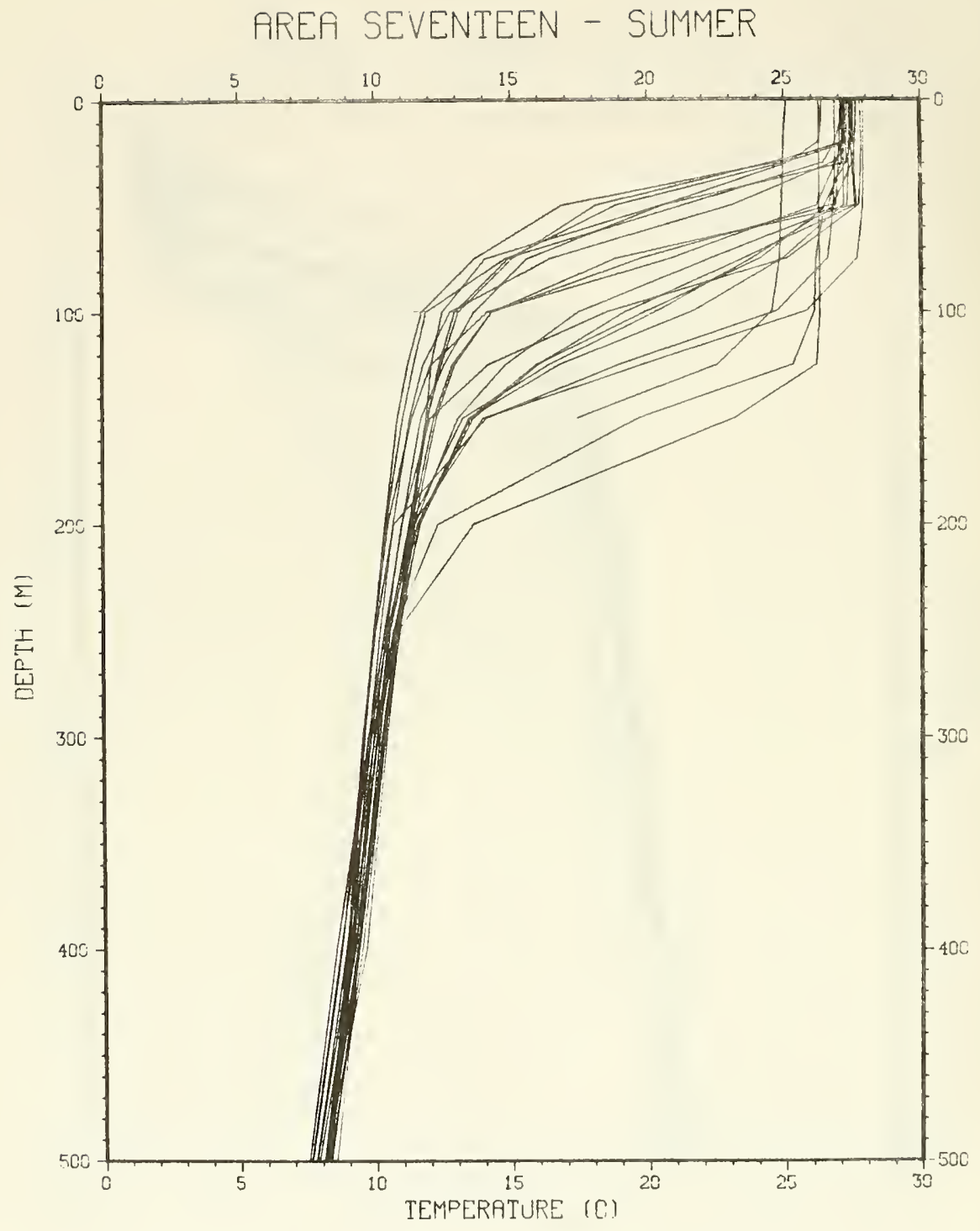

Figure B.68. 


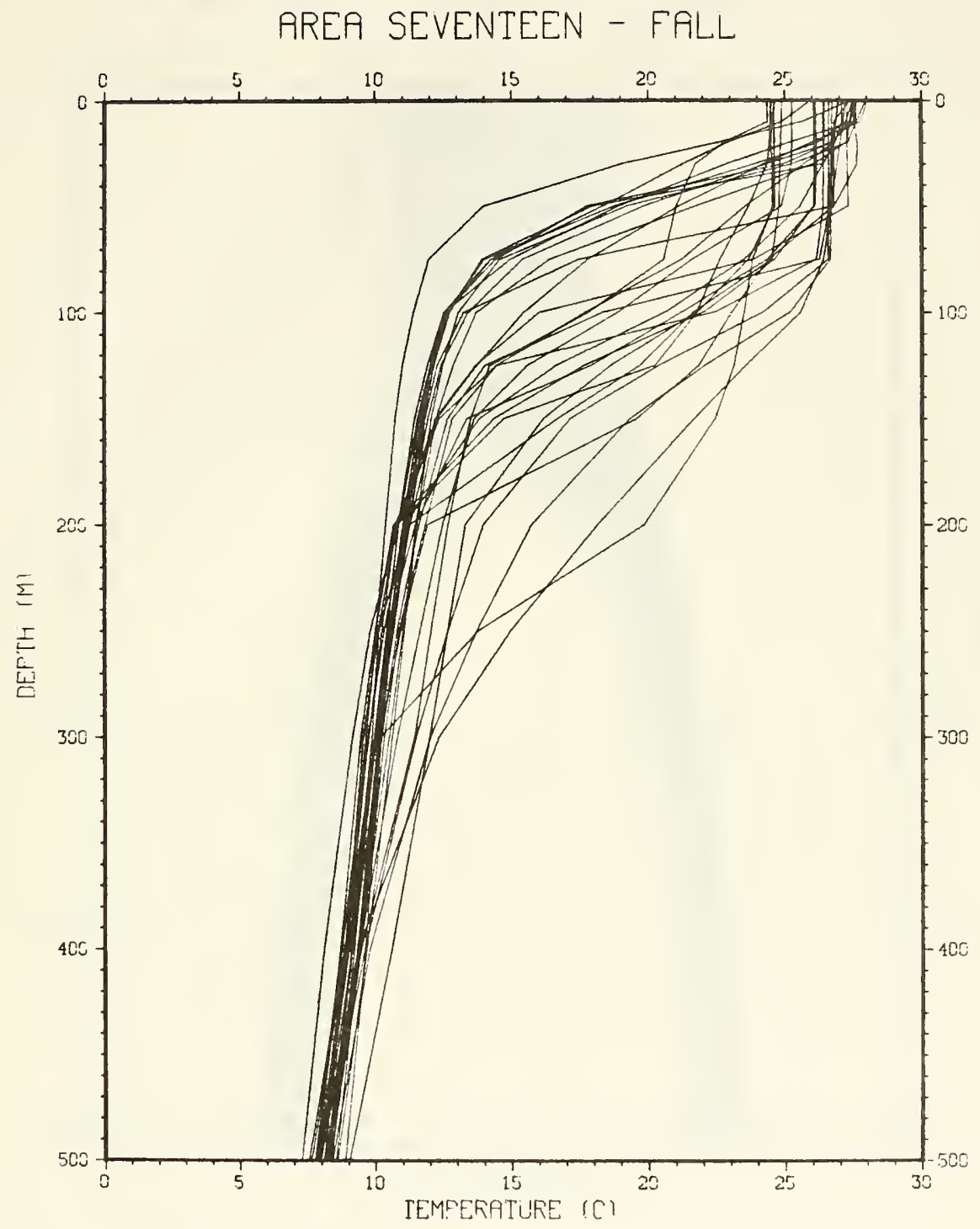

Figure B.69. 


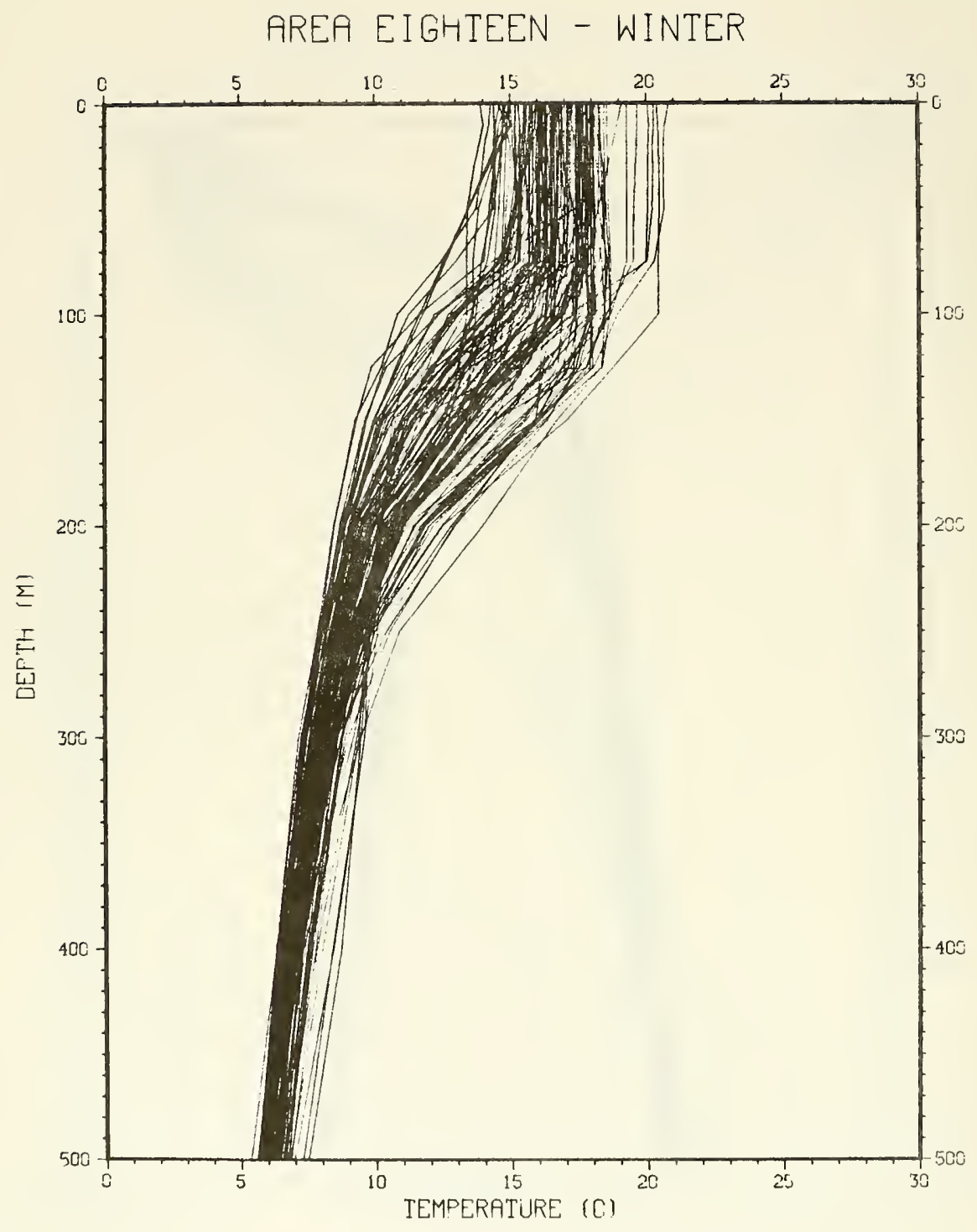

Figure B.70. 


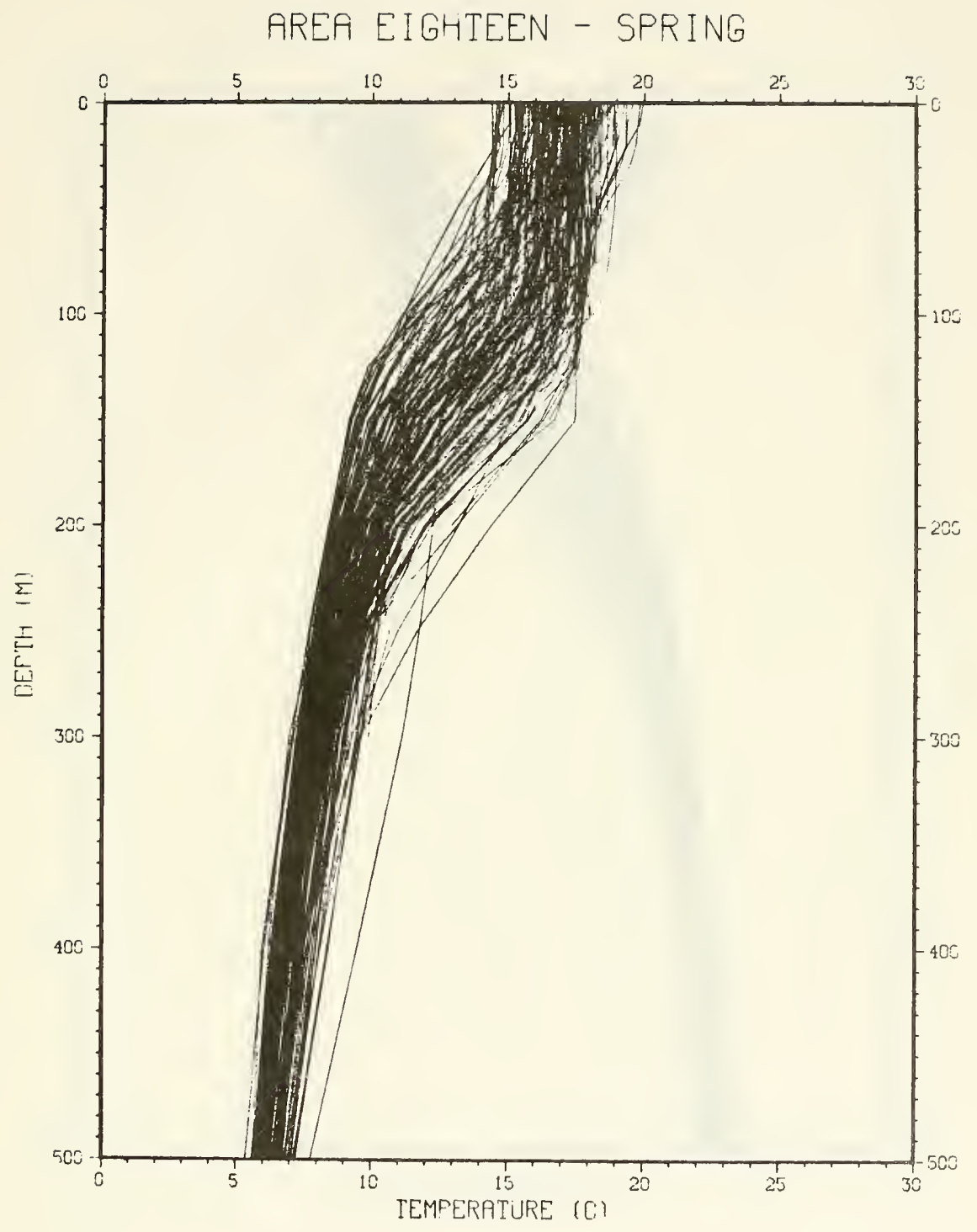

Figure B.71. 


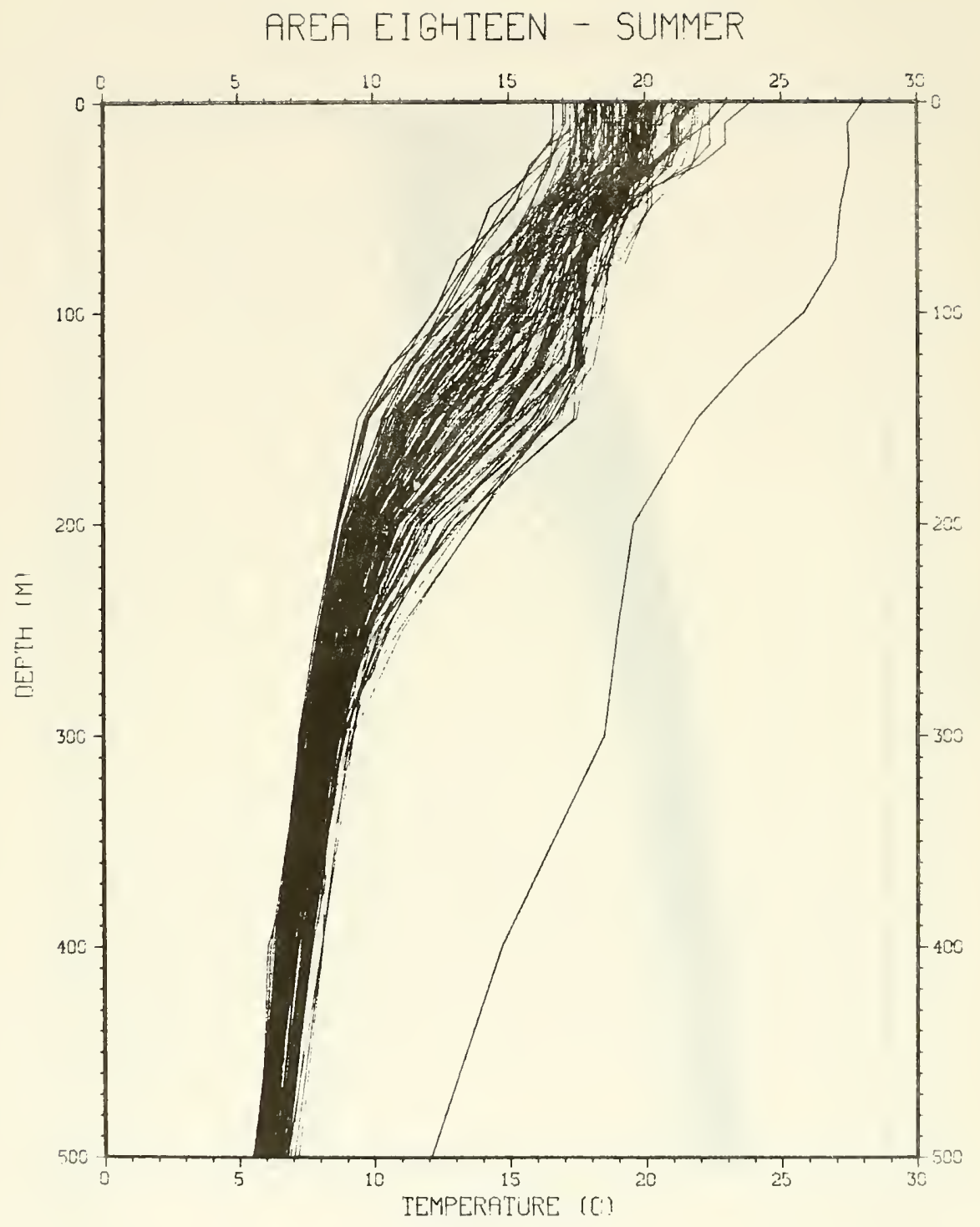

Figure B.72. 


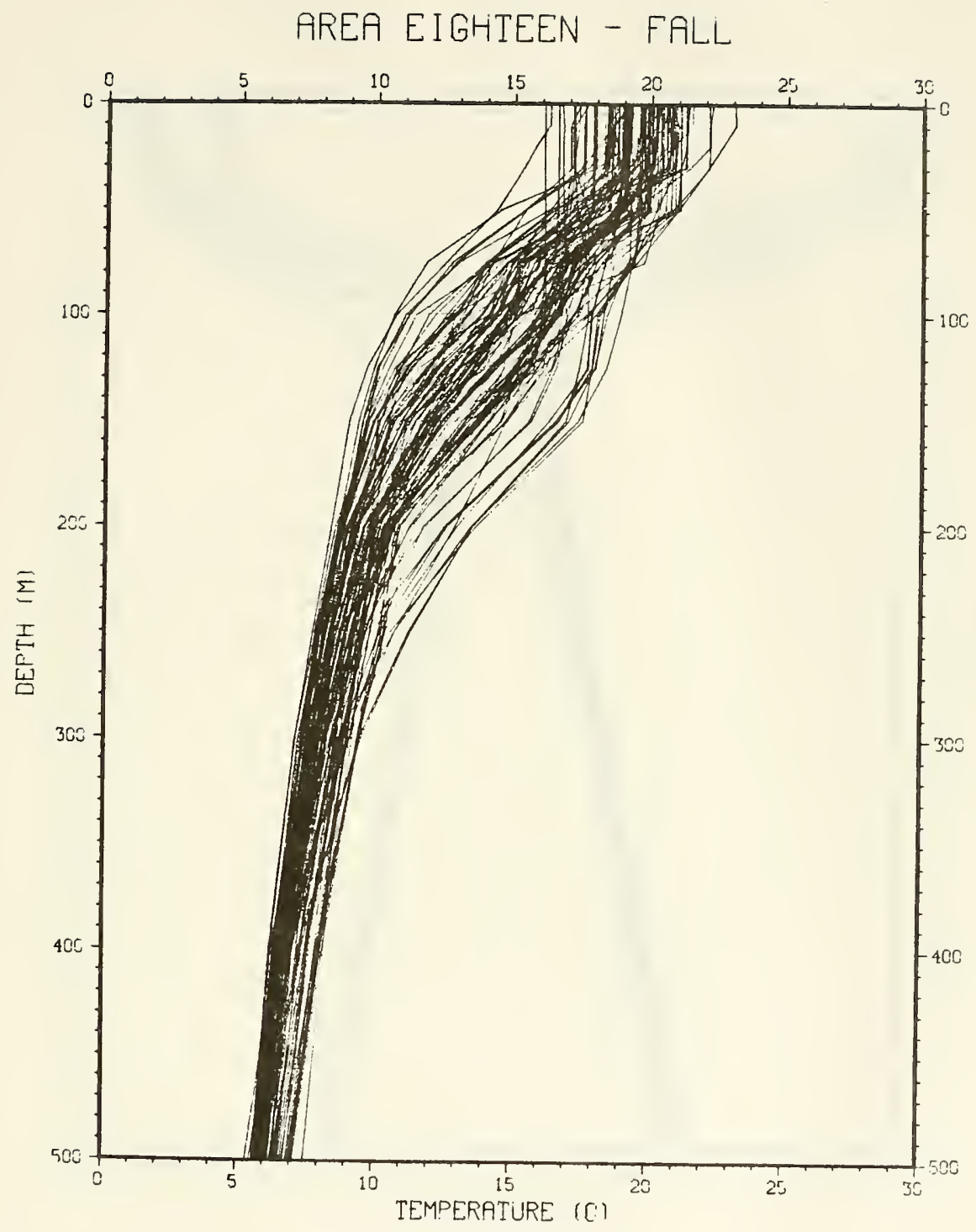

Figure B.73. 


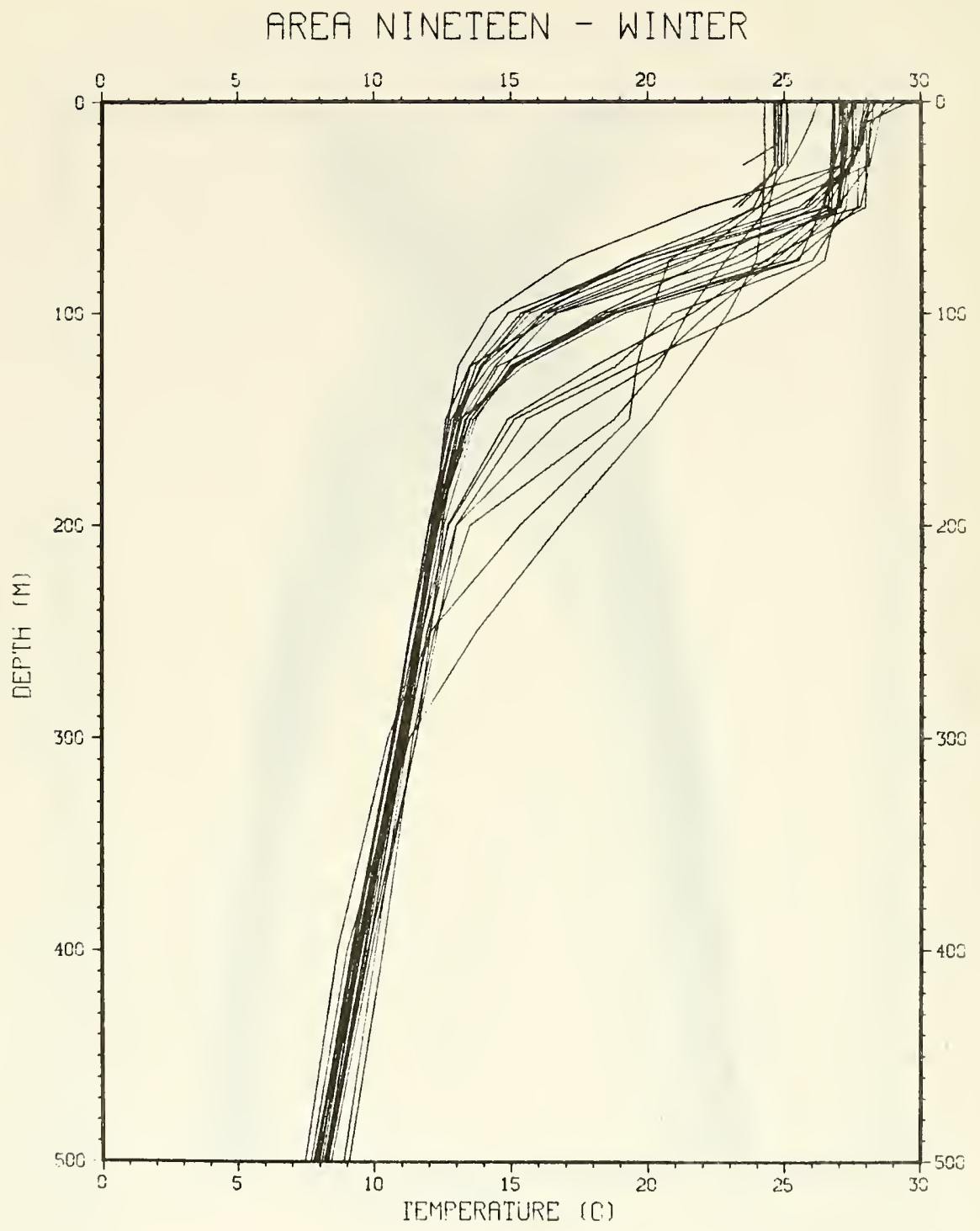

Figure B.74. 


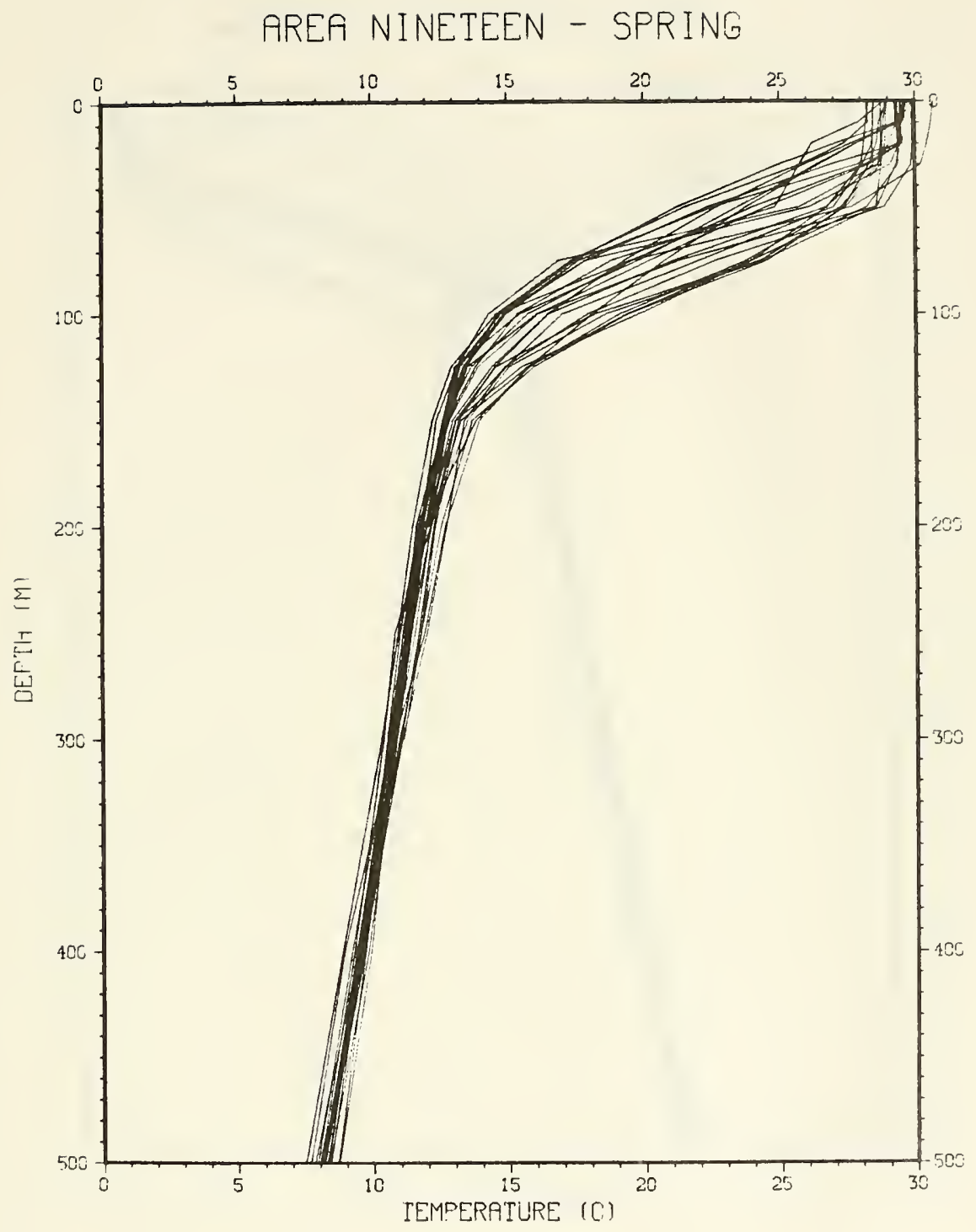

Figure B.75. 


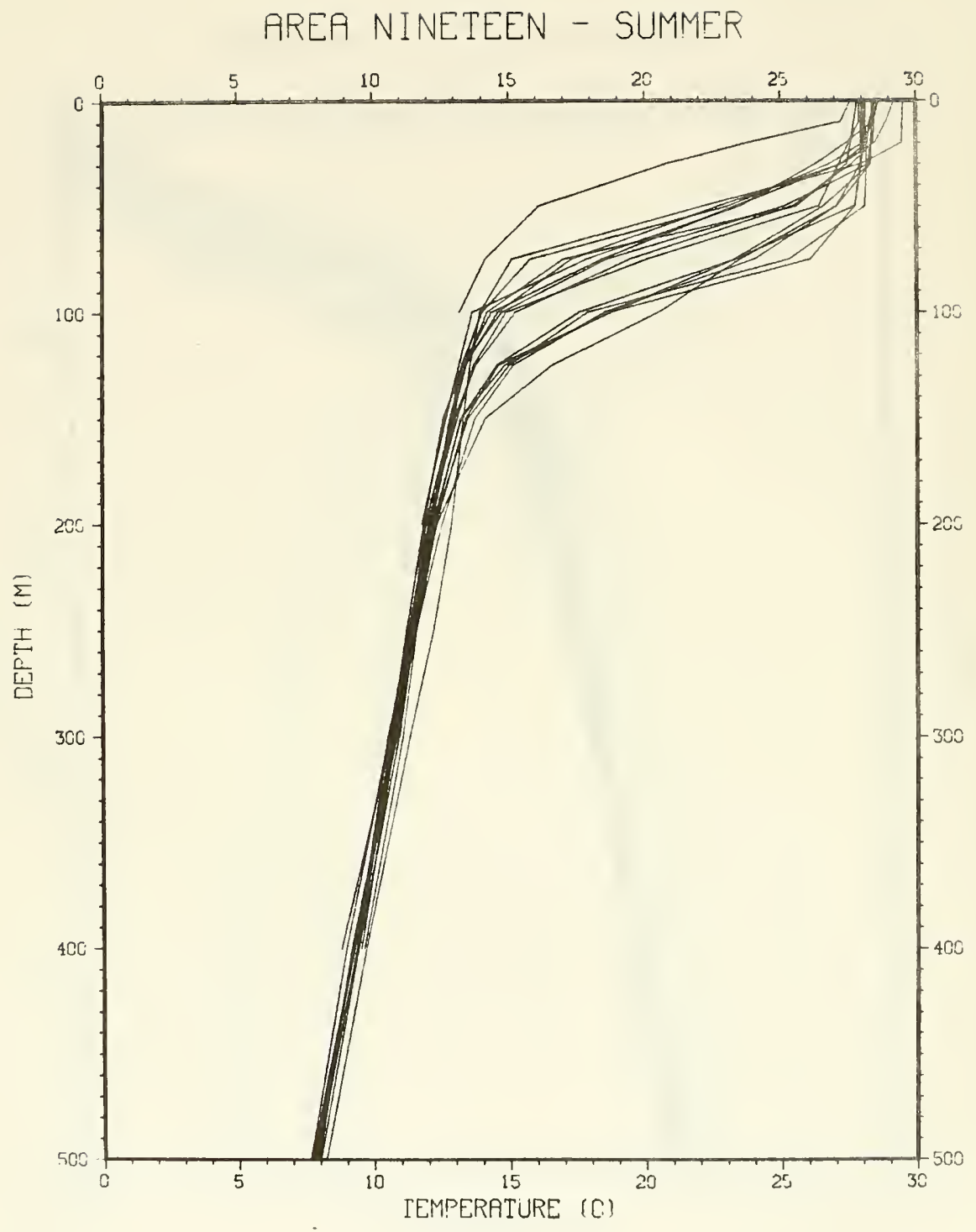

Figure B.76. 


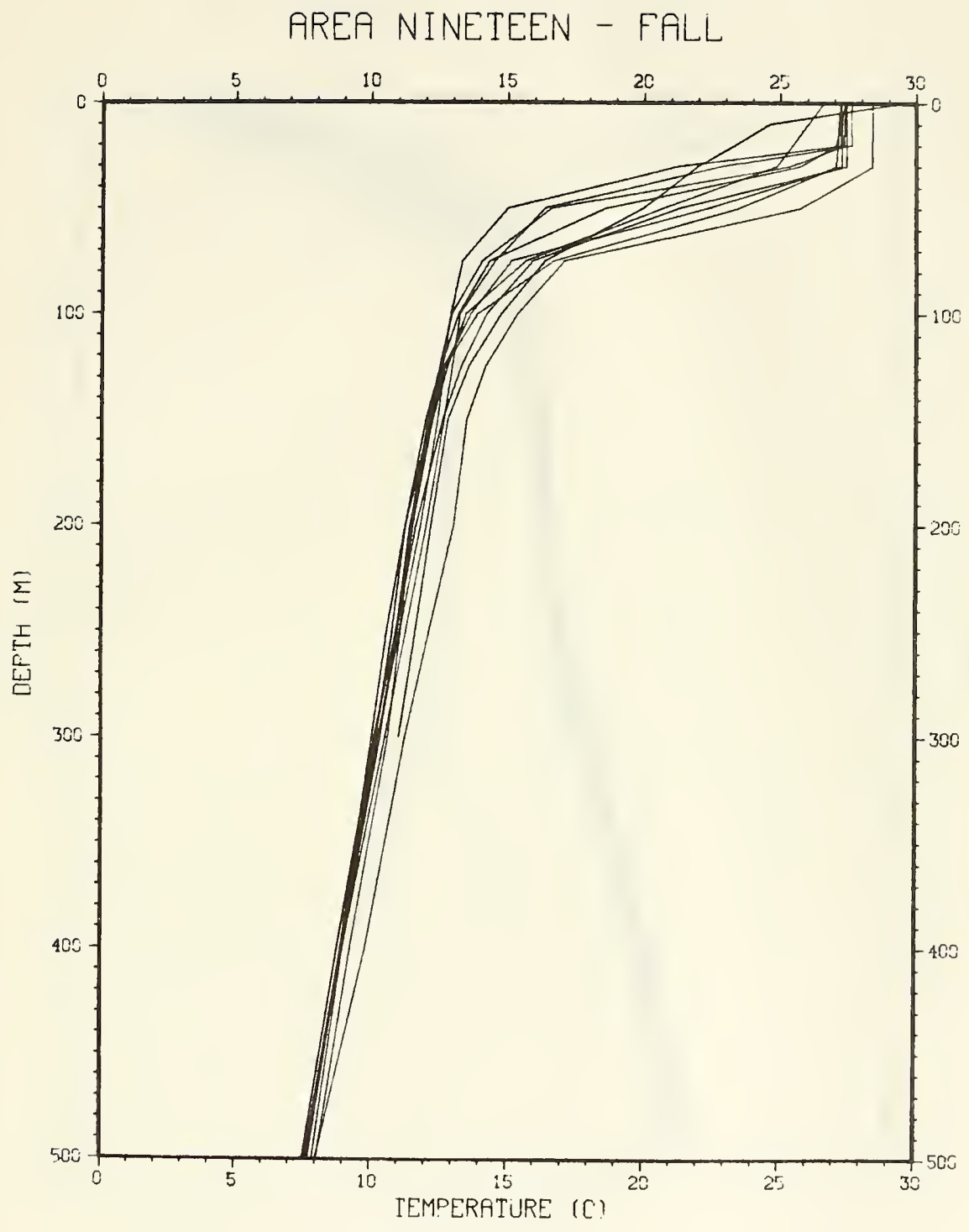

Figure B.77. 


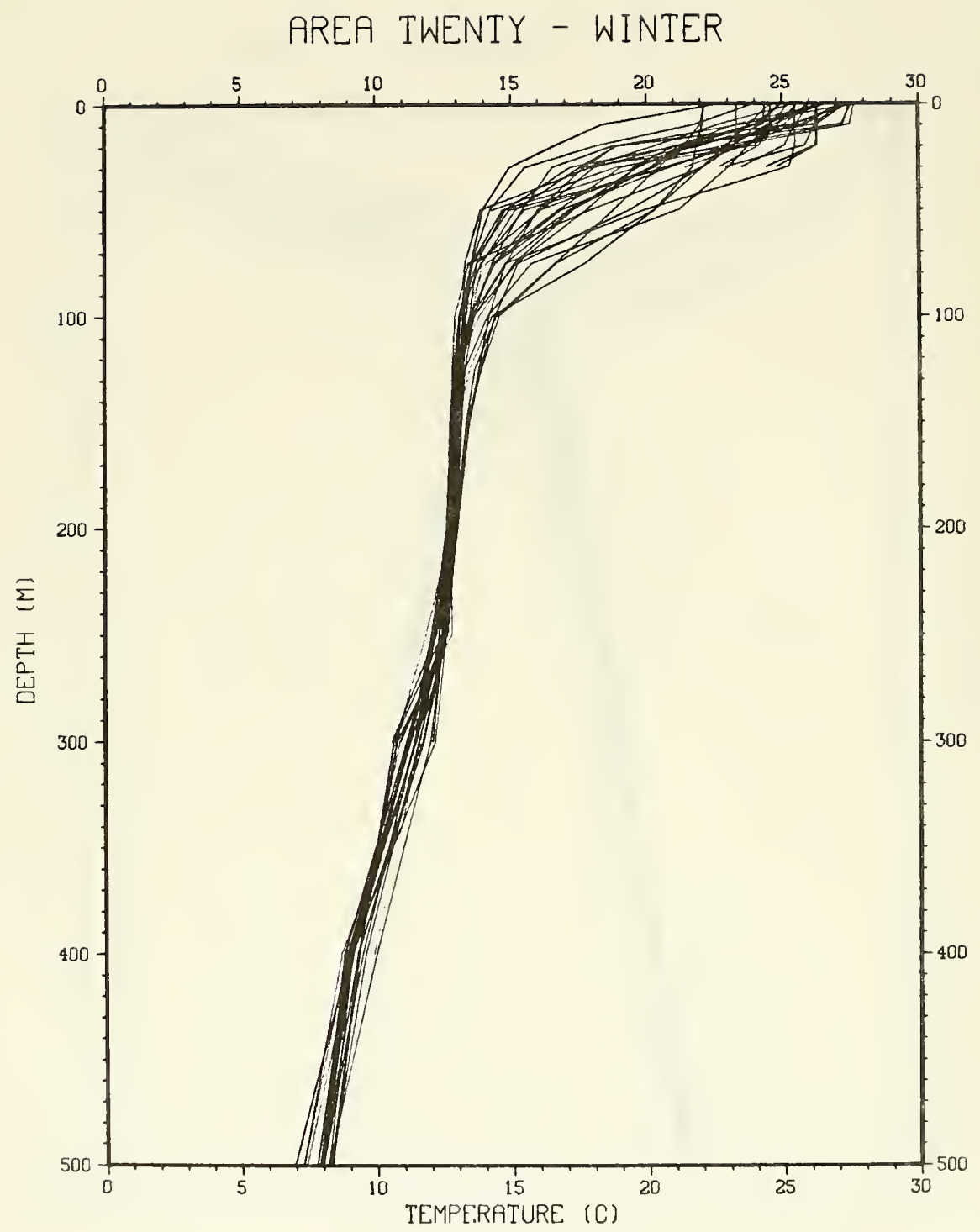

Figure B.78. 


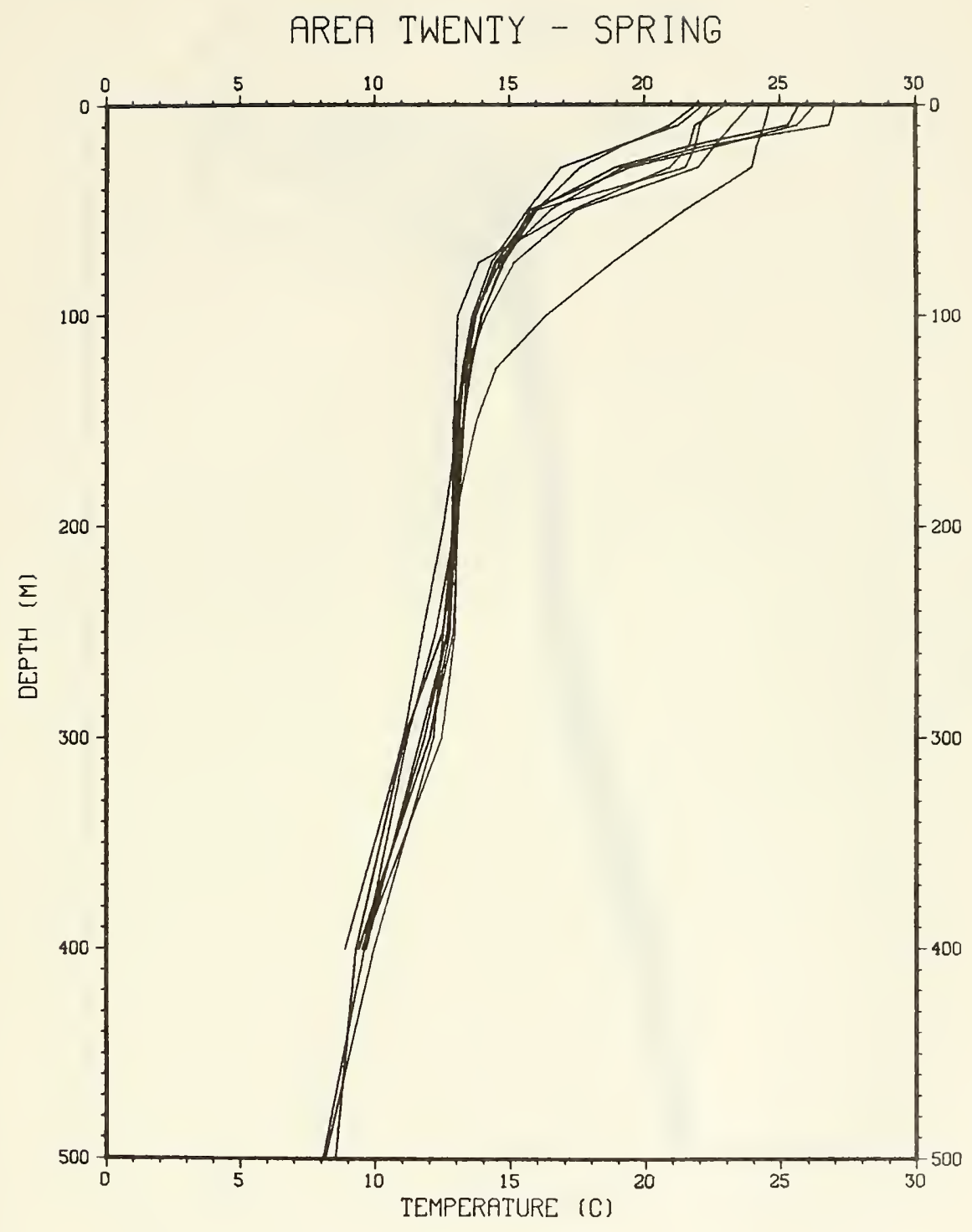

Figure B.79. 


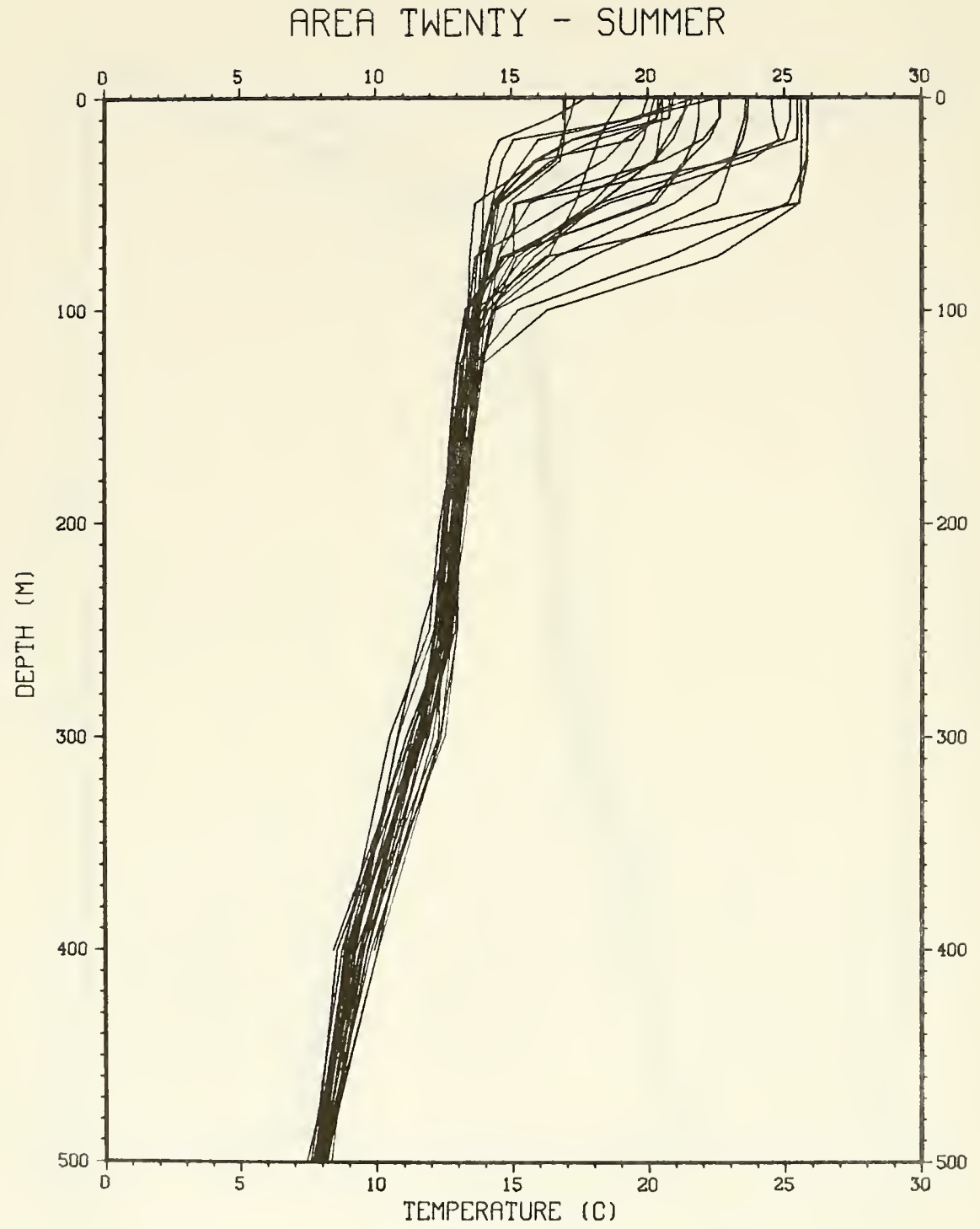

Figure B.80. 


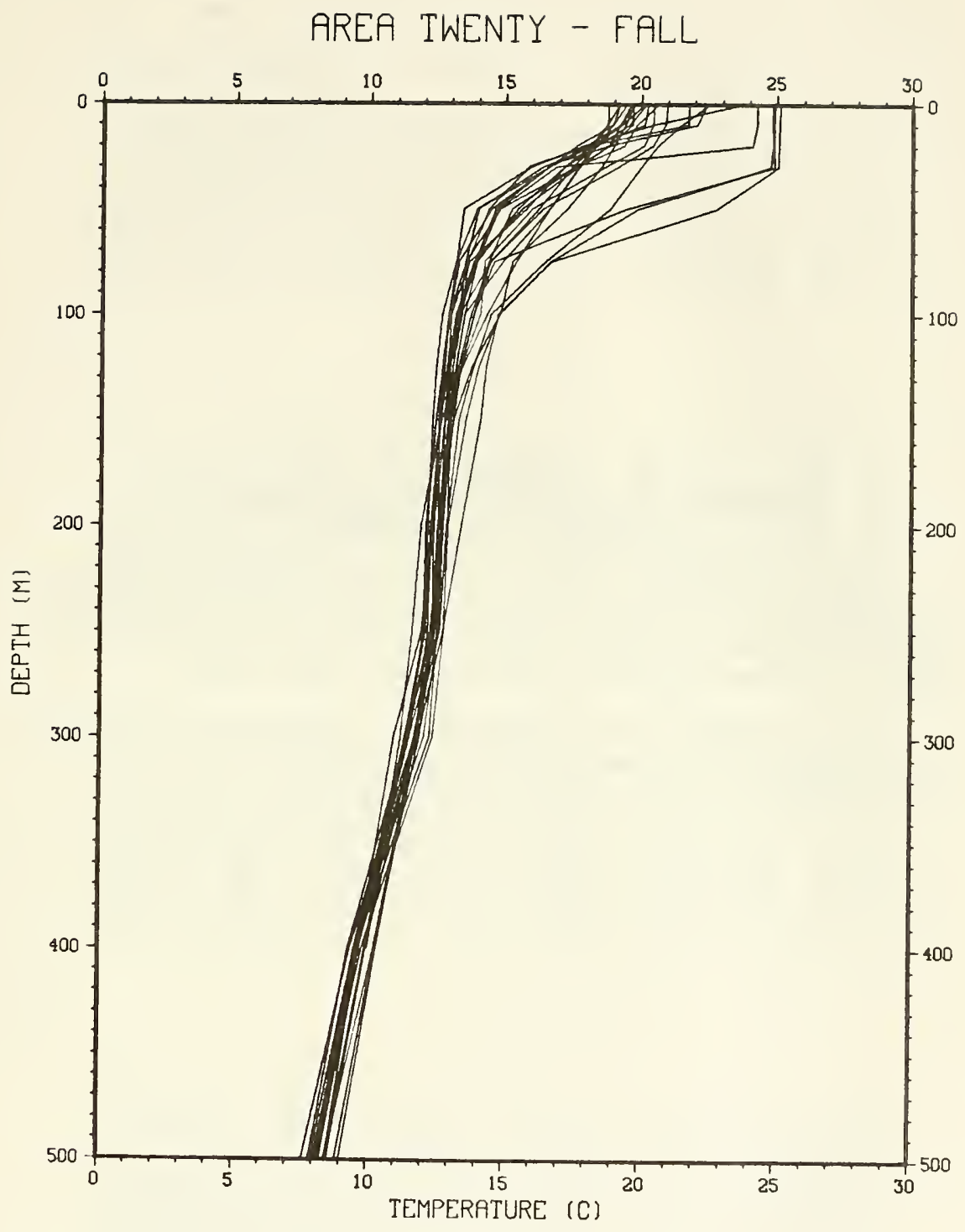

Figure B.81. 


\section{APPENDIX C \\ STATISTICAL SUMMARY OF PHYSICAL OCEANOGRAPHIC \\ DATA BY SEASON AND AREA}

Data from the National Oceanographic Data Center was analyzed on the Naval Undersea Center UNIVAC 1110 computer to obtain maximum, mean, minimum and standard deviation of temperature $\left({ }^{\circ} \mathrm{C}\right.$ ), salinity (parts per thousand), and sigma-t (density). The number of hydrocasts analyzed is given. Areas are shown in Figure 1 and B.1.

Data can be utilized for future modeling programs for OFEF, such as growth simulation, sinking rate and structural and total farm buoyancy models. 


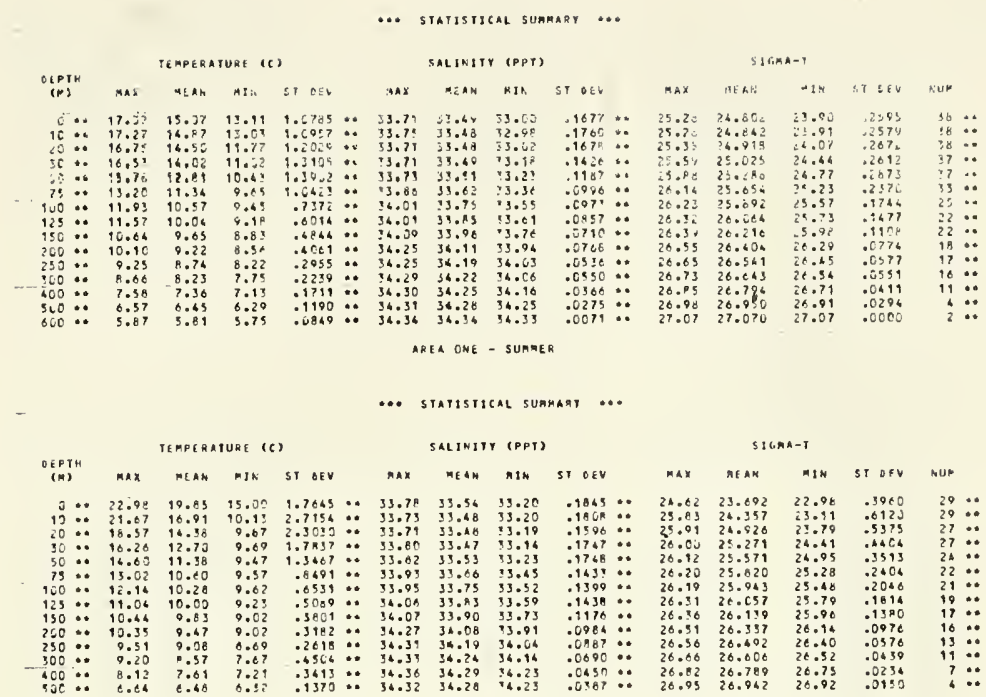

ARIA ONE - SPRIHE

... STATISTICal suthary A.

\begin{tabular}{lllllllllllllll}
\multicolumn{9}{c}{ SALINITV (PPT) } \\
DEPIH \\
(1)
\end{tabular}

AKEA ONE - MALL

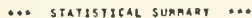

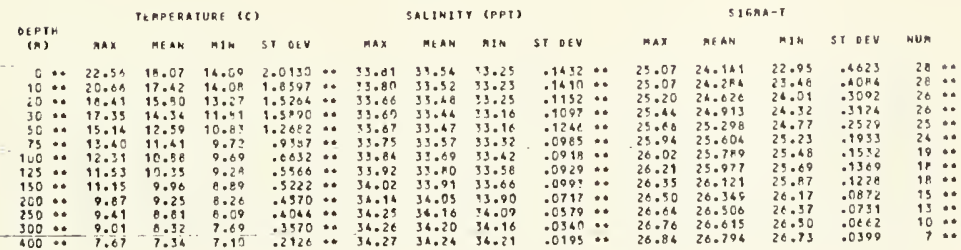

Figure C.1. 


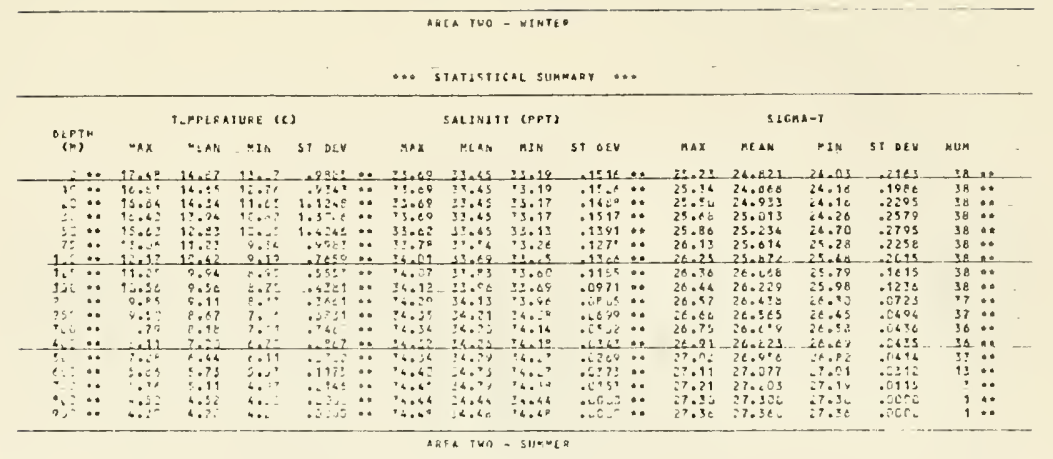

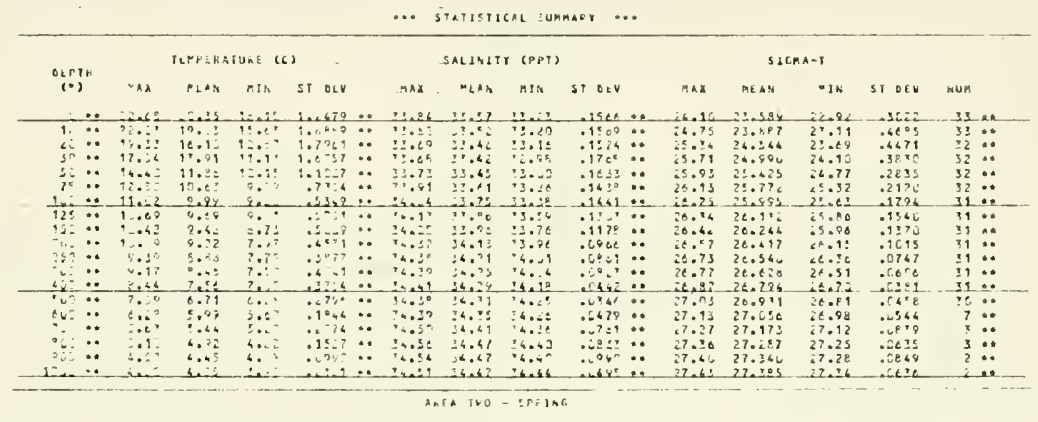

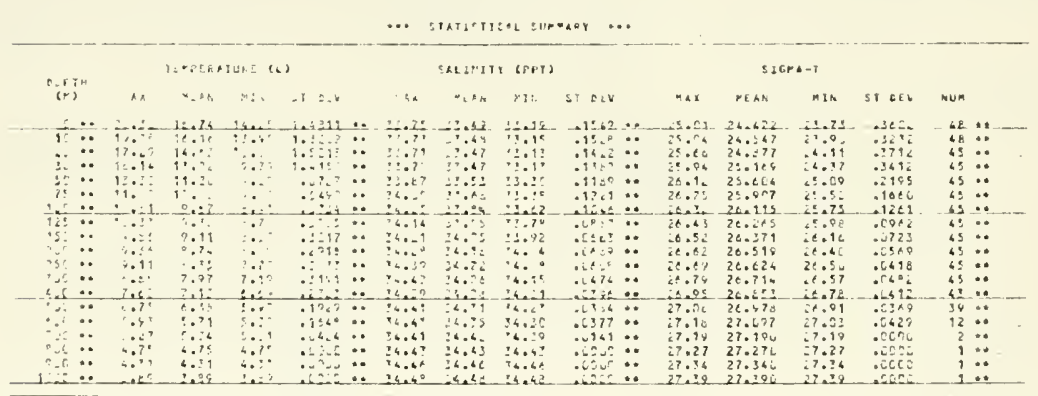

AREA TWO - TALL

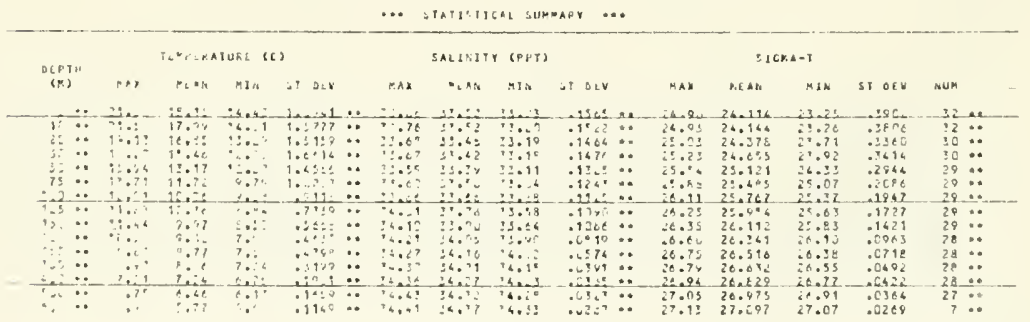

Figure C.2. 


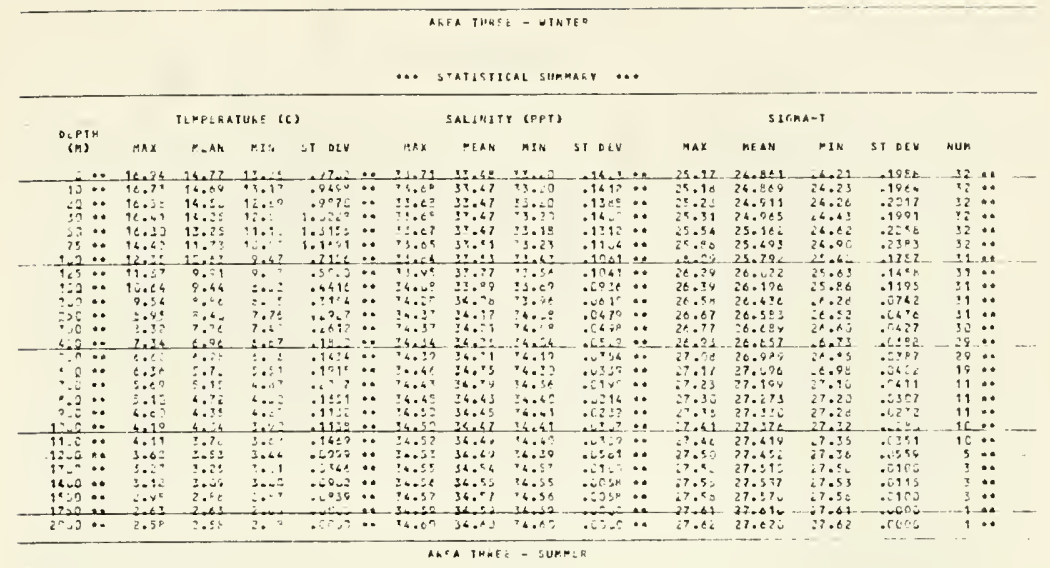

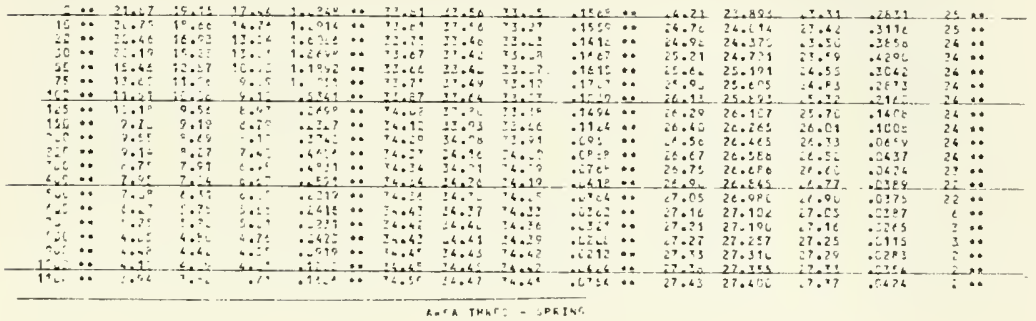

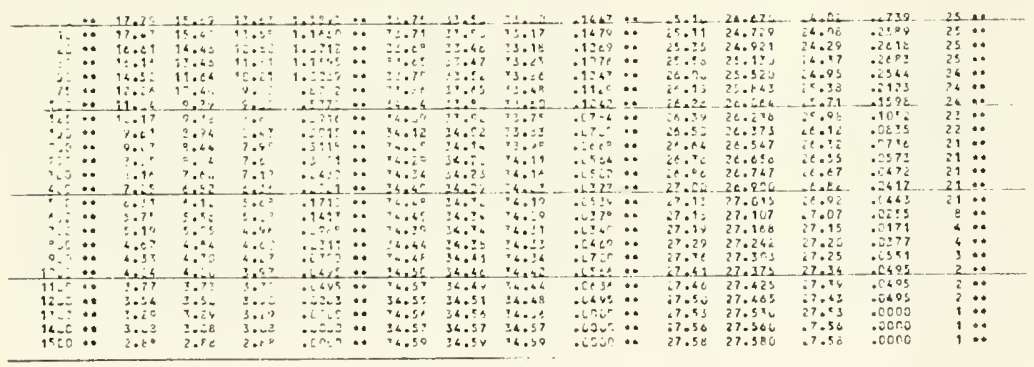

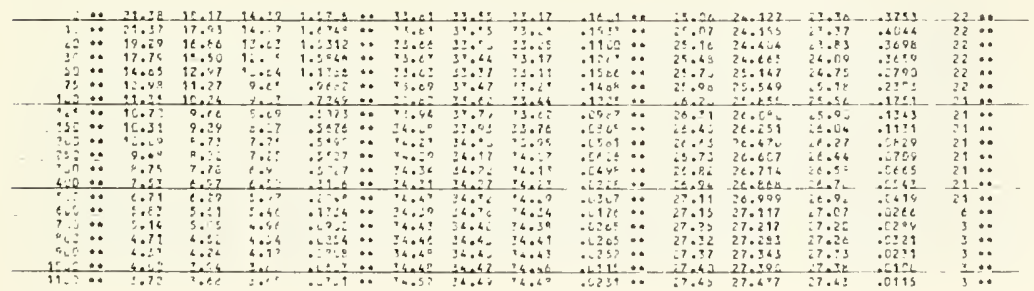

Figure C.3. 

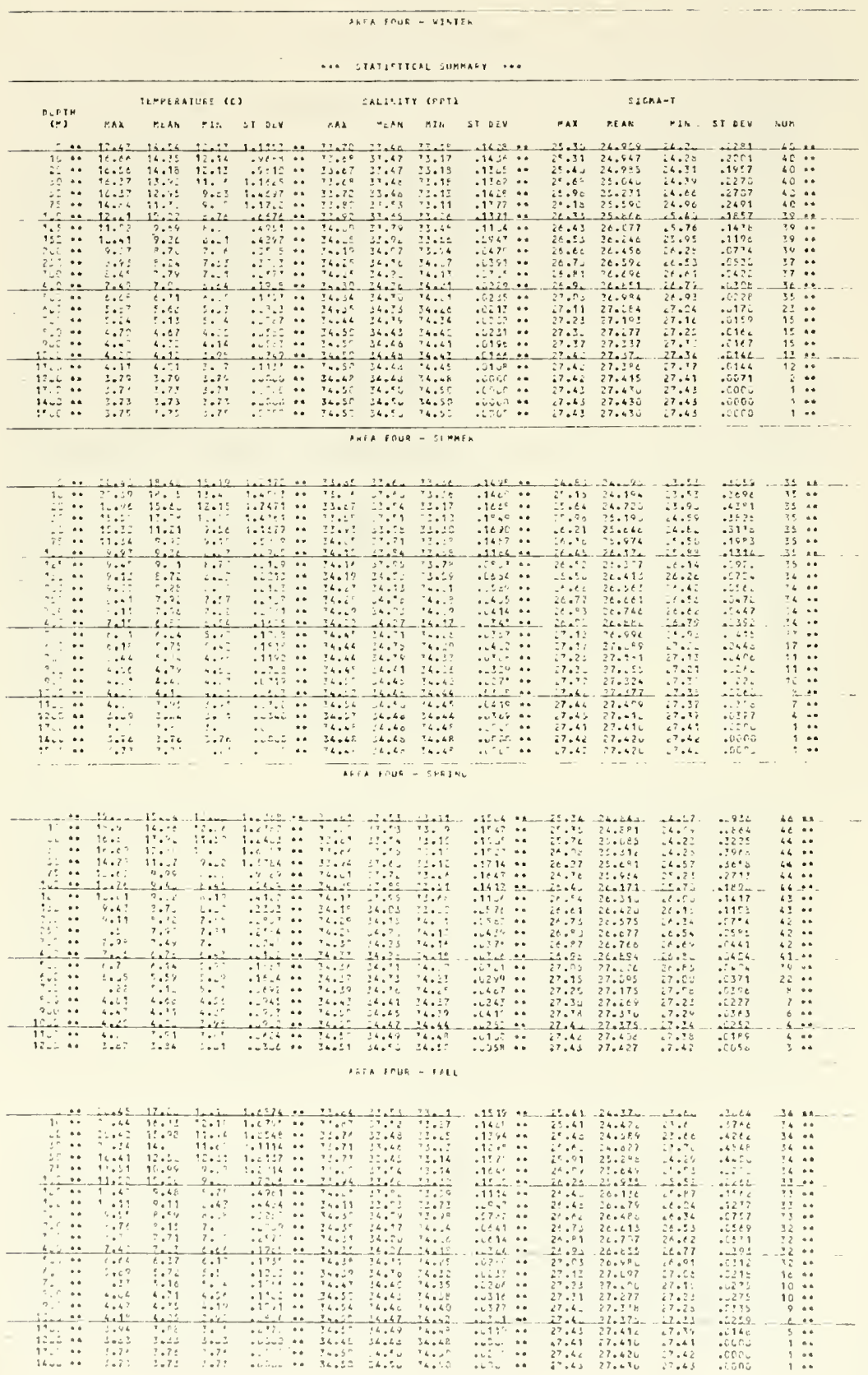

Figure C.4. 


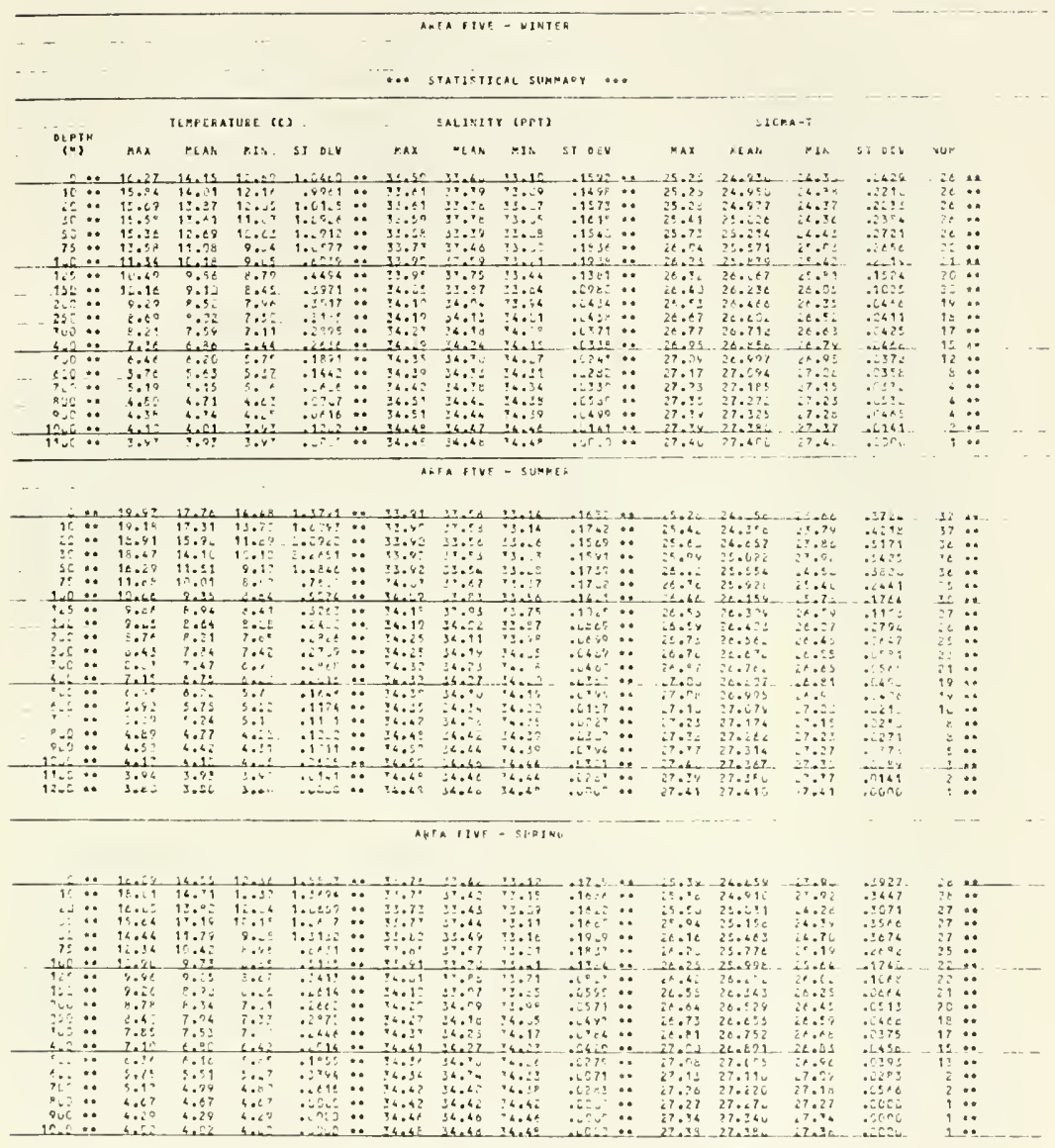

AREA GIVE - FALL

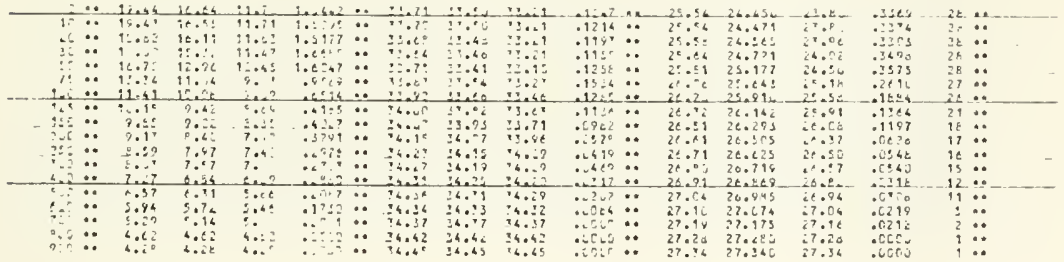

Figure C.5. 


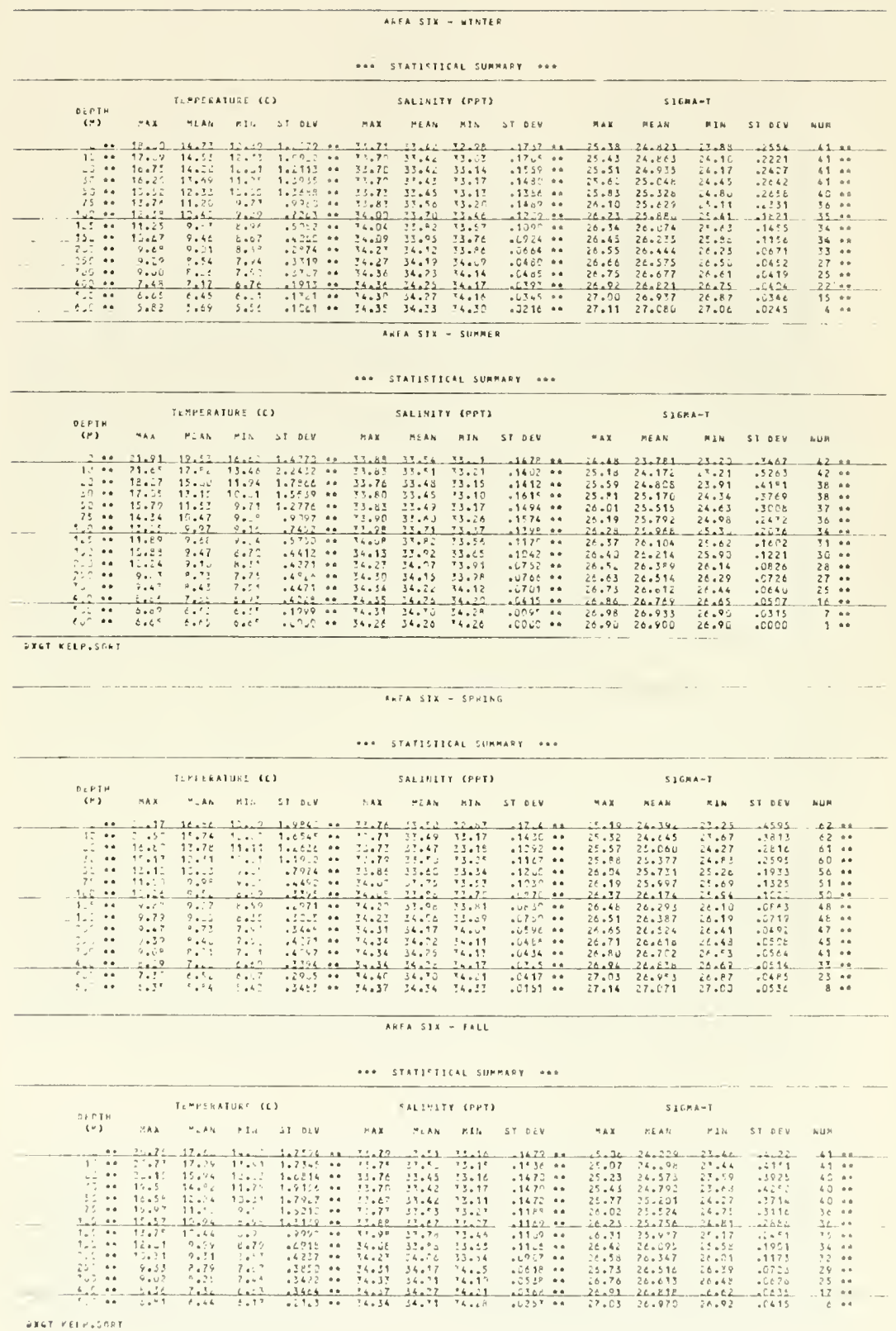

Figure C.6. 


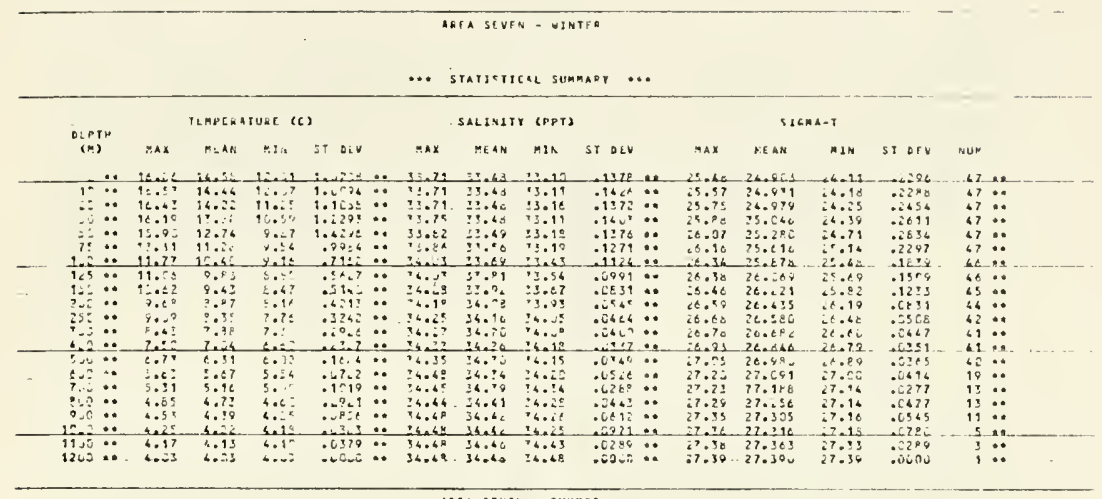

AREA SEVEN - SUMAEO

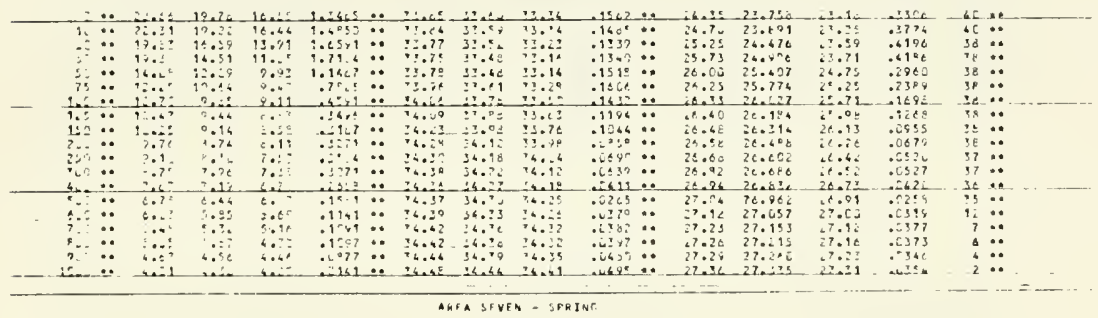

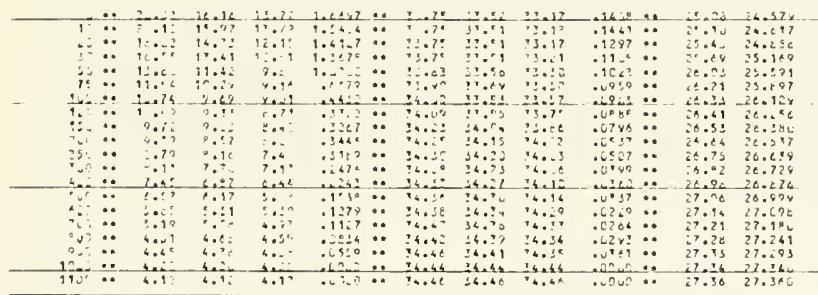

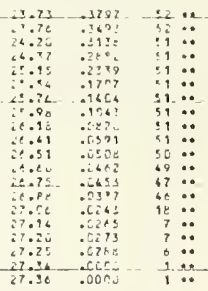

ARTA SFYFA-IALL

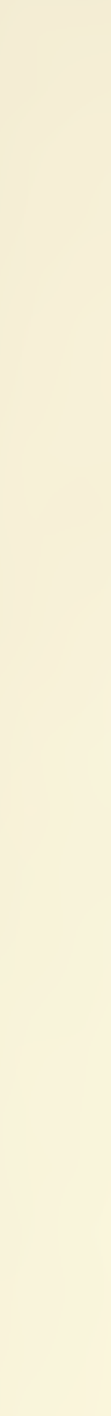

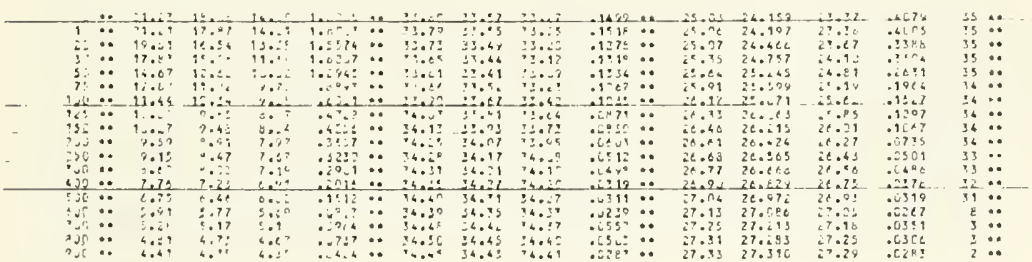

Figure C.7. 


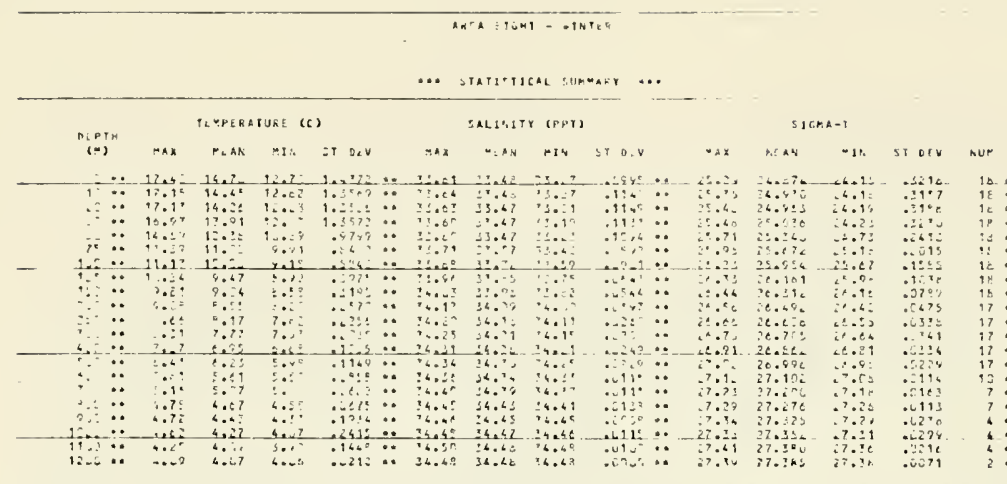

ARFA CIG, TI - SURA.
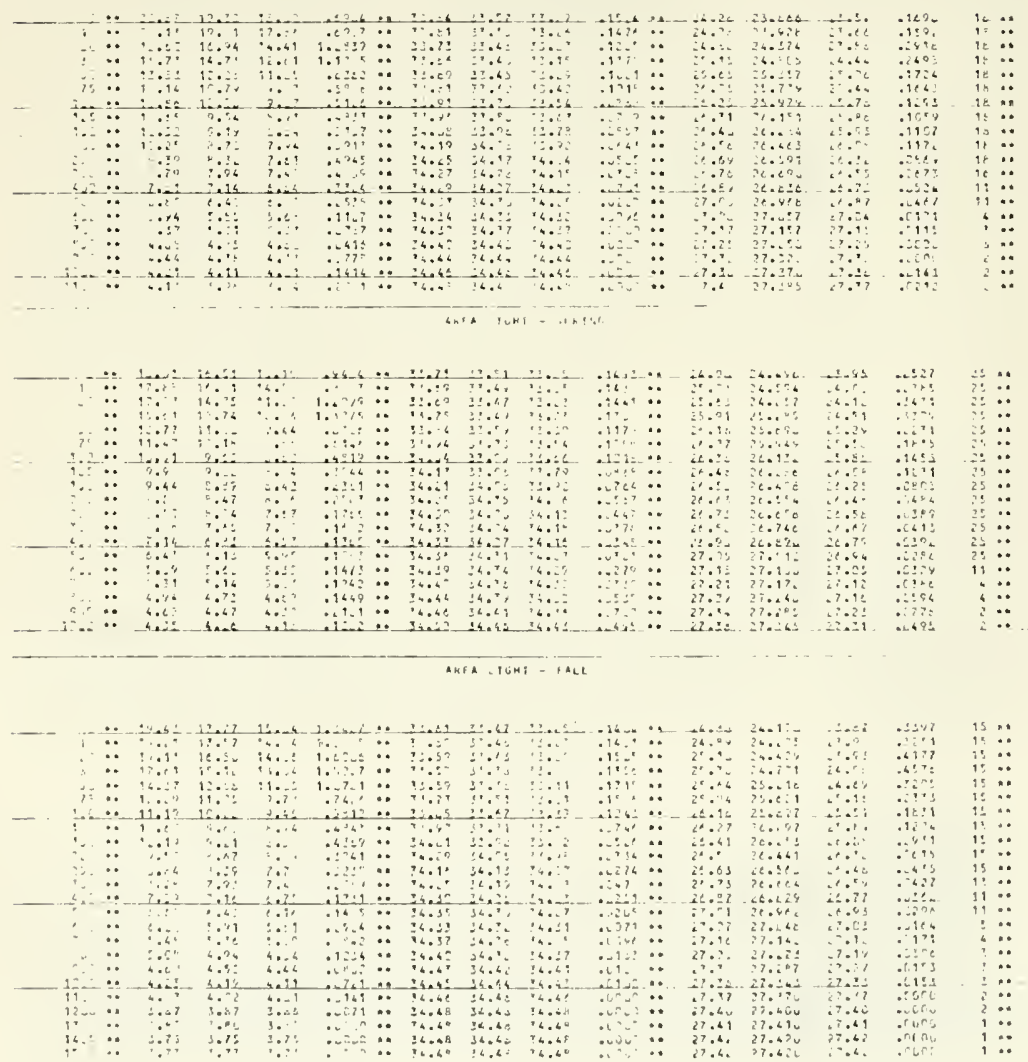

Figure C.8. 


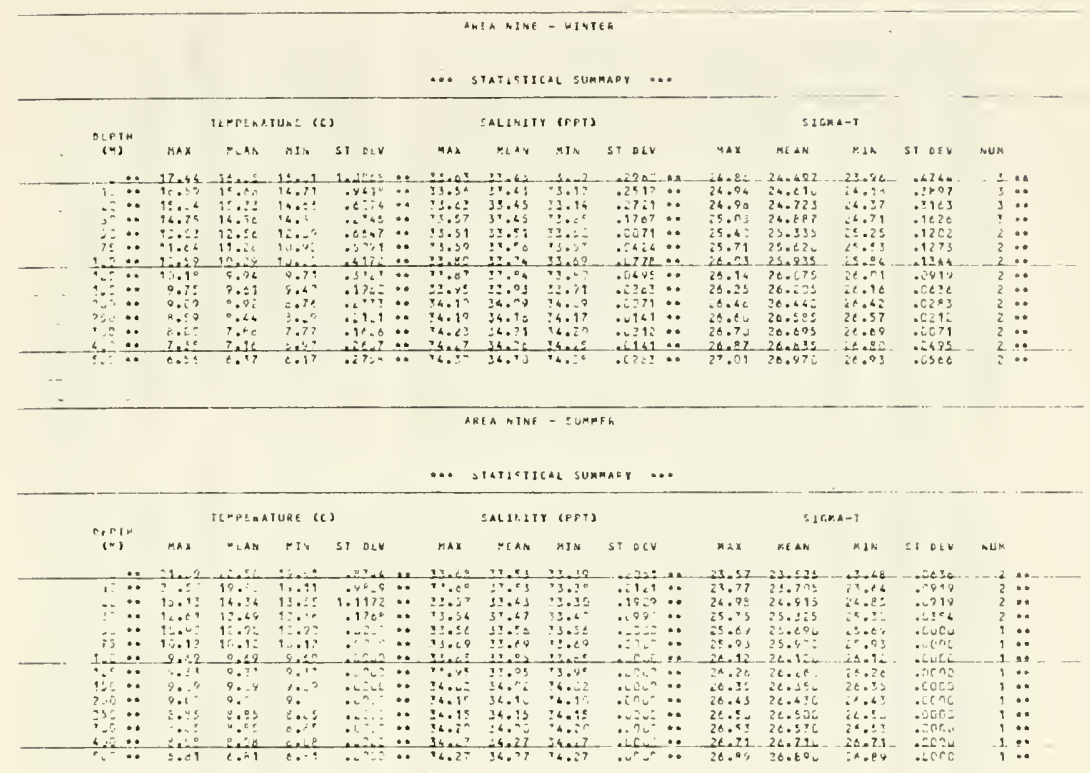

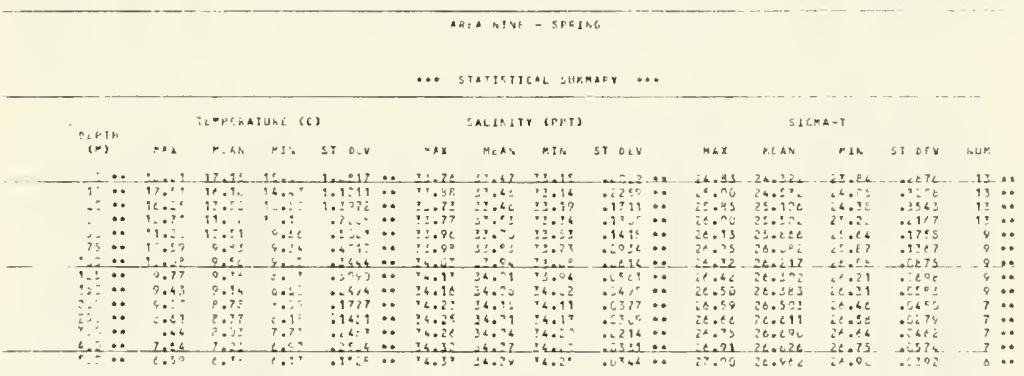

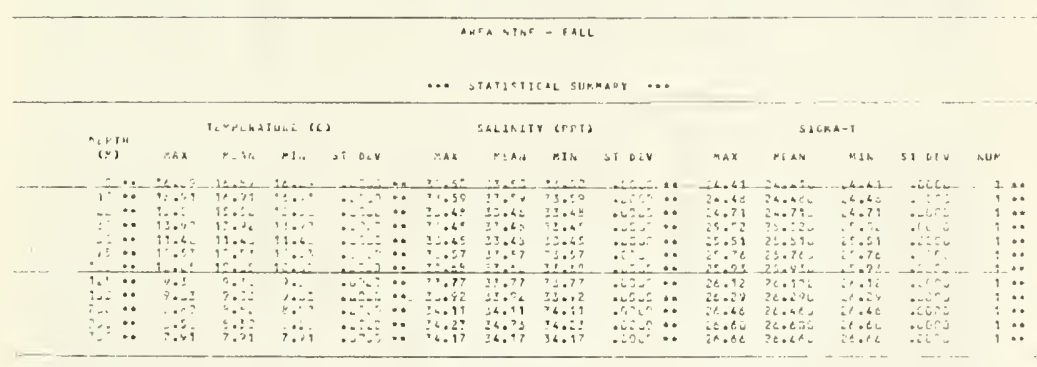

Figure C.9. 


\begin{tabular}{|c|c|c|c|c|c|c|c|c|}
\hline \multirow{2}{*}{$\begin{array}{l}\text { OEPTH } \\
\text { (M) }\end{array}$} & \multicolumn{4}{|c|}{ DEAPERATURE (C) } & \multicolumn{3}{|r|}{ SALINLTY } & $(P P Y)$ \\
\hline & $\max$ & REAN & NIs & ST OEV & & $\max$ & REAH & MIN \\
\hline & 29.07 & 16.04 & 12.39 & 1.6158 & .. & 36.59 & 33.03 & 33.00 \\
\hline 10 . & 21.00 & 15.99 & 12.33 & 1.6266 & $\ldots$ & & 32.63 & 33.12 \\
\hline$\angle C$. & 21.07 & 13.94 & 12.57 & 1.4526 & $\ddot{0}$ & 34.39 & 39.03 & 5.03 \\
\hline & 29.08 & 13.86 & 11.91 & 9.5072 & 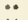 & 36.59 & 55.63 & 33.19 \\
\hline & 29.03 & 15.43 & 10.52 & 1.7176 & $\cdots$ & 96.60 & 33.62 & 33.06 \\
\hline 75 . & 10.51 & 14.00 & 8.46 & 2.0375 & $\cdots$ & 36.48 & 33.57 & 39.05 \\
\hline $1000^{\circ}-2 x-1$ & $17 \cdot 40$ & 12.20 & 6.08 & 1.5892 & $\cdots$ & 36.57 & 53.58 & 33.67 \\
\hline $125 \cdot$ & 15.33 & 11.00 & 8.89 & 1.0037 & * & 34.53 & 33.72 & 33.16 \\
\hline $150^{\circ}$ & 13.92 & 10.24 & 8.50 & .83370 & $\because$ & 34.53 & 33.97 & 93.23 \\
\hline $2000^{\circ}$ & 12.01 & 9.66 & $7.7 \mathrm{~A}$ & .7633 & $\because$ & 34.65 & 34.11 & 33.34 \\
\hline $230^{\circ}$ & 11.27 & 3.91 & 7.11 & .7547 & $\cdots$ & 34.67 & 34.23 & 33.96 \\
\hline $300:$ & 10.64 & 8.38 & 6.70 & .6970 & $\because$ & 36.62 & 36 & \\
\hline 400. & 8.97 & 7.37 & & .3445 & $\Leftrightarrow$ & 36.55 & 34.72 & 36.06 \\
\hline $560^{\circ}$ & 7.78 & 6. & 5.58 & .3709 & 40 & 34.56 & 34.33 & 36.05 \\
\hline 600. & 0.06 & 5.79 & 5.07 & .2050 & $\cdots$ & 34.68 & 34.37 & 34.13 \\
\hline 700. & 5.50 & 5.23 & 6.75 & .1771 & 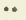 & 36.50 & 34.39 & 34.21 \\
\hline $100 \cdot$ & 5.04 & 4.77 & 4.47 & .1355 & $\leftrightarrow$ & 54.52 & 34.43 & 34.28 \\
\hline $900^{\circ}$ & 4.00 & 4.38 & 4.17 & .1066 & $\cdots$ & 34.55 & 34.46 & 36.32 \\
\hline $1000 \cdot$ & 4.23 & 4.0 & 3. & .0896 & $\bullet$ & 34.58 & 34.48 & 36.31 \\
\hline 1150. & 3.93 & 3.7 & $3.5 \pi$ & .0749 & “0 & 34. & 36.50 & 36.51 \\
\hline $1200^{\circ}$ & 3.66 & 3.51 & 3.30 & .0606 & $\because$ & 34. & 36.52 & 34.30 \\
\hline $1300^{\circ}$ & 3.3 & 3.2 & & .0585 & $\bullet$ & 34.53 & 36.54 & 34.53 \\
\hline 1600. & 3.09 & 3.0 & 2.06 & .0518 & $\ldots$ & 34.57 & 36.35 & 36.33 \\
\hline 1300 & 2.90 & 2.9 & 2.75 & .0506 & $\Delta$ & 34.56 & 34.57 & 34.56 \\
\hline & 2.46 & 2.41 & 2.32 & .0432 & 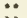 & 34.61 & 35.60 & 34.50 \\
\hline 2000 & 2.15 & 2.90 & 2.08 & .0336 & $\because$ & 34.63 & & 56.69 \\
\hline $2500^{\circ}$ & 1.89 & 1.70 & 1. & .0192 & $\ddot{*}$ & 34 & 36.65 & 36.05 \\
\hline 100 & 1.63 & 1.02 & 1.68 & .0100 & •. & 54.68 & 34.06 & 34.06 \\
\hline
\end{tabular}

\begin{tabular}{|c|c|c|c|}
\hline T. OEV & & $\operatorname{Rax}$ & YKA AM \\
\hline .2687 & $\ddot{*}$ & 25.29 & 26.694 \\
\hline .2659 & 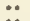 & 29.20 & 26.701 \\
\hline $.2 t 84$ & $\cdots$ & 25.33 & 26.716 \\
\hline .2705 & .. & 25.40 & 26.737 \\
\hline .2707 & $\because$ & 25.75 & 24.815 \\
\hline .2603 & 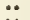 & 25.96 & 25.077 \\
\hline .1033 & $\cdots$ & 26.18 & 25.454 \\
\hline .1863 & $\cdots$ & 26.28 & 25.788 \\
\hline .9863 & $\because$ & 26.61 & 26.041 \\
\hline & $\because$ & 26.58 & 26.350 \\
\hline .1678 & 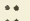 & 26.69 & 20.549 \\
\hline .1250 & $\ddot{\bullet}$ & 28.82 & 26.864 \\
\hline - $c 8 \theta_{2}$ & 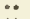 & 27.00 & 26.844 \\
\hline .0656 & 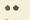 & 27.91 & 26.987 \\
\hline .0515 & 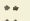 & 27.20 & 27.000 \\
\hline .0662 & $\because$ & 27.29 & 27.169 \\
\hline $.043 c$ & $\cdots$ & 27.35 & 27.205 \\
\hline .0615 & *. & 27.41 & 27.330 \\
\hline .0400 & $\cdots$ & 27.48 & $27.3 A 5$ \\
\hline .0397 & $\cdots$ & 27.51 & 27.633 \\
\hline .0449 & $\because$ & 27.53 & 27.476 \\
\hline $.006 \pi$ & $\because$ & 27.33 & 27.519 \\
\hline .0076 & 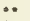 & 27.56 & 27.547 \\
\hline $.009 n$ & 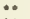 & 27.59 & 27.577 \\
\hline .0070 & $\because$ & 27.65 & 27.643 \\
\hline .0000 & «* & 27.69 & 27.689 \\
\hline .0000 & 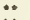 & 27.73 & 27.730 \\
\hline .0000 & $\omega$ & 27.75 & 27.750 \\
\hline
\end{tabular}

$516 M A-1$

DTEA TEM - SUMFE*

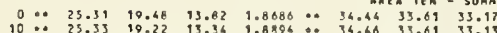

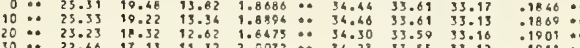

$25.16 \quad 23.849$

1901

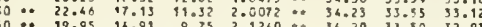

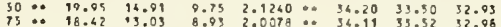

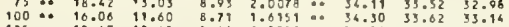

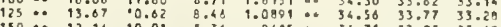

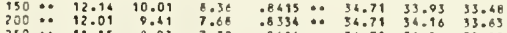

$250 \therefore 11.15 \quad 0.93 \quad 7.32 \quad .8616 \therefore 34.7134 .2033 .05$

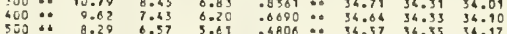

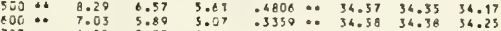

$700 \cdots \quad 6.15 \quad 3.33$

$900:-4.63 \quad 4.65$

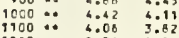

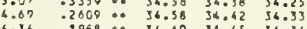

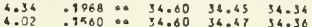

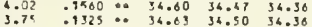

$1200 \cdots 3.78$

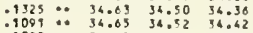

$1300 \cdots 3.36$

$3.37 \quad .1033 \cdots 34.69 \quad 34.55 \quad 34.48$

$1500 \cdots 3.20 \quad 3.93$

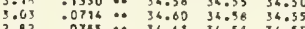

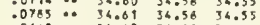

2500

$2500 \% \quad \begin{array}{lllllll}2.89 & 2.96 & 2.12 & .0379 & =34.63 & 34.69 & 34.00\end{array}$

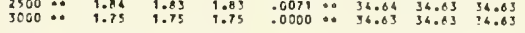

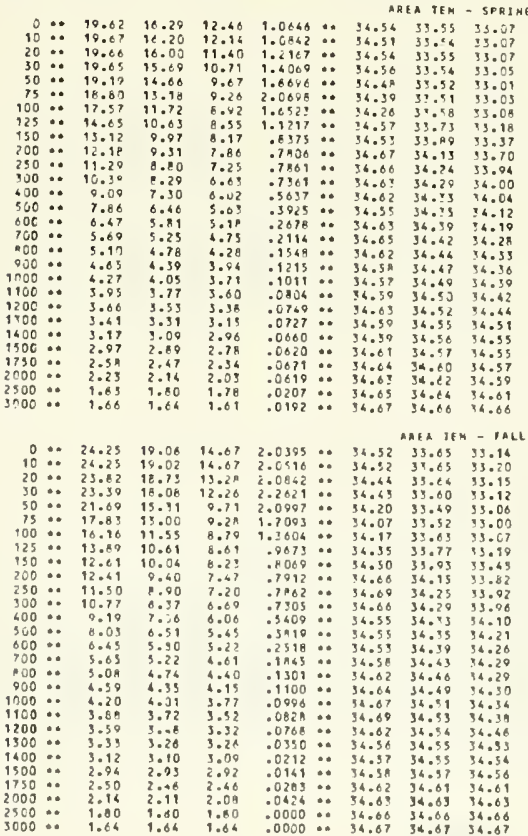

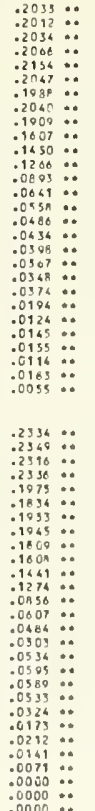

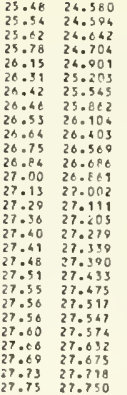

\begin{tabular}{|c|c|c|}
\hline $1 \mathrm{~N}$ & 7 OFV & NบP \\
\hline 4.0 & .1868 & 647 \\
\hline - & .1553 & 447 \\
\hline 4. & $-18 A ?$ & 493 \\
\hline 16. & .7003 & 635. \\
\hline 4.0 & .2374 & 632 \\
\hline 6.3 & .3140 & 427 \\
\hline . & .2955 & 425. \\
\hline 26. & .22 & \\
\hline 25. & .17 & 422. \\
\hline 3. & .0909 & 498 \\
\hline . & .000 & 410. \\
\hline & & 402 \\
\hline$t$. & & 301 \\
\hline A. & .04 & 376 \\
\hline t. 9 & .03 & 221 \\
\hline 8 & .0 & 135 \\
\hline & .03 & 126 \\
\hline 7 & .03 & 122 \\
\hline 27.2 & .03 & 109 \\
\hline 7.2 & X & o3 \\
\hline 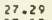 & .03 & 36 \\
\hline 7.5 & .01 & 10 \\
\hline 8 & .00 & 8 \\
\hline & & $?$ \\
\hline & .00 & 7 \\
\hline .0 & 9 & 7 \\
\hline & & , \\
\hline & 00 & \\
\hline
\end{tabular}

.1883

.1917 .0

$.2015 \div 0$

$.1560 \div$

$.0631 \ldots$

.0327

$.0587: 0$

$.0675 \div$

$.0267: 0$

$.0222: 0$

$.0238=$

$\begin{array}{ll}25.20 & 23.859 \\ 25.40 & 24.112 \\ 25.73 & 24.307\end{array}$

22.56

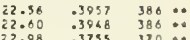

$28.04 \quad 24.851$

$26.23 \quad 25.260$

$26.90 \quad 25.900$

$\begin{array}{ll}26.56 & 26.127 \\ 26.71 & 26.406\end{array}$

$26.00 \quad 26.363$

27.0526 .865

$27.20 \quad 26.984$

$\begin{array}{ll}27.27 & 27.097 \\ 27.37 & 27.106 \\ 27.36 & 27.253\end{array}$

27.66
27.46
27.335

27.50
27.52
27.392
27.50

27.50
27.56 27.5816

$27.57 \quad 27.555$

27.60
27.06
27.0657

$27.68 \quad 27.608$ $\begin{array}{ll}27.71 & 27.710 \\ 27.71 & 27.790\end{array}$

$23.11 \quad 3955 \quad 370 \ldots$

$\begin{array}{llll}23.96 & .4086 & 368 \cdots & 0.0\end{array}$

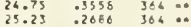

$25.00 \quad .1945 \quad 363 \ldots$

$2 t .61 \quad .0700 \quad 3: 4 \ldots$

$26.67 \quad .0336 \quad 543 \ldots$

$20.89 \quad .0463 \quad 326 \ldots$

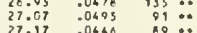

$\begin{array}{lll}27.17 & .0448 & 89\end{array} 2$.

$\begin{array}{lll}27.28 & .0380 & 51 \\ 27.39 & .0378 & 68\end{array}$

$\begin{array}{lll}27.41 & .0378 & 038 \\ 27.46 & .0378 & \end{array}$

$\begin{array}{lll}27.53 & .09799 & 019\end{array}$

$27.62 \quad .0206 \quad 40$

$\begin{array}{lll}27.71 & .0000 & 2000\end{array}$

$23.92 \quad .1972 \quad 609$.

$\begin{array}{llll}29.92 & .2205 & 593 & 0\end{array}$

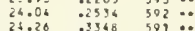

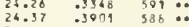

$\begin{array}{lll}26.60 & .3517 & 339: \\ 26.88 & .2750 & 385: 0\end{array}$

$\begin{array}{lll}25.45 & .2027 & 5850\end{array}$

$20.23 \quad-0725 \quad 589 \cdots$

$26.40 \quad .0509 \quad 940: 0$

$28.83 \quad .0411 \quad 512: 0$

$\begin{array}{lll}29.96 & 0409 & 209 \\ 27.04 & 0379 & 139\end{array}$

$\begin{array}{lll}27.20 & 0.0207 & 160.0\end{array}$

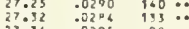

$\begin{array}{lll}27.36 & .0295 & 98\end{array} 2$

$27.48 \quad .0173 \quad 10.0$

$\begin{array}{lll}27.55 & .0095 & 13\end{array} 2.5$

$\begin{array}{lll}27.60 & .0144 \quad 13 & 0\end{array}$ $\begin{array}{lllll}27.75 & 27.798 & 27.69 & .0185 & 6\end{array}$

$25.00 \quad 23.908$

23.96

.6215

1.44.

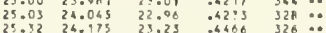

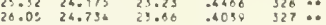

$\begin{array}{llllll}20.15 & 25.252 & 24.48 & .337 \mathrm{C} & 323 & \cdots\end{array}$

$26.49 \quad 75.901 \quad 25.19 \quad .2208 \quad 329 \quad \because$

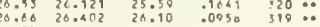

$36.25 \quad 26.309$

$26 . \mathrm{H}^{\prime} \quad 26 . \mathrm{t} 78$

$2 \% .1026 .906$

$\begin{array}{ll}27.23 & 77.115 \\ 27.37 & 27.217\end{array}$

$\begin{array}{rl}27.44 & 77.294 \\ 27.50 & 27.359\end{array}$

$27.5 \% \quad 27.412$

$\begin{array}{ll}27.56 & 27.692 \\ 27.53 & 27.515\end{array}$

27.53527 .540

27.0477 .060

.6927 .690

$\begin{array}{ll}27.79 & 27.770 \\ 27.75 & 27.730\end{array}$

$26.27 \quad .0693$

$\begin{array}{ll}2 C .50 & .05 \mathrm{~A} \\ 26.70 & .06 \mathrm{~A}\end{array}$

$26.80 \quad .0603$

$\begin{array}{lll}27.09 & .0373 & 302 \\ 37 & 0\end{array}$

$\begin{array}{lll}27.23 & .0669 & 77 \\ 27.28 & 0.0495 & 08\end{array}$

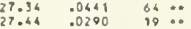

$\begin{array}{lll}27.90 & .0129 & 4 \\ 27.53 & .0149 & 2\end{array}$

$27.36 \quad .0169$

$\begin{array}{ll}27.04 & .01000 \\ 27.09 & .0000\end{array}$

$\begin{array}{ll}27.73 & .0000 \\ 27.75 & .0000\end{array}$

Figure C.10. 


\begin{tabular}{|c|c|c|c|}
\hline & OEPIn & MAX & MrA, \\
\hline & . & 14.73 & 11.01 \\
\hline 10 & $\ddot{*}$ & 14.71 & 11.18 \\
\hline 20 & 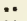 & 14.73 & 11.1. \\
\hline 30 & •. & 14.73 & 11.10 \\
\hline 50 & .. & 14,71 & $11.0 \mathrm{~B}$ \\
\hline 75 & ". & 13.04 & 10,32 \\
\hline 100 & $\cdots$ & $\{2.1\}$ & Q.52 \\
\hline$: 25$ & •. & 10.47 & Q.11 \\
\hline iso & ". & 10.20 & 0.13 \\
\hline 200 & •. & 9.00 & $0,0 j$ \\
\hline 250 & . & 0.50 & $7.4 t^{2}$ \\
\hline 560 & . & 8.02 & $B .91$ \\
\hline 400 & . & 0.96 & 0,06 \\
\hline suo & •. & 0.26 & 5.46 \\
\hline 500 & $\cdots$ & 4.65 & 9.45 \\
\hline Tuo & $\therefore$ & 4.85 & 4.56 \\
\hline 100 & .. & 4.43 & $4.2 \mathrm{~J}$ \\
\hline 900 & . & 4.16 & 3.95 \\
\hline 1000 & 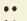 & 3.08 & 3.70 \\
\hline 1100 & •. & 3.64 & $3.4 \mathrm{r}$ \\
\hline 1200 & . & 3.37 & 3,23 \\
\hline 1300 & •• & 3.13 & $3.0^{\circ}$ \\
\hline 1400 & .. & 2.95 & $2.8 \mathrm{n}$ \\
\hline isuo & *. & 2,78 & a. $7 !$ \\
\hline 1750 & .. & 2.36 & 2.31 \\
\hline 2000 & .. & 2.07 & 2.03 \\
\hline 2500 & $\cdots$ & 1.78 & 1.77 \\
\hline 3000 & . & 1.04 & 1.62 \\
\hline
\end{tabular}

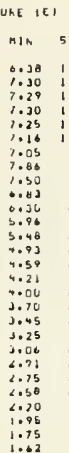

$5 \%$ or.$$
19477 \text {. } 33.59 \quad 31030 \quad 19032 \quad 3.7095
$$

SALINETT IPPTI

$\begin{array}{llllll}1.5997 & \because & 33.61 & 32.07 & 27.36 & 1.0780\end{array}$

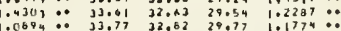

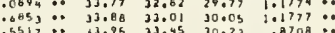

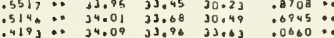

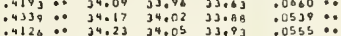

$.35 \mathrm{~A}_{4}: 0.034 .25$ 34.11 333.94

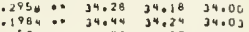

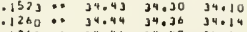

$\$ 1216 \ldots 34,4634,40034,13$

$: 119 .: 034.50 \quad 34,45 \quad 34: 10$

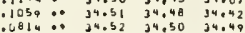

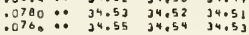

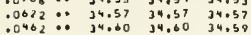

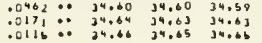

$.0024 \ldots$

AREA ELEVEN - SUMAER

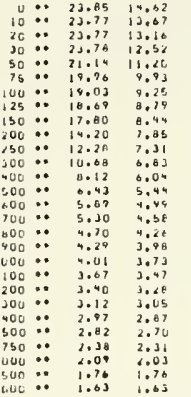

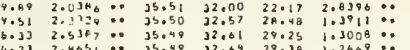

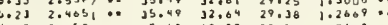

$\begin{array}{lllllll}1.97 & 2.059 . & 0.0 & 35.19 & 32.89 & 29.53 & 1.0163: \\ 7.75 & 1.6049 & 0.0 & 35.14 & 33.02 & 29.48 & 1.0271\end{array}$

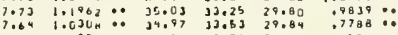

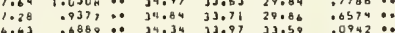

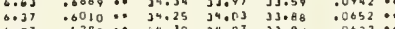

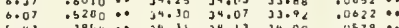

$5043 \quad .3914, \because 340.31 \quad 34.13 \quad 34.00$

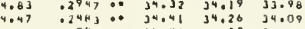

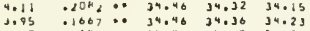

$0.53 \quad: 1206: \because 34.52 \quad 34.43 \quad 340.36$

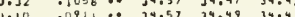

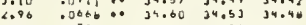

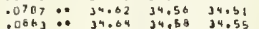

$.0541 .034 .05 \quad 34.61 \quad 34.55 \quad .04240$

2.25

$1,16,3$

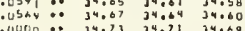

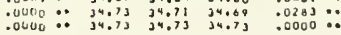

$$
\text { AREA ELEVLA - 5PRJNG }
$$

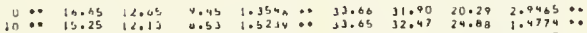

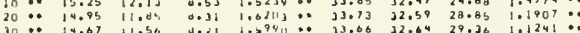

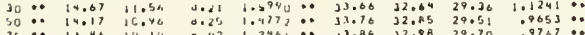

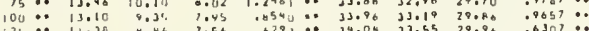

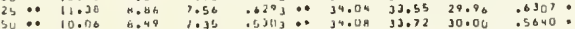

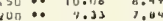

$\begin{array}{lll}250 & \cdots & 0.51 \quad 1,311\end{array}$

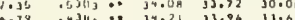

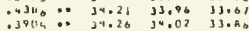

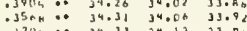

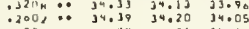

$\begin{array}{rllll}1973 & 34.44 & 34.28 & 34.13 \\ : 1002 & 34.46 & 34.32 & 34.13\end{array}$

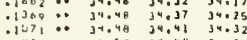

$.0431034 .52 \quad 34.44 \quad 34.32$

$.0814: \because 34.54 \quad 34.46 \quad 34.40$

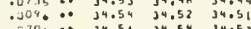

$.0200,: 340.56 \quad 34.54 \quad 34.53$

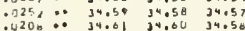

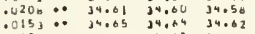

$.0664 \ldots$

$.0660: 0$

$.0568:$.

.0448 :.0

.00369

.01190

$.0141 \%$

.0100

$\begin{array}{llll}1750 & : 2 & 2.31 & 2,26 \\ 2000 & 2.07 & 2,05\end{array}$

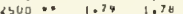

AHEA CLLVEN - ALtL

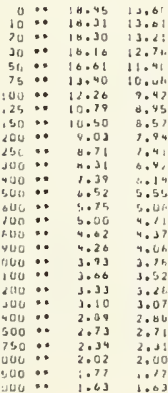

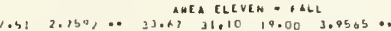

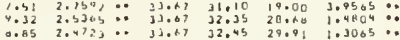

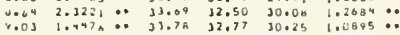

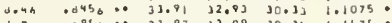

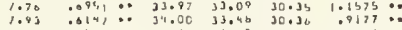

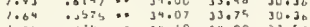

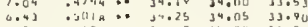

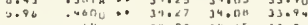

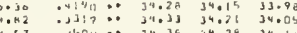

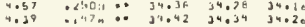

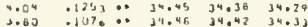

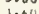

3.36

3.05

$3.6 \mathrm{C}$
$2.6 \%$

1:s?

in?

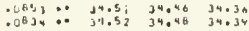

$.0159: 2 \quad 24.54 \quad 34.51 \quad 34.50$

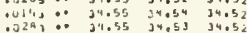

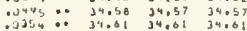

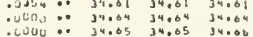

Figure C.11.

$.0071 \%$

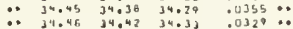

$.0596: 2$

$.0575: 0$

$.0480 \cdots$

.0646.

$.0707: 0$

.0203
.0075

$.0000: 0045$

.0045
.0058

.0059
.0674

SIGMA-T

\begin{tabular}{|c|c|c|c|c|c|}
\hline $4 \pm x$ & {$[\in \mathrm{N}$} & MIN & St OEV & NUT & \\
\hline .66 & 23.764 & 15.19 & 2.6090 & 124 & \\
\hline 160 & 24.461 & 21.34 & 1.2321 & 124 & \\
\hline .65 & 24.607 & 22.27 & 09976 & 124 & \\
\hline .69 & 24,071 & 2.62 & .9392 & 124 & \\
\hline .98 & 24.923 & 2.87 & .0235 & 116 & - \\
\hline .21 & 26.204 & 2.48 & .0597 & 114 & . \\
\hline .30 & 25.489 & 23.10 & .9180 & iis & \\
\hline .42 & $25.90 \mathrm{~A}$ & 3.26 & .7163 & 102 & \\
\hline .50 & 20.1 & a. & & 99 & \\
\hline .63 & 26.473 & 1 & .0746 & 92 & ( \\
\hline .73 & 26.600 & 4,42 & .0012 & 92 & - \\
\hline .82 & 20.763 & b.5] & .0532 & $9 \mathrm{c}$ & \\
\hline $.9 \mathrm{a}$ & 26.862 & 6.73 & .04 & $B \theta$ & \\
\hline .08 & & & .0 & 65 & \\
\hline 7.25 & 27.095 & 6.92 & .04 & 49 & • \\
\hline 7.28 & 27.193 & 7.02 & .0435 & 42 & \\
\hline 7.33 & 27.2 & , & .03 & +2 & \\
\hline .39 & 27.3 & . & .042 & 39 & \\
\hline .43 & 27.3 & 7. & .05 & 34 & \\
\hline .46 & 27,4 & 27.1 & .08 & $2 \theta$ & \\
\hline .5 & & & & 10 & \\
\hline .52 & 27.507 & 27.49 & .0121 & & \\
\hline & 27.5 & 27 & .010 & & \\
\hline 1,5 & & & & 5 & \\
\hline & & & & 5 & \\
\hline 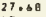 & 27.6 & 27. & .0071 & 5 & \\
\hline & & & & 4 & \\
\hline & & 21 & .0054 & & \\
\hline
\end{tabular}

$\begin{array}{ll}25.85 & 23.747 \\ 25.85 & 24.272\end{array}$ $\begin{array}{ll}25.98 & 24.496 \\ 26.06 & 24.641\end{array}$ $26.21 \quad 25.094$

$26.50 \quad 25.717$

26.5826 .210 26.6626 .506

26.8926 .724

$27.00 \quad 26.874$

$27.25 \quad 27.112$

$\begin{array}{ll}27.31 & 27.204 \\ 27.35 & 27.273\end{array}$

$\begin{array}{ll}27.35 & 27.273 \\ 27.40 & 27.328\end{array}$

$27.45 \quad 27.303$

$27.53 \quad 27.472$

27.6027 .562

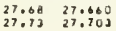

27.79
27.00
27.0700

$26.00 \quad 24.069$

$\begin{array}{ll}25.94 & 24.8611 \\ 25.96 & 24.752 \\ 20.02 & 24.045\end{array}$

$26.17 \quad 25.114$

$26.44 \quad 25.664$

$\begin{array}{lll}28.57 & 25.6023\end{array}$

$\begin{array}{lll}20.63 & 26.208 \\ 30.73 & 26.497\end{array}$

$\begin{array}{ll}21.79 & 26.623 \\ 26.85 & 26.720\end{array}$

$27.01 \quad 26.878$

$27.12 \quad 27.006$

$27.32 \quad 27.206$

$27.37 \quad 27.261$

$27.46 \quad 27.391$

$\begin{array}{ll}27.50 & 27.433 \\ 27.50 & 27.408\end{array}$

$27.53 \quad 27.0612$

$\begin{array}{lll}27.558 & 27.5612\end{array}$

27.64
27.680 .630
27.667

$27.73 \quad 27.720$

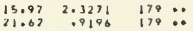

$\begin{array}{lll}22.55 & .8316 & 169 \\ 32.70 & .8499 & 169\end{array}$

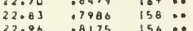

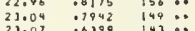

23.11 .5401 134::

$25.85 \quad-1251 \quad 132 \ldots$

26.17 .0978 $128: \because$

$\begin{array}{lll}26.50 & .0590 & 120 \\ 26.73 & .0503 & 114\end{array}$

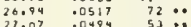

$27.17 \quad 0380 \quad 53 \quad:$

$\begin{array}{lll}27.26 & 00328 & 50 \\ 27.32 & .0300 & 43\end{array}$

$21.42 \quad .0302 \quad 340$

$27.46 \quad .0403 \quad 4$.

$\begin{array}{lll}27.53 & .0299 & 4.0 \\ 27.58 & .0230 & 4\end{array}$

$27.64: 0103 \quad, \because$

$\begin{array}{lll}27.76 & 0212 & 2 \\ 27.60 & 0000 & 1\end{array}$

$15.20 \quad 2.2654 \quad 187 \%$

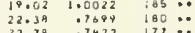

$12,87 \quad .7074 \quad 1700$

22.86 , $1582 \quad 169$.

$\begin{array}{lll}23.06 & : 1708 & 169 \\ 23.12 & : 19282 & 150\end{array}$

$23.13 \quad 04797 \quad 157: 0$

$\begin{array}{lll}24.37 & .6719 & 147 . .\end{array}$

$36.17 .0466 \quad 1410$

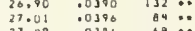

$27.19 \quad 00336$ :0 $\because 0$

$27.31 \quad: 0279 \quad 59: 0$

$\begin{array}{lll}27.43 & .0246 \quad 13: 0 \\ 27.54 & 02126 & 13\end{array}$

$37.53 \quad .0126 \quad: .:$

$\begin{array}{lll}27.62 & : 0050 & 0100 \\ 27.65 & 0153 & 3\end{array}$

$\begin{array}{lll}27.65 & .0153 & 3\end{array}$

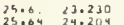

$14: 73 \quad 208612 \quad 1140$

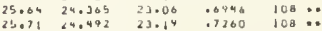

$\begin{array}{ll}24.020 & 25.230\end{array}$

$24.36 \quad 25.513$

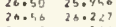

23.27

$\begin{array}{lll}23.22 & .0081 & 96\end{array}:$

$\begin{array}{lll}33.34 & .9529 & 97\end{array}$

23.37 .5604 83 $\ldots$

$26.42,0096 \quad$ is $: 0$

26.7326 .632

26.75

$.04 a z+770$

$27.04 \quad 0044$ b2 $:$

$\begin{array}{ll}27.72 & 27.11 \\ 27.28 & 27.204\end{array}$

$27.33 \quad 27.27$

$\begin{array}{ll}27.36 & 27.340 \\ 27.044 & 27.347\end{array}$

$\begin{array}{ll}11.27 & 0.026\end{array}$

3s $::$

$\begin{array}{lll}2 ?, 38 & 0279 & 30\end{array}: 0$

$.0191:$

$27.51 \quad 77.442$

$\begin{array}{lll}21.08 & .0150 \\ 27.32 & 0000 & 0\end{array}$

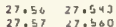

$\begin{array}{lll}21.53 & 00153 \\ 27.55 & .0154 & 0\end{array}$

$.0212 \because$

$\begin{array}{ll}27.63 & 27.630 \\ 27.64 & 37.675\end{array}$

$\begin{array}{lll}27.63 & 0000 & 0 \\ 27.47 & 0071 & 2\end{array}$

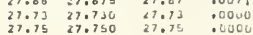


-.. STLTISTICAL SUMmat $\cdots$

\begin{tabular}{|c|c|c|c|c|c|c|c|c|c|c|c|c|c|c|c|c|c|}
\hline \multirow{2}{*}{\multicolumn{2}{|c|}{$\begin{array}{l}U[P T H \\
(M]\end{array}$}} & \multicolumn{5}{|c|}{ TEMPERATUKE ICI } & \multicolumn{5}{|c|}{ SALINITY IPPTI } & \multicolumn{4}{|c|}{ SIGAATT } & \multirow{2}{*}{\multicolumn{2}{|c|}{ NUm }} \\
\hline & & $\max$ & $a$ & 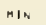 & 51 OI V & & max & Me & $\mathrm{MIN}$ & $5 Y$ OEV & & $\max$ & $m[A N$ & nis & ST OEY & & \\
\hline 0 & $\cdots$ & 11.69 & 9.77 & 7.40 & .1174 & *. & 32.96 & 32.56 & 32.20 & .1257 & $\because$ & $25.5:$ & 25.100 & , & 6 & 3 & 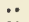 \\
\hline 10 & 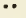 & 11.00 & 9.15 & 1.40 & .7275 & $\cdots$ & 32.96 & 32.56 & 32.27 & .1260 & 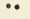 & 25.51 & $25 \cdot 105$ & 24.67 & -11110 & 603 & $\ddot{*}$ \\
\hline 36 & $\ddot{\theta}$ & 11.88 & 9.72 & 1.44 & .1217 & 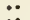 & 32.96 & 32.50 & 32.27 & .1276 & $\cdots$ & 25.52 & 250111 & 24.87 & .1138 & 163 & $\bullet$ \\
\hline Jo & $\cdots$ & 11.6 , & 9.69 & 1.48 & .7316 & $\cdots$ & 33.06 & 32.37 & 32.26 & .1333 & $\bullet$ & 25.53 & 25.123 & 24.87 & .1187 & 163 & $\because$ \\
\hline 50 & 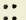 & 11.00 & 9.63 & 1.83 & .7125 & $\because$ & 33.23 & $32 \cdot 61$ & 32.24 & $\begin{array}{rl}-1063 & 663 \\
2 & 6447\end{array}$ & $\because$ & & 25.167 & 24.66 & .1501 & 163 & $\because$ \\
\hline & $\ddot{*}$ & 10.72 & 9.12 & 7.63 & .6334 & $\ddot{*}$ & 33.64 & 32. & 32. & .2547 & $\ddot{0}$ & & 26.506 & 25.04 & .2606 & 163 & \\
\hline 100 & 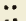 & 9.91 & $A .52$ & 1.50 & .48115 & $\because$ & 33.84 & 33,38 & 32.50 & .2342 & 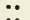 & 26.37 & 25.946 & 25.21 & .2052 & 161 & $\cdots$ \\
\hline i/s & $\ddot{\theta}$ & 4.78 & 3.18 & 1.42 & .4107 & •• & 33.96 & 33.45 & 32.95 & .1441 & $\cdots$ & 26.44 & 26.204 & 25.31 & .1312 & 159 & $\cdots$ \\
\hline ino & 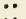 & 9.46 & 1.09 & 1.13 & .3790 & $\cdots$ & $33.9 h$ & 33. no & 33.30 & .0906 & $\cdots$ & 26.51 & 26.370 & $2 \mathrm{~h} .02$ & .0844 & 150 & . \\
\hline 200 & $\because$ & b. 40 & 7.31 & 0.57 & .3616 & $\cdots$ & $3 \% .05$ & 33.93 & 33.68 & .0455 & .. & 26.64 & 26.551 & 26.23 & $.05 B 4$ & 144 & \\
\hline $2 \div n$ & $\cdots$ & 8.52 & b. 15 & 5.84 & $.36 / 3$ & .. & 34.06 & 33.97 & $33.8 \%$ & .0339 & 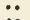 & 26.76 & 200050 & 20.34 & .0503 & 147 & 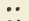 \\
\hline 3114) & ** & 10.00 & 6.26 & 3.53 & $.34 \mathrm{~Hz}$ & $\because$ & 34.07 & 34.00 & 33.92 & .0307 & $\because$ & 26.85 & 26.747 & 26.48 & $.041 A$ & 142 & $\ddot{*}$ \\
\hline The & $\ddot{*}$ & 0.55 & 5.35 & 4.70 & .3172 & $\ddot{0}$ & 34.14 & 34.06 & $33.9 \mathrm{H}$ & .0313 & $\because$ & & $26.84 z$ & & & 198 & . \\
\hline suo & $\because$ & 5.97 & $\mathrm{s.0}$ & 4.20 & .2416 & $\cdots$ & 34.21 & 34.13 & 34.01 & .0312 & $\cdots$ & 27. & 26.898 & & 38 & 138 & .. \\
\hline ono & $\because$ & 5.48 & 4.66 & 4.14 & .1943 & $\ddot{*}$ & 34.25 & 24.20 & 34.00 & .0204 & 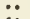 & 27.15 & 27.098 & 20.90 & .0346 & 135 & 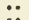 \\
\hline rou & 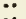 & 4.90 & 4.35 & 4.03 & .1300 & $\ddot{0}$ & 34.32 & 34.27 & & .0245 & 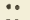 & 27 & 27.6 & & & 129 & 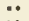 \\
\hline awo & $\ddot{\theta}$ & 4.39 & 4.06 & $3 . A_{3}$ & - Insto & $\ddot{0}$ & 34. & 34. & 34.20 & .0243 & 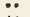 & 23 & 27.262 & 27 & .0237 & 127 & 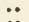 \\
\hline $9 T^{2} \mathrm{~L}$ & $\cdots$ & 4.13 & 3,70 & 2.56 & .1010 & $\cdots$ & 34.43 & 34.37 & 34.31 & .0200 & $\cdots$ & 27.37 & 27.328 & 27 & .0209 & 123 & \\
\hline owo & 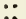 & 3.8 & 3.5 & $3 \cdot 37$ &.$O^{A} \cap B$ & $\because$ & $3 \%=8$ & 34.41 & 32.33 & .0163 & $\ddot{0}$ & 27.45 & 27.386 & 27 & .0198 & 97 & 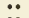 \\
\hline 60 & $\bullet$ & 3. & 3. & 3. &.$\cdots 1$ & $\cdots$ & & & & .0158 & 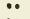 & 27.49 & 27.433 & 27.36 & .0176 & 62 & .. \\
\hline 7,0 & $\cdots$ & 3.10 & 3. & 2.94 & $.16 \% 2$ & .. & 34 & & & .0252 & $\cdots$ & 27.52 & 27.475 & 27.45 & .0158 & 51 & .. \\
\hline 1300 & “. & $2.9 A$ & 2.67 & 2,72 & .06113 & $\cdots$ & 34.51 & 34.44 & 34.48 & .0099 & $\because$ & 3 & 1 & & & 20 & .. \\
\hline$+45[17)$ & *. & 2.81 & $\angle .6 \mathrm{~A}$ & 2.55 & .0036 & 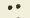 & 34.53 & 34.51 & 34.50 & .0091 & .. & 27 & 27.545 & 27 & .0 & 20 & $\ddot{*}$ \\
\hline 1500 & 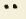 & 2.59 & 2.3 & $2,4 !$ & $.055_{1}$ & $\bullet$ & 34.54 & 34.53 & 34.51 & .0093 & $\because$ & 27,59 & 27.574 & 27.56 & .0105 & 20 & \\
\hline 1350 & $\because$ & 2,20 & 2. & 2.09 & .04137 & 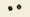 & 24.59 & 34.55 & 34.56 & .0097 & . & 27.66 & 27.640 & 27.62 & .0124 & 13 & •. \\
\hline 1000 & $\because$ & 1.95 & 1.9 & 1.86 & .0219 & $\cdots$ & 34.62 & 34.61 & 34.50 & .0005 & $\bullet$ & & & & & 13 & $\because$ \\
\hline Li! & $\because$ & 178 & 1.75 & 1.74 & .01178 & 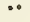 & 34.65 & 34.64 & 34.63 & .0067 & - & 27.73 & 27.722 & 27.71 & .0079 & 10 & $\cdots$ \\
\hline \multicolumn{18}{|c|}{ aAE a THELVE - SUAmEA } \\
\hline “ & -. & $20 \cdot 20$ & $2 b$ & 9.40 & 4167 & 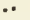 & $33.4 \mathrm{~A}$ & 31.50 & 26.49 & 1.02 & $\because$ & 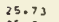 & 23.014 & & & 86 & $\cdots$ \\
\hline in & : & 19.83 & 15.91 & 4.44 & $5[31$ & $\because$ & 59 & 1. & 8.96 & .7687 & & 25.96 & 265 & 94 & .7621 & 380 & \\
\hline 20 & .. & $\{0.57$ & 14.53 & 6,71 & & $\cdots$ & 0 & 32. & 30 & .4430 & •• & 26.10 & 419 & & & 364 & • \\
\hline si & * & 28,42 & 12.76 & 2 & & $*$ & & & & $?$ & & & & & & 384 & 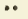 \\
\hline 50 & $\because$ & 14.35 & 10.2 & 1.36 & 1.2951 & $\because$ & 33 & 320 & 32.19 & 1 & $\bullet$ & 26 & 10 & & & 376 & $\cdots$ \\
\hline 75 & • & 111.95 & 8.99 & 9 & $.008 y$ & $\because$ & 33.96 & 32.66 & 32.42 & .3091 & $\cdots$ & 26.59 & 25.460 & 24 & .29 & 361 & - \\
\hline 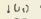 & $\cdots$ & 111.39 & 8 & 7 & .5361 & $\because$ & 33.93 & 33.23 & 32.54 & .3047 & $\because$ & 26.50 & 25.835 & $1 A$ & .2691 & 333 & •. \\
\hline 125 & & & & & & $\cdots$ & 33 & 33 & 32. & $.21>0$ & 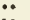 & & 26.12 & & & 321 & $\cdots$ \\
\hline$i \leq 0$ & .. & $=.35$ & 7.0 & 0.06 & .40 & $\cdots$ & $33.9 \mathrm{~A}$ & 33 & 33. & & $\because$ & $2 b a$ & & & & 317 & a. \\
\hline mo & $\because$ & 8.31 & 7.27 & 6.61 & .380 & 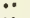 & 34.04 & 33. & 33. & .0638 & •. & & & & & 267 & 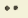 \\
\hline ists & $\ddot{*}$ & $\because$. & D & $a$ & .3 & $\cdots$ & & & 33. & & $\because$ & & & & & 232 & - \\
\hline Juc & • & $\therefore$ & & & & $\cdots$ & & & & & $\because$ & & & & & 6 & \\
\hline 400 & .. & $\therefore$ & 5.0 & 4.0 & $.2^{A B} 3$ & $\bullet$ & 3 & & 33. & & & & & & & 209 & 。 \\
\hline 500 & $\because$ & s. & 5.0 & & b & $\because$ & & & & & - & & & & & 190 & \\
\hline 660 & •. & 3.43 & 4 & 4 & .1 & *. & & & & & 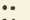 & & & & & 288 & $\cdot$ \\
\hline 700 & 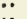 & 4. & & & & $\because$ & & & & & $\bullet$ & & & & & & \\
\hline atio & 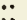 & 4 & & & & 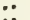 & & & & & 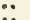 & & & & & 0 & $\ddot{*}$ \\
\hline Ho & ・. & 4. & & & & $\because$ & & & & & $\because$ & & & & & 172 & $\cdots$ \\
\hline bio & -. & s.h & & 3 & & $\bullet$ & & & & & .0 & & & & & 137 & 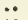 \\
\hline & 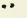 & 3.60 & & &. $\mathrm{C}^{902}$ & $\cdots$ & & & & .0293 & $\because$ & & & & & 62 & . \\
\hline 00 & *. & 1.2 & & & & $\because$ & & & 34. & .03 & $\because$ & & & & & & .. \\
\hline to & *. & & & ¿. & & $\cdots$ & & & & & $\bullet$ & & & & & $1 \theta$ & \\
\hline & & 2.78 & 2.7 & & .0524 & $\because$ & 34.54 & & & .0 & -. & & & & .0 & 15 & . \\
\hline & & 2.6 & & 2.45 & .0433 & $\cdots$ & & & & & 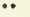 & & & & & 2 & •. \\
\hline$T$ & 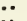 & 2 & & & .03 & $\cdots$ & & & & & .. & & & & & & $\cdot$ \\
\hline 04 & & a. & & 1.08 & & $\cdots$ & 34.85 & 34.60 & 34.57 & & “. & & & & & 10 & \\
\hline & & 1.17 & 1.35 & $1 \cdot 11$ & $.023^{6}$ & •• & 14.64 & $34.0^{4}$ & 34.62 & .0127 & *. & 27.73 & 27.723 & 27.21 & .0095 & , & .. \\
\hline
\end{tabular}

AREA TWELVE - SPRIRG

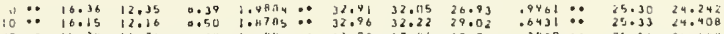

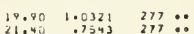

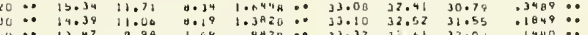

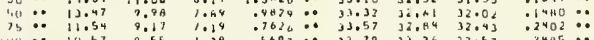

fwo $\because 10.57 \quad 9.55 \quad 1.38 \quad .5607 \quad 0 \quad 33.7933 .26 \quad 32.37$

(2) 310.16

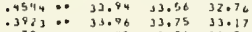

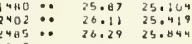

$\begin{array}{ll}26.43 & 26.132 \\ 26.52 & 26.324\end{array}$

$\begin{array}{lll}12390 & 26.52 & 26.324 \\ .0574 & 20.09 & 26.334\end{array}$

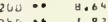

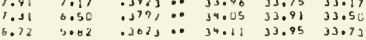

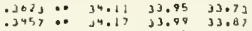

$\begin{array}{lll}3100 & \cdots & 1.35 \\ -600 & 0.27\end{array}$

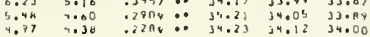

aifid $\because \quad 5.03$

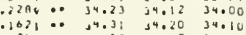

$\begin{array}{llll}.0462 & 0.026 .78 & 26.8351 \\ .0459 & 26.0 A & 26.7444\end{array}$

$\begin{array}{lll}.0430 & 0.027 .00 & 26.084 \\ .0302 & 27.09 & 27.003\end{array}$

$\begin{array}{llll}.0362 & 00 & 27.09 & 27.003 \\ .0313 & 0.0 & 27.07 & 27.104\end{array}$

$\begin{array}{ll}27.27 & 27.0192 \\ 27.31 & 27.268\end{array}$

$.0254: 0$

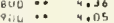

0.02
3,76

$3075 \quad .1080: \because 34,42 \quad 34,13 \quad 34.18$

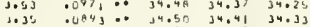

$\begin{array}{lllll}.0843 & \because .0 & 34.50 & 34.41 & 34.33 \\ .0030 & 34.54 & 34.45 & 34.34\end{array}$

. $4222 \cdots$

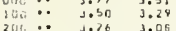

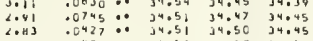

$.0402 \ldots 34.53 \quad 34.52 \quad 34.50$

$404 \ldots 2077$

2.70

$\begin{array}{llll}.040 .0 & 34.53 & 34.52 & 34.550 \\ .060 .55 & 34.54 & 34.55\end{array}$

27.50
27.47
27.52 27.513

$.0003 \because 27.56 \quad 27.546$

$22.64 \quad 04780$
$23.52 \quad .201:$

$2>>\cdots$

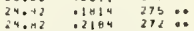

$25.25 \quad .2133 \quad 268 \cdots$

25061 12:3 $206 \cdots$

$26.44 \quad 0541233 \cdots$

$20.70 \quad .0369200 \%$

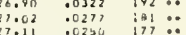

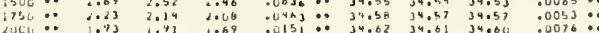

22,05 21.:041

AREA TWELYE - TALL

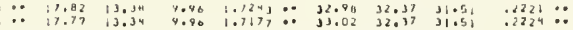

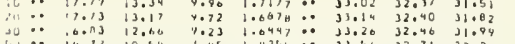

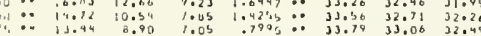

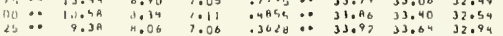

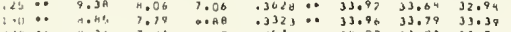

1.10 $\because 11.36 \quad 7.23 \quad 0.42$

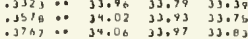

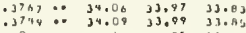

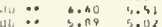

4.41
4.43
4.40

$\begin{array}{llll}7007 \ldots & 34.14 & 34.05 & 33.82 \\ .2494 & 34.20 & 34.12 & 34.02\end{array}$

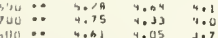

$\begin{array}{llll}\because 21, \cdots & 34.20 & 34.12 & 34.02\end{array}$

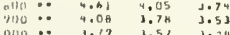

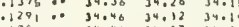

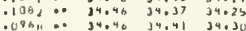

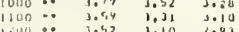

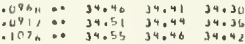

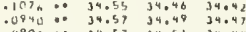

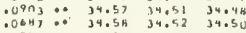

$\begin{array}{lllll}14110 & \cdots & 2.08 & 1.09 & 2062 \\ 13013 & 0.01 & 2.02 & \therefore 36\end{array}$

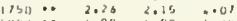

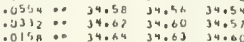

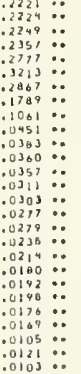

$24.99 \quad 24.248$

$22.04 \quad: 426$
22,84 $25.51 \quad 24.353$

$26.02 \quad 25.045$

27.96
23.39

24.16
24.59

$26.44 \quad 25.98$

26.5726 .213

$\begin{array}{ll}26.61 & 26.0316 \\ 26.70 & 26.561\end{array}$

2607826.664

$28.96 \quad 26.080$

27.17
27.27 27.006

$\begin{array}{ll}27.34 & 27.2204 \\ 27.40 & 21.324 \\ 37.90 & 21.94\end{array}$

$\begin{array}{ll}27.43 & 27.0311 \\ 27.50 & 27.427\end{array}$

$21,055 \quad 27.469$

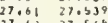

25.36
25.67

26.00

56.53
26,58

$26.75 \quad .03+4$

$27.00 \quad .0292$

$27.11 \quad .0210$ 156:

$27.25 \quad .02350 \quad 1520$

27.29
21.35 $.0210 \quad 1170$

$\begin{array}{lll}27.43 & .0190 \quad 56 & 019\end{array}$

$27.52 \quad 0200 \quad 23: 0$

$\begin{array}{lllll}27.05 & 27.631 & 27.61 & .0091 & 20 \\ 27.70 & 27.676 & 27.65 & 0112 & 19 \\ 27.93 & 27.0714 & 27.09 & .0117 & 17\end{array}$

Figure C.12. 
TEMPLWATURE ICI

SALINJTY IPPTI

\begin{tabular}{|c|c|c|c|c|}
\hline \multicolumn{2}{|c|}{$\begin{array}{c}\text { OLPTH } \\
\text { Im! }\end{array}$} & $\max$ & MEAN & $\mathrm{H} \mid \mathrm{N}$ \\
\hline & 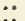 & 18 & it & $\theta$ \\
\hline 10 & 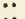 & 69,97 & 17.80 & 14001 \\
\hline 20 & * & 20.00 & 17.97 & 13.02 \\
\hline 30 & 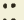 & 20.02 & 11.96 & 12.68 \\
\hline sc & $\because$ & 20.00 & : ?:94 & 13086 \\
\hline is & $\cdots$ & 20.05 & 17.73 & 13.66 \\
\hline 500 & 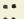 & 14.60 & $(7,6)$ & 13.74 \\
\hline 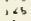 & $\cdots$ & 18.97 & 17.07 & 1.065 \\
\hline 150 & $\because$ & 18.71 & $15.4 \mathrm{H}$ & 11.44 \\
\hline 200 & 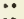 & 16.92 & 13,27 & 10.12 \\
\hline 250 & 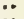 & 13.37 & 11.41 & 9.31 \\
\hline 360 & 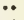 & 11.02 & 10. & 6.43 \\
\hline 400 & $\because$ & O. AO & 7, & 6. 49 \\
\hline 500 & $\because$ & 7.94 & 4.16 & 0.12 \\
\hline 600 & 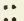 & $6.7 \%$ & 5.16 & 4048 \\
\hline 700 & 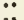 & 4,00 & 4.65 & 4.14 \\
\hline$A 00$ & $\ddot{i}$ & $\because 0$ & 4.36 & - A4 \\
\hline 960 & $\because$ & 4.15 & 3.9 & j.b7 \\
\hline 101.0 & 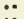 & 3,87 & 3.66 & J.33 \\
\hline 60 & $\because$ & 3.62 & 3.45 & 3.10 \\
\hline 0 & $\because$ & 2.4 & 3.2 & $\therefore .90$ \\
\hline 1300 & $\because$ & 3.2 & 3. & $\angle 089$ \\
\hline 1400 & $\because$ & & & $\because . \Delta 0$ \\
\hline 1500 & $\because$ & 2.90 & 2. & 1035 \\
\hline 775 & $\because$ & 2045 & 2.31 & 2011 \\
\hline s & $\cdots$ & & & 93 \\
\hline 60 & 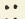 & 1.79 & 1.7 & .70 \\
\hline 10 & $\cdots$ & 1.64 & 1.57 & 1.53 \\
\hline 0 & - & & & \\
\hline in & . & 26.31 & 22.20 & $1201^{\circ}$ \\
\hline 20 & 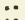 & 25.75 & 21.42 & 11.91 \\
\hline 30 & -. & 24.50 & 2 2..5s & $1 i .1 i$ \\
\hline st & $\because$ & 23 & 10 & 9.70 \\
\hline 75 & $\because$ & 21. & & 10 \\
\hline 1.00 & $\ddot{*}$ & $19.6 A$ & 17.03 & OA A \\
\hline 176 & $\because$ & 10.00 & 17.0 & 6.16 \\
\hline ise & $\because$ & 16. & & \\
\hline 200 & 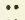 & i6. & & \\
\hline 250 & $\cdots$ & 13. & $i$ & . \\
\hline 300 & & 11. & 10 & $\therefore$ \\
\hline 400 & .. & 4. & 1. & 3 \\
\hline sec & $\cdots$ & & & \\
\hline 600 & $\ddot{B}$ & & s & \\
\hline 700 & 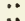 & & & 4.22 \\
\hline & $\because$ & & & \\
\hline 900 & .. & & & \\
\hline orso & 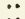 & & & \\
\hline ill & 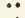 & & & \\
\hline & $\ddot{*}$ & & & \\
\hline & 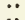 & & & \\
\hline & $\because$ & & & \\
\hline 500 & 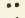 & 2. & 32 & $\alpha$, \\
\hline & $\cdots$ & & & \\
\hline & $\bullet$ & & & \\
\hline & 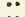 & & & \\
\hline ou & & 1. & 1. & 1. \\
\hline &. & & & \\
\hline & & & & \\
\hline
\end{tabular}
$\begin{array}{llll}.4633 \ldots & 35.25 & 34.02 & 33.62 \\ .8930 & 35.26 & 34.02 & 33.64\end{array}$ $.9905 \ldots 35.26 \quad 34.83 \quad 33.64$ $\begin{array}{lllll}8905 & \because 0 & 35.25 & 34.83 & 33.64\end{array}$

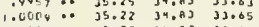

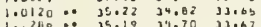
$1.5030 \ldots 3503034.5331,7$ $1.2560 .034 .7234 .22 \quad 33.73$ $.6674034 .28 \quad 34.11 \quad 33.05$ $\begin{array}{lllll}.4303 & 0 & 34.18 & 34.07 & 33.93 \\ .3578 & \cdots & 34.12 & 34.01 & 33.92\end{array}$ $\because 2758034.1534 .0033 .81$ $\begin{array}{lllll}.2374 & 0 & 34.16 & 34.06 & 33.89 \\ .1766 & 0.24 & 34.24 & 34.17 & 3309\end{array}$

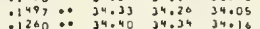

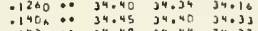
$01547 \ldots$ 34.52 34.48 34.38

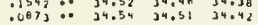
$\because 1770.834 .55$ 34.52 34.44

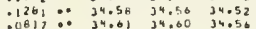

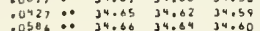
$\begin{array}{lllll}1.4716 & \ldots & 35.554 & 34.03 & 32.71 \\ 1.5328 & 0 & 35.53 & 34.94 & 32.75\end{array}$ $\begin{array}{lllll}1.6216 & 0 & 35.53 & 34.96 & 32.77 \\ 1.7637 & 0 & 35.52 & 34.96 & 32.06\end{array}$ $1.7274 \ldots$ 35.J8 34.8h 32.89 $\begin{array}{lllll}1.4358 & \cdots & 35.29 & 34.77 & 33.20 \\ .3349 & 0 & 35.25 & 34.74 & 33.49\end{array}$

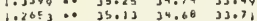
$1.3412 \ldots 35.0534 .5733 .78$ 1.2640.. 34.64 34.25 33.75 A277 $\because$ J4.4? $34,14 \quad 33 . A 1$

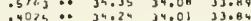
$.250, \cdots 34.22 \quad 34.0133 .84$ $.2054 \ldots 34.28 \quad 34.07 \quad 33.08$ $.1937 \ldots 24.33 \quad 34.18340 .05$ $\begin{array}{rllll}01636 & 0.034 & 34.38 & 34.27 & 34015 \\ .1226 & 0 & 34.42 & 34.35 & 34.25\end{array}$

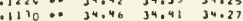
$\begin{array}{llll}11590.034,46 & 34.44 & 34.27 \\ 34.46 & 34.44 & 34.41\end{array}$

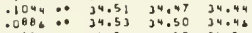
.1122034 .5434 .5234 .50

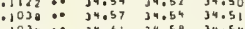
.1032 .0 34.68 34,58 34.54 .0581034 .6734 .6034 .56 $.0056 \ldots 34.6534 .66234 .58$

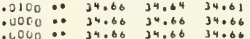

HAX MEAN MIN $5 T$ OLA ARE IMIATEEN - SUMHE

\begin{tabular}{|c|c|}
\hline .3038 & \\
\hline .2961 . & \\
\hline .2848 & \\
\hline .2916 & \\
\hline .2850 & \\
\hline $.2627:$ & \\
\hline .2807 & \\
\hline $.1650^{\circ}$ & \\
\hline .0789 & \\
\hline .0534 & \\
\hline .0276 & \\
\hline .0336 & \\
\hline $.0378:$ & \\
\hline .0427. & \\
\hline .0374 & \\
\hline .0322 & \\
\hline .0390. & \\
\hline .0382 & \\
\hline $.0363:$ & \\
\hline .0249. & \\
\hline .0219. & \\
\hline .0250. & \\
\hline & \\
\hline
\end{tabular}

.3897
3885 $.0 .3799 .:$ .03543 .29960 .2535
.2280. 25.2231

.0A38.. 26.45 26.025

$.0452 \cdots 26.74 \quad 26.242$
$.0336 \because 26.80 \quad 26.530$

$\begin{array}{llll}.0357 & \cdots & 27.01 & 26.764\end{array}$

$\begin{array}{rrr}.0304 \cdots & 27.12 & 26.940 \\ .0355 & 27.20 & 27.079\end{array}$

$\begin{array}{llll}.0313 & 0 . & 27.28 & 27.197 \\ .0235 & .0 & 27.34 & 27.291\end{array}$

$.0265 \therefore \quad 27.41 \quad 27.368$

$.0175027,4427.415$

$.0256 \cdots 27.5427 .505$

$.0162 \because \quad 27.56 \quad 27.534$

$.03290 \quad 27.67 \quad 27.628$

.04360 .27 .7329 .070

$.0252 \ldots$

$.0000 \ldots$

ARE $\triangle$ THIATEEN - SPAING

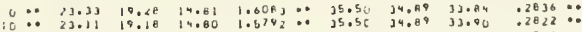

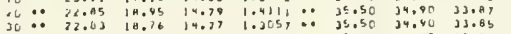

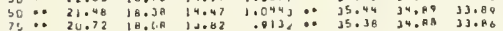

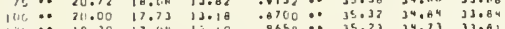

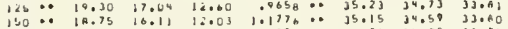

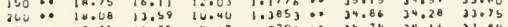

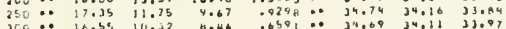

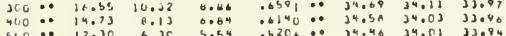

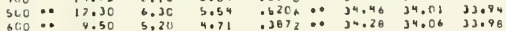

rou $\cdots \quad 9.50 \quad 5,200$

$81,0 \quad 2 . C_{1} \quad 4,29$

$900 \cdots \quad 301 \quad 3.97 \quad 3.7$

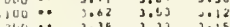

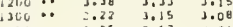

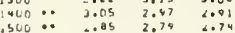

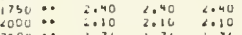

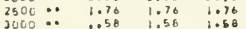

3.4.

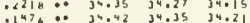

-128 A 34.48 34.41 34.24

$.0634034 .52 \quad 34.5034 .48$

.0373034 .5434 .5234 .51

$.036 \% 034.5534 .5434 .52$

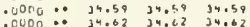

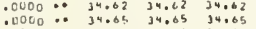

$\begin{array}{ll}27.75 & 27.717 \\ 27.75 & 27.743\end{array}$

27.7627 .760

$25.36 \quad 25.012$ $25.37 \quad 25.103$

$25.54 \quad 25.229$

$\begin{array}{ll}25.54 & 25.229 \\ 25.71 & 25.310\end{array}$

$\begin{array}{ll}25.06 & 750416 \\ 26.12 & 25,324\end{array}$

$26.2 b \quad 06.000$

$26.6,260507$

$\begin{array}{ll}26.86 & 26.747 \\ 27.03 & 26.910\end{array}$

$27.16 \quad 27.073$

$\begin{array}{ll}27.28 & 27.196 \\ 27.30 & 27.294\end{array}$

$27.45 \quad 27.370$

$27.50 \quad 27,461$

$27.53 \quad 27.115$

$27.55 \quad 27.542$

$27.63 \quad 27.630$

$\begin{array}{ll}27.68 & 27.040 \\ 27.73 & 27.730\end{array}$

$27.75 \quad 27,7=0$

$.0000 \because 34.65340 .6534065$

$$
\text { ARE THIRTEEN - TALL }
$$

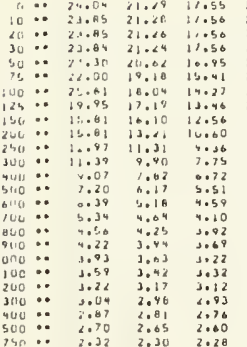

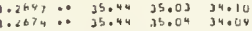

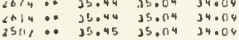

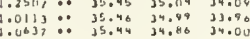
$.061,0.35 .40$ 34.76 33.08 $\begin{array}{llll}35.28 & 34.66 & 33.64\end{array}$

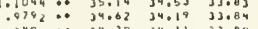

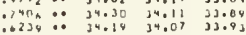

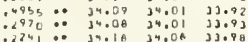
$.2241039 .18 \quad 34.08 \quad 33.96$ $\begin{array}{llll}1475 & 0.345 & 34.28 & 34.17 \\ : 1151 & 14.43 & 34.35 & 34.27\end{array}$ .1160 .034 .48 34.41 34.34 -OEDS $\because-34.4434 .4534 .44$

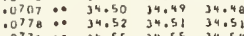

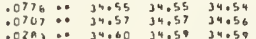

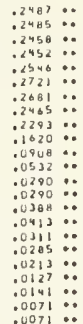

$36 M A=7$ MIR ST DEL NUT

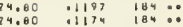

$24.80 \quad: 1166 \quad 164 \ldots$

24.01 :1197 184 $\because$

24.64 -1140 124
2400

25.11.1304

$26,27 \quad 0677 \quad 161 \cdots$

$20.02 \quad 1003$ 161 $: 0$

$36.36 \quad .0471 \quad 174 \ldots$

$26.50 \quad: 0426 \quad 167.0$

$26.95 \quad .0324$ 116.:

$27.05 \quad .0318 \quad .1600$

$27.30 \quad 0235 \quad 39 \ldots$

$27.38 \quad .0287 \quad 17 \%$

$27.45 \quad .0270 \quad 14 \ldots$

$27.56 \quad .0235 \quad 5.0$

$27.69 \quad .0163 \quad 40$

$22.20 \quad .3283 \quad 265 \ldots$

$22.26 \quad .3235 \quad 264 \ldots$

23.17
21.03 $.22009 \quad 264 \ldots$

$24.46 \quad-1473$

24.04 :1355 250 \%

$25.11 \quad: 1450 \quad 259 \ldots$

$25.79 \quad .1098 \quad 255 \ldots$

$26.03 \quad .0837 \quad 254 \ldots$

$\begin{array}{lll}26.35 & .0001 & 242 \ldots \\ 20.67 & .0416 & 239\end{array}$

$26.83 \quad .0361 \quad 222 \ldots$

27.08 . त297 $148 \ldots$

$27.27 \quad 0.0230 \quad 47 \ldots$

$27.39 \quad .018$

$27.48-0235$

$\begin{array}{ll}27.51 & .0105 \\ 27.54 & .0230\end{array}$

$27.00 \quad .0342$

$27.04 \quad: 00306$

$\begin{array}{ll}27.13 & .0115 \\ 37.76 & 0000\end{array}$

$.0000 \quad 3.0$

$33.03 \quad 03524 \quad 1910$

13.02
23.48 $2543 \quad 190 \ldots$

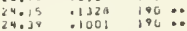

$24.60 \quad$ UA7A $\$ 80 \ldots$

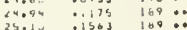

25.c5 .1274 107 :

25.13 .0750 175:.

$26.13 \quad .05 \mathrm{~d} 7$ 175

$26.40 \quad .0462 \quad 161:$

26.94 .031 97 .

27.21 .0310 42

27.40 .0250 13 \%

27.50 .0043 is 0

27.53 .0075 11 :

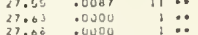

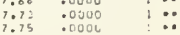

$\begin{array}{lll}025.20 & 24.1600 \\ \cdots \quad 25.27 & 24.878\end{array}$

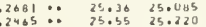

$.22930 \quad 25.7325 .372$

$26.46 \quad 28.039$

$23 . a 4$

$30 \mathrm{~B}$

$202 \ldots$

$3.05, \quad .2479 \quad 201 \ldots$

$24.03 \quad .2209 \quad 201 \ldots$

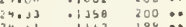

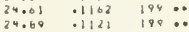

25.13 :UBGE $197 \ldots$

$26.70 \quad 26.54$

$26.40 \quad .0624 \quad 192 \ldots$

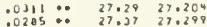

$.0213 \because 027.42 \quad 27.376$

$\begin{array}{ll}27.45 & 27.42 \mathrm{~A} \\ 27.048 & 27.4580\end{array}$

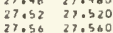

.00710

$27.59 \quad 27.590$

$36.40 \quad .0307$

21.030 .0311

2.23 $0.0250 \quad 108 \%$

$\begin{array}{lll}77.31 & 0205 & 49 \\ 27.40 & 0140 & 10\end{array}$

$37.44 \quad .0000$

$27.52 \quad .0000$

$27.04 \quad .0000$

$\begin{array}{lll}2 & \because \\ 2 & \because\end{array}$

Figure C.13. 
GREA FOURTEEN - MINTER

\begin{tabular}{|c|c|c|c|c|c|c|c|c|c|c|c|c|c|c|c|}
\hline \multirow{2}{*}{$\begin{array}{l}\text { QEPTH } \\
|M|\end{array}$} & \multicolumn{5}{|c|}{ TE MPLEATUKE IG } & \multicolumn{5}{|c|}{ SALINITY IPPI) } & \multicolumn{4}{|c|}{$51 \mathrm{GMA}$} & \\
\hline & $1 ; x$ & Af $\# \mathrm{~N}$ & $\mathrm{MIN}$ & 51 & & 2 & $M E \Delta$ & HIN & SI OEF & & MAX & $=4$ & HIN & STo & \\
\hline 5 & $2: 92$ & $2 \% .00$ & 23.00 & 1.0455 & .. & 2.13 & 34.38 & ग3.84 & .2720 & $\because$ & 24.00 & & 2 & .3 & \\
\hline $\ln \cdots$ & 21.95 & 24.04 & 21.05 & 1.0525 & •. & 33.15 & 34.40 & $3, \theta_{1}$ & .2713 & $\because$ & & 23.007 & $21.0 \mathrm{~A}$ & & 92 \\
\hline $20 \cdots$ & $\therefore 1.93$ & 24.34 & 23.04 & 1.0547 & $\because$ & 35.13 & 34.42 & 33. & .2698 & $\because$ & 24.00 & 23.039 & 1.98 & .3736 & 92 \\
\hline ;0 $\cdots$ & 21.93 & 24.54 & $23.0 \mathrm{~s}$ & $1.00 y_{2}$ & . & 33.13 & 34.44 & $33.9 \%$ & .2743 & $\because$ & 24.00 & 23.070 & 2.02 & & 92 \\
\hline su $\ldots$ & 21.95 & 24.42 & 21.67 & 14 & $\because$ & 35. & 34.49 & 34.04 & .2974 & 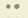 & 24.18 & 23.141 & 22.11 & .4 & 92 \\
\hline 30 & 27.56 & 23.24 & 16.69 & 1.9994 & $\because$ & 35,25 & 34.64 & 34.00 & .2918 & $\cdots$ & 25.23 & 23.592 & 22.50 & .6027 & 92 \\
\hline 100 & 20.45 & 20.48 & 12.09 & $3.0 E 70$ & $\ddot{0}$ & 35.14 & 34.79 & 34.13 & .2525 & $\because$ & 26.05 & 24.341 & 22.01 & & 92 \\
\hline 125 & 20.73 & 18.08 & 11.01 & 3.5337 & .. & 36.20 & 34,80 & 34.26 & .2819 & $\because$ & 26.40 & 24.9 & 6 & & 91 \\
\hline 150. & $7+.02$ & 16.78 & b.ou & 3.5189 & .. & 35.25 & 34.73 & 34.25 & .2738 & 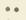 & 20.52 & 25.332 & 23 & .6016 & 91 \\
\hline :UU: & 19.56 & 13.37 & 10.03 & $2.656 \mathrm{~A}$ & .. & 35.13 & 34.64 & 34.14 & .2111 & $\because$ & 26.63 & 23.946 & 24.96 & & $9 i$ \\
\hline 250. & 130.46 & 11.17 & 4.54 & 1.3222 & 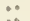 & 34.75 & 34.45 & 34.14 & .1952 & $\because$ & 26.73 & 20.120 & 25.43 & & $9 i$ \\
\hline $300^{\circ}$ & 11.50 & 9. & $0,+5$ & $.6\left[77_{1}\right.$ & $\because$ & 34. & 34.44 & 34.06 & .2130 & $\cdots$ & 26.80 & 26.050 & & & $9 i$ \\
\hline $400:$ & 0.53 & $8.3 n$ & $\because .67$ & $.019 \mathrm{H}$ & $\because$ & 34. & 34.45 & 34.06 & .1780 & $\ddot{0}$ & 26.92 & 26.801 & 26.58 & .0 & 91 \\
\hline 500 & $\begin{array}{l}8.63 \\
1.82\end{array}$ & 7.30 & 3086 & & 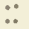 & & 34,47 & $\begin{array}{l}34.18 \\
34.28\end{array}$ & .1191 & $\because$ & 27.05 & & & & $\begin{array}{l}89 \\
87\end{array}$ \\
\hline 900 & $\begin{array}{l}1.82 \\
6.67\end{array}$ & $\begin{array}{l}6.5 n \\
5.02\end{array}$ & $\begin{array}{l}3.34 \\
4.91\end{array}$ & $\begin{array}{l}.5303 \\
.4198\end{array}$ & $\because$ & 30.50 & $\begin{array}{l}34.47 \\
34.48\end{array}$ & $\begin{array}{l}34 \\
34\end{array}$ & .0 & $\because$ & & $\begin{array}{l}85 \\
87\end{array}$ & & & $\begin{array}{l}87 \\
84\end{array}$ \\
\hline 800 & b.11 & 3.15 & 4,57 & .3362 & $\ldots$ & 34. & 34.50 & & & $\because$ & 27 & 2.267 & 17 & & A2 \\
\hline 400 & 5.39 & 4,81 & 4.22 & .2630 & 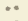 & 34.55 & 24,52 & 34.44 & .0218 & •. & 21.38 & 7.311 & 27.27 & & 82 \\
\hline & 4.31 & 4.41 & 3.90 & .2207 & 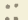 & 34.56 & 34.53 & 34048 & .0193 & $\cdots$ & 27 & 27.381 & 27.33 & & ei \\
\hline $\begin{array}{l}100: \\
200:\end{array}$ & $\begin{aligned} 4,51 \\
2,14\end{aligned}$ & 4.06 & 1.64 & .2823 & $\because$ & & 34.54 & 34.50 & & $\because$ & & 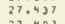 & & & 81 \\
\hline 300. & 3.83 & 3.10 & $\begin{array}{l}3.41 \\
3,19\end{array}$ & $\begin{array}{l}.1245 \\
.507\end{array}$ & $\because$ & $3+00$ & $\begin{array}{l}34.58 \\
34,57\end{array}$ & $34.5=$ & .0154 & $\because$ & & 27.483 & & & 78 \\
\hline $400 \ldots$ & 3.55 & 3.24 & $\therefore 98$ & .1399 & .. & & & $\begin{array}{l}34.54 \\
34.55\end{array}$ & .0135 & 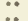 & 27 & 27.514 & 7.48 & .0 & 72 \\
\hline $00 \ldots$ & 3.31 & 2.94 & 2.76 & .13 ho & .. & 34.61 & 34.59 & $\begin{array}{l}14.55 \\
34.68\end{array}$ & $\begin{array}{l}.0118 \\
.0120\end{array}$ & $\because$ & 27.58 & 7.540 & & & 64 \\
\hline su. & 2.72 & 2.31 & 2.52 & .0103 & .• & 4.02 & 34.01 & 34.61 & & $\because$ & 27.51 & d & 27. & & 33 \\
\hline cone & 2.33 & 2.21 & 2.16 & .0637 & .. & 8 & 34.63 & 34. & & $\because$ & $\begin{array}{l}27 \\
27\end{array}$ & & & & $:$ \\
\hline दue? & 1.42 & 1.86 & 1.77 & $.65 \mathrm{~A} /$ & .. & 34.86 & 24 & 34 & & $\cdots$ & & 7. & 73 & & 5 \\
\hline 3000 & .75 & 1.69 & $1 . .2$ & .0520 & • & 34.64 & 34. & 34.67 & .0 & $\because$ & 27.76 & 27. & 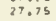 & & s \\
\hline & 1044 & 1,4 & 1,42 & - U10 11 & $\because$ & $34.7 n$ & 34.68 & 34064 & .0 & $\because$ & 27 & 37. & & & 3 \\
\hline & & 1.4 & 1.41 & .0000 & $\cdots$ & 34.70 & 34,70 & 2407 & & e & . & 27. & 27. & .0 & $\therefore$ \\
\hline & & & & & & 5,2 & the & & $m E R$ & & & & & & \\
\hline & os & & & 8 & $\cdots$ & $\begin{array}{l}3.29 \\
4.2 E\end{array}$ & 34,50 & 33.20 & & $\because$ & & .615 & 1.25 & .53010 & 47 \\
\hline$\angle U \cdots$ & 111 & & . 78 & $\{, \infty]_{3}$ & $\because$ & $\begin{array}{l}2 F \\
.27\end{array}$ & 24.58 & 28 & & 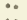 & & & & & , \\
\hline 3c. & .73 & 01 & .33 & 1.4454 & . & $\begin{array}{l}.27 \\
.24\end{array}$ & 24.63 & $.6 A$ & 33 & $\because$ & & & & & ? \\
\hline xe & - AO & & .43 & $2.47 \mathrm{A3}$ & . & .26 & 34.87 & & 13 & $\therefore$ & & $\begin{array}{l}.911 \\
.1801\end{array}$ & & & $\begin{array}{l}47 \\
47\end{array}$ \\
\hline 14. & $27 . A 9$ & 37 & 04 & & .. & .26 & 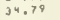 & 34.27 & .2297 & •. & 14 & $(, b) 9$ & & 2 & 47 \\
\hline $10 t_{1} \cdot$ & 20.42 & & 19 & & $\because$ & & $.6^{\circ}$ & 1.37 & B & . & & & & & 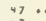 \\
\hline $124^{\circ}$ & .48 & & 86 & 3.7968 & $\bullet$ & .27 & .91 & +5 & .2 & $\because$ & & 10754 & & & 47 \\
\hline 150 & 24.67 & .18 & 10.01 & 3.0453 & *. & & 24.8 & 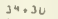 & & .9. & 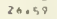 & (2) & & & 47 \\
\hline & .47 & & & $20.15 j$ & $\cdots$ & & .02 & 1.11 & 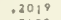 & $\bullet$ & 108 & 2 & & & 47 \\
\hline "1. & $\$ 4$ & & so & 1.487 月 & 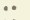 & & - & 1 & 20 & 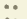 & 8.70 & & & & 47 \\
\hline - & 12.12 & & 96 & $.05: 2$ & $\because$ & & .42 & & & $\cdots$ & & & & a & 45 \\
\hline & 10.25 & & 14 & . & $\because$ & & $1.4 \mathrm{C}$ & & & . & & & & & \\
\hline & 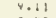 & & $.6 \mathrm{v}$ & $:$ & $\cdots$ & & 34.42 & & & & & 94 & & & 42 \\
\hline & , & & & & *. & & & 3 & & - & & & & & 40 \\
\hline - & & & . & & $\cdots$ & & .48 & 3 & & & & & & & 30 \\
\hline - & & 3.20 & .54 & $.280 \mathrm{n}$ & . & 59 & .50 & & & $\cdots$ & & 273 & & & 18 \\
\hline$\cdot$ & 5.17 & 75 & .23 & & $\because$ & & & & & & & & & & 3 \\
\hline$:$ & 4.70 & & & & $\cdots$ & & .52 & 3 & & $\cdots$ & 16 & 7.390 & & & Is \\
\hline • & 34 & & $د .4 B$ & & .. & 68 & 4.54 & & .0349 & $\cdots$ & & & & & 33 \\
\hline : & & 3.10 & 0,43 & & $\ddot{0}$ & & $e^{5}$ & & & 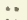 & & & & & 30 \\
\hline - & & 3 & .16 & & $\cdots$ & & & & & & & & & & 2) \\
\hline : & 3.52 & 3.17 & & & $\because$ & & & & & .. & & & & & 25 \\
\hline & & & & & $\cdots$ & & .58 & 1.55 & .0173 & 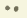 & 7.60 & & & & 10 \\
\hline & & $\therefore 44$ & QOSA & .10 & $\because$ & 4.61 & 1.54 & 14,57 & & $\because$ & & & & & 3 \\
\hline & 2 & $\therefore 1$ & 2,48 & & 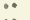 & & & & & & & & & & 2 \\
\hline & & & 1076 & & $\because$ & & & & & & & & & & \\
\hline & & & $\begin{array}{l}1.69 \\
1.42\end{array}$ & & 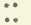 & & to & & & & & & & & 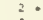 \\
\hline & 1.37 & : & 1,37 & - nouv & $\because$ & $\begin{array}{l}34.66 \\
34.68\end{array}$ & 34.68 & $\begin{array}{l}34.67 \\
34.88\end{array}$ & $\begin{array}{l}.0071 \\
.00000\end{array}$ & $\because$ & $\begin{array}{r}27.78 \\
27.79\end{array}$ & 27.790 & 7,29 & 1 & 2 \\
\hline
\end{tabular}

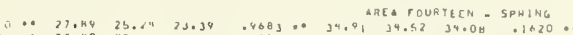

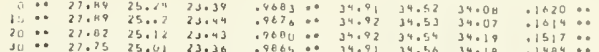

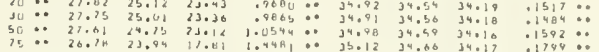

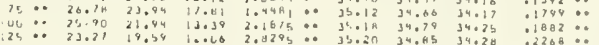

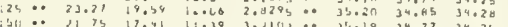

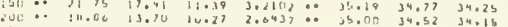

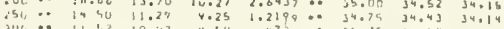

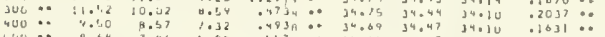

$23.53 \quad 22.922$

$2: .99 \quad .28$

$23.150 \quad 22.974$

$23, \mathrm{H}^{3} \mathrm{23.117}$

$\begin{array}{ll}25.02 & 23,411 \\ 25.45 & 24.072\end{array}$

$26.3420,731$

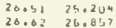

$50.13 \quad 50.545$

$\begin{array}{ll}28.47 & 26.327 \\ 24.93 & 26.785\end{array}$

$\begin{array}{llll}09 & A .64 & 1.46 & 3.44\end{array}$

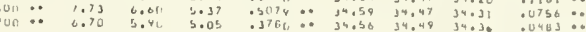

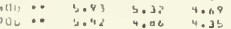

uev :-

$27.03-6.83$

$27.23 \quad 27.178$

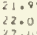

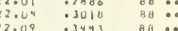

$22.65 \quad 07711 \quad 80 \cdots$

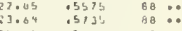

$\begin{array}{lll}24.10 & 5401 & 80 \\ 25.00 & 5916 & 88\end{array}$

25.62 3184 38 .

$26.54 \quad 00816 \quad 87: 0$

27.001 .0308 और

47.11 .0251 B7 $\ldots$

$\begin{array}{lll}27.19 & .0230 & 87 \\ 27.28 & .0220 & 87\end{array}$

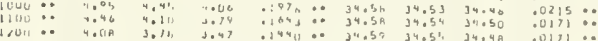

(3)

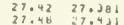

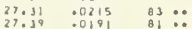

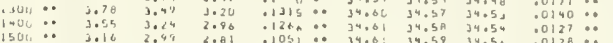

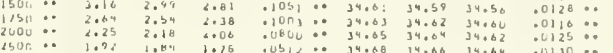

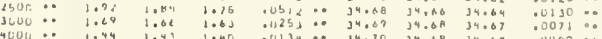

$27.34 \quad 27.514$

$\begin{array}{rr}27.50 & 27.545 \\ 27.60 & 27.577\end{array}$

$\begin{array}{lll}27.41 & .0203 & 90 \\ 17.48 & .0154 & 70\end{array}$

$27.50 \quad 0150 \quad 69: 0$

$27: 06027.042$

$27.63 \quad 0134 \quad$ a 010

$\begin{array}{lll}27.71 & .01140 & 8 \\ 27.75 & 10004 & 8\end{array}$

AREA FOUREER - THL

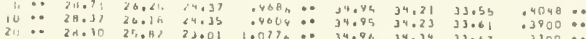

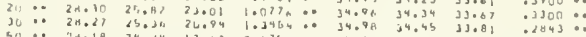

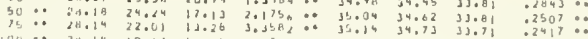

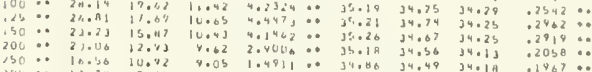

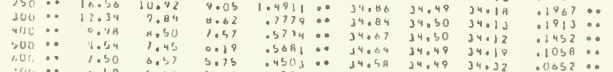

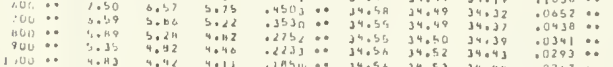

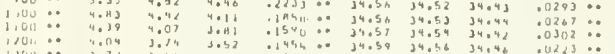

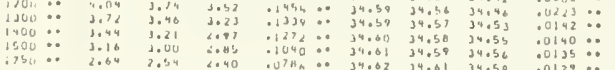

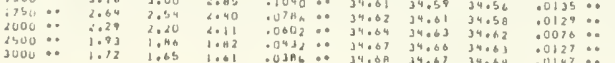

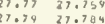

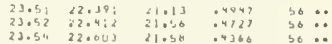

$\begin{array}{ll}27.177 & .0079 \\ 27.78 & .0071\end{array}$

$\because$

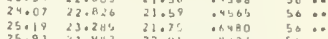

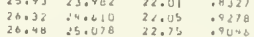

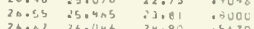

$26.77 \quad 26.344 \quad 25.37 \quad \$ 3320$

$\begin{array}{llll}26.116 & 26.600 & 25.96 & 02128 \\ 26.48 & 26.817 & 26.56 & 0407\end{array}$

$\begin{array}{llll}27.00 & 26.904 & 26.53 & 0001 \\ 27.14 & 27.040 & 27.06 & .0463 \\ 27.26 & 27.108 & 27.00 & .0423\end{array}$

$21,32 \quad 27,267$

27.03517 .300

$\begin{array}{ll}21,42 & 27.443 \\ 27,56 & 27.520\end{array}$

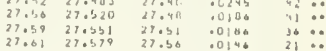

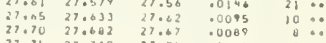

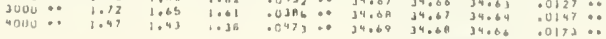

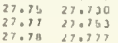

0.0115

Figure C.14. 
a. stattstigal summar ...

\begin{tabular}{|c|c|c|c|c|c|c|c|c|c|c|c|c|c|c|c|c|c|}
\hline & \multicolumn{5}{|c|}{ TEAPERATUHE (C) } & \multicolumn{5}{|c|}{ SALINITY IPPTI } & & \multirow{2}{*}{\multicolumn{2}{|c|}{ Nun }} \\
\hline & & mat & MEAN & $\mathrm{Min}$ & ST UEV & & n & $n C A N$ & HIN & T OEV & & $14 x$ & MLAN & HIA & ST OEV & & \\
\hline & $\cdots$ & 20.20 & 16.06 & 11.05 & $1.000_{0}$ & $\because$ & 35.09 & 4.61 & 35.86 & .3440 & $\because$ & 25.03 & 14.022 & 24.44 & .0073 & 23 & \\
\hline iu & 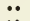 & 30.19 & 10.60 & $17.0 b$ & 1,0034 & $\bullet$ & 35.09 & 4.61 & 33.84 & .3424 & $\because \cdot$ & 23.03 & $408<1$ & $24+63$ & .0440 & 23 & \\
\hline 20 & .. & 20.32 & 10.67 & $1 \%$ & .4984 & 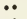 & $3 b .09$ & 4.62 & 33.84 & . 0368 & 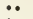 & & 4.0126 & $\{4.6\}$ & .0947 & 23 & \\
\hline 30 & •. & 20.23 & is.on & 17. & .9920 & 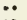 & 36.08 & 4.63 & 33.A5 & .3304 & $\bullet$ & & 14.831 & 3 & .0434 & 23 & \\
\hline 50 & .. & 20.12 & 10.72 & 17.07 & .4804 & *. & $35.0 B$ & 4.66 & $33 . A_{6}$ & .3246 & 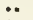 & 5.00 & $\{4.043$ & 14.64 & .0425 & 23 & \\
\hline & 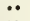 & 20.27 & 18.10 & $n+1$ & CAAB & $\bullet$ & 35.12 & 4.67 & 33.90 & .3230 & $\bullet$ & 5.00 & 4.860 & 24.60 & .0940 & 23 & \\
\hline 100 & $\ddot{*}$ & 20.75 & 10.49 & 10.33 & 1.1013 & 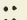 & 35.12 & 4,47 & 33.92 & .3178 & $\because$ & 5.14 & 4.909 & 4.74 & .0946 & 2 & \\
\hline 123 & .. & 19.62 & 17.19 & 13.50 & 1.1434 & •. & 25.00 & 4.61 & iv & .2 & $\bullet$ & 9 & 5,034 & 84 & & 3 & \\
\hline 150 & 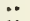 & $10 . c_{2}$ & 16.75 & 14.17 & 1.2254 & 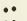 & $34, A 7$ & 34.50 & 34.00 & .2510 & $\because$ & 25.48 & $25 \cdot 198$ & 24.90 & .1 & 3 & \\
\hline 200 & $\bullet$ & 15.55 & 33.04 & 11.30 & $1,409^{8}$ & •• & 4.48 & 14.15 & & $.22 ; \theta$ & $\bullet$ & & 25.411 & se & $i$ & 3 & \\
\hline 250 & $\cdots$ & 12.00 & is.10 & 9.40 & 1.0035 & •• & 34.18 & 4.03 & 3.86 & $.09 a \theta$ & $\bullet$ & 26.26 & 26.014 & 25.18 & $\theta 9$ & 3 & \\
\hline 300 & 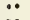 & 10.91 & 9.43 & 0.23 & .7101 & •• & 34.14 & 4.01 & 33.01 & .0641 & $\cdots$ & 24.01 & 26.209 & 26.10 & & 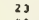 & \\
\hline 400 & .. & 7.09 & $7.2 \mathrm{R}$ & 0.58 & .4372 & $\ddot{*}$ & 34.09 & 34. & $33, A 2$ & .0527 & 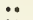 & 7 & 6.620 & 26.45 & .0 & 23 & \\
\hline Soo & -. & 6.44 & 5.94 & b.si & $.2540^{\circ}$ & •. & 34.23 & 34. & 33.98 & .0612 & $\because$ & & 20 & & & $3 i$ & \\
\hline$\triangle 00$ & $\cdots$ & 5,76 & 5.26 & 4.00 & .2535 & *. & 34,30 & 340 & 34 & .0779 & . & & & & & 16 & \\
\hline 700 & $\cdots$ & 5.17 & 4.04 & 4.61 & .2037 & •. & 34.39 & 4 & 34 & .0509 & $\bullet$ & & 58 & & & 12 & \\
\hline evo & •. & 4.65 & 4.43 & 4.19 & .1620 & •• & 34.45 & 34.30 & 34.32 & .0409 & 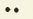 & 27 & 27.267 & 27.23 & .0261 & 12 & \\
\hline 800 & $\ddot{*}$ & 4.26 & 4.00 & 1.92 & - 1314 & •. & 34.51 & 34.44 & $34.4 j$ & .0333 & $\bullet$ & 38 & 27.364 & $3 i$ & & 8 & \\
\hline lovo & 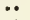 & 3,15 & 3,75 & 3.75 & .0000 & $\bullet$ & 34.50 & 34.50 & 34.50 & .0000 & $\bullet$ & 27 & 7,430 & & & 1 & \\
\hline 100 & $\bullet$ & 3.57 & 3.57 & 3.57 & .0000 & •• & 34.53 & 34 & 34 & .0 & $\because$ & & & 27.48 & & $i$ & \\
\hline \multicolumn{18}{|c|}{ ahEA DIFTEEN - SUMHEA } \\
\hline 0 & $\cdots$ & 23.52 & 2 & 2 & $1.154 \mathrm{~g}$ & - & .09 & 34.62 & 33.90 & .2997 & $\cdots$ & 5 & 03 & & & 47 & \\
\hline 10 & .• & 23.11 & 2 & i & & •. & & & & & • & & 3 & & & 47 & \\
\hline 20 & .. & 22.95 & 20 & 14. & דוד & - & 35 & 34 & 33 & .2 & - & & 2 & & & 47 & \\
\hline so & 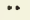 & $22.4 p$ & 20. & 10.92 & & $\because$ & 35 & & & & & & & & & 47 & \\
\hline 50 & . & 22.37 & 19.64 & 16.86 & 1.1751 & •• & 35.15 & 34.63 & 33.0 & .2865 & 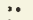 & 24.84 & 530 & 23.91 & .1683 & 40 & \\
\hline $7 b$ & $\ddot{*}$ & 20.15 & 10.70 & 10.90 & .4325 & 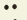 & 35 & 34.60 & 33 & $.2+72$ & $\ddot{*}$ & 04 & 1.785 & 17 & .1 & 46 & \\
\hline 100 & $\cdots$ & 19.77 & ba. is & 10.64 & .7637 & $\cdots$ & j5 & 34,02 & 3. & .2 & - & & 24.958 & & & 46 & \\
\hline $12 \mathrm{~s}$ & .. & 10. & 1 & 1 & & $\cdots$ & & & & & & & & & & 44 & \\
\hline (5i) & $\because$ & 18.59 & & 14. & .9791 & $\cdots$ & & & & & & & & & & 46 & \\
\hline 2011 & .. & 10.35 & 13.39 & $|4.7\rangle$ & 1.2573 & •• & 34.60 & 34.08 & 33.75 & .1 & $\bullet$ & 25.80 & 25.619 & 8 & .1 & 44 & \\
\hline 250 & $\ddot{*}$ & 13.17 & 10.86 & 9.29 & ABD4 & $\ddot{0}$ & 34,24 & 34,00 & & & $\ddot{0}$ & & 2 & & & 44 & \\
\hline 300 & .. & 10. & & & & •. & & & & & • & & & & & $4 !$ & \\
\hline 400 & $\because$ & & & & & 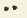 & & & & & & & & & & $4 i$ & \\
\hline suo & .. & & & & & $\cdots$ & & & & & & & 26 & & & 39 & \\
\hline \&Ua & 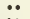 & $5 . \theta$ & 5 & & .28 & . & & & 34 & .07 & & 27) & 2 & 26 & & 34 & \\
\hline 700 & •. & & 4. & 4.5 & .2493 & $\cdots$ & & & & & & & & & & 5 & \\
\hline 800 & $\because$ & 4 & 4. & 4. & .2070 & 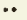 & & & & .0 & - & & & & & 25 & \\
\hline 900 & 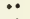 & & & & & 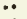 & & & & & & & & & & 73 & \\
\hline neo & .. & & & & & •. & & & & & : & & & & & 13 & \\
\hline ive & $\because$ & 3.8 & 3. & 3. & - isei & $\bullet$ & & S & 34 & .0 & • & & .456 & 27 & & it & \\
\hline 1200 & $\because$ & 3.5 & 3. & s. & .0716 & •. & 34 & & & & 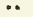 & & & & & 7 & \\
\hline & .. & I. & & & & •• & & & & & & & & & & & \\
\hline 0 & $\ddot{*}$ & & & & & $\because$ & & & & & & & & & & & \\
\hline 300 & 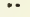 & 2. & 2. & .. & .0 & - & & & & & - & & & & & & \\
\hline 175 & $\cdots$ & 20 & 2. & 2. & .02 & - & 34 & & & .0 & & & 40 & 27 & .0 & & \\
\hline 100 & $\cdots$ & 2. & & 2. & & - & 34 & & & & & & & & & & \\
\hline & 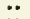 & & & & & & & & & & & & & & & & \\
\hline & $\cdots$ & 2 & & 100 & & & & & & & & & & & & & \\
\hline Uu & $\cdots$ & 3.50 & .30 & 1.50 & 0000 & - & 34.68 & 34.64 & 34068 & .0000 & & 27,77 & 27.770 & 27.77 & .0000 & & \\
\hline
\end{tabular}

ahEA FITIEEN - SPAING

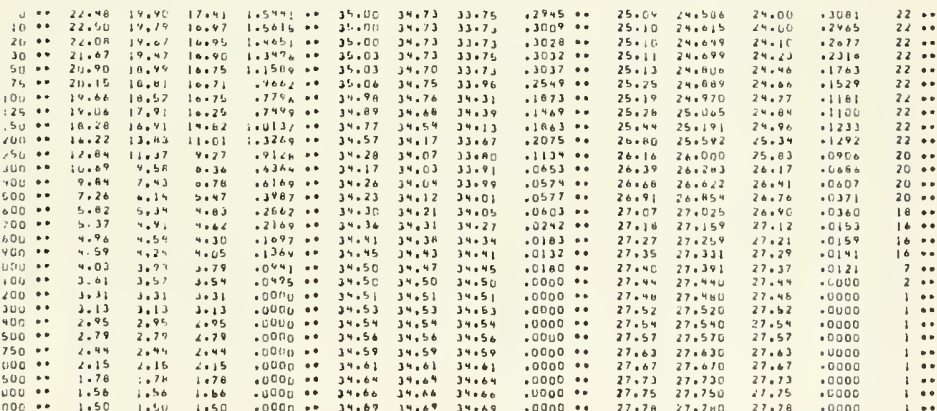

ARE TIFTECH - ROLL

\begin{tabular}{|c|c|c|c|c|c|c|c|c|c|c|c|c|c|c|c|}
\hline . & [... A J & . 1 & 6 & $1,3+1$ & & 35.16 & 34.67 & 33.94 & .3581 & •• & 24.92 & 0 & 60 & 9 & 23 \\
\hline & 22.80 & 20. & 17.01 & $1.033_{6}$ & $\cdots$ & 35.16 & $34.6 \mathrm{~A}$ & 33.93 & .3550 & & 24.03 & 24,334 & 23.63 & .0367 & \\
\hline $20 \ldots$ & $2:-F 1$ & 0.72 & 10.15 & 1.3106 & 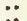 & 34.16 & 34,70 & 33.93 & .3437 & $\because$ & 24.44 & 24,350 & 63.68 & .3267 & 23 \\
\hline & 22.82 & 10.04 & 16.14 & $1.247 \mathrm{H}$ & $\because$ & 35.16 & 34.71 & 33.91 & .3398 & $\cdots$ & 24.94 & 24.170 & 3.17 & .3627 & 23 \\
\hline so . & $2 . .78$ & $2 \mathrm{v}, \mathrm{v} 7$ & 17.78 & $1.2^{8} 34$ & •. & 35.14 & 34.60 & 33.00 & .3644 & .. & 24.95 & 24.312 & 24.10 & & 23 \\
\hline 75 & 21.19 & 17,07 & 16.10 & 1.0970 & 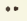 & 35.05 & 34.64 & $33.0_{0}$ & .3202 & . & 24.95 & 24,739 & 24.39 & .1279 & 23 \\
\hline $00 \because$ & inas & 18,52 & 10.34 & . USE & $\because$ & 35.03 & 34.06 & 33.99 & .2789 & & 5.00 & 240 & & & \\
\hline & 18.53 & 17. & is. & 1.us:A & $\because$ & & "n & 33.0 & 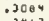 & 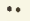 & & & & & \\
\hline 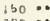 & $|d .0|$ & 16. & $1+.63$ & 1.4420 & *. & 35 & 34.46 & 33. & .3462 & $\because$ & 40 & 25 & 25 & 196 & 23 \\
\hline $10 \cdots$ & 15.60 & $: 3.25$ & 140.02 & $1.54 \varepsilon_{1}$ & $\cdots$ & 24.44 & 24.10 & 33.80 & .2366 & $\cdots$ & 5.96 & $25.6 \times H$ & 25.41 & .1402 & 23 \\
\hline b) $\cdots$ & $1<+70$ & 10.95 & 4.14 & 1.0021 & $\cdots$ & 34 & 34 & 33 & .1075 & . & 6.28 & 20 & 5.83 & .1176 & 23 \\
\hline D... & 10.37 & 4.31 & 4.05 & guts & 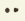 & 34.07 & & & .0290 & 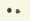 & & 42 & 26.64 & .0 & 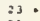 \\
\hline$\because$ & 8.13 & 7. & 0.53 & .43 & $\because$ & 4. & 3 & 33.9 & .0 & & & & & & \\
\hline & 0.75 & 5. & 4.41 & .2510 & $\because$ & 34 & on & 340 & .0 & - & 7 & & & & 23 \\
\hline & 3.76 & $5,1.3$ & 4.91 & .1834 & $\because$ & 340 & 34 & & .0 & $\cdot$ & 10 & 2 & 26 & & 22 \\
\hline . & 5.25 & 4.83 & 1.51 & .1636 & $\because$ & 340 & & & .0354 & & & & 27 & & 10 \\
\hline 605 & 4.78 & & & & $\because \bullet$ & & & & & & & & & & 8 \\
\hline 04 & 4.36 & 4. & 4. & .0941 & •. & 34 & & & & - & 34 & 27.325 & 27.29 & 109 & 8 \\
\hline $6 t_{1}$ & $\because .06$ & บ. 44 & 4.02 & $.112 v_{3}$ & & 34.48 & 34.40 & 34,43 & .0212 & & 27.19 & 27.375 & 27.36 & .0212 & \\
\hline
\end{tabular}

Figure C.15. 
ตละ

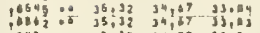

10 is $25,14 \quad 23,25 \quad 21,08$

$20 \ldots 25,14 \quad 29,20 \quad 2100$

ग. 25, $23,1721,0$

1,48, $38,3034,70$ 39, 39

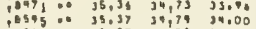

$73025.0423,01020.13$

$0.35,37$ 31, 30,00

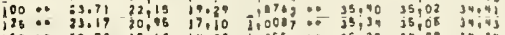

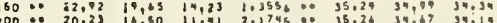

$745035,2634,67 \quad 34,19$

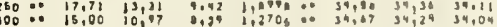

$100010,10,97$

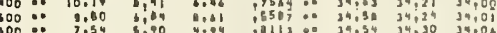

$300 \ldots 7,54 \quad 5,90 \quad 4194 \quad 11113 \ldots 34,5434,30 \quad 3406$

1000

$900: 0 \quad 5.26 \quad 4,4, \quad 40$

$30 \frac{7}{3} \ldots 34,3534,4434,20$

$12307 \cdots 34,53$ 24, 30 34, 34

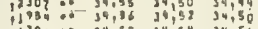

$1100 \div 4.91 \quad 3,663.43$

i $706 \ldots 34,5034,5434,51$

$30003,3,46 \quad 3,38 \quad 2,12$

1000

$3,17 \quad 2,7120,4$

$1269 \ldots$ 34, 31 34,57 94,54

$10020.34,02$ j4, $34,14,5$ ?

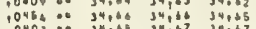

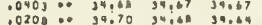

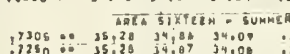

- - $\quad \because 023,33 \quad 28,11322013$

$2+22 \div \quad 24.0125 .374$

27,66271640

$721: \therefore 35,29,34,00$ 34, $20 \quad .2251: 0$

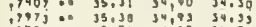

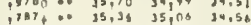

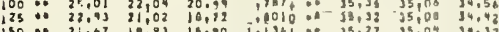

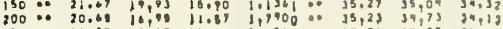

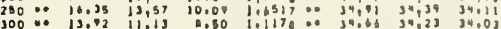

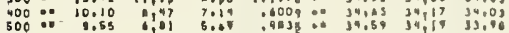

t00 7,3,

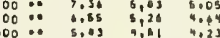

$100 \cdots 5,59$

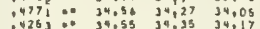

$0263 \cdots 39,53 \quad 39,13 \quad 34,17$

$384, \ldots 34,55 \quad 34,42234,28$

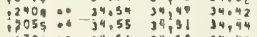

$17,23 \cdots 34,56 \quad 34,53 \quad 34,43$

1282034,14 j4,51 3N, 34

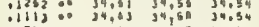

$, 1744 \ldots 34,04034,0004,34$

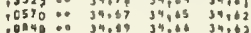

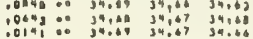

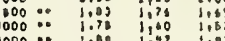

$000 \% \quad 3,49$

Ainta SIXYCEN = SPIIHE

$0 \because 23010$ 23,4, 21.2

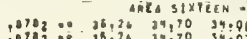

27.12 2 27.254

Hin ST OEV hut

$20020.0123,1921.2$

$50.026 .02 \quad 32,1021,29$

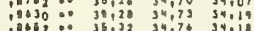

$19210.39,30 \quad 34,0234,16$

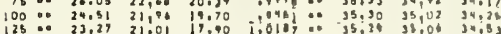

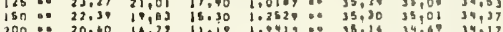

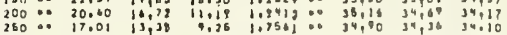

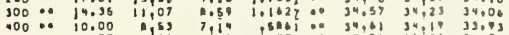

\$00 $:: \begin{aligned} & 10.00 \\ & 700\end{aligned}$

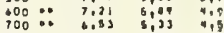

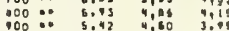

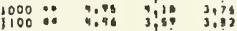

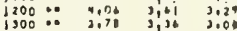

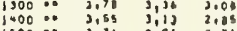

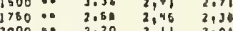

$3500 \because$ i, ins 1,77 1,80

$3000: \because$ li,

4000

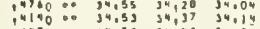

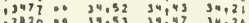

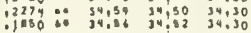

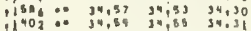

11402
11340
11270

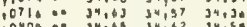

, 0540 - $340.00 \quad 34,65 \quad 340.62$

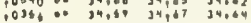

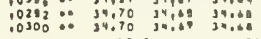

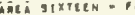

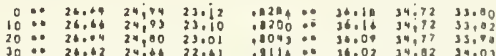

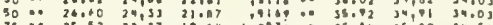

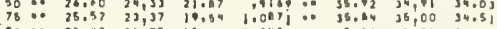

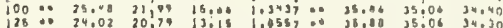

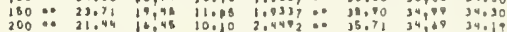

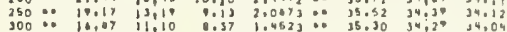

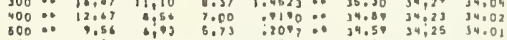

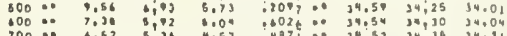

31 $014,52 \quad 14,36 \quad 34,2$

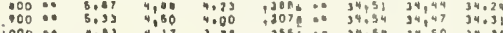

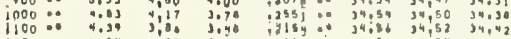

$2000: 304$ 3,3a 3.10

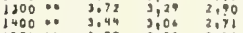

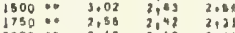

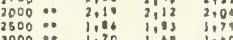

4000 .

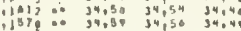

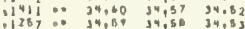

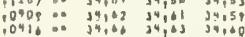

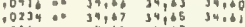

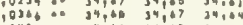

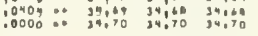

Figure C. 16.
35211
$3512 \div-$

$3430 \cdots 24,73 \quad 23,630$

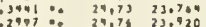

$, 2105: 024,90 \quad 24,204$

$1756 \% 25.65 \quad 24.860$

i $1364 \therefore \quad 24,0720,197$

$1042 \cdots$

ij 3170

$10571 \%$

01800

.01970

$0117: 0$

, 00013

$, 0045:$.

.0271 .

$24.0426,004$

27,04 26,056

$\begin{array}{ll}27,26 & 27,143 \\ 27,33 & 27.243\end{array}$

$27,43 \quad 27,392$

$27,43 \quad 27.441$

$27,52 \quad 27,493$

$27,58 \quad 27.549$

27.70
$27,75 \quad 27,734$

27,740

22800
22000

$24.20 \quad 23.210$

23,3
.2462

1194:-

$\$ 1970$

isis:-

i1 $1+70$ :

i) 13040

$.0652 \div$

.02390.
.02050

$0211 \div$

$00136: 0$

$.2240: 0$
$.050 \%: 0$

$10160 \div$

0,1120

$24.20 \quad 21.224$

$24.23 \quad 23.323$

$24,36 \quad 21,49$ ?

$\begin{array}{ll}24,86 & 24,245 \\ 25,00 & 24,540\end{array}$

$21,40 \quad 24,01$ ?

24.5825 .001

$26.7126 .01+5$

26.90
27.02
26.8025

$27.23 \quad 27.015$

$27.04 \quad 27.327$

$27.52 \quad 22,470$

$27.52 \quad 22.470$

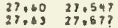

$\begin{array}{ll}27.67 & 27,0427 \\ 27.013 & 27,6082\end{array}$

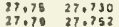

27,70
27,70
27,7770

1860
25620

$24,01 \quad 21,462$

22.5

$\begin{array}{ll}24,010 & 23,473 \\ 34,000 & 23,838 \\ 24081 & 23,59\end{array}$

$27430 \quad 24,12 \quad 23.707$

\begin{tabular}{|c|c|c|c|}
\hline $22.4 y$ & $\begin{array}{r}4811 \\
4\end{array}$ & 138 & $\ldots$ \\
\hline $\begin{array}{l}22,0, \\
22,4,\end{array}$ & $\begin{array}{l}47968 \\
; 4741\end{array}$ & ${ }_{136}^{136}$ & \\
\hline 22,47 & :4706 & $130 .$. & \\
\hline 22.47 & 4705 & 1940 & \\
\hline $\begin{array}{l}22,13 \\
23,32\end{array}$ & 4319 & ${ }_{130}^{130}$ & \\
\hline 23.14 & .25si & ijo $\because$ & $m$ \\
\hline $\begin{array}{l}24.05 \\
24.78\end{array}$ & .7427 & $\begin{array}{l}1360 \\
1360\end{array}$ & \\
\hline 25,23 & .2006 & $136 .$. & \\
\hline $\begin{array}{l}25,00 \\
26,25\end{array}$ & 2403 & 1360 & \\
\hline $20,4: 1$ & $: 1072$ & $134 \ldots$ & \\
\hline $\begin{array}{l}24,67 \\
27,04\end{array}$ & $\begin{array}{l}.0708 \\
.0475\end{array}$ & 3130 & \\
\hline 27,18 & .0314 & $128 \%$ & \\
\hline 27,27 & .0256 & $127 \%$ & \\
\hline 27,30 & .0214 & $110 .$. & \\
\hline 27,44 & .0186 & $116 \%$ & \\
\hline $27.4 \mathrm{n}$ & $\begin{array}{l}.0164 \\
.0140\end{array}$ & 90 & \\
\hline 27.51 & $\begin{array}{r}.0160 \\
\end{array}$ & $4:$ & \\
\hline $\begin{array}{l}27,042 \\
27.40\end{array}$ & $\begin{array}{l}.0107 \\
.0094\end{array}$ & $\because:$ & - \\
\hline 37.73 & 0110 & $3:$ & \\
\hline 27.75 & $\begin{array}{l}.0000 \\
.0200\end{array}$ & $\because \because$ & \\
\hline & & & \\
\hline $\begin{array}{l}22.25 \\
22,25\end{array}$ & $\$ 3336$ & 89 & \\
\hline 22.51 & issos & $\because \ddot{*}$ & \\
\hline 22.06 & :3401 & 89 & \\
\hline $\begin{array}{l}22.05 \\
23.02\end{array}$ & $\begin{array}{l}9683 \\
4218\end{array}$ & :9: : & \\
\hline 33.38 & 93178 & $\because \because$ & - \\
\hline $\begin{array}{l}24,11 \\
24,32\end{array}$ & $\begin{array}{r}\$ 235 \\
.2050\end{array}$ & & \\
\hline 20.77 &, 2509 & At : & \\
\hline 25.13 & $: 2423$ & :9: & \\
\hline $\begin{array}{l}26,75 \\
36,29\end{array}$ & $\begin{array}{l}23150 \\
: 1500\end{array}$ & $\because a$ & \\
\hline $\begin{array}{l}26,28 \\
76,58\end{array}$ & $\begin{array}{l}: 1506 \\
: 1078\end{array}$ & o: & - \\
\hline & & & \\
\hline 27.03 & $.04 \mathrm{~A} 2$ & 730 & \\
\hline 27.19 & $\begin{array}{r}0310 \\
00220\end{array}$ & $\begin{array}{l}73 \\
13\end{array}$ & \\
\hline $\begin{array}{l}27,28 \\
27,31\end{array}$ & $\begin{array}{l}.0220 \\
.0247\end{array}$ & & \\
\hline 27,37 & .0240 & $60 \ldots$ & \\
\hline $\begin{array}{l}27,40 \\
27,48\end{array}$ & $: 0243$ & $\begin{array}{l}55 \\
47\end{array}$ & \\
\hline 27,48 & $\begin{array}{l}.0179 \\
.0195\end{array}$ & & \\
\hline 27.51 & .0221 & is & \\
\hline 27.56 & 10324 & & \\
\hline 27,640 & 0190 & & \\
\hline 27,710 & $\begin{array}{l}: 0153 \\
00232\end{array}$ & & \\
\hline 27,78 & :0iso & $5:$ & \\
\hline & & & \\
\hline
\end{tabular}

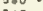

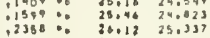

$1002 \because 24,65125,032$

.1814: 2170026057

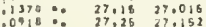

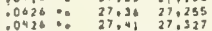

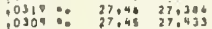

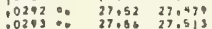

$\$ 0292: \because$

$.0770: 0$

$.020:-$

$27,5927.543$

27.06270007

$27.76 \quad 27.737$

$0146: 027 \% 7927,770$

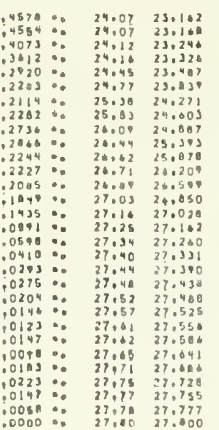

ijo01 100.

imon $190 \%$

insos

-13012 1040

$\$ 2622$ 164:

.2646
162

is 1100 161 0

20,96 .0725 1610

$\begin{array}{lll}27.08 & 00340 & 151 \\ 27,17 & 0290 & 143\end{array}$

${ }_{27}^{27}: 23 \quad 002740 \quad 132: 0$

$29.20 \quad 0204 \quad 121 \ldots$

$27,38 \quad .0274 \quad 100.0$

$27,44 \quad 0065 \quad 11: 0$

$27.74 \quad 0141 \quad: \because:$

27,76 :0181 : $: 0$

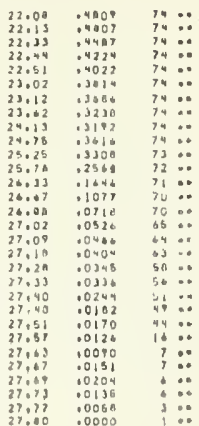




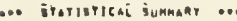

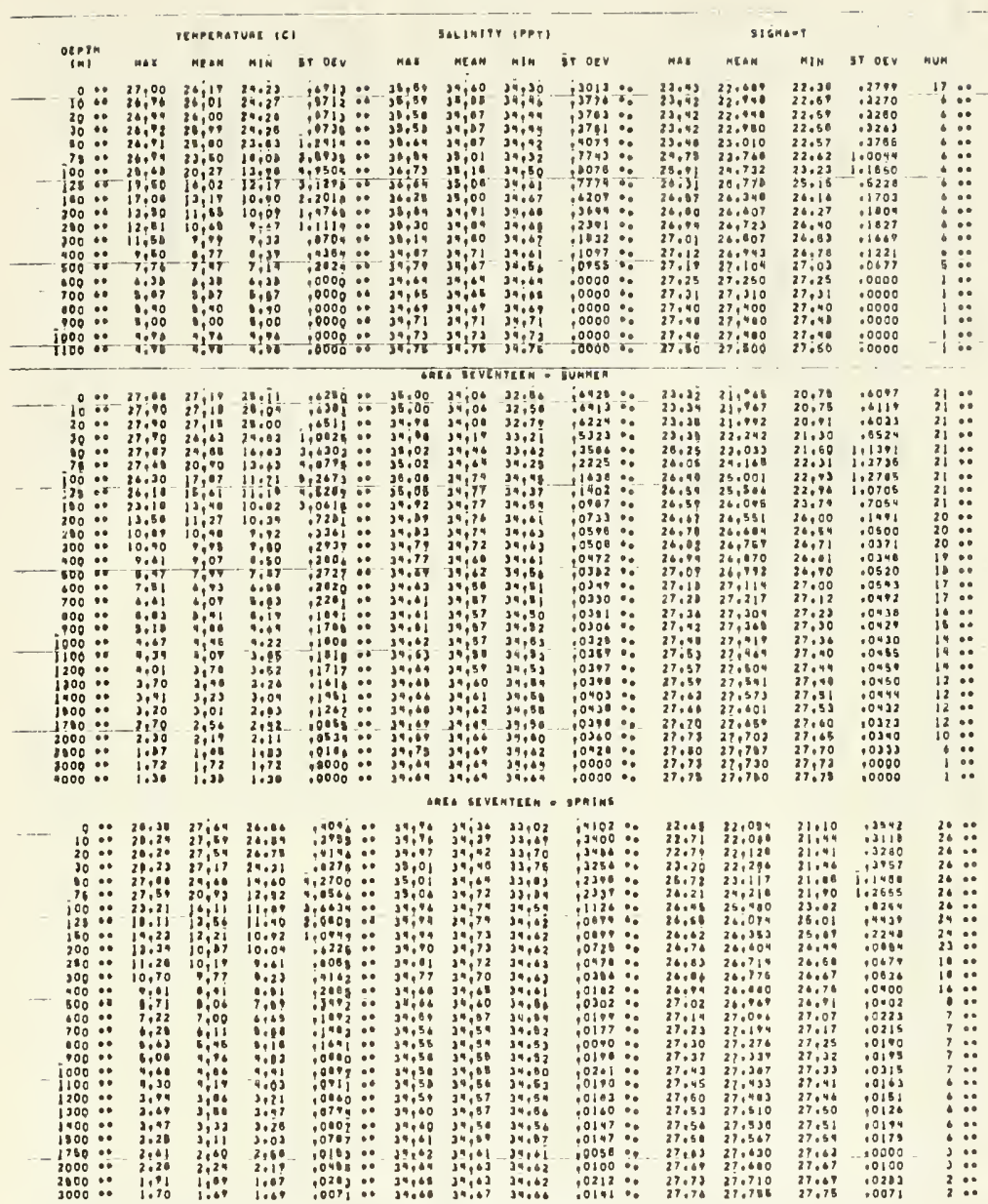

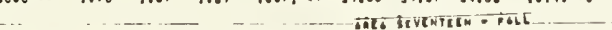

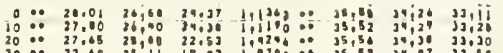

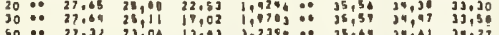

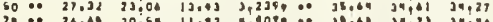

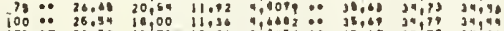

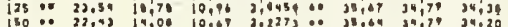

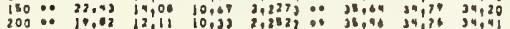

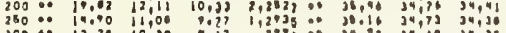

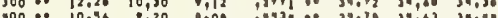

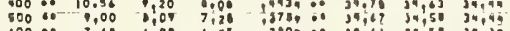

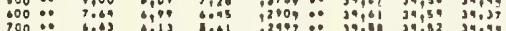

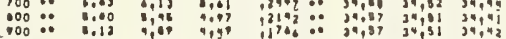

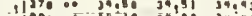

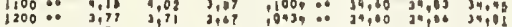

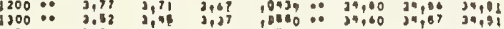

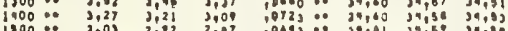

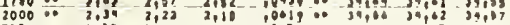

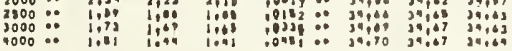

\begin{tabular}{|c|c|c|c|c|c|c|c|}
\hline & & 3 & 103 & 21,16 & $.00 \% 4$ & & \\
\hline 612 & $\because$ & 23,34 & 22,304 & 21,40 & (6)37 & 20 & $\bullet$ \\
\hline 5006 & $\because$ & 23.46 & 22.614 & 21.62 & .6158 & 20 & •. \\
\hline, 4261 & $\bullet$ & 20,64 & 22,000 & 21.04 & .6273 & 20 & •• \\
\hline 3136 & $\bullet$ & 25006 & 23,301 & 22.00 & 976 & 26 & $\cdots$ \\
\hline, 2063 & $\bullet$ & 26.39 & 24,328 & 22,34 & 1.2002 & 20 & .. \\
\hline $1^{2403}$ & & 26.60 & 20.03 & 23,31 & $1.033 \%$ & 20 & \\
\hline 2403 & $\because$ & 26.66 & 25,505 & 23,7 & -040s & 20 & $\cdots$ \\
\hline 12370 & $\bullet$ & 26,60 & 29.071 & 24,01 & $(4432$ & 26 & •. \\
\hline ,jopo & $\because$ & 26,67 & 26,377 & 24,70 & $.3+77$ & 20 & $\bullet$ \\
\hline (i) $=0$ & $\bullet$ & 26.73 & 26,680 & 26.04 & (1) 742 & 20 & .. \\
\hline 1020 & $\because$ & 34001 & 26006 & 26,44 & .0121 & 20 & $\cdots$ \\
\hline .0632 & $\bullet$ & 26.72 & 26,014 & 26,67 & .0534 & 20 & .. \\
\hline, $05 \% 4$ & $\bullet$ & 27,07 & 20,047 & 2tions & .0800 & 30 & $\cdots$ \\
\hline .0511 & $\because$ & 27.15 & 27,073 & 27.00 & .0000 & 20 & $\cdots$ \\
\hline 030 & $\bullet$ & 27,26 & 29.176 & 27,11 & .0391 & 27 & $\bullet$ \\
\hline 042 & $\therefore$ & 27,33 & 27,257 & 27,10 & .0305 & 26 & $\therefore$ \\
\hline .0427 & 6 & 27,30 & $(29,323$ & 27,23 & .000 & 23 & $\bullet$ \\
\hline 0046 & $\bullet$ & 27.40 & 27.375 & 27.30 & .046" & is & 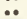 \\
\hline 0304 & 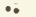 & 27,50 & 22,426 & 27,55 & .0308 & 12 & . \\
\hline 0322 & $\bullet$ & 27.32 & 29,400 & 27.44 & .0303 & 6 & \\
\hline 036 & $\bullet$ & 21,3 & 37.822 & 27,40 & .0277 & 3 & $\bullet$ \\
\hline & & 27,8 & 22,350 & 27,51 & .0206 & 8 & $\because$ \\
\hline $.02 \%$ & & $n+\infty$ & 27.5e4 & 27,8 & $.0230^{\circ}$ & 8 & .. \\
\hline 10099 & 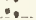 & mabs & 22,002 & .27 .39 & .0249 & 3 & $\cdots$ \\
\hline 10332 & & 27,70 & 29070 & 27,4 & .0245 & i & \\
\hline 0130 & $\because$ & 27.28 & 23,724 & 27,71 & .0019 & 8 & \\
\hline 0236 & $\because$ & 27,97 & 22,750 & 27,3 & .0180 & i & $\cdots$ \\
\hline .0274 & $\because$ & 27,10 & 27,772 & 27.78 & .0275 & , & . \\
\hline
\end{tabular}

Figure C.17. 


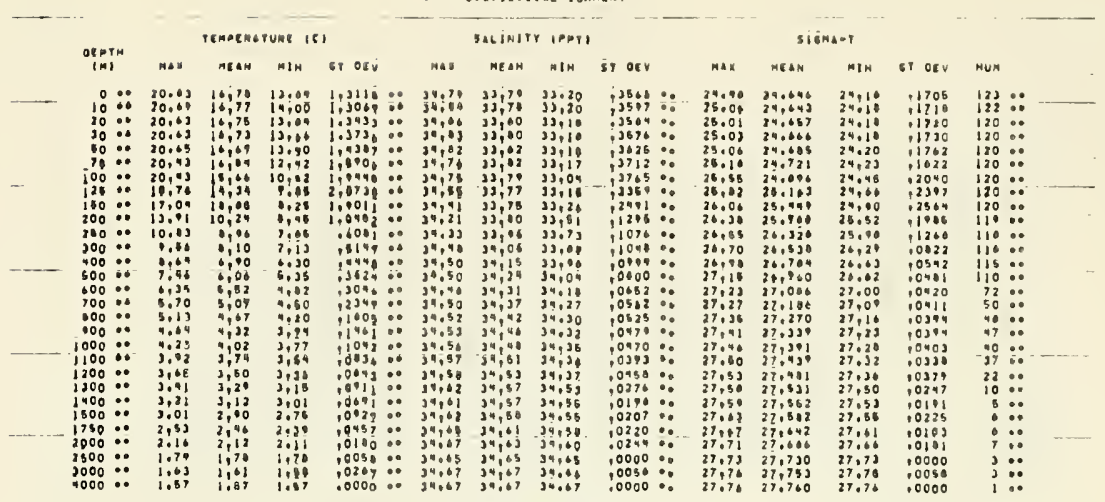

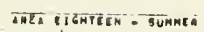

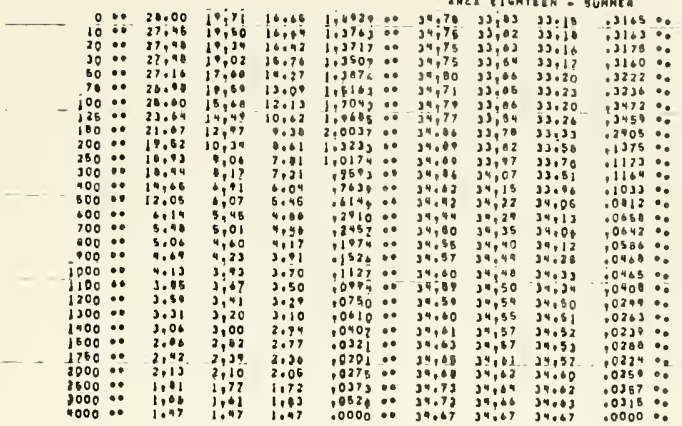

$24.93 \quad 23.951$

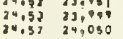

$\begin{array}{lll}54,733 & 24,6140\end{array}$

25.0125
25.16
25.9736

$25,360240,943$
$25,73 \quad 25,102$

$26,0025,453$

26,60
36,65
26,06
26,9316

26.9026 .776

37.10 27,060

$27.38 \quad 27.269$

27.90 27.0394

27,52
37,34
37.43

27.86
37.89
37.87 .529

$\begin{array}{ll}27.50 & 27.657 \\ 27.62 & 27.600\end{array}$

$27,63 \quad 27.041$

27,75
27,75
27,7324

21,02

0.341

160

$22.17 \quad 02760$ ise.

$32.31 \quad 12530 \quad 150: 0$

$32.037 \quad: 2401$
32.02

$34.016 \quad: 32240$

$29,02 \quad: 11092$

25.77

26,14 .0011

26,030

$37.02 \quad: 0464$

27.270411

37.40

27.32 .019:

$37.54 \quad .0240$

$27,61 \quad 0190$

$37.70 \quad .02 \%$

$135: 0$

is $30 .:$

ise.:

$155::$

146 $: 2$

in $\because$

$82: 0$

$-51,0$

2. $\because$

$12 \because$

$\pm \because$

$? \because \because$

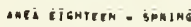

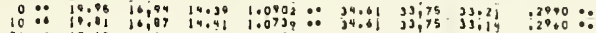

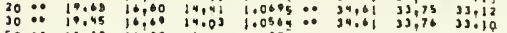

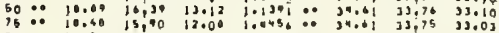

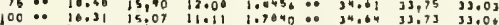

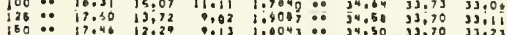

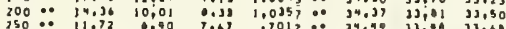

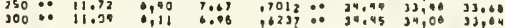
$400 \ldots$ :.45

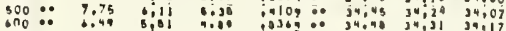

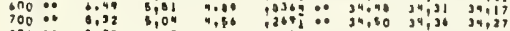

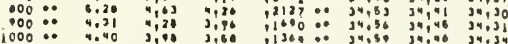

$1100 \because 4: 94 \quad 3,72$

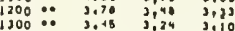

,i30.

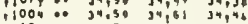
$, 0070 \ldots 34,8,34,83 \quad 34,40$

$\begin{array}{llll}1400 \\ 11000 & 3,17 & 3,02 & 2,90 \\ 2,1000 & 3,03 & 3,73\end{array}$

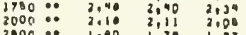

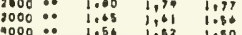

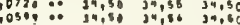

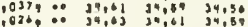

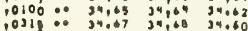

2056
2070 $.3061:$

.024510

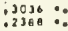

1929

iils

$0771: 0$

1045

, 0340

$0377: 0$
00350

, $0207 \div$

,0140

$.0060: 0102$

$00102: 0$

27.7723 .710

7,7

28.03
25.02
24.5663

25.01
25.08
$254,064]$

$28.25 \quad 24.712$

$26.33 \quad 24,816$

26.07
26.10
25,2542

$36.43 \quad 36.029$

$36: 06 \quad 26,1350$

26.0326 .7195

$3: 1929,000$

$27.30 \quad 27,105$

$37,34 \quad 27,037$

$27,50 \quad 22: 340$

27,475

$37,37 \quad 27,541$

27,65
37,69
$37,0,072$

$37,72 \quad 27,724$

24.00

:10\}

$\log _{105}::$

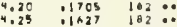

24,18 :1615 $182: 0$

34.85 :1971 170.

$24: 70 \quad: 2357 \quad 170: 0$

$30.44 \quad .2016 \quad 1910$

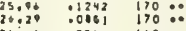

$26.0150894 \quad 162: 0$

29,000 :0350 $117: 0$

$37.16 \quad .0300 \quad 100 \%$

37,2,
27,39 $.0320 \quad \because 030$

$27,439,00304 \quad 40.0$

37.48 .0156 $20 \%$

27.81 .0144 $26: 0$

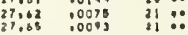

27,70 :0113 :0172

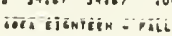

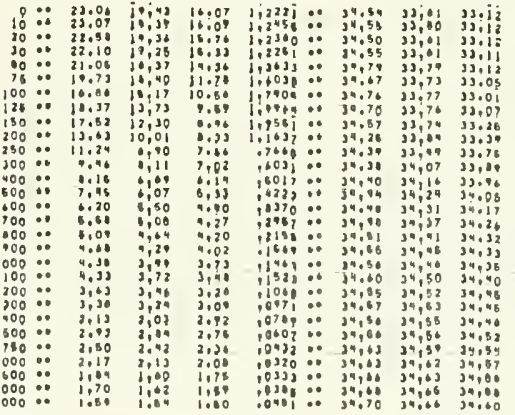

,313: ::

$34.7 \% \quad 24.017$

$31710240,0824,020$

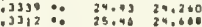

$.3256: 25.17 \quad 34.194$

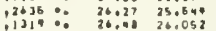

$.12000: 26.06126 .054$

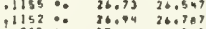

0008

$.0761 \%$

0.0420

$00007: 0$

$.0269: 0$

.02020

80,02460

$0177: 0$

$: 0340: 0$

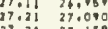

$37.43 \quad 37.330$

$37: 50 \quad 27,394$

$\begin{array}{ll}27.51 & 27.470 \\ 37.83 & 27.600\end{array}$

$27.56 \quad 37.691$

$37.66 \quad 27.634$

37,99896969

37.76 .0060

$$
\text { ?. }
$$

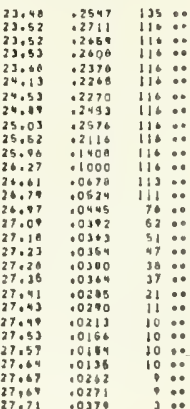




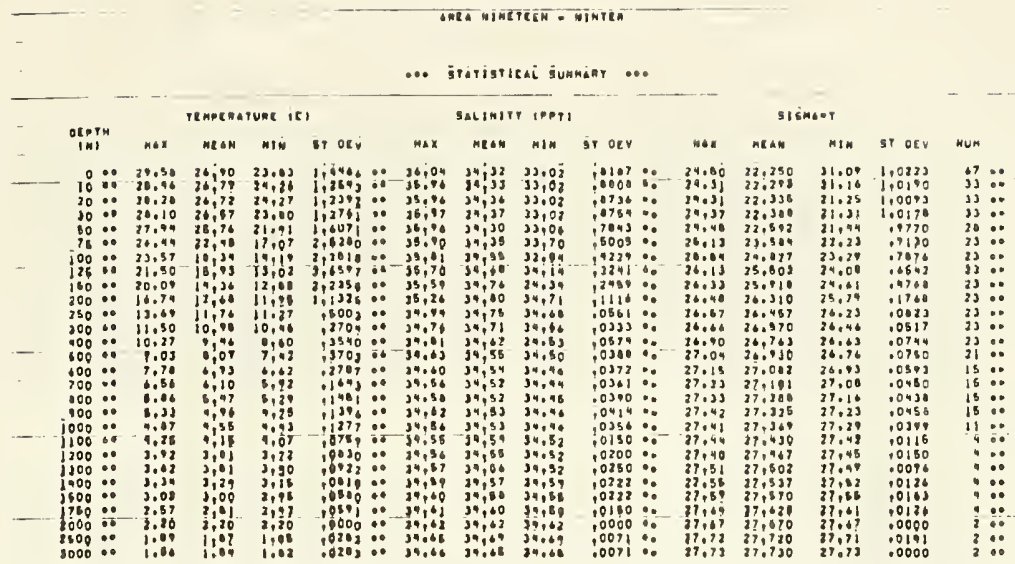

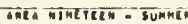

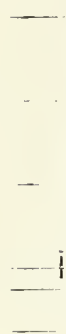

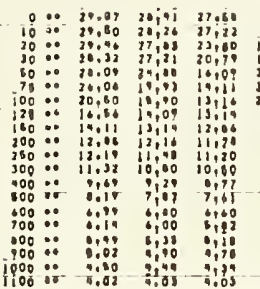

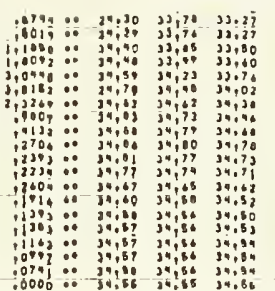

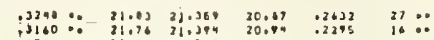

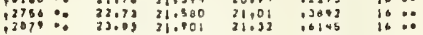

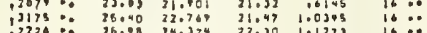

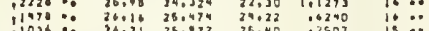

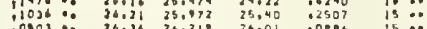

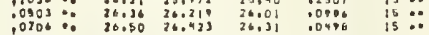
0001060 $00179: 07000$

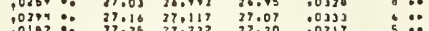

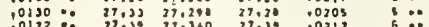

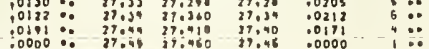
10.0
20
30

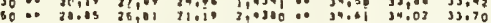

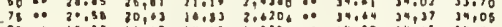

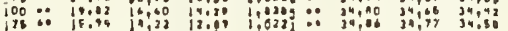

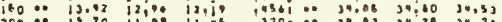

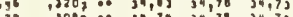

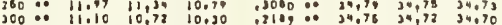

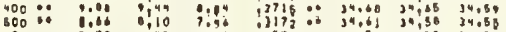

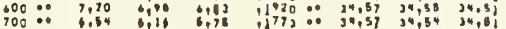

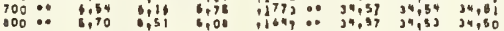

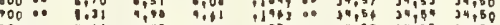

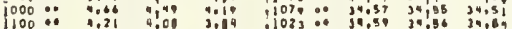

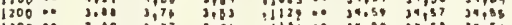

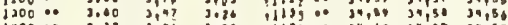

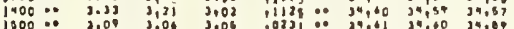

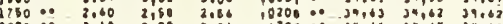

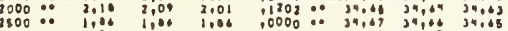

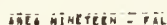

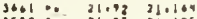

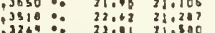

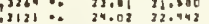

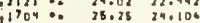

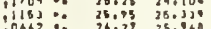

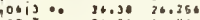
$\begin{array}{lll}.0267 & 0.026 .51 \quad 26.436\end{array}$

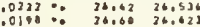

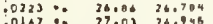

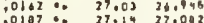

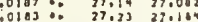

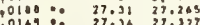
1010.: $27,0337,37.190$ $0136027,5127,9,9$ $.0107 .027 .54 \quad 21.623$

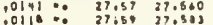
$.0060: 027,05 \quad 37,640$

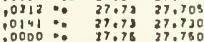

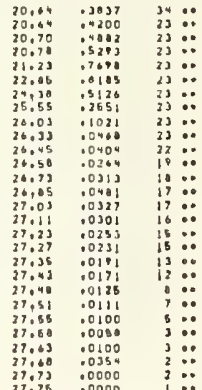

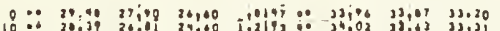

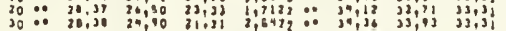

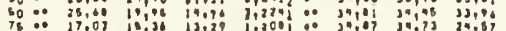

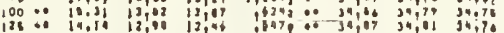

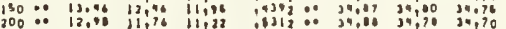

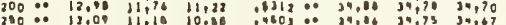

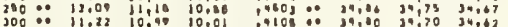

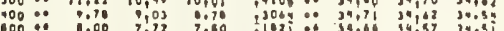

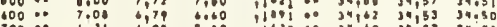
900
$\because$

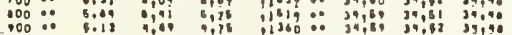

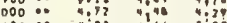

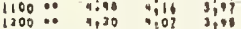

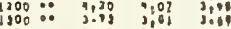

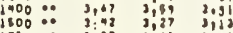

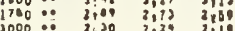

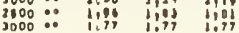

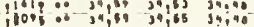

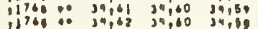
,

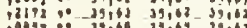
(890

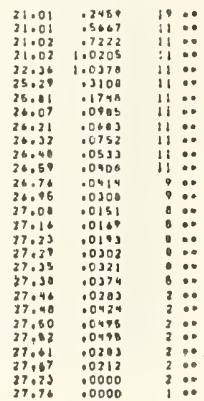




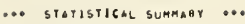

\begin{tabular}{|c|c|c|c|c|c|c|c|c|c|c|c|c|c|c|c|c|}
\hline \multirow{2}{*}{\multicolumn{2}{|c|}{$\begin{array}{l}\text { GEPTH } \\
\text { INI }\end{array}$}} & \multicolumn{5}{|c|}{ TEMFIFATUNE (GI } & \multicolumn{4}{|c|}{ 5ALINIYY (PPT) } & \multicolumn{5}{|c|}{ SIGMLEI } & \multirow[b]{2}{*}{ NUM } \\
\hline & & aAd & HE AT. & $111 \mathrm{~N}$ & $510 \mathrm{CV}^{2}$ & & $\max$ & $M E \& N$ & MIN & ST OEV & & $M \notin x$ & $m[a n$ & $\min$ & ST OEY & \\
\hline & & 3 & 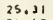 & 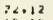 & 8022 & $\because$ & 4.92 & 34.12 & . & .69 .8 & $\because$ & 24.00 & 22.506 & 20.04 & .9098 & \\
\hline 10 & & & & & 247 & •. & & & & & $\cdots$ & 25.21 & 22.680 & 21.03 & $\cos \theta \theta$ & is \\
\hline 26 & . & 20.27 & 22.25 & {$[0.5]$} & 2.28117 & 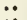 & 35.14 & 34.60 & $\mathrm{BJ} \cdot \mathrm{Az}_{2}$ & .3544 & $\because$ & 25.65 & 23.636 & 22.12 & - Bys4 & 35 \\
\hline 30 & $\cdots$ & 25.25 & 20.20 & 14. & $2.57 \mathrm{~A}_{0}$ & $\cdots$ & 35. & 34. & 34. & .0038 & $\because$ & 26.03 & 24.5 & & & \\
\hline 5o & $\ddot{*}$ & $2 \ldots 20$ & 16.78 & 13.87 & 2.1636 & $\because$ & & & & & $\because$ & 26.23 & 25. & & .3 & 26 \\
\hline 75 & $\ddot{*}$ & 17.73 & & & 1.15 & $\because$ & 35. & & & .1064 & $\ddot{*}$ & 26.31 & 26,0 & 25.57 & & \\
\hline 100 & $\cdots$ & 10.54 & 13. & 1 & .4731 & *. & Js. & j4 & & & $\because$ & 200 & 20. & & & 5 \\
\hline 125 & $\cdots$ & 13.88 & & & & $\cdots$ & & & & & & & & & & \\
\hline ise & “ & i.s.43 & $i_{3}$. & $1 \ll$ & .1955 & $\cdots$ & 35.01 & & & & • & & & & & \\
\hline 200 & 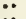 & 12.97 & $|2.7|$ & 12.58 & $.121 \theta$ & $\cdots$ & 34. & 34 & 34 & .01 & - & 26.40 & 26 & & & \\
\hline 250 & $\cdots$ & 12.75 & 12.1 & 11. & .2211 & •. & 34. & 34 & & .0 & $\because$ & 28.51 & & & & 25 \\
\hline 300 & •. & & 11. & Iu. & & •. & & & & & $\bullet$ & & & & & \\
\hline 400 & $\because$ & 4. & $\therefore$ & & & $\bullet$ & 4. & & & .02 & & 26. & & & & 17 \\
\hline 500 & "• & 4.2 & & & & •• & & & & & & 27. & & & & 16 \\
\hline noo & $\ddot{\circ}$ & 7.38 & 6 & 0. & . & $\ddot{0}$ & 34 & & & .0313 & $\because$ & & & & & \\
\hline 700 & $\cdots$ & 6. & & & .2 & $\cdots$ & & & & & & & & & & \\
\hline 600 & 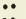 & 5. & s. & b. & .30 & $\ddot{*}$ & & & & .0 & : & & & & & \\
\hline 900 & & & & 4.10 & .2218 & ○. & 34.53 & 34. & 34.53 & .0000 & $\bullet$ & 27. & 27.3 & 27.28 & & \\
\hline & & $40 \mathrm{AB}$ & 4.79 & 4.67 & 1007 & & 34.54 & 34.54 & 34.53 & $.005 \theta$ & & 27.37 & 27.350 & 27.34 & .0173 & \\
\hline
\end{tabular}

DEFA THENTY - SUMAER

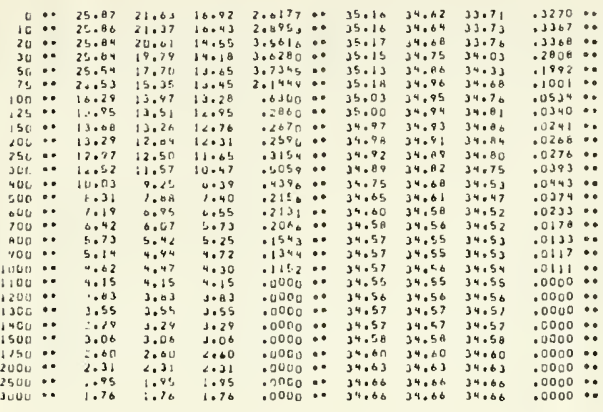

ZHE, TAENTY - SPAZNG

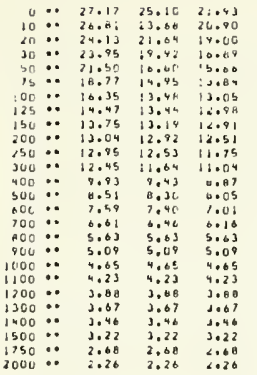

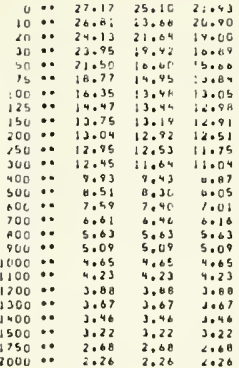

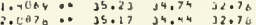
$1.565 .535 .17 \quad 34.32 \quad 34.20$

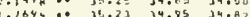
$\begin{array}{llll}1.2640 & 31.23 & 34.85 & 34.82\end{array}$ $.0774 \ldots$ 35.06 54.04 34.83 $.1602 \therefore 34.93 \quad 34.90 \quad 34.80$ $.2477 \ldots 34.91$ 34.98 34.81 $.5202 \because 34.8134 .8234 .70$ $.2792 \because 340734,7003406$ $\begin{array}{llll}34470.0 & 34.64 & 34,053 & 34.62 \\ 34.06 & 34.59 & 34.54\end{array}$

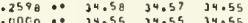
$.0060 \ldots 34.55 \quad 34.5534 .55$

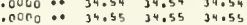
$\begin{array}{rrrr}.0000 & 0.034 .55 & 34.55 & 34.55 \\ .0000 & 34.56 & 34.58 & 34.56\end{array}$ $.0000 \ldots 34.5634 .56 \quad 34.56$

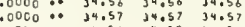
.0000034 .5834 .5834 .58 $.0000 \cdots 34.58 \quad 34.5834 .58$ $\begin{array}{rrrr}.0000 & 0.034 .62 & 34.02 & 34.62 \\ 0000 & 34.63 & 34.03 & 34.063\end{array}$

ARE T TWENT, FALL 34.A4

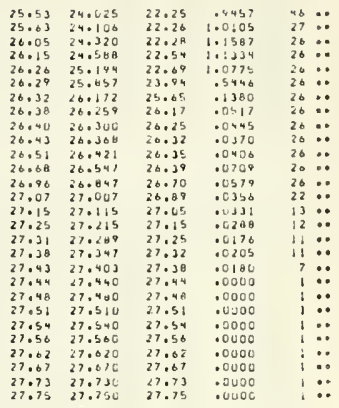

.02010 $24.45 \quad 23.013$ $.32910025010 \quad 24.113$ $.1407 \ldots 200125.526$ $.0547 \therefore$ 70.35 20.155

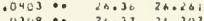
$\begin{array}{lll}.03690 & 20.37 & 26.307 \\ .01900 & 20.34 & 26.351\end{array}$ $.0324 \because 26.5026 .403$ $.0244026 .60 \quad 26.533$

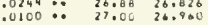
$.0115: \because \quad 27.10 \quad 27.000$ $: 0000 \therefore \quad 27.14 \quad 27.170$ $27.32 \quad 27,320$ $.0000 \because \quad 27.39 \quad 27.380$ $.0000 \ldots 27.40 \quad 27.400$

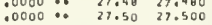
$.0000 \cdots \quad 27.52 \quad 27.520$ .0000 .0000 :. $\begin{array}{ll}27.52 & 27.520 \\ 27.56 & 27.560\end{array}$ $\begin{array}{ll}27.63 & 27.630 \\ 27.67 & 27.670\end{array}$

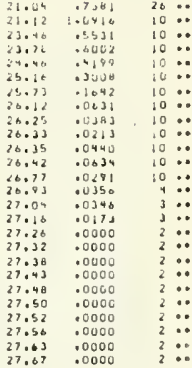
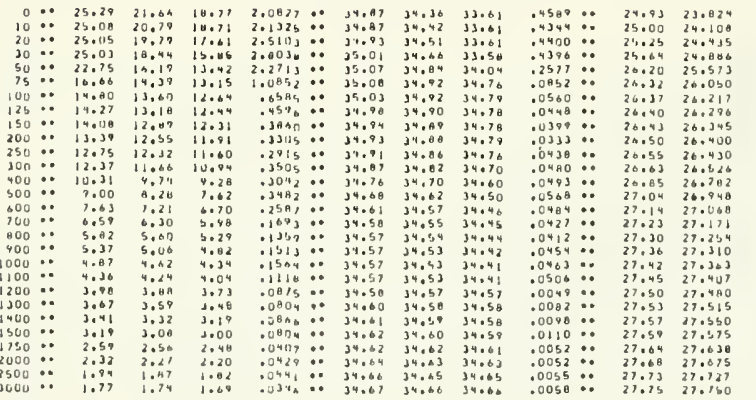

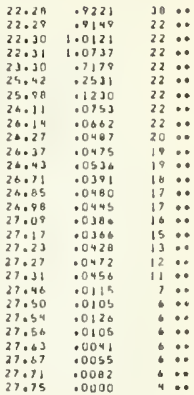

Figure C.20. $\because$

$-2$

(n)

$\because$

$\because$

$\because$

$\because$

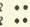

$\begin{array}{lll}2 & \because: \\ 2 & \because\end{array}$

$\begin{array}{lll}2 & \because: \\ 2 & \because\end{array}$

2
2 $\because$ $\because:$ $\because$ 每 $\because$ - - - - - - - - -

is $::$

12:

$\because$

.

$\because$ ... 


\section{APPENDIX D \\ METEOROLOGICAL DATA FOR EASTERN PACIFIC SURVEY AREA}

Data showing various tropical cyclone stages and wind roses for eastern Pacific areas are given.

Data from U. S. Naval Weather Service sources.

Note: $1 \mathrm{knot} \approx 0.5 \mathrm{~m} / \mathrm{sec}$ for the figures in this appendix. 


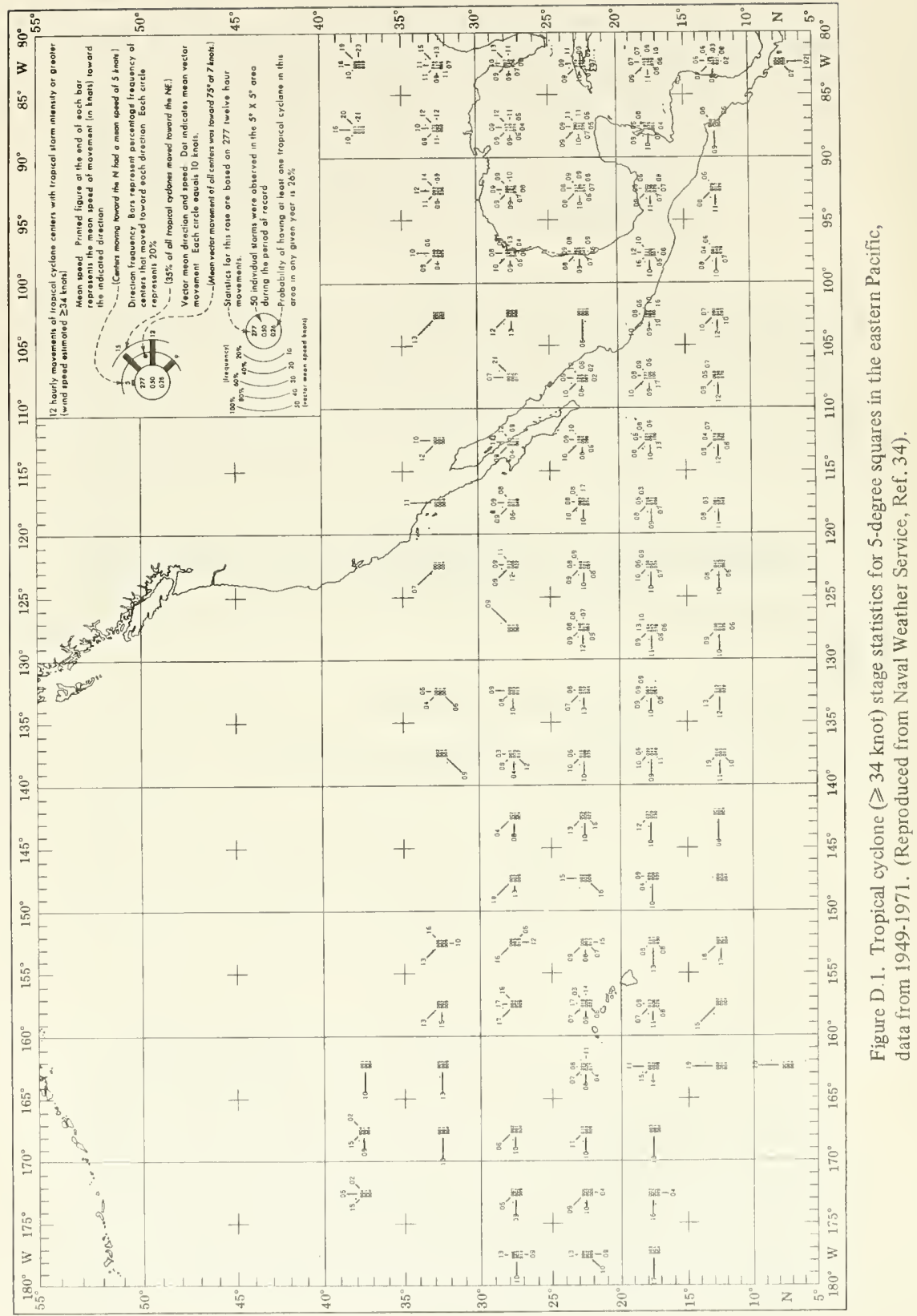




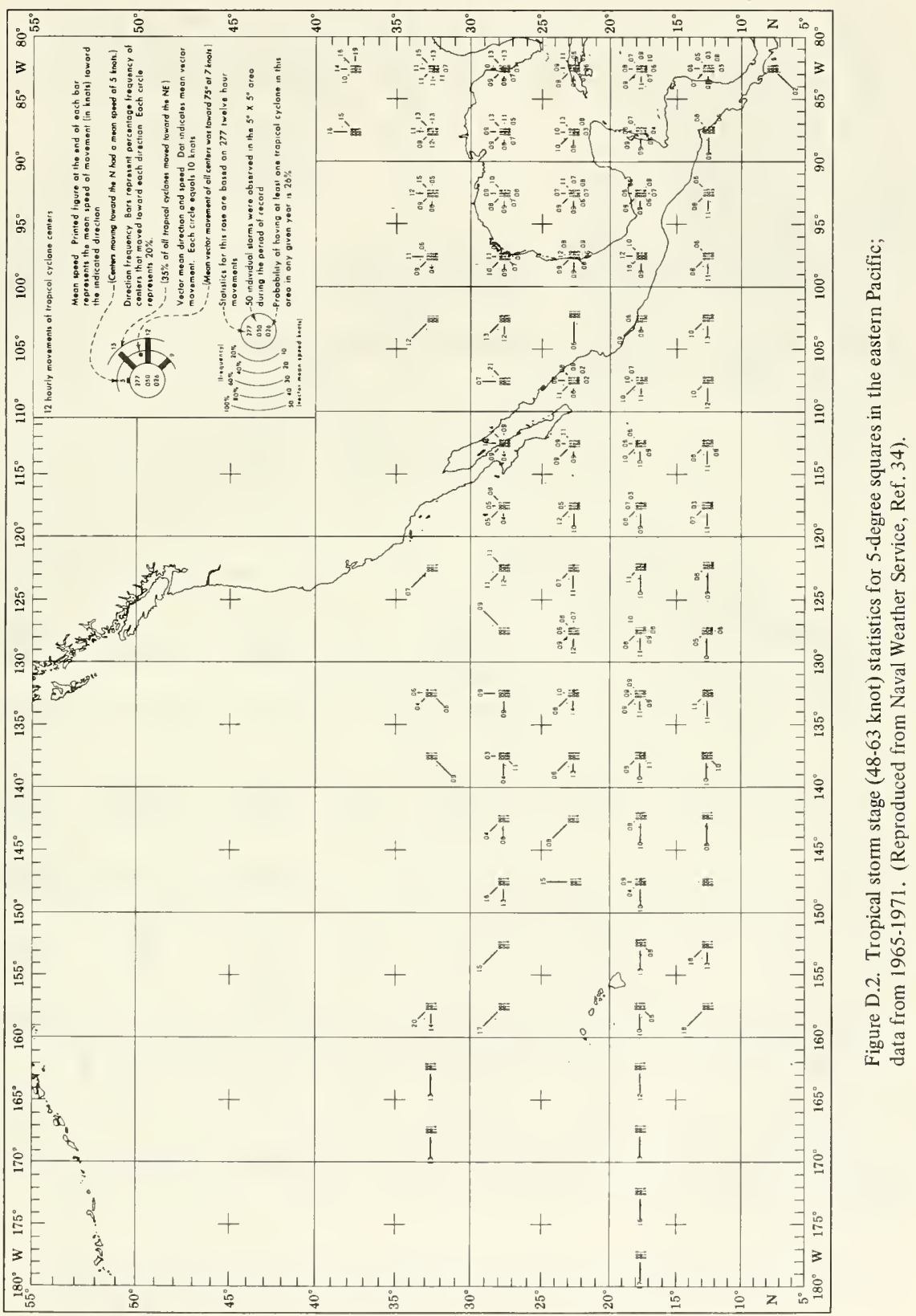




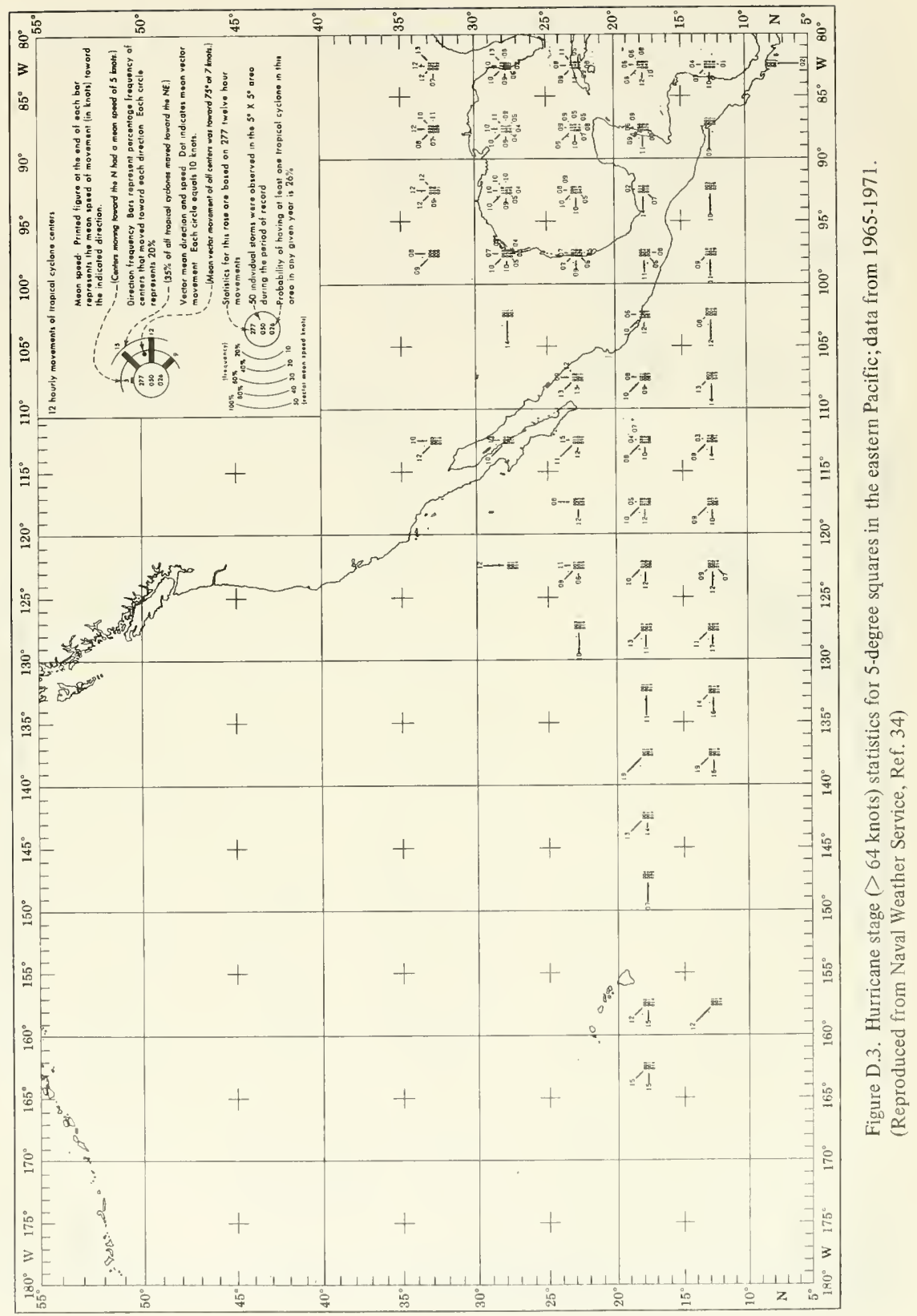




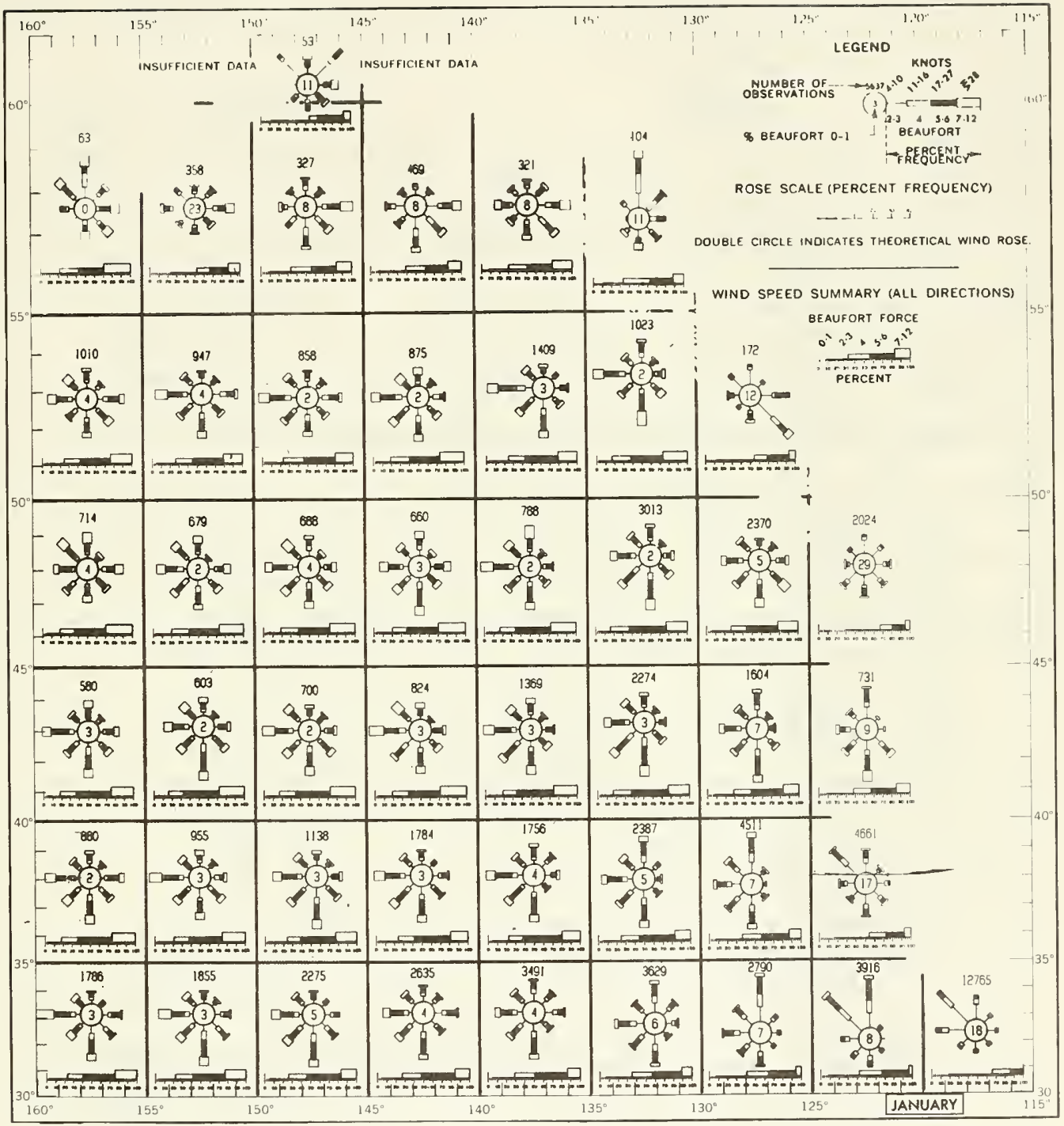

Figure D.4. Wind roses giving percent frequency of speed and direction for the northeastern Pacific north of $30^{\circ} \mathrm{N}$ for January. (U. S. Navy sources). 


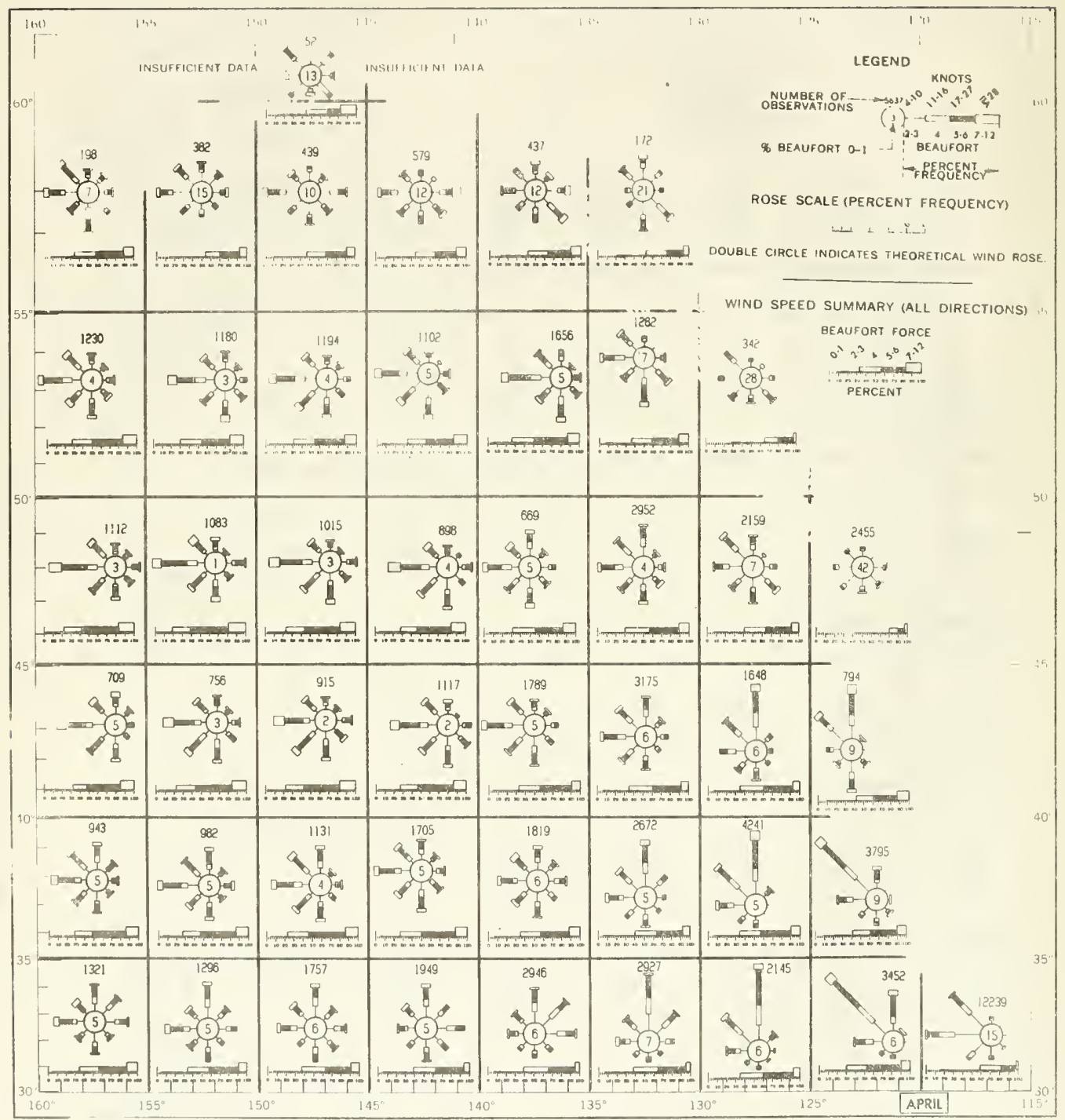

Figure D.5. Wind roses giving percent frequency of speed and direction for the northeastern Pacific north of $30^{\circ}$ for April. (U. S. Navy sources). 


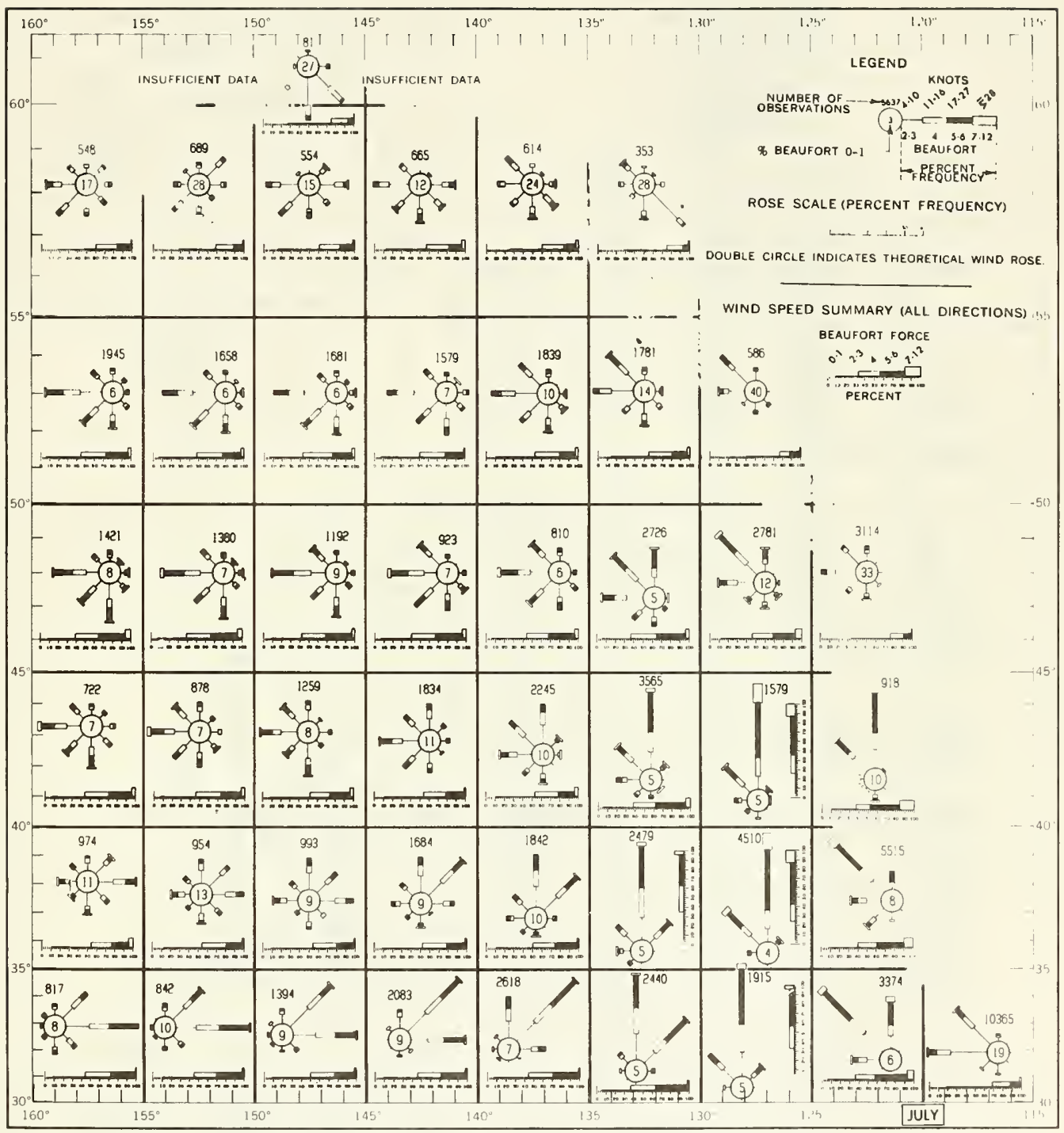

Figure D.6. Wind roses giving percent frequency of speed and direction for the northeastern Pacific north of $30^{\circ} \mathrm{N}$ for July. (U. S. Navy sources). 


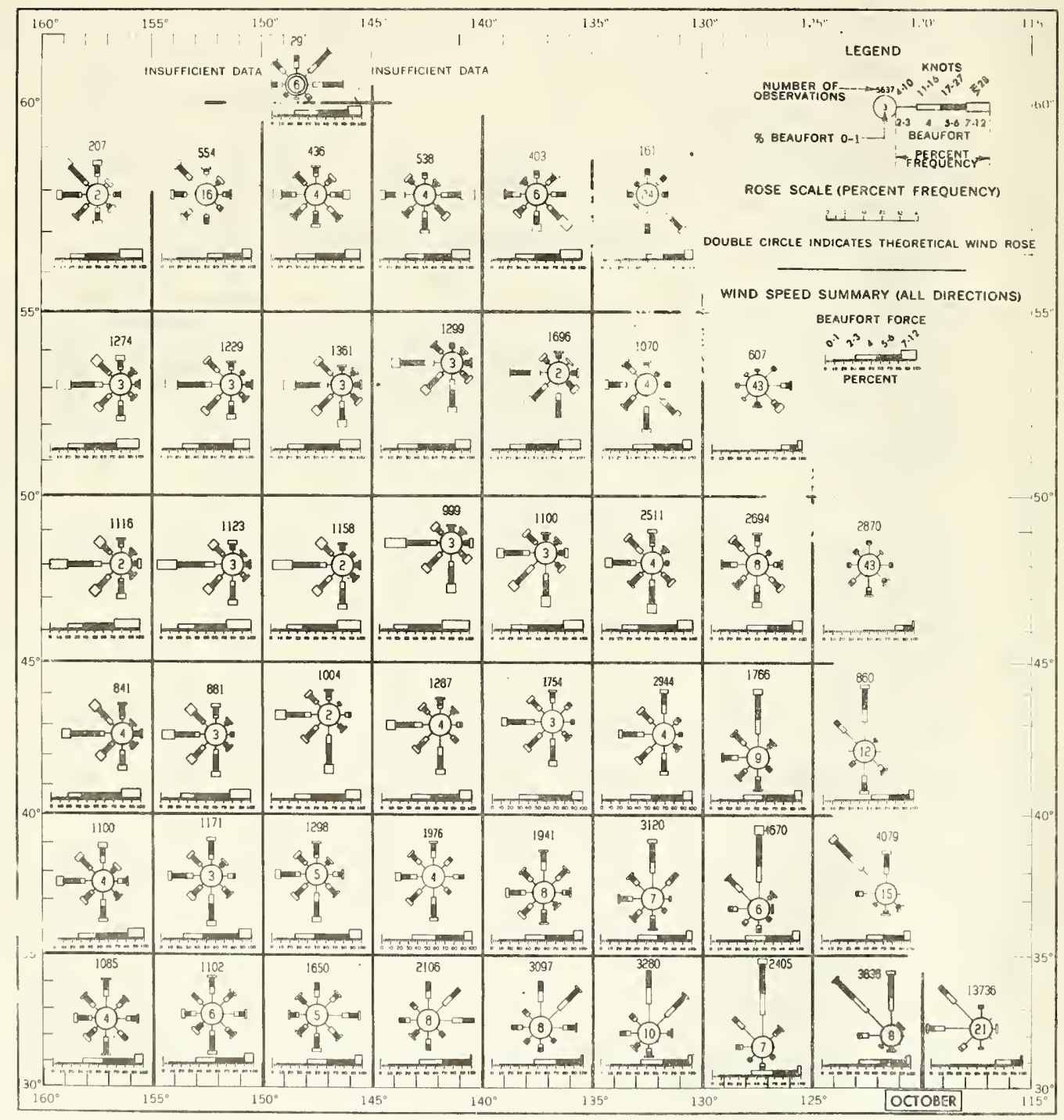

Figure D.7. Wind roses giving percent frequency of speed and direction for the nor theastern Pacific north of $30^{\circ}$ for October. (U. S. Navy sources). 


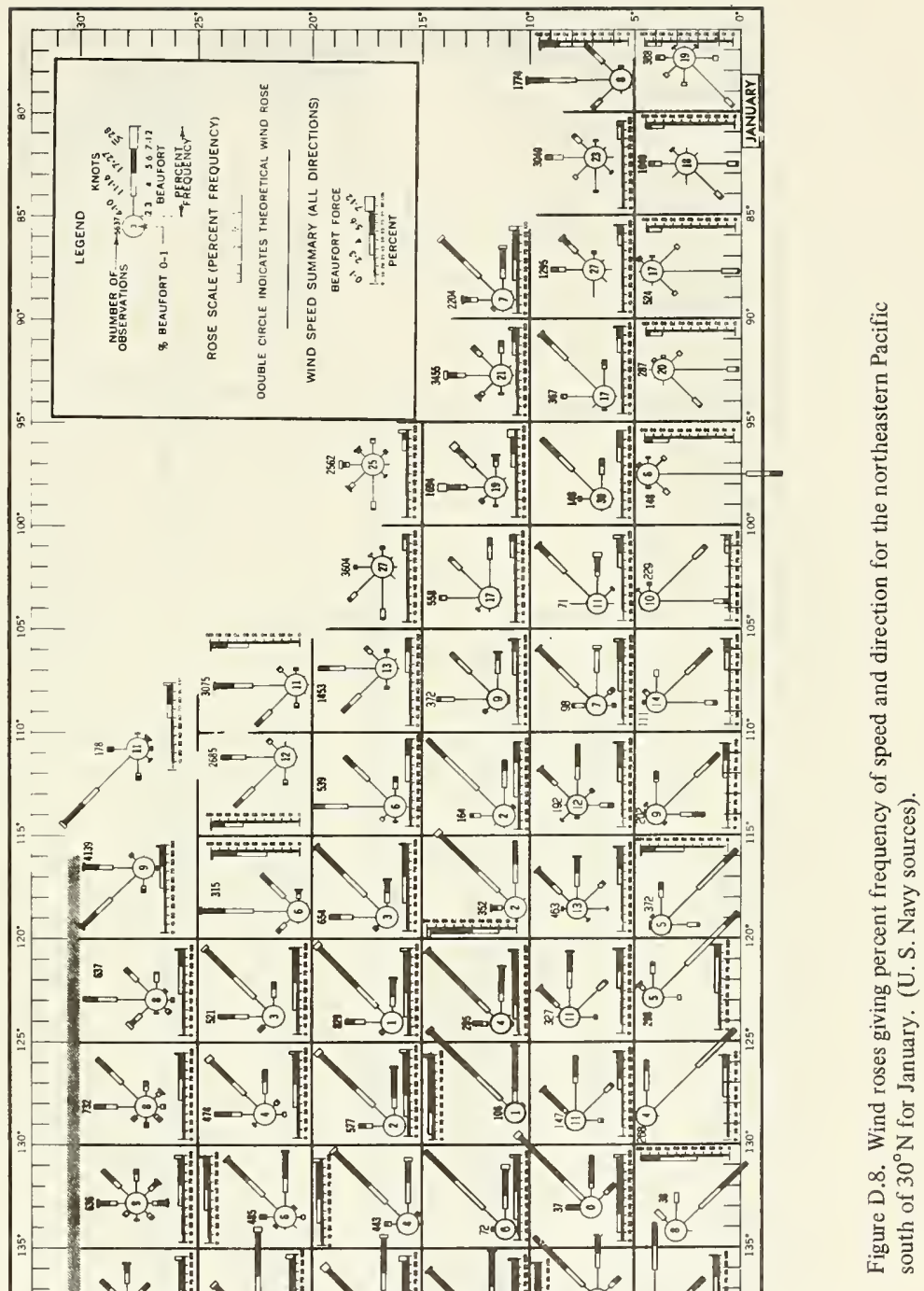




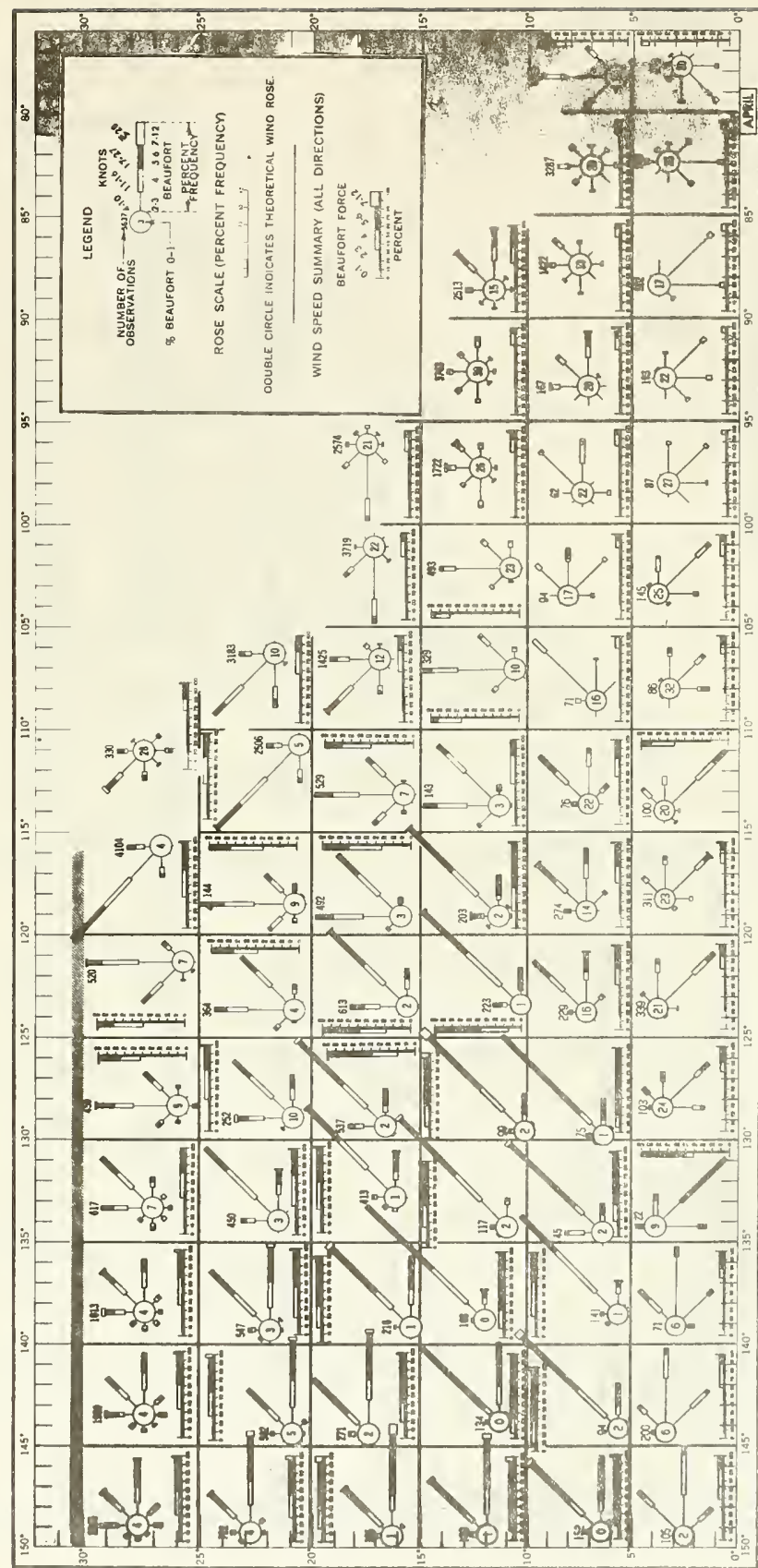

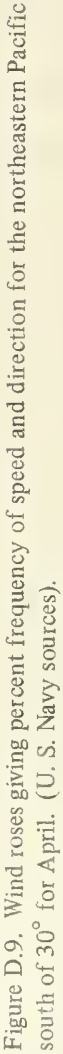




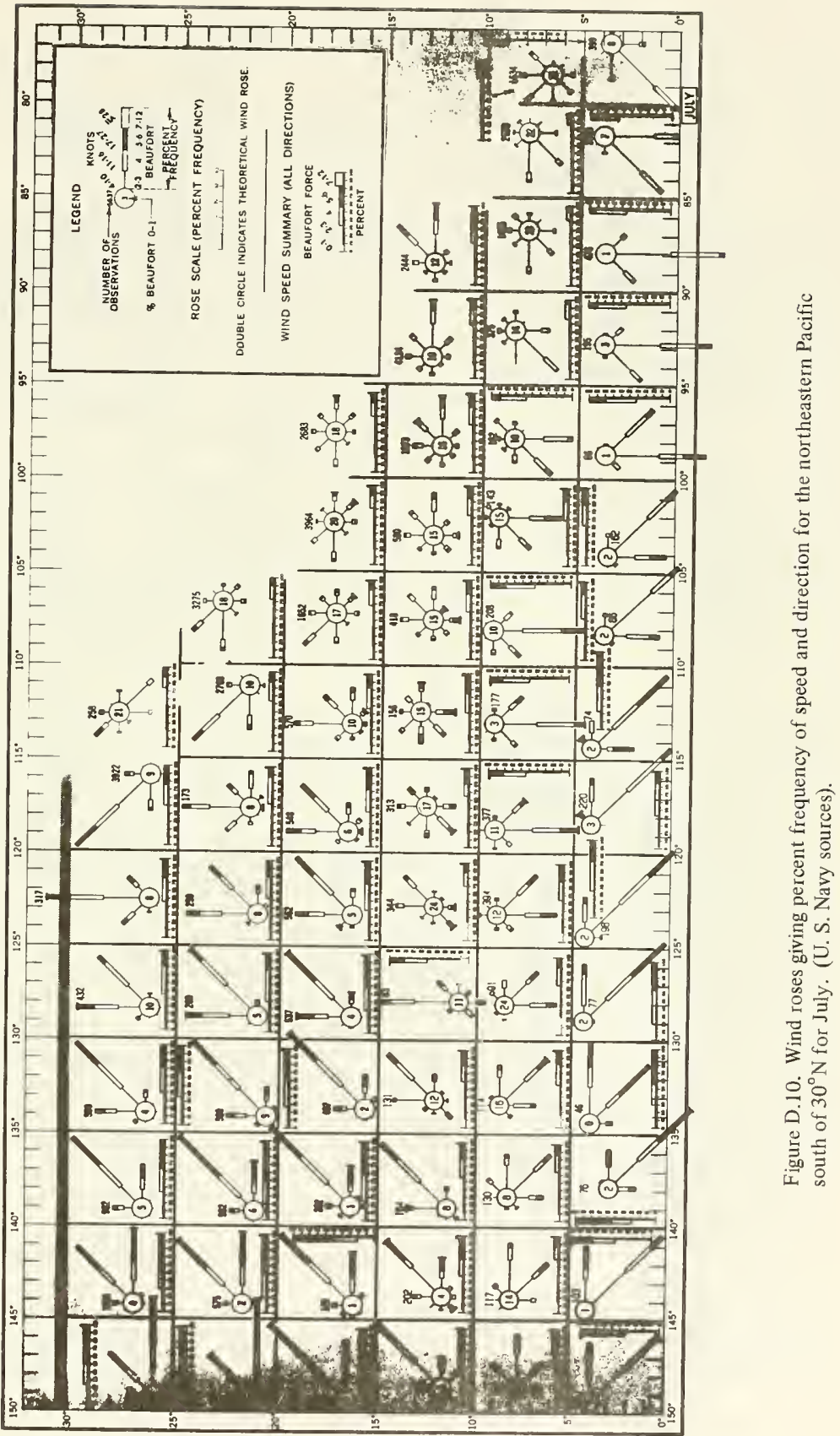




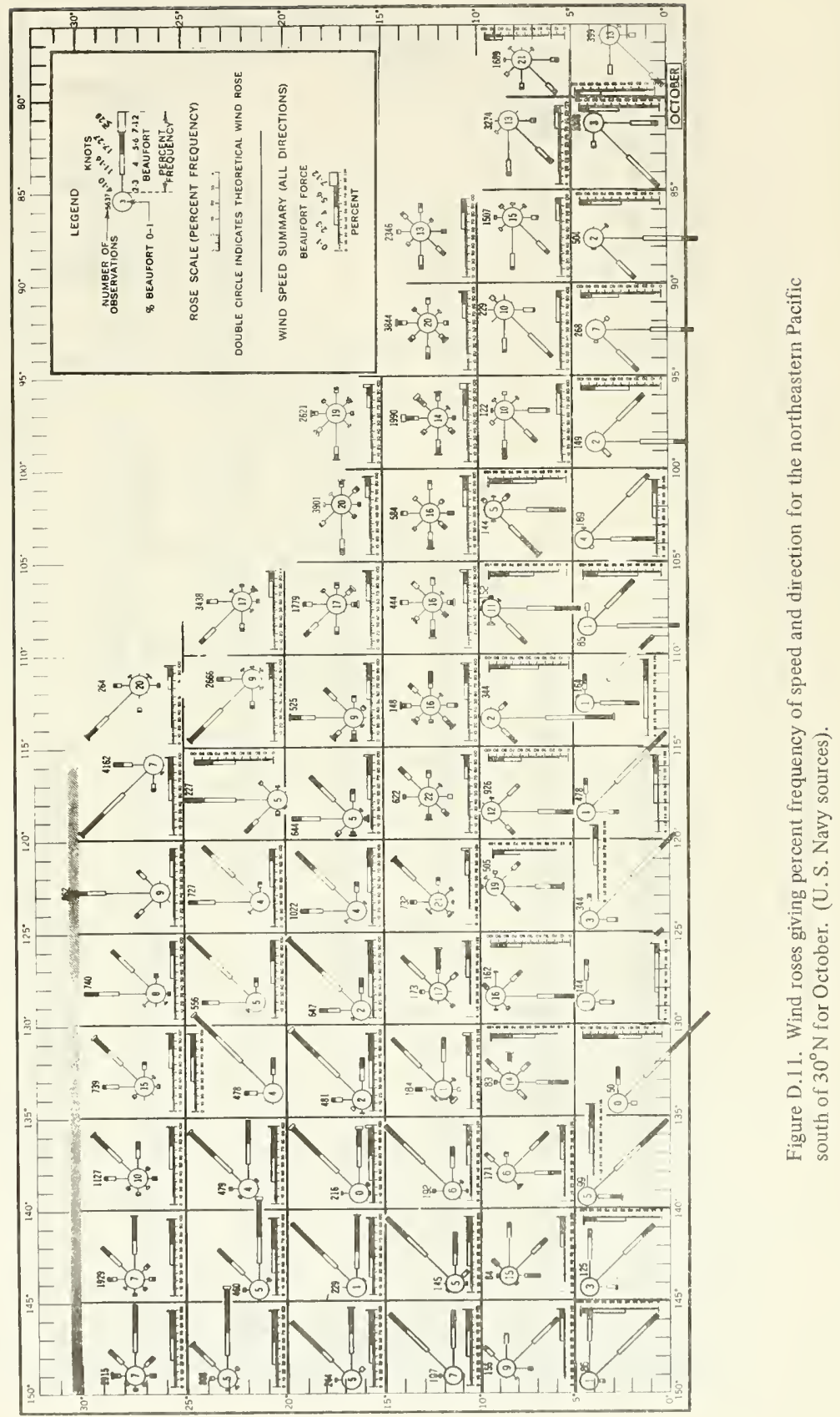




\section{APPENDIX E DISCUSSION OF STORM-GENERATED CURRENTS}

Severe storms and hurricanes can generate intense temporary current fields in the vicinity of the storm. The potential magnitude of these currents is of concern to OFEF for engineering design and overall survivability of the farm structure and kelp plants. Actual measurements of currents during severe storms are rare, principally due to the difficulty of making them under extremely adverse conditions. Nearly all literature references on stormdriven currents deal with theoretical computation of currents associated with storm surge (Ref. 50). Until very recently, these computational methods employed highly simplified equations that could at best only produce rough estimates of current conditions.

The response of the ocean surface-to-wind stresses is realized in several ways. The most apparent responses, and the most important in terms of OFEF structural dynamics, are surface waves and horizontal water transport. The total flow field to which a structure is subjected during storm-induced periods consists of wave-associated particle velocities plus the more slowly varying current component. Two papers which consider the effect of currents and waves on moored systems, and are applicable to Phase 1,2, and possibly early Phase 3 OFEF's are Refs. 51 and 52.

The only actual current measurement ever made during a severe cyclonic storm of hurricane intensity was taken from NOAA Buoy EB-10 during Hurricane Eloise, September 1975 (Ref. 53). This hurricane reached the coast of Florida with $110-\mathrm{knot}(57-\mathrm{m} / \mathrm{sec})$ winds at 1200, 23 September 1975. The wind magnitude, current speed, and wave height chronology are given in Figure E.1. The eye of the hurricane passed within 10 miles ( 16 kilometers) of buoy EB-10 at 0200, 23 September, approximately 150 miles (240 kilometers) south of Mississippi (Position (a) on Fig. E.1). The maximum measured wind speed by aircraft was 95 knots $(49 \mathrm{~m} / \mathrm{sec})$, the wind speed at the buoy was 68 knots $(35 \mathrm{~m} / \mathrm{sec})$ and occurred at 0100, 23 September, just prior to the passage of the eye. Wave response parallels wind speed precisely showing a maximum height of 8.8 meters during the same hour as the maximum wind speed. Currents at 50 meters, however, showed a delay of nearly 24 hours between the build up of the wind and the increase in current speed. Average current speed prior to the storm passage was $0.6 \mathrm{knot}(0.3 \mathrm{~m} / \mathrm{sec})$ increasing to $1.8 \mathrm{knots}(0.9 \mathrm{~m} / \mathrm{sec})$ over a 12-hour period (about the same length of time as the increase in wind speed to maximum magnitude). Shortly after the storm, oscillations (26- to 27-hour periods) in current speed with decreasing magnitude and direction were observed; these were detectable for two weeks after passage of the hurricane. Although the data for Figure E.1 were taken in the Gulf of Mexico, the general relationships probably are similar for cyclonic storms in the eastern Pacific. Surface currents were not measured from EB-10 and would be extremely difficult to measure in a storm due to wave and surface chop action.

Surface currents can be measured indirectly by measuring ship drift. One such measurement was made shortly after the passage of a typhoon in the northwest Pacific. A Japanese research vessel showed an anticyclonic drift pattern, 48 hours after the passage of a 

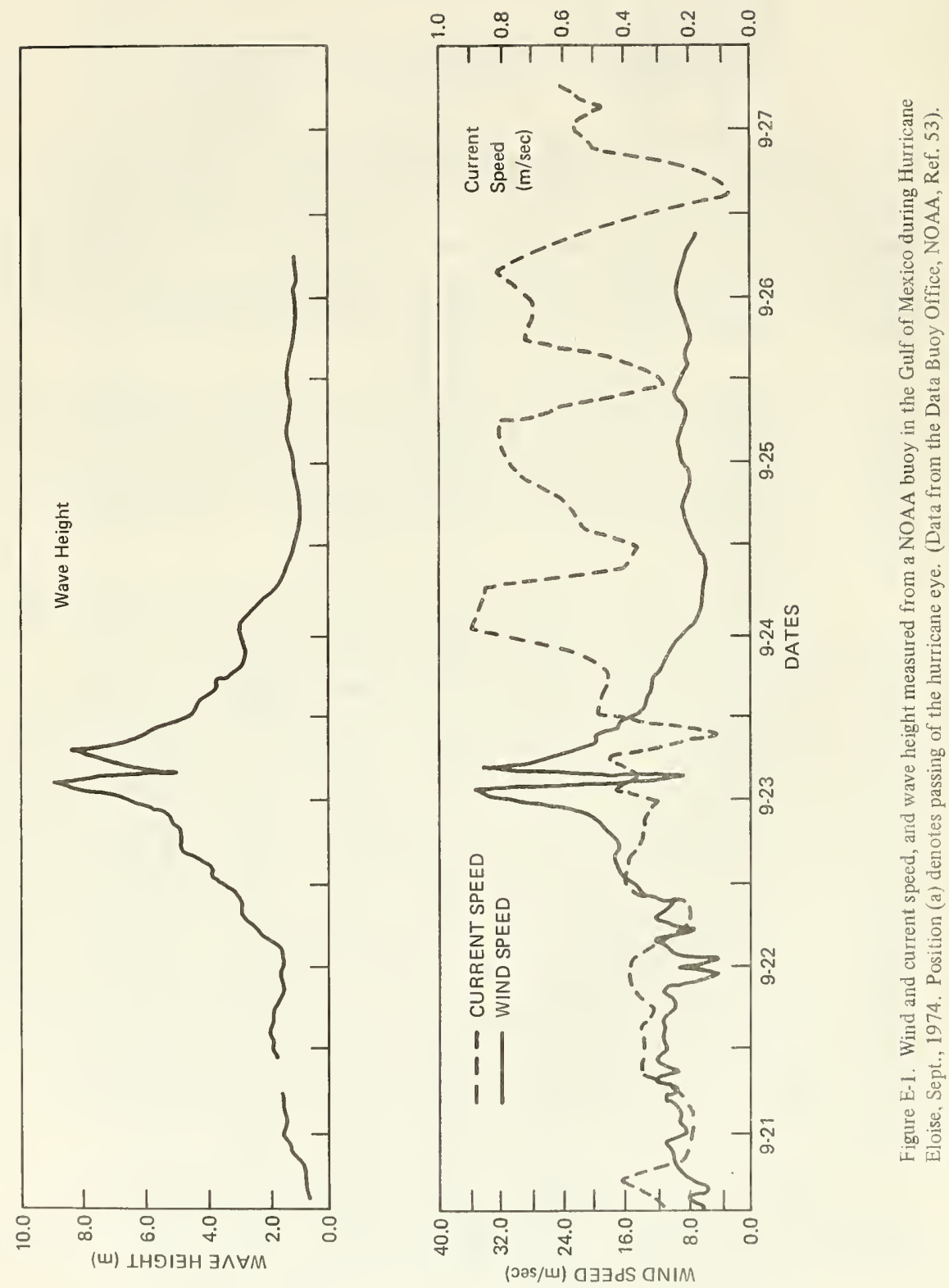
typhoon, approximating a 6-knot ( $3 \mathrm{~m} / \mathrm{sec}$ ) maximum drift (Ref. 54). Prior to the passage of the typhoon, the current drift was relatively straight to the northwest at 2 to 3 knots ( 1 to 1.5 $\mathrm{m} / \mathrm{sec}$ ). This demonstrates the dramatic change in both speed (2-3 to 6 knots) and direction (northwest to northeast) that can occur for a significant period of time after a hurricane.

Besides limited ship drift data and the single current measurement in the Gulf of Mexico reported above, no other data giving current measurements in severe storms could be located. Theoretical predictions of the effect of high winds on currents do exist, however; some of the available literature are given in Refs. 55 to 59 . A recent paper by Forristall gives a detailed discussion of the three-dimensional structure of storm-generated currents (Ref. 60), where a theoretical model for three-dimensional wind-driven currents is also provided. The driving force comes from the boundary condition of wind shear at the surface. The model solution comes from two major steps: first, a two-dimensional finite difference scheme is used to solve for current transports and storm surge; second, the current profiles at selected points are calculated from convolution integrals, which may be evaluated given a wind stress and sea surface slope at those points.

Some of the important conclusions follow. Wind-driven waves generally produce the dominant forces on offshore structures; however, since the hydrodynamic force is proportional to the square of the water particle velocity, a current of a few feet per second can increase the total force by 50 percent over that caused by waves alone (Refs. 50 and 60).

Solutions for a hurricane in the Gulf of Mexico were derived. An example solution was conducted using given data from Hurricane Camile (August 1969). Surface currents as high as 15.5 knots $(8 \mathrm{~m} / \mathrm{sec})$ were predicted; current speeds at other depths were as follows: 8.75 knots $(4.5 \mathrm{~m} / \mathrm{sec})$ at 10 meters, 4.5 knots $(2.3 \mathrm{~m} / \mathrm{sec})$ at 20 meters, $2.1 \mathrm{knots}(1.1 \mathrm{~m} / \mathrm{sec})$ at 30 meters, and $1 \mathrm{knot}(0.5 \mathrm{~m} / \mathrm{sec})$ at 50 meters. A current speed versus depth curve from these data are given in Fig. E.2. These velocities were predicted for a station a few miles east of the hurricane in 100 meters of water, based on a maximum wind velocity of approximately 122 knots $(63 \mathrm{~m} / \mathrm{sec})$ and a maximum wave height of 22 meters (Ref. 61). The effect of sloping bathymetry was strong, producing primarily longshore currents, which for deep water OFEF's will not be a consideration; thus, open ocean surface currents may be somewhat less. The model demonstrates that a tight circular wind can spin the water column to velocities much higher than those generated by a linear wind, and that the outward flow at the surface is balanced by an inward flow near the bottom. P. Black (personnel communication) has estimated that there is an approximate $10: 1$ wind velocity to surface current speed ratio in severe cyclonic storms. The predicted current in Forristall's model above (Ref. 60) approximates this estimated ratio (122-knot winds to 15.5-knot surface current).

Because of the lack of measured data, models such as the one described above will have to be used to estimate the current field in the event of a storm in the vicinity of an OFEF. A program to obtain storm-generated current data has been started by the Shell Development Company, Ref. 50, and as data are reported they should be incorporated into OFEF engineering design. Table E. 1 gives a list of personnel working in the wind-generated ocean current field for future contact as needed. 


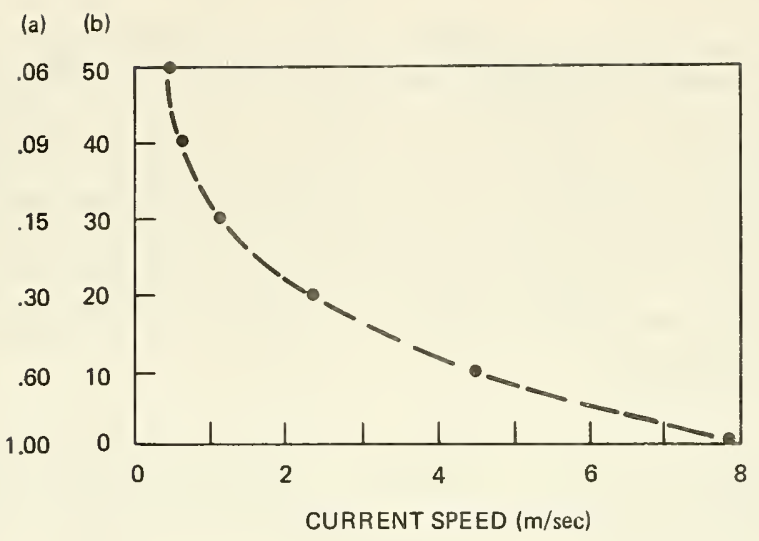

Figure E.2. Predicted current profile in the vicinity of Hurricane Camile with a maximum of 122 -knot winds. (a) Ratio of current speed at given depth-to-surface current speed. (b) Depth of predicted current in meters. (Computed data from Forristall, Ref. 60).

Table E.1. Personnel working in the field of wind-generated ocean current measurement and theory.

NAME

AFFILIATION

STUDY AREA

PHONE

Vincent Cardone New York University Inst. of Oceanography 675 W. 252 Street

Bronx, NY 10471

J. H. Hinchman General Dynamics

Electronics Division

Ocean Systems, Engineer

San Diego, CA

Peter Black NOAA

National Hurricane Center

Hurricane Environmental

Meterological Laboratory

Miami, Florida
Forecasting wave \&

212-796-8300 current data.

Current measurement \& 714-279-7301 buoy development.

Response of watermass $\quad 305-350-4150$ to hurricanes. 
Table E.1. (Continued).

\begin{tabular}{lllc}
\hline \multicolumn{1}{c}{ NAME } & \multicolumn{1}{c}{ AFFILIATION } & \multicolumn{1}{c}{ STUDY AREA } & \multicolumn{1}{c}{ PHONE } \\
\hline Duncan Ross & $\begin{array}{l}\text { Sea Air Interaction Lab. } \\
\text { Miami, Florida }\end{array}$ & 305-361-3361 \\
$\begin{array}{l}\text { George Forristall } \\
\text { J. Michael Hall }\end{array}$ & $\begin{array}{l}\text { Shevelopment Co. } \\
\text { Houston, TX }\end{array}$ & $\begin{array}{l}\text { Storm-generated } \\
\text { current modeling. }\end{array}$ & 713-667-5661 \\
Roy Clem & NOAA & $\begin{array}{l}\text { Current data from } \\
\text { National Data Buoy Office } \\
\text { Meritt Stevensons. }\end{array}$ & 601-688-2211 \\
& Bay St. Louis, Mississippi & & \\
& NOAA & Current measurement \\
& Service & $714-453-2820$ \\
& S.W. Fisheries Center & & \\
La Jolla, CA & & \\
\hline
\end{tabular}




\section{REFERENCES}

1. Wilcox, H.A. 1975

The Ocean Food and Energy Farm Project.

A paper presented to the 141st Annual Meeting of the American Association for the Advancement of Science. New York; 29 Jan 1975.

2. Budhraja, V.S. et al. 1976

Systems Analysis of the Ocean Food and Energy Farm (OFEF) Volume 1: Overall Economic Analysis of the Base Line Design.

Integrated Sciences Corp., Santa Monica, California, June 30, 1976.

3. Wilcox, H. A. 1976

The Ocean Farm Project - A concept for using the open sea as a vast renewable source for the production of fuels, woods, and other products. A paper presented at the Energy Bioconversion Symposium, Campinas, Sao Paulo, Brazil, 5-10 July, 1976.

4. Thomas, W.H. 1969

Phytoplankton nutrient experiments off Baja California and in the eastern equatorial Pacific Ocean.

J. Fish, Res. Board Can. 26:1133-1145.

5. Thomas, W.H. 1970

On nitrogen deficiency in tropical Pacific oceanic phytoplankton: photosynthetic parameters in poor and rich water.

Limnol, Oceanogr. 15:380-385.

6. Thomas, W.H., D. L.R. Seibert and A.N. Dodson 1974

Phytoplankton enrichment experiments and bioassays in natural coastal sea water and in sewage outfall receiving waters off Southern California. Estuarine and Coastal Mar. Sci. 2:191-206.

7. Waite, T. and R. Mitchell, 1972

The effect of nutrient fertilization on the benthic alga Ulva lactuca.

Botanica Marina 15:151-156.

8. Dawes, C. J., A.C. Mathieson and D.P. Cheney 1974

Ecological Studies of Floridian Eucheuma (Rhodophyta, Gigartinales). I.

Seasonal growth and reproduction.

Bull. Mar. Sci. 24:235-273.

9. Jackson, G.A. 1976

Nutrients and productivity of the giant kelp Macrocystis pyrifera, in the nearshore.

PhD Thesis, California lnstitute of Technology. 134 pp. 
10. Lindner, E., C.A. Dooley and R.H. Wade 1976

The seasonal variation of chemical constituents in Macrocystis pyrifera. NUC Technical Note in preparation.

11. Holmes, R.W. (unk)

Physical, chemical and biological observations

Ellwood Pier 1969-1971

Marine Science Institute

Data Report No. 1

University of California at Santa Barbara

12. North, W. 1976

Ocean Food and Energy Farm Project Fourth Quarterly Report, 1975.

13. North, W. 1976

Ocean Food and Energy Farm Project, May 1976, Progress Report.

14. North, W. J. 1971

Growth of individual fronds of the mature giant kelp., Macrocystis In W.J. North (Ed)

The biology of giant kelp beds (Macrocystis) in California

Nova Hedwigia 32:123-168.

15. Clendenning, K.A. 1971

Photosynthesis and general development in Macrocystis

In W.J. North (Ed)

The biology of giant kelp beds (Macrocystis) in California.

Nova Hedwigia 32:169-190.

16. Wilcox, H.A. 1976

A preliminary Drag Model for the Ocean Food and Energy Farm.

Naval Undersea Center, San Diego, CA.

17. James, A. L. and D.W. Murphy 1976

Kelp substrate structures for use in the Ocean Food and Energy Farm

Project, A study for ERDA.

Naval Undersea Center - Preliminary Report.

18. Wilcox, H.A. 1975

Artificial Oceanic Upwelling

Naval Undersea Center, San Diego, CA

19. Sverdrup, H.V., M.W. Johnson and R.H. Fleming 1942

The Oceans, $1087 \mathrm{p}$.

Prentice-Hall lnc., Englewood Cliffs, NJ

20. Hela, I. and T. Laevastu 1962

Fisheries Hydrography.

Fishing News (Books) Ltd. London. 
21. Laevastu, T. and E.C. LaFond 1970

Oceanic Fronts and their Seasonal Positions on the Surface.

Naval Undersea Center, Technical Publication 204.

22. Love, C.M. (Ed) 1972

Eastropac Atlas, vol. 1-7

U. S. Dept. Comm. NOAA. Nat. Mar. Fish Serv. Circ. 330

23. Wyllie, J.G. and R.J. Lynn 1971

Distribution of temperature and salinity at 10 meters, 1960-1969 and mean temperature, salinity and oxygen at 150 meters, 1950-1968 in the California current.

California Cooperative Oceanic Fisheries Investigations, State of California Marine Research Committee. Atlas No. 15, 188p.

24. Wyrtki, K. 1964

Upwelling in the Costa Rica Dome

Fish Bull. 63(2):355-371.

25. Broenkow, W.W. 1965

The distribution of nutrients in the Costa Rica Dome in the eastern tropical Pacific Ocean.

Limnol Oceanogr. 10:40-52

26. Newshul, M. 1971

The species of Macrocystis with particular reference to those of North and South America.

Nova Hedwigia 32:211-222

In W. J. North (Ed)

The biology of giant kelp beds (Macrocystis) in California.

27. Naval Weather Service 1974

Northeast Pacific - Environmental Scenario.

Prepared by Naval Weather Service, Environ. Detachment

Asheville, NC $263 \mathrm{p}$.

28. Naval Oceanographic Office 1969.

Major currents off the west coasts of North and South America.

Naval Oceanographic Office Tech. Report TR-221

29. Smith, R.L. 1968, Upwelling

Oceanic Mar. Biol. Ann. Rev.

6:11-46.

30. LaViolette, P.E. and S.E. Seim 1969

Monthly charts of mean, minimum, and maximum sea surface tempera-

ture of the North Pacific Ocean.

Naval Oceanographic Office Special Publ. - 12357 p. 
31. Anderson, G.C. 1969

Subsurface chlorophyll maximum in the northeast Pacific Ocean. Limnol Oceanogr. 14(3):386-391.

32. Thomas, W.H. and D.L.R. Seibert 1974

Distribution of nitrate, nitrite, phosphate and silicate in the California Current region 1969.

California Coop. Oceanic Fish. Invest. Atlas No. 20. pp 1-97.

33. Bathen, K.H., R.M. Kamins, D. Kornreich, and J.E.T. Moncur 1975

An evaluation of oceanographic and socio-economic aspects of a nearshore Ocean Thermal Conversion Pilot plant in subtropical Hawaiian waters.

University of Hawaii Report, submitted to NSF and ERDA.

34. Crutcher, H. L. and R.G. Quayle 1974

Mariners Worldwide Climatic Guide to Tropical Storms at Sea.

Naval Weather Service Environmental Detachment, Asheville, NC $36 \mathrm{p}$ and 312 charts, NAVAIR 50-1C-61.

35. National Oceanic and Atmospheric Administration 1974-1976

Principal Tracks of Center of Cyclones at Sea Level, North Pacific.

Mariners Weather Log.

Various issues 1974-1976.

36. Klein, W.H. 1957

Principal Tracks and Mean Frequencies of Cyclones and Anticyclones in the Northern Hemisphere.

U.S. Dept. of Comm. Weather Bureau Res. Paper No. 4060 p.

37. Thom, H.C.S. 1973

Extreme Wave Height Distributions Over Oceans.

J. Waterways, Harbors and Coastal Eng. Div., ASCE 99 (WWI) Proc. paper 9556:1-17.

38. Quayle, R.G. and D.C. Fulbright 1975

Extreme wind and wave return periods for the U.S. Coast.

Mariners Weather Log 19(2):67-70

National Oceanic and Atmospheric Administration.

39. Whitemarsh, R.P. 1938

Great Sea Waves

U.S. Naval Inst. Proc. $\underline{60(8)}$

40. U.S. Naval Weather Service Command 1970

Summary of Synoptic Meteorological Observations, North American

Coastal Areas

Asheville, NC 
41. Thom, H.C.S. 1968

Toward a universal climatological extreme wind distribution.

National Research Council Proceedings

Int. Res. Seminar, Wind effects on Buildings and Structures, O'Hara, Canada, Oct 1967.

42. Thom, H.C.S. 1973

Distributions of extreme winds over oceans.

J. Waterways, Harbors and Coastal Eng. Div., Proceedings.

Am. Soc. Civil Eng. 99: 1-77

43. Thom, H.C.S. 1971

Asymptotic extreme - value distributions of wave heights in the Open Ocean.

J. Mar. Res. 29(1):

44. Baum, R.A. 1975

Eastern North Pacific Tropical Cyclones, 1974.

Mariners Weather Log 19(2):75-84.

45. Naval Weather Service 1971

Climatological Study - Southern California Operating Area

Prepared by Naval Weather Service Detachment, Asheville, NC, 245 p.

46. Holm-Hansen, O., J.D.H. Strickland and P.M. Williams 1966.

A detailed analysis of biologically important substances in a profile off Southern California

Limnol, Oceanogr. 11(4):548-561.

47. Wyllie, J.G. 1966

Geostrophic flow of the California Current at the surface and at 200 meters.

California Coop. Fish, Invest.

Atlas 4, 1-288.

48. Scripps Institution of Oceanography 1962

Results of current measurements with drogues, 1958-1961

Data Rep. SIO Ref. 62-27:1-68

49. Kolpack, R. L. 1971

Oceanography. In: Biological and oceanographical survey of the Santa Barbara channel oil spill 1969-1970. Vol II. Physical, chemical and geological studies. pp 90-180 Ed. by R. L. Kolpack.

Allan Hancock Foundation, Los Angeles.

50. Hall, J.M. 1972

Hurricane-generated ocean currents - Part 1: The development of a measurement program.

Offshore Technol. Conf. Pap. 1518:69-77

Dallas, TX 1972. 
51. Hicks, J. B., and L. G. Clark 1972

On the dynamic response of buoy-supported cables and pipes to currents and waves.

Offshore Technol. Conf. Pap. 1556:453-462

Dallas, TX 1972.

52. Wang, H.T. 1972

Effect of nonplanor current profiles on the configuration of moored cable systems.

Offshore Technol. Conf. Pap. 1532:215-225.

53. Withee, G.W. and A. Johnson 1975

Buoy observations during Hurricane Eloise (September 1975 to October 11, 1975).

Data Report: Environmental Sciences Division, Data Buoy Office.

NOAA. Bay St. Louis, Mississippi.

54. Maeda, A. 1971

Changes of water temperature near Ocean Weather Station T before and after Passage of a Typhoon.

J. Oceanogr. Soc. Japan 27(3): 109-115.

55. Welander, P. 1957

Wind action on a shallow sea: some generalizations of Ekman's theory.

Tellus, 9:47-52.

56. Wilson, B.W. 1960

Note on surface wind stress over water at high and low wind speeds.

J. Geophys. Res. 65(10):3377-3382.

57. Welander, P. 1968

Wind-driven circulation in one and two-layer oceans of variable depth.

Tellus 20:1-15.

58. Goldstein, M.E., W.H. Braum and R.T. Gedney 1970

A method for obtaining analytical solutions to the equation for winddriven circulation in a shallow sea or lake, NASATN D-5989.

59. Gedney, R.T. 1971

Numerical calculations of the wind driven currents in Lake Erie.

PhD thesis, Case Western Reserve Univ., Cleveland, Ohio.

60. Forristall, G.Z. 1974

Three-dimensional structure of storm-generated currents.

J. Geophys. Res. 79(18):2721-2729.

61. Baylor Company 1969

Summary of Storm Report for participants of the Gulf of Mexico Ocean

Data Gathering Program.

Report \#2 covering Hurricane Camille, 17 Aug 1969

Baylor Company, Houston, TX. 


